UNIVERSIDADE DE SÃO PAULO

ESCOLA DE ENGENHARIA DE SÃO CARLOS

BRUNO CANOZA DA SILVA

\title{
ESTIMATIVA DA CAPACIDADE DE CARGA À TRAÇÃO DE ESTACAS HELICOIDAIS COM BASE NO ENSAIO SPT
}

São Carlos

2014 


\author{
UNIVERSIDADE DE SÃO PAULO \\ ESCOLA DE ENGENHARIA DE SÃO CARLOS \\ PROGRAMA DE PÓS-GRADUAÇÃO EM GEOTECNIA
}

\title{
ESTIMATIVA DA CAPACIDADE DE CARGA À TRAÇÃO DE ESTACAS HELICOIDAIS COM BASE NO ENSAIO SPT
}

\author{
BRUNO CANOZA DA SILVA
}

Dissertação apresentada à Escola de Engenharia de São Carlos, da Universidade de São Paulo, como parte dos requisitos para obtenção do título de Mestre em Ciências, Programa de Pós Graduação em Geotecnia.

ORIENTADOR: PROFA DRA. CRISTINA DE HOLLANDA CAVALCANTI TSUHA

São Carlos-SP

2014 
AUTORIZO A REPRODUÇÃO TOTAL OU PARCIAL DESTE TRABALHO, POR QUALQUER MEIO CONVENCIONAL OU ELETRÔNICO, PARA FINS DE ESTUDO E PESQUISA, DESDE QUE CITADA A FONTE.

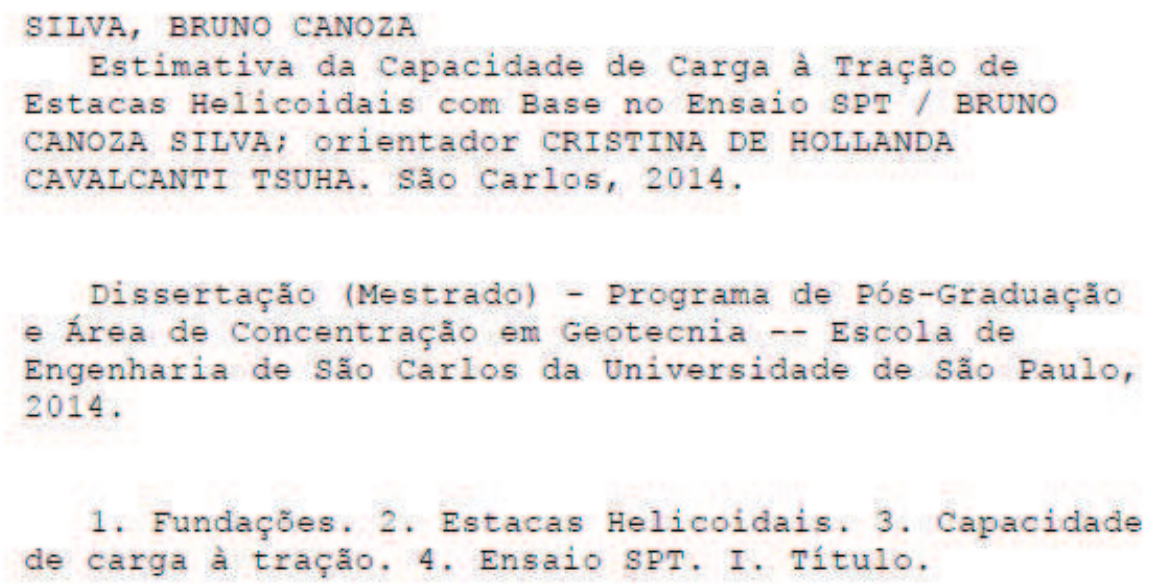




\section{FOLHA DE JULGAMENTO}

Candidato: Engenheiro BRUNO CANOZA DA SILVA.

Titulo da dissertação: "Estimativa da capacidade de carga à tração de estacas helicoidais com base no ensaio SPT".

Data da defesa: 07/07/2014

\section{Comissāo Julgadora:}

Profa. Dra. Cristina de Hollanda Cavalcanti Tsuha (Orientadora)

(Escola de Engenharia de São Carlos/EESC)

Prof. Dr. Nelson Aoki

(Escola de Engenharia de São Carlos/EESC)

\section{Prof. Dr, Jeselay Hemetério Cordeiro dos Reis
(Universidade Estadual de Maringá/UEM) \\ Prof. Dr, Jeselay Hemetério Cordeiro dos Reis
(Universidade Estadual de Maringá/UEM)}

\section{Resultado:}

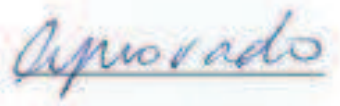

ApHovsDO

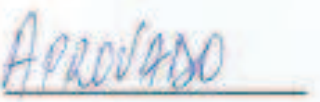

Coordenador do Programa de Pós-Graduação em Geotecnia:

Prof. Titular Osni José Pejon

Presidente da Comissão de Pós-Graduaçāo:

Prof. Associado Paulo César Lima Segantine 
dedicatória

Aos meus pais, Wilson e Lúcia, Às minhas irmãs Camila e Tatiana, À minha esposa Ana Paula e minha filha Alice. 


\section{AGRADECIMENTOS}

Agradeço a Deus, todos os dias, por sua generosidade e bondade. Ele me deu a família que eu precisava: uma mãe carinhosa, amiga, dedicada, com um amor imenso e incondicional. Um pai trabalhador, honesto, que superou as dificuldades da vida e pode me dar a melhor educação. Um irmão para me ensinar a superar as diferenças, o qual eu preciso aprender a compreender. Duas irmãs maravilhosas, lindas, inteligentes e independentes.

Deus é caprichoso. Ele ainda me presenteou com uma esposa maravilhosa, amiga, confidente, e uma linda filha. Elas me dão forças para vencer meus medos e insegurança e ser, a cada dia, um homem melhor. Ele também me deu bons amigos, pessoas muito especiais e queridas.

Deus me deu oportunidades, muitas. Ele me deu a oportunidade de estudar numa das melhores universidades do país, ser orientado por uma profissional competente, dedicada, amiga; conhecer novas pessoas, fazer novas amizades. Tudo contribuiu muito para a minha formação e crescimento pessoal.

Ele me deu tudo o que eu preciso, na medida e forma certa. Muito obrigado Deus. Peço a você sabedoria e saúde para corresponder aos seus planos e que ilumine os caminhos de todas as pessoas com a qual você me presenteou nesta vida.

Amém.

O autor também agradece a Vértice Engenharia pelos dados do ensaio fornecidos. 


\section{EPÍGRAFE}

"Ninguém é suficientemente perfeito, que não possa aprender com o outro, e ninguém é totalmente destituído de valores que não possa ensinar algo ao seu irmão”.

São Francisco de Assis 


\section{Resumo}

Silva, B. C. (2013). Estimativa da capacidade de carga à tração de estacas helicoidais com base no ensaio SPT. Dissertação de Mestrado. Escola de Engenharia de São Carlos, Universidade de São Paulo, São Carlos, 2014.

Na prática brasileira, usualmente a previsão da capacidade de carga de fundações por estacas é baseada em métodos semi-empíricos, por meio de correlações diretas da resistência de ponta e por atrito lateral ao longo da estaca com os valores de $N_{S P T}$. Entretanto, no caso de fundações por estacas helicoidais, ainda utilizam-se métodos teóricos que necessitam de valores de parâmetros geotécnicos obtidos indiretamente a partir de correlações com os valores de $N_{S P T}$ (coesão, peso específico, ângulo de atrito, coeficiente de empuxo).

Portanto, nesta dissertação foi desenvolvido um método semi-empírico para estimar a capacidade de carga à tração de fundações por estacas helicoidais profundas por meio de correlações diretas com o valor de $N_{S P T}$ do solo de instalação da estaca. Além disso, são apresentados no presente trabalho valores de fator de torque $K_{T}$, obtidos por análise estatística, para a verificação da capacidade de carga à tração da estaca usando-se medidas do torque necessário para instalá-la no terreno.

Nesta pesquisa dois diferentes modelos para estimativa da capacidade de carga foram desenvolvidos e analisados estatisticamente. O estudo das características das amostras de fundações por estacas helicoidais usadas nesta pesquisa permitiu a subdivisão em grupos (tipo de solo e quantidade de hélices) de modo a se obter modelos mais precisos.

Com os resultados deste trabalho, foi possível elaborar recomendações para projeto e execução de estacas helicoidais, bem como desenvolver um modelo para estimar a capacidade de carga à tração de estacas helicoidais instaladas em solos similares aos das estacas usadas neste estudo. SPT.

Palavras-chave: Fundações, estacas helicoidais, capacidade de carga à tração, ensaio 


\section{Abstract}

Silva, B. C. (2013). Semi-empirical estimation of the uplift capacity of helical piles based on SPT results. Dissertation. Escola de Engenharia de São Carlos, Universidade de São Paulo, São Carlos, 2013.

The pile capacity in Brazil is usually predicted by semi-empirical methods based on direct correlations between SPT-N values and pile shaft and pile base resistance. However, the uplift capacity of helical piles is still calculated using theoretical methods based on soil parameters, as: cohesion, unit weight, friction angle, and lateral earth pressure coefficient. In this case, these parameters are obtained indirectly from correlations with values of SPT-N.

This dissertation was inspired by the need of a more appropriate method to calculate the uplift capacity of helical piles, by correlating the capacity of the bearing plates directly with the soil type and SPT-N values. In this work, it was developed a semi-empirical method for estimating the pullout capacity of deep helical piles by using SPT test results, similarly to the other methods used for conventional piles. Also, this work presents some results of torque factor, obtained by statistical analysis, to the verification of the pile capacity by using the torque recorded at the end of pile installation.

In this research, it was performed several statistical analysis to obtain appropriate models to estimate the uplift capacity of helical piles. The cases of helical piles used in this investigation are classified into groups according to the soil type and the number of helices. As a result, detailed evaluations and recommendations for improvement of helical pile design are presented. The proposed model is recommended to calculate the uplift capacity of helical piles installed in similar soils to that used in this study.

Key- words: foundations, helical piles, uplift capacity, SPT test. 


\section{LISTA DE FIGURAS}

Figura 2. 1: Estaca helicoidal metálica (Asel-Tech, 2012).

Figura 2. 2: Aplicação da estaca metálica helicoidal para controle de flutuação de dutos (A

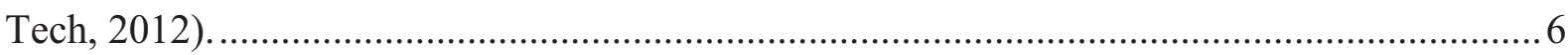

Figura 2. 3: Estaca metálica helicoidal (modificado de Perko, 2009) ..................................... 7

Figura 2. 4: Adaptação do motor hidráulico em uma retro escavadeira (Perko, 2009).............9

Figura 2. 5: Procedimentos gerais de instalação (modificado de Perko, 2009)........................ 10

Figura 2. 6: Estaca helicoidal instalada em areia (Das, 1990)............................................... 13

Figura 2. 7: Superfície de ruptura de estacas helicoidais trancionadas (Das, 1990): a) ancoragem rasa, b) ancoragem profunda.

Figura 2. 8: Método da capacidade de carga individual para estacas helicoidais tracionadas (Perko, 2009)

Figura 2. 9: Método do cilindro de cisalhamento para estacas helicoidais tracionadas (Perko, 2009)

Figura 2. 10: Exemplo hipotético do efeito de instalação de uma estaca helicoidal com 3 hélices: a) areia fofa, b) areia compacta (Tsuha et al., 2012)................................................20

Figura 2. 11: Mecanismo de penetração para uma hélice (Kanai, 2007) ................................20

Figura 2. 12: Resistência individual de cada hélice nas provas de carga: a) compressão, b)

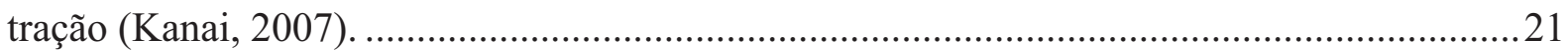

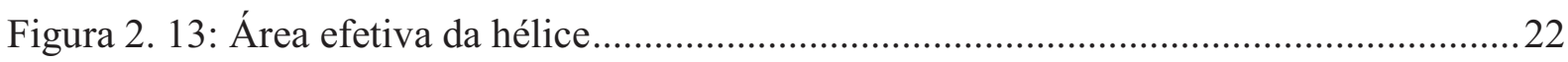

Figura 2. 14: Mobilização das resistências na estaca helicoidal de acordo com Kanai (2007).

Figura 2. 15: Carga de ruptura conforme Davisson (1972)

Figura 2. 16: Comportamentos típicos de solos cimentados em ensaios (adaptado de Pinto 2006).

Figura 2. 17: Desvios ao redor da reta de regressão linear....................................................29

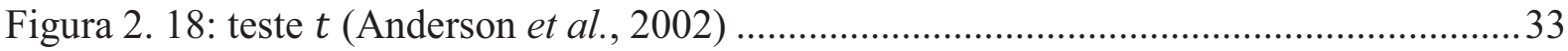

Figura 2. 19: Representação gráfica do intervalo de confiança................................................36

Figura 2. 20: Exemplos de plotagens residuais (Anderson et al., 2002)............................... 37

Figura 3. 1: Formas de interpretação da prova de carga a serem utilizadas neste trabalho......43

Figura 3. 2: Alteração da profundidade da hélice de uma altura $\Delta h$..................................... 45 
Figura 3. 3: Numeração convencionada para as hélices.

Figura 3. 4: Situações de projeto.

Figura 4. 1: Tela de programação do NetBeans .................................................................52

Figura 4. 2: Tela para retirada da carga de ruptura.................................................................54

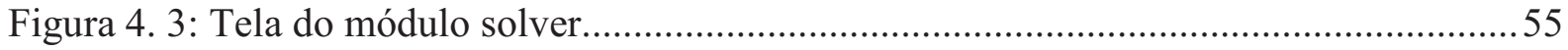

Figura 4. 4: Seleção das estacas no módulo solver....................................................................56

Figura 4. 5: Escolha das unidades no modulo solver ...............................................................56

Figura 4. 6: Resultado de um cálculo no módulo solver. .....................................................57

Figura 4. 7: Botões para importar e exportar estacas do HPT para o Excel.............................58

Figura 4. 8: Configuração do módulo calculadora. ...................................................................59

Figura 4. 9: Tela do cálculo da relação NSPT versus resistência.............................................60

Figura 4. 10: Tela das variáveis para relação NSPT versus resistência. .................................60

Figura 4. 11: Tela do cálculo da relação torque versus resistência......................................61

Figura 4. 12: Tela com gráfico de resumo das relações NSPT versus resistência e torque

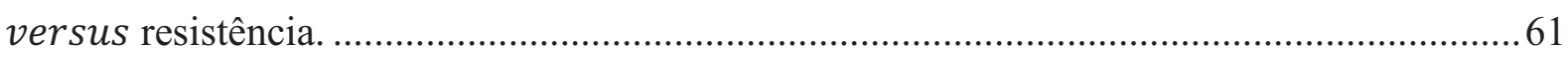

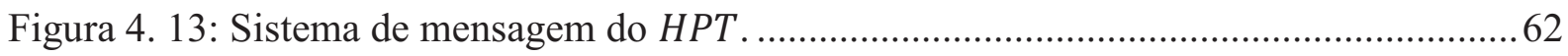

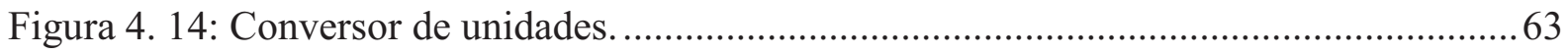

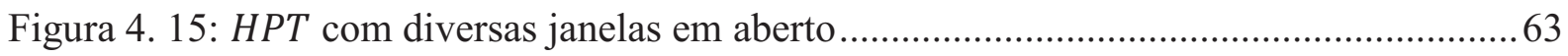

Figura 5. 1: Histogramas de $k$ t utilizando D/10 para: a) todas as amostras, b) situação $A$, c)

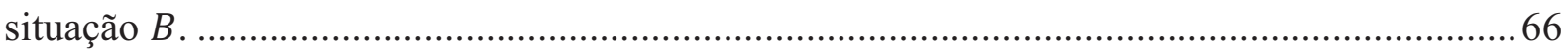

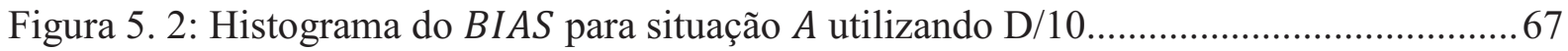

Figura 5. 3: Gráfico de resistência observada versus resistência estimada para situação $A$

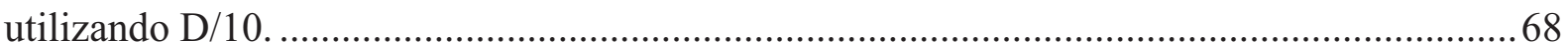

Figura 5. 4: Histograma de resíduo padrão para situação $A$ utilizando $\mathrm{D} / 10$........................... 68

Figura 5. 5: Histograma do $B I A S$ para situação $B$ utilizando $\mathrm{D} / 10$. .......................................... 69

Figura 5. 6: Histogramas de $k t$ utilizando Livneh e Naggar para: a) todas as amostras, b)

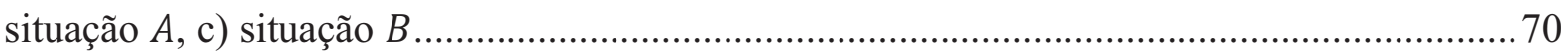

Figura 5. 7: Histograma do BIAS para situação $A$ utilizando Livneh e Naggar (2008).......... 71

Figura 5. 8: Gráfico de resistência observada versus resistência estimada para situação $A$

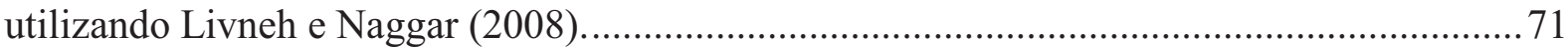


Figura 5. 9: Histograma de resíduo padrão para situação $A$ utilizando Livneh e Naggar (2008).

Figura 5. 10: Histograma do BIAS para situação $A$ utilizando Livneh e Naggar (2008). 72

Figura 6. 1: Gráfico de resistência estimada versus resistência observada utilizando D/10. .79

Figura 6. 2: Histograma do BIAS utilizando D/10. 79

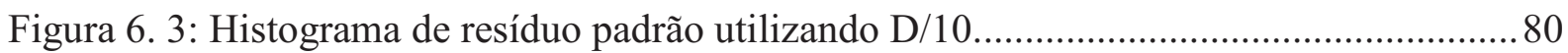

Figura 6. 4: Gráfico de resíduo padrão versus resistência estimada utilizando $\mathrm{D} / 10 \ldots \ldots \ldots \ldots . . . .80$

Figura 6. 5: Correção do $B I A S$ para $\mathrm{D} / 10$ na situação $A$........................................................... 81

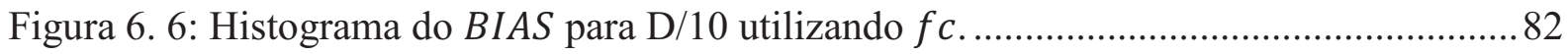

Figura 6. 7: Fator de correção para estacas com 6 hélices utilizando $\mathrm{D} / 10$............................ 83

Figura 6. 8: Comparação entre os $f c$ para estacas com até 4 hélices e 6 hélices.....................84

Figura 6. 9: Gráfico de resistência estimada versus resistência observada utilizando Livneh e

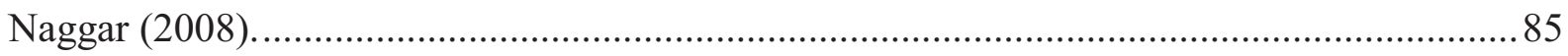

Figura 6. 10: Histograma do BIAS utilizando Livneh e Naggar (2008)..................................86

Figura 6. 11: Histograma de resíduo padrão utilizando Livneh e Naggar (2008)...................86

Figura 6. 12: Gráfico de resíduo padrão versus resistência estimada utilizando Livneh e

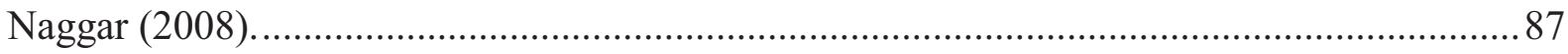

Figura 6. 13: Correção do BIAS para Livneh e Naggar (2008) na situação $A$. ........................87

Figura 6. 14: Histograma do BIAS para Livneh e Naggar (2008) utilizando $f c$. ....................88

Figura 6. 15: Comparação entre os $f c$ para estacas com até 4 hélices utilizando Livneh e

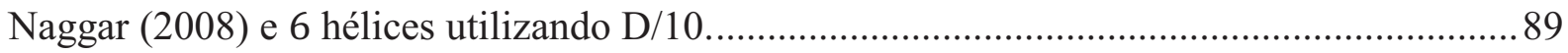

Figura 6. 16: Histograma do BIAS para Livneh e Naggar (2008) no modelo II . ...................93

Figura 6. 17: Gráfico de resistência estimada versus resistência observada utilizando Livneh

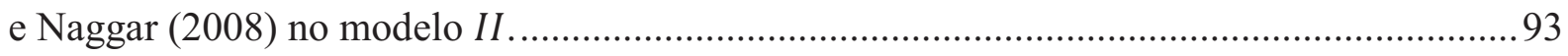

Figura 6. 18: Gráfico de resíduo padrão versus resistência estimada utilizando Livneh e

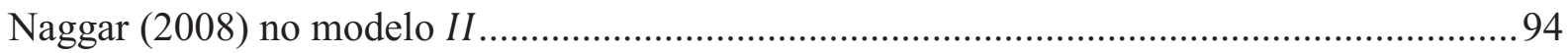

Figura 6. 19: Histograma de resíduo padrão utilizando Livneh e Naggar (2008) no modelo II.

Figura 6. 20: Correção do BIAS para Livneh e Naggar (2008) no modelo II . ....................... 95

Figura 6. 21: Fatores de correção para D/10 e Livneh e Naggar (2008).................................96

Figura 7. 1: Comparação entre o torque estimado $(k N . m)$ e o torque observado $(k N . m) \ldots 102$ 
Figura 7. 2: Histograma do resíduo padrão para estimativa do torque de instalação. 102

Figura 7. 3: Gráfico de resíduo padrão versus torque estimado. ......................................... 103

Figura 7. 4: Histograma $B I A S$ do torque estimado na situação $A$........................................ 103

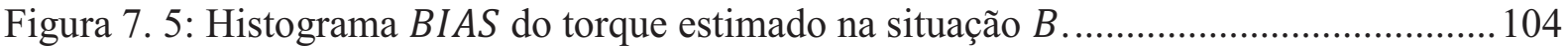

Figura 8. 1: Resultados do método teórico: a) todas as estacas, b) na situação $A$, c) na situação $C, \mathrm{~d})$ todas as estacas utilizando o fator de correção.

Figura 8. 2: Resultados do modelo $I$ a) todas as estacas, b) na situação $A$, c) na situação $C .108$

Figura 9. 1: Comportamento das estacas com 6 hélices.....

Figura 1: Histogramas de kt utilizando Davisson (1972) para: a) todas as amostras, b) situação $A$, c) situação $B$ e d) somente estacas com 6 hélices.

Figura 2: Histogramas de $k t$ utilizando Davisson (1972) para estacas entre 2 e 4 hélices na situação $A$.

Figura 3: Gráfico de resistência observada versus resistência estimada para $A$ utilizando Davisson (1972)...... 118

Figura 4: Histograma de resíduo padrão para situação $A$ utilizando Davisson (1972). ......... 118

Figura 5: Histograma de resíduo padrão para situação $A$ utilizando Davisson (1972). ......... 119

Figura 6: Histograma do BIAS para situação $A$ utilizando Davisson (1972). 119

Figura 7: Gráfico de frequência acumulada do BIAS para situação A utilizando Davisson (1972).

Figura 8: Histogramas de $k t$ utilizando Davisson (1972) para estacas entre 2 e 4 hélices na situação $B$.

Figura 9: Histograma do BIAS para situação $B$ utilizando Davisson (1972). 121

Figura 10: Gráfico de frequência acumulada do $B I A S$ para situação $B$ utilizando Davisson (1972).

Figura 11: Histogramas de $k t$ utilizando Davisson (1972) para estacas com 6 hélices na situação: a) todas as estacas, b) $A$, c) $B$.

Figura 12: Histograma do BIAS para estacas com 6 hélices utilizando Davisson (1972)..... 123 Figura 13: Gráfico de frequência acumulada do BIAS para estacas com 6 hélices utilizando Davisson (1972) 123 
Figura 14: Histogramas de kt utilizando NBR 6122 (2010) para: a) todas as amostras, b) situação $A$, c) situação $B$ e d) somente estacas com 6 hélices.

Figura 15: Histogramas de $k t$ utilizando NBR 6122 (2010) para estacas entre 2 e 4 hélices na situação $A$. 126

Figura 16: Gráfico de resistência observada versus resistência estimada para situação $A$ utilizando NBR 6122 (2010).

Figura 17: Histograma de resíduo padrão para situação $A$ utilizando NBR 6122 (2010) ...... 127

Figura 18: Histograma de resíduo padrão para $A$ utilizando NBR 6122 (2010). ................... 128

Figura 19: Histograma do BIAS para situação $A$ utilizando NBR 6122 (2010).................... 128

Figura 20: Gráfico de frequência acumulada do BIAS para $A$ utilizando NBR 6122 (2010).129

Figura 21: Histogramas de $k t$ utilizando NBR 6122 (2010) para estacas entre 2 e 4 hélices na situação $B$.

Figura 22: Histogramas do BIAS utilizando NBR 6122 (2010) para estacas entre 2 e 4 hélices na situação $B$ 130

Figura 23: Gráfico de frequência acumulada do BIAS para situação $B$ utilizando NBR 6122 (2010).

Figura 24: Histogramas do BIAS utilizando NBR 6122 (2010) para estacas com 6 hélices. 131 Figura 25: Gráfico de resistência estimada versus resistência observada utilizando Davisson (1972). 134

Figura 26: Histograma do BIAS utilizando Davisson (1972). 134

Figura 27: Histograma de resíduo padrão utilizando Davisson (1972). 135

Figura 28: Gráfico de resíduo padrão versus resistência estimada utilizando Davisson (1972).

Figura 29: Histograma do BIAS para estacas com 6 hélices para os regressores da situação $A$ utilizando Davisson (1972). 136

Figura 30: Gráfico de resistência estimada versus resistência observada utilizando NBR 6122 (2010). 137

Figura 31: Histograma do BIAS utilizando NBR 6122 (2010). 138

Figura 32: Histograma de resíduo padrão utilizando NBR 6122 (2010). 138

Figura 33: Gráfico de resíduo padrão versus resistência estimada utilizando NBR 6122 (2010). 139

Figura 34: Histograma do $B I A S$ para estacas com 6 hélices para os regressores da situação de projeto utilizando NBR 6122 (2010). 



\section{LISTA DE TABELAS}

Tabela 2. 1: Valores de $q w$ proposto por PERKO (2009).....................................................2 23

Tabela 2. 2: Características do ensaio de carga estática com carregamento rápido e lento. ....24

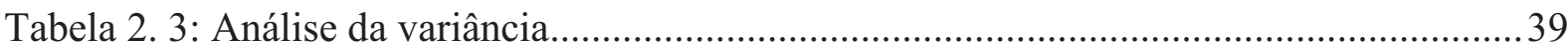

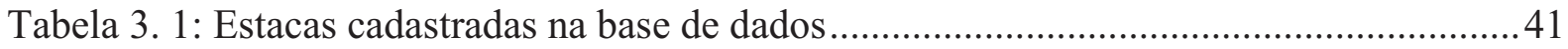

Tabela 3. 2: Diâmetros predominantes na base de dados ....................................................... 42

Tabela 3. 3: Agrupamento dos solos padronizados areia, silte arenoso, silte argiloso e argila.

Tabela 4. 1: Principais informações dos objetos da uma estaca ..............................................53

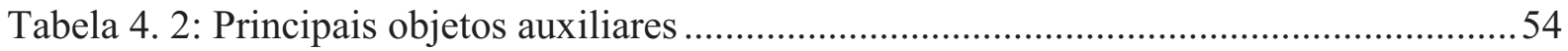

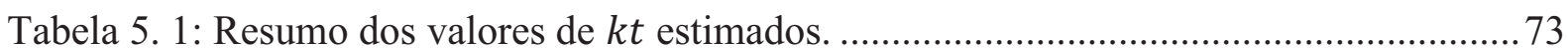

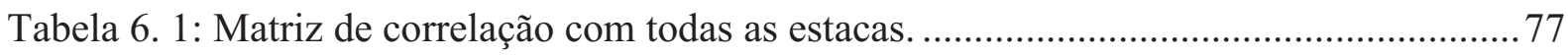

Tabela 6. 2: Regressores estimados utilizando D/10 para o modelo da equação 6. 2.............78

Tabela 6. 3: Resistência estimada para estacas com 6 hélices utilizando $\mathrm{D} / 10$ com e sem $f c .83$

Tabela 6. 4: Regressores estimados utilizando Livneh e Naggar (2008) para o modelo I.......84

Tabela 6. 5: Resistência estimada para estacas com 6 hélices utilizando Livneh e Naggar

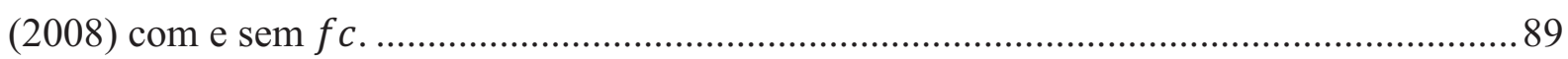

Tabela 6. 6: Cálculo dos fatores de correção para D/10 e Livneh e Naggar (2008).................91

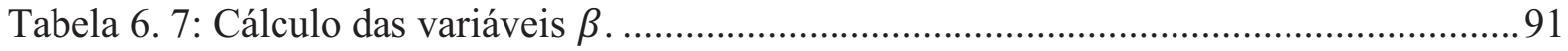

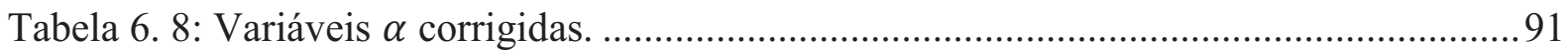

Tabela 6. 9: Valores estimados de $\alpha$ e $\beta$ para Livneh e Naggar (2008) no modelo II ............ 92

Tabela 6. 10: Resumo dos regressores para relação entre resistência e NSPT . ...................... 96

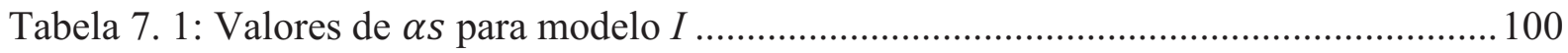

Tabela 7. 2: Valores de $\alpha s$ para a situação $B$......................................................................... 100

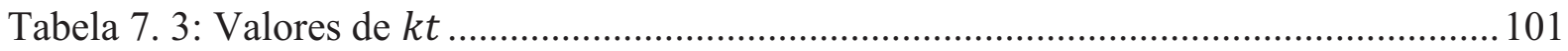


Tabela 8. 1: Peso específico para solos argilosos (Godoy (1972) apud Cintra e Aoki (2010)): 106

Tabela 8. 2: Peso específico para solos arenosos (Godoy (1972) apud Cintra e Aoki (2010)): 106

Tabela 1: Regressores estimados utilizando Davisson (1972). ........................................... 133

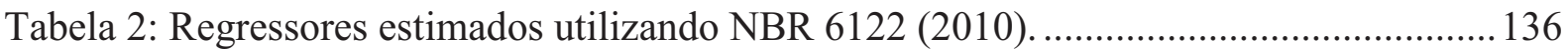




\section{LISTA DE ABREVIATURAS E SÍMBOLOS}

a: Coeficiente de resistência

$\mathrm{A}_{1}$ : Área da hélice superior.

A ehi: Área projetada da hélice $i$

$\mathrm{A}_{\mathrm{h}}$ : Área projetada da hélice num plana perpendicular ao eixo do tubo

$\mathrm{A}_{\mathrm{p}}$ : Área da seção transversal da ponta da estaca

ASTM : American Society for Testing and Materials

b: Coeficiente de resistência

B: Comprimento do elemento de fundação

c: Coesão

$\mathrm{C}_{\mathrm{a}}$ : Adesão ao longo do tubo da estaca

$\mathrm{CV}$ : Coeficiente de variação

d: Diâmetro da haste

D: Diâmetro

D: Profundidade da hélice na vertical

$\mathrm{D}_{\mathrm{a}}$ : Diâmetro médio das hélices

$\mathrm{d}_{\mathrm{c}}$ : Fator de profundidade

$\mathrm{D}_{\mathrm{n}}$ : Diâmetro da hélice inferior

DPN: Distribuição de probabilidade normal

$\mathrm{d}_{\mathrm{q}}$ : Fator de profundidade

$\mathrm{d}_{\gamma}$ : Fator de profundidade

$\mathrm{E}(\mathrm{y}):$ Esperança de $\mathrm{y}$

E: Módulo de elasticidade

EESC : Escola de Engenharia de São Carlos

f: Coeficiente de resistência

F: Eficiência de uma hélice

F: Parâmetro da estatística do teste $F$

$\mathrm{F}_{1}$ : Coeficiente de correlação da resistência de ponta

$\mathrm{F}_{2}$ : Coeficiente de correlação da resistência lateral

$\mathrm{f}_{\mathrm{c}, \alpha}:$ Fator de correção da variável $\alpha$

$\mathrm{f}_{\mathrm{c}, \alpha}^{\prime}:$ Fator de correção da variável $\alpha$

$\mathrm{f}_{\mathrm{c}, \beta}$ : Fator de correção da variável $\beta$ 
$\mathrm{f}_{\mathrm{c}}$ : Fator de correção

$\mathrm{f}_{\mathrm{i}}$ : Resistência unitária do fuste

H: Comprimento da haste acima da hélice superior

$\mathrm{H}_{0}$ : Hipótese nula

$\mathrm{H}_{1}$ : Hipótese alternativa

$\mathrm{H}_{\mathrm{i}}$ : Profundidade da hélice $i$

$\mathrm{H}_{\mathrm{n}}$ : Profundidade da hélice inferior

HPT: Helical Piles Tools

IBC: International Building Code

IC: Intervalo de confiança

k: Graus de liberdade da regressão

$\mathrm{K}$ : Fator de conversão da resistência de ponta do cone para $\mathrm{N}_{\mathrm{SPT}}$

K: Parâmetro de escala

$\mathrm{K}_{\mathrm{t}}$ : Fator empírico de torque

$\mathrm{K}_{\mathrm{u}}$ : Coeficiente de empuxo

L: Comprimento da Estaca

$\mathrm{L}_{\mathrm{i}}$ : Comprimento efetivo do fuste

$\mathrm{l}_{\mathrm{j}}$ : Espessura da camada $j$ ao longo da haste

m : Metro

m: Número máximo de hélices

min: Valor mínimo de uma função

MMQ: Método dos mínimos quadrados

MSE: Média dos quadrados do erro

MSR: Soma dos quadrados devido à regressão

$\bar{N}_{S P T}$ : Média dos $N_{S P T}$ na profundidade da hélice $i$ e 1,0 metro acima e abaixo dela.

$\overline{N_{S P T}}$ : Valor médio de $N_{S P T}$ de todas as hélices da estaca.

$\mathrm{N}_{\overline{\mathrm{SPT}}}$ : Médida do $\mathrm{N}_{\mathrm{SPT}}$ das hélices da estaca

$N_{S P T}$ : Índice obtido no ensaio SPT.

n: Número de elementos da amostra

n: Número de camadas de solo ao longo da haste da estaca

$\mathrm{N}: \mathrm{N}_{\mathrm{spt}}$

N: Número de hélices 
NBR : Norma Brasileira

$\mathrm{N}_{\mathrm{c}}$ : Fator de capacidade de carga

$\mathrm{N}_{\mathrm{cu}}$ : Fator de capacidade de carga a tração para solos coesivos

$\mathrm{N}_{\mathrm{q}}$ : Fator de capacidade de carga

$\mathrm{N}_{\mathrm{qu}}$ : Fator de capacidade de carga a tração para areias

$\mathrm{N}_{\mathrm{qu}}$ : Fator de capacidade de carga que varia com o ângulo de atrito e profundidade relativa da hélice

$\mathrm{N}_{\mathrm{SPT}}$ : Número de golpes necessários à penetração dos $30 \mathrm{~cm}$ finais do amostrador no ensaio SPT

OC: Fator dependente do diâmetro da estaca

p: Maior número de divisões de comprimento do fuste

$\mathrm{p}_{\mathrm{s}}$ : Perímetro do tubo da estaca

q': Tensão efetiva acima da hélice

Q: Força aplicada

$\mathrm{Q}_{\mathrm{hi}}$ : Capacidade de carga à tração da hélice $i$

$\mathrm{Q}_{\mathrm{s}}$ : Resistência ao atrito lateral do fuste

$\mathrm{Q}_{\mathrm{u}}$ : Capacidade de carga à tração da estaca helicoidal

$\mathrm{Q}_{\mathrm{u}, \text { estimado: }}$ Resistência estimada pelo ensaio $S P T$

$\mathrm{q}_{\text {wi }}$ : Capacidade de suporte unitária de cada hélice

$r^{2}$ : Coeficiente de determinação

$\mathrm{r}_{\mathrm{L}}$ : Resistência lateral unitária

RLS: Regressão linear simples

$\mathrm{r}_{\mathrm{p}}$ : Resistência de ponta unitária

RPM: Rotação por minuto

s: Desvio padrão da amostra.

$\mathrm{s}^{2}$ : Variância da amostra

$\mathrm{s}_{\mathrm{c}}$ : Fator de fórmula

$\mathrm{S}_{\mathrm{f}}$ : Deslocamento máximo admissível.

SPT : Starndart Penetration Test

$\mathrm{s}_{\mathrm{q}}$ : Fator de fórmula

SSE: Soma dos quadrados devido ao erro

SSR: Soma dos quadrados devido à regressão

SST: Soma total dos quadrados 
$\mathrm{S}_{\mathrm{u}}$ : Resistência não drenada das argilas

$\mathrm{s}_{\gamma}$ : Fator de fórmula

$\mathrm{T}$ : Torque

t: Parâmetro da distribuição $t$ de Student

T: Resistência ao cisalhamento

$\mathrm{t}_{\alpha}$ : Parâmetro da distribuição $t$ de Student para o nível $\alpha$

U: Perímetro do fuste da estaca

USP : Universidade de São Paulo

$\mathrm{x}$ : Variável independente

$\bar{y}$ : Valor médio de $\mathrm{y}$.

y: Variável dependente

ŷ: Valor estimado

$\sum \overline{N_{S P T}}$ : Somatório do valor médio de $N_{S P T}$ da hélice.

$\alpha_{s(\operatorname{com} \beta)}$ : Variável $\alpha_{s}$ :para o modelo que considera a variável $\beta$

$\alpha_{s(\operatorname{sem} \beta)}$ : Variável $\alpha_{s}$ :para o modelo que não considera a variável $\beta$

$\alpha_{s}$ : Resistência unitária de ponta

$\beta_{s}$ : Resistência unitária por atrito lateral

$\Delta:$ Encurtamento elástico

$\Delta h:$ Deslocamento da estaca

$\Delta \mathrm{l}$ : Espessura da camada

$\alpha$ : Fator de adesão

$\alpha$ : Nível de significância.

$\alpha$ : Relação entre as resistências de ponta e lateral do ensaio de penetração estática

$\gamma$ : Peso específico do solo

$\gamma$ ': Peso específico efetivo do solo

$\sigma:$ Desvio padrão da população.

$\sigma^{2}$ : Variância da população

$\epsilon:$ Erro

$\phi:$ Ângulo de atrito 


\section{SUMÁRIO}

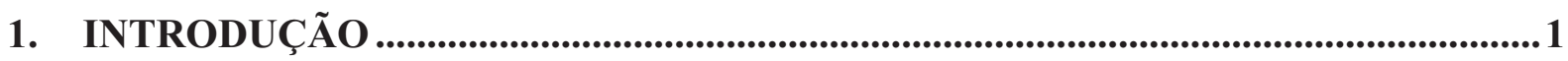

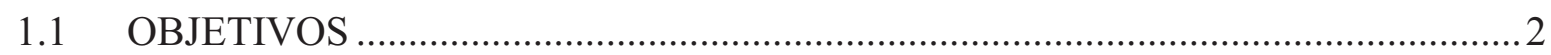

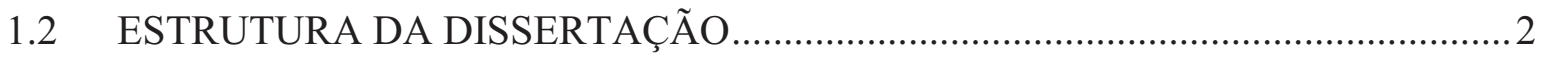

2. REVISÃO BIBLIOGRÁFICA.....................................................................................5

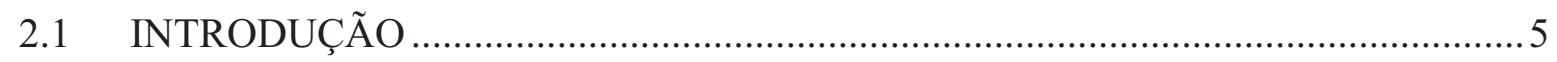

2.2 ESTACAS METÁLICAS HELICOIDAIS …......................................................

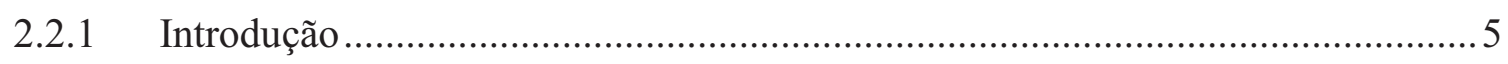

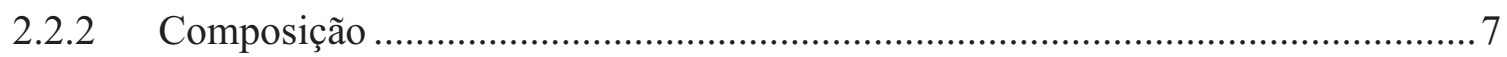

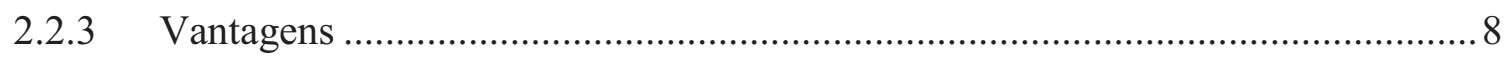

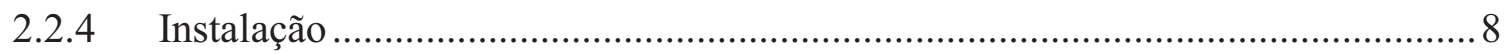

2.2.4 Capacidade de carga à tração................................................................................ 12

2.2.5 Correlação entre torque de instalação e capacidade de carga.............................. 19

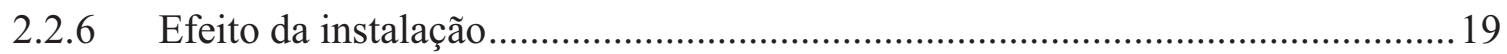

2.2.7 Previsão da capacidade de suporte com base no SPT para projeto ....................21

2.3 INTERPRETAÇÃO DA PROVA DE CARGA EM ESTACAS .............................23

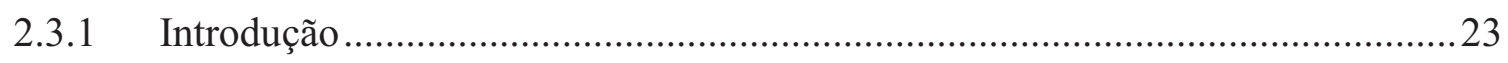

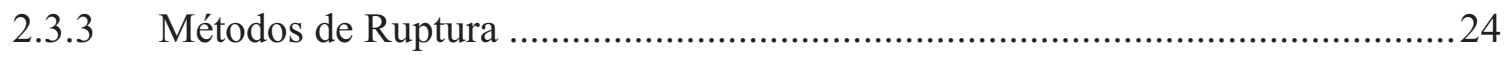

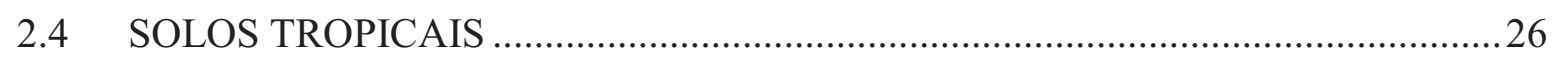

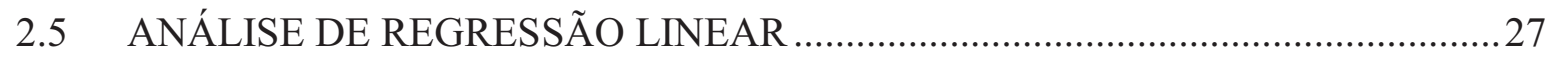

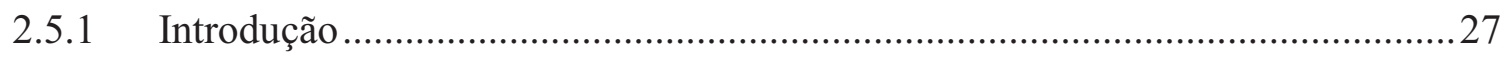

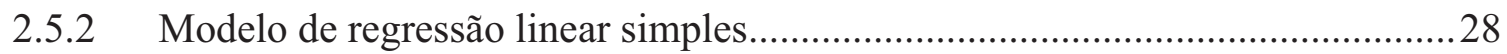

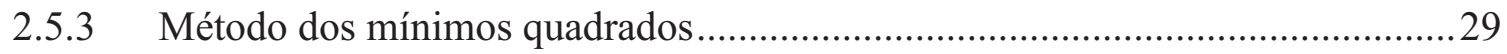

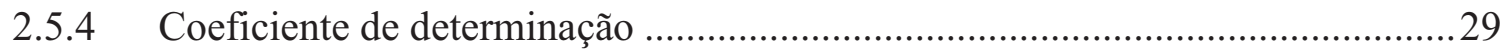

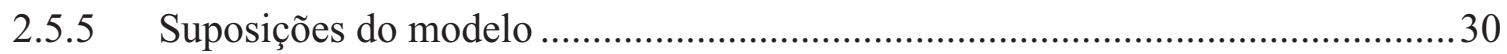

2.5.6 Teste de significância para regressão linear simples ......................................... 31 
2.5.7 Usando a equação de regressão estimada para estimativa e previsão

2.5.8 Análise residual: validando as suposições do modelo ........................................ 36

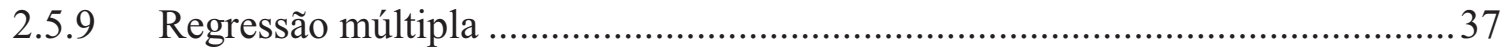

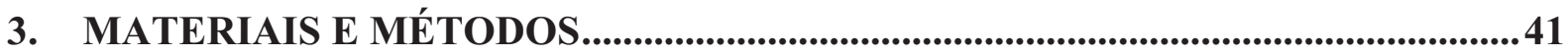

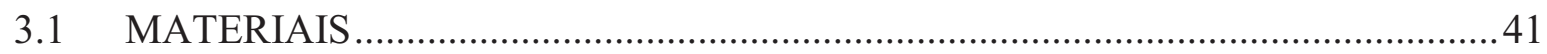

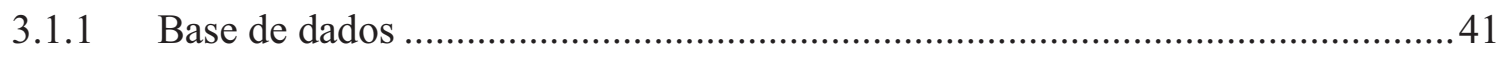

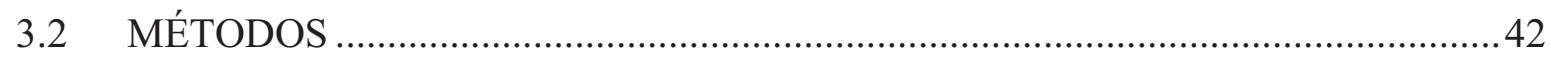

3.2.1 Classificação granulométrica padronizada dos solos ..................................... 42

3.2.2 Métodos de interpretação da prova de carga ................................................... 43

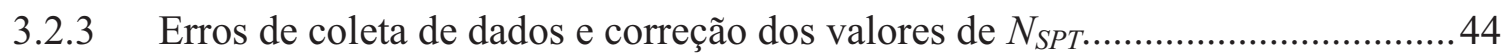

3.2.4 Algumas considerações quanto à numeração das hélices, efeito de sombra para o

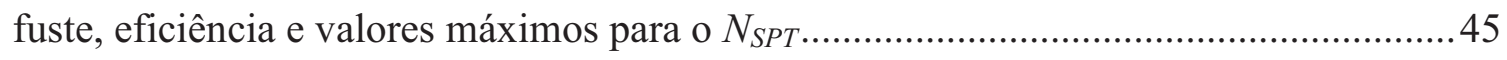

3.2.5 Agrupamento das estacas por tipo de solo...........................................................46

3.2.6 Situações A (recomendada) e B (não recomendada) de projeto...........................46

3.2.7 Modelo de regressão para relação entre torque e capacidade de carga à tração. 47

3.2.8 Modelo de regressão para relação entre $N_{S P T}$ e capacidade de carga ..................48

3.2.9 Análise estatística dos modelos de regressão linear múltipla............................48

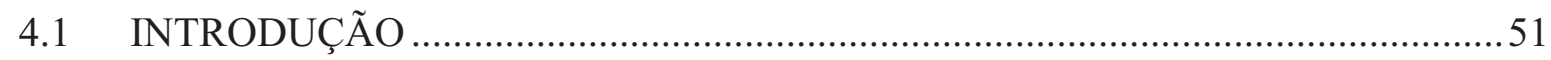

4.2 AMBIENTE DE DESENVOLVIMENTO E ESTRUTURA DO PROGRAMA .....51

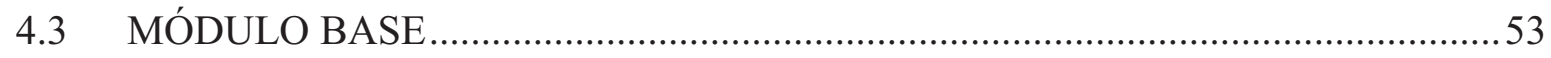

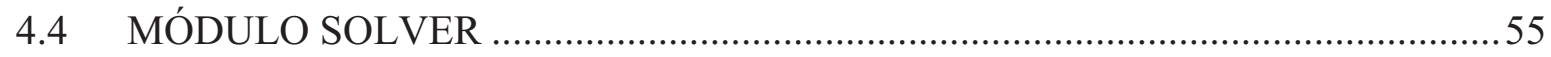

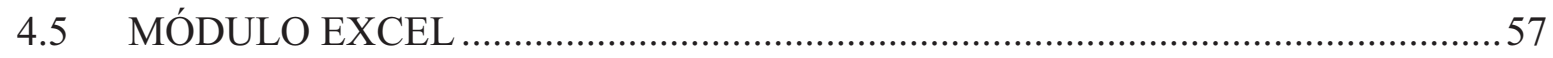

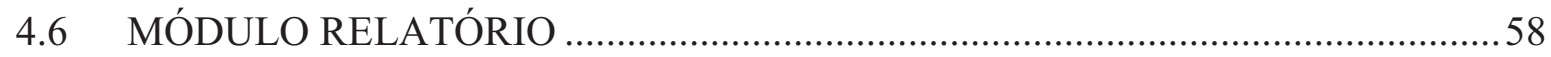

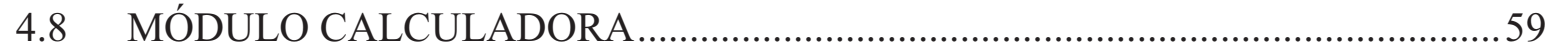

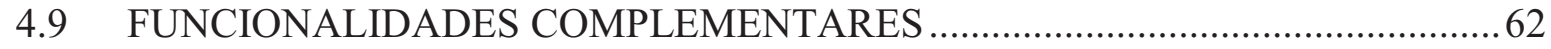

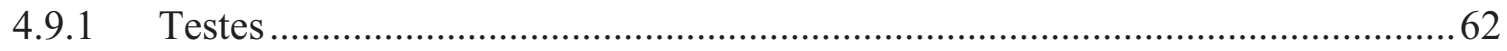

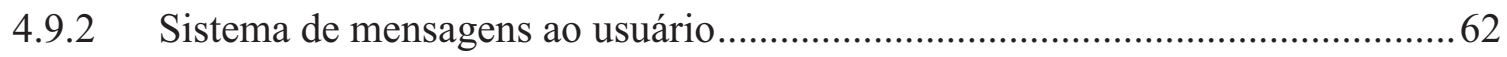


4.9.3 Conversor de unidades 63

4.9.4 Sistema multi-janela 63

5. ANÁLISE DA CORRELAÇÃO ENTRE TORQUE E CAPACIDADE DE CARGA DAS ESTACAS HELICOIDAS. 65

5.1 INTRODUÇÃO 65

5.2 ANÁLISE COM CARGAS DE RUPTURA OBTIDAS PELO CRITÉRIO D/10 ...65

5.2.1 Análise Geral 65

5.5.2 Situação $A$ 67

5.2.3 Situação $B$ 68

5.3 ANÁliSE COM CARGAS DE RUPTURA OBTIDAS PELO CRITÉRIO DE

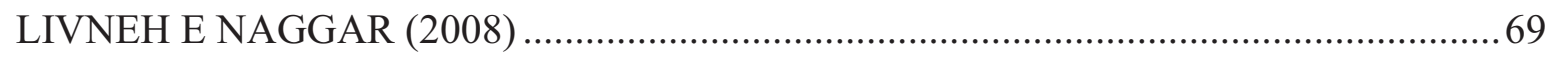

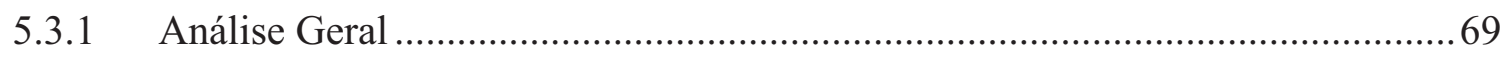

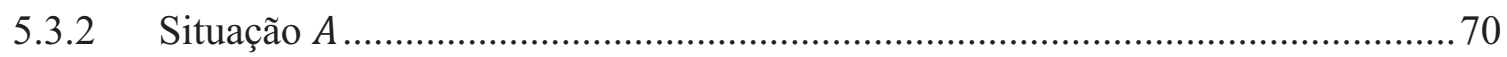

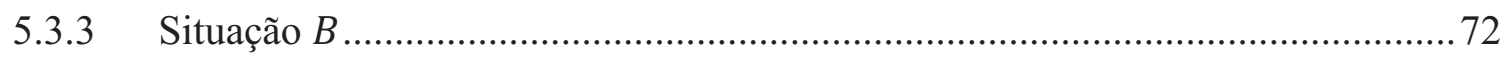

5.4 COMPARAÇÃO DAS METODOLOGIAS …........................................................ 73

6 ANÁLISE DA CORRELAÇÃO ENTRE $N_{S P T}$ E CAPACIDADE DE CARGA DAS ESTACAS HELICOIDAIS ANCORADAS EM SOLOS COM RESISTÊNCIA

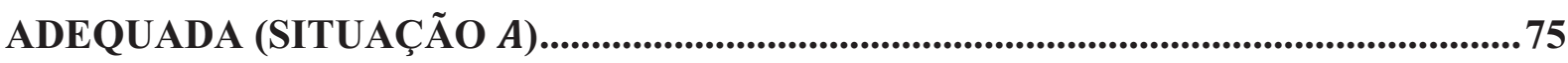

6.1 INTRODUÇÃ

6.2 ANÁLISE DA MATRIZ DE CORRELAÇÃO ….................................................. 76

6.3 REGRESSÃO DO MODELO 1 PARA CARGA DE RUPTURA DO CRITÉRIO $\mathrm{D} / 1078$

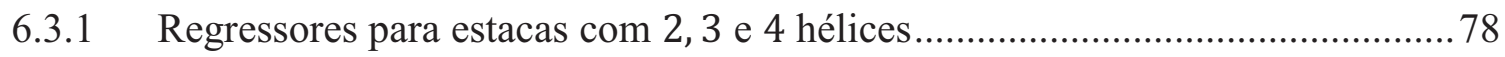

6.3.2 Estatística da regressão para situação $A$ em estacas com 2, 3 e 4 hélices ...........78

6.3.3 Fator de correção para estacas com 2, 3 e 4 hélices na situação $A$...................... 80

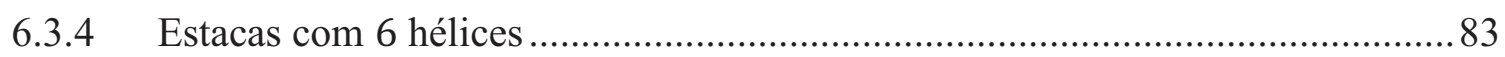

6.4 REGRESSÃO DO MODELO I PARA LIVNEH E NAGGAR (2008) .................... 84

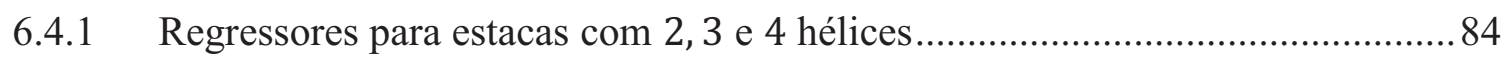


6.4.2 Estatística da regressão para situação $A$ e estacas com 2, 3 e 4 hélices 85

6.4.3 Fator de correção para estacas com 2, 3 e 4 hélices situação $A$............................87

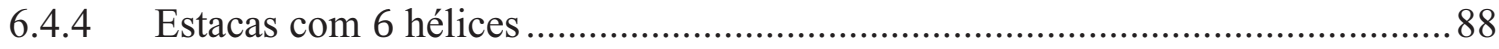

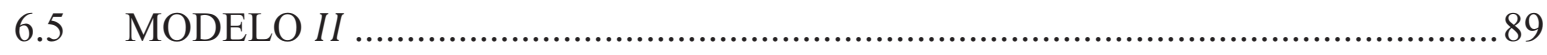

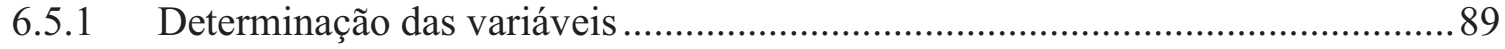

6.5.2 Análise estatística resumida para Livneh e Naggar (2008) na situação $A$...........92

6.6 COMPARAÇÃO ENTRE MODELO I E MODELO II........................................95

7 RECOMENDAÇÕES PARA PROJETO DE ESTACAS HELICOIDAIS ...............99

INTRODUÇÃ

7.2 INTERPRETAÇÃO DA PROVA DE CARGA ................................................... 99

7.3 ESTIMATIVA DA CARGA DE RUPTURA COM BASE NO $N_{S P T} \ldots \ldots \ldots \ldots \ldots \ldots . . . . . . . . . . . .99$

7.4 ESTIMATIVA DA CAPACIDADE DE CARGA COM BASE NO TORQUE DE

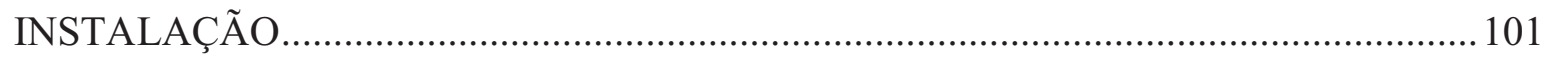

7.5 ESTIMATIVA DO TORQUE DE PROJETO...................................................... 101

8 COMPARAÇÃO DO MODELO PROPOSTO (MODELO I) COM MÉTODO TEÓRICO DA CAPACIDADE DE CARGA INDIVIDUAL ..........................................105

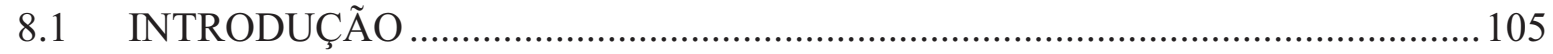

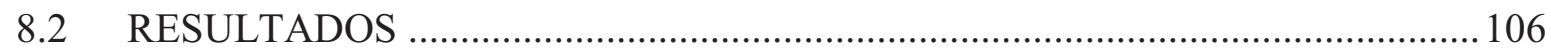

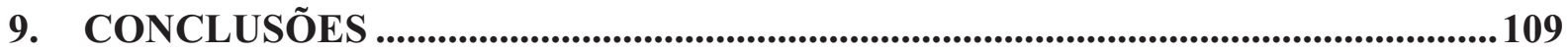

9.1 PROVA DE CARGA E MÉTODOS DE INTERPRETAÇÃO............................... 109

9.2 SOLOS POROSOS E ESTRUTURADOS .......................................................... 109

9.3 MODELOS DE REGRESSÃO E SITUAÇÕES DE PROJETO.............................. 109

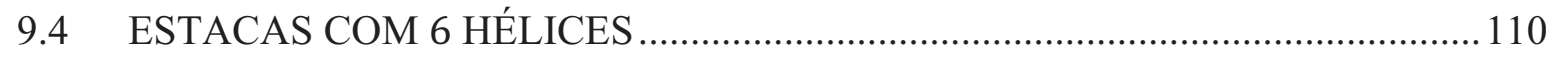

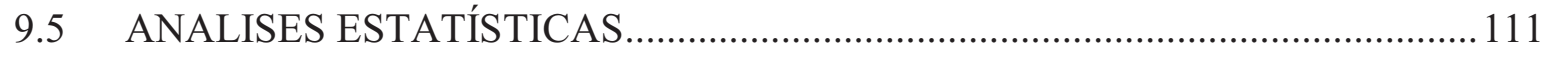

REFERÊNCIAS BIBLIOGRÁFICAS ..............................................................113

ANEXO I $Q u$ vs TORQUE PARA DAVISSON (1972) E NBR 6122 (2010).............. 115

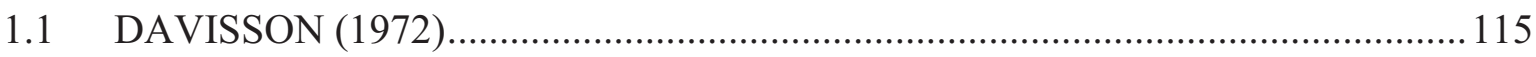




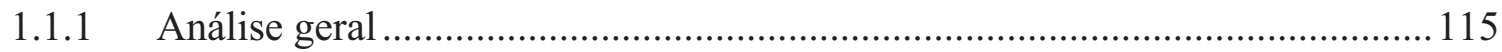

1.1.2 Estacas com 2, 3 e 4 hélices: situação $A$....................................................... 117

1.1.3 Estacas com 2, 3 e 4 hélices: situação $B$...................................................... 120

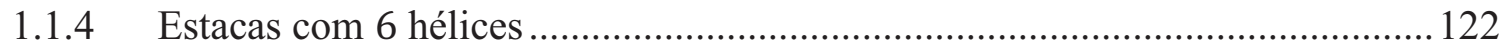

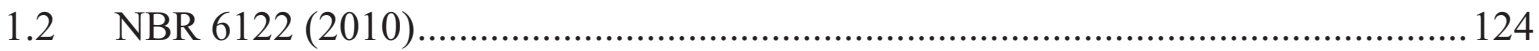

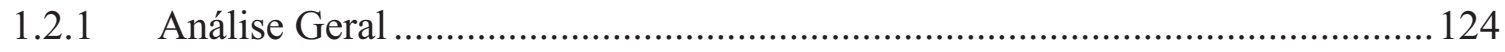

1.2.2 Estacas com 2, 3 e 4 hélices: situação $A$...................................................... 126

1.2.3 Estacas com 2, 3 e 4 hélices: situação $B$...................................................... 129

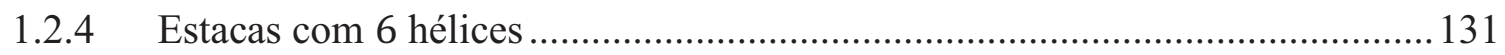

ANEXO II $Q u$ vs $N_{S P T}$ PARA DAVISSON (1972) E NBR 6122 (2010)......................133

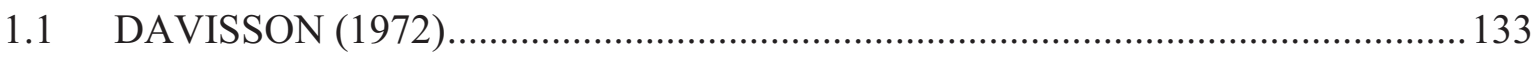

1.1.1 Regressores para estacas com 2, 3 e 4 hélices............................................. 133

1.1.2 Estatística da regressão para situação $A$ em estacas com 2, 3 e 4 hélices ......... 133

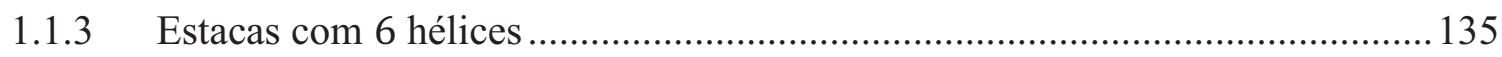

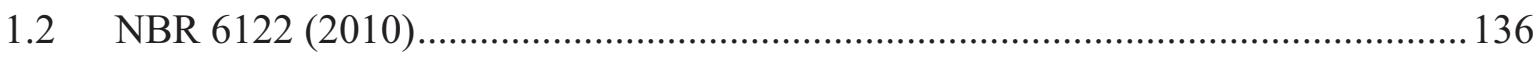

1.2.1 Regressores para estacas com 2, 3 e 4 hélices............................................ 136

1.2.2 Estatística da regressão para situação $A$ em estacas com 2, 3 e 4 hélices .........137

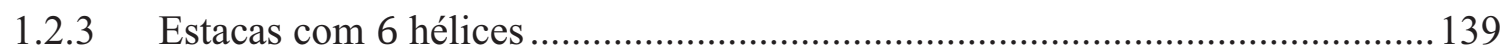

ANEXO III EXEMPLO DE RELATÓRIO DO MÓDULO CALCULADORA ............141

ANEXO IV EXEMPLO DE RELATÓRIO DO MÓDULO SOLVER ...........................147

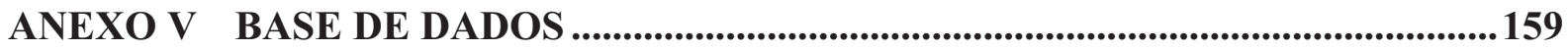




\section{INTRODUÇÃO}

A engenharia pode ser definida como a arte de transformar recursos naturais em formas adequadas de produtos para atender às necessidades humanas. Simploriamente, os serviços de engenharia podem ser agrupados em duas grandes áreas: projetos e execução (Tisaka, 2006).

Dentre os diversos projetos de engenharia civil, existe o de fundação. Ele deve assegurar que os elementos dimensionados apresentem segurança quanto ao: a) estado-limite último, associado ao colapso parcial ou total da obra, e b) estado-limite de serviço, quando ocorrem deformações, fissuras, etc. que comprometem o uso da obra (NBR 6122, 2010).

Na prática brasileira, para a previsão de capacidade de carga de fundações por estacas na fase de projeto, o engenheiro geralmente dispõe unicamente de resultados de ensaios SPT. Portanto, é usual criar correlações entre o $N_{S P T}$ e o desempenho das fundações. Existem diferentes métodos, usados pela comunidade brasileira, baseados em dados do ensaio SPT, mas nenhum específico para as estacas helicoidais.

Os principais métodos teóricos de previsão de capacidade de carga de fundações por estacas helicoidais são baseados em parâmetros do solo como: coesão, ângulo de atrito, peso específico e coeficiente de empuxo. Estes parâmetros são estimados indiretamente a partir do ensaio SPT. No entanto, os resultados proporcionados por estes métodos teóricos são, na maioria das vezes, bem distantes dos medidos em provas de carga, como observado em Hoyt e Clemence (1989).

Portanto, devido ao rápido crescimento deste tipo de estaca no Brasil como fundação de torres de linhas de transmissão de energia, é urgente a necessidade de métodos mais acurados para a previsão da capacidade de carga de fundações por estacas helicodiais. Esta necessidade também é importante para diminuir os gastos das obras, visto que pelo fato dos métodos disponíveis não serem eficientes: um grande número de provas de carga têm sido executadas nestas obras (praticamente em quase todas as estacas).

Devido a esta necessidade citada acima, foi desenvolvido nesta dissertação um método semi-empírico para a estimativa da capacidade de carga à tração de fundações por estacas helicoidais profundas, que correlaciona a capacidade de carga relativa às hélices com valores de $N_{S P T}$. Este método foi calibrado a partir de um grande número de resultados de provas de carga rápida (para obras de torres de linha de transmissão) realizadas em solos brasileiros. 
Portanto este método é válido para ser aplicado apenas no dimensionamento de fundações por estacas helicoidais profundas instaladas em solos semelhantes ao desta dissertação.

A estaca helicoidal tipo profunda é o tipo mais usual na prática deste tipo de fundação. Neste caso, a hélice superior da estaca é instalada em profundidade suficiente para que a superfície de ruptura, quando solicitada em tração, não atinja a superfície do terreno. Portanto, como citado em Mitch e Clemence (1985), neste caso o comportamento da hélice superior carregada em tração é similar ao da ponta de uma estaca, e a superfície de ruptura é desenvolvida diretamente acima da hélice é confinada pela zona de solo acima da hélice superior.

Portanto, o modelo proposto nesta dissertação foi calibrado e é indicado para a condição de estaca helicoidal profunda. Neste caso, os modelos de cálculo típicos para ancoragens rasas, em que é considerado o peso do volume de solo movimentado acima da placa (superfície de ruptura equivalente a um tronco de cone, etc.) até a superfície do terreno não são adequados para o presente trabalho.

\section{$1.1 \quad$ OBJETIVOS}

O objetivo principal deste trabalho é desenvolver um método de cálculo, mais acurado que os disponíveis até então, para a previsão da capacidade de carga à tração de fundações por estacas helicoidais, instaladas em solos similares ao desta pesquisa, para quando o projetista dispuser de resultados de ensaios SPT para caracterizar o terreno da fundação. Os objetivos específicos são:

1. Compreender os efeitos das principais variáveis do problema na capacidade de carga à tração da fundação por estaca helicoidal;

2. Avaliar estatisticamente a correlação entre o torque medido no final da instalação com a capacidade de carga à tração da fundação por estaca helicoidal.

\subsection{ESTRUTURA DA DISSERTAÇÃO}

A dissertação foi estruturada em oito capítulos. O capítulo 1 apresenta uma introdução ao tema abordado, os objetivos da pesquisa e a organização da dissertação. No capítulo 2 é mostrada a revisão bibliográfica dos temas relacionados ao presente trabalho. 
O capítulo 3 apresenta os materiais e métodos usados nessa pesquisa. Quanto aos materiais, o desenvolvimento do trabalho teve como base um grupo de dados composto de 76 provas de carga à tração, executadas em estacas helicoidais com diferentes dimensões, instaladas em terrenos distintos em que foram realizados ensaios SPT. Quanto aos métodos, neste capítulo são apresentadas as análises estatísticas usadas para o tratamento dos dados.

No capítulo 4 é detalhado o software desenvolvido nesta pesquisa para o tratamento dos dados. Nos capítulos 5 e 6 são apresentadas análises dos resultados. No capítulo 7 é proposto um método para o projeto de fundações em estacas helicoidais em solos similares aos dos dados usados nesta dissertação.

Por fim, o capítulo 8 apresenta as conclusões sobre os resultados obtidos, e sugestões para o desenvolvimento de estudos futuros relacionados ao tema estudado. Após este capítulo são mostrados os documentos em anexo relativos aos dados da pesquisa. 


\section{REVISÃO BIBLIOGRÁFICA}

\subsection{INTRODUÇÃO}

As estacas metálicas helicoidais são usadas há mais de 200 anos. No início, ela era uma alternativa interessante para problemas geotécnicos específicos, porém, nos últimos 50 anos, seu uso aumentou e passou, em algumas regiões, a ser adotada com maior frequência como fundação profunda (Perko, 2009).

Sob o ponto de vista de projetistas, as estacas helicoidais podem ser adaptadas para suportar vários tipos de estruturas em diversos tipos de solo. Para os proprietários e executores, elas são simples de instalar, e sua capacidade de carga pode ser facilmente verificada por meio de correlações com o torque final de instalação, diminuindo-se as incertezas quanto à capacidade de carga. Na perspectiva pública, ela é talvez um dos tipos de fundação profunda mais interessante, inovadora, e ambientalmente correta (Perko, 2009).

Pode-se estimar a capacidade de carga de fundações por estacas helicoidais com base em resultados de ensaios $S P T$ e verificá-la durante a execução, utilizando-se medidas do torque necessário para instalá-las no terreno. Este torque é uma medida indireta da resistência do terreno atravessado pelas hélices da estaca durante sua instalação.

No Brasil, o ensaio SPT (Standart Penetration Test) é o ensaio de investigação do subsolo mais usado. Quando comparado aos demais, este ensaio apresenta simplicidade no manuseio de seus equipamentos, baixo custo, ampla base de dados, facilidade de interpretação dos resultados e obtenção de um índice $\left(N_{S P T}\right)$, o qual pode ser usado para obter os parâmetros de projeto mediante uso de regras empíricas (Schnaid, 2000). No entanto, este tipo de ensaio é criticado quanto à diversidade de procedimentos utilizados na sua execução e pouca racionalidade na sua interpretação.

\subsection{ESTACAS METÁLICAS HELICOIDAIS}

\subsubsection{Introdução}

As estacas metálicas helicoidais (Figura 2. 1) são amplamente utilizadas em vários países, principalmente como fundações de torres de linhas de transmissão de energia e de telecomunicação, gasodutos, casas e prédios comerciais, postes de luz, passarelas, e também 
como reforço de fundação. São usadas principalmente em casos em que a fundação é solicitada a esforços de tração e compressão.

No Brasil, seu uso se intensificou no final da década de 90 para resistir a esforços de tração em obras de torres de linhas de transmissão de energia elétrica e de telecomunicações (Tsuha, 2007).

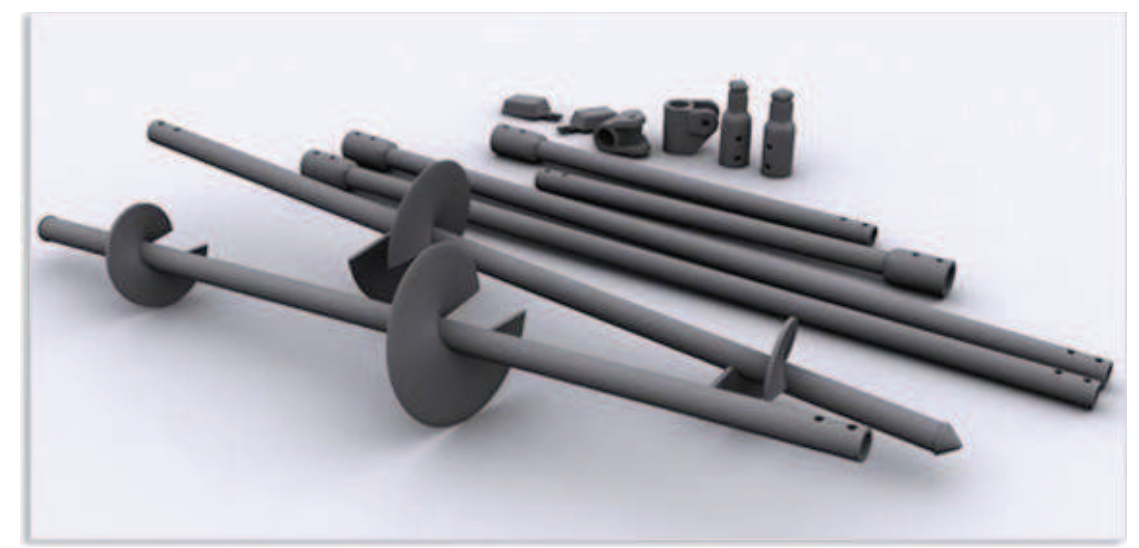

Figura 2. 1: Estaca helicoidal metálica (Asel-Tech, 2012).

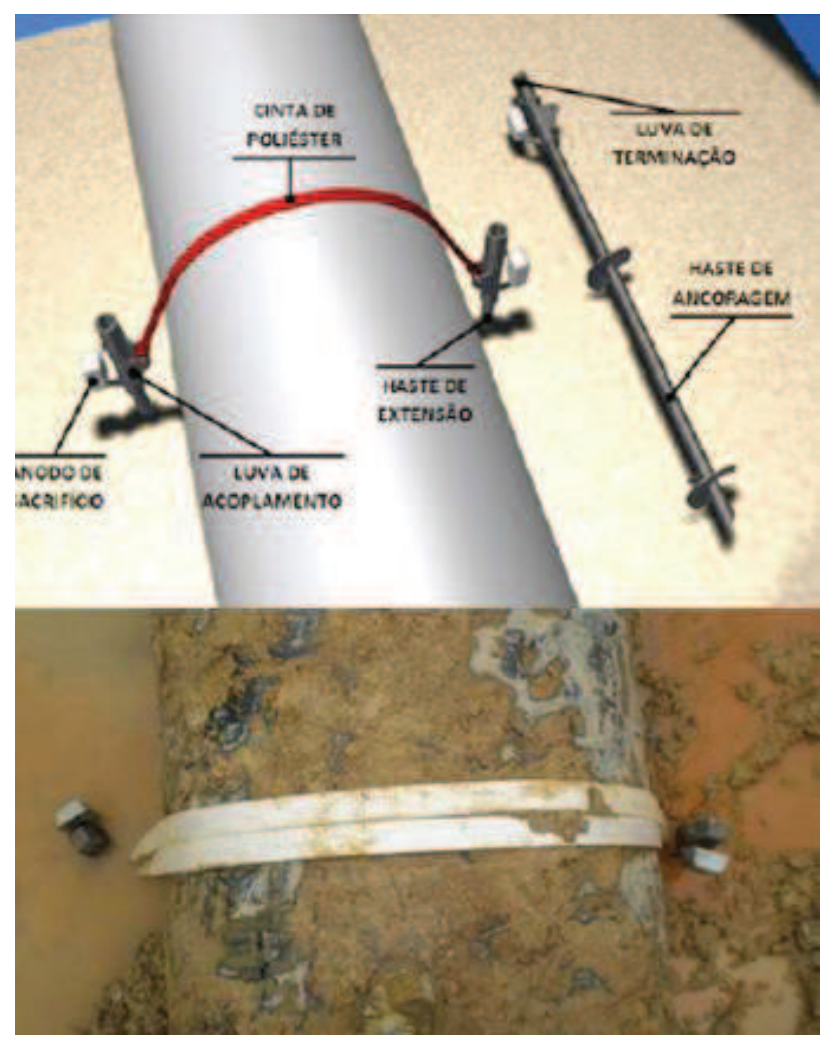

Figura 2. 2: Aplicação da estaca metálica helicoidal para controle de flutuação de dutos (AselTech, 2012). 
Esta estaca pode ser instalada horizontalmente ou inclinada para suportar cargas de compressão e/ou tração como em muros de contenção (onde é comum serem usadas como tirantes), sistema de telhados membrana, torres de transmissão, controle de flutuação de dutos (Figura 2. 2), entre outras (Perko, 2009).

\subsubsection{Composição}

As estacas helicoidais são compostas por uma seção guia, seções de extensão e cabeça da estaca, conforme ilustra a Figura 2. 3

A seção guia é formada por uma haste com uma ou mais hélices soldadas e espaçadas para se comportem individualmente quando a estaca for solicitada.

As extensões são usadas para aprofundar as hélices da estaca no terreno quando necessário. Elas possuem seção quadrada cheia ou circular vazada (igual a da seção guia) e uma extremidade alargada a fim de permitir seu engate e aparafusamento.

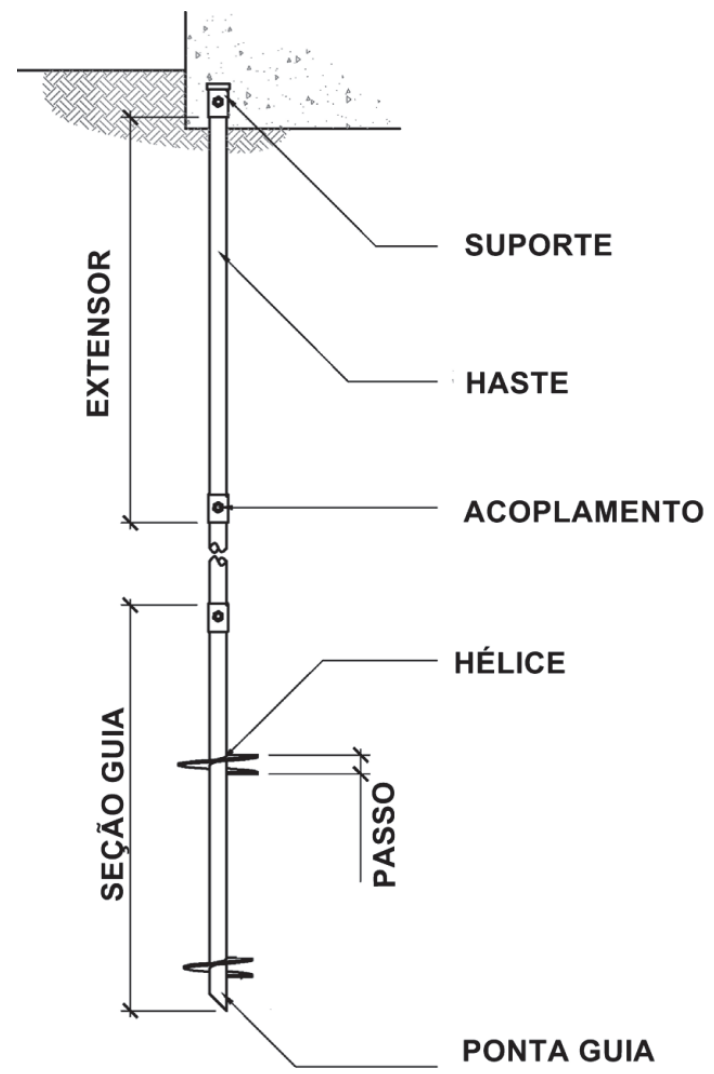

Figura 2. 3: Estaca metálica helicoidal (modificado de Perko, 2009) 


\subsubsection{Vantagens}

Esta fundação possui vantagens únicas, dentre as quais Perko (2009) destaca:

- A instalação é:

1) rápida e sem risco de desmoronamento do solo,

2) pode ser feita abaixo do nível d'água e em áreas de difícil acesso com equipamentos portáteis,

3) não produz vibrações e barulhos excessivos;

- A estaca pode ser carregada imediatamente após a instalação;

- Ela pode ser removida e reinstalada possibilitando corrigir eventuais erros de posicionamento, mudanças da planta de fundação ou reaproveitamento em outras obras.

- É fácil de transportar para lugares distantes;

- Pode ser instalada com inclinação para aumentar a resistência lateral;

- Pode ser galvanizadas para evitar a corrosão;

- São ambientalmente sustentáveis.

\subsubsection{Instalação}

A instalação da estaca helicoidal é feita com aplicação de torque em sua haste por meio de um sistema de motor hidráulico portátil, ou montado sobre um caminhão, retroescavadeira, guindastes, etc (Figura 2. 4). O motor deve ser capaz de girar no sentido horário e anti-horário, permitir controlar e ajustar o número de voltas por minutos durante a instalação (Perko, 2009).

As etapas de execução da estaca, ilustradas na Figura 2.5, são (Perko, 2009):

1. Montar o equipamento acoplando-se a seção guia ao sistema de aplicação de torque.

2. Posicionar e alinhar a seção guia no local com inclinação desejada.

3. Introduzir a ponta da seção guia no solo.

4. Ajustar a posição da seção guia.

5. Conferir a inclinação e o alinhamento do motor de torque antes de iniciar a rotação.

6. Iniciar a rotação da estaca pressionando-a para baixo. 
7. Verificar a inclinação da estaca sempre que necessário.

8. Anotar a profundidade e o torque de instalação para os intervalos desejados.

9. Parar a instalação acima do terreno onde o operador possa ver claramente o pino de acionamento.

10. Adicionar as hastes extensoras se necessário.

11. Continuar a instalação, verificar a inclinação da haste se necessário.

12. Parar a instalação quando a atingir a profundidade e torque especificados em projetos.

13. Cortar os extensores até a elevação final.

14. Perfurar buracos dos parafusos.

15. Instalar a cabeça da estaca.

16. Anotar a profundidade e torque final.

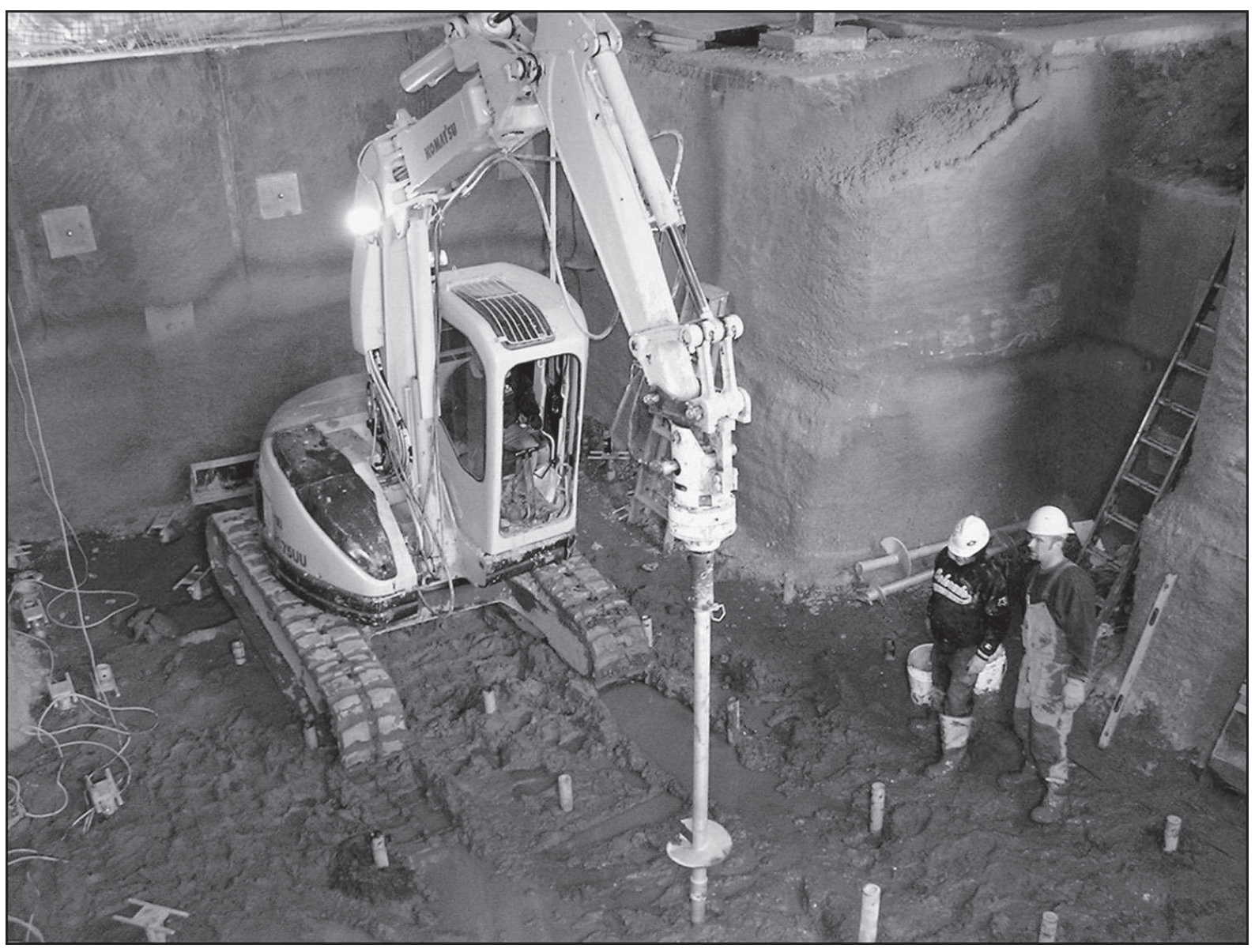

Figura 2. 4: Adaptação do motor hidráulico em uma retro escavadeira (Perko, 2009) 

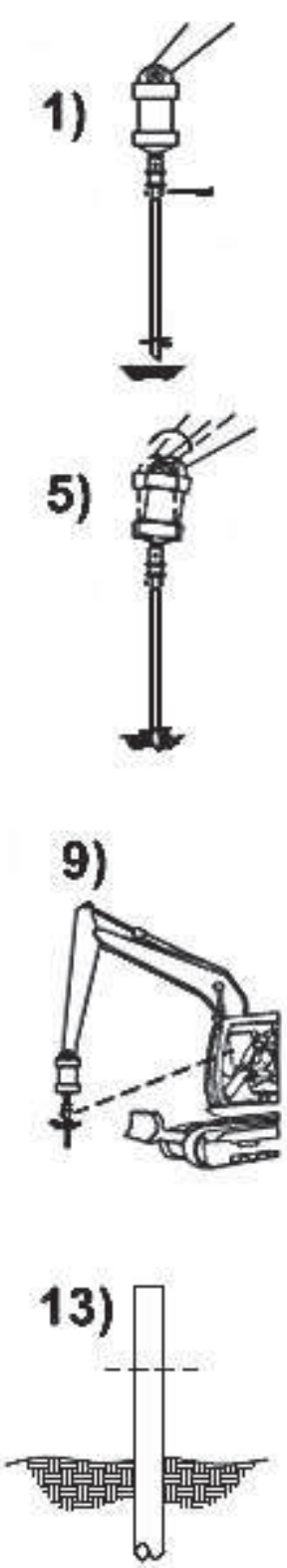

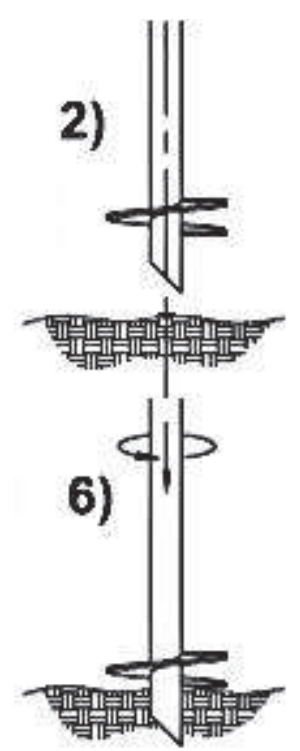

10)

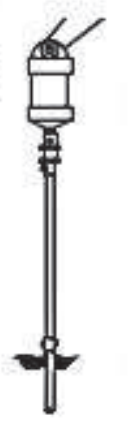

14)

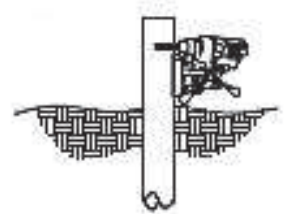

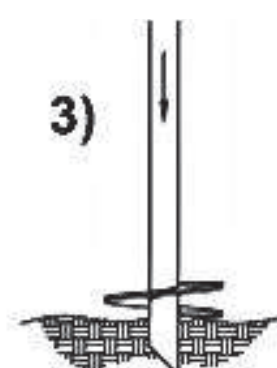
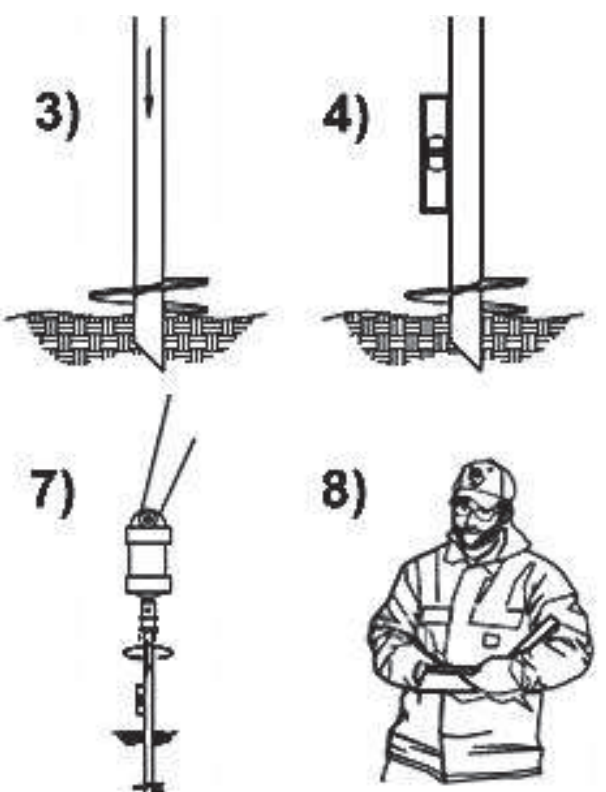

11)

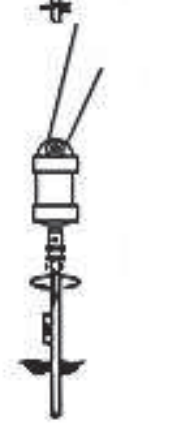

12)

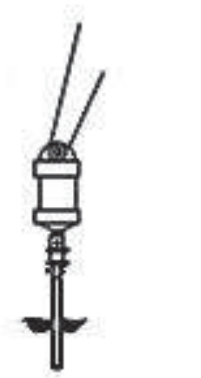

15)
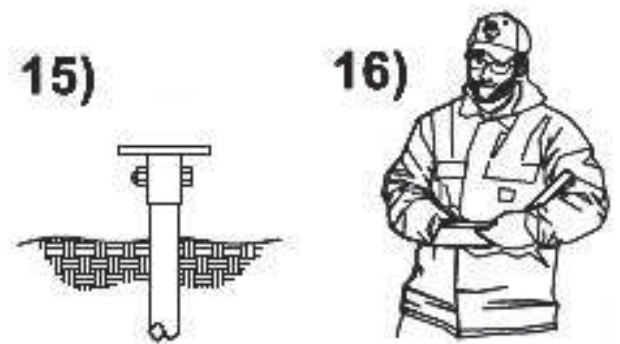

Figura 2. 5: Procedimentos gerais de instalação (modificado de Perko, 2009)

Durante a instalação da estaca no terreno, o avanço (em geral igual a um passo de hélice por volta) deve ser suave e com rotação contínua. Não há estudos sobre o efeito de elevadas velocidades de rotação no solo de instalação da estaca, porém taxas menores que 30 rpm permitem que o operador reaja rapidamente às mudanças das características do solo (Perko, 2009).

Uma força axial constante deve ser aplicada enquanto a estaca helicoidal estiver sendo instalada para garantir o avanço no terreno igual a, no mínimo, 80\% do passo das hélices por volta (Perko, 2009). 
Deve-se atentar para não se aplicar um valor de torque superior ao máximo que pode ser resistido pelos componentes e encaixes da estaca. Caso o torque máximo ocorra antes que a ponta da estaca alcance a profundidade mínima definida em projeto, Perko (2009) sugere as seguintes ações:

1. Retroceder a estaca entre 0,5 e 1,0 metros revertendo-se o sentido do torque na tentativa de reduzir a força de compressão e avançar pela obstrução. Em algumas situações, esse processo deverá ser repetido várias vezes.

2. Remover a estaca helicoidal e reinstalar uma nova com componentes mais resistentes e/ou hélices com diâmetros menores.

3. Remover a estaca helicoidal e fazer um pequeno furo guia no mesmo local a reinstalar a estaca.

4. Se a obstrução é rasa, retirar a estaca helicoidal e escavar para removê-la.

5. Remover a estaca a realocá-la próxima ao local de instalação.

6. Não prosseguir com a escavação e reavaliar a capacidade de carga da estaca (instalação de estacas helicoidais extras pode ser necessária).

7. Remover a estaca e retirar a hélice na extremidade superior e/ou reduzir o seu diâmetro cortando-a in loco. Reinstalar a estaca com configuração das hélices revisadas.

8. Remover a estaca e reinstalar outra com formato mais adequado.

O valor de torque final de instalação é definido no projeto por ser diretamente proporcional à capacidade de carga da fundação por estaca helicoidal mediante uso de correlações empíricas. Caso ele não seja alcançado até a profundidade da instalação calculada em projeto (para atender a capacidade de carga desejada), podem ser adotadas as seguintes soluções, segundo Perko (2009):

1. Continuar a instalação adicionando mais hastes extensoras.

2. Adicionar hastes extensoras com hélices, com a finalidade de aumentar o torque e a capacidade de carga.

3. Remover a estaca e instalar uma nova com mais hélices e/ou maior diâmetro.

4. Diminuir a capacidade de carga da estaca. Compensar a diferença instalando-se outras estacas nos locais especificados pelo engenheiro. 


\subsubsection{Capacidade de carga à tração}

Dimensionar uma fundação por estaca helicoidal consiste em determinar a quantidade e o diâmetro de suas hélices e as dimensões da haste para suportar as cargas definidas no projeto.

Em geral, sua capacidade de carga é função de: 1) características do solo de instalação; 2) dimensões das hélices; 3) atrito ou adesão entre a haste e o solo envolvente; 4) espaçamento entre as hélices da estaca; 5) inclinação da estaca; 6) profundidade da instalação das hélices. Qualquer diferença na combinação dessas variáveis alterará seu modo de ruptura e sua capacidade de carga (Merifield e Smith, 2011).

Os principais métodos de previsão de capacidade de carga utilizados para as estacas metálicas helicoidais são: 1) método da capacidade de carga individual e 2) método do cisalhamento do cilindro (ambos são utilizados para determinar a resistência à tração e compressão).

O método da capacidade de carga individual (Figura 2.8) considera que as hélices da estaca trabalham isoladamente, sendo indicado quando elas estão suficientemente distantes uma da outra.

O método do cisalhamento do cilindro (Figura 2.9) é utilizado quando o espaçamento entre as hélices é pequeno. Nele, a capacidade de carga da estaca é considerada como o somatório da resistência da ponta (hélice superior para tração, e inferior na compressão) com a resistência ao cisalhamento lateral ao longo do cilindro de solo formado entre a hélice inferior e superior da estaca (Perko, 2009).

Nos dois métodos, quando a dimensão da haste da estaca for significante (diâmetro e comprimento), considera-se também a parcela de resistência por atrito lateral na haste.

A distância necessária entre as hélices para que estas se comportem individualmente ou se sobreponham causando a ruptura do cilindro de solo é uma medida relativa e dependente da geometria da estaca e do solo ao seu redor. Portanto, Perko (2009) sugere que a capacidade de carga em projeto seja o menor valor calculado por meio dos dois métodos.

Hoyt e Clemence (1989) avaliaram os métodos citados acima para um grande número de dados de provas de carga em estacas helicoidais em diferentes tipos de solo, e concluíram que estes métodos são pouco acurados.

Posteriormente, Merifield e Smith (2011) comentaram que os métodos listados acima são inadequados para estimar a capacidade de carga das estacas helicoidais, e desenvolveram 
um método de previsão do comportamento das estacas helicoidais em argila baseado em métodos numéricos.

\subsubsection{Ancoragem profunda e rasa}

A superfície de ruptura do solo em torno de uma estaca helicoidal tracionada depende da relação $H_{1} / D_{1}$ (Das, 1990; Mitsch e Clemence, 1985).

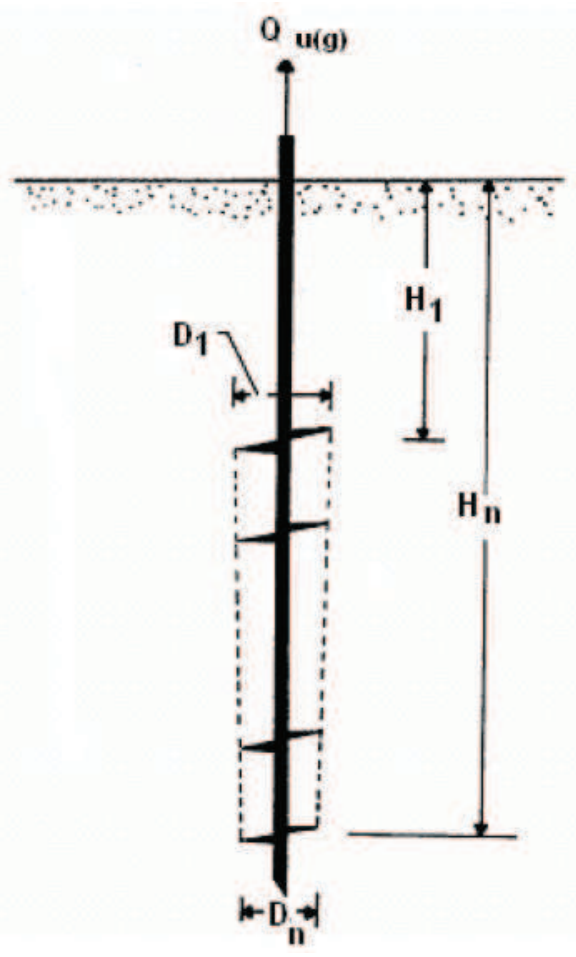

Figura 2. 6: Estaca helicoidal instalada em areia (Das, 1990).

Quando a relação $H_{1} / D_{1}$ é menor que um valor crítico, a superfície de ruptura é formada por um cone que se encontra com o terreno e um cilindro abaixo da hélice de topo (Figura 2.7 a) e ancoragem é denominada rasa. No caso da hélice superior instalada abaixo da profundidade crítica, a superfície de ruptura acima da hélice não atingirá a do terreno (Figura 2. 7 b), e a ancoragem é denominada de profunda (Das, 1990).

O valor crítico sugerido por Das (1990) é $\left(\frac{H_{1}}{D_{1}}\right)_{c r}=5$. 

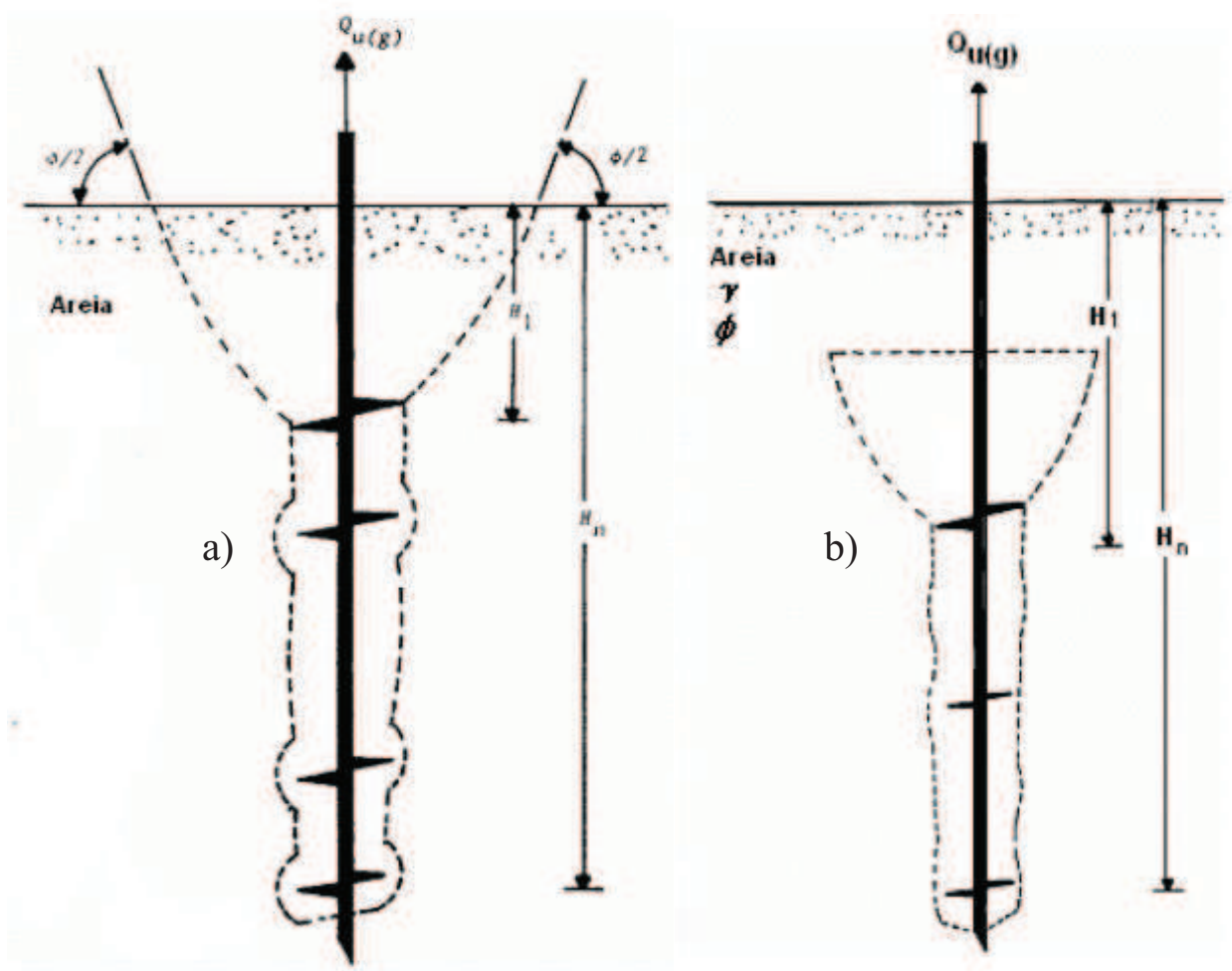

Figura 2. 7: Superfície de ruptura de estacas helicoidais trancionadas (Das, 1990): a) ancoragem rasa, b) ancoragem profunda.

\subsubsection{Método da capacidade de carga individual}

Este método é recomendado para quando as hélices de estacas multi-hélices (hélice superior na condição profunda) são espaçadas o suficiente de modo que trabalhem individualmente como mostra a Figura 2. 8. Neste caso, a capacidade de carga de cada hélice é calculada com base na equação de Terzaghi para estimar capacidade de carga de sapatas.

Adams e Klym (1972) foram os primeiros a utilizar este método para estacas multihélices onde a capacidade de carga à tração de cada hélice em solo arenoso é dada pela equação 2 . 1 , e capacidade de carga total da estaca relativa às hélices $\left(Q_{h}\right)$ é calculada pela equação 2. 2. Neste caso, não se considerou a resistência por atrito lateral na haste da estaca $\left(Q_{s}\right)$, portanto a capacidade de carga total da estaca $\left(Q_{u}\right)$ é igual à parcela relativa à capacidade de carga das hélices $\left(Q_{h}\right)$. 
$Q_{h i}=\gamma^{\prime} H_{i} N_{q u} A_{e h i}$

onde:

$i=$ índice de $1 \mathrm{a} N$, onde $N$ é o número de hélices,

$Q_{h i}=$ capacidade de carga da hélice i,

$\gamma^{\prime}=$ peso específico efetivo do solo acima da hélice,

$H i=$ profundidade da hélice $\mathrm{i}$,

$N_{q u}=$ fator de capacidade de carga que varia com o ângulo de atrito e profundidade relativa da hélice,

$A_{e h i}=$ área projetada da hélice

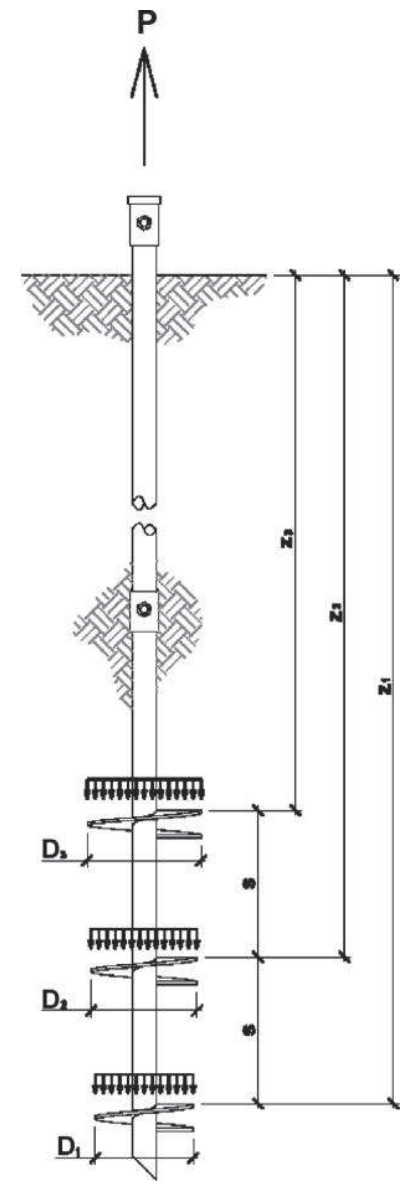

Figura 2. 8: Método da capacidade de carga individual para estacas helicoidais tracionadas (Perko, 2009) 
Neste caso, a capacidade de carga da estaca devido às hélices é dada por:

$Q_{h}=\sum_{1}^{N} Q_{h i}$

Como mostrado no manual de projeto da Hubbell (2003), a capacidade de carga à tração relativa a cada hélice de estacas helicoidais $Q_{h}$, em argila, em areia e em solos intermediários pode ser estimada pelas expressões:

Argila) $Q_{h}=A_{h} c N_{c}=A_{h} c 9$

Areia) $Q_{h}=A_{h} q^{\prime} N_{q}=A_{h} \gamma^{\prime} D N_{q}$

Solo $c-\phi) Q_{h}=A_{h}\left(c N_{c}+q^{\prime} N_{q}\right)$

Onde:

$\mathrm{A}_{\mathrm{h}}=$ área projetada da hélice em um plano perpendicular ao eixo do tubo

$\mathrm{c}=$ coesão

$\mathrm{q}^{\prime}=$ tensão efetiva acima da hélice

$\mathrm{N}_{\mathrm{c}}=$ fator de capacidade de carga à tração para solos coesivos (igual a 9 neste caso)

$\mathrm{N}_{\mathrm{q}}=$ fator de capacidade de carga à tração para solos sem coesão

$\mathrm{D}=$ profundidade da hélice na vertical

$\gamma=$ peso específico efetivo do solo

O fator de capacidade de carga $N_{q}$ proposto pela Hubbel (2003) para estacas helicoidais profundas em areia depende do ângulo de atrito do solo (ø) e é dado por:

$N_{q}=0,5(12 \phi)^{\phi / 54}$

Para o caso de solos intermediários ( $\operatorname{solos} c-\phi$ ), onde não se conheça os parâmetros de coesão e ângulo de atrito do maciço de solo, é sugerido pela Hubbell (2003) que se façam 
duas estimativas, uma para solo coesivo (equação 2. 3), e a outra para solo não coesivo (equação 2. 4), e utilize a que dê o menor resultado de capacidade de carga.

\subsubsection{Método do cisalhamento do cilindro}

Este método foi desenvolvido para estacas helicoidais rasas e profundas. Neste trabalho mostra-se apenas as expressões para estimativa da capacidade de carga à tração de estacas helicoidais profundas, porque este é o caso mais comum no Brasil e o estudado nesta dissertação.

A estaca helicoidal é chamada de rasa quando a superfície de ruptura cônica acima da hélice de topo atinge o nível do terreno. Porém, quando a razão $\mathrm{H}_{1} / \mathrm{D}_{1}\left(\mathrm{H}_{1}\right.$ é a profundidade da hélice superior, e $\mathrm{D}_{1}$ é o diâmetro externo da hélice superior) apresenta um valor elevado, a superfície de ruptura acima da hélice de topo é local e não atinge a superfície do terreno, e nesta condição é denominada estaca helicoidal profunda (Das, 1990).

Com base na hipótese de ruptura mostrada na Figura 2. 9, e considerando-se a resistência por atrito na haste, a capacidade de carga à tração de fundações por estacas helicoidais profundas $\left(Q_{u}\right)$ pode ser estimada pelas Equações 2. 7, 2. 8 e 2. 9. A Equação 2. 7 é para estacas helicoidais em areia (Mitsch e Clemence, 1985), e as Equações 2. 8 e 2. 9 são para estacas em argila e em silte (Mooney et al., 1985):

$$
\begin{aligned}
& \mathrm{Q}_{\mathrm{u}}=\gamma^{\prime} H_{1} A_{1} N_{q u}+\frac{\pi}{2} D_{a} \gamma^{\prime}\left(H_{n}{ }^{2}-H_{1}^{2}\right) K_{u} \tan \phi^{+} p_{s} H_{1}\left(\frac{\gamma^{\prime} H_{1}}{2}\right) K_{u} \tan \phi \\
& \mathrm{Q}_{\mathrm{u}}=A_{1} c N_{c u}+\pi D_{a} c\left(H_{n}-H_{1}\right)+p_{s} H_{1} C_{a} \\
& \mathrm{Q}_{\mathrm{u}}=\gamma^{\prime} H_{1} A_{1} N_{q u}+A_{1} c N_{c u}+\frac{\pi}{2} D_{a} \gamma^{\prime}\left(H_{n}{ }^{2}-H_{1}{ }^{2}\right) K_{u} \tan \phi+\pi D_{a} c\left(H_{n}-H_{1}\right)+p_{s} H_{1} C_{a}+ \\
& p_{s} H_{1}\left(\frac{\gamma^{\prime} H_{1}}{2}\right) K_{u} \tan \phi+p_{s} H_{1} C_{a}
\end{aligned}
$$


onde:

$\mathrm{K}_{\mathrm{u}}=$ coeficiente de empuxo

$\mathrm{A}_{1}=$ área da hélice superior

$\mathrm{D}_{\mathrm{n}}$ e $\mathrm{H}_{\mathrm{n}}=$ diâmetro e profundidade da hélice inferior (da ponta)

$\mathrm{D}_{\mathrm{a}}=$ diâmetro médio das hélices

$\mathrm{N}_{\mathrm{qu}}=$ fator de capacidade de carga à tração para areias (do trabalho de Mitsch \& Clemence 1985)

$\mathrm{N}_{\mathrm{cu}}=$ fator de capacidade de carga à tração para solo coesivo (do trabalho de Mooney et al. 1985)

$\mathrm{p}_{\mathrm{s}}=$ perímetro do tubo da estaca

$\mathrm{C}_{\mathrm{a}}=$ adesão ao longo do tubo da estaca

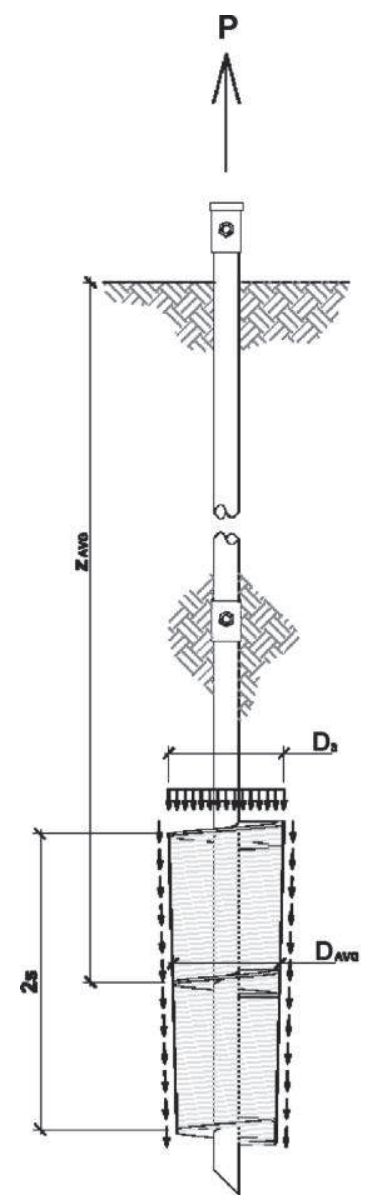

Figura 2. 9: Método do cilindro de cisalhamento para estacas helicoidais tracionadas (Perko, 2009) 
2.2.5 Correlação entre torque de instalação e capacidade de carga

Espera-se que o torque requerido para avançar a estaca no terreno indique a resistência do solo atravessado. Por esse motivo, ele é comumente utilizado para estimar a capacidade de carga à tração e à compressão da estaca helicoidal. A relação entre capacidade de carga à tração da estaca $\left(Q_{u}\right)$ e o torque medido ao final da instalação é dada por:

$Q_{u}=K_{t} T$

Onde:

$K_{t}=$ fator empírico de torque e possui unidade de $m^{-1}$

$T=$ torque medido ao final da instalação da estaca no terreno

Na prática, a utilização do torque para controle da capacidade de carga da estaca helicoidal é baseado em regras empíricas estabelecidas pela experiência das empresas executoras (Tsuha, 2012).

Valores típicos de $K_{t}$ foram propostos por Hoyt e Clemence (1989), onde $33 \mathrm{~m}^{-1}$ é recomendado para todas as estacas com hastes quadradas e circulares com diâmetro inferior a $89 \mathrm{~mm}, 23 \mathrm{~m}^{-1}$ para $89 \mathrm{~mm}$ e $9.8 \mathrm{~m}^{-1}$ para $219 \mathrm{~mm}$.

\subsubsection{Efeito da instalação}

A instalação da estaca helicoidal modifica o solo atravessado pelas hélices. Durante o processo de instalação, o solo penetrado pelas hélices é cisalhado, deslocado lateralmente e verticalmente. Vários fatores de redução para alguns parâmetros do solo são encontrados na literatura com a finalidade de se considerar o efeito de instalação nos principais métodos de capacidade de carga da estaca helicoidal (Tsuha et al., 2012).

Tsuha et al. (2012) analisou a eficiência das hélices da estaca helicoidal em areia mediante ensaios em centrífuga. Eles concluíram que a contribuição da primeira hélice é mais importante nas areias compactas do que nas areias fofas. Com isso, para as estacas com várias hélices instaladas em areias compactas, a diferença da compacidade do solo acima de cada hélice é significativa (Figura 2. 10). 
Para Kanai (2007), a instalação das estacas helicoidais causam menor perturbação no solo quando comparado às técnicas tradicionais. No entanto, durante a penetração da estaca, o solo na face inferior da hélice move-se em direção à superfície superior, e deste modo, a tensão confinante em torno da hélice pode ser reduzida (Figura 2. 11).

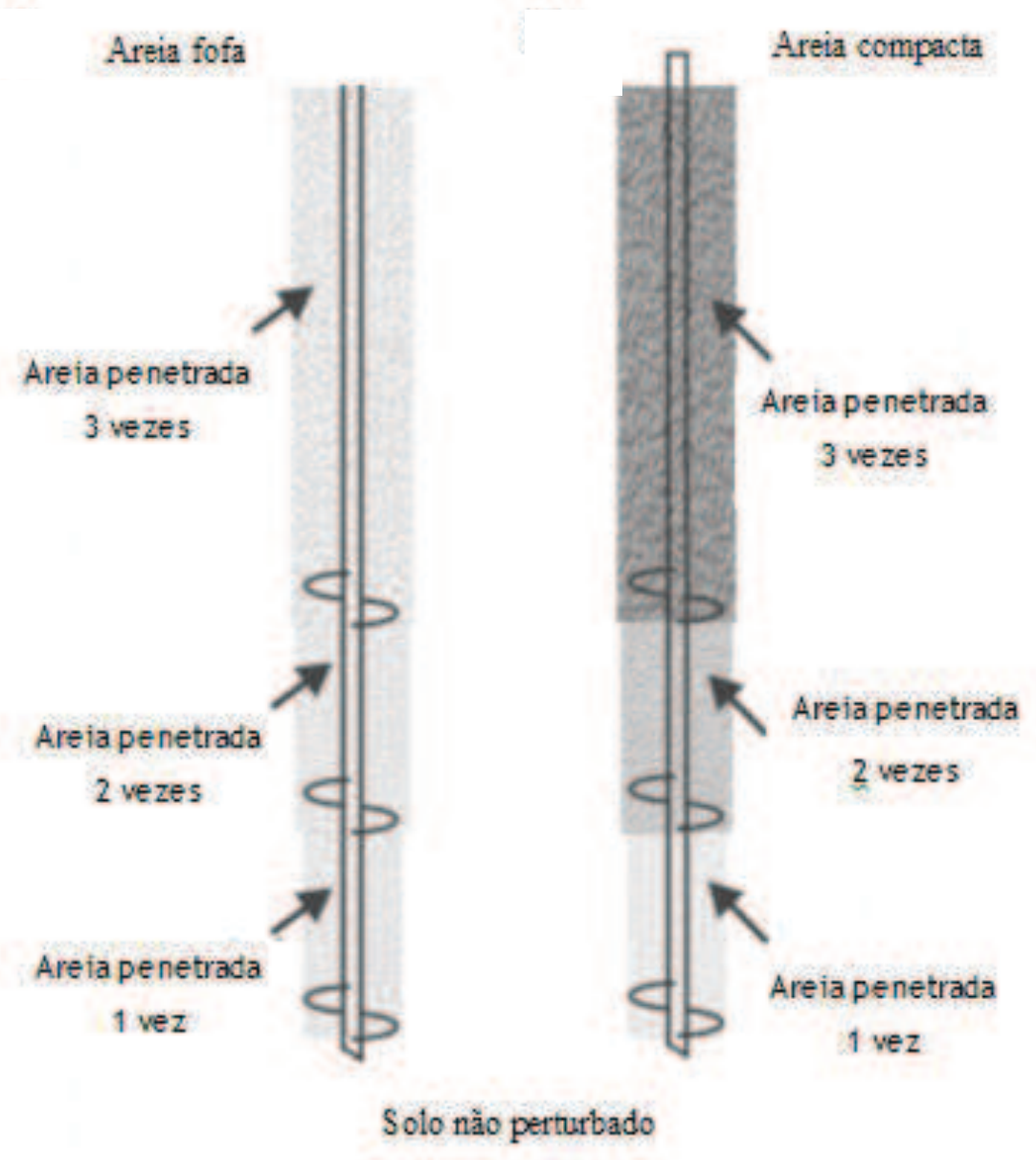

Figura 2. 10: Exemplo hipotético do efeito de instalação de uma estaca helicoidal com 3 hélices: a) areia fofa, b) areia compacta (Tsuha et al., 2012).

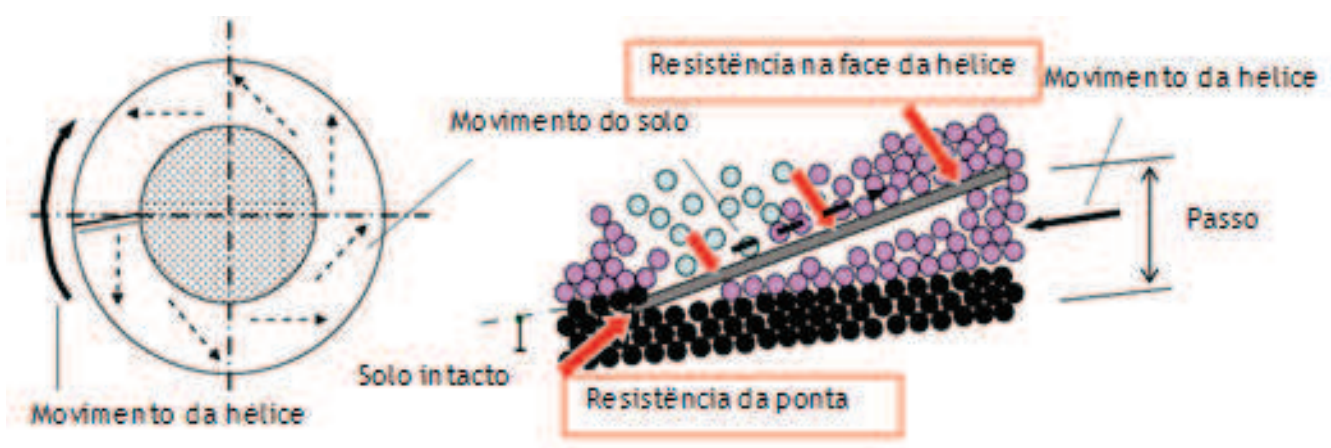

Figura 2. 11: Mecanismo de penetração para uma hélice (Kanai, 2007) 
Kanai (2007) instrumentou e realizou prova de cargas à tração e compressão em estacas helicoidais (Figura 2. 12). Concluiu-se, neste caso, que a resistência por atrito do lateral do fuste foi praticamente nula, e que a primeira hélice é quem possui maior eficiência. Este fato ilustra o efeito da instalação na capacidade de carga da hélice, que é maior nas hélices superiores, visto que o solo acima destas foi penetrado mais vezes.

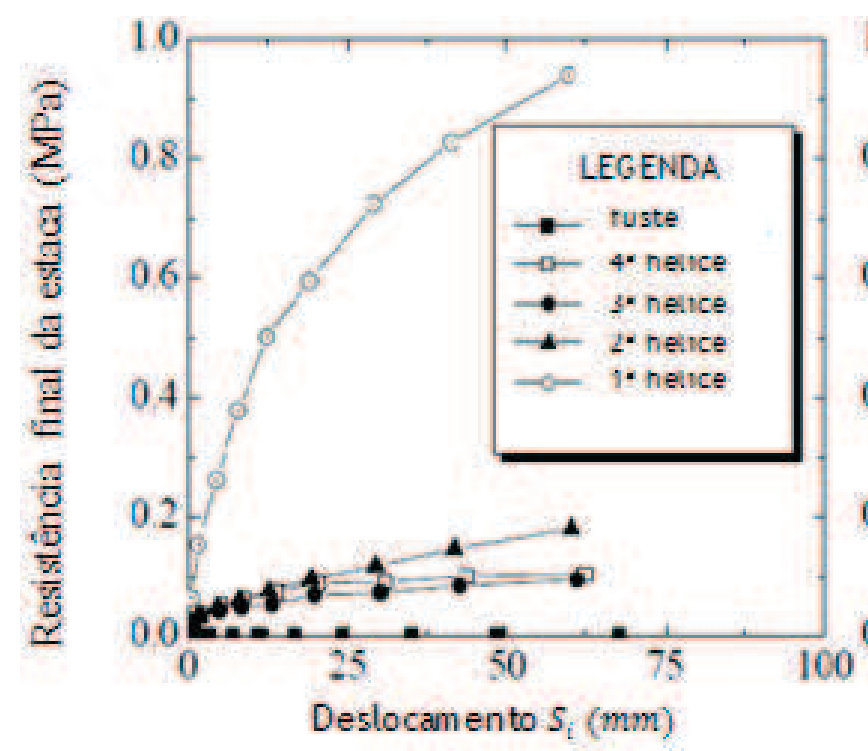

b) Compressảo

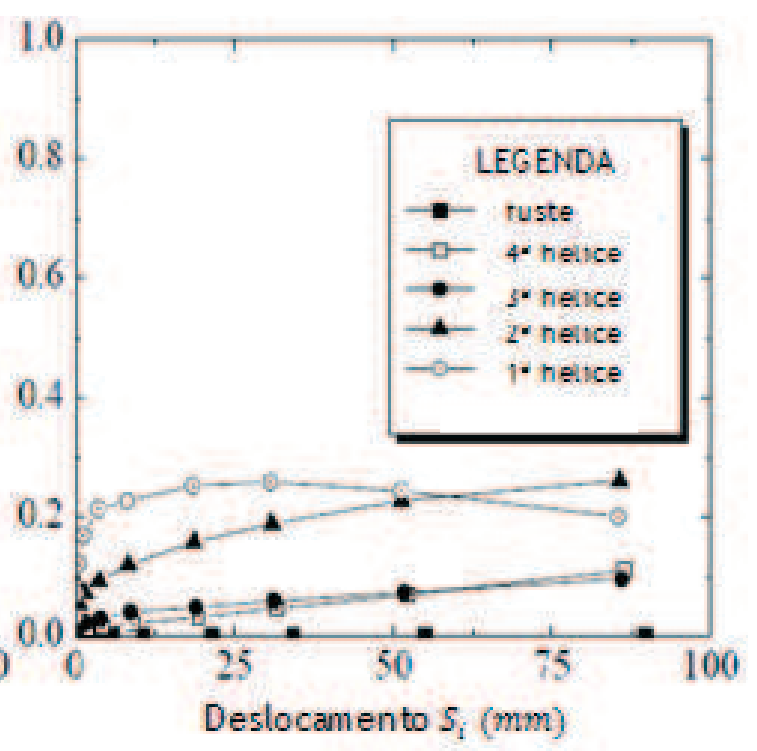

a) Iraçào

Figura 2. 12: Resistência individual de cada hélice nas provas de carga: a) compressão, b) tração (Kanai, 2007).

\subsubsection{Previsão da capacidade de suporte com base no SPT para projeto}

\subsubsection{Proposta de KANAI (2007)}

Kanai (2007) adotou o modelo de interação solo-estaca da Figura 2. 14, onde a resistência é o somatório de duas parcelas: capacidade de suporte de cada hélice e atrito lateral do fuste com o solo. Este autor propôs correlacionar os valores de $N_{S P T}$ e com a capacidade de carga por meio da equação:

$$
Q_{u}=\sum q_{w i} \times A_{w i}+U \sum L_{i} f_{i}
$$


Onde:

$q_{w i} \quad$ : capacidade de suporte unitária de cada hélice $=\mathrm{a} * \mathrm{~N}(\mathrm{kPa})$

$A_{w i} \quad$ : área efetiva da hélice (área da hélice menos área do fuste, Figura 2.13)

$U \quad$ : perímetro do fuste da estaca

$L_{i} \quad$ : comprimento efetivo do fuste

$f_{i} \quad$ : resistência unitária do fuste $=\mathrm{b} * \mathrm{~N}(\mathrm{kPa})$

$a, b \quad$ : coeficientes de resistência

$N \quad: \mathrm{N}_{\mathrm{spt}}$

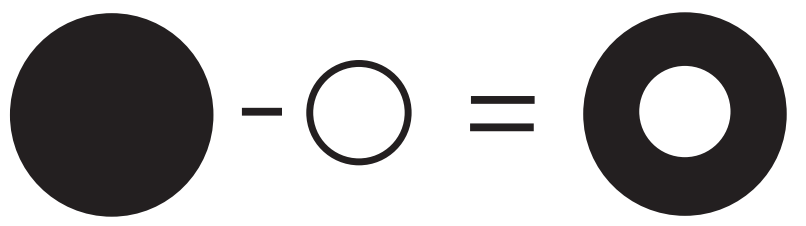

Figura 2. 13: Área efetiva da hélice

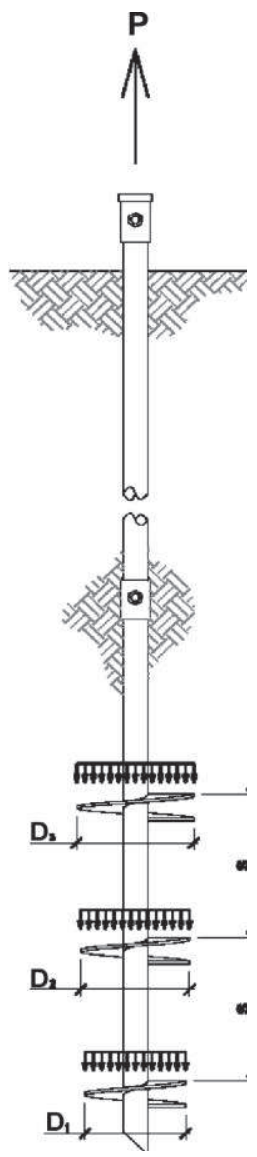

Figura 2. 14: Mobilização das resistências na estaca helicoidal de acordo com Kanai (2007). 
PERKO (2009) apresentou relações empíricas para estimar a tensão de ruptura de uma hélice $\left(q_{u}\right)$ em solos finos, grossos e rochas alteradas, mostradas na Tabela 2. 1. O atrito ao longo do fuste foi ignorado para o modelo ser mais conservador. Os valores dos coeficientes para tração e compressão são os mesmos, porém, se o projetista desejar trabalhar em favor da segurança, pode multiplicar o valor calculado por 0,87 no caso de estacas solicitadas à tração.

Tabela 2. 1: Valores de $q_{w}$ proposto por PERKO (2009).

\begin{tabular}{lcl}
\hline Solo & Compressão (kPa) & Tração (kPa) \\
\hline Argilosos & $68 N_{70}$ & $59 N_{70}$ \\
Arenosos & $74 N_{70}$ & $64 N_{70}$ \\
Rochas alteradas & $81 N_{70}$ & $70 N_{70}$ \\
\hline
\end{tabular}

\subsection{INTERPRETAÇÃO DA PROVA DE CARGA EM ESTACAS}

\subsubsection{Introdução}

A prova de carga consiste, basicamente, em aplicar carregamentos estáticos crescentes à estaca e registrar os deslocamentos correspondentes. Os carregamentos aplicados podem ser axiais de tração ou compressão, ou transversais. Por meio deste ensaio é possível avaliar o comportamento carga $x$ deslocamento da estaca e estimar a sua capacidade de carga (NBR 12131, 2006).

Segundo a NBR 12131 (2006), na execução da prova de carga, a estaca é carregada até a ruptura ou ao menos até duas vezes o valor previsto para sua carga de trabalho. O ensaio pode ser com carregamento lento ou rápido. A Tabela 2. 2 apresenta um resumo das características dos dois ensaios. 
Tabela 2. 2: Características do ensaio de carga estática com carregamento rápido e lento.

\begin{tabular}{|c|c|c|}
\hline Características & Ensaio Lento & Ensaio Rápido \\
\hline $\begin{array}{l}\text { Carregamento em } \\
\text { estágios iguais e } \\
\text { sucessivos: }\end{array}$ & $\begin{array}{l}\text { Máximo de } 20 \% \text { da carga de trabalho } \\
\text { prevista }\end{array}$ & $\begin{array}{l}\text { Máximo de } 10 \% \text { da carga } \\
\text { de trabalho prevista }\end{array}$ \\
\hline $\begin{array}{l}\text { Tempo decorrido após } \\
\text { estabilização da carga } \\
\text { para mudança de } \\
\text { estágio: }\end{array}$ & 30 minutos & $\begin{array}{l}5 \text { minutos, independente da } \\
\text { estabilização do sistema. }\end{array}$ \\
\hline $\begin{array}{l}\text { Leitura } \\
\text { deslocamentos: }\end{array}$ & $\begin{array}{l}\text { Imediatamente após início, } 2,4,8,15 \text { e } 30 \\
\text { minutos contados do início do estágio } \\
\text { anterior. Posteriormente a cada } 30 \text { minutos } \\
\text { até atingir a estabilização. }\end{array}$ & Início e fim do estágio. \\
\hline $\begin{array}{l}\text { Não atingindo a carga } \\
\text { de ruptura do ensaio }\end{array}$ & $\begin{array}{l}\text { Manter a carga por } 12 \text { horas entre a } \\
\text { estabilização e início do recalque }\end{array}$ & Sem recomendação. \\
\hline $\begin{array}{l}\text { Mínimo de estágios no } \\
\text { descarregamento: }\end{array}$ & $\begin{array}{l}\text { 4, com duração mínima de } 15 \text { minutos, } \\
\text { respeitando o mesmo critério de } \\
\text { estabilização do carregamento. }\end{array}$ & $\begin{array}{l}4, \text { com duração de } 5 \\
\text { minutos. }\end{array}$ \\
\hline $\begin{array}{l}\text { Leitura final do } \\
\text { descarregamento: }\end{array}$ & Até estabilização. & $\begin{array}{l}\text { Após } 10 \text { minutos do } \\
\text { descarregamento total. }\end{array}$ \\
\hline
\end{tabular}

\subsubsection{Métodos de Ruptura}

A International Building Code (IBC) de 2009, na seção 1810.3.3.1.2 estabelece que a carga de ruptura estimada com base em prova de carga deve ser determinada com uso dos métodos listados na sua seção 1810.3.3.1.3, sendo eles:

\section{Davisson Offset Limit}

2. Brinch e Hansen $90 \%$

3. Butler e Hoy

4. Algum outro aprovado pelo comitê oficial.

DAVISON Offset Limit (1972 apud Perko, 2009) define a carga de ruptura como sendo o valor correspondente ao deslocamento que excede o encurtamento elástico da haste 
(equação 2. 12) acrescido de um fator dependente do diâmetro da estaca (equação 2. 13), conforme apresenta a equação 2. 14 e ilustra a Figura 2. 15.

$\Delta=\frac{Q L}{A E}$

$O C=3,8 \mathrm{~mm}+D / 120$

$s_{f}=\Delta+O C$

Onde $Q$ é a força aplicada, $L$ o comprimento da estaca, $A$ área da seção transversal, $E$ o módulo de elasticidade do material da estaca, $D$ o diâmetro da estaca, $\Delta$ o encurtamento elástico da estaca, $O C$ o fator dependente do diâmetro da estaca e $S_{f}$ o deslocamento máximo admissível.

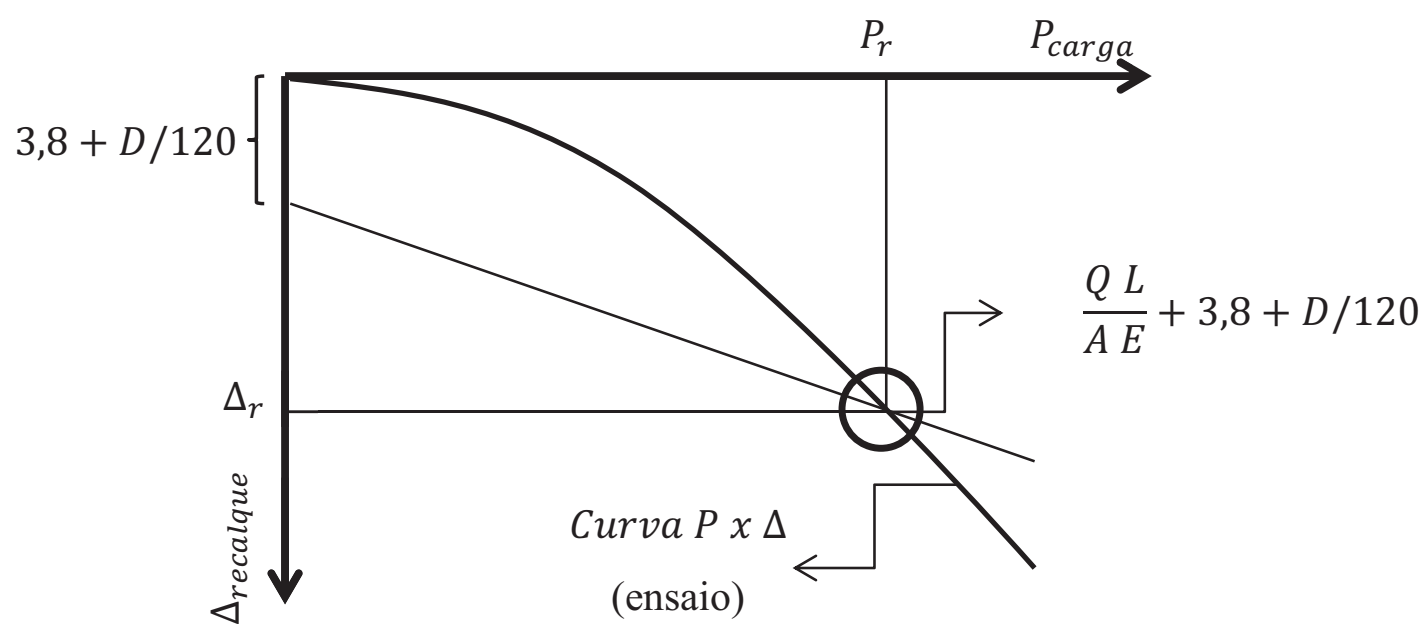

Figura 2. 15: Carga de ruptura conforme Davisson (1972)

No método de Brinch e Hansen 90\% (1963 apud Perko, 2009) a carga de ruptura é aquela na qual o deslocamento é dobro quando comparado a ao deslocamento correspondente a $90 \%$ da mesma carga.

Butler e Hoy (1977 apud Perko, 2009) definem a carga de ruptura como o valor da interseção da parte reta inicial da curva com a parte reta final com inclinação igual a 0,05 polegadas/toneladas (ou $0,14 \mathrm{~mm} / \mathrm{kN}$ ). 
Livneh e Naggar (2008), sugerem para a carga de ruptura de estacas helicoidais como sendo o valor onde o deslocamento corresponde ao alongamento elástico da haste acrescido de $8 \%$ do diâmetro (equação 2. 15).

$s_{f}=\frac{Q L}{A E}+0.08 D$

A norma Ac358 (2007) define a carga de ruptura como a interseção da curva de prova de carga com a reta correspondente ao deslocamento relativo a 10\% do diâmetro médio das hélices. Este critério é comumente chamado D/10 e foi adaptado de Terzaghi (1942).

No Brasil, a norma de fundações, NBR 6122 (2010), afirma que no caso de não ocorrer ruptura nítida (deslocamentos continuam importantes mesmo sem acréscimo de carga), pode-se convencionar a carga de ruptura como à equivalente ao recalque obtido pela expressão:

$s_{f}=\frac{Q L}{A E}+\frac{D}{30}$

Onde $D$ é o diâmetro da estaca.

\subsection{SOLOS TROPICAIS}

Este pequeno item foi incluído neste capítulo para auxiliar no entendimento do comportamento de uma parcela dos dados de estacas helicoidais instaladas em solos tropicais.

Os solos são produtos da desagregação de rochas e do intemperismo. Nas regiões tropicais, como o Brasil, eles apresentam conjunto de atributos comuns, como composição mineralógica simples, grande espessura e horizontes com cores dominantemente amarelas ou vermelhas (Teixeira et al., 2009).

Existem solos com substâncias cimentantes nos contatos intergranulares. Nestes casos, o deslocamento entre as partículas são resistidos por essas ligações aglomerantes, agindo como uma cola, para depois mobilizar o atrito (Pinto, 2006).

Os solos transportados acima do nível d'água sofrem cimentação após a sua formação devido à percolação de água. Nos solos residuais, ela é resultante das próprias ligações químicas remanescentes da rocha original, cuja intensidade decorre do grau de evolução do 
solo (Pinto, 2006). O efeito da cimentação no comportamento mecânico do solo pode ser analisado por ensaios triaxiais. Três situações típicas são observadas.

A primeira ocorre quando a tensão confinante é baixa (Figura 2. 16 a.). Nela, a resistência máxima (tensão de cedência) é atingida com pequenos deslocamentos (quando a cimentação é destruída) e a resistência passa a ser devido ao atrito entre as partículas.

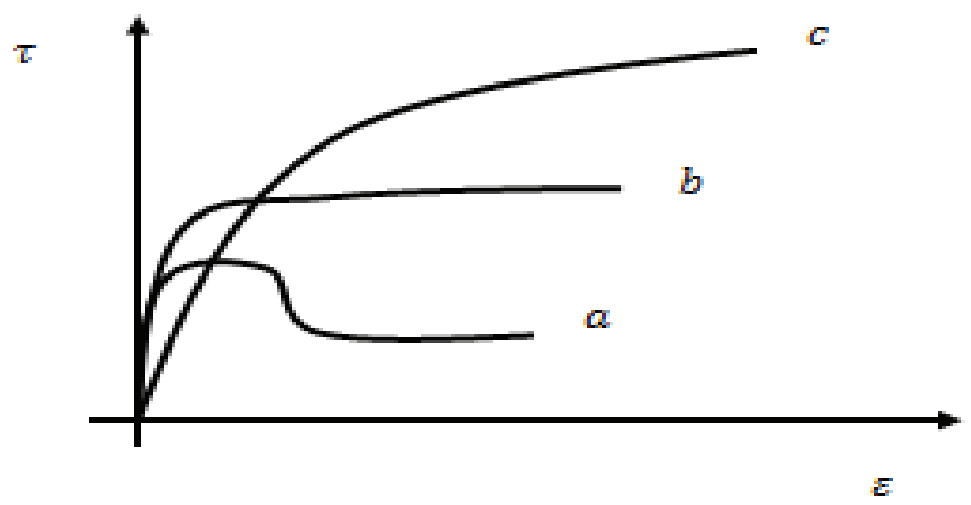

Figura 2. 16: Comportamentos típicos de solos cimentados em ensaios (adaptado de Pinto 2006)

Para uma tensão confinante mais alta, mas ainda abaixo da tensão de cedência, a curva tensão versus deformação apresenta mudança de comportamento quando a cimentação é destruída (Figura 2. 16 b.). Nela, a resistência final devido ao atrito é maior que a tensão de cedência.

Para tensões confinantes acima de da tensão de cedência (Figura 2. 16 c.), o comportamento do solo é típico de solo não cimentado, pois o próprio confinamento destruiu a cimentação.

\subsection{ANÁLISE DE REGRESSÃO LINEAR}

\subsubsection{Introdução}

A análise de regressão linear é frequentemente utilizada para desenvolver uma equação envolvendo várias variáveis. Na regressão, a variável que está sendo calculada é chamada de variável dependente, e as utilizadas para calcular a variável dependente são chamadas de independentes. 
O tipo mais simples de análise de regressão é a linear simples e envolve estimar uma variável dependente por meio de uma variável independente, ou seja, utilizando a equação de uma reta. A análise envolvendo duas ou mais variáveis independentes é chamada de regressão linear múltipla.

\subsubsection{Modelo de regressão linear simples}

No modelo de regressão linear simples, $y$ é função linear de $x$ conforme explicita a equação 2. 17.

$y=\beta_{0}+\beta_{1} x+\epsilon$

Onde $\beta_{0}, \beta_{1}$ são parâmetros do modelo, e $\epsilon$ é uma variável aleatória definida como o erro. $\mathrm{O}$ erro mede a variabilidade de $y$ que não pode ser explicada pela relação linear entre $x$ e $y$.

Existem diversas suposições do modelo de regressão linear simples e elas serão estudas mais a diante. Uma delas é que o valor médio (ou esperado) de $\epsilon$ é zero. Uma consequência dessa suposição é que o valor médio (ou esperado) de y, denotado $E(y)$, é igual a $\beta_{0}+\beta_{1} x$, em outras palavras, o valor médio de $y$ é função linear de $x$.

A equação que descreve como o valor médio de $y$ se relaciona com $x$ é chamada de equação de regressão. A equação de regressão para a regressão linear simples é:

$E(y)=\beta_{0}+\beta_{1} x$

Se os valores $\beta_{0}, \beta_{1}$ fossem conhecidos, eles poderia ser utilizado na equação 2. 18 para calcular os valores médios de $y$ dado um valor médio de $x$. Infelizmente, na prática, os valores dos parâmetros devem ser calculados utilizando os dados da amostra. Pode-se desenvolver uma equação de regressão linear a partir da amostra, a qual recebe o nome de equação de regressão linear estimada (equação 2. 19), onde os parâmetros $\beta_{0}, \beta_{1}$ são substituídos pelas estatísticas da amostra $b_{0}, b_{1}$, respectivamente.

$\hat{y}=b_{0}+b_{1} x$ 
A análise de regressão linear não pode ser interpretada como um procedimento para estabelecer uma relação de causa e efeito entre as variáveis. Ela pode apenas indicar como ou até que ponto as variáveis estão relacionadas entre si. As conclusões sobre causa e efeito devem ser feita em função dos conhecimentos individuais da aplicação (Anderson et al., 2002).

\subsubsection{Método dos mínimos quadrados}

O método dos mínimos quadrados é utilizado para calcular a equação de regressão estimada a partir de dados de uma amostra, em outras palavras, ele serve para determinar os valores de $b_{0}, b_{1}$ da equação 2. 19 que minimizam a soma dos quadrados dos desvios entre os valores observados da variável dependente $y$ e os estimados $\hat{y}$. O critério para o método dos mínimos quadrados é dado por:

$\min \sum\left(y_{i}-\hat{y}_{i}\right)^{2}$

\subsubsection{Coeficiente de determinação}

O coeficiente de determinação é utilizado para calcular a eficiência do ajuste para a equação de regressão calculada. Para um valor $y_{i}$ da amostra existem três distâncias (desvios) de interesse (Figura 2. 17): 1) distância de $y_{i}$ em relação ao valor estimado $\left.\left(y_{i}-\hat{y}_{i}\right), 2\right)$ distância de $y_{i}$ em relação à média $\left.\left(y_{i}-\bar{y}\right), 3\right)$ distância entre o valor estimado e a média $\left(\hat{y}_{i}-\bar{y}\right)$.

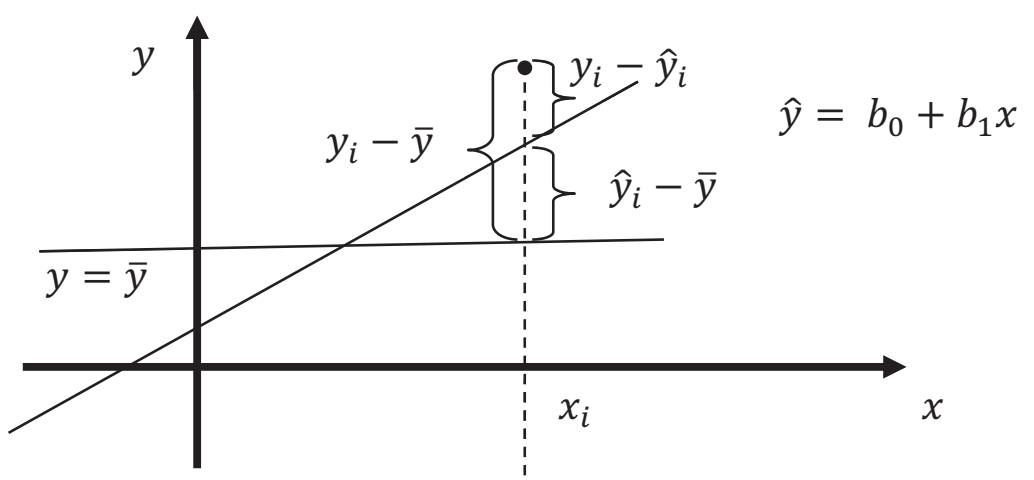

Figura 2. 17: Desvios ao redor da reta de regressão linear 
Pode-se calcular a soma dos quadrados dos desvios acima, onde a soma dos quadrados devido ao erro (SSE), a soma total dos quadrados $(S S T)$ e soma dos quadrados devido à regressão (SSR) são dadas, respectivamente, pelas equações 2. 21, 2. 22 e 2. 23.

$$
\begin{aligned}
& S S E=\sum\left(y_{i}-\hat{y}_{i}\right)^{2} \\
& S S T=\sum\left(y_{i}-\bar{y}\right)^{2} \\
& S S R=\sum\left(\hat{y}_{i}-\bar{y}\right)^{2}
\end{aligned}
$$

Existe uma relação entre $S S E, S S T$ e $S S R$, dada por:

$S S T=S S E+S S R$

O coeficiente de determinação $\left(r^{2}\right)$ é expresso por:

$$
\begin{aligned}
& r^{2}=S S R / S S T \\
& r^{2}=1-S S E / S S T
\end{aligned}
$$

Quando o coeficiente de determinação é expresso em porcentagem, ele pode ser interpretado como a porcentagem da soma dos totais dos quadrados que pode ser explicada usando a equação de regressão estimada.

Valores maiores de $r^{2}$ simplesmente implicam que a linha de mínimos quadrados dá um melhor ajuste de dados. Não se pode concluir que a relação entre $x$ e $y$ é estatisticamente significante. Tal conclusão deve ser baseada em considerações que envolvem o tamanho da amostra e propriedades das distribuições de amostragem apropriadas dos estimadores dos mínimos quadrados (Anderson et al., 2002).

\subsubsection{Suposições do modelo}

O valor do $r^{2}$ é a medida da eficiência do ajuste da equação de regressão estimada. Entretanto, mesmo com um alto valor de $r^{2}$, a equação de regressão estimada só deve ser 
utilizada após análise da sua conveniência, o qual envolve testes de significância. Os testes de significância são baseados nas seguintes suposições sobre o termo de erro $\epsilon$ (Anderson et al., 2002):

1. O termo $\epsilon$ é uma variável aleatória com valor médio (ou esperado) igual a zero. Implicação: como $\beta_{0}, \beta_{1}$ são constantes, para um dado valor de $x$, o valor esperado de $y$ é dada pela equação 2. 19.

2. A variância de $\epsilon\left(\sigma^{2}\right)$ é a mesma para todos os valores de $x$.

3. Os valores de $\epsilon$ são independentes. Implicação: os valores de $\epsilon$ para um determinado valor de $x$ não é relacionado com o valor de $\epsilon$ para qualquer outro valor de $x$; portanto, o valor de $y$ para um determinado valor de $x$ não é relacionado com o valor de $y$ para qualquer outro valor de $x$.

4. O termo $\epsilon$ é uma variável aleatória normalmente distribuída. Implicação: como y é uma função linear de $\epsilon, y$ também é uma variável aleatória normalmente distribuída.

\subsubsection{Teste de significância para regressão linear simples}

Em uma equação de regressão linear simples, o valor médio esperado de $y$ é uma função linear de $x$, como, por exemplo, a equação 2. 18. Nela, caso o valor de $\beta_{1}$ seja zero (equação 2. 27), o valor médio de $y$ não dependerá de $x$, o qual significa dizer que as duas variáveis não estão linearmente relacionadas.

$E(y)=\beta_{0}+(0) x=\beta_{0}$

Para testar o se uma relação de regressão é significante, deve-se realizar um teste de hipótese para determinar se o valor de $\beta_{1}$ é zero. Dois testes são geralmente usados e ambos requerem o calculo da variância de $\epsilon\left(\sigma^{2}\right)$.

As suposições do modelo de regressão permite concluir que a variância dos valores de $y$ em torno da reta de regressão pode ser representada pela variância de $\epsilon$. Os desvios dos valores de $y$ em torno da reta de regressão são chamados de resíduos. Assim, a SSE (a soma dos quadrados dos resíduos) é uma medida de variabilidade dos valores de $y$ em torno da reta de regressão. A média dos quadrados do erro (MSE) permite estimar o valor de $\sigma^{2}$ e ela é calculada dividindo-se SSE pelo grau de liberdade. Para a regressão linear simples, pode-se calcular o valor de MSE pela equação 2. 28. 
Toda soma de quadrados tem a ela associado um número o qual é chamado de grau de liberdade. Ele equivale ao número de elementos da amostra $(n)$ menos os números de parâmetros a serem estimados (para regressão linear simples, $\beta_{0}$ e $\beta_{1}$, ou seja, o grau de liberdade de $n-2$ ). Em estatística, $\sigma^{2}$ é utilizado para denotar a variância da população, quando se calcula a variância da amostra, e comum utilizar a letra $s$.

O primeiro teste realizado é o Teste $t$. Se $x$ e $y$ estão linearmente relacionados, então $\beta_{1} \neq 0$. O objetivo deste teste é verificar se os dados da amostra permitem concluir que $\beta_{1} \neq 0$. Serão testadas as seguintes hipóteses:

$$
\begin{aligned}
& H_{0}: \beta_{1}=0 \\
& H_{1}: \beta_{1} \neq 0
\end{aligned}
$$

Se $H_{0}$ for rejeitado, conclui-se que $\beta_{1} \neq 0$ e que as duas variáveis tem relação estatisticamente significante. Caso $H_{0}$ não seja rejeitado, não se pode afirmar que há evidências suficientes para afirmar que as duas variáveis possuem relação estatisticamente significante.

É importante saber que os estimadores de mínimos quadrados da amostra ( $b_{0}$ e $\left.b_{1}\right)$ são estatísticas da amostra e possuem suas próprias distribuições. As propriedades da distribuição amostra de $b_{1}$ são: 1) o valor esperado de $b_{1}$ é $\beta_{1}$, ou seja: $E\left(b_{1}\right)=\beta_{1}$; 2) O desvio padrão de $\beta_{1}\left(\sigma_{\beta_{1}}\right)$ é dado pela equação $\left.2.29,3\right)$ a forma da distribuição de $\beta_{1}$ é normal.

$$
\sigma_{\beta_{1}}=\frac{\sigma}{\sqrt{\sum x_{i}^{2}-\left(\sum x_{i}\right)^{2} / n}}
$$

Como não se conhece $\sigma$, estima-se $\sigma_{\beta_{1}}$, a qual é denominada $s_{\beta_{1}}$, por meio da estimativa de $\sigma(s)$. Então, tem-se:

$$
s_{b_{1}}=\frac{s}{\sqrt{\sum x_{i}^{2}-\left(\sum x_{i}\right)^{2} / n}}
$$


O teste $t$ para uma relação significante é baseado no fato de que a estatística do teste (valor $t$, equação 2. 31) segue uma distribuição $t$ com $n-2$ graus de liberdade. Se a hipótese nula é verdadeira, então $\beta_{1}=0$ e $t=b_{1} / s_{b_{1}}$.

$t=\frac{b_{1}-\beta_{1}}{s_{b_{1}}}$

Os passos do teste $t$ são:

1. Teste $t$ para a significância:

$$
\begin{aligned}
& H_{0}: \beta_{1}=0 \\
& H_{1}: \beta_{1} \neq 0
\end{aligned}
$$

2. Estatística do teste: equação 2. 31 .

3. Regra de rejeição em um nível de significância $\alpha$ : rejeita-se $H_{0}$ se $t<-t_{\alpha / 2}$ ou se $t>t_{\alpha / 2}$

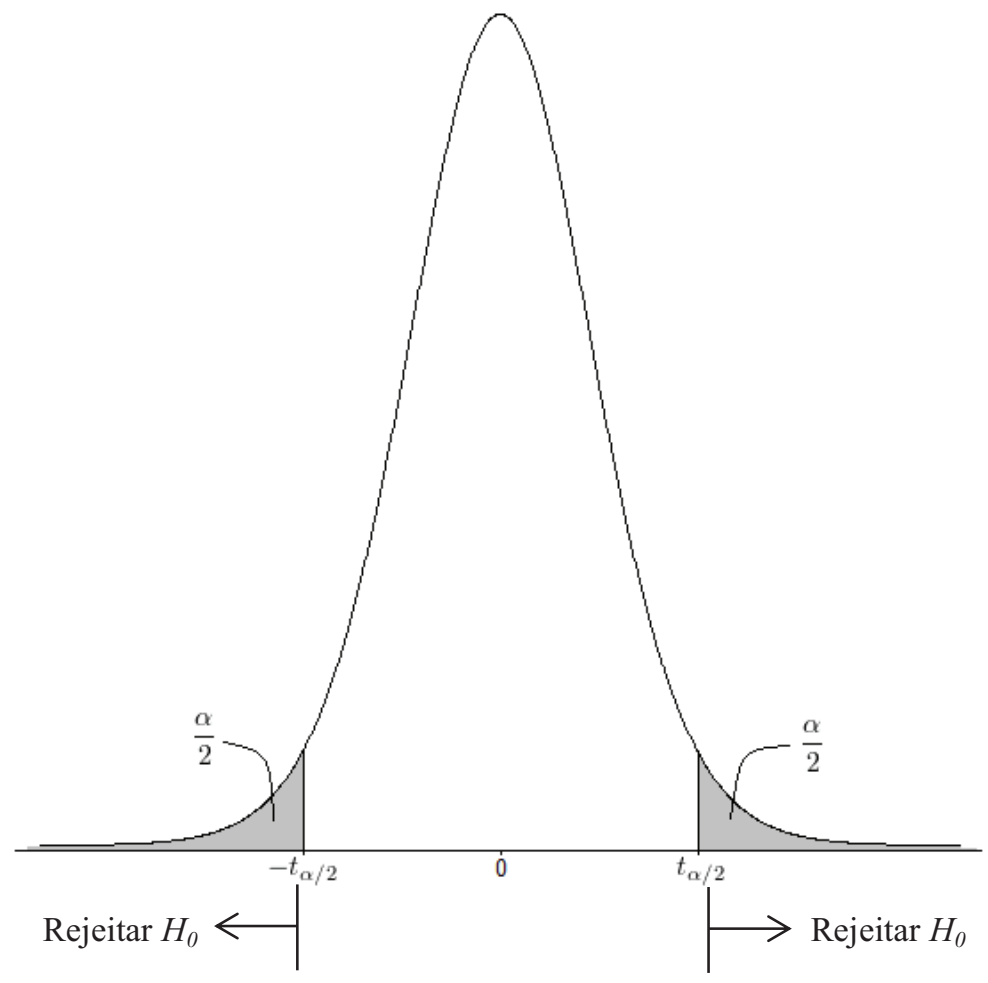

Figura 2. 18: teste $t$ (Anderson et al., 2002) 
O segundo teste realizado e o Teste $F$. Ele é baseado na distribuição de probabilidade F. Com apenas uma variável independente (caso da regressão linear simples), ele permite concluir o mesmo que o teste $t$, isto é, se $\beta_{1} \neq 0$. Porém, com mais de uma variável independente, apenas o teste $F$ pode ser utilizado para testar se há uma relação significante.

O teste $F$ utiliza duas estimativas independentes de $\sigma^{2}$, uma é o MSE utilizado no teste $T$. Se a hipótese nula $H_{0}: \beta_{1}=0$ é verdadeira, a soma dos quadrados devido à regressão $(S S R)$, dividida pelos graus de liberdade da regressão é uma estimativa independente de $\sigma^{2}$. Esta estimativa é chamada de média dos quadrados devido à regressão, ou simplesmente regressão média dos quadrados $(M S R)$. Os graus de liberdade da regressão $(k)$, para as regressões lineares, são, geralmente, o número de variáveis independentes. A estatística do teste $F(F)$ é dada pela equação 2.33 .

$$
\begin{aligned}
& M S R=\frac{S S R}{k} \\
& F=\frac{M S R}{M S E}
\end{aligned}
$$

Os passos do teste $F$ são:

1. Teste $F$ para significância:

$$
\begin{aligned}
& H_{0}: \beta_{1}=0 \\
& H_{1}: \beta_{1} \neq 0
\end{aligned}
$$

2. Estatística do teste: equação 2.33

3. Regra de rejeição a um nível de significância $\alpha$ : rejeitar $H_{0}$ se $F>F_{\alpha}$

Mesmo que os resultados do teste de significância do modelo afirmem que a hipótese nula é falsa, a conclusão de causa e efeito entre $x$ e $y$ só é garantida se o analista tem algum tipo de justificativa teórica de que a relação é de fato causal. Mesmo quando a relação é significativa, não se pode concluir que a relação entre $x$ e $y$ é linear, apenas é possível afirmar que $x$ e $y$ estão relacionados e que uma relação linear explicar uma porção significativa da variabilidade de $y$ sobre o intervalo de valores para $x$ observados na amostra (Anderson et al., 2002). 
2.5.7 Usando a equação de regressão estimada para estimativa e previsão

Quando os resultados mostram que há uma relação estatisticamente significante entre $x$ e $y$, e se o ajuste dado pela regressão linear estimada for bom, ela pode ser boa para estimar e prever.

A estimativa pode ser pontual ou por intervalo de confiança. Na pontual, utiliza-se a equação de regressão estimada para desenvolver uma estima pontual do valor médio de $y$ para um valor particular de $x\left(x_{p}\right)$. As estimativas pontuais não dão nenhuma informação sobre a precisão a elas associada.

$\mathrm{O}$ intervalo para o qual se pode afirmar com determina probabilidade que o verdadeiro valor do parâmetro populacional está nele contido é denominado intervalo de confiança (IC). Esta estimação é feita usualmente utilizando a distribuição $t$ de Student. Sendo $\alpha$ a significância considerada, a confiança será $1-\alpha$. Pode-se escrever o IC como:

$I C=\hat{y} \pm t_{\alpha / 2} S_{\hat{y}_{p}}$

Onde $s_{\hat{y}_{p}}$ é o desvio padrão de $\hat{y}$ para um valor particular de $x\left(x_{p}\right)$. Para uma regressão linear simples, $s_{\hat{y}}$ é dado por:

$$
s_{\hat{y}_{p}}=s \sqrt{\frac{1}{n}+\frac{\left(x_{p}-\bar{x}\right)^{2}}{\sum x_{i}^{2}-\left(\sum x_{i}\right)^{2} / n}}
$$

A representação gráfica do intervalo de confiança é apresentada na Figura 2. 19. 


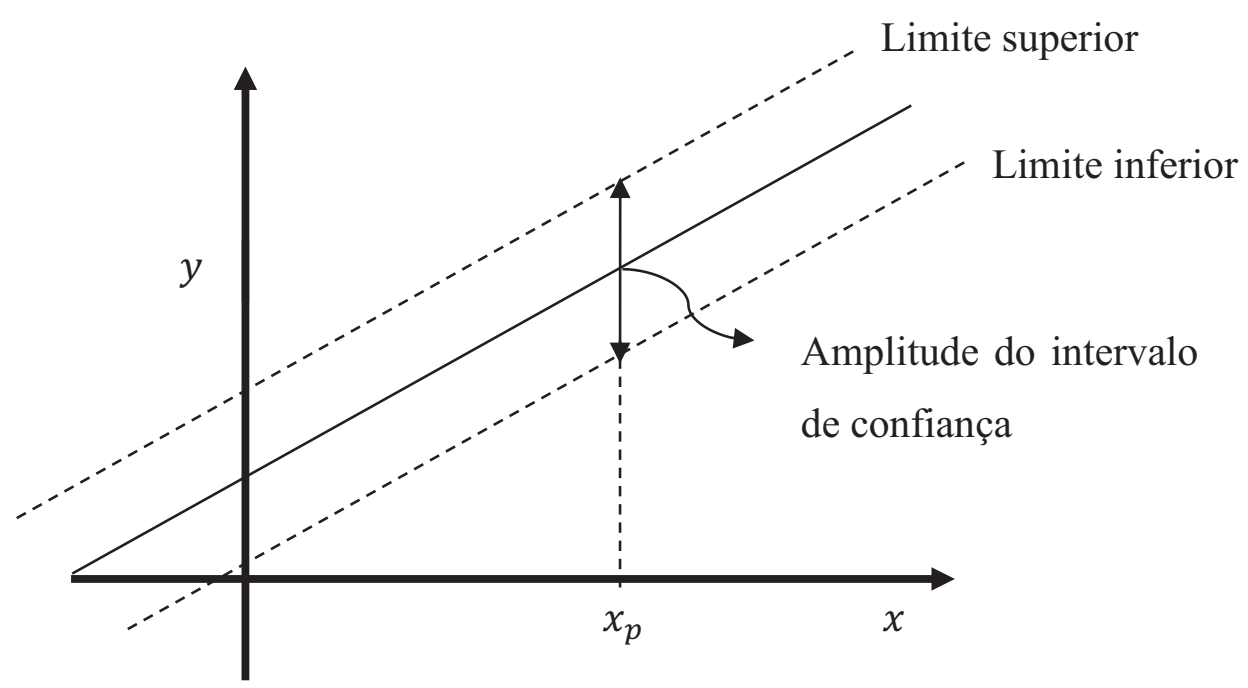

Figura 2. 19: Representação gráfica do intervalo de confiança.

2.5.8 Análise residual: validando as suposições do modelo

O resíduo é a diferença entre o valor observado da variável dependente $\left(y_{i}\right)$ e o valor estimado da variável dependente $\left(\widehat{y}_{l}\right)$, portanto:

resíduo $=y_{i}-\widehat{y_{l}}$

Os resíduos fornecem a melhor informação sobre $\epsilon$, por isso sua análise é um passo importante para determinar se as suposições para $\epsilon$ estão apropriadas. A técnica mais usual consiste em construir um gráfico de resíduos em função de $x$ (Figura 2. 20) e verificar se o seu padrão é bom.

A experiência e bom julgamento são sempre fatores importantes na interpretação eficaz de plotagens residuais sendo comum realizar estudos de regressão (Anderson et al., 2002). 

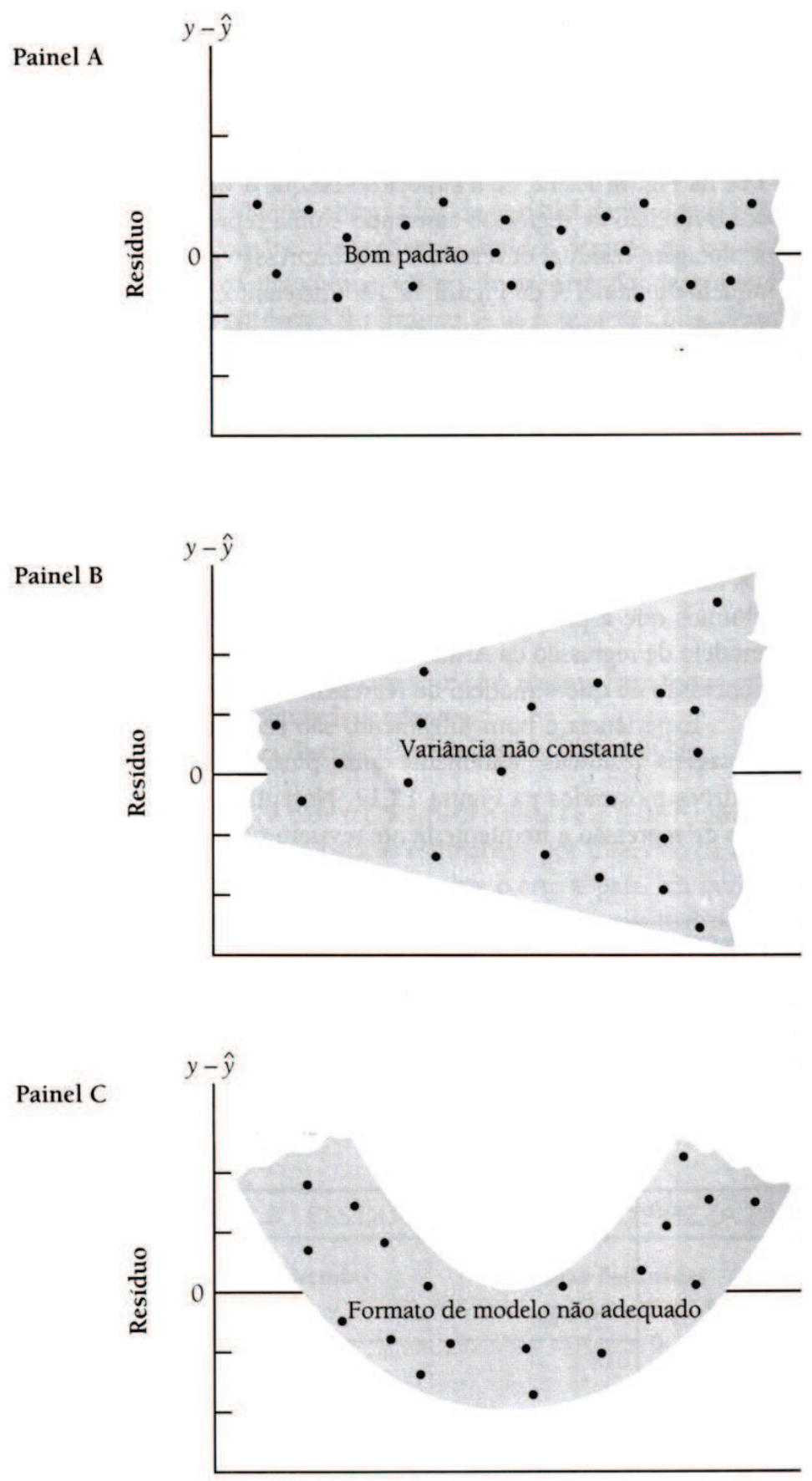

Figura 2. 20: Exemplos de plotagens residuais (Anderson et al., 2002).

\subsubsection{Regressão múltipla}

A análise de regressão múltipla é o estudo de como uma variável dependente y é relacionada com duas ou mais variáveis independentes. É usual utilizar a letra $k$ para denotar o número de variáveis independentes. Os mesmos conceitos de modelo de regressão e equação de regressão apresentados para a regressão simples valem para a regressão múltipla. 
O modelo de regressão (equação 2. 37) e equação de regressão (equação 2. 38) para a regressão linear múltipla é apresentado abaixo.

$$
\begin{aligned}
& y=\beta_{0}+\beta_{1} x_{1}+\beta_{2} x_{2}+\cdots+\beta_{p} x_{p}+\epsilon \\
& E(y)=\beta_{0}+\beta_{1} x_{1}+\beta_{2} x_{2}+\cdots+\beta_{p} x_{p}+\epsilon
\end{aligned}
$$

Se os valores de $\beta_{p}$ não forem conhecidos, eles podem ser estimados a partir de uma amostra utilizando, por exemplo, o método dos mínimos quadrados. A equação da regressão múltipla estimada é dada por:

$\hat{y}=b_{0}+b_{1} x_{1}+b_{2} x_{2}+\cdots+b_{p} x_{p}+\epsilon$

Os testes de significância utilizados na regressão múltipla são os mesmos da regressão simples, porém eles possuem finalidades diferentes. O teste $F$ é usado para determinar se há uma relação significante entre a variável dependente e o conjunto de todas as variáveis independentes. O teste $t$ tem como finalidade determinar se cada variável independente é individualmente significativa.

Com duas ou mais variáveis independentes, as hipóteses usadas para determinar se uma relação é significativa é expressa por:

$$
\begin{gathered}
H_{0}: \beta_{1}=\beta_{2}=\cdots=\beta_{p}=0 \\
H_{1}: \beta_{1} \text { e/ou } \beta_{2} \text { e/ou } \ldots \beta_{p} \neq 0
\end{gathered}
$$

O coeficiente múltiplo de determinação $R^{2}$ é interpretado e calculado (equação 2. 25) da mesma forma que na regressão linear simples.

A estimativa da variância pode ser realizada por meio da equação 2. 40, onde $k$ representa o número de variáveis independentes do modelo. Um resumo da análise da variância é apresentado na Tabela 2. 3.

$S^{2}=S S E /(n-k-1)$ 
Tabela 2. 3: Análise da variância

\begin{tabular}{rccc}
\hline \multicolumn{1}{c}{$\begin{array}{c}\text { Fonte de } \\
\text { Variação }\end{array}$} & \multicolumn{1}{c}{$\begin{array}{c}\text { Soma dos } \\
\text { quadrados }\end{array}$} & $\begin{array}{c}\text { Graus de } \\
\text { liberdade }\end{array}$ & Quadrado médio \\
\hline $\begin{array}{r}\text { Regressã } \\
\text { o (explicada) }\end{array}$ & $S S R=\sum\left(\hat{y}_{i}-\bar{y}\right)^{2}$ & $k$ & $M S R=S S R / k$ \\
Erro (não & $S S E=\sum\left(y_{i}-\hat{y}_{i}\right)^{2}$ & $n-k-1$ & $M S E=S S E /(n-k-1)$ \\
explicada) & & & \\
Total & $S S T=\sum\left(y_{i}-\bar{y}\right)^{2}$ & $n-1$ & \\
\hline
\end{tabular}




\section{MATERIAIS E MÉTODOS}

\subsection{MATERIAIS}

\subsubsection{Base de dados}

A base de dados usada nesta pesquisa é composta por um total de 76 estacas, ensaiadas a tração (Tabela 3. 1), onde duas foram retiradas de Carvalho (2007), oito de Santos (2013) e as demais cedidas por empresas executoras de estacas helicoidais no Brasil.

Para todas as estacas têm-se os valores de torque medidos ao longo da profundidade de instalação e resultados de prova de carga (rápida). No entanto, nem sempre foram atingidos deslocamentos equivalentes ao início da ruptura nas provas de carga.

Em alguns casos a profundidade do ensaio SPT foi inferior à cota de ponta da estaca. $\mathrm{O}$ resumo da base de dados é apresentado no ANEXO $\mathrm{V}$.

$\mathrm{Na}$ Tabela 3.1 nota-se que os critérios de ruptura convencionada de Davisson e da NBR puderam ser aplicados em um maior número de curvas "carga x deslocamento" do que os critérios de D/10 e de Livneh e Nagar. Também, nesta tabela os números entre parênteses indicam os casos de estacas que possuem ensaio $S P T$ até a profundidade da ponta da estaca.

Tabela 3. 1: Estacas cadastradas na base de dados

\begin{tabular}{|c|c|c|c|c|c|}
\hline Número de Hélice & $\begin{array}{c}\text { Quantidade } \\
\text { de estacas }\end{array}$ & Davisson & NBR & $\mathrm{D} / \mathbf{1 0}$ & Livneh e Naggar \\
\hline 1 & 2 & $2(2)$ & $2(2)$ & $2(2)$ & $2(2)$ \\
\hline 2 & 8 & $8(8)$ & $8(8)$ & $8(8)$ & $8(8)$ \\
\hline 3 & 9 & 7 (7) & $7 \quad(7)$ & $7(7)$ & 7 (7) \\
\hline 4 & 36 & $31(23)$ & $31(23)$ & 27 (19) & 27 (19) \\
\hline 6 & 21 & $19(14)$ & $18(13)$ & $8(6)$ & $5 \quad(3)$ \\
\hline Soma & 76 & $67(54)$ & $66(53)$ & $52(42)$ & 49 (39) \\
\hline
\end{tabular}

* valores entre parênteses possuem ensaio SPT até a profundidade da ponta da estaca.

Foram disponibilizados dados de estacas com 1, 2, 3, 4 (predominante) e 6 hélices. As estacas foram fabricadas de forma padronizada, existindo uma repetição significativa de sequências de diâmetros (Tabela 3. 2). Todas as hélices na posição 4, 5 e 6 (quarta, quinta e 
sexta hélice a partir da ponta da estaca) possuem diâmetro idêntico ao da posição 3 , ou seja, a partir da terceira hélice não há variação de diâmetro.

Tabela 3. 2: Diâmetros predominantes na base de dados

\begin{tabular}{cc}
\hline $\begin{array}{c}\text { Número de hélices da } \\
\text { estaca }\end{array}$ & $\begin{array}{c}\text { Diâmetros das hélices } \\
\mathbf{D}_{1}, \mathbf{D}_{\mathbf{2}}, . . \mathbf{D}_{\mathbf{n}}(\mathbf{c m})\end{array}$ \\
\hline $\mathbf{2}$ & Variado \\
$\mathbf{3}$ & $25,30,36$ \\
$\mathbf{4}$ & $25,30,36,36 / 30,36,41,41$ \\
$\mathbf{6}$ & $25,30,36,36,36,36$ \\
\hline
\end{tabular}

O número de amostras para determinada análise depende da combinação entre: o tipo de ensaio, método de ruptura utilizado para interpretar a prova de carga, tipo de solo e o $N_{S P T}$, número de hélices, etc.

As provas de cargas da base de dados são do tipo rápida, geralmente com 3 ciclos de 10 estágios. É a mais usual para fundações de torre de transmissão.

A base de dados utilizada possui somente estacas com estaca helicoidais (ancoragem) profundas.

\subsection{MÉTODOS}

\subsubsection{Classificação granulométrica padronizada dos solos}

A classificação granulométrica será padronizada em 15 grupos conforme indicado na Tabela 3. 3. Ela é a mesma utiliza no método de capacidade de carga em estacas de Aoki \& Velloso (1975, apud Cintra e Aoki, 2010). Todo o ensaio de SPT da base de dados segue rigorosamente esta classificação, porém, nas análises ocorreu o agrupamento para simplificálas.

A classificação granulométrica padrão com base nos dados utilizados, pode ser resumida em quatro grupos maiores: areia, silte arenoso, silte argiloso e argila, como ilustrado no lado direito da Tabela 3. 3. Estes grupos são os mesmos adotados por Decourt e Quaresma (1978). 
Tabela 3. 3: Agrupamento dos solos padronizados areia, silte arenoso, silte argiloso e argila.

$\left.\begin{array}{l}\hline \multicolumn{1}{c}{\text { Tipo de Solo }} \\ \hline \text { Areia } \\ \text { Areia siltosa } \\ \text { Areia silto argilosa } \\ \text { Areia argilosa } \\ \text { Areia argilo siltosa } \\ \text { Silte arenoso } \\ \text { Silte areno argiloso } \\ \text { Silte } \\ \text { Silte argilo arenoso } \\ \text { Silte argiloso } \\ \text { Argila arenosa } \\ \text { Argila silto arenosa } \\ \text { Argila areno siltosa } \\ \text { Argila siltosa } \\ \text { Argila }\end{array}\right\}$ Silte arenoso

\subsubsection{Métodos de interpretação da prova de carga}

Neste estudo foram utilizados quatro critérios distintos para definir a capacidade de carga por meio da curva de provas de carga (Figura 3. 1). Estes critérios são: Davisson (1972), NBR 6122 (2010), Livneh e Naggar (2008) e D/10. Portanto, para cada hipótese de cálculo testada existem quatro correlações diferentes entre capacidade de carga da hélice e o valor de $N_{S P T}$ (quatro valores de capacidade de carga diferentes obtidos na mesma curva cargadeslocamento).

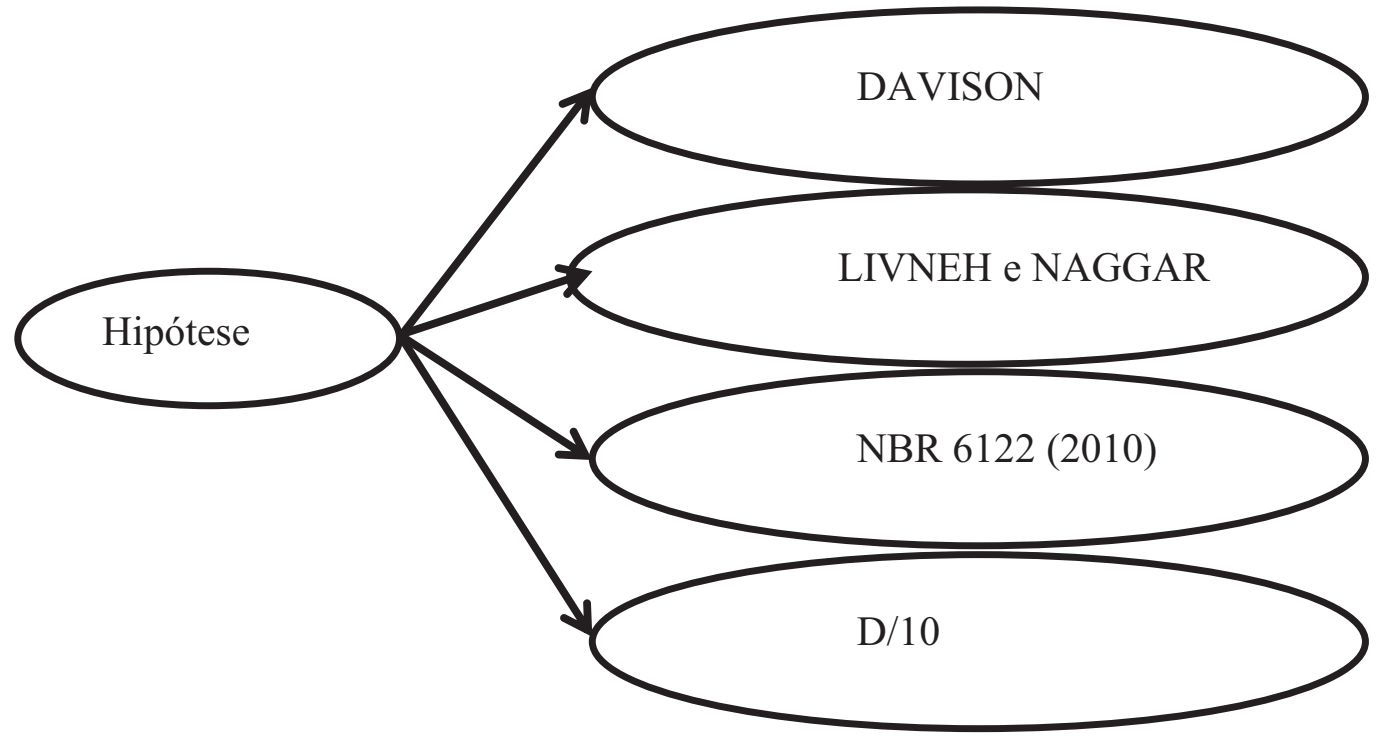

Figura 3. 1: Formas de interpretação da prova de carga a serem utilizadas neste trabalho. 
O mecanismo de ruptura das estacas helicoidais é semelhante ao da resistência de ponta de uma estaca porque a resistência por atrito na haste é quase desprezível. Portanto, é esperada uma não adequação dos modelos propostos para o método de Davisson (1972) e NBR (2010) - ambos são para estacas onde a parcela de atrito é preponderante para resistência. Por este motivo, os resultados das análises usando-se estes métodos serão apresentados apenas no ANEXO I e ANEXO II.

Para utilizar o método $\mathrm{D} / 10$ foi utilizado o diâmetro médio das hélices como referência. Este critério é análogo ao de Terzaghi (1942), cuja capacidade de carga de uma placa submetida a um carregamento é a tensão correspondente a um recalque equivalente a $10 \%$ do seu diâmetro.

\subsubsection{Erros de coleta de dados e correção dos valores de $N_{S P T}$}

Durante o levantamento de dados, foi verificada a imprecisão de duas informações para algumas estacas: 1) distância do ensaio $S P T$ até o local da prova de carga e 2) desconhecimento entre a cota zero da sondagem e a cota zero da estaca - muitos ensaios de prova de carga foram realizados em estacas instaladas onde houve escavação do terreno.

Quando necessária, a diferença entre as cotas $(\Delta h)$ foi estimada em função da comparação entre o perfil do torque de instalação e ensaio SPT. A mesma estratégia foi adotada para validar se a sondagem recebida equivale à estaca ensaiada.

Com base em levantamentos realizados com as empresas que cederam os dados, o $\Delta h$ para corrigir o problema de divergência de cota varia entre 0 e 2 metros, pois nesse intervalo se inserem as medidas usuais de pré-escavação do solo.

Quando ocorreu divergência entre as cotas, a correção dentro do programa implica em deslocar a estaca em $\Delta h$, com isso a classificação granulométrica do solo e o $N_{S P T}$ será a da nova profundidade. Por exemplo, na Figura 3. 2, na posição $p_{0}$ as hélices estavam apoiadas no solo $A$. Após o deslocamento $\Delta h$, a estaca foi para a posição $p_{1}$, onde os solos das hélices são o $B$. 


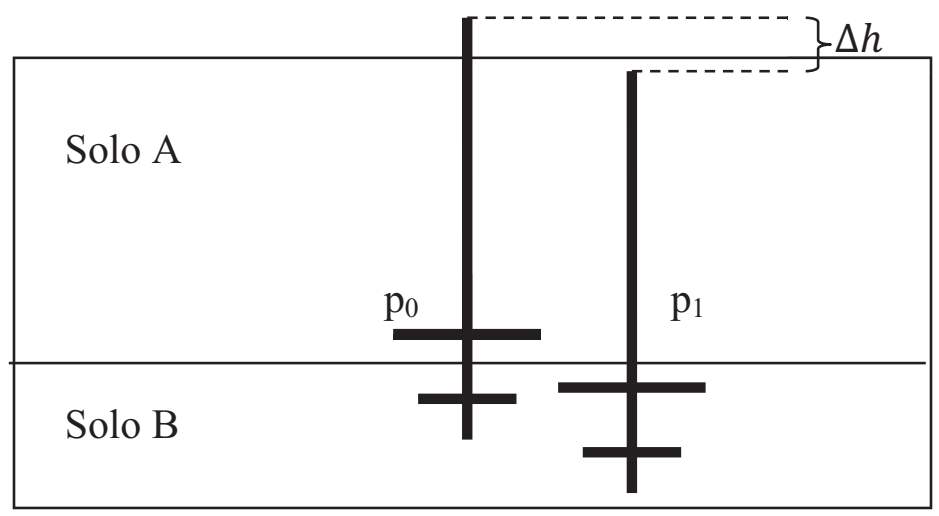

Figura 3. 2: Alteração da profundidade da hélice de uma altura $\Delta h$.

3.2.4 Algumas considerações quanto à numeração das hélices, efeito de sombra para o fuste, eficiência e valores máximos para o $N_{S P T}$

As hélices serão numeradas de baixo para cima, ou seja, a primeira hélice sempre será a mais profunda (Figura 3.3).

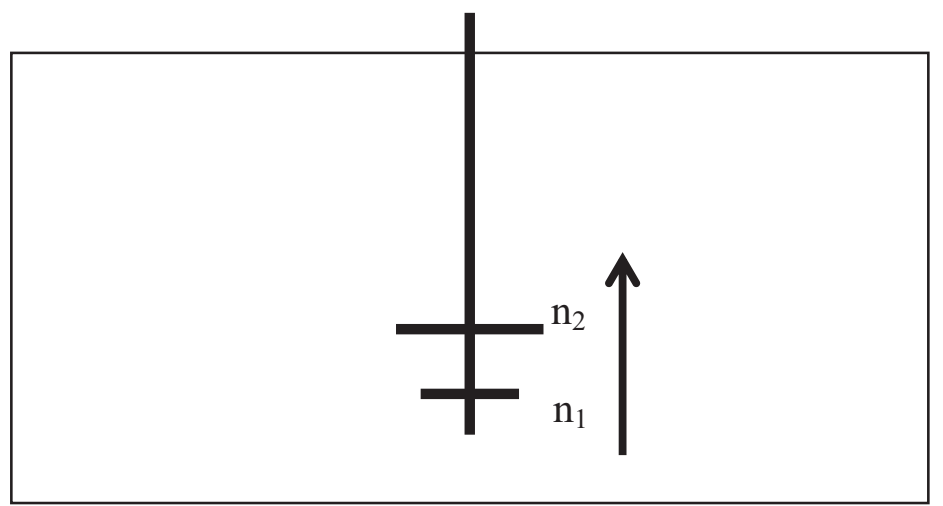

Figura 3. 3: Numeração convencionada para as hélices.

Utilizou-se o efeito de sombra na estimativa da capacidade de carga. Este efeito considera o comprimento efetivo do fuste igual ao seu comprimento total menos um diâmetro da hélice superior, porque durante a ruptura esta parcela de resistência acima da hélice não é mobilizada (Zhang, 1999).

Nas análises, os valores de $N_{S P T}$ superiores a 50 golpes $/ 30 \mathrm{~cm}$ finais serão reduzidos para o máximo de 50 golpes $/ 30 \mathrm{~cm}$ finais. A não aplicação desta condição aumenta significativamente o número de outliers. Este problema também é relatado por Gomes (2000).

Não se considerará nesta pesquisa o efeito da eficiência nos ensaios SPT porque esta não foi medida durante execução. 


\subsubsection{Agrupamento das estacas por tipo de solo}

Foi necessário agrupar as estacas por tipo de solo. Nestes casos, o solo de referência adotado é o da hélice mais profunda $\left(n_{1}\right)$, porque, como mostra (Kanai, 2007), ela é a responsável pela maior parcela da capacidade de carga da estaca.

O agrupamento das estacas por tipo de solo é apenas para estatística da base de dados. No entanto, os modelos de regressão usados na pesquisa consideram os solos de cada hélice.

\subsubsection{Situações A (recomendada) e B (não recomendada) de projeto}

Há três situações típicas de instalação da estaca helicoidal encontradas no banco de dados usado neste trabalho: 1) toda instalada em solo de baixa resistência (Figura 3. 4 a.), 2 ) parcialmente ancorada em solo de alta e baixa resistência (Figura 3. 4 b.) e 3) todas as hélices (ou as 4 primeiras nas estacas com 6) instalada em solo de alta resistência (Figura 3. 4 c).

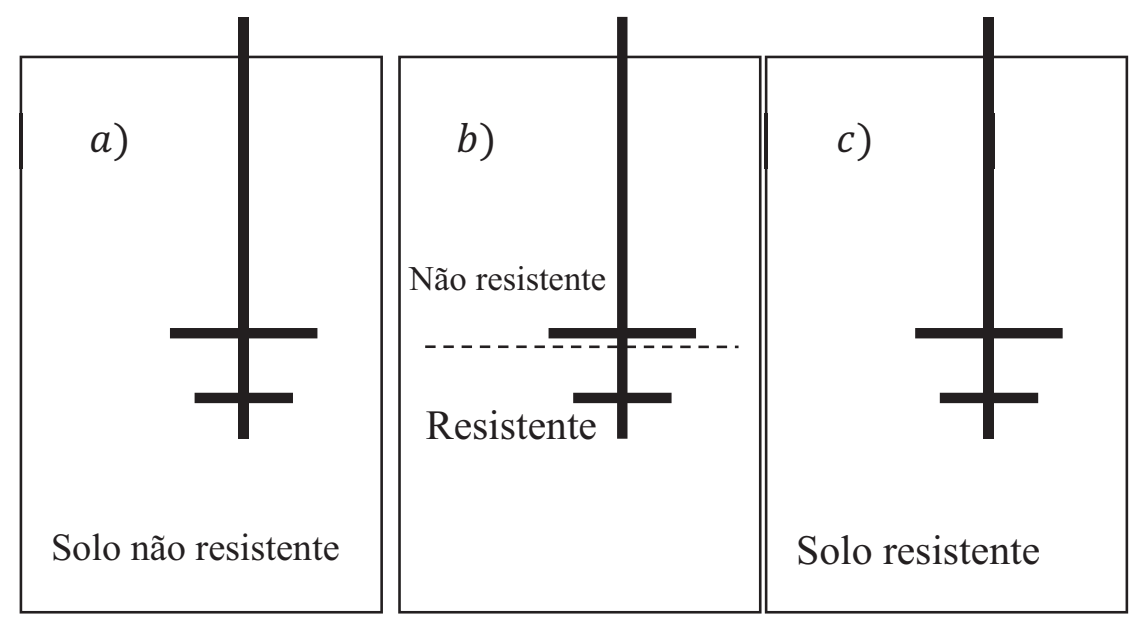

Figura 3. 4: Situações de projeto.

Os solos de baixa resistência do banco de dados desta pesquisa, em geral, são porosos, estruturados (solos tropicais). Para instalar a estaca nestes solos, é necessária a quebra de cimentação e/ou alguma estrutura reliquiar, portanto o solo apresenta razoável à penetração da estaca durante a instalação, verificada pela medida contínua de torque. Neste caso, os valores de capacidade de carga à tração são muito baixos, devido à desestruturação do solo durante a instalação, portando não é recomendada a instalação das hélices de estacas helicoidais neste 
solo. Esta situação de projeto não recomendada é denominada no presente trabalho de “situação B” de projeto.

Em alguns casos de solos porosos e não saturados deste trabalho (Santos, 2013), observou-se que pelo processo de instalação da estaca helicoidal o solo perdeu o contato com o fuste. Portanto, nas camadas de solo poroso e estruturado, desconsiderou-se a contribuição para a resistência por atrito lateral (pelo fato do contato haste-solo ser quase nulo). Este fenômeno foi constatado em estacas instaladas no Centro de Recursos Hídricos e Ecologia Aplicada (CRHEA) da EESC de São Carlos. Menezes et al. (2004) estudou as estacas prémoldadas cravadas em solos com baixos valores de $N_{S P T}$ (até 4 golpes $/ 30 \mathrm{~cm}$ ) e constatou que devido à alta porosidade e compressibilidade do solo, o atrito lateral é extremamente baixo.

A instalação das hélices das estacas em solo com resistência superior é recomendada para o projeto, e será denominada de "situação A" (a não recomendada para o projeto de situação $B)$.

A estaca com hélices ancoradas em solos de situações de projeto diferentes (algumas hélices em solos resistentes outras em não resistentes) devem ser analisadas com cautela: somente considerar-se-á predomínio da "situação $A$ " se a primeira hélice estiver em solo resistente ou, se as 4 primeiras hélices estiverem em solo competente. Para este trabalho, o solo resistente é aquele com $N_{S P T}$ próximo de 20 golpes $/ 30 \mathrm{~cm}$ e o competente superior a 7 golpes $/ 30 \mathrm{~cm}$.

$\mathrm{Na}$ prática, a importância de se definir a situação de projeto é: 1) determinar correlação adequada (fator de torque $K_{T}$ ) com o torque de instalação na situação $A$ e na situação $B$, e 2) a partir de certa profundidade, considerar a resistência por atrito lateral na haste. Estes dois fatores interferem diretamente nos modelos de regressão.

3.2.7 Modelo de regressão para relação entre torque e capacidade de carga à tração

O modelo de regressão adotado para a relação entre torque e capacidade de carga será:

$Q_{u}=K_{t} T+\varepsilon$

Onde $\varepsilon$ representa o erro do modelo. As demais variáveis já foram definidas anteriormente. A relação será analisada para situação $A$ e $B$ de projeto. Não serão analisadas estacas com apenas 1 hélice. 
3.2.8 Modelo de regressão para relação entre $N_{S P T}$ e capacidade de carga

O modelo de regressão para a relação entre o $N_{S P T}$ e a capacidade de carga é dado por:

$Q_{u}=\sum Q_{h}+Q_{s}+\varepsilon$

onde $Q_{h}$ é a resistência à tração de cada hélice e $Q_{s}$ a resistência por atrito lateral na haste.

A capacidade de carga à tração de cada hélice (equação 3. 3) é definida como o produto entre a sua área efetiva $\left(A_{e h}\right)$, valor médio de $N_{S P T S}$ na profundidade de interesse e imediatamente superior e inferior $\left(\bar{N}_{S P T}\right)$, e o coeficiente $\alpha_{s}$ do solo acima da hélice (em $\mathrm{kN} / \mathrm{m}^{2}$ ).

$Q_{h}=\alpha_{S} A_{e h} \bar{N}_{S P T}$

Nos casos onde as sondagens apresentam grandes variações nos valores de $N_{S P T s}$, a resistência das hélices altera-se muito. Como há imprecisão em qual camada de solo a hélice se apoiou, adotar um valor médio permite reduzir o erro.

A parcela de atrito lateral na haste da estaca é dada por:

$Q_{S}=U \sum l \beta_{S} N_{S P T}$

onde $U$ é o perímetro da seção transversal do fuste, $\beta_{S}$ é um coeficiente equivalente à resistência unitária por atrito lateral, $N_{S P T}$ o valor do ensaio $S P T$ e $l$ o comprimento da camada.

Os coeficientes $\beta_{s}$ e $\alpha_{s}$ são calculados para os seguintes grupos de solos: areia, argila, silte arenoso e silte argiloso. O modelo não será aplicado para estacas com apenas uma hélice, e também será analisado somente para situação $A$.

3.2.9 Análise estatística dos modelos de regressão linear múltipla 
A análise estatística seguirá o seguinte roteiro: estudo do coefíciente de determinação $\left(R^{2}\right)$, significância do modelo (tabela ANOVA) e dos regressores (pvalor), matriz de correlação, análise dos resíduos, gráfico de capacidade de carga estimada versus capacidade de carga observada e avaliação do BIAS do método (valor estimado/valor medido).

O coeficiente de determinação é uma medida de quanto da variação o modelo é capaz de explicar. Valores acima de 0,80 serão considerados satisfatórios.

A significância do modelo e dos regressores será analisada com o teste de hipótese. A forma de interpretação consistirá em rejeitar a hipótese nula quando sua a probabilidade de ser verdadeira (pvalor) for inferior a $5 \%$.

$\mathrm{Na}$ matriz de correlação será analisado o problema de multicolinearidade porque variáveis com correlação moderada $(0,30$ a 0,70$)$ e alta (acima de 0,70$)$ tendem a distorcer o modelo.

O método dos mínimos quadrados postula que os resíduos devem ter distribuição normal, com média igual a zero. Essa hipótese pode ser validada estudando a conformação do histograma de resíduos. Outra prerrogativa é que os resíduos devem ter variância constante, a qual será verificada no gráfico de resíduos versus capacidade de carga estimada.

O gráfico de capacidade de carga estimada versus capacidade de carga observada permite verificar se o modelo apresenta algum vício, o qual se caracteriza quando valores superestimados e subestimados não se arranjam de forma aleatória ao longo de todo o gráfico.

A análise do gráfico de frequência acumulada do BIAS permite relacionar a probabilidade do modelo superestimar ou subdimensionar a capacidade de carga à tração da estaca. 


\section{SOFTWARE DESENVOLVIDO}

\subsection{INTRODUÇÃO}

Devido à necessidade de tratamento dos dados desta pesquisa, foi desenvolvido um software próprio, denominado Helical Piles Tools (HPT), com a finalidade de:

1. Ser uma base de dados para centralizar as informações coletadas.

2. Realizar e/ou facilitar os tratamentos matemáticos e estatísticos necessários neste trabalho.

3. Conversão automática de unidades: como não há padrão na entrada de dados deve-se convertê-los a uma mesma unidade para realizar alguma operação. Num programa convencional, esta conversão teria de ser manual ou desenvolver-se-ia uma sub-rotina externa.

4. Dimensões das matrizes desconhecidas: a estaca com maior número de hélices ou com maior divisão do comprimento do fuste não é conhecida a priori. Utilizar uma planilha do Excel, por exemplo, é eficiente quando os dados possuem uma formatação de entrada padronizada.

5. Automação de rotinas e geração de relatórios: com o software próprio é possível automatizar algumas rotinas, como, por exemplo, plotar os gráficos de análise de resíduos e gerar relatórios diversos, reduzindo significativamente o tempo de análise.

\subsection{AMBIENTE DE DESENVOLVIMENTO E ESTRUTURA DO PROGRAMA}

A linguagem de programa escolhida foi JAVA, com o banco de dados $H S Q L$. As principais vantagens dessa escolha são:

1. A linguagem JAVA é orientada a objeto, gratuita, com muitas bibliotecas disponíveis e com ambiente de desenvolvimento produtivo.

2. O HSQL é um banco de dados de código livre e pode trabalhar de forma embarcada, não exigindo qualquer configuração prévia na máquina do usuário.

O HPT foi inteiramente programado no NetBeans 7.1.2., que é um ambiente de desenvolvimento integrado, completo, gratuito e mantido por grandes empresas. Uma tela do ambiente de programação é apresentada na Figura 4. 1. 


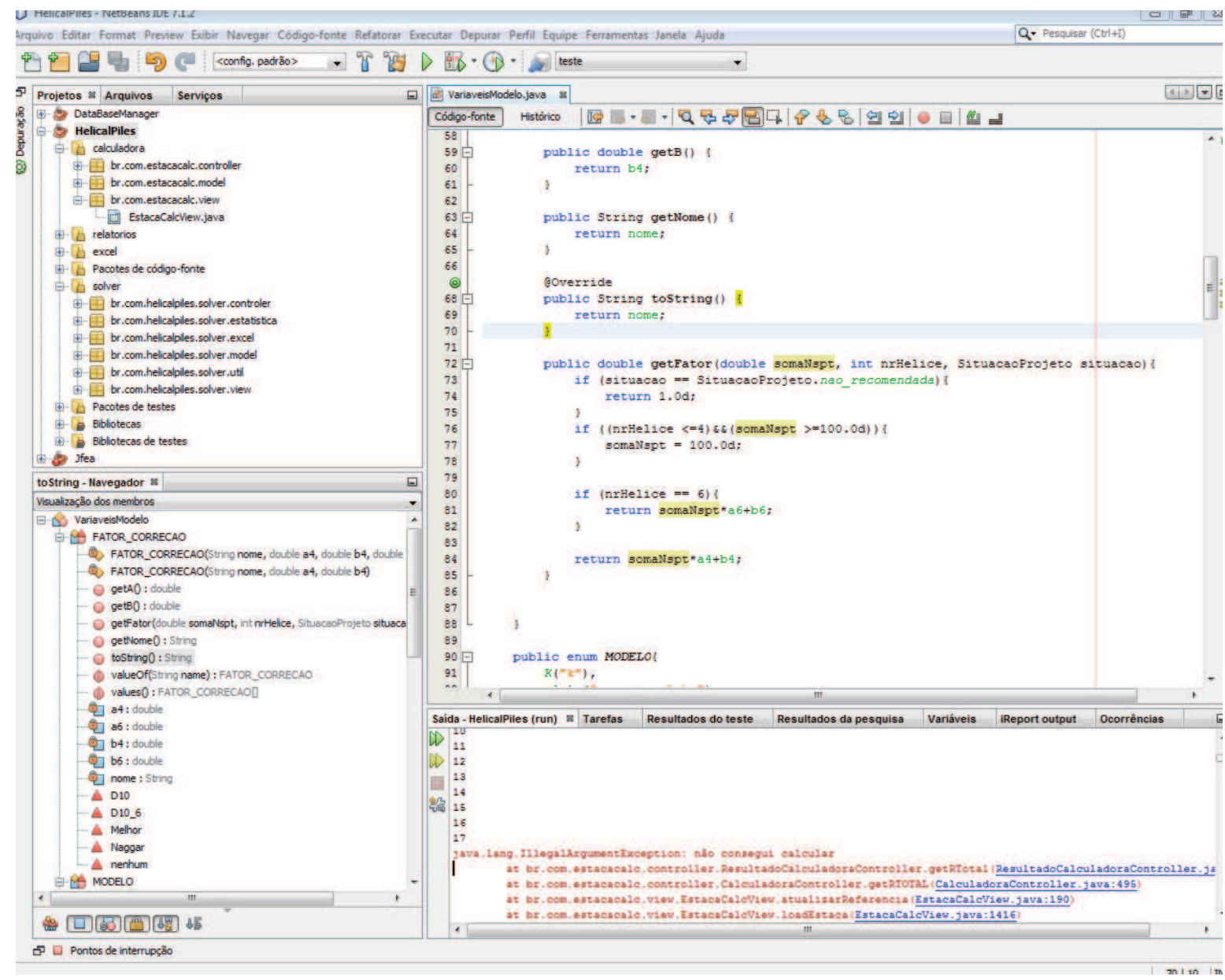

Figura 4. 1: Tela de programação do NetBeans

O programa foi estruturado em 5 módulos: 1) módulo base: tem o objetivo de armazenar as informações, 2) módulo solver: realizar as análises estatísticas, 3) módulo excel: implementar as rotinas necessárias para o HPT comunicar com o Excel, 4) módulo relatórios: exportar os relatórios em formato $p d f$ e 5) módulo calculadora: dimensionar uma estaca com base em diversos modelos de cálculo.

Cada módulo possui três camadas: $1^{\mathrm{a}}$ ) camada de visualização: onde são criadas as telas do programa, $2^{\mathrm{a}}$ ) camada de modelo: contêm as classes que representam os objetos, $3^{\mathrm{a}}$ ) camada de controle, cuja função é conectar a camada de modelo com a de visualização e armazenar as regras de negócio. Essa estrutura é denominada MVC (model, view, controller). 


\subsection{MÓDULO BASE}

O módulo base permite o cadastro das características das estacas helicoidais (hélices, haste, ensaios de prova de carga, ensaio SPT equivalente, etc.) e a extração de informações pertinentes, como, por exemplo, valor de carga de ruptura das curvas carga $\mathrm{x}$ deslocamento das provas de carga.

Neste módulo, cada estaca é caracterizada por sete tipos de objeto: 1) Dados gerais, 2) resultados do ensaio SPT próximo, 3) Torque de instalação, 4) Prova de Carga, 5) Hélices, 6) Haste, 7) Carga de ruptura. As principais informações de cada um são apresentadas na Tabela 4. 1 .

Tabela 4. 1: Principais informações dos objetos da uma estaca

\begin{tabular}{|c|c|}
\hline Objeto & Informações \\
\hline Dados gerais & $\begin{array}{l}\text { Local e data de instalação, comprimento total, empresa responsável e código de } \\
\text { referência }\end{array}$ \\
\hline SPT & $\begin{array}{l}\text { Empresa responsável pela execução, data e cota do nível d'água (NA) do ensaio. } \\
\text { Resultado do ensaio SPT. }\end{array}$ \\
\hline Torque & $\begin{array}{l}\text { Os valores de toques medidos e suas respectivas profundidades. O torque de instalação } \\
\text { utilizado para análises. }\end{array}$ \\
\hline Prova de Carga & Os pares de força e deslocamento do ensaio de prova de carga. O tipo e data de execução. \\
\hline Hélices & $\begin{array}{l}\text { A lista de hélices da estaca. Cada hélice é composta por profundidade de instalação, } \mathrm{N}_{\mathrm{spt}} \\
\text { e dimensões da seção transversal. }\end{array}$ \\
\hline Haste & $\begin{array}{l}\text { Comprimento total, dados da seção transversal, lista de valores de } N_{S P T} \text { e comprimento da } \\
\text { haste associada. }\end{array}$ \\
\hline Carga de ruptura & $\begin{array}{l}\text { Os valores de carga de ruptura resultantes da interpretação da curva carga x } \\
\text { deslocamento da prova de carga (por meio de diferentes critérios de interpretação). }\end{array}$ \\
\hline
\end{tabular}

Foi necessário criar neste trabalho objetos auxiliares para inclusão de dados secundários para cada estaca, cuja listagem encontra-se na Tabela 4. 2. 
Tabela 4. 2: Principais objetos auxiliares

\begin{tabular}{ll}
\hline \multicolumn{1}{c}{ Objeto } & \multicolumn{1}{c}{ Informações } \\
\hline Método de ruptura & Nomes dos métodos de ruptura utilizados para interpretar a prova de carga. \\
Tipos de solo & Grupos de solos específicos (exemplo: residual e não residual). \\
Unidade & Os nomes das unidades (metro, Newton, etc) \\
Tipos de unidade & Os tipos de unidade (pressão, força, comprimento, etc) \\
Empresas & Os dados cadastrais da empresa como nome, endereço e meios contatos. \\
Formas de contato & Como os contatos podem ser realizados (telefone, email, celular, etc). \\
Estado & O estado de cada endereço \\
País & O país de cada estado \\
\hline
\end{tabular}

Diversas sub-rotinas foram desenvolvidas para facilitar a extração de informações, dentre elas uma ferramenta gráfica para determinar a carga de ruptura da estaca utilizando diversos métodos de interpretação da prova de carga (Figura 4. 2).

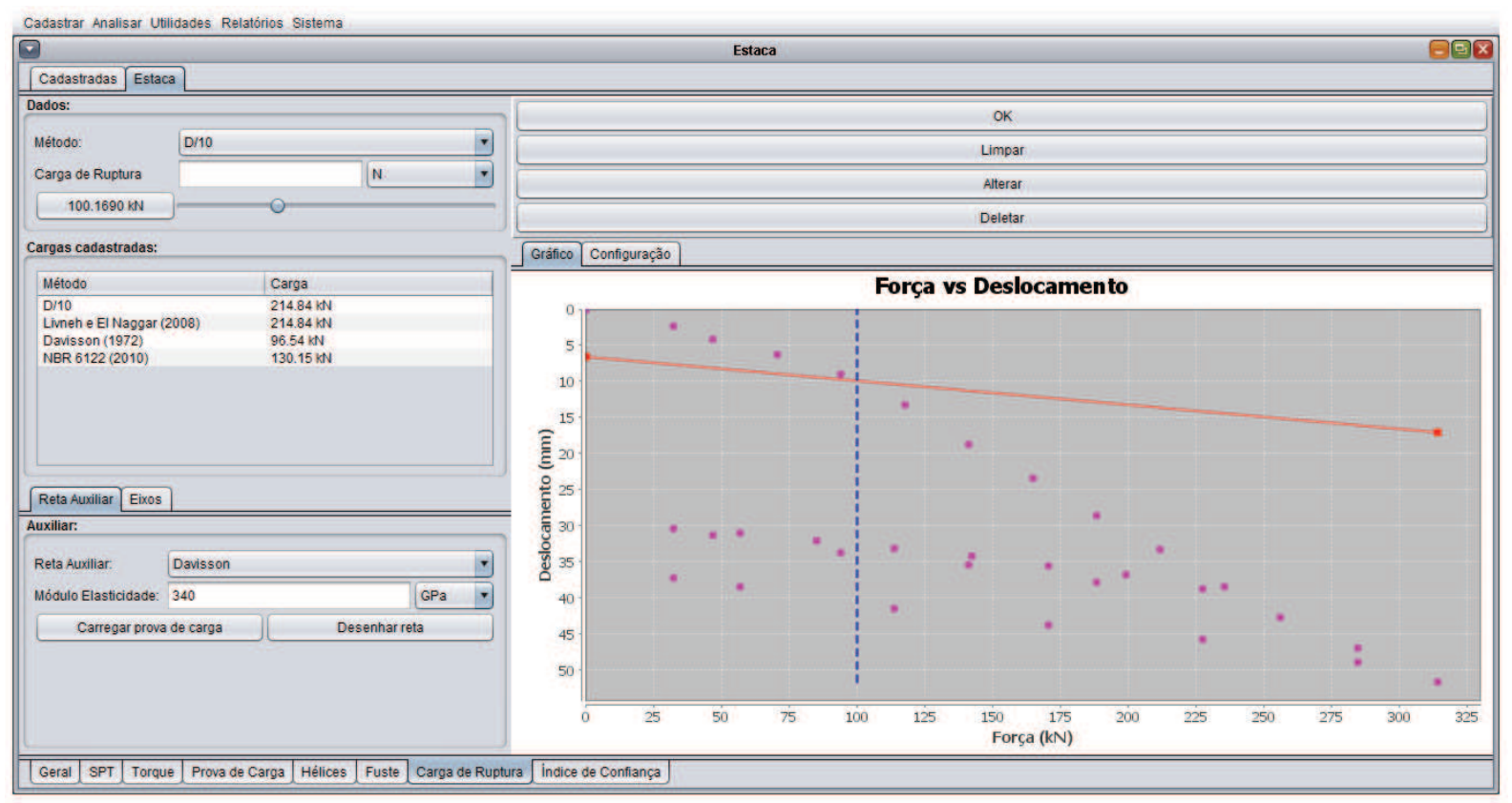

Figura 4. 2: Tela para retirada da carga de ruptura.

Todos os gráficos e dados podem ser salvos/expressos em qualquer unidade, onde a conversão é feita automaticamente. 


\subsection{MÓDULO SOLVER}

O módulo solver (Figura 4. 3) implementa toda a estrutura das análises estatísticas disponíveis no programa, dentre elas: regressão linear simples e múltipla, cálculo do $B I A S$, aplicação do fator de correção, cálculo da tabela ANOVA, pvalor, matriz de correlação, dentre outros.

A parte de visualização também é extensa. Todos os gráficos estatísticos, resumos e tabelas relevantes (ver capítulo 5 e 6) são apresentados e atualizados a cada cálculo, tornando sua programação morosa e complexa.

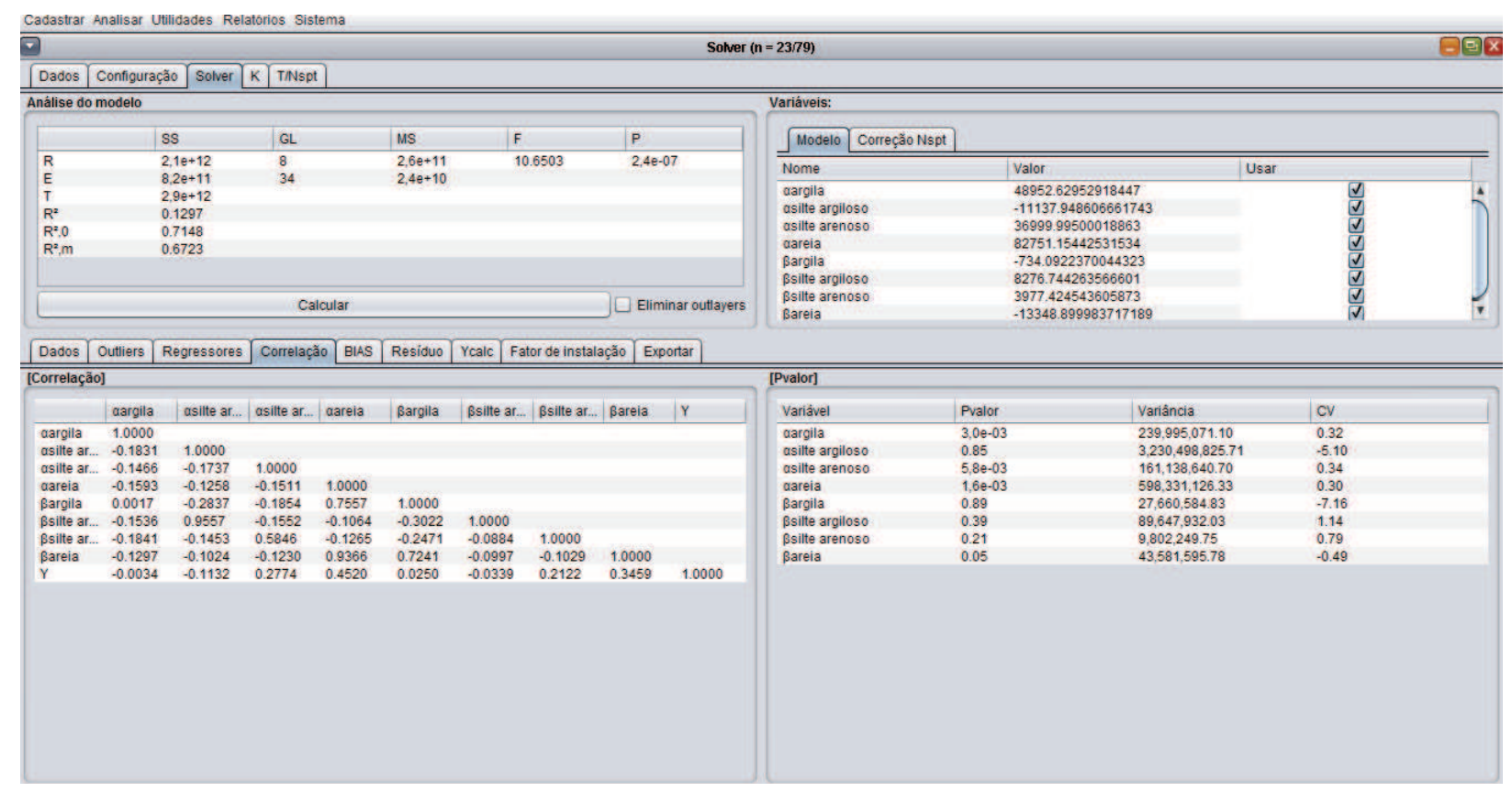

Figura 4. 3: Tela do módulo solver.

A parte de visualização foi desenvolvida para ser a mais flexível possível, destacandose a fácil remoção de variáveis do modelo e outliers do conjunto amostral.

O fluxo de trabalho é intuitivo. A primeira etapa consiste em selecionar e configurar a análise (Figura 4. 4), onde é informado se a estaca foi ensaiada à tração ou compressão, método de interpretação de prova de carga, modelo de regressão, restrições quanto ao tipo de solo e quantidade de hélice. Com base nas opções, o programa vai excluindo automaticamente as estacas que não se adequam na configuração. 


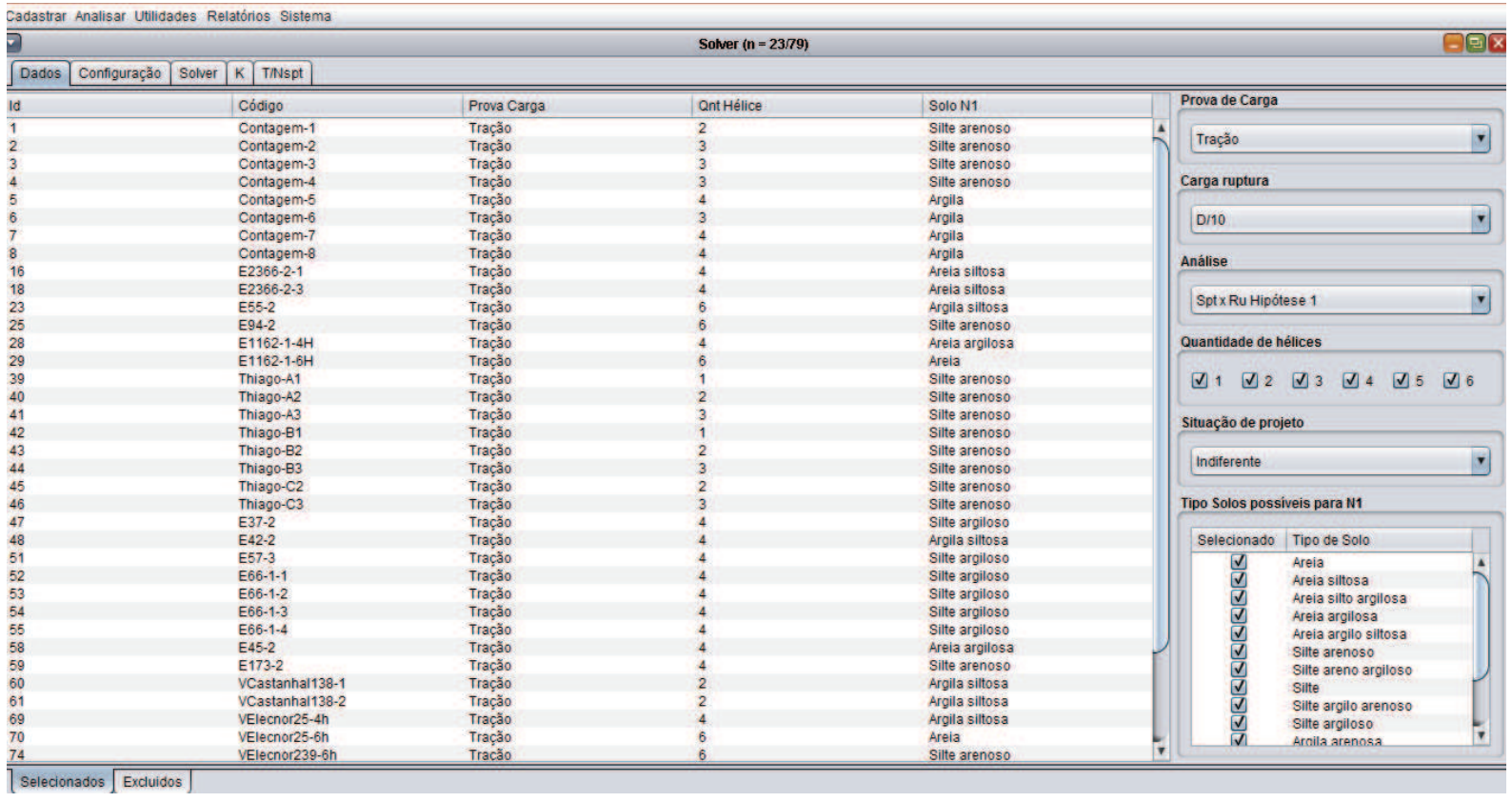

Figura 4. 4: Seleção das estacas no módulo solver.

No próximo passo devem-se configurar as unidades com as quais se deseja trabalhar (Figura 4. 5) e se deve considerar o $\Delta h$ (comentado anteriormente no texto).

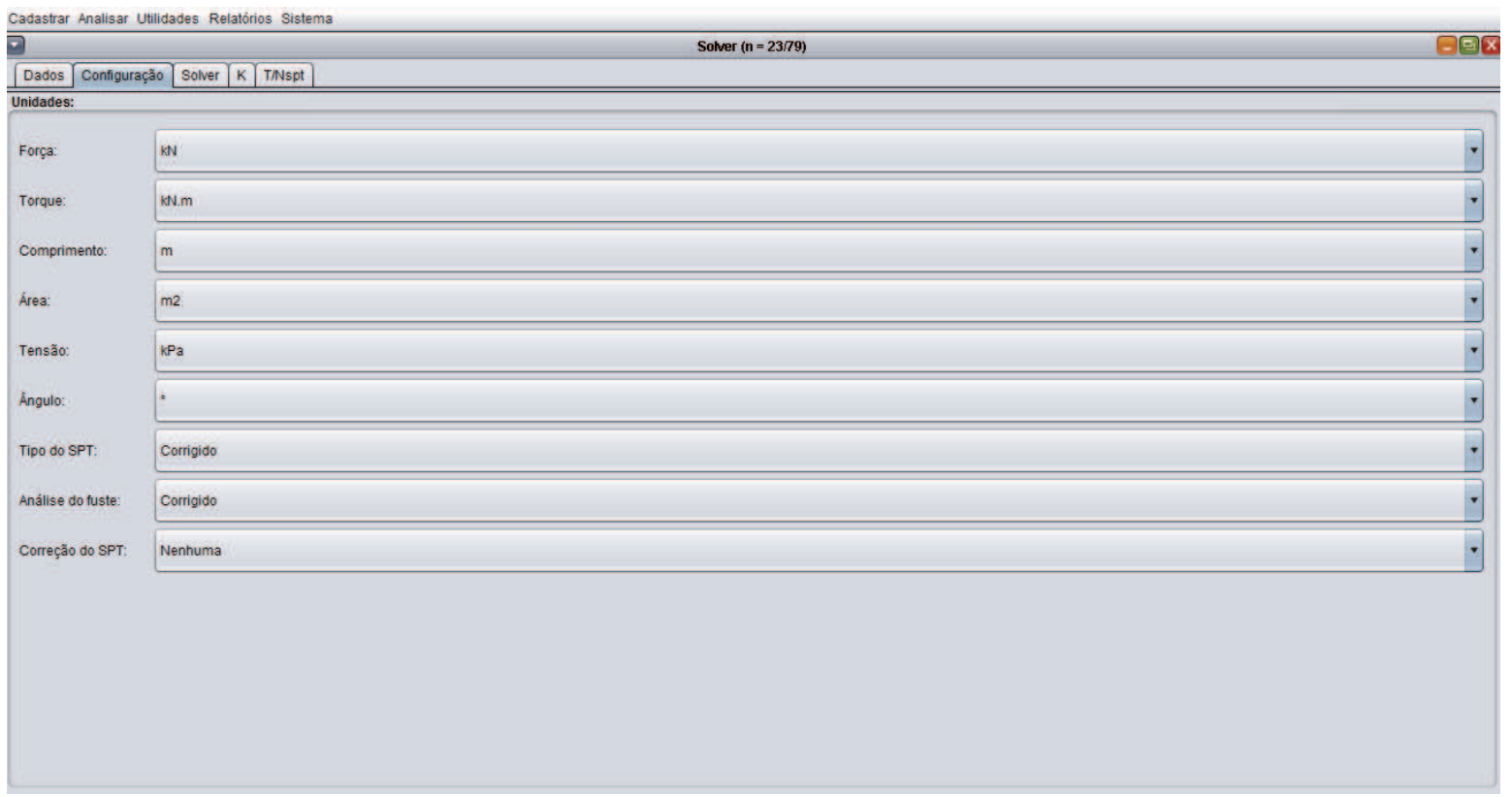

Figura 4. 5: Escolha das unidades no modulo solver

Concluídos os passos 1 e 2, pode-se iniciar o processo de análise dos dados. Um tipo de análise é exemplificado na (Figura 4. 6). 


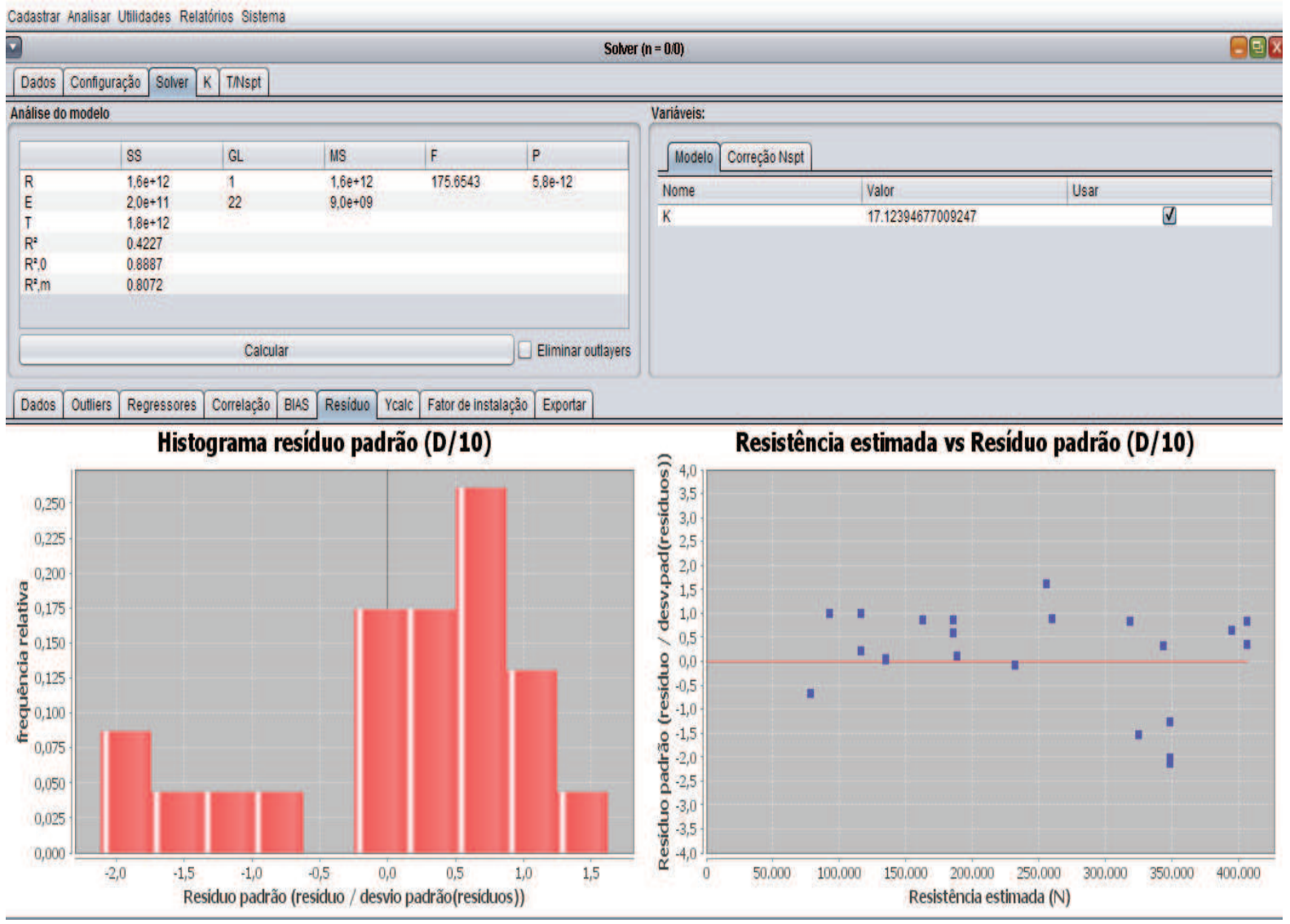

Figura 4. 6: Resultado de um cálculo no módulo solver.

\subsection{MÓDULO EXCEL}

O módulo Excel permite a comunicação entre HPT e o Excel. Nele é implementada uma série de rotinas para criação, exclusão, edição, formatação, validação de dados e tabelas. As duas principais funcionalidades deste módulo são: cadastrar e exportar estacas, e criar uma planilha estruturada para utilizar suas ferramentas estatísticas.

O cadastro da estaca helicoidal poderá ser feito utilizando-se uma planilha no Excel especialmente desenvolvida para este fim. O sistema é capaz de importar e exportar os dados nela. Há algumas limitações quanto a este recurso, como, por exemplo, os valores deverão ser preenchidos em campos específicos, algumas informações deverão seguir os padrões estabelecidos pelo programa (os nomes das unidades, formas das seções e etc). Na própria tabela há uma explicação que orienta o usuário quanto ao seu uso. 
O HPT apenas resolve problemas de regressão linear (simples ou múltipla). Quando há necessidade de impor restrições ou resolver problemas de otimização com múltiplos objetivos, faz-se necessário utilizar o Excel. Ao exportar uma análise do HPT, o arquivo Excel é estruturado para utilizar a ferramenta solver, o que simplifica o uso, diminui a chance de erros e o tempo gasto.

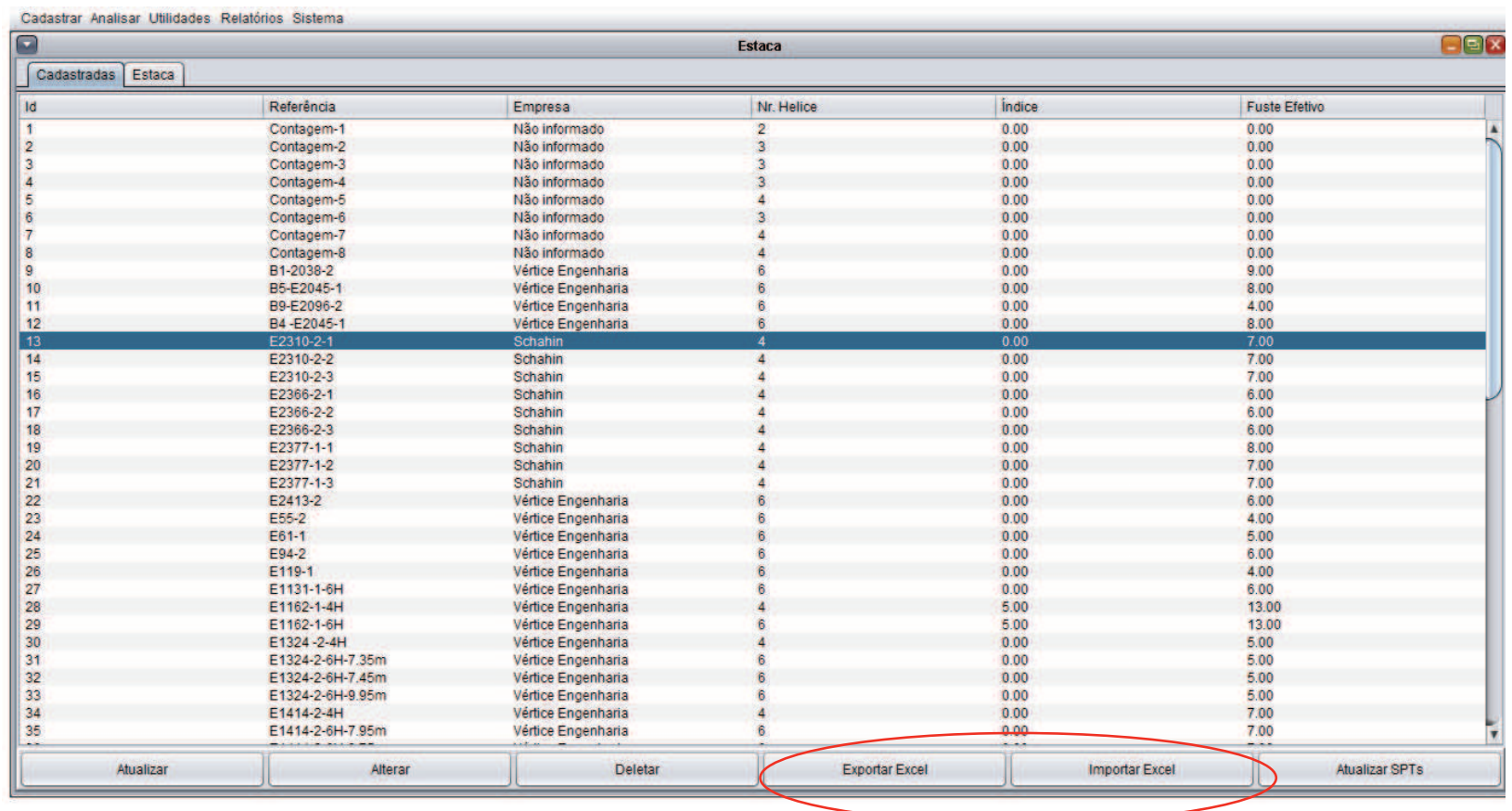

Figura 4. 7: Botões para importar e exportar estacas do HPT para o Excel.

Não há uma tela específica para este módulo. Ele é um comando e aparece na tela em forma de botão (Figura 4. 7).

\subsection{MÓDULO RELATÓRIO}

O módulo relatório exporta gráficos, textos e tabelas para arquivos em formato $p d f$. Ele é o responsável por criar toda a estrutura do arquivo texto como seções, capítulos, etc.

Existem diversos relatórios no programa, destacando-se: resumo analítico e/ou gerencial da base de dados (vide ANEXO $\mathrm{V}$ ), resultado das análises do módulo solver (ANEXO IV) e calculadora (ANEXO III). 


\subsection{MÓDULO CALCULADORA}

O módulo calculadora foi inicialmente estruturado para estimar a capacidade de carga de qualquer tipo de estaca por meio de diversos métodos de cálculo. Entretanto, se tornou muito complexo criar uma estrutura única para armazenar, calcular e apresentar os resultados. Desta forma, ele foi adaptado para funcionar somente para as estacas helicoidais cadastradas na base dados.

É possível estimar a capacidade de carga da estaca utilizando-se: 1) todos os modelos de correlação com o ensaio SPT e com o torque de instalação, desenvolvidos nesta dissertação; 2) método teórico da capacidade de carga individual. Não foi implementado o método do cilindro de cisalhamento porque seria necessário recriar todo o módulo. Também, como nos modelos de estacas helicoidais usadas no Brasil o espaçamento entre hélices é maior que três vezes o diâmetro da hélice inferior, a método da capacidade de carga individual é o mais apropriado.

A primeira etapa consiste em selecionar a estaca da base de dados para se definir a geometria, ensaio SPT e torque de instalação. Na segunda (Figura 4. 8), deve-se escolher as unidades, os métodos de cálculo, qual fator de correção utilizar, etc.

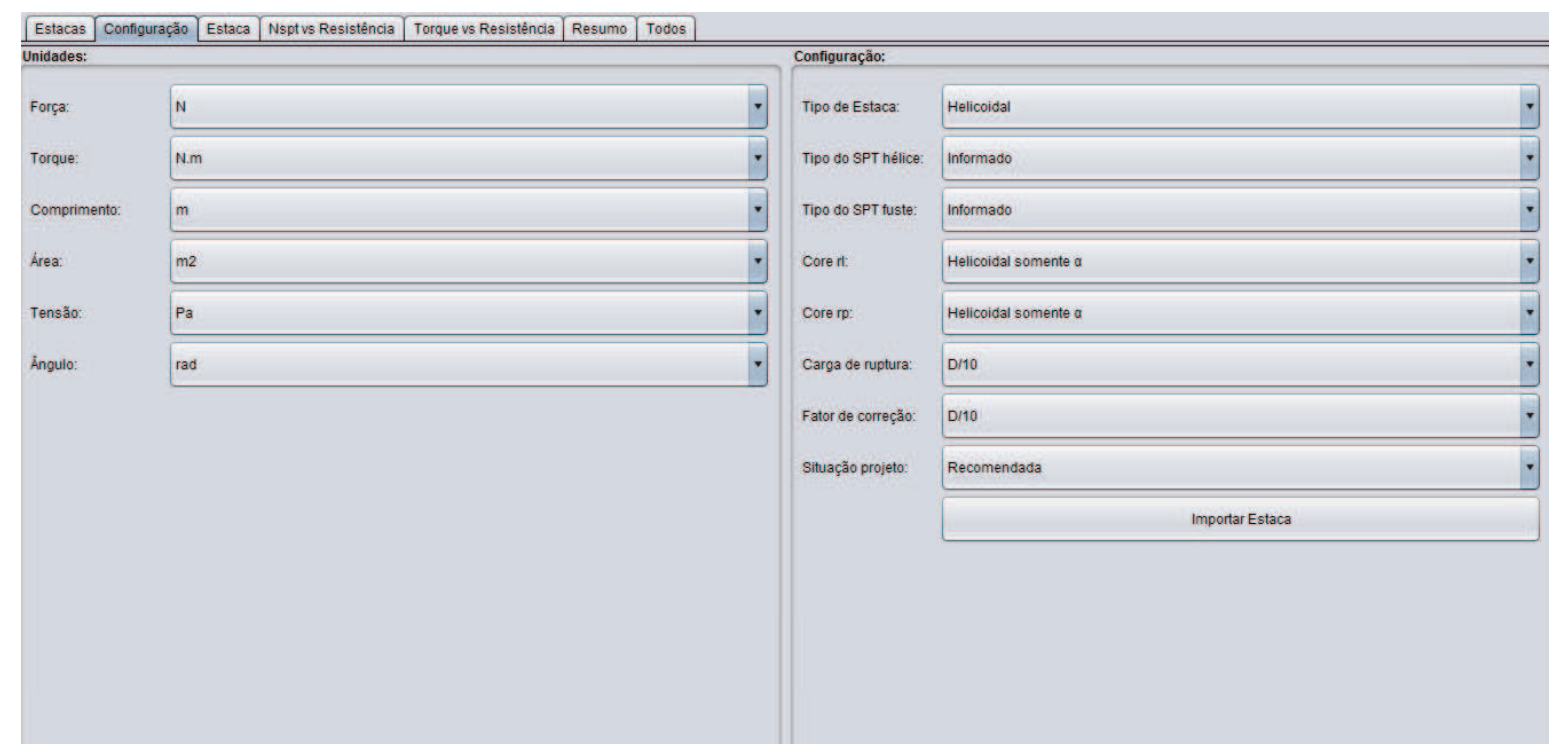

Figura 4. 8: Configuração do módulo calculadora.

Depois de configurado, podem-se realizar as estimativas de capacidade de carga da estaca. Nelas são apresentados gráficos de capacidade de carga ou resistência estimada 
(Figura 4. 9, Figura 4. 11), memória de cálculo e as variáveis do modelo com respectivos valores (Figura 4. 10).

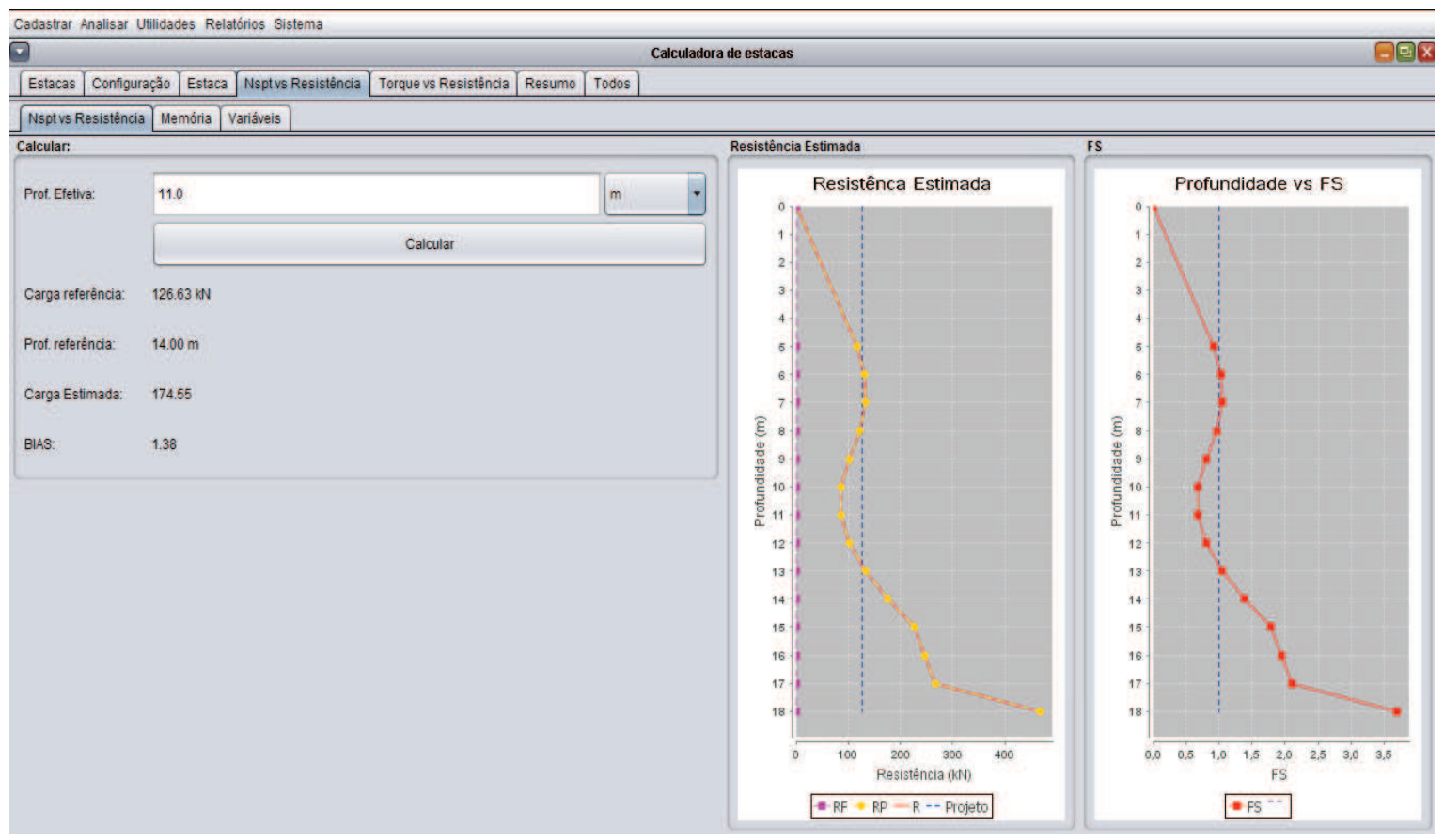

Figura 4. 9: Tela do cálculo da relação $N_{S P T}$ versus resistência.

As variáveis do modelo podem ser alteradas para testar outros ajustes. A situação de projeto é automaticamente definida pelo programa.

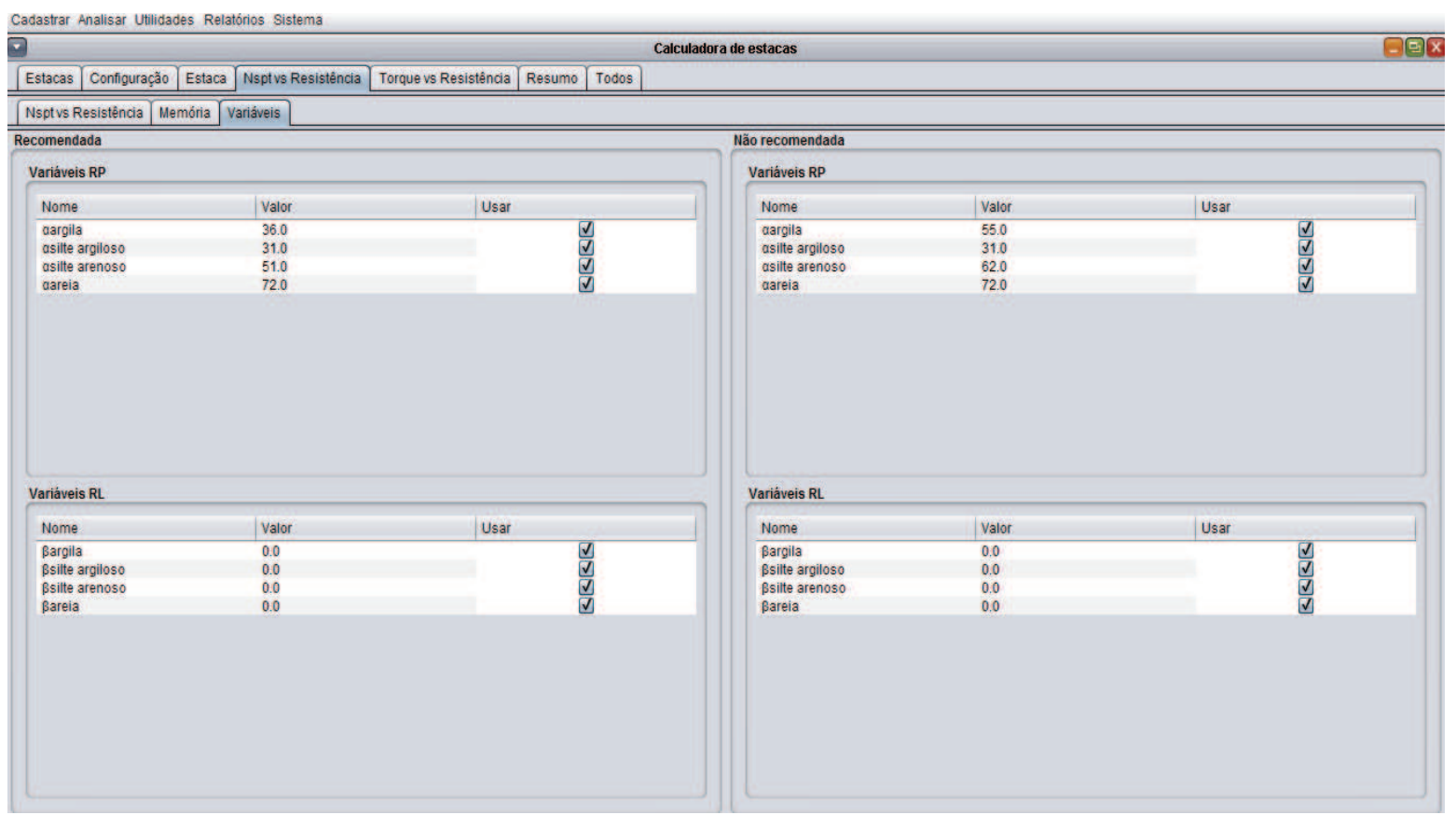

Figura 4. 10: Tela das variáveis para relação $N_{S P T}$ versus resistência. 


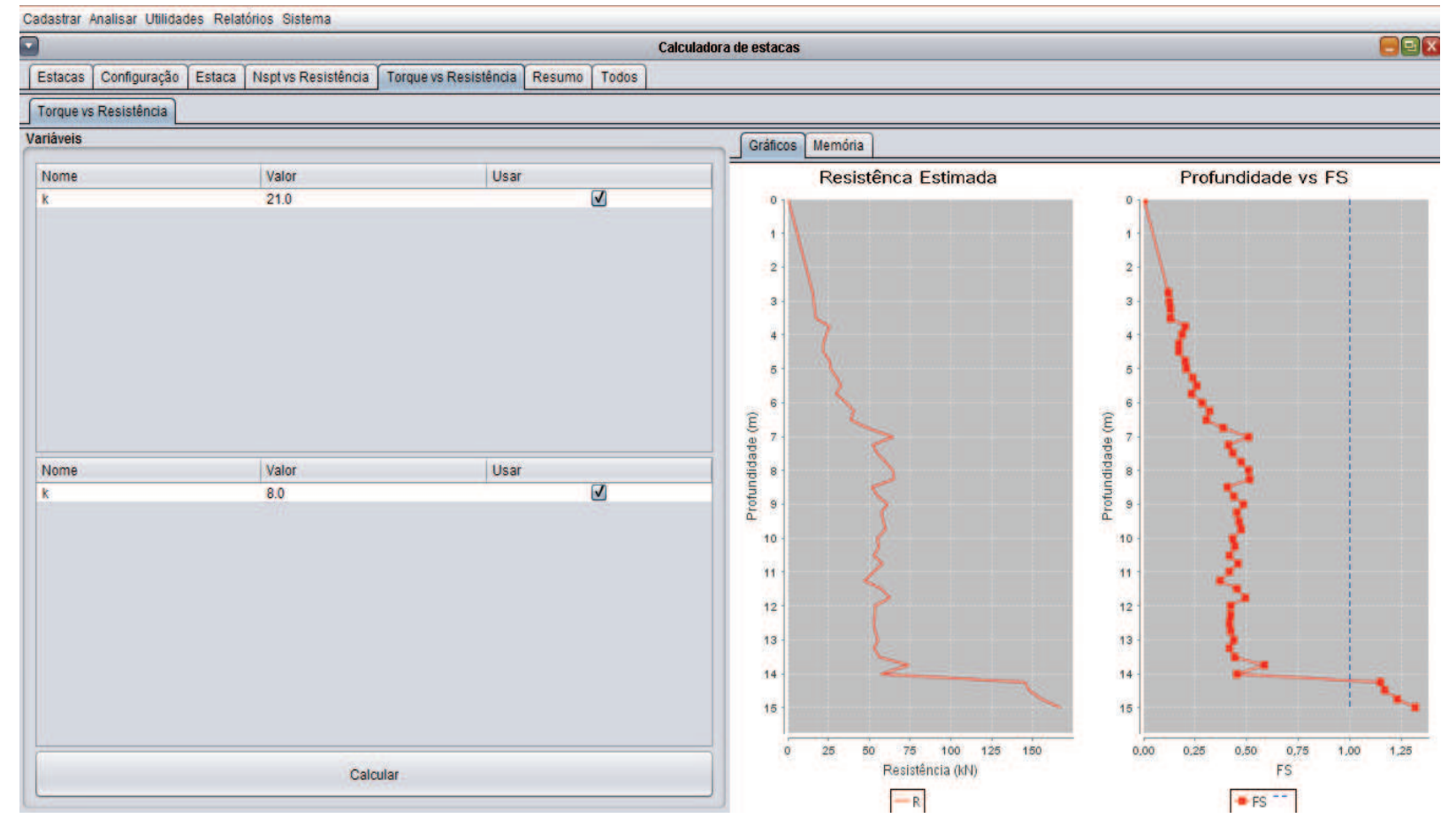

Figura 4. 11: Tela do cálculo da relação torque versus resistência.

Há ainda uma tela com o resumo dos cálculos (Figura 4. 12) onde são apresentados os valores estimados pelo torque e SPT no mesmo gráfico.

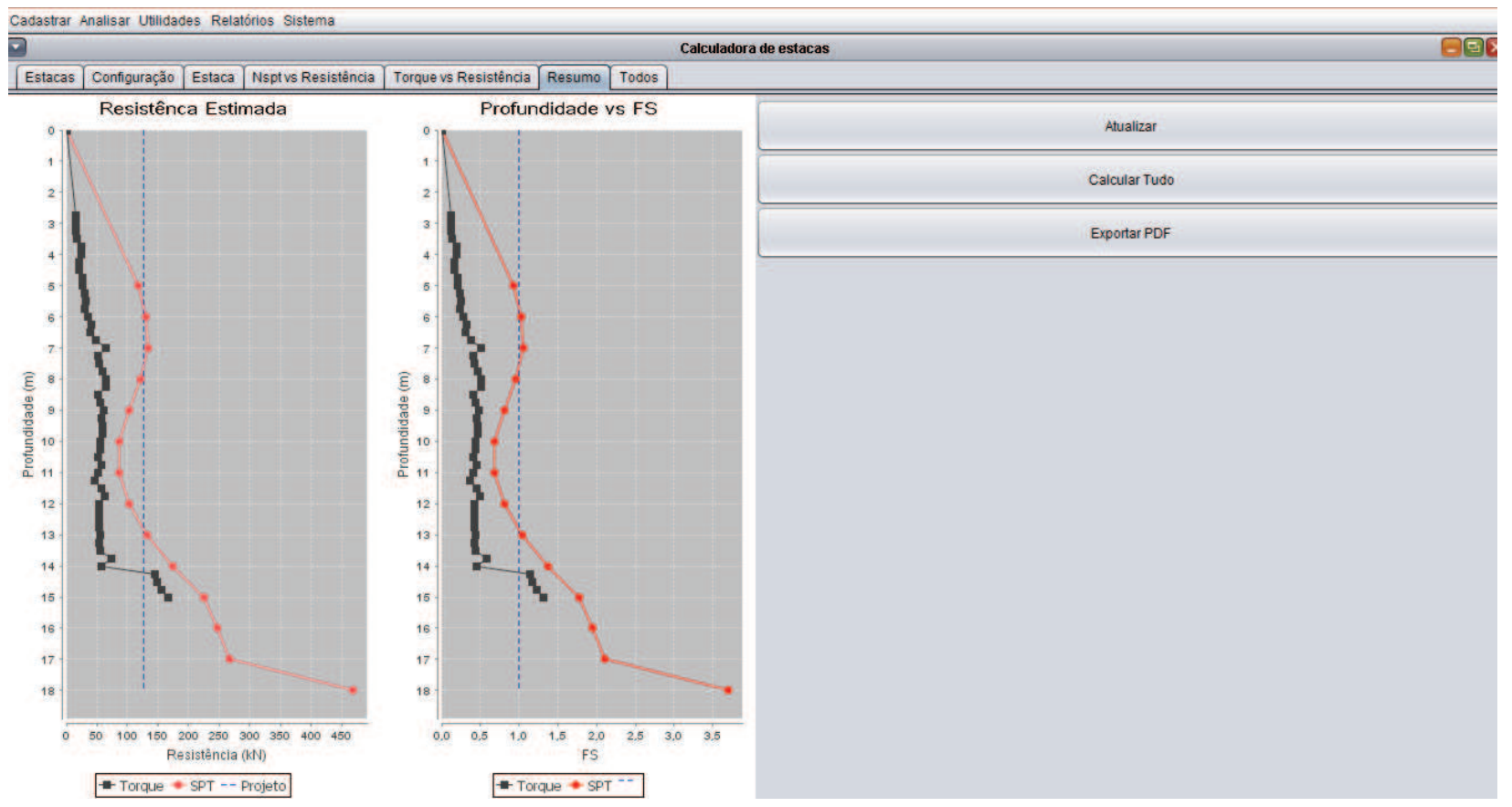

Figura 4. 12: Tela com gráfico de resumo das relações $N_{S P T}$ versus resistência e torque versus resistência. 
Uma sub-rotina para cálculo de todas as estacas na profundidade de instalação com o modelo selecionado foi desenvolvida. A única saída de dados é um relatório com as memórias de cálculo e o histograma do BIAS com estatística descritiva. Ela é utilizada para comparar acurácia de cada método de cálculo na base de dados.

\subsection{FUNCIONALIDADES COMPLEMENTARES}

\subsubsection{Testes}

O programa conta com rotinas internas de testes unitários para verificar se o funcionamento ocorre de forma adequada. A cada nova versão, eles são executados. Especial atenção foi dada às rotinas matemáticas, como cálculo de áreas, conversão de unidades e operações com sistema de unidades distintas.

\subsubsection{Sistema de mensagens ao usuário}

O HPT envia ao usuário mensagens confirmando ou não o sucesso de uma ação (Figura 4. 13). Quando ocorre um erro, ele emite um aviso indicando o porquê de não executar determinado comando.

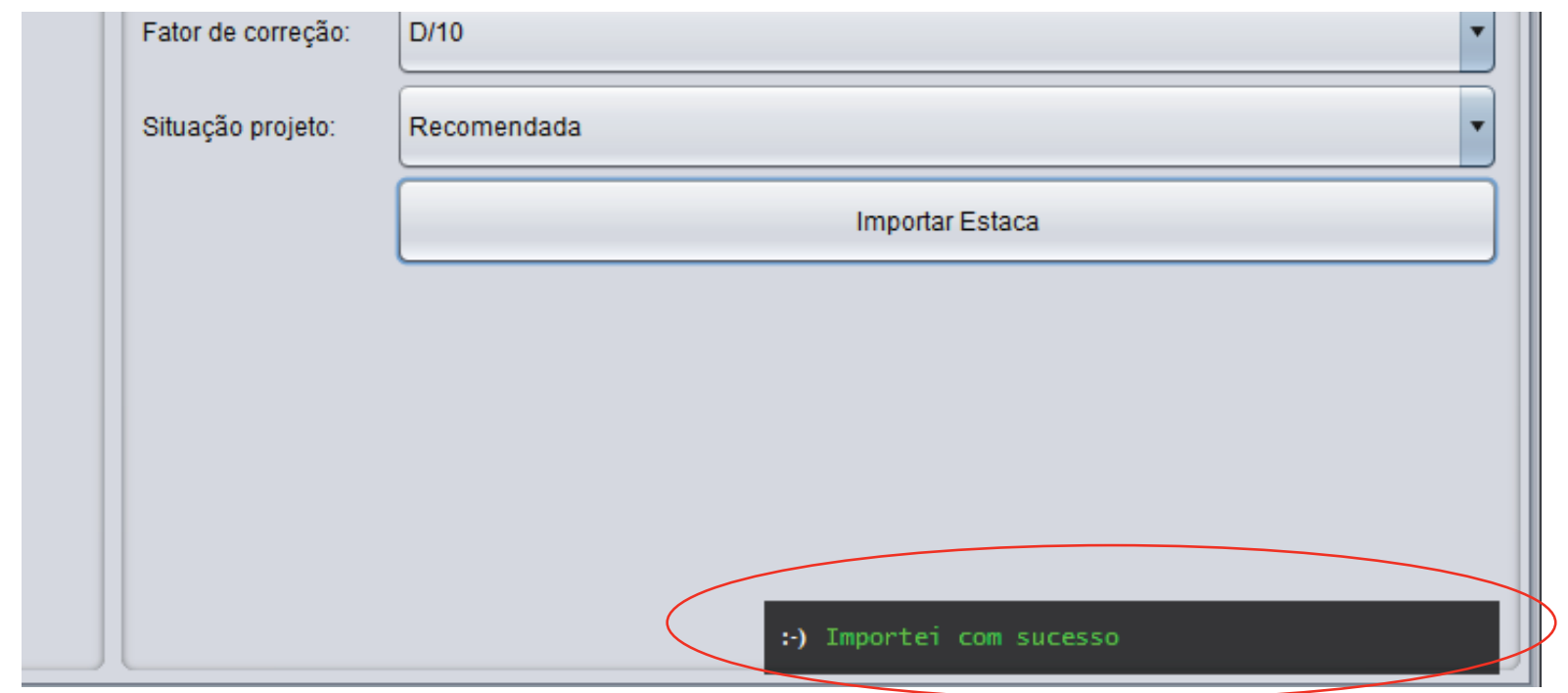

Figura 4. 13: Sistema de mensagem do HPT. 


\subsubsection{Conversor de unidades}

O HPT possui um conversor de unidades para facilitar e testar as unidades cadastradas.

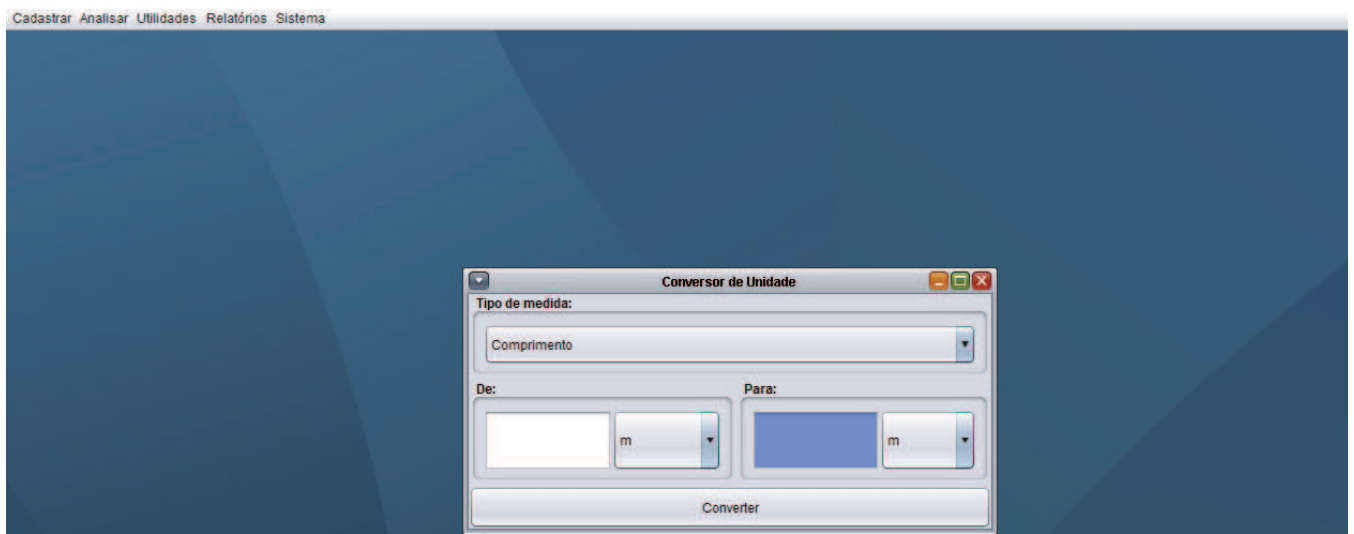

Figura 4. 14: Conversor de unidades.

\subsubsection{Sistema multi-janela}

O HPT foi desenvolvido com suporte a multi-janela (similar ao do Windows, Figura 4. 15). O usuário pode abrir diversas janelas simultâneas, minimizar, maximizar e fechá-las a qualquer momento.

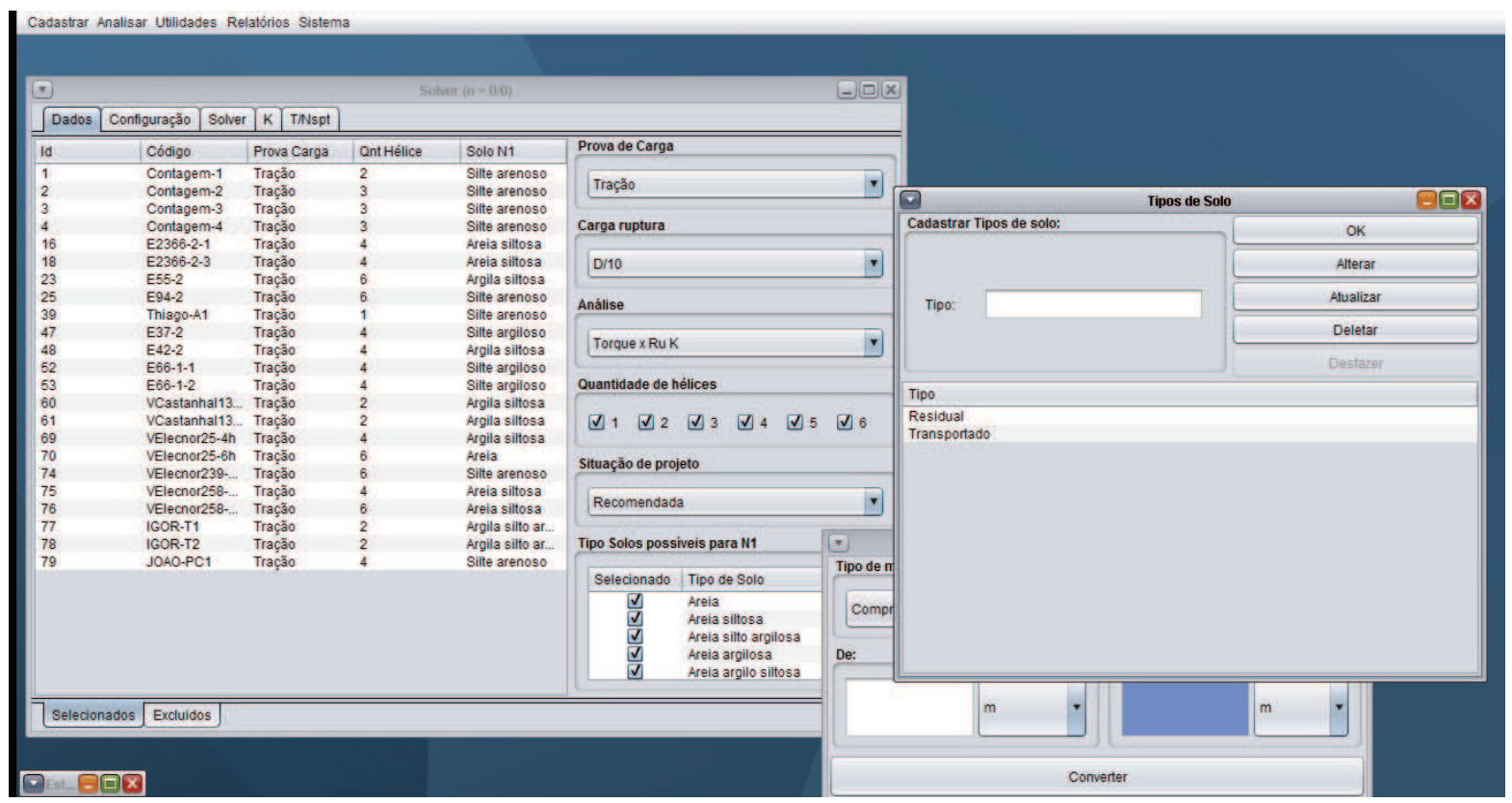

Figura 4. 15: HPT com diversas janelas em aberto 
Pela forma como o sistema foi desenvolvido, caso uma informação seja alterada numa janela, ela é automaticamente atualizada nas demais, evitando a apresentação de dados defasados.

Esta estrutura proporciona uma forma amigável e prazerosa de se utilizar o programa. 


\section{ANÁlise da CORRELAÇÃO ENTRE TORQUE E CAPACIDADE DE CARGA DAS ESTACAS HELICOIDAS.}

\subsection{INTRODUÇÃO}

Neste capítulo analisa-se o método de previsão de capacidade de carga de fundações por estacas helicoidais por meio de torque de instalação, para as situações de projeto A e B (definidas anteriormente).

Nesta análise são utilizados os valores de carga de ruptura interpretada pelo método de Livneh e Naggar (2008) e D/10 a partir das curvas carga x deslocamento das provas de carga. No ANEXO I encontram-se as análises para os valores de carga de ruptura interpretados usando-se os critérios de Davisson (1972) e da NBR 6122 (2010).

A formulação do modelo para a relação entre torque de instalação e capacidade de carga à tração da estaca é apresentada na equação 3. 1.

$Q_{u}=k_{t} T+\varepsilon$

$\mathrm{O}$ método dos mínimos quadrados $(M M Q)$ postula que o os estimadores devem ter distribuição de probabilidade normal $(D P N)$. Portanto, somente deve-se estimar $k_{t}$ por meio de regressão linear simples $(R L S)$ se esta condição for verificada no histograma - nas distribuições simétricas (como na $D P N$ ) a média é igual à mediana e moda (esta representada pelo pico do gráfico).

Outros estimadores possíveis são a média e mediana. Não é recomendado utilizar a média em distribuições assimétricas porque ela é fortemente influenciada pelos valores extremos.

\subsection{ANÁLISE COM CARGAS DE RUPTURA OBTIDAS PELO CRITÉRIO D/10}

\subsubsection{Análise Geral}

O histograma de $k_{t}$ para todas as estacas (Figura 5. 1 a.) possui dois picos: um próximo de $9 \mathrm{~m}^{-1}$ e outro de $20 \mathrm{~m}^{-1}$. O inferior está associado à situação $B$, o superior à $A$. 
A intercessão entre a situação $A$ (Figura 5.1 b.) e a $B$ (Figura 5.1 c.) é praticamente nula, indicando bom ajuste à metodologia proposta. Nenhum histograma da Figura 5. 1 possui forma de distribuição de probabilidade normal.

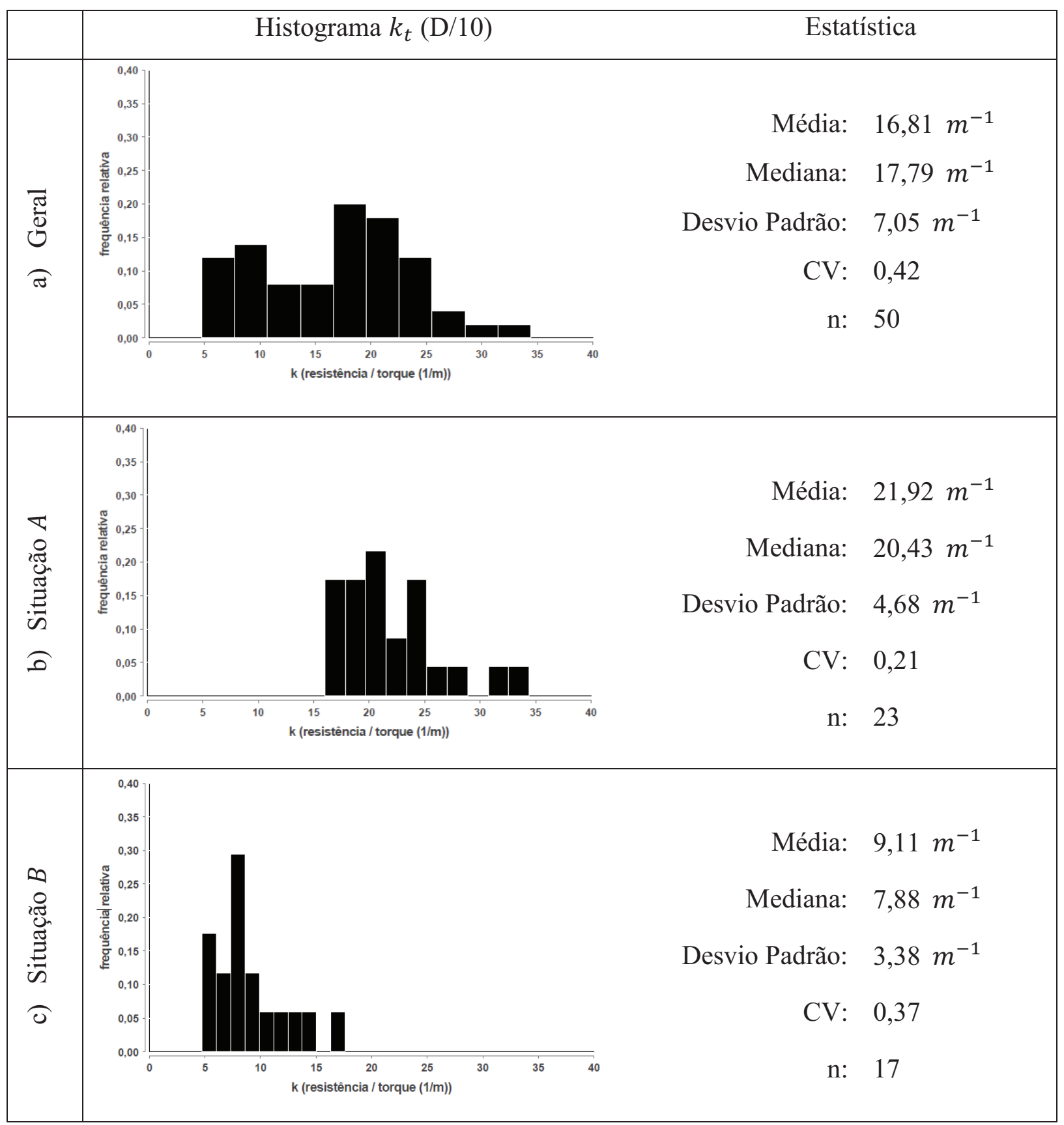

Figura 5. 1: Histogramas de $k_{t}$ utilizando D/10 para: a) todas as amostras, b) situação $A$, c) situação $B$.

As estacas com 6 hélices não apresentaram comportamento diferenciado das demais. Portanto, as análises podem ser feitas conforme a situação de projeto (A ou B). 


\subsubsection{Situação $A$}

O histograma da situação $A$ (Figura 5.1 b.) não possui valores inferiores a $15 \mathrm{~m}^{-1}$. Sua forma é típica de distribuição de probabilidade lognormal. O valor estimado pela mediana é igual a $21 \mathrm{~m}^{-1}$. Com o valor de $k_{t}$ retroanalisado calculou-se a capacidade de carga (ou resistência) à tração da estaca helicoidal para elaboração do histograma do BIAS (resistência calculada via torque/ resistência observada) mostrado na Figura 5. 2.

O histograma do BIAS (Figura 5. 2) possui média e mediana próximos de 1,0, CV de 0,19 (considerado baixo). Os valores se distribuem no intervalo de previsão $(0,6$ a 1,3) de forma pouco concentrada (o desejado é um pico próximo de 1,0). $\mathrm{O}$ erro máximo contra a segurança é de $30 \%$. Aproximadamente $80 \%$ do BIAS se encontram dentro do intervalo 0,80 e 1,20 .

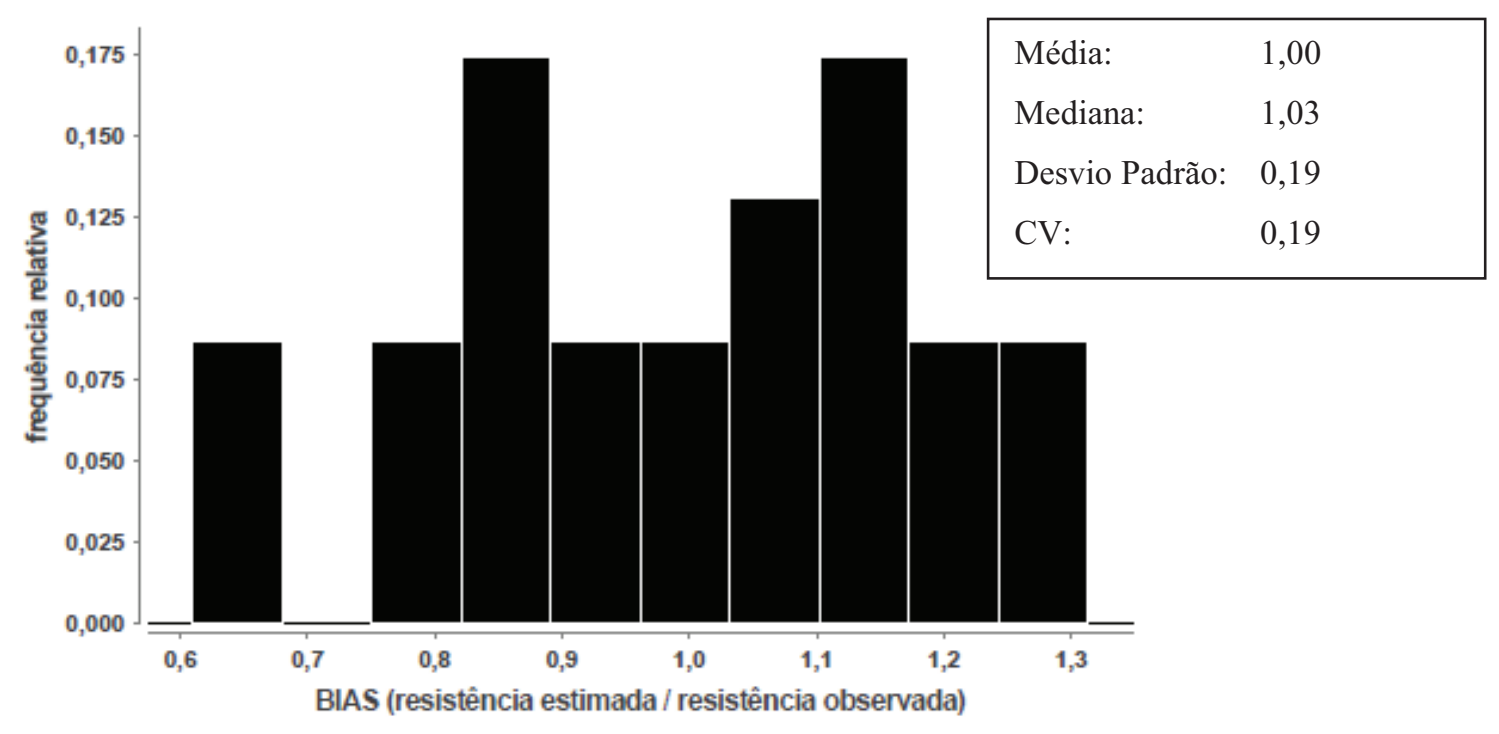

Figura 5. 2: Histograma do BIAS para situação $A$ utilizando D/10

O $M M Q$ possui determinadas premissas, por isso é obrigatório realizar a análise estatística detalhada da regressão. Como ele não foi utilizado, somente será apresentado as que permitem melhor entender o comportamento do estimador.

A aleatoriedade no gráfico de resistência estimada versus observada (Figura 5. 3) é a desejada, indicando que o estimador erra e acerta de maneira uniforme. Com isso, a variância é constante e o gráfico de resíduo padrão versus resistência estimada a (Figura 5.4) possui forma típica de ajuste linear adequado. 


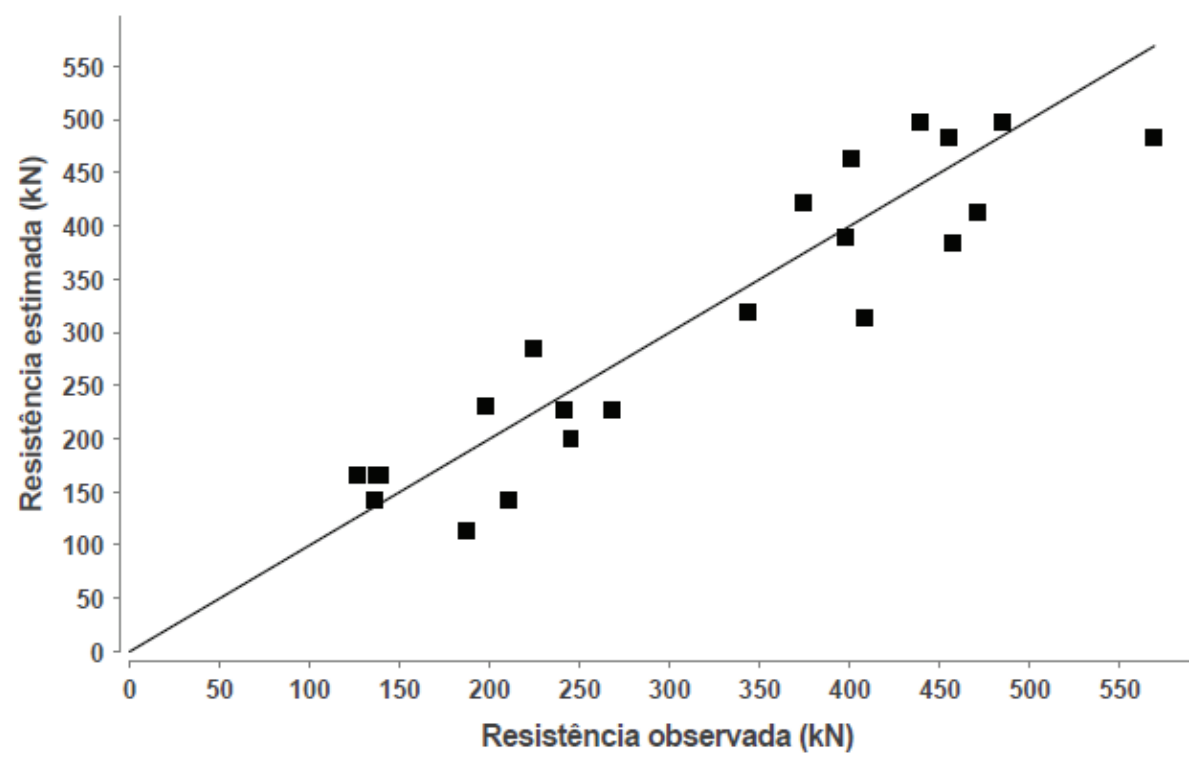

Figura 5. 3: Gráfico de resistência observada versus resistência estimada para situação $A$ utilizando $\mathrm{D} / 10$.

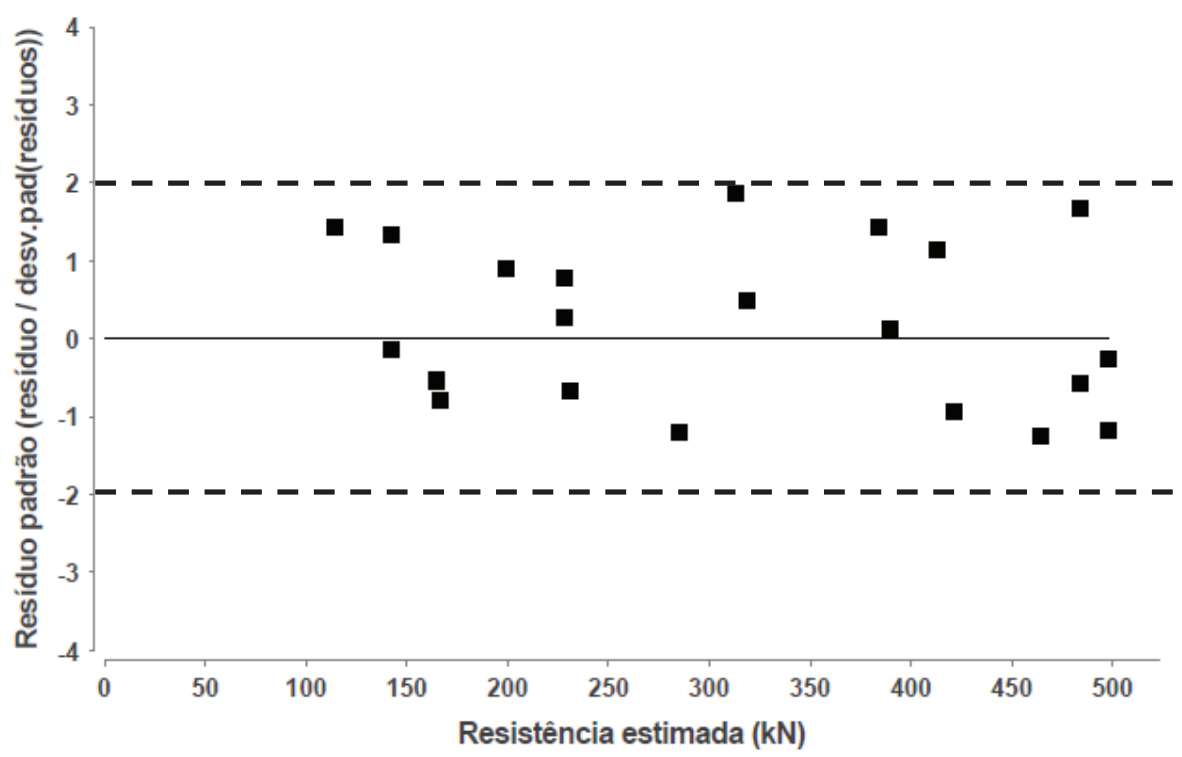

Figura 5. 4: Histograma de resíduo padrão para situação $A$ utilizando D/10.

\subsubsection{Situação $B$}

O histograma de $k_{t}$ para a situação $B$ (Figura 5.1 c.) é assimétrico. $O$ valor estimado de $k_{t}$ a partir da mediana é $8 \mathrm{~m}^{-1}$. Do mesmo modo que foi feito para a situação A de projeto no item anterior, a Figura 5. 5 mostra o histograma do BIAS (resistência calculada via torque/ resistência observada) para a situação B. Este histograma mostra que o BIAS possui média, mediana e moda próximo de 1,0 (combinação desejada). 


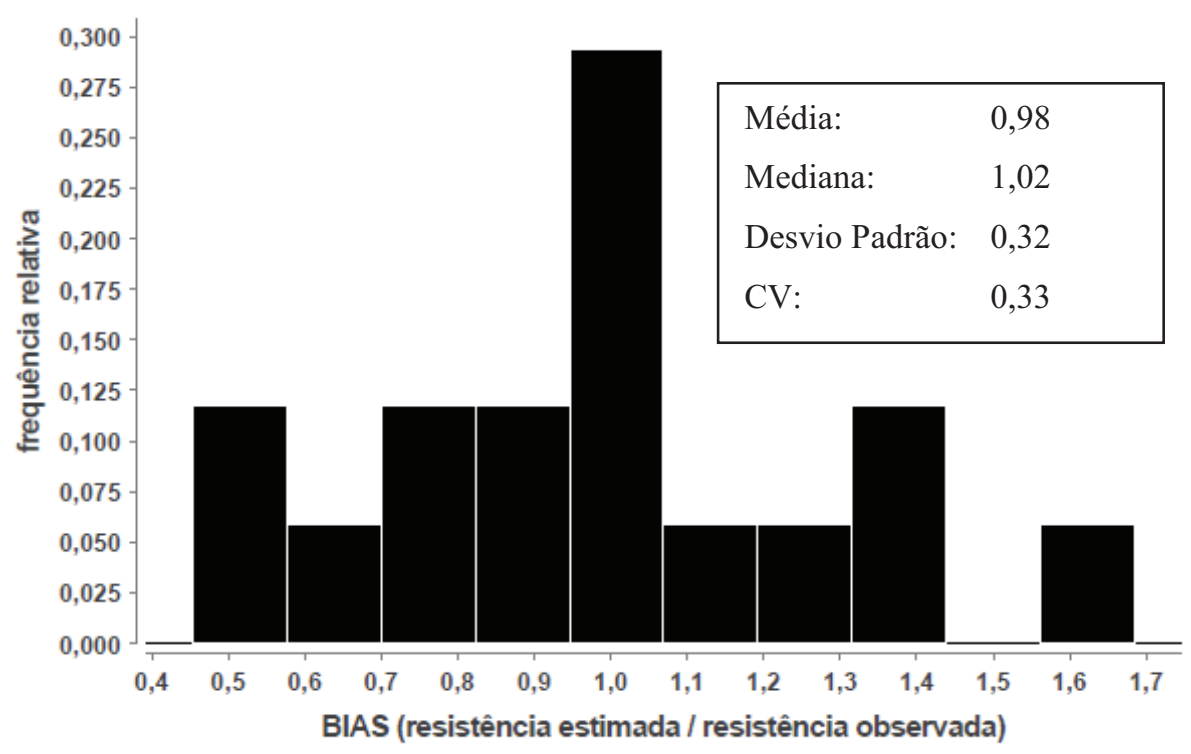

Figura 5. 5: Histograma do BIAS para situação $B$ utilizando D/10.

5.3 ANÁLISE COM CARGAS DE RUPTURA OBTIDAS PELO CRITÉRIO DE LIVNEH E NAGGAR (2008)

\subsubsection{Análise Geral}

O histograma de $k_{t}$ com todas as estacas (Figura 5. 6 a.) possui dois picos (um próximo de $9 \mathrm{~m}^{-1}$ e outro de $20 \mathrm{~m}^{-1}$ ), a média e mediana estão ligeiramente afastadas e o $\mathrm{CV}$ é elevado. Portanto, as análises serão separadas para as situações A e B de projeto (Figura 5. 6 b. e Figura 5.6 c).

A intercessão entre a situação $A$ (Figura 5.6 b.) e $B$ (Figura 5.6 c.) é praticamente nula, indicando bom ajuste à metodologia proposta. Nenhum histograma da Figura 5. 6 possui forma típica de distribuição de probabilidade normal.

O comportamento das estacas com 6 hélices não se diferenciaram das demais. Portanto, as análises podem ser resumidas para as situações de projeto A e B. 


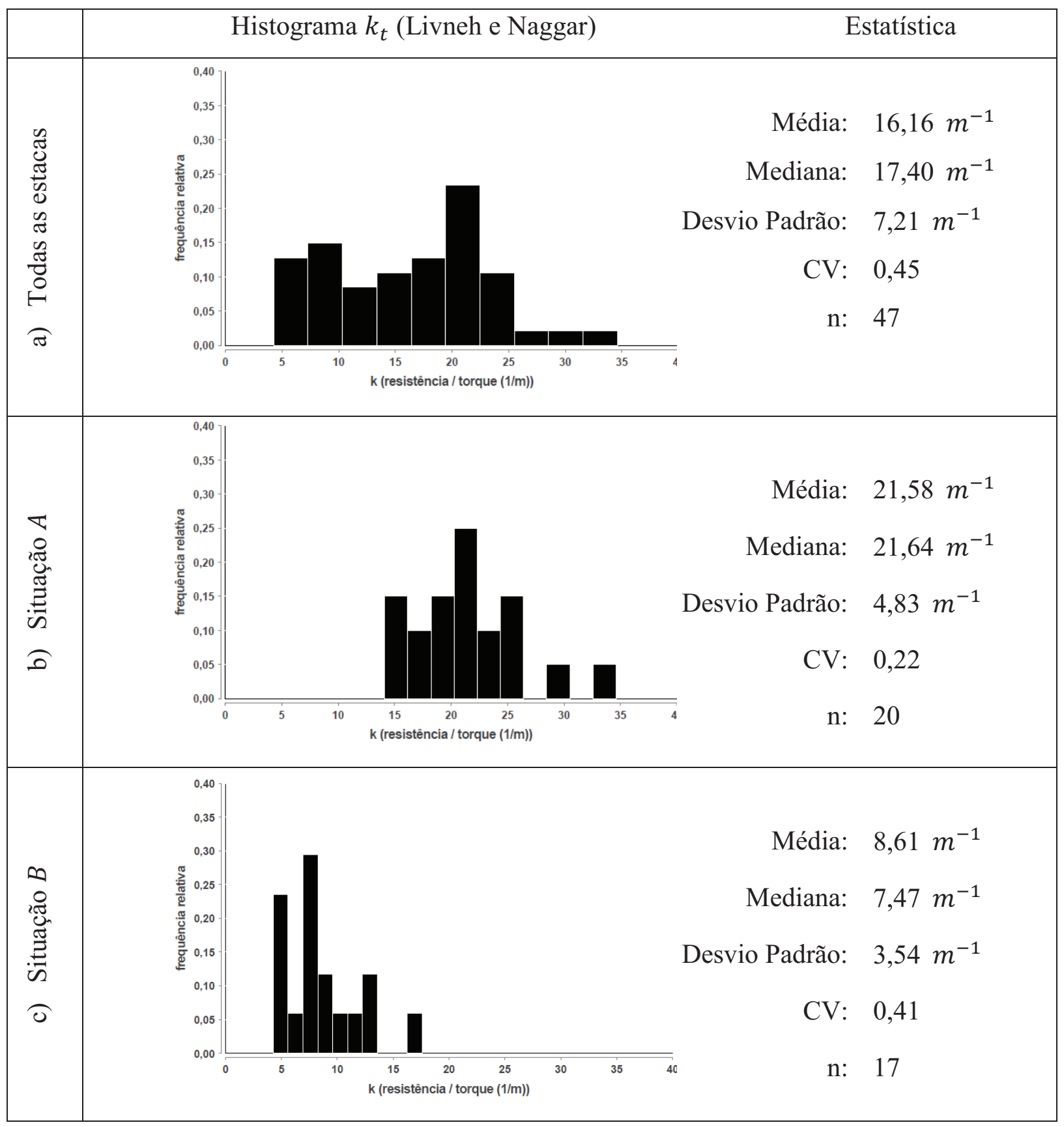

Figura 5. 6: Histogramas de $k_{t}$ utilizando Livneh e Naggar para: a) todas as amostras, b) situação $A$, c) situação $B$.

\subsubsection{Situação $A$}

O valor de $k_{t}$ estimado a partir de mediana é de $21 \mathrm{~m}^{-1}$. Deste modo, foram determinados para as estacas da situação A os valores da razão entre capacidade de carga (resistência) estimada e observada (BIAS). O histograma do BIAS de resistência (Figura 5. 7) mostram que a maioria dos valores são próximos de 1,0 e com pouca dispersão $(\mathrm{CV}=0,21)$. 
Os valores mínimos e máximos foram, respectivamente, 0,6 e 1,50, com 70\% dos pontos entre 0,80 e 1,20 .

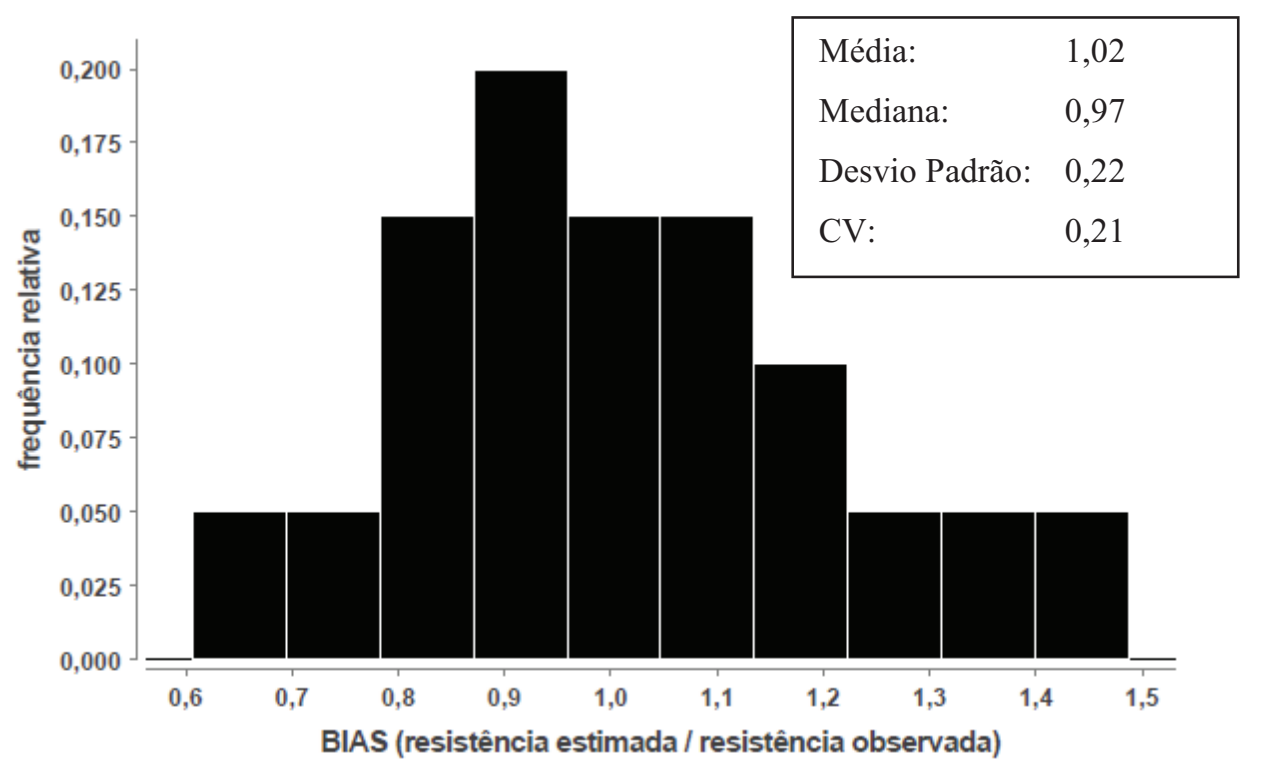

Figura 5. 7: Histograma do BIAS para situação $A$ utilizando Livneh e Naggar (2008).

O gráfico de resistência observada versus resistência estimada (Figura 5. 8) possui a aleatoriedade desejada. A dispersão dos resíduos no gráfico de resíduo padrão versus resistência estimada (Figura 5.9) é típica de ajuste linear adequado.

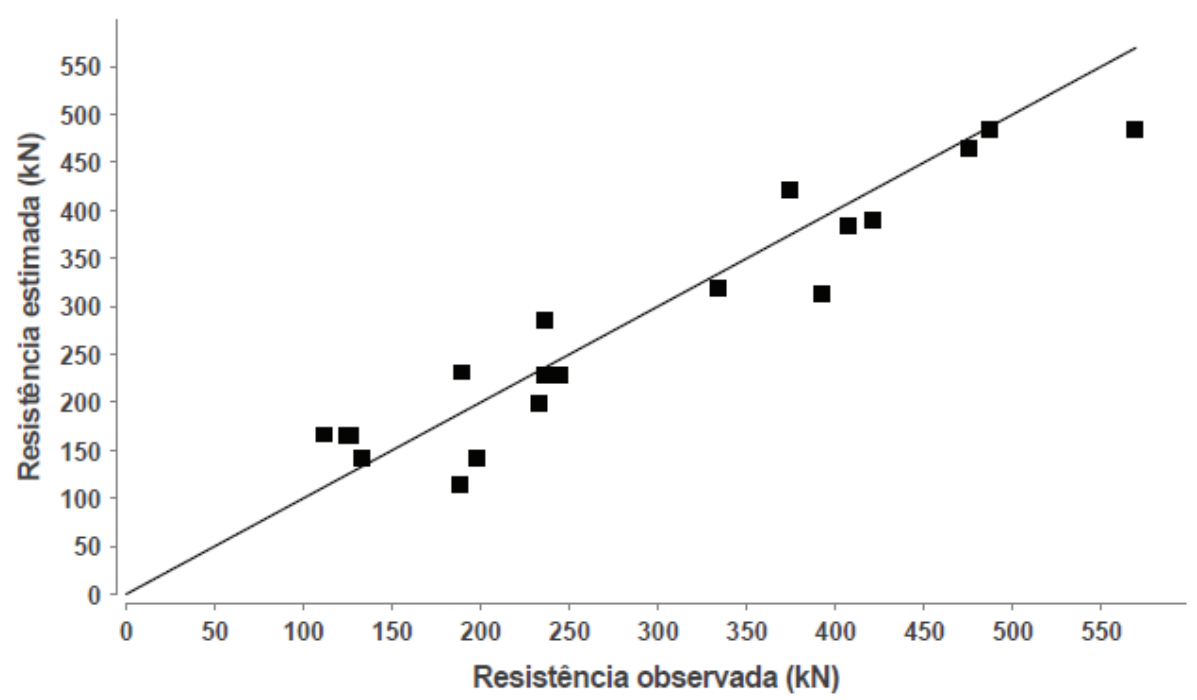

Figura 5. 8: Gráfico de resistência observada versus resistência estimada para situação $A$ utilizando Livneh e Naggar (2008). 


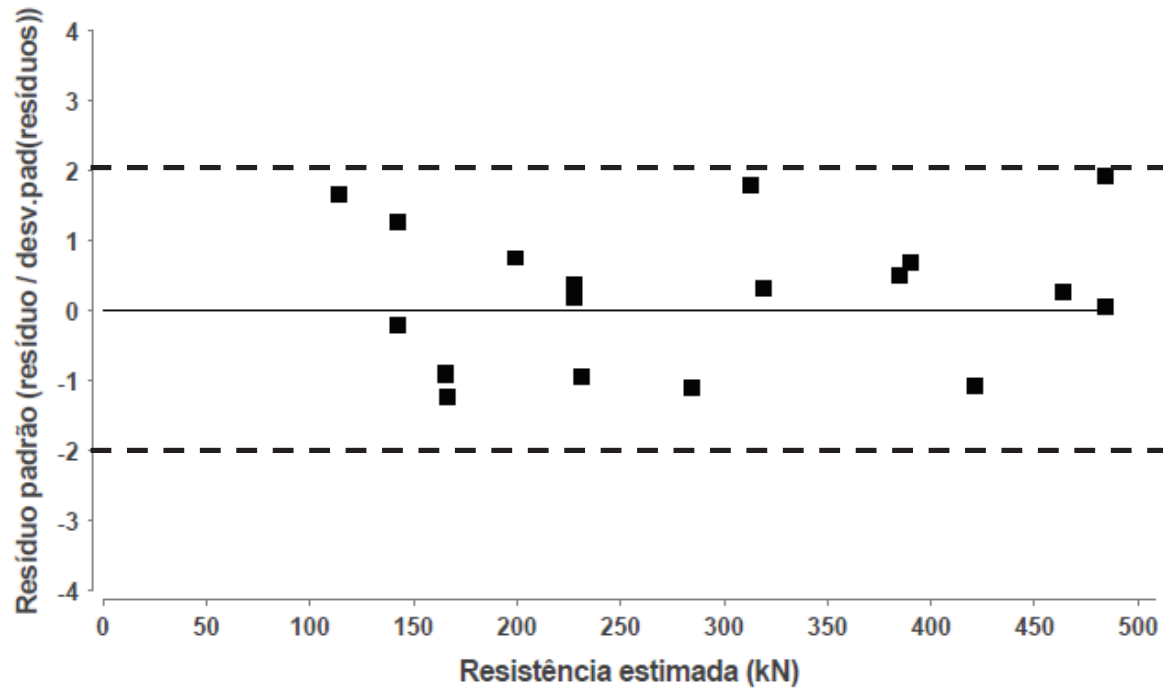

Figura 5. 9: Histograma de resíduo padrão para situação $A$ utilizando Livneh e Naggar (2008).

\subsubsection{Situação $B$}

$\mathrm{O}$ valor de $k_{t}$ estimado a partir de mediana é de $8 \mathrm{~m}^{-1}$. Para este caso, o histograma do BIAS de resistência (Figura 5. 10) possui um pico central próximo de 1,1. Os valores máximos e mínimos são, respectivamente, 1,9 e 0,40, com, aproximadamente, 55\% dos valores entre 0,80 e 1,20.

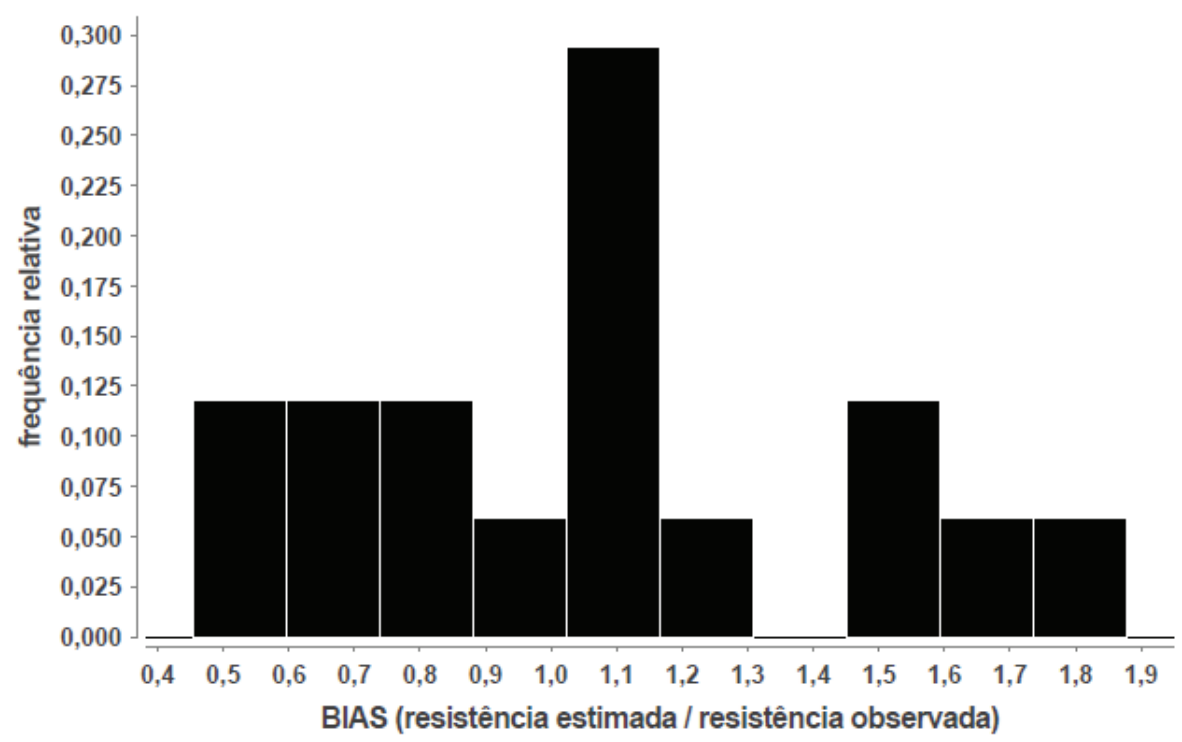

Figura 5. 10: Histograma do BIAS para situação $A$ utilizando Livneh e Naggar (2008). 


\subsection{COMPARAÇÃO DAS METODOLOGIAS}

Quanto aos valores de carga de ruptura obtidos nas provas de carga, os critérios de Davisson (1972) e da NBR 6122 (2010) são conservadores, enquanto que os critérios D/10 e o de Livneh e Naggar (2008) estimam resistências mais elevadas. O menor valor de $k_{t}$ estimado nas duas últimas é quase igual ao valor máximo estimado nas duas primeiras (Tabela 5. 1).

Tabela 5. 1: Resumo dos valores de $k_{t}$ estimados.

\begin{tabular}{|r|c|c|c|c|}
\hline & Davisson (1972) & NBR 6122 (2010) & D/10 & Livneh e Naggar (2008) \\
\hline Situação $\boldsymbol{A}\left(\boldsymbol{m}^{\mathbf{- 1}}\right)$ & $9^{1}$ & $13^{1}$ & 21 & 21 \\
\hline Situação $\boldsymbol{B}\left(\boldsymbol{m}^{\mathbf{- 1}}\right)$ & $4^{1}$ & $5^{1}$ & $8^{1}$ & $8^{1}$ \\
\hline 6 Hélices $\left(\boldsymbol{m}^{-1}\right)$ & 15 & 19 & $21^{2}$ & $21^{2}$ \\
\hline
\end{tabular}

${ }^{1}$ Aplica-se somente às estacas com 2, 3 e 4 hélices.

${ }^{2}$ Adotar valores da situação $A$.

Como mostra a Tabela 5. 1, para qualquer que seja o critério de interpretação da carga de ruptura da estaca, os valores de $k_{t}$ para a situação $B$ são aproximadamente $40 \%$ dos valores da situação $A$. Este fato mostra o efeito da significante perda de estrutura do solo após a penetração das hélices (que ocorre nas estacas da situação B) e consequente redução na razão entre capacidade de carga à tração e torque final de instalação da estaca, representada por $k_{t}$.

As estacas com 6 hélices possuem resultado diferenciado em relação às estacas com 2,3 e 4 hélices usando-se os critérios de Davisson (1972) e NBR 6122 (2010). Neste caso de 6 hélices, pelo fato de serem adicionadas mais duas hélices, uma maior carga foi suportada, no entanto o valor de torque de instalação não foi aumentado não foi aumentado na mesma proporção, por isso os valores de $k_{t}$ (capacidade de carga/torque) são superiores. Pelos critérios D/10 e Livneh e Naggar (2008) as estacas com 6 hélices se comportam de modo similar às com 2, 3 e 4 hélices na situação $A$.

A separação das situações de projeto mostrou ser mais eficiente usando-se os valores de carga de ruptura obtidos pelos critérios D/10 e Livneh e Naggar (2008), com pequena área de intercessão dos histogramas e $C V$ moderado na situação $A$ (próximo de 0,20 ).

Usando-se as cargas de ruptura obtidas via critérios de Davisson (1972) e da NBR 6122 (2010), a área de intercessão dos histogramas das situações A e B é maior, aumentando 
significativamente a variabilidade. Por isso estes resultados não fazem parte do corpo principal da dissertação, e são mostrados na seção de Anexos deste texto.

Em todas as análises, a situação $B$ mostra maior variabilidade nos resultados do BIAS de resistência obtida via torque de instalação, devendo ser evitada na prática de estacas helicoidais o uso da correlação com o torque para este caso (Figura 5.5 e Figura 5. 10).

A maioria das estacas da base de dados possui fuste superior a $89 \mathrm{~mm}$, e o valor proposto por Hoyt e Clemence (1989) para este grupo foi de $23 \mathrm{~m}^{-1}$, o qual é muito próximo ao valor de $K_{t}$ na situação $A\left(21 \mathrm{~m}^{-1}\right)$. No entanto, o fator de torque proposto em Hoyt e Clemence (1989) é para a capacidade de carga equivalente à carga de ruptura física da estaca.

Não foram encontrados na literatura valores de $K_{t}$ para comparar com o tipo de solo da situação $B$. Nela, o valor de torque de instalação é elevado em relação à capacidade de carga, por isso o valor de $K_{t}$ é inferior. A elevação do torque de instalação ocorre porque o solo da situação $B$ é poroso, não saturado e estruturado. Porém, após a quebra da estrutura devido à instalação da hélice, o solo revolvido acima desta perde grande parte da sua resistência, e consequentemente, a capacidade de carga à tração das estacas helicoidais neste tipo de solo é baixa em relação ao torque de instalação, ficando os valores de $K_{t}$ nesta situação bem inferior aos obtidos na situação $A$. 


\section{ANÁLISE DA CORRELAÇÃO ENTRE $N_{S P T}$ E CAPACIDADE DE CARGA DAS ESTACAS HELICOIDAIS ANCORADAS EM SOLOS COM RESISTENCIA ADEQUADA (SITUAÇÃO A)}

\subsection{INTRODUÇÃO}

Neste capítulo analisa-se o modelo de cálculo que correlaciona a capacidade de carga à tração de fundação por estaca helicoidal com o $N_{S P T}$ do solo, para a situação $A$ de projeto. Serão aplicadas restrições nos valores elevados de $N_{S P T}\left(N_{S P T}<50\right.$ golpes $\left./ 30 \mathrm{~cm}\right)$. Será desconsiderada a contribuição da resistência por atrito lateral na haste da estaca em solos com $N_{S P T}$ inferiores a 7 golpes $/ 30 \mathrm{~cm}$. Não serão aceitos regressores negativos.

Nesta pesquisa, foram analisados dois modelos: um que considera a parcela de resistência por atrito lateral na haste da estaca (modelo $I I$, equação 6. 1) ), e outro que considera somente a capacidade de carga das hélices, pela variável $\alpha_{s}$ (modelo $I$, equação 6 . 2). Nestas equações considera-se que o efeito do confinamento, ou profundidade das hélices da estaca já está embutido no resultado do $N_{S P T}$.

$Q_{u}=\sum_{i=1}^{N} \alpha_{s i} A_{e h i} N_{S P T i}+U \sum_{j=1}^{n} l_{j} \beta_{S j} N_{S P T j}$ (modelo II)

onde:

$N=$ número de hélices;

$i$ = índice relativo à posição da hélice (varia de 1 a $N$ );

$n=$ número de camadas de solo ao longo da haste da estaca

$j$ = índice relativo ao número de camadas de solo ao longo da haste da estaca (varia de 1 a $n$ )

$A_{\text {ehi }}=$ área projetada da hélice $i$

$N_{S P T i}=N_{S P T}$ do solo na hélice $i$

$N_{S P T j}=N_{S P T}$ do solo na camada $j$

$l_{j}=$ espessura da camada $j$ ao longo da haste.

$\alpha_{s i}=$ Resistência unitária de ponta da camada de solo na posição da hélice $i$

$\beta_{S j}=$ Resistência unitária por atrito lateral da camada de solo $j$ 
$Q_{u}=\sum_{i=1}^{N} \alpha_{s i} A_{e h i} N_{\text {SPTi }}($ modelo I $)$

Não há quantidade de amostra de curvas carga x deslocamento suficiente para analisar as estacas com 6 hélices, aplicando-se os critérios D/10 e de Livneh e Naggar (2008). Portanto, os modelos são propostos para estacas com 2, 3 e 4 hélices.

Também não existe na base de dados estacas em solos silto-argilosos na situação $A$. As variáveis do modelo deste solo serão estimadas a partir de um grupo de estacas na situação $B$.

As análises utilizando-se os critérios de Davisson (1972) e da NBR 6122 (2010) são apresentadas no ANEXO II, considerando-se que estes critérios não são apropriados para a presente dissertação.

\subsection{ANÁLISE DA MATRIZ DE CORRELAÇÃO}

A matriz de correlação é fundamental para interpretação física dos regressores. Uma variável tem elevada probabilidade de ser nula quando é alta sua correlação com outra independente, fenômeno chamado de multicolinearidade.

Uma correlação e dita fraca se seu valor for inferior a 0,30 , moderada se estiver entre 0,30 e 0,70 e forte acima de 0,70 .

Os regressores para as variáveis $\alpha$ é o produto da área efetiva da hélice vezes o $N_{S P T}$ médio $\left(A_{e h} \bar{N}_{S P T}\right)$. Para as variáveis $\beta$, o produto entre a área lateral da haste e o $N_{S P T}$ da camada $\left(U l \beta_{S} N_{S P T}\right)$. A matriz de correlação para todas as amostras $(n=52)$ é apresentada na Tabela 6. 1. No modelo proposto neste capítulo, a quantidade de amostra varia de uma análise para a outra, mas a ordem de grandeza das correlações permanece a mesma. O tipo da situação de projeto pouco interfere.

Pela análise da Tabela 6. 1, a correlação dentro das variáveis $\alpha$ é fraca e possui sinal negativo. Ser fraca indica que elas tendem a ser independentes. A análise do sinal somente faz sentido para relações fortes. Dentro das variáveis $\beta$ há um relacionamento moderado entre os solos argilosos e arenosos, podendo ocorrer multicolinearidade. 
Tabela 6. 1: Matriz de correlação com todas as estacas.

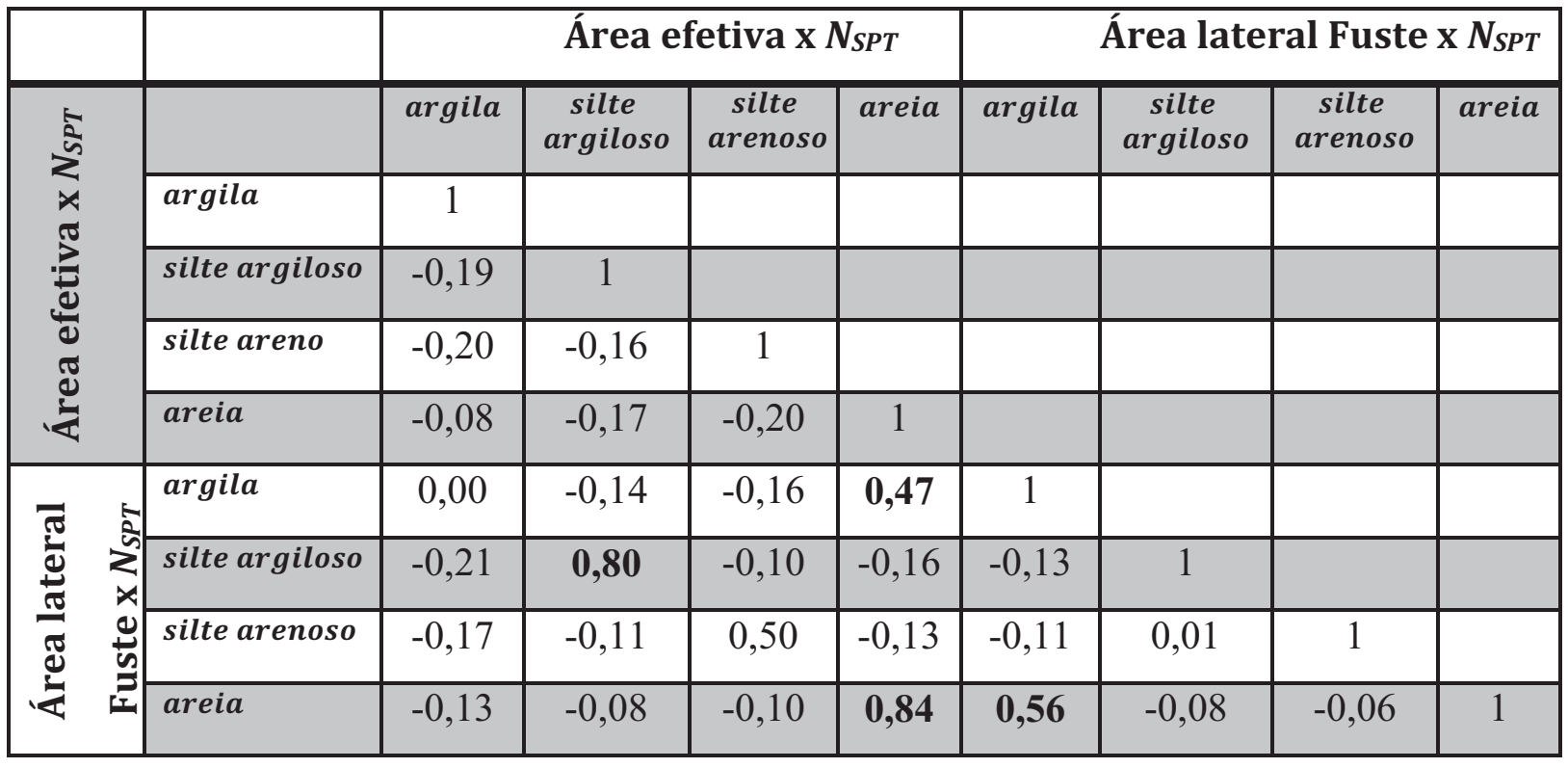

Surgem relações fortes entre $\alpha$ e $\beta$ dos solos silto-argilosos, $\alpha$ e $\beta$ dos arenosos, e moderada entre $\alpha$ das argilas e $\beta$ da areia.

Quando há multicolinearidade, a solução estatística é excluir a variável com maior probabilidade de ser nula e recalcular o modelo. Nesta situação, o sentido físico é prejudicado porque a resistência das hélices ou por atrito lateral na haste é nula.

O que ocorre quando se anula uma variável por multicolinearidade é o rearranjo dos regressores, onde apenas um regressor passa a explicar toda a variação da resistência de ponta e atrito lateral.

$\mathrm{Na}$ análise global, todas as a variáveis $\alpha$ são significativas para o modelo, já nas $\beta$, somente para solos silto-arenoso. Quando as estacas com 6 hélices foram removidas, a correlação entre $\alpha$ e $\beta$ para os solos silto-arenosos é igual a 0,66 , podendo ocorrer multicolinearidade.

Considerando todas as combinações de cenários, as variáveis significativas são apenas as de $\alpha$. Pode-se, então, realizar a análise estatística somente com elas, considerando-se o modelo I mostrado pela equação 6. 2 . 


\subsection{REGRESSÃO DO MODELO 1 PARA CARGA DE RUPTURA DO CRITÉRIO D/10}

\subsubsection{Regressores para estacas com 2, 3 e 4 hélices}

Os regressores estimados pelo método dos $M M Q$ são apresentados na Tabela 6. 2. A probabilidade de serem nulos para a situação $A$ foi inferior a 6,0e-7.

Tabela 6. 2: Regressores estimados utilizando D/10 para o modelo da equação 6. 2.

\begin{tabular}{|r|c|c|c|c|}
\hline & \multicolumn{4}{|c|}{$\alpha_{\boldsymbol{S}}\left(\boldsymbol{k N} / \mathbf{m}^{\mathbf{2}}\right)$} \\
\hline & Argila & Silte Argiloso & Silte Arenoso & Areia \\
\hline Situação $\boldsymbol{A}$ & 34 & $32^{*}$ & 58 & 73 \\
\hline Situação $\boldsymbol{B}$ & 58 & 32 & 72 & $73^{*}$ \\
\hline
\end{tabular}

* Regressor estimado com base na situação de projeto oposta devido ao reduzido número de amostras.

Devido à ausência de amostra em solos silte-argilosos na situação $A$ e solos arenosos na situação $B$, os valores adotados dos regressores foram de $32 \mathrm{kN}$ e $73 \mathrm{kN}$, respectivamente, e são considerados conservadores.

Usando-se os valores de carga de ruptura obtidos por Davisson (1972) e pela NBR 6122 (2010), os regressores da situação $A$ e $B$ são próximos. Mas usando-se o critério de D/10 eles se distanciam: os valores de $\alpha$ da situação $A$ são menores.

\subsubsection{Estatística da regressão para situação $A$ em estacas com 2, 3 e 4 hélices}

O $R^{2}$ da regressão é igual a 0,97 , indicando que o modelo proposto é capaz de explicar a variação da capacidade de carga da estaca. O conjunto amostral é composto por 24 estacas, onde 22 foram utilizadas na regressão e 2 são outliers.

O gráfico de resistência (ou capacidade de carga) observada versus estimada (Figura 6. 1) possui boa aleatoriedade. Existem poucas amostras com resistência observada acima de $300 k N$, onde apenas uma foi superestimada. 


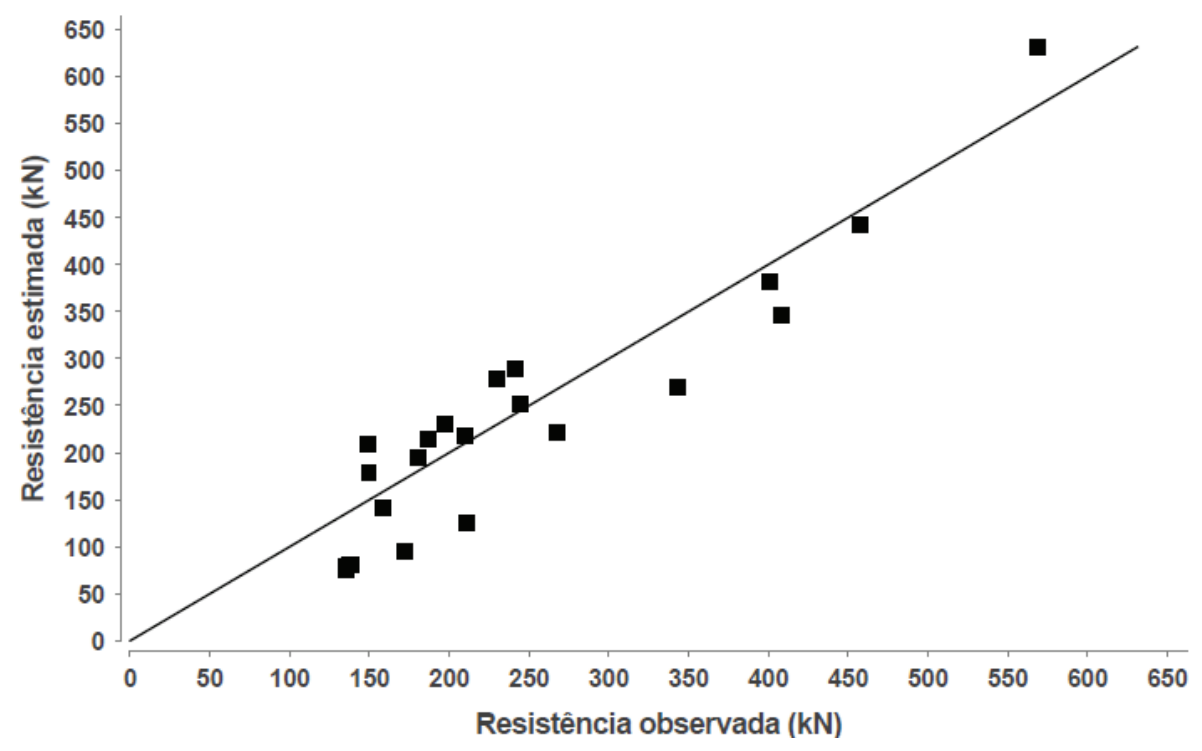

Figura 6. 1: Gráfico de resistência estimada versus resistência observada utilizando D/10.

O histograma do BIAS (Figura 6. 2) possui um pico próximo de 0,60 e outro em 1,2, indicando que alguma variável não foi considerada no modelo.

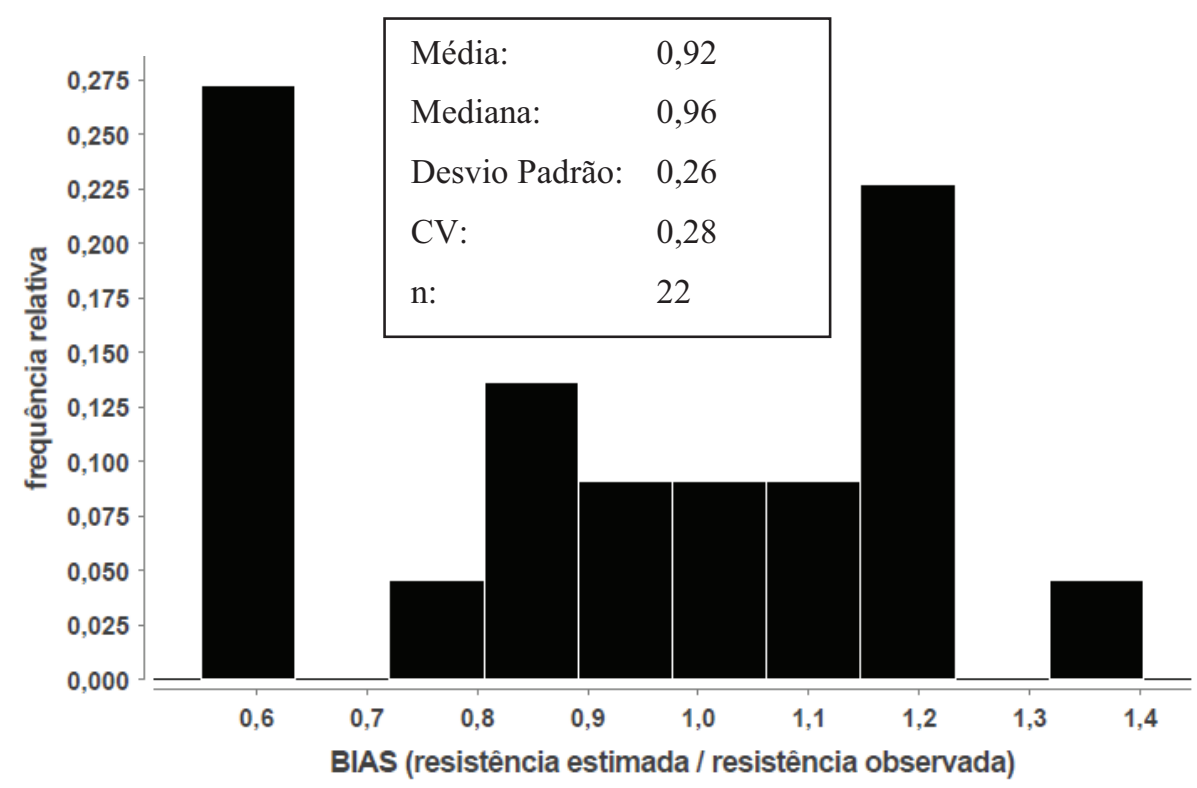

Figura 6. 2: Histograma do BIAS utilizando D/10. 


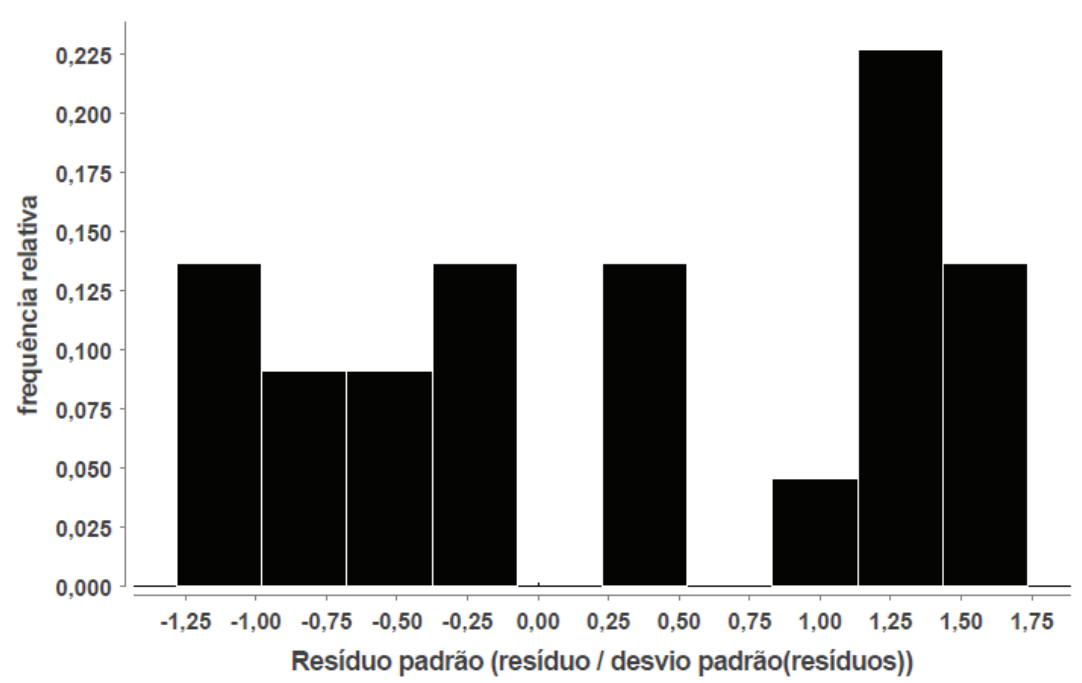

Figura 6. 3: Histograma de resíduo padrão utilizando D/10.

Não há conformação normal no histograma de resíduo padrão (Figura 6. 3). No gráfico de resíduo padrão versus resistência estimada (Figura 6. 4) verifica-se que o modelo subdimensiona estacas com resistências inferiores a $150 \mathrm{kN}$. Sua forma é típica de ajuste não linear.

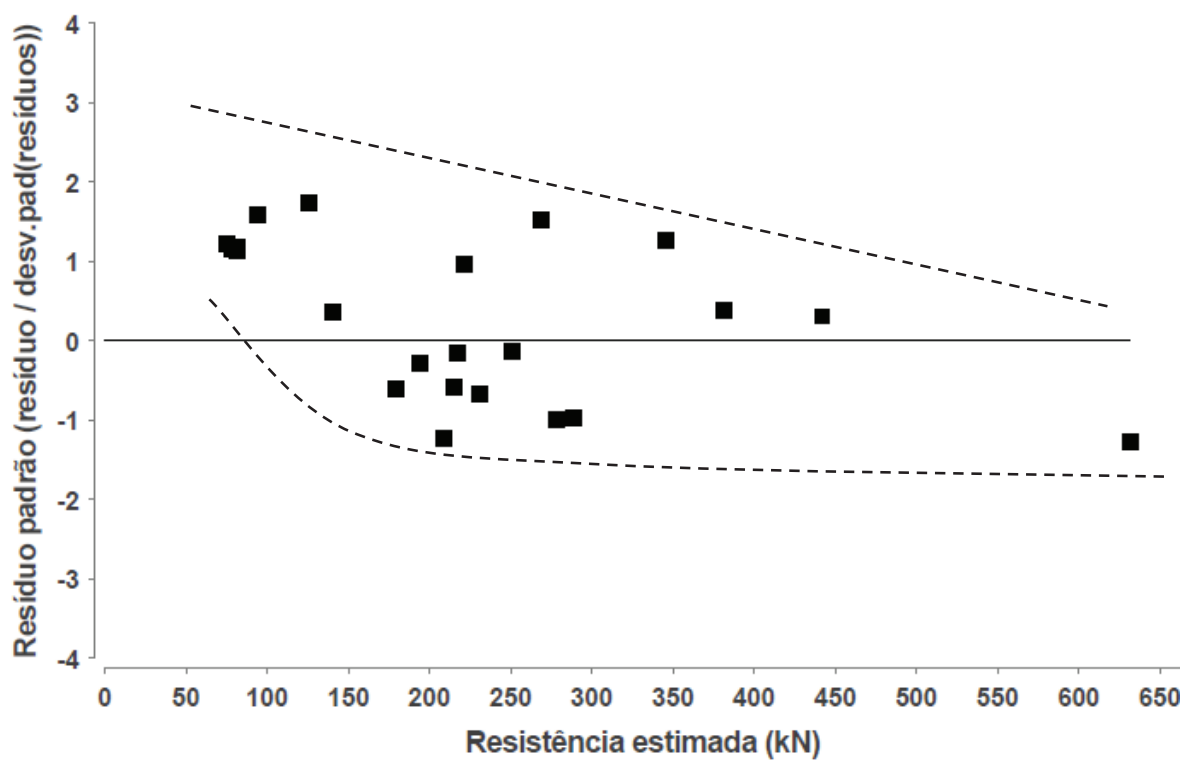

Figura 6. 4: Gráfico de resíduo padrão versus resistência estimada utilizando D/10.

\subsubsection{Fator de correção para estacas com 2, 3 e 4 hélices na situação $A$}

O modelo desta dissertação propõe uma relação linear entre a capacidade de carga individual de cada hélice e o valor respectivo de $N_{S P T}$ na profundidade desta. Esta é a relação 
mais simples possível. Porém, as estacas helicoidais possuem comportamento complexo devido ao efeito de instalação, configuração das hélices (diâmetros iguais ou crescentes), etc.

$\mathrm{Na}$ análise estatística dos resultados obtidos pelo critério $\mathrm{D} / 10$, ocorre $\mathrm{o}$ subdimensionamento de estacas com resistências inferiores a $160 \mathrm{kN}$. Plotando-se o gráfico do BIAS versus somatório do $N_{S P T}$ das hélices $\left(\sum \overline{N_{S P T}}\right)$ (Figura 6. 5) nota-se uma relação linear entre as variáveis, implicando em: 1) estaca com 2 hélices tendem a ser subdimensionadas, 2) estacas com 6 hélices tendem a ser superdimensionadas, 3) pode-se usar a relação para criar um fator de correção $\left(f_{c}\right)$ (equação 6. 4).

O resultado da (Figura 6. 5) é explicado pelo fato que para as estacas com muitas hélices a contribuição das hélices superiores é pouco importante, pois o solo acima destas foi atravessado e cortado mais vezes durante a instalação perdendo, deste modo, maior parte da resistência inicial (representada pelo $N_{S P T}$ ) em comparação com o caso das hélices da ponta da estaca. Portanto, este fator de correção que varia de acordo com o número de hélices é essencial para o dimensionamento adequado da capacidade de carga à tração de estacas helicoidais.

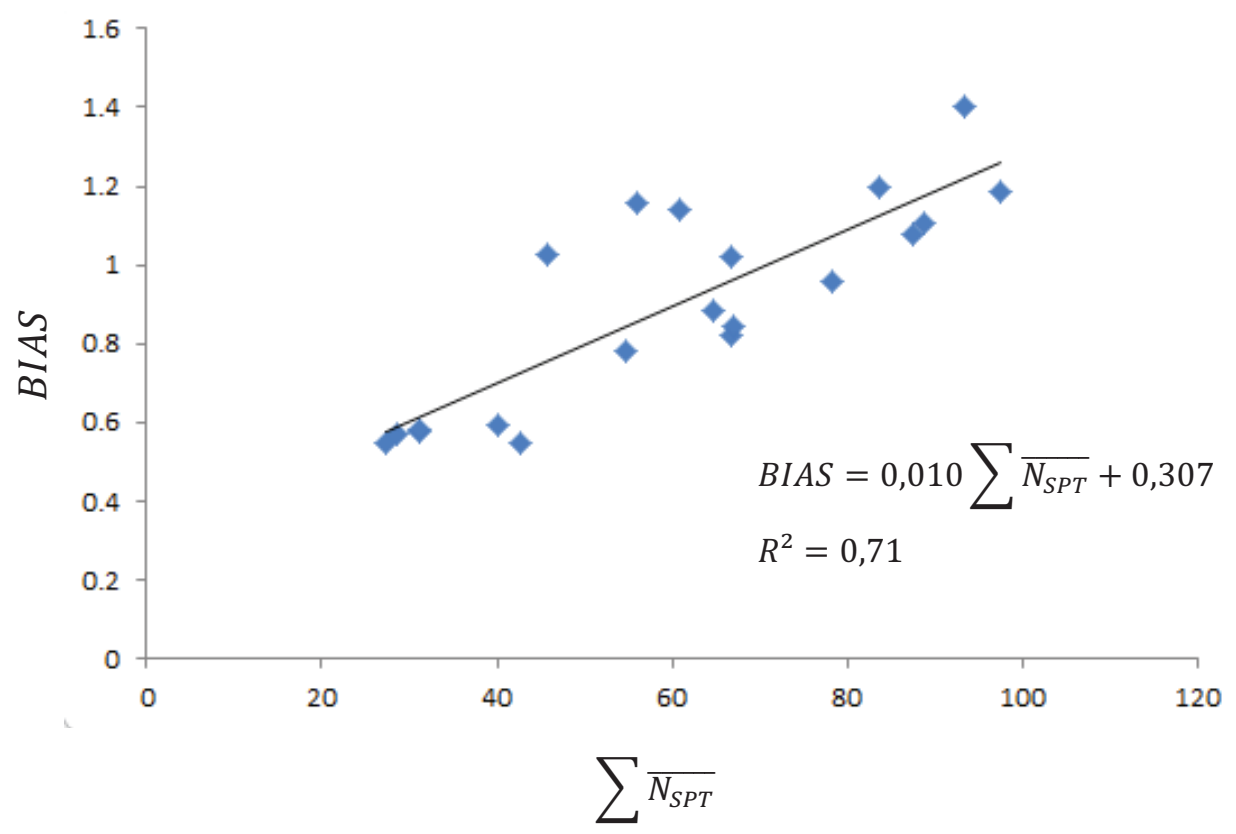

Figura 6. 5: Correção do BIAS para $\mathrm{D} / 10$ na situação $A$. 
Portanto, o valor da capacidade de carga à tração da estaca na situação de projeto $\mathrm{A}$ deve ser corrigido:

$Q_{u, \text { corrigido }}=Q_{u} / f_{c}$

$f_{c}=0,010 \sum_{i=1}^{N} N_{S P T i}+0,307$

onde:

$\mathrm{N}=$ número de hélices.

Com os dados disponíveis para estacas com até 4 hélices, somente foi possível analisar o fator de correção para $\sum \overline{N_{S P T}}$ até 100 . Pode-se: 1) adotar o valor máximo do somatório igual ao 100 ou 2) extrapolar a curva até o valor desejado.

Comparando o histograma do BIAS sem correção (Figura 6. 2), com aquele onde os valores foram corrigidos (Figura 6. 6), verifica-se redução da dispersão, a moda está mais próxima de 1,0 e o pico no limite inferior $(0,60)$ inexiste.

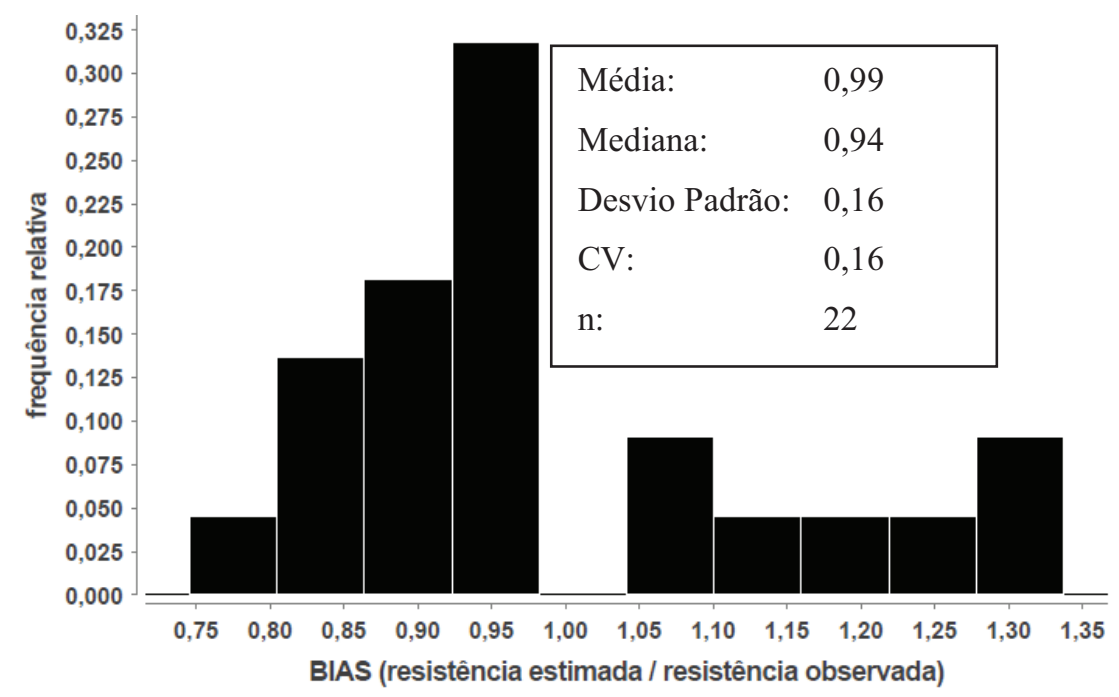

Figura 6. 6: Histograma do BIAS para D/10 utilizando $f_{c}$. 


\subsubsection{Estacas com 6 hélices}

Existem apenas 6 estacas com 6 hélices na base de dados. Utilizando os valores para a situação $A$, o modelo tende a superestimar a resistência $(B I A S>1)$, conforme expresso na Tabela 6. 3.

Tabela 6. 3: Resistência estimada para estacas com 6 hélices utilizando D/10 com e sem $f_{c}$.

\begin{tabular}{|c|c|c|c|c|c|c|}
\hline Nr. & \multicolumn{2}{|c|}{ Sem $\mathbf{f}_{\mathbf{c}}$} & \multicolumn{2}{c|}{ Com $\mathbf{f}_{\mathbf{c}}$ das $\mathbf{6}$ hélices } & \multicolumn{2}{c|}{ Com $\mathbf{f}_{\mathbf{c}} \mathbf{c o m}$ das $\mathbf{4}$ hélices } \\
\hline & $Q_{\text {estimada }}(\mathrm{kN})$ & BIAS & $Q_{\text {estimada }}(\mathrm{kN})$ & BIAS & $Q_{\text {estimada }}(\mathrm{kN})$ & BIAS \\
\hline $\mathbf{2 3}$ & 179,01 & 0,48 & 320,76 & 0,86 & 173,27 & 0,46 \\
\hline $\mathbf{2 5}$ & 845,33 & $\mathbf{2 , 1 3}$ & 377,96 & 0,95 & 356,77 & 0,90 \\
\hline $\mathbf{2 9}$ & 759,29 & $\mathbf{1 , 6 1}$ & 339,64 & 0,72 & 311,86 & 0,66 \\
\hline $\mathbf{7 0}$ & 1365,84 & $\mathbf{3 , 1 1}$ & 492,51 & $\mathbf{1 , 1 2}$ & 496,62 & $\mathbf{1 , 1 3}$ \\
\hline $\mathbf{7 4}$ & 432,18 & 0,89 & 508,18 & 1,05 & 343,07 & 0,71 \\
\hline $\mathbf{7 6}$ & 455,03 & $\mathbf{1 , 2 7}$ & 622,42 & $\mathbf{1 , 3 7}$ & 438,47 & 0,96 \\
\hline & Média & $\mathbf{1 , 5 3}$ & Média & $\mathbf{1 , 0 0}$ & Média & $\mathbf{0 , 8 0}$ \\
\hline & Desvio padrão & $\mathbf{0 , 9 3}$ & Desvio padrão & $\mathbf{0 , 2 2}$ & Desvio padrão & $\mathbf{0 , 2 4}$ \\
\hline & CV & $\mathbf{0 , 6 1}$ & CV & $\mathbf{0 , 2 2}$ & CV & $\mathbf{0 , 3 0}$ \\
\hline
\end{tabular}

Pode-se calcular o fator de correção para estacas com 6 hélices. O gráfico do BIAS versus $\sum \overline{N_{S P T}}$ (Figura 6.7) possui relação linear. O $f_{c}$ e dado por:

$$
f_{c}=0,013 \sum \overline{N_{S P T}}-0,379
$$

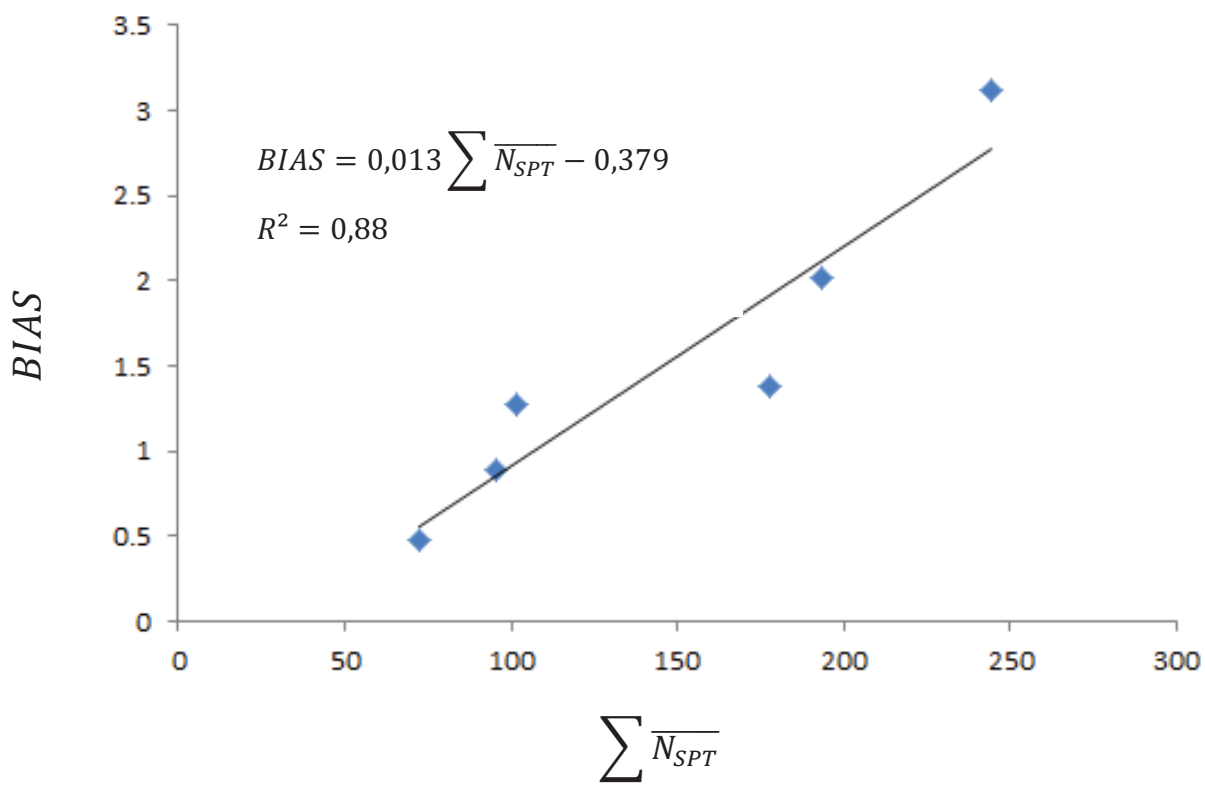

Figura 6. 7: Fator de correção para estacas com 6 hélices utilizando D/10. 
Utilizando o $f_{c}$ das estacas com 6 hélices, o $B I A S$ se aproxima de 1,0 e o $C V$ é reduzido de 0,61 para 0,22. Adotar o $f_{c}$ das estacas com até 4 hélices está a favor da segurança para $\sum \overline{N_{S P T}}<230$ (Figura 6. 8). Acima deste valor, o erro máximo é de $7 \%$ contra a segurança. Portanto, para o caso de 6 hélices deve-se adotar o valor de $f_{c}$ obtido na Figura 6.7

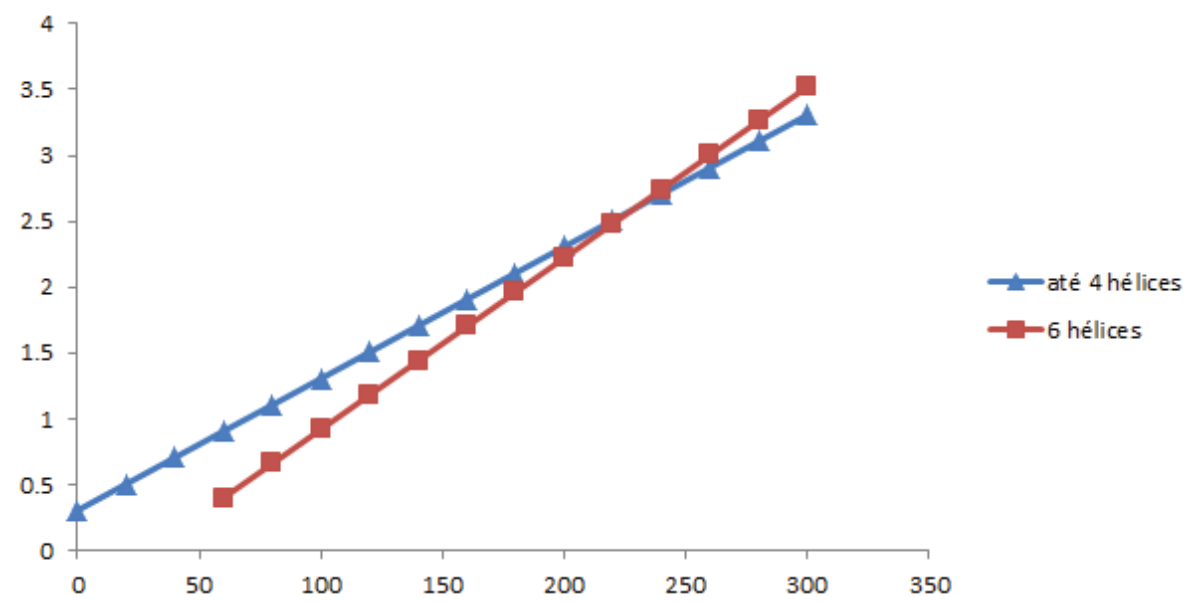

Figura 6. 8: Comparação entre os $f_{c}$ para estacas com até 4 hélices e 6 hélices.

\subsection{REGRESSÃO DO MODELO I PARA LIVNEH E NAGGAR (2008)}

\subsubsection{Regressores para estacas com 2, 3 e 4 hélices}

Os regressores estimados pelo método dos $M M Q$ são apresentados na Tabela 6. 2. A probabilidade de serem nulos para a situação $A$ foi inferior a $6,0 \mathrm{e}-9$.

Tabela 6. 4: Regressores estimados utilizando Livneh e Naggar (2008) para o modelo I.

\begin{tabular}{|r|c|c|c|c|}
\hline & \multicolumn{3}{|c|}{$\alpha_{\boldsymbol{S}}\left(\boldsymbol{k N} / \mathbf{m}^{\mathbf{2}}\right)$} \\
\hline & Argila & Silte Argiloso & Silte Arenoso & Areia \\
\hline Situação $\boldsymbol{A}$ & 36 & $31^{*}$ & 51 & 72 \\
\hline Situação $\boldsymbol{B}$ & 55 & 31 & 62 & $72^{*}$ \\
\hline
\end{tabular}

* Regressor estimado com base na situação de projeto oposta devido ao reduzido número de amostras. 
Devido à ausência de amostra em solos silte-argilosos na situação $A$ e solos arenosos na situação $B$, o valor adotado dos regressores foi de $31 k N$ e $72 k N$, respectivamente. Estes valores são considerados conservadores.

\subsubsection{Estatística da regressão para situação $A$ e estacas com 2, 3 e 4 hélices}

O $R^{2}$ é igual a 0,97 , indicando que o modelo proposto é capaz de explicar a variação da resistência. O conjunto amostral é composto por 23 estacas, onde 22 foram utilizadas na regressão e 1 considerada outlier.

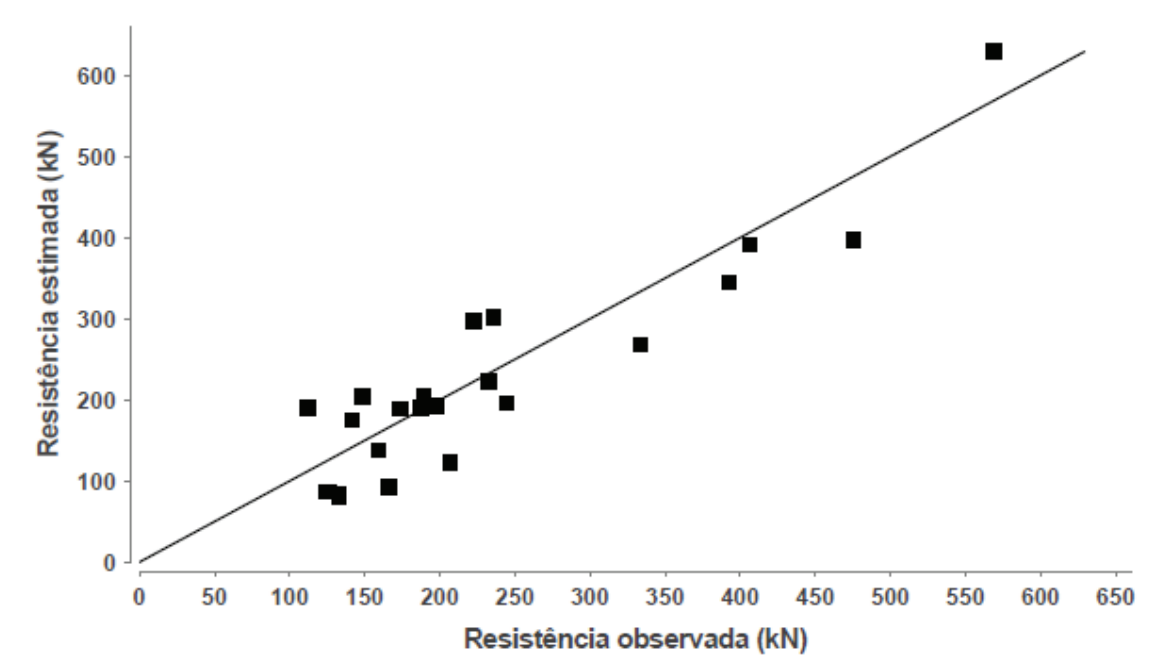

Figura 6. 9: Gráfico de resistência estimada versus resistência observada utilizando Livneh e Naggar (2008).

O gráfico de resistência estimada versus resistência observada (Figura 6. 9) tem aleatoriedade desejada. Existem poucos valores de resistência observada superiores a $300 \mathrm{kN}$. 


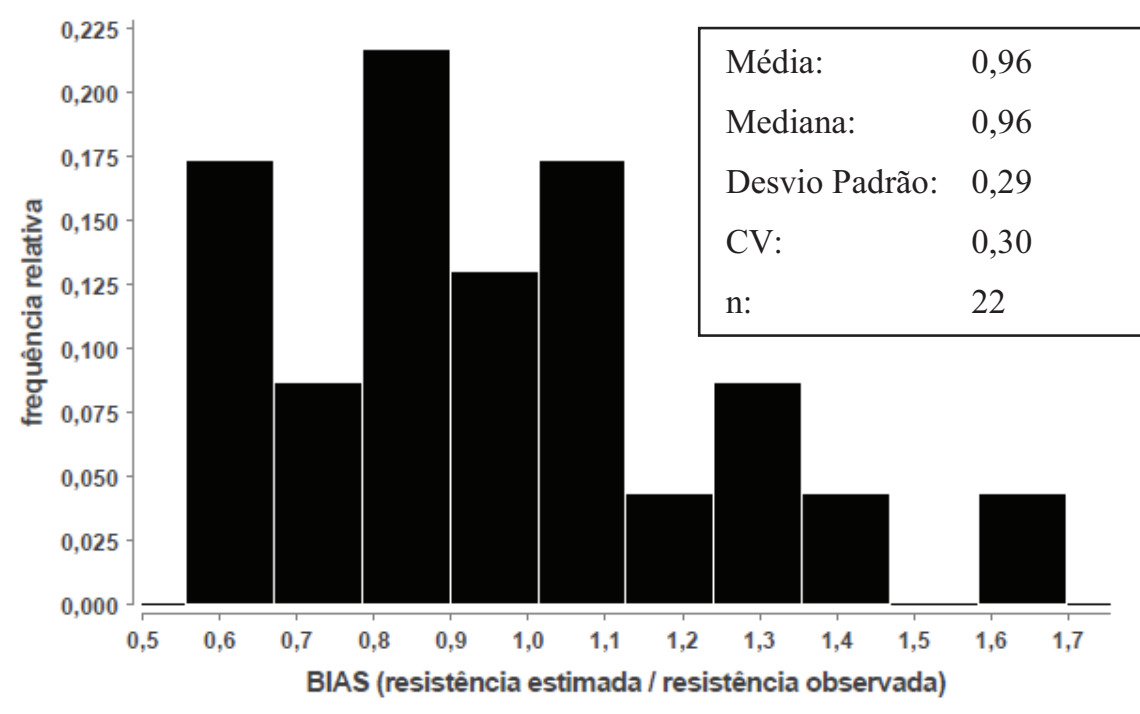

Figura 6. 10: Histograma do BIAS utilizando Livneh e Naggar (2008).

No histograma do BIAS (Figura 6. 10), aproximadamente $80 \%$ das amostras possuem valores inferiores a 1,1, e apenas uma é superior a 1,4. Existem 3 picos, nenhum centrado em 1,0 .

A forma do histograma de resíduo padrão (Figura 6.11) não é típica de distribuição normal e a moda encontra-se deslocada do zero. Analisando o gráfico de resíduo padrão versus resistência estimada (Figura 6.12), o modelo subdimensiona estacas com resistências inferiores a $150 \mathrm{kN}$ e sua forma é típica de ajuste não linear.

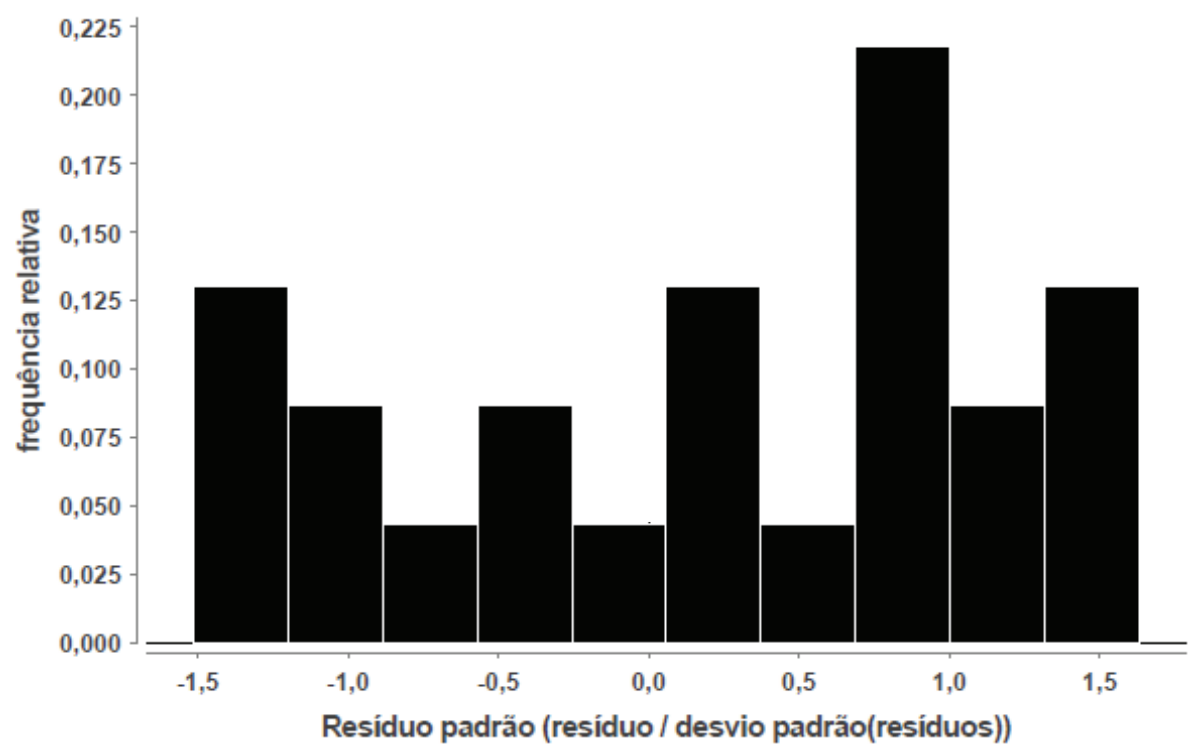

Figura 6. 11: Histograma de resíduo padrão utilizando Livneh e Naggar (2008). 


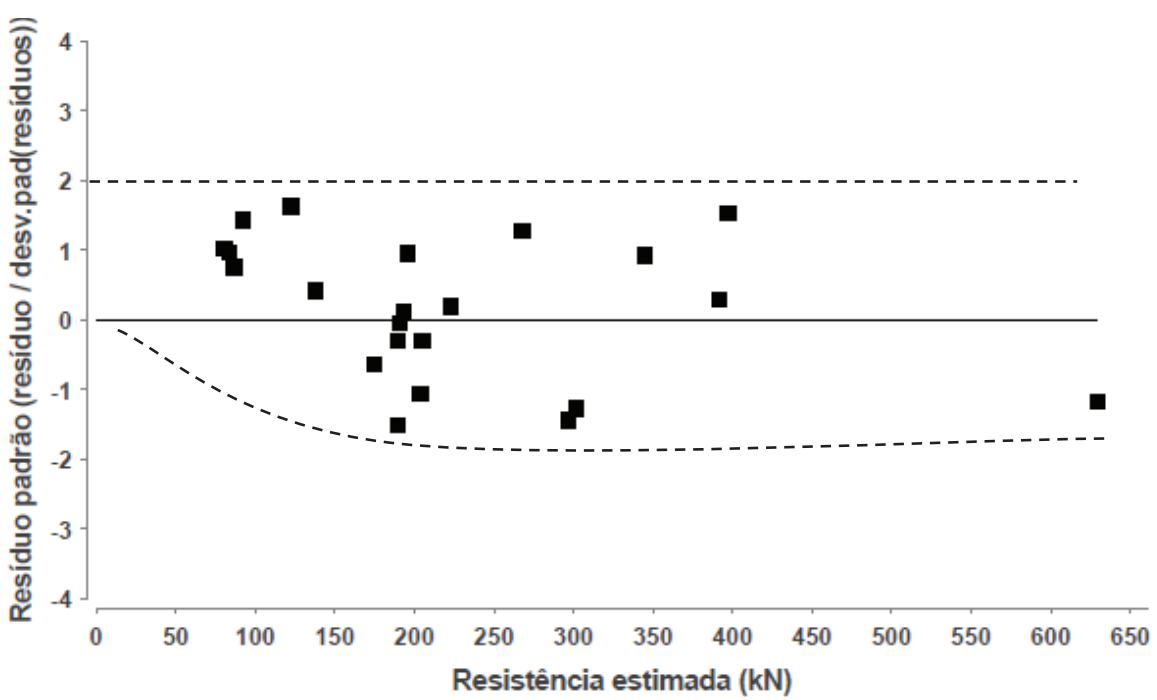

Figura 6. 12: Gráfico de resíduo padrão versus resistência estimada utilizando Livneh e Naggar (2008).

\subsubsection{Fator de correção para estacas com 2, 3 e 4 hélices situação $A$}

Como no item anterior, usando-se o critério de ruptura " $\mathrm{D} / 10$ ", ocorreu para os resultados obtidos via critério de Livneh e Naggar (2008) uma relação linear entre o BIAS e o somatório do $N_{S P T}$ médio das hélices $\left(\sum \overline{N_{S P T}}\right)$ (Figura 6. 13). ). O fator de correção para esta situação é dado por:

$f_{c}=0,009 \sum \overline{N_{S P T}}+0,342$

6. 6

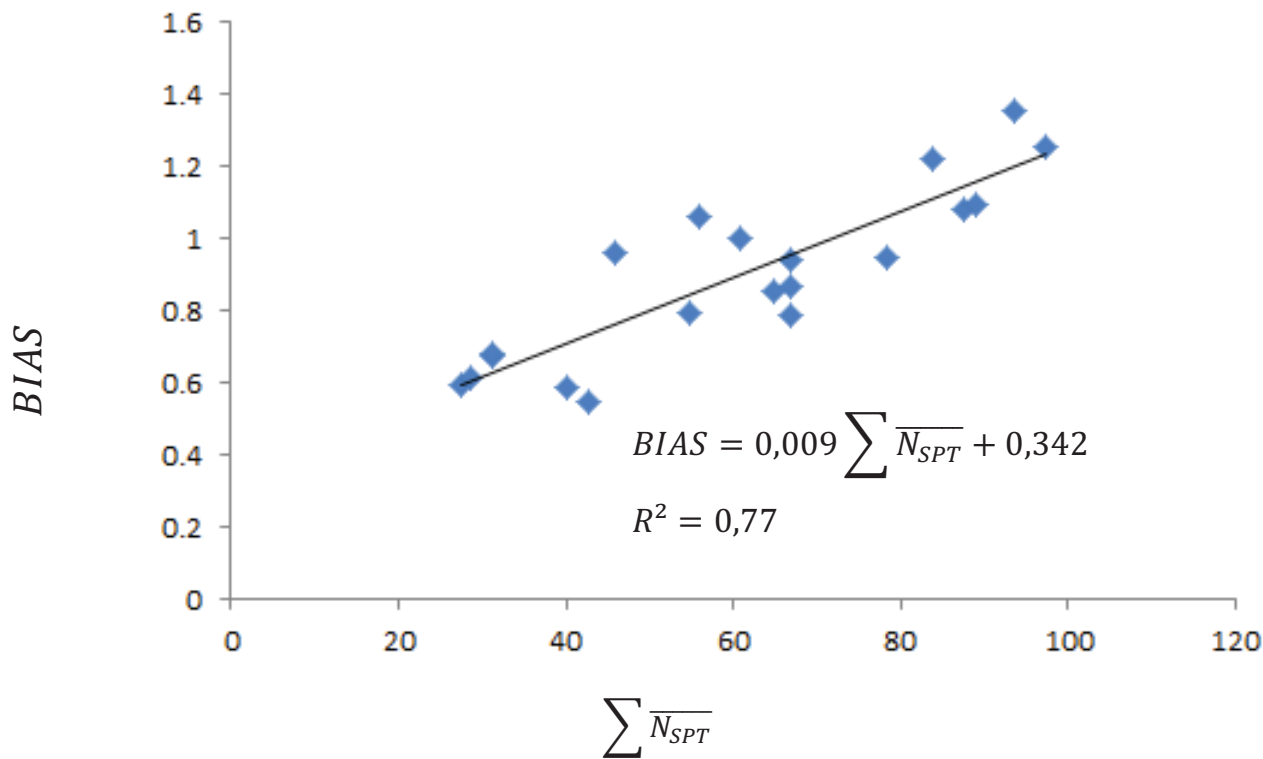

Figura 6. 13: Correção do BIAS para Livneh e Naggar (2008) na situação $A$. 


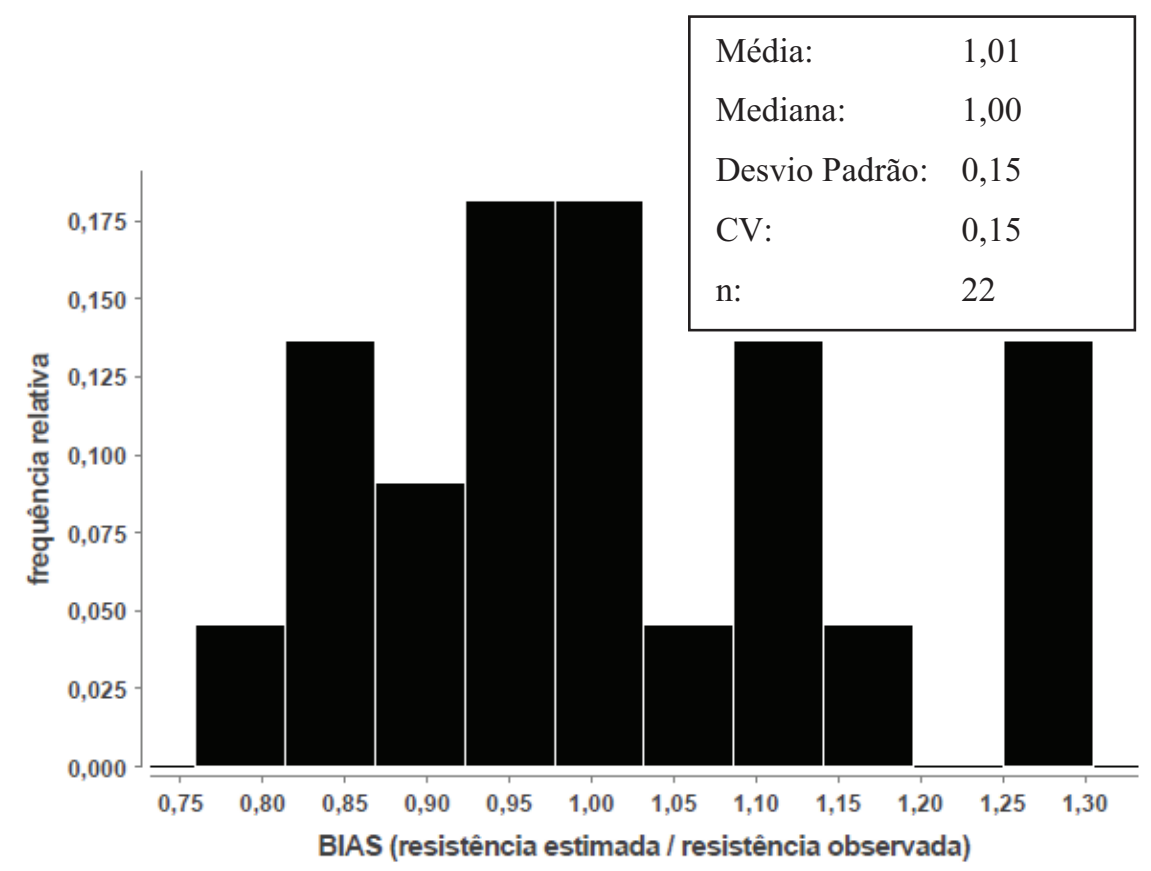

Figura 6. 14: Histograma do BIAS para Livneh e Naggar (2008) utilizando $f_{c}$.

Quando utilizado o $f_{c}$, o histograma do BIAS (Figura 6. 14) possui menor $C V$, a moda e os valores máximos e mínimos se aproximam de 1,0.

Não foi possível estudar o fator de correção para somatórios superiores a 100. Podemse adotar os mesmo procedimentos usados no item anterior para o critério D/10 (extrapolar ou adotar o valor máximo de 100).

\subsubsection{Estacas com 6 hélices}

Existem apenas três estacas com 6 hélices no banco de dados onde pode-se obter a carga de ruptura via critério de Livneh e Naggar (2008), não sendo possível então realizar uma análise estatística baseada em um número adequado de dados. Das três, duas foram superdimensionadas - este comportamento é esperado devido à semelhança com o resultado obtido via critério $\mathrm{D} / 10$. Uma medida a favor da segurança é utilizar o fator de correção calculado via critério D/10 para estacas com 6 hélices. 
Tabela 6. 5: Resistência estimada para estacas com 6 hélices utilizando Livneh e Naggar (2008) com e sem $f_{c}$.

\begin{tabular}{|c|c|c|c|c|c|c|}
\hline & \multicolumn{2}{|c|}{ Sem $\boldsymbol{f}_{\boldsymbol{c}}$} & \multicolumn{2}{c|}{ Com $\boldsymbol{f}_{c}$ das 6 hélices D/10 } & \multicolumn{2}{c|}{ Com $\boldsymbol{f}_{c}$ com das 4 hélices } \\
\hline & $Q_{\text {estimada }}(k N)$ & $B I A S$ & $Q_{\text {estimada }}(k N)$ & $B I A S$ & $Q_{\text {estimada }}(k N)$ & $B I A S$ \\
\hline $\mathbf{2 3}$ & 189,54 & 0,51 & 335.50 & 0.90 & 190.39 & 0.51 \\
\hline $\mathbf{2 5}$ & 709,86 & 1,69 & 332.96 & 0.79 & 341.22 & 0.81 \\
\hline $\mathbf{7 6}$ & 572,12 & 1,18 & 607.53 & 1.25 & 455.38 & 0.94 \\
\hline & Média & $\mathbf{1 , 1 2}$ & Média & $\mathbf{0 . 9 8}$ & Média & $\mathbf{0 . 7 5}$ \\
\hline & Desvio padrão & $\mathbf{0 , 5 9}$ & Desvio padrão & $\mathbf{0 . 2 4}$ & Desvio padrão & $\mathbf{0 . 2 2}$ \\
\hline & $\mathrm{CV}$ & $\mathbf{0 , 5 3}$ & $\mathbf{C V}$ & $\mathbf{0 . 2 4}$ & CV & $\mathbf{0 . 2 9}$ \\
\hline
\end{tabular}

Utilizar o $f_{c}$ para estacas com até 4 hélices é a favor da segurança até $\sum \overline{N_{S P T}}<180$ (Figura 6. 15). Acima deste valor, o erro máximo é de $16 \%$ contra a segurança. Pela Tabela 6.5 observa-se que o valor de $f_{c}$ mais adequado (BIAS mais próximo a 1,0$)$ neste caso é o estimado para estacas com 6 hélices usando-se o critério D/10.

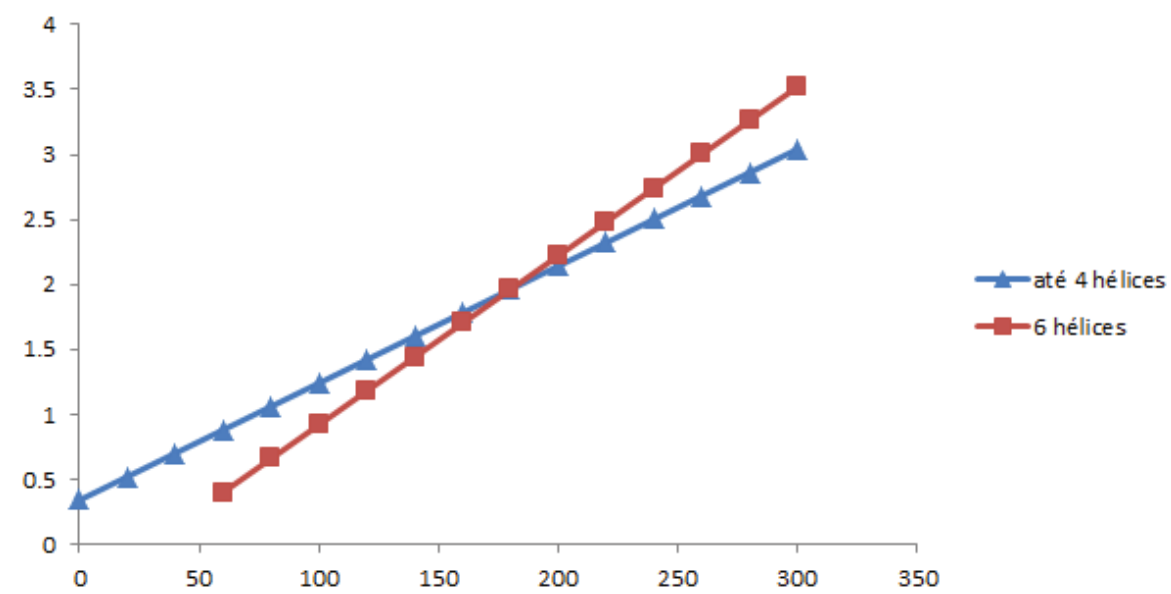

Figura 6. 15: Comparação entre os $f_{c}$ para estacas com até 4 hélices utilizando Livneh e Naggar (2008) e 6 hélices utilizando D/10.

\subsection{MODELO $I I$}

\subsubsection{Determinação das variáveis}

Devido ao problema de multicolinearidade, algumas variáveis de resistência por atrito na haste da estaca apresentaram valores nulos, passando as relativas à resistência das hélices 
também a explicar a "pequena" parcela de resistência por atrito lateral na haste (a exclusão de uma variável foi compensada pela outra com alta correlação).

Uma alternativa de se obter um modelo com as duas parcelas (capacidade das hélices e por atrito na haste) é estabelecer uma relação matemática entre as variáveis por meio de uma equação. Outra forma seria realizar provas de carga instrumentadas com medida individuais das parcelas de resistência (atrito na haste e capacidade das hélices).

No entanto, outros autores (Hubbell 2003 e Perko 2009) também não consideram esta parcela de resistência por atrito lateral em seus modelos de cálculo de capacidade de carga de estacas helicoidais.

Para estabelecer uma equação que relacione as variáveis são necessárias duas etapas: 1 ) estimar os valores das variáveis nulas $(\beta)$ e 2) reduzir os valores das variáveis $\alpha$.

As variáveis $\beta$ (referente ao atrito na haste, como mostra a Equação 6. 1) são estimadas por meio do método de Aoki \& Velloso (equação 6. 7). Os valores médios de $(\alpha \times k)_{\text {Aoki \& Velloso }}$ para os solos em análise são: areia $15,7 \mathrm{kN} / \mathrm{m}^{2}$, silte arenoso $12,2 \mathrm{kN} /$ $\mathrm{m}^{2}$, silte argiloso $7,7 \mathrm{kN} / \mathrm{m}^{2}$ e argila $9,5 \mathrm{kN} / \mathrm{m}^{2}$. Como foi possível calcular o regressor para o solo silto-arenoso, pode-se aplicar um fator de correção $\left(f_{c, \beta}\right)$ para melhorar o ajuste (equação 6. 7).

$\beta=f_{c, \beta} \times(\alpha \times k)_{\text {Aoki \& Velloso }}$

O próximo passo consiste em retirar das variáveis $\alpha$ a parcela de contribuição da resistência por atrito lateral. Pode-se utilizar o mesmo raciocínio feito para $\beta$, onde:

$\alpha_{S(\operatorname{com} \beta)}=f_{c, \alpha} \cdot \alpha_{S(\operatorname{sem} \beta)}$

Outra alternativa é estabelecer uma relação entre $\alpha$ e $\beta_{\text {Aoki \& Velloso }}$ conforme a equação 6. 9.

$\alpha_{S(\operatorname{com} \beta)}=\alpha_{S(\operatorname{sem} \beta)}-\beta_{A \& V} \times f_{c, \alpha}^{\prime}$

Os valores dos fatores de correção ajustados para capacidade de carga definida pelos critérios D/10 e Livneh e Naggar (2008) são apresentados na Tabela 6. 6. Pode-se, então, calcular as variáveis $\beta$ (Tabela 6.7) e $\alpha_{S}$ (Tabela 6. 8). 
Tabela 6. 6: Cálculo dos fatores de correção para D/10 e Livneh e Naggar (2008).

\begin{tabular}{|c|l|c|c|c|c|c|c|c|c|}
\hline \multicolumn{2}{|c|}{} & \multicolumn{4}{|c|}{$\boldsymbol{\alpha}\left(\mathbf{k N} / \mathbf{m}^{\mathbf{2}}\right)$} & $\boldsymbol{\beta}\left(\boldsymbol{k N} / \mathbf{m}^{\mathbf{2}}\right)$ & \multicolumn{3}{c|}{ Correção } \\
\hline Metodologia & & Argila & Silte Argiloso & Silte Arenoso & Areia & Silte Arenoso & $f_{c, \alpha}$ & $f_{c, \alpha}^{\prime}$ & $f_{c, \beta}$ \\
\hline \multirow{2}{*}{$\begin{array}{c}\text { Livneh e } \\
\text { Naggar (2008) }\end{array}$} & $\operatorname{Sem} \beta$ & 36 & 31 & 51 & 72 & 0 & - & - & - \\
\cline { 2 - 11 } & $\operatorname{Com} \beta$ & 37 & 31 & 29 & 69 & 10 & 0,57 & 1,8 & 0,79 \\
\hline \multirow{2}{*}{ D/10 } & $\operatorname{Sem} \beta$ & 34 & 32 & 58 & 73 & 0 & - & - & - \\
\cline { 2 - 10 } & $\operatorname{Com} \beta$ & 31 & 32 & 30 & 62 & 6 & 0,52 & 2,3 & 0,44 \\
\hline
\end{tabular}

Tabela 6. 7: Cálculo das variáveis $\beta$.

\begin{tabular}{|l|c|c|c|}
\hline \multicolumn{1}{|c|}{ Variável } & Aoki \& Velloso $\left(\boldsymbol{k N} / \boldsymbol{m}^{2}\right)$ & D/10 $\left(\boldsymbol{k N} / \boldsymbol{m}^{2}\right)$ & Livneh e Naggar (2008) $\left(\boldsymbol{k N} / \boldsymbol{m}^{2}\right)$ \\
\hline $\boldsymbol{\beta}_{\text {argila }}$ & 9,5 & 4,2 & 7,5 \\
\hline $\boldsymbol{\beta}_{\text {silte argiloso }}$ & 7,7 & 3,4 & 6,1 \\
\hline $\boldsymbol{\beta}_{\text {silte arenoso }}$ & 12,2 & 5,5 & 10,0 \\
\hline $\boldsymbol{\beta}_{\text {areia }}$ & 15,8 & 6,9 & 12,4 \\
\hline
\end{tabular}

Tabela 6. 8: Variáveis $\alpha$ corrigidas.

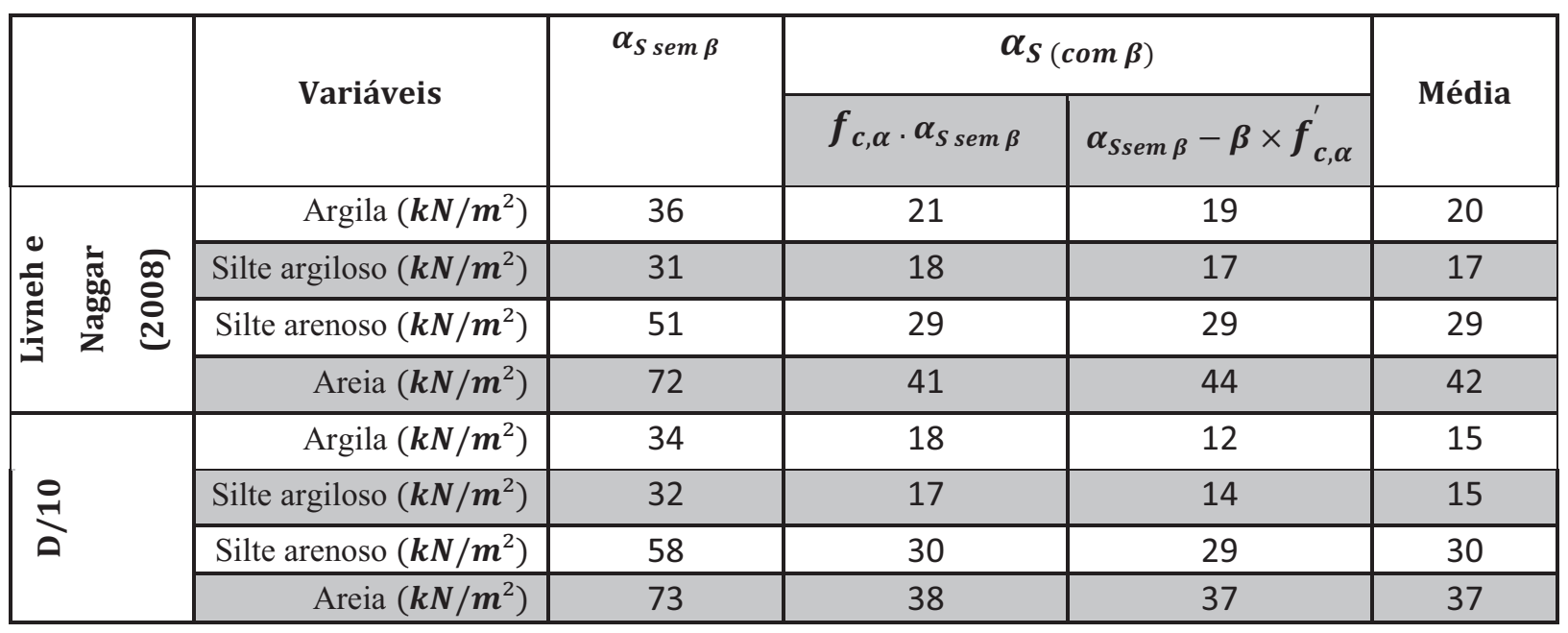

A Tabela 6.8 mostra que os valores de $\alpha_{S}(\operatorname{com} \beta)$ estimados por $f_{c, \alpha}$ foram muito próximos para os dois critérios de ruptura usados, porém houve diferença significativa nas variáveis $\beta$ e nas $\alpha_{S(\operatorname{com} \beta)}$ estimadas por $f_{c, \alpha}^{\prime}$. O cálculo de $\alpha_{S(\operatorname{com} \beta)}$ com capacidade de carga definida pelo critério de Livneh e Naggar (2008) apresenta valores semelhantes, para as duas alternativas. 
6.5.2 Análise estatística resumida para Livneh e Naggar (2008) na situação $A$

Foi realizada análise estatística resumida do modelo com resistência por atrito lateral na haste e das hélices, para situação $A$, utilizando-se os regressores calculados no tópico anterior.

O modelo escolhido para esta análise adotou $\alpha_{s}$ médio e os valores de $\beta$ de Livneh e Naggar (2008) por este ter apresentado melhor consistência no cálculo das variáveis $\alpha_{S(\operatorname{com} \beta)}$. Os valores dos regressores são apresentados na Tabela 6. 9. Na retroanálise, a variável $\alpha_{S(\operatorname{com} \beta)}$ para argila mostrou-se conservadora. O melhor ajuste é com $30 \mathrm{kN} / \mathrm{m}^{2}$.

Não serão removidos os outliers porque o objetivo é analisar o comportamento geral. O coeficiente de determinação foi de 0,89 e o número de amostra igual a 27. Diferente dos outros, não há necessidade de separar as estacas com 6 hélices. Devido ao problema de multicolinearidade, diversos regressores tiveram alta probabilidade de serem nulos.

Tabela 6. 9: Valores estimados de $\alpha$ e $\beta$ para Livneh e Naggar (2008) no modelo $I I$.

\begin{tabular}{|l|c|c|c|}
\hline \multicolumn{1}{|c|}{ Variável } & Valor $\left(\boldsymbol{k N} / \mathbf{m}^{2}\right)$ & Pvalor & CV (\%) \\
\hline $\boldsymbol{\alpha}_{\text {argila }}$ & $30^{*}$ & $1,1 \mathrm{e}-3$ & 27 \\
\hline $\boldsymbol{\alpha}_{\text {silte argiloso }}$ & 17 & 0,4 & 105 \\
\hline $\boldsymbol{\alpha}_{\text {silte arenoso }}$ & 29 & $6,0 \mathrm{e}-4$ & 25 \\
\hline $\boldsymbol{\alpha}_{\text {areia }}$ & 42 & $4,4 \mathrm{e}-3$ & 32 \\
\hline $\boldsymbol{\beta}_{\text {argila }}$ & 8 & 0,2 & 80 \\
\hline $\boldsymbol{\beta}_{\text {silte argiloso }}$ & 6 & 0,2 & 76 \\
\hline $\boldsymbol{\beta}_{\text {silte arenoso }}$ & 10 & 0,1 & 57 \\
\hline $\boldsymbol{\beta}_{\text {areia }}$ & 12 & $4,0 \mathrm{e}-2$ & 47 \\
\hline
\end{tabular}

* Valor alterado pela retroanálise

O modelo II é conservador, com 95\% das estacas com BIAS inferior a 1,3 (Figura 6. 16). O histograma possui duas modas $(0,5$ e 1,0). O grupo com $B I A S$ igual a 0,5 é formado, na sua maioria, por estacas curtas (comprimento total inferior a 6 metros) ou com alguma hélice com $N_{S P T}$ menor que 7.

Portanto, supõe-se que o modelo II deve proporcionar melhor ajuste em caso de estacas compridas e de maior diâmetro de haste (em contato com solo resistente) de modo que a parcela de resistência por atrito lateral na estaca seja mais significante. 


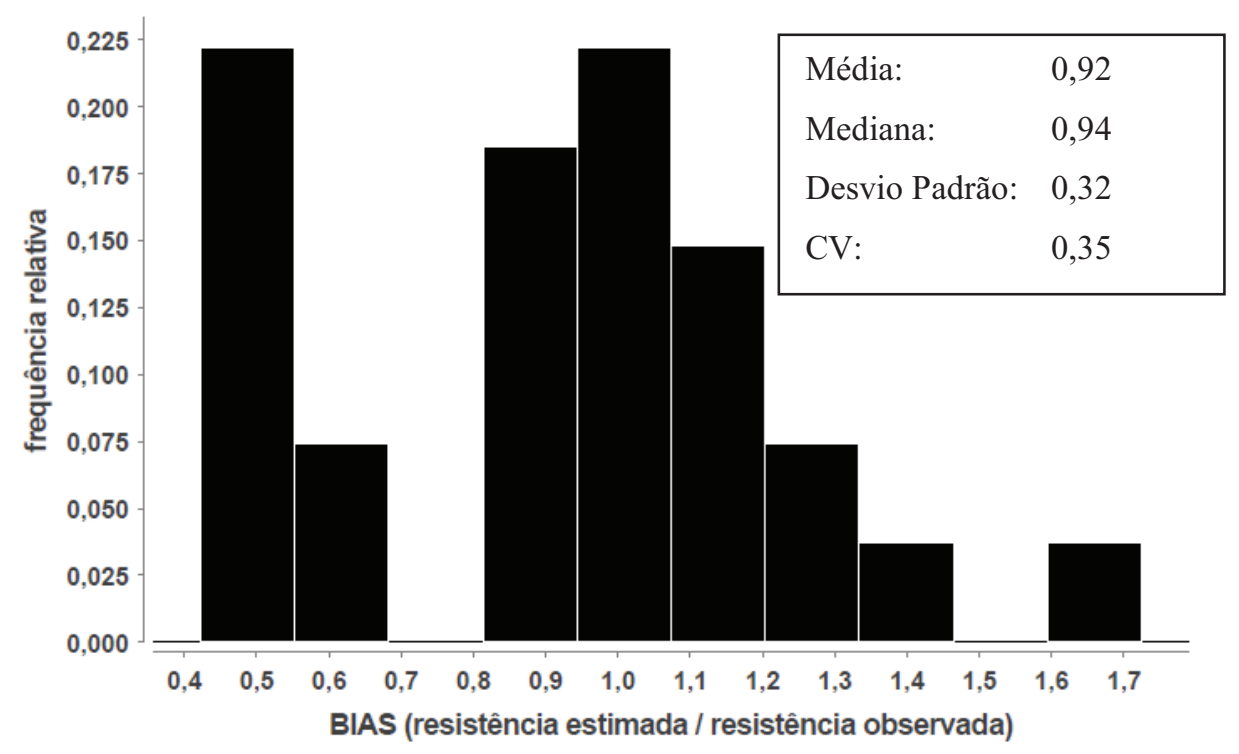

Figura 6. 16: Histograma do BIAS para Livneh e Naggar (2008) no modelo II.

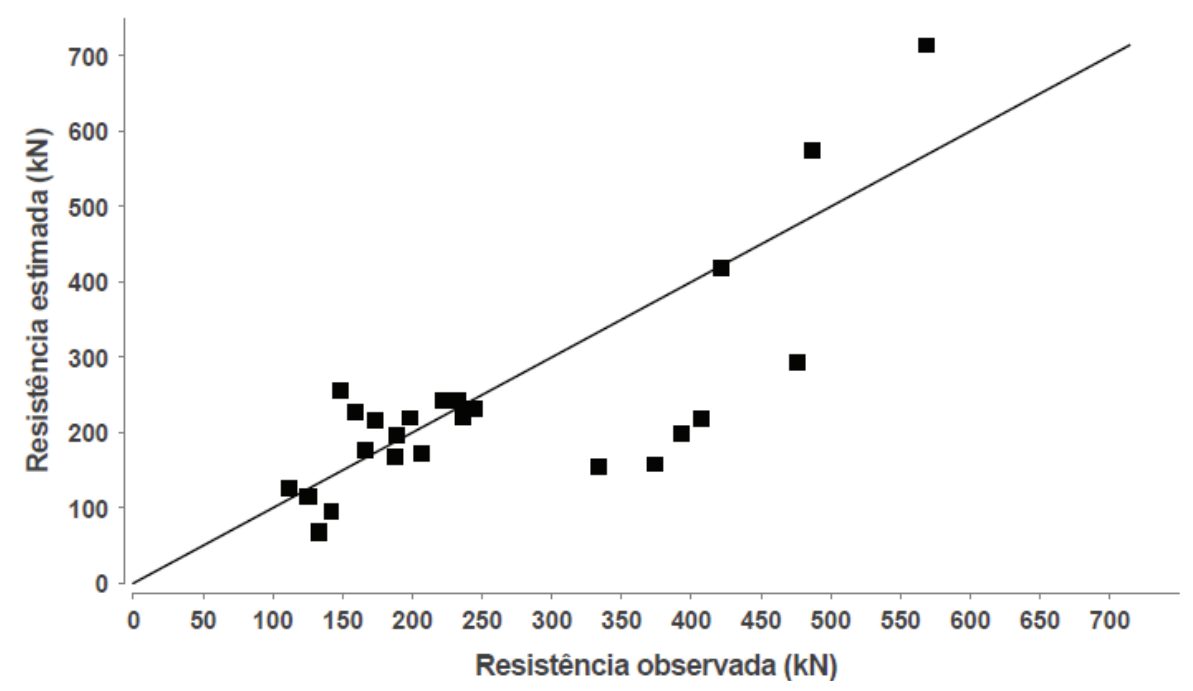

Figura 6. 17: Gráfico de resistência estimada versus resistência observada utilizando Livneh e Naggar (2008) no modelo II.

O gráfico de resistência estimada versus resistência observada (Figura 6. 17) não possui aleatoriedade desejada, indicando vício no estimador (efeito da multicolinearidade). $\mathrm{O}$ reflexo pode ser visto no gráfico de resíduo padrão versus resistência estimada (Figura 6. 18), o qual possui forma típica de ajuste linear mal calculado. O histograma de resíduo padrão (Figura 6.19) se aproxima de uma distribuição normal. 


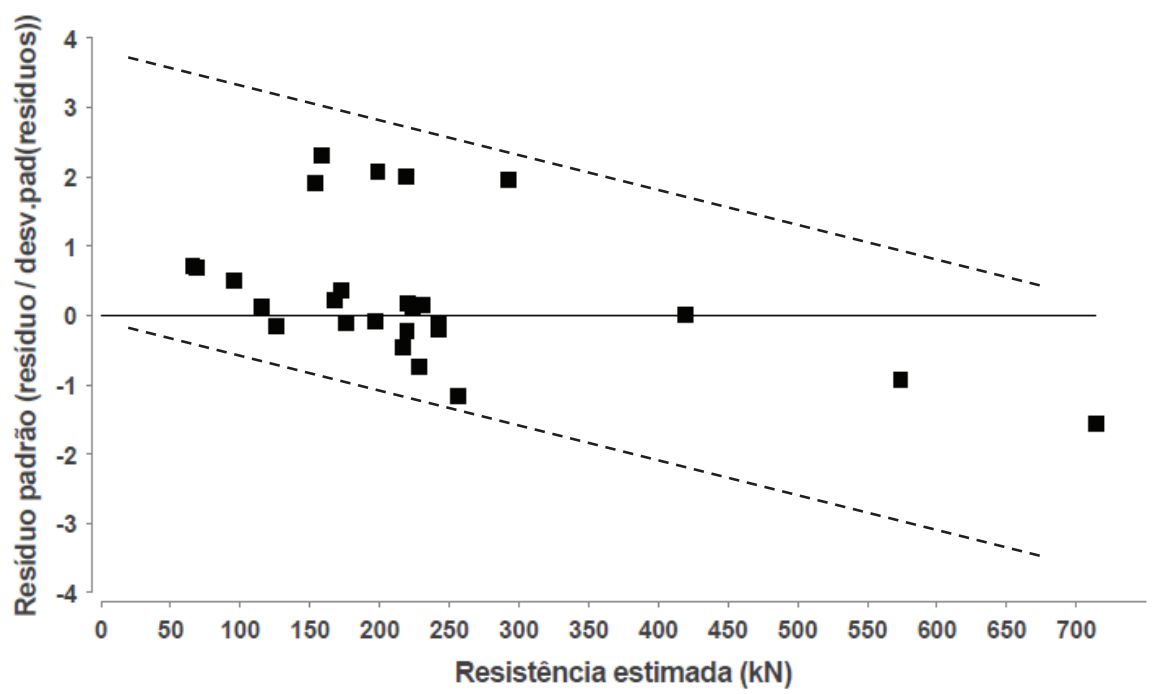

Figura 6. 18: Gráfico de resíduo padrão versus resistência estimada utilizando Livneh e Naggar (2008) no modelo II.

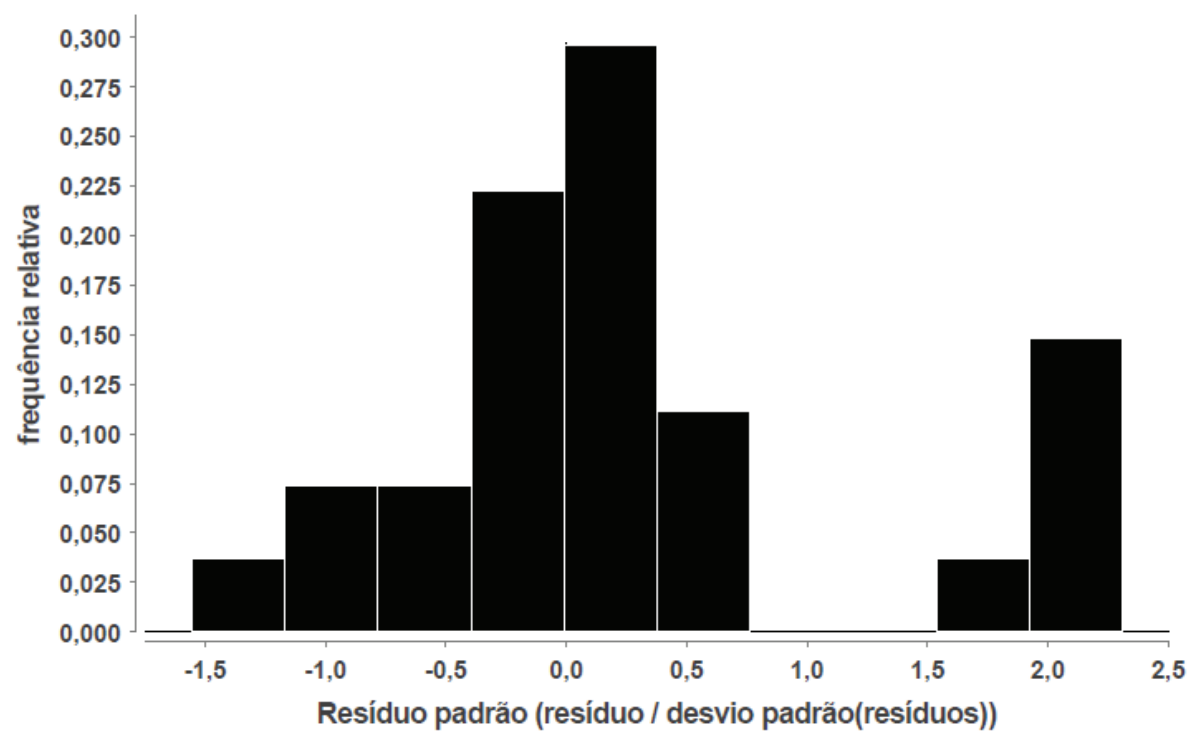

Figura 6. 19: Histograma de resíduo padrão utilizando Livneh e Naggar (2008) no modelo II.

Não há uma relação linear entre as variáveis $B I A S$ e somatório do $N_{S P T}$ médio das hélices $\left(\sum \overline{N_{S P T}}\right)$ (Figura 6. 20), não sendo aplicável nenhum fator de correção. 


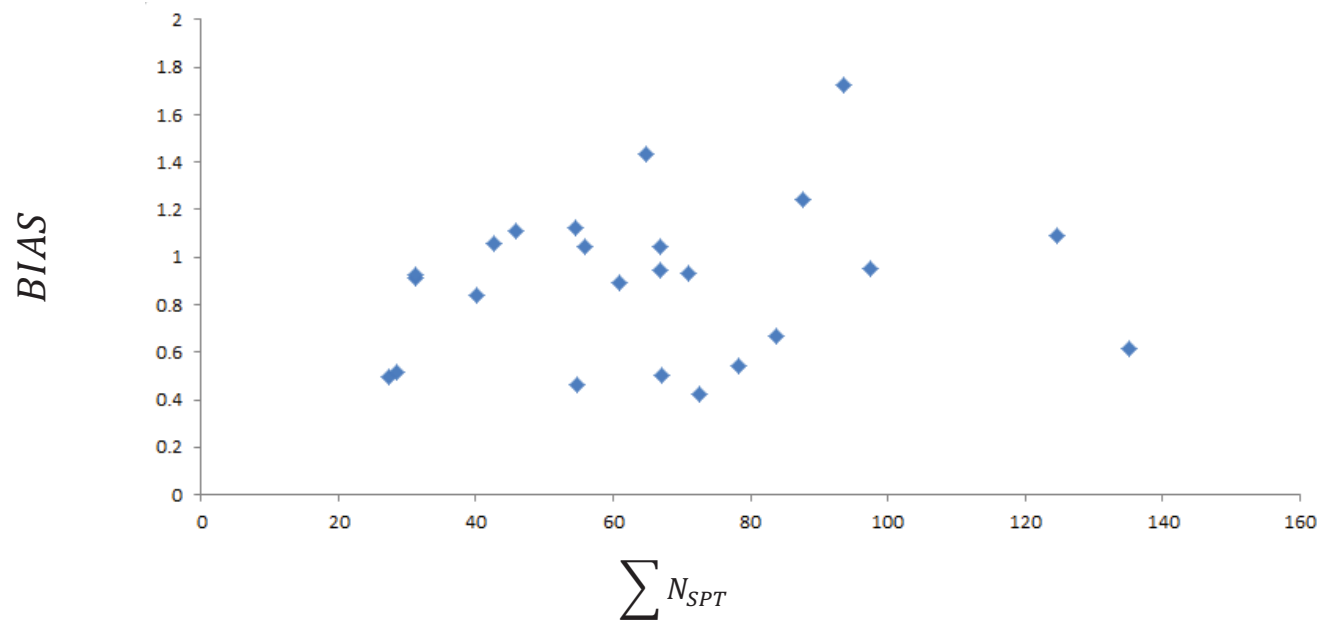

Figura 6. 20: Correção do BIAS para Livneh e Naggar (2008) no modelo II.

\subsection{COMPARAÇÃO ENTRE MODELO I E MODELO II}

Como mostram as análises deste capítulo, o Modelo I, testado para o cálculo de capacidade de carga a tração de estacas helicoidais nos solos usados nesta pesquisa (descrito na Equação 6. 2), o qual não considera a parcela de resistência por atrito na haste, mostrou-se mais apropriado do que o Modelo II.

Todos modelos apresentaram alto $R^{2}$ e problemas na análise de resíduos. Usando-se os valores de carga de ruptura de Davisson (1972) e NBR 6122 (2010) foram obtidos 10 outliers, valor considerado elevado.

Os resultados das análises para as estacas com 6 hélices apresentaram comportamento distinto das demais. Pelos modelos calibrados a partir dos resultados de carga última obtidos pelos critérios de Davisson (1972) e da NBR 6122 (2010) ocorreu subdimensionamento das estacas. No entanto, usando-se os valores obtidos via critérios de D/10 e Livneh e Naggar (2008) ocorreu o contrário. Pelos valores dos regressores e comportamento nos testes estatísticos, pode-se agrupar Davisson (1972) e NBR 6122 (2010) numa categoria (conservadora) e D/10 e Livneh e Naggar (2008) em outra.

Os valores dos regressores do Modelo I são apresentados na Tabela 6. 10. O valor de $\alpha_{S}$ para argila é próximo para todos os critérios de ruptura adotados nas análises, indicando que toda a resistência é mobilizada com pequenos deslocamentos. Este fato não ocorre para os demais 
Tabela 6. 10: Resumo dos regressores para relação entre resistência e $N_{S P T}$.

\begin{tabular}{|r|c|c|c|c|}
\hline \multirow{2}{*}{ Metodologia } & \multicolumn{4}{|c|}{$\boldsymbol{\alpha}_{\boldsymbol{S}}\left(\boldsymbol{k N} / \mathbf{m}^{\mathbf{2}} \mathbf{}\right.$} \\
\cline { 2 - 5 } & Argila & Silte Argiloso & Silte Arenoso & Areia \\
\hline Davisson (1972) & 32 & 16 & 24 & 18 \\
\hline NBR 6122 (2010) & 38 & 18 & 32 & 36 \\
\hline D/10 & 34 & 32 & 58 & 73 \\
\hline Livneh e Naggar(2008) & 36 & 31 & 51 & 72 \\
\hline
\end{tabular}

Perko (2009) propôs um modelo de regressão com base no ensaio SPT para solos grossos e solos finos, desconsiderando a resistência por atrito na haste. Neste caso, os regressores para solos arenosos são $64 \mathrm{kN} / \mathrm{m}^{2}$, próximos dos valores de $\alpha$ para os critérios de D/10 e de Livneh e Naggar (2008). Para solos finos foi $59 \mathrm{kN} / \mathrm{m}^{2}$, aplicando apenas para silte arenosos.

Concluiu-se, a partir das análises deste capítulo, que se deve utilizar um fator de correção no Modelo I na situação de projeto $A$ ajustado pelas cargas de ruptura obtidas pelos critérios de D/10 e de Livneh e Naggar (2008). Para estacas com até 4 hélices, somente foi possível analisar o somatório dos SPTS até 100, e não há grande diferença entre os valores de $f_{c}$ nas calibrações do modelo pelos dois critérios de ruptura .

As estacas com 6 hélices possuem fator de correção próprio. Analisando a Figura 6. 21 , adotar $f_{c}$ do modelo baseado no critério $\mathrm{D} / 10$ para estacas com 4 hélices é uma alternativa para simplificar o processo de cálculo.

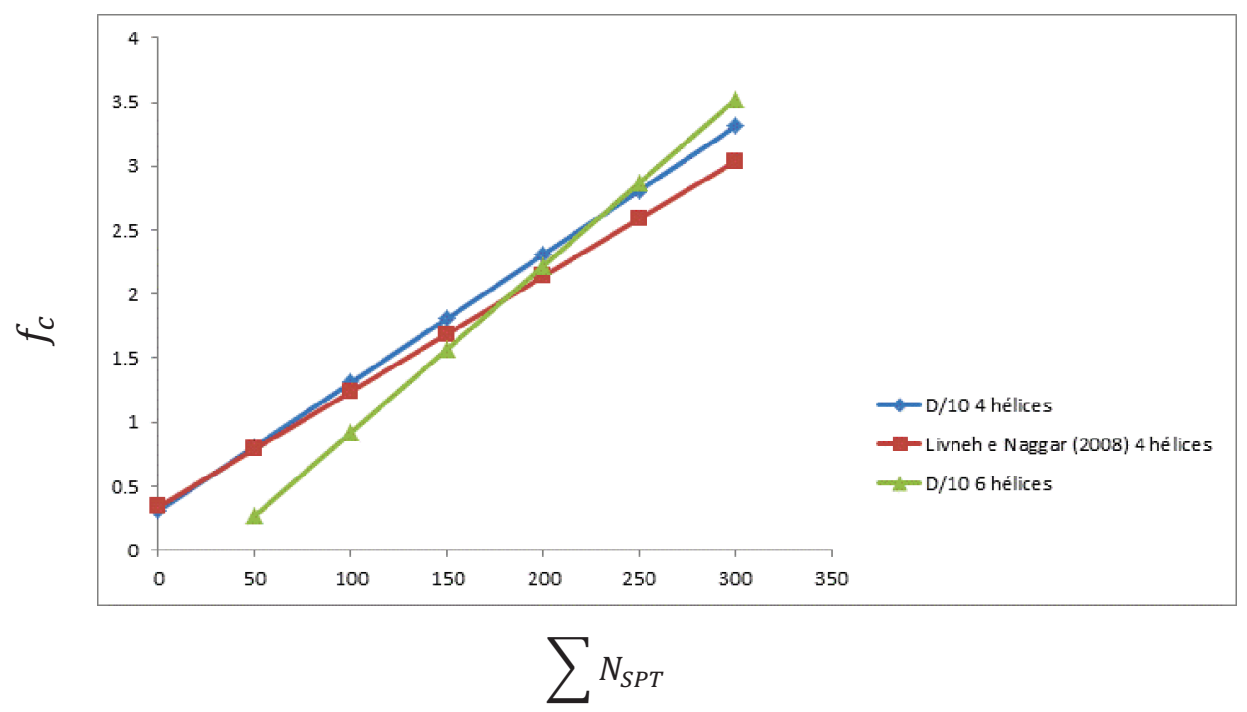

Figura 6. 21: Fatores de correção para D/10 e Livneh e Naggar (2008). 
O modelo II, que considera separadamente a parcela de atrito na haste, não é adequado pela análise estatística. No geral, ele mostrou ser conservador para as estacas deste trabalho, e provavelmente pode apresentar melhor ajuste para estacas longas com fuste em solo resistente. Os valores estimados para os regressores ajustados com base nas cargas de ruptura via critério Livneh e Naggar (2008) convergiram melhor que os de cargas de ruptura via critério $\mathrm{D} / 10$. 


\subsection{INTRODUÇÃO}

Com base nas análises dos capítulos 5 e 6, apresentam-se nesta dissertação recomendações para o projeto de estacas helicoidais em condições de subsolo e dimensões geométricas similares aos casos usados nesta pesquisa.

Para o uso deste procedimento, é necessário definir previamente qual método de interpretação da capacidade de carga em prova de carga será adotado, ou seja, qual a carga de ruptura (de uma curva carga recalque) que pretende-se atender em projeto.

\subsection{INTERPRETAÇÃO DA PROVA DE CARGA}

A partir das análises estatísticas desta pesquisa, é recomendado utilizar, para a definição da carga de ruptura em provas de carga, os valores obtidos pelo critério de Livneh e Naggar (2008) ou pelo D/10. Estes critérios proporcionaram modelos com poucos outliers, elevados coeficiente de determinação, e valores de capacidade de carga próximos aos casos de projetos de torres de linha de transmissão.

Em estacas com até 13 metros de comprimento, os valores calculados de capacidade de carga à tração, pelos modelos ajustados com cargas de ruptura de provas de carga definidas pelos critérios de D/10 e Livneh e Naggar (2008) são semelhantes. À medida que se aumenta o comprimento do haste da estaca, a parcela de alongamento elástico passa a ser significativa. Para estacas com 23 metros, o critério de D/10 estima valores próximos de Davisson (1972). Portanto, recomenda-se utilizar um método que considerada alongamento elástico e evitar o uso do critério D/10 para estacas compridas.

\subsection{ESTIMATIVA DA CARGA DE RUPTURA COM BASE NO $N_{S P T}$}

O modelo recomendado para estimar a capacidade de carga de estaca helicoidal tracionada com base no $N_{S P T}$, para estacas similares às usadas neste trabalho, é o modelo I (que desconsidera a contribuição da resistência por atrito na haste). Este modelo se mostrou estatisticamente mais adequado para estacas comprimento menor que 13 metros (usadas nesta pesquisa). Entretanto, para estacas mais longas e de maior diâmetro, quando a parcela de 
resistência por atrito lateral for muito significativa (esses dois casos são exceções), o modelo II deve apresentar melhor ajuste. Além disso, os resultados mostram que as estacas devem ser instaladas em solos resistentes (situação de projeto $A$ ).

$$
Q_{u, S P T}=\sum \alpha_{S} A_{e h} \bar{N}_{S P T}(\text { modelo I })
$$

Tabela 7. 1: Valores de $\alpha_{s}$ para modelo $I$

\begin{tabular}{|c|c|c|c|l|}
\hline & Argila & Silte argiloso & Silte arenoso & Areia \\
\hline$\alpha_{\boldsymbol{s}}\left(\boldsymbol{k N} / \boldsymbol{m}^{2}\right)$ & 36 & 31 & 51 & 72 \\
\hline
\end{tabular}

Deve-se aplicar o fator de correção $\left(f_{c}\right)$ no modelo I na situação $A$, especialmente para estacas com 6 hélices.

$$
\begin{array}{lr}
R_{u, \text { corrigido }}=R_{u} / f_{c} & \text { (bis) } 6.3 \\
f_{c}=0,010 \sum \overline{N_{S P T}}+0,307 \text { (todas as estacas) } & \text { (bis) } 6.4 \\
f_{c}=0,013 \sum \overline{N_{S P T}}-0,379 \text { (somente 6 hélices) } & \text { (bis) } 6.5
\end{array}
$$

O modelo da situação $A$ é a favor da segurança quando utilizado na $B$. Pode-se estimar a capacidade de carga da estaca na situação $B$, utilizando os regressores da Tabela 7.2.

Tabela 7. 2: Valores de $\alpha_{s}$ para a situação $B$

\begin{tabular}{|c|c|c|c|c|}
\hline & Argila & Silte argiloso & Silte arenoso & Areia \\
\hline$\alpha_{\boldsymbol{s}}\left(\boldsymbol{k N} / \boldsymbol{m}^{2}\right)$ & 55 & 31 & 62 & 72 \\
\hline
\end{tabular}

Não se deve utilizar o fator de correção $f_{c}$ proposto para a situação A para as estacas correspondentes à situação $B$. 


\subsection{ESTIMATIVA DA CAPACIDADE DE CARGA COM BASE NO TORQUE DE INSTALAÇÃO}

Pode-se estimar a capacidade de carga à tração $\left(Q_{u}\right)$ com base no torque final de instalação por meio da seguinte equação:

$Q_{u}=K_{t} T$

$\mathrm{O}$ valor de $k_{t}$ é apresentado na Tabela 7. 3. Ao contrário do que ocorre no modelo do $S P T$, o estimador da situação $A$ é maior que o da $B$. Os regressores para estacas com 6 hélices independem da situação de projeto.

Tabela 7. 3: Valores de $k_{t}$

\begin{tabular}{|r|c|}
\hline & $\boldsymbol{k}_{\boldsymbol{t}}$ \\
\hline Situação $\boldsymbol{A}\left(\boldsymbol{m}^{-1}\right)$ & 21 \\
\hline Situação $\boldsymbol{B}\left(\boldsymbol{m}^{-1}\right)$ & 8 \\
\hline 6 Hélices $\left(\boldsymbol{m}^{-1}\right)$ & 21 \\
\hline
\end{tabular}

\subsection{ESTIMATIVA DO TORQUE DE PROJETO}

Com base na capacidade de carga estimada pelo modelo I $\left(Q_{u \text {,estimado }}\right)$ é possível determinar o torque mínimo que deverá ser atingido ao final da instalação da estaca por meio da seguinte equação:

$T=\frac{Q_{u, e s t i m a d o}}{k_{t}}$

Os regressores $\alpha$ e $k_{t}$ não foram estimados para minimizar o erro desta equação, assim, não faz sentido realizar uma análise estatística detalhada. Entretanto, para melhor entender o comportamento da equação acima, é interessante analisar alguns testes estatísticos. Não serão removidos os outliers para melhor compreensão. $Q_{u}$ estimado é estimado pelo modelo $I$ e não é empregado o fator de correção. 
O gráfico de torque estimado em fase de projeto, com base em $N_{S P T}$, versus torque observado (Figura 7. 1) possui 3 pontos desalinhados. Eliminando-os, a aleatoriedade do modelo é a desejada.

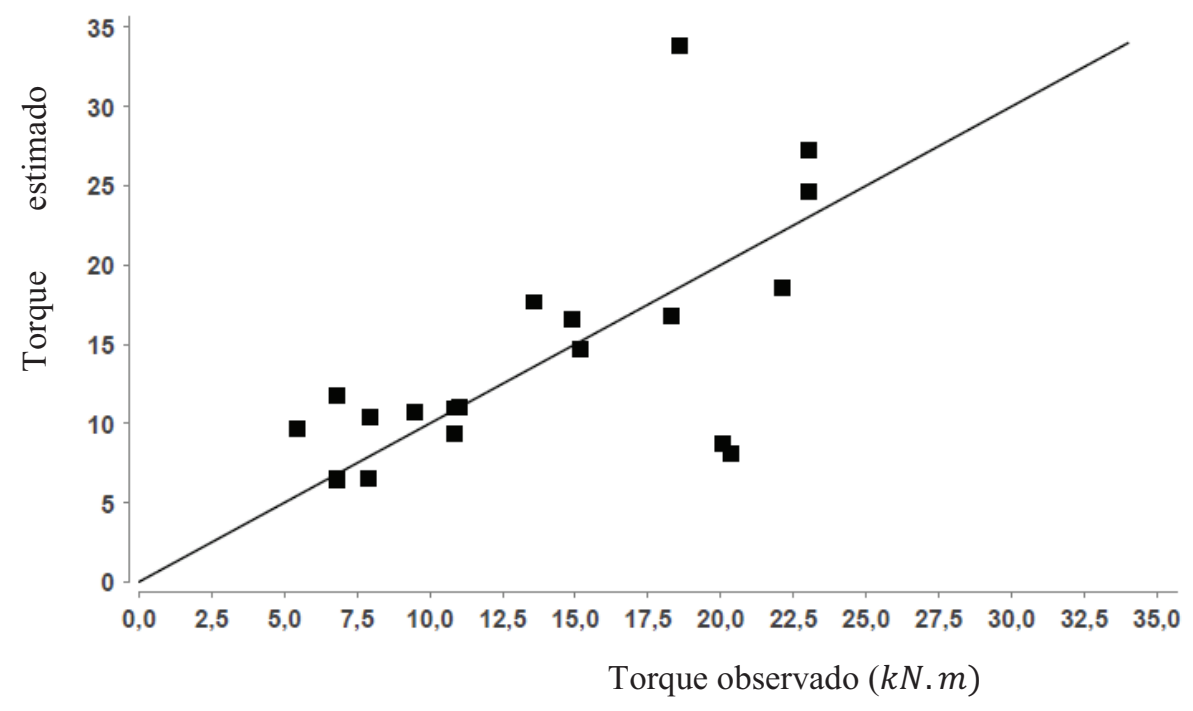

Figura 7. 1: Comparação entre o torque estimado $(k N . m)$ e o torque observado $(k N . m)$.

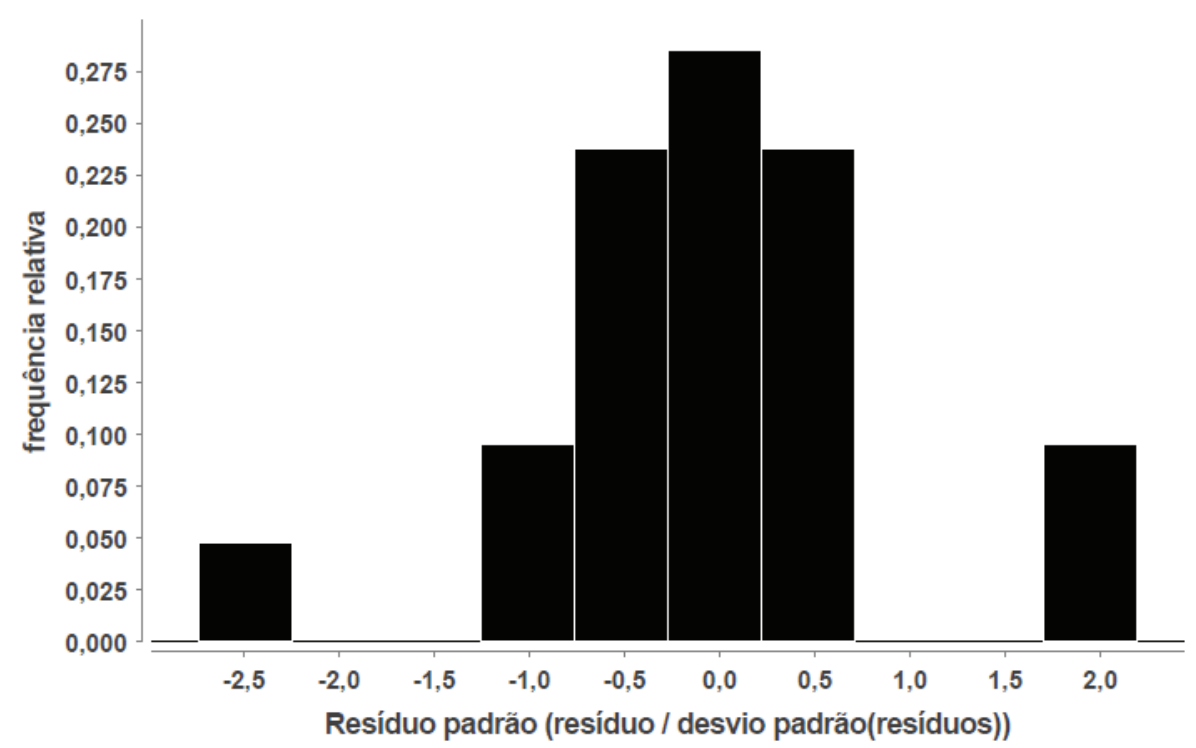

Figura 7. 2: Histograma do resíduo padrão para estimativa do torque de instalação.

O histograma da análise do resíduo (Figura 7. 2) possui boa conformação normal e valores centrados em zero. O gráfico de resíduo padrão versus torque estimado (Figura 7. 3) tem forma de ajuste linear adequado quando retirado os outliers. 


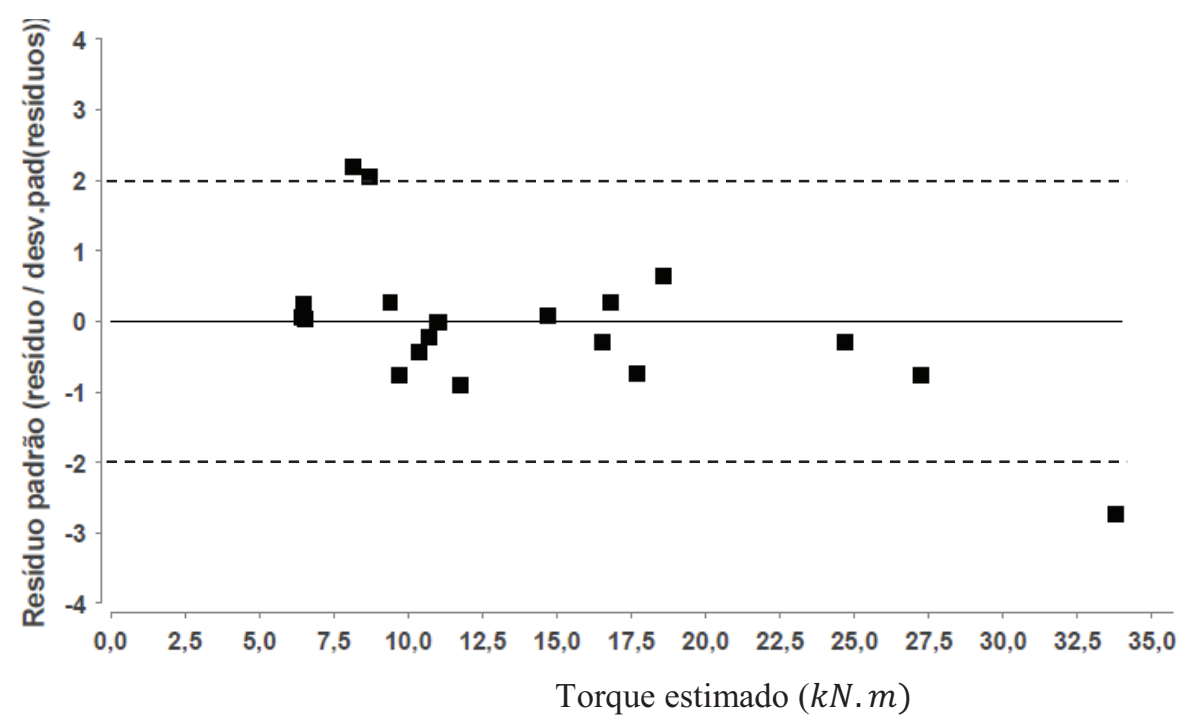

Figura 7. 3: Gráfico de resíduo padrão versus torque estimado.

O histograma do BIAS (Figura 7. 4) possui média, moda e mediana próxima de 1,0. $80 \%$ dos valores estão entre 0,8 e 1,4. Fora deste intervalo estão os outliers.

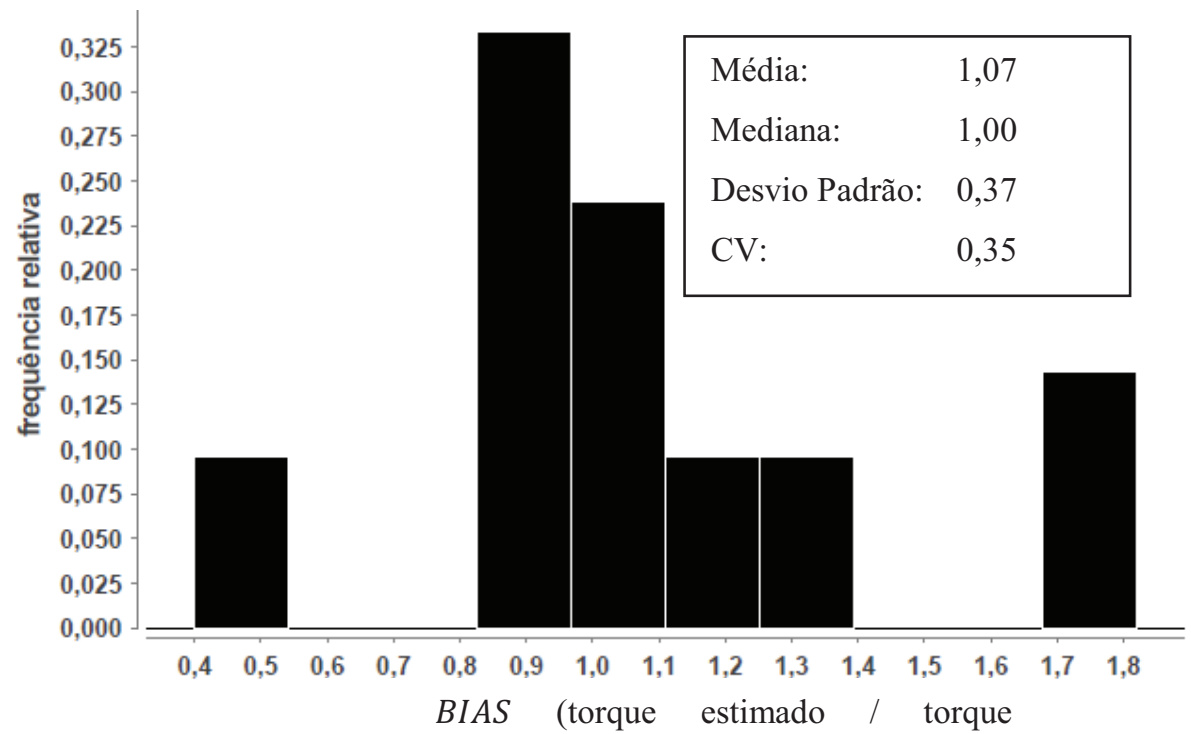

Figura 7. 4: Histograma $B I A S$ do torque estimado na situação $A$.

Devido ao alto $C V$ do histograma do BIAS (Figura 7. 5), o modelo é impreciso para estimar o torque na situação $B$. No entanto, a situação B não é adequada para se instalar estacas helicoidais. 


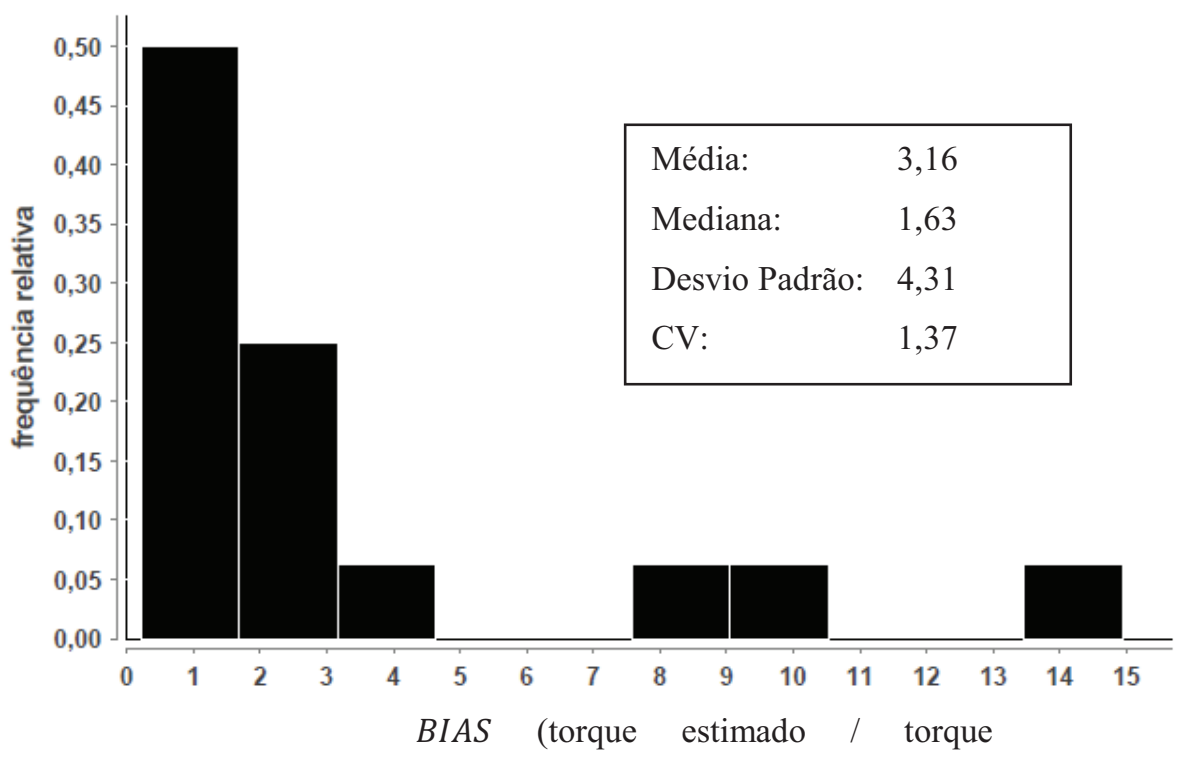

Figura 7. 5: Histograma $B I A S$ do torque estimado na situação $B$. 


\section{COMPARAÇÃO DO MODELO PROPOSTO (MODELO I) COM MÉTODO TEÓRICO DA CAPACIDADE DE CARGA INDIVIDUAL}

\subsection{INTRODUÇÃO}

O método teórico da capacidade de carga individual é recomendado para estacas da base de dados porque o espaçamento entre as hélices é igual a 3 vezes o diâmetro da hélice inferior. Além disso, ele é de fácil programação devido à forma como o software desenvolvido foi estruturado.

O método da capacidade de carga individual utilizado é o da Hubbell (2003), expresso por:

$Q_{h}=\sum_{1}^{N} Q_{h i}$

Argila) $Q_{h}=A_{h} c N_{c}=9 c A_{e h}$

Areia) $Q_{h}=A_{e h} q^{\prime} N_{q}$

$N_{q}=0,5(12 \times \phi)^{\phi / 54}$

Para solos intermediários, deve-se calcular a resistência para os dois casos e adotar o menor valor.

Por ter maior conjunto amostral, foi adotado o critério $\mathrm{D} / 10$ como método de interpretação da prova de carga. O método teórico foi comparado apenas com o modelo $I$, mesmo para estacas com grandes comprimentos.

As correlações para o $N_{S P T}$ adotadas são as de Teixeira e Godoy (1996 apud Cintra e Aoki (2010)):

$c=10 N_{S P T}$

8. 1

$\Phi=\sqrt{20 N_{S P T}}+15$

O peso específico foi retirado de Godoy (1972 apud Cintra e Aoki (2010)) e são apresentados na Tabela 8. 1 e Tabela 8. 2. Silte arenoso foi tratado como areia e silte argiloso como argila. 
Tabela 8. 1: Peso específico para solos argilosos (Godoy (1972) apud Cintra e Aoki (2010)):

\begin{tabular}{ccc}
\hline $\boldsymbol{N}_{\boldsymbol{S P T}}$ & Consistência & $\boldsymbol{\gamma}\left(\boldsymbol{k N} / \boldsymbol{m}^{3}\right)$ \\
\hline $\mathbf{2} \mathbf{2}$ & Muito mole & 13 \\
$\mathbf{3 - 5}$ & Mole & 15 \\
$\mathbf{6 - 1 0}$ & Média & 17 \\
$\mathbf{1 1 - 9}$ & Rija & 19 \\
$\geq \mathbf{2 0}$ & Dura & 21 \\
\hline
\end{tabular}

Tabela 8. 2: Peso específico para solos arenosos (Godoy (1972) apud Cintra e Aoki (2010)):

\begin{tabular}{ccccc}
\hline \multirow{2}{*}{$\boldsymbol{N}_{\boldsymbol{S P T}}$} & Compacidade & \multicolumn{3}{c}{$\boldsymbol{\gamma}\left(\boldsymbol{k N} / \mathbf{m}^{3}\right)$} \\
\cline { 3 - 5 }$<\mathbf{5}$ & Areia seca & Areia úmida & Areia Saturada \\
$\mathbf{5 - 8}$ & Pouco compacta & 16 & 18 & 19 \\
$\mathbf{9 - \mathbf { 1 8 }}$ & Mediamente Compacta & 17 & 19 & 20 \\
$\mathbf{1 9 - 4 0}$ & Compacta & 18 & 20 & 21 \\
$>\mathbf{4 0}$ & Muito compacta & & & \\
\hline
\end{tabular}

\subsection{RESULTADOS}

$\mathrm{Na}$ análise geral, o método teórico (Figura 8. 1 a.) apresenta maior dispersão do que o método I proposto (Figura 8. 2 a.). Nele, existe uma estaca com 6 hélices em solo arenoso, $N_{S P T}$ maiores que 40, com BIAS próximo de 9. Removendo-a, o $C V$ é igual a $0,49$.

O método teórico superdimensionou $75 \%$ das amostras, onde $40 \%$ tiveram BIAS maiores que 1,5. O modelo $I$ possui apenas $8 \%$ das estacas com $B I A S$ maior que 1,5 , e o valor máximo foi de 1,8 , demonstrando melhor ajuste.

Na situação $A$, o método teórico (Figura 8.1 b.) apresentou média e mediana próximas de 1,7 e 2,0, respectivamente, indicando que ele é contra a segurança. Já no modelo I (Figura 8. 2 b.), elas se encontram em torno do 1,0 .

Já na situação $B$, o método teórico (Figura 8.1 c.) possui menor dispersão $(C V=$ 0,36), mas o modelo I continua a apresentar melhor ajuste (Figura 8. 2 c.). 


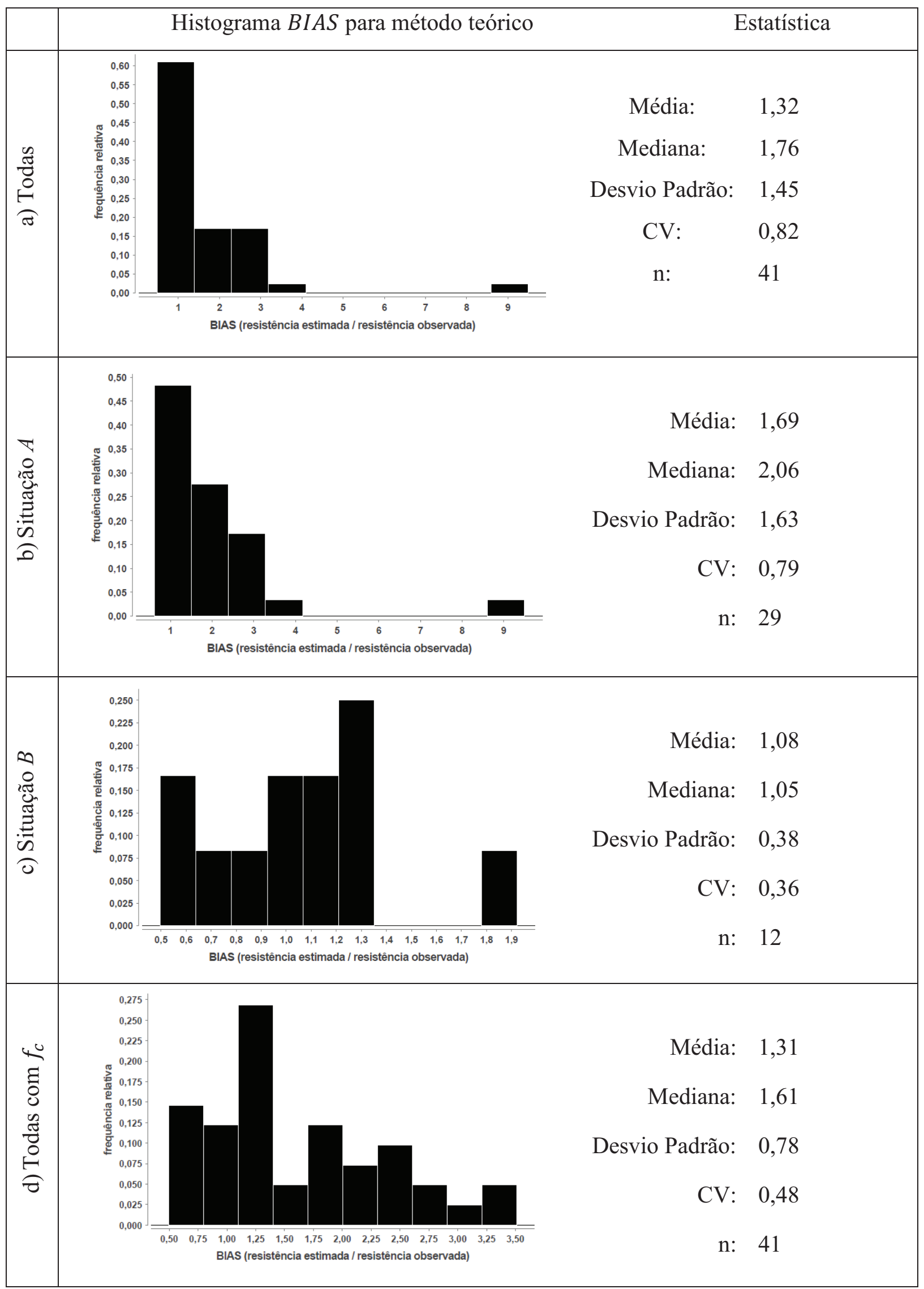

Figura 8. 1: Resultados do método teórico: a) todas as estacas, b) na situação $A$, c) na situação $C, \mathrm{~d})$ todas as estacas utilizando o fator de correção. 


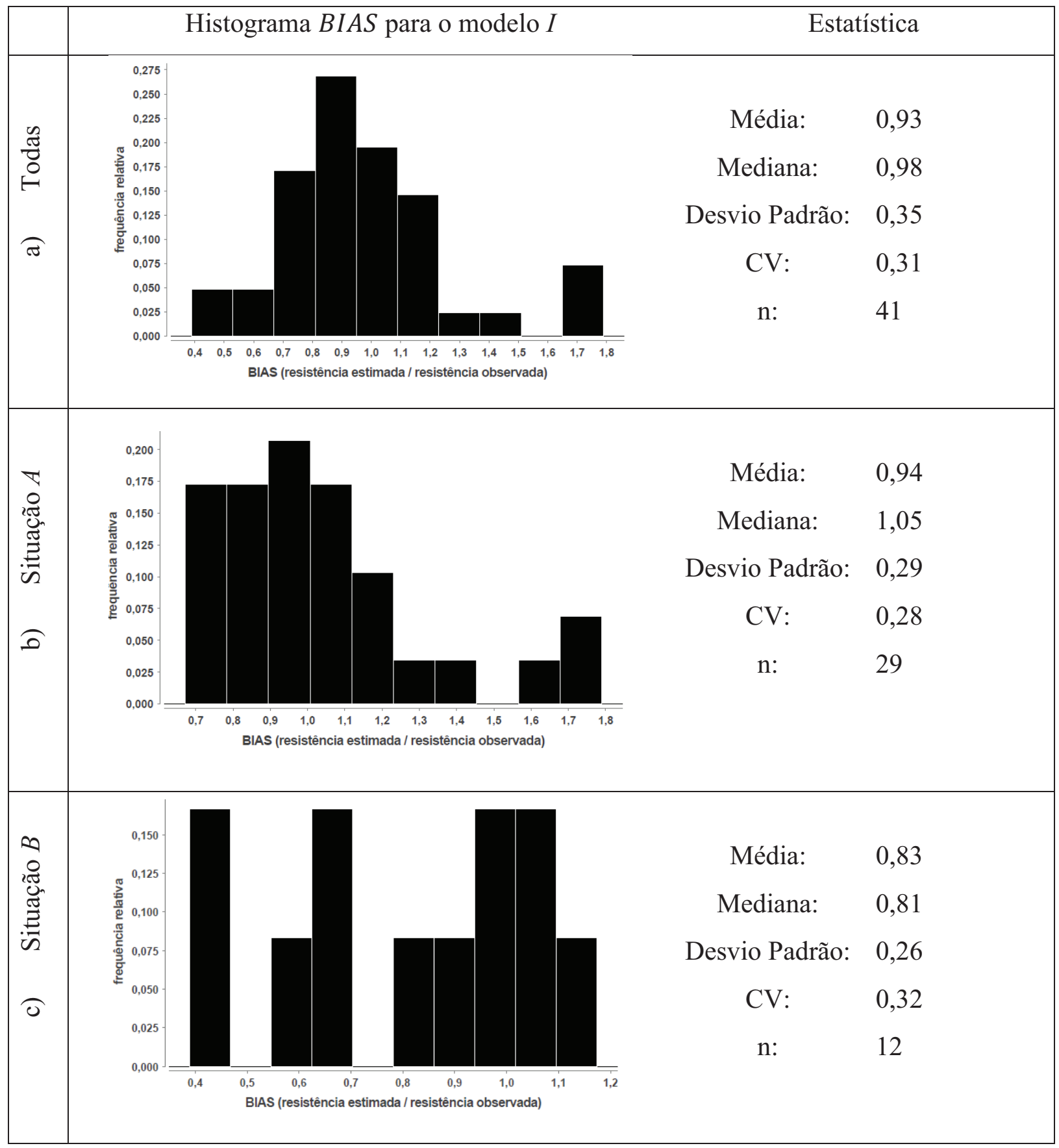

Figura 8. 2: Resultados do modelo $I$ a) todas as estacas, b) na situação $A$, c) na situação $C$.

O modelo teórico com melhor ajuste ocorreu quando utilizou-se o fator de correção (Figura 8.1 d.), cuja dispersão diminuiu significativamente e o maior valor do BIAS foi de 3,5 . 


\section{CONCLUSÕES}

\subsection{PROVA DE CARGA E MÉTODOS DE INTERPRETAÇÃO}

Diversas provas de carga não puderam ser interpretadas usando-se os critérios de $\mathrm{D} / 10$ e Livneh e Naggar (2008). Para evitar este problema, recomenda-se que os deslocamentos axiais atingidos nos ensaios sejam superiores a 10\% do diâmetro médio das hélices das estacas.

Os critérios de Davisson (1972) e NBR (6122) foram mais conservadores para se determinar a carga de ruptura convencional.

\subsection{SOLOS POROSOS E ESTRUTURADOS}

As análises demonstraram que não é adequado instalar as hélices de estacas helicoidais em solos porosos e de baixa capacidade de suporte. $\mathrm{O}$ valor do fator de torque $k_{T}$, que é a razão entre a capacidade de carga à tração e o torque final de instalação, é bem menor para estes solos (situação B). Isso mostra que o valor de torque a ser aplicado na instalação nestes solos é elevado em relação à capacidade de carga proporcionada pela estaca.

O valor de $N_{S P T}$ igual a 7 foi uma referência para separar o comportamento da estaca helicoidal. Ele foi eficiente para identificar solos porosos e estruturados.

\subsection{MODELOS DE REGRESSÃO E SITUAÇÕES DE PROJETO}

A escolha da situação de projeto é um ponto fundamental para estimar a capacidade de carga à tração das estacas helicoidais, porque interfere diretamente no comportamento dos modelos de regressão.

Tanto o modelo do torque quanto o do $N_{S P T}$ foram capazes de estimar a capacidade de carga da estaca. Eles podem ser utilizados de forma complementar com a finalidade de validar as premissas de projeto.

A regressão para a relação entre $N_{S P T}$ e a capacidade de carga da estaca não possibilitou separar a resistência das hélices e por atrito lateral na haste. Para tanto, foi proposto um modelo de relação entre eles. O efeito de instalação da estaca em solos da situação A é representado por um fator de correção $\left(f_{c}\right)$. 
Novos estudos sobre a resistência por atrito lateral na haste de estacas helicoidais permitirão refinar os modelos propostos nesta dissertação.

A partir do modelo I proposto (com base em $N_{S P T}$ ), foi possível criar um método de previsão de capacidade de carga à tração mais eficiente e abrangente, para os casos das estacas analisadas, do que os métodos teóricos atualmente utilizados.

Um modelo incluindo a parcela de resistência por atrito na haste poderia ser ajustado em pesquisas futuras a partir de uma base de dados suficientemente grande de estacas longas e de grande diâmetro.

Quando forem disponibilizados resultados de $N_{S P T}$ e tipo de solo de instalação da estaca, o torque mínimo de instalação para estacas instaladas na situação A pode ser estimado em projeto usando a capacidade de carga obtida pelo modelo $I$ (sem uso do fator de correção).

Recomenda-se para trabalhos futuros estudar a influência da variação de energia do ensaio SPT nos métodos de previsão de capacidade de carga desenvolvidos nesta dissertação.

\subsection{ESTACAS COM 6 HÉLICES}

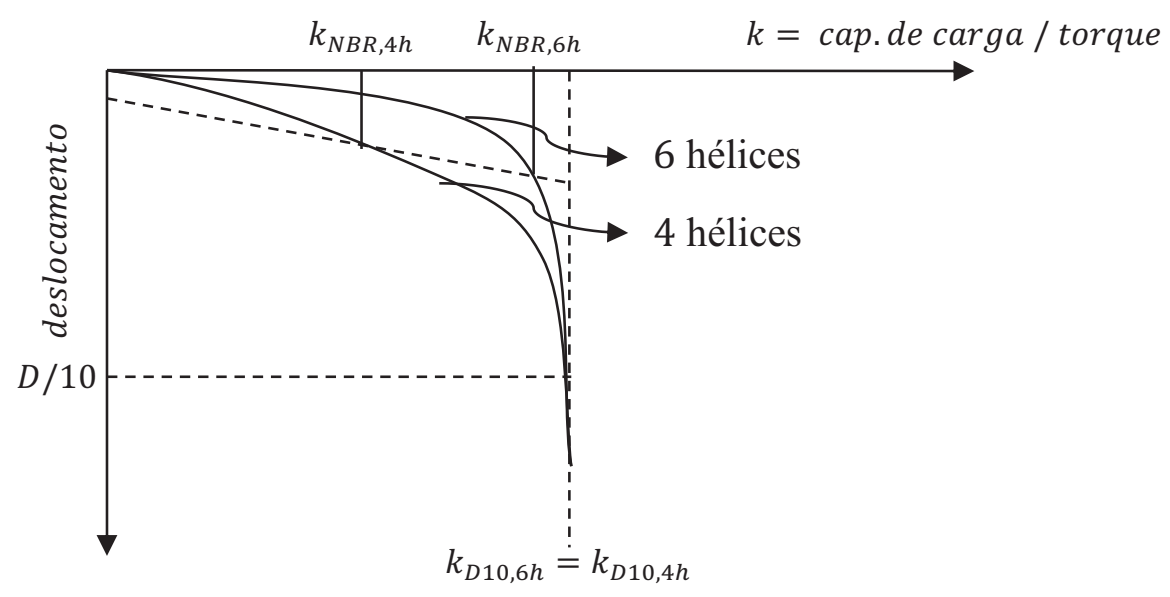

Figura 9. 1: Comportamento das estacas com 6 hélices

As estacas com 6 hélices tiveram comportamento diferenciado das demais como mostra a Figura 9. 1. Para grandes deslocamentos, os valores de $k_{t}$ delas foram iguais à com 4 ou menos hélices (por exemplo). Usando-se o critério D/10, na definição da carga de ruptura, os valores de $k_{t}$ independem da quantidade de hélice $\left(k_{D 10,6 h}=k_{D 10,4 h}\right)$ já que a carga de ruptura convencionada é a mesma para os dois casos.. Para pequenos deslocamentos, a resistência mobilizada foi superior (por exemplo, para NBR 6122 (2010), $k_{N B R, 6 h}>k_{N B R, 4 h}$ ). 
Um reflexo deste comportamento é o número de estacas com prova de carga capazes de serem interpretadas com o critério D/10 e/ou Livneh e Naggar (2008): enquanto existem 19 estacas para Davission (1972) e 18 para NBR 6122 (2010), há apenas 6 e 3 para D/10 e/ou Livneh e Naggar (2008), respectivamente.

Para estacas com 6 hélices, deve-se sempre utilizar o fator de correção no modelo I para estimativas de capacidade de carga à tração com base no $N_{S P T}$, devido ao efeito de instalação.

\subsection{ANALISES ESTATÍSTICAS}

As cargas de ruptura das estacas helicoidais da base de dados estimadas com os critérios D/10 e Livneh e Naggar (2008) proporcionaram um melhor ajuste dos modelos de regressão. Portanto, esta faixa de deslocamento se mostrou mais sensível às mudanças das variáveis quando comparados a Davisson (1972) e NBR 6122 (2010).

Devido ao comportamento diferenciado das estacas com 6 hélices, pode-se realizar uma análise estatística modelo $I$ e $I I$ (proposto no capítulo 6) específica para ela. Entretanto, a base de dados deve ser aumentada.

Das 76 estacas da base de dados, apenas 22 foram efetivamente usadas para calibrar os modelos de regressão da relação $N_{S P T}$ e capacidade de carga (capítulo 6) na situação $A$. 


\section{REFERÊNCIAS BIBLIOGRÁFICAS}

ASSOCIAÇÃO BRASILEIRA DE NORMAS TÉCNICAS. NBR 6122: projeto e execução de fundações, Rio de Janeiro, 2010.

ASSOCIAÇÃO BRASILEIRA DE NORMAS TÉCNICAS. NBR 12131: estacas - prova de carga estática, Rio de Janeiro, 2006.

International Code Council Evaluition Service (ICC-ES). AC358: acceptance criteria for helical pile systems and devices, 2007.

ADAMS, J. I.; KLYM, T. W. A Study of Anchorages for Transmission Tower Foundations. Canadian Geotechnical Journal, v. 9, n. 1, 1972.

ANDERSON, D. R.; SWEENEY, D. J.; WILLIAMS, T. A. Estatística Aplicada à Administração e Economia. 2. Editora Pioneira, 2002.

ASEL-TECH. Pipeline screw anchor system. Disponível em: <http://www.aseltech.com/products-anchor.html>, 2012. Acesso em: 16/08/2012.

CARVALHO, I. P. G. D. Estudo teórico-experimental da capacidade de carga à tração e compressão de estacas metálicas helicoidas. 2007. Departamento de Estruturas, Universidade Federal de Minas Gerais, Belo Horizonte.

CINTRA, J. C. A.; AOKI, N. Fundações por estacas: projeto geotécnico. São Paulo: Oficina de Textos, 2010.

DAS, B. M. Earth Anchors. New York: Elsevier Science Publisher, 1990. 241

DÉCOURT, L; QUARESMA, A. R. Capacidade de carga de estacas a partir de valores SPT. Proc. VI COBRAMSEF; Rio de Janeiro, 1978.

GOMES, M. C. V. Estimativa da carga última compressiva em estacas a partir do SPT por regressão linear múltipla. 2000. Departamento de Engenharia Civil, Universidade Federal do Rio de Janeiro.

HOYT, R. M.; CLEMENCE, S. P. Uplift Capacity of Helical Anchors in Soil. 12th International Conference of Soil Mechanics and Foundation Engineering. Rio de Janeiro, Brasil 1989.

HUBBELL, I. Helical Screw Foundation System Design Manual for New Construction. CHANCE, A. B. 2003.

KANAI, S. A seismic retrofitting applications by means of multi-helix micropiles. 2007. Proceedings of the 23 U.S. - Japan Bridge Engineering Workshop, Tsukuba - Japan.

LIVNEH, B.; NAGGAR, M. H. E. Axial testing and numerical modeling of square shaft helical piles under compressive and tensile loading. NRC Canada, p. 1142-1155, 2008. 
MENEZES, S. M. et al. Provas de carga em estacas pré-moldadas ensaiadas em areias porosas. Rem: Revista Escola de Minas, v. 57, n. 4, p. 285-289, 20042004.

MERIFIELD, R. S.; SMITH, C. C. The ultimate uplift capacity of multi-plate strip anchors in undrained clay. Journal of the geotechnical And Geoenvironmental Enginnering, v. 137, n. 7, p. 704-716, 2011.

MITSCH, M. P.; CLEMENCE, S. P. The uplift capacity of helix anchors in sand. Uplift Behavior of Anchor Foundations in Soil. In Proceedings of a session sponsored by the Geotechnical Engineering Division of the American Society of Civil Engineers in conjunction with the ASCE Convention, 1985.

MOONEY, J. S.; ADAMCZAK, S. J.; CLEMENCE, S. P. Uplift Capacity of Helix Anchors in Clay and Silt. ASCE, 1985.

PERKO, H. A. Helical Piles: a practical guide to design and installation. Unided States of America: Wiley, 2009.

PINTO, C. D. S. Curso básico de mecânica dos solos em 16 aulas. São Paulo: Oficina de Texto, 2006.

SANTOS, T. D. C. Efeito da configuração das hélices na capacidade de carga à tração de estacas metálicas helicoidais em solo tropical. 2013. Departamento de Geotecnia, Universidade de São Paulo, São Carlos.

SCHNAID, F. Ensaios de campo e suas aplicações à engenharia de fundações. São Paulo: Oficina de Texto, 2000.

TEIXEIRA, W. et al. Decifrando a Terra. São Paulo: Companhia Editora Nacional, 2009.

TERZAGHI, K. Discussion on pile driving formulas. Proc. Asce, 68 (2), p. 311-323, 1942.

TISAKA, M. Orçamento na construção civil: consultoria, projeto e execução. São Paulo: Pini, 2006.

TSUHA, C. D. H. C. Modelo teórico para controle da capacidade de carga à tração de estacas metálicas helicoidais em solo arenoso. 2007. (Tese de doutorado). Departamento de Geotecnia, Universidade de São Paulo, São Carlos.

. Fundações em estacas helicoidais. Fundações e Obras Geotécnicas, v. 18, n. Ano 2, p. 56-66, 2012.

TSUHA, C. D. H. C. et al. Evaluation of the efficiencies of helical anchor plates in sand by centrifuge model tests. Canadian Geotechnical Journal, v. J. 49, p. 1102-1114, 2012.

ZHANG, D. J. Y. Predicting capacity of helical screw piles in alberta soils. 1999. Departament of Civil and Enviromental Engineering, University of Alberta, Edmonton, Alberta. 


\section{ANEXO I $Q_{u} v S T O R Q U E$ PARA DAVISSON (1972) E NBR 6122 (2010)}

\section{$1.1 \quad$ DAVISSON (1972)}

\subsubsection{Análise geral}

O histograma de frequência de $k_{t}$ para todas as amostras (Figura 1 a.) apresenta concentração de valores próximo do centro $\left(k_{t} \cong 10 \mathrm{~m}^{-1}\right)$ e um em cada extremidade $\left(k_{t} \cong 5 m^{-1}\right.$ e $\left.k_{t} \cong 16 m^{-1}\right)$, indicando a existência de variáveis não consideradas no modelo. A concentração central está associada à situação $A$ (Figura 1 b.), a inferior à $B$ (Figura 1 c.). Analisando a base de dados, os picos superiores estão relacionados às estacas com 6 hélices (Figura 1 d.).

$\mathrm{Na}$ análise com todos os dados, a média e mediana de $k_{t}$ estão próximas de $10 \mathrm{~m}^{-1}$, mas o gráfico não apresenta boa conformação normal por ter mais de um pico. O coeficiente de variação $(C V)$ é de 0,54 , desvio padrão $5,18 \mathrm{~m}^{-1}$ e quantidade de amostra $(n)$ igual a 65.

Para a situação $A$, a média e mediana de $k_{t}$ possuem valores próximos a $11 \mathrm{~m}^{-1} \mathrm{e}$ histograma apenas com um pico. Nela, o $M M Q$ é recomendado para estimar a variável. $\mathrm{O}$ desvio padrão é de 4,19 $\mathrm{m}^{-1}, C V$ 0,37 e $n$ 28. O valor central é um pouco superior ao encontrado na análise de todos os dados.

A situação $B$ é assimétrica com a média de $k_{t}$ muito superior à mediana devido aos valores da estaca com 6 hélices. O desvio padrão foi de 5,86 $\mathrm{m}^{-1}, C V$ 0,81 (elevado) e $n 24$. A moda encontra-se abaixo dos valores centrais da análise com todos os dados.

Nas estacas com 6 hélices, a média e mediana de $k_{t}$ estão ligeiramente afastadas e com valores muito superiores às demais análises. Não se recomenda utilizar $M M Q$ porque gráfico não possui conformação normal. $\mathrm{O} C V$ é menor dentre as situações analisadas $(0,20)$.

Para uma melhor compreensão da relação torque e capacidade de carga utilizando Davisson (1972), a amostra será dividida em três grupos: estacas com 2, 3 e 4 hélices nas situações $A$ e $B$ e estacas com 6 hélices . 


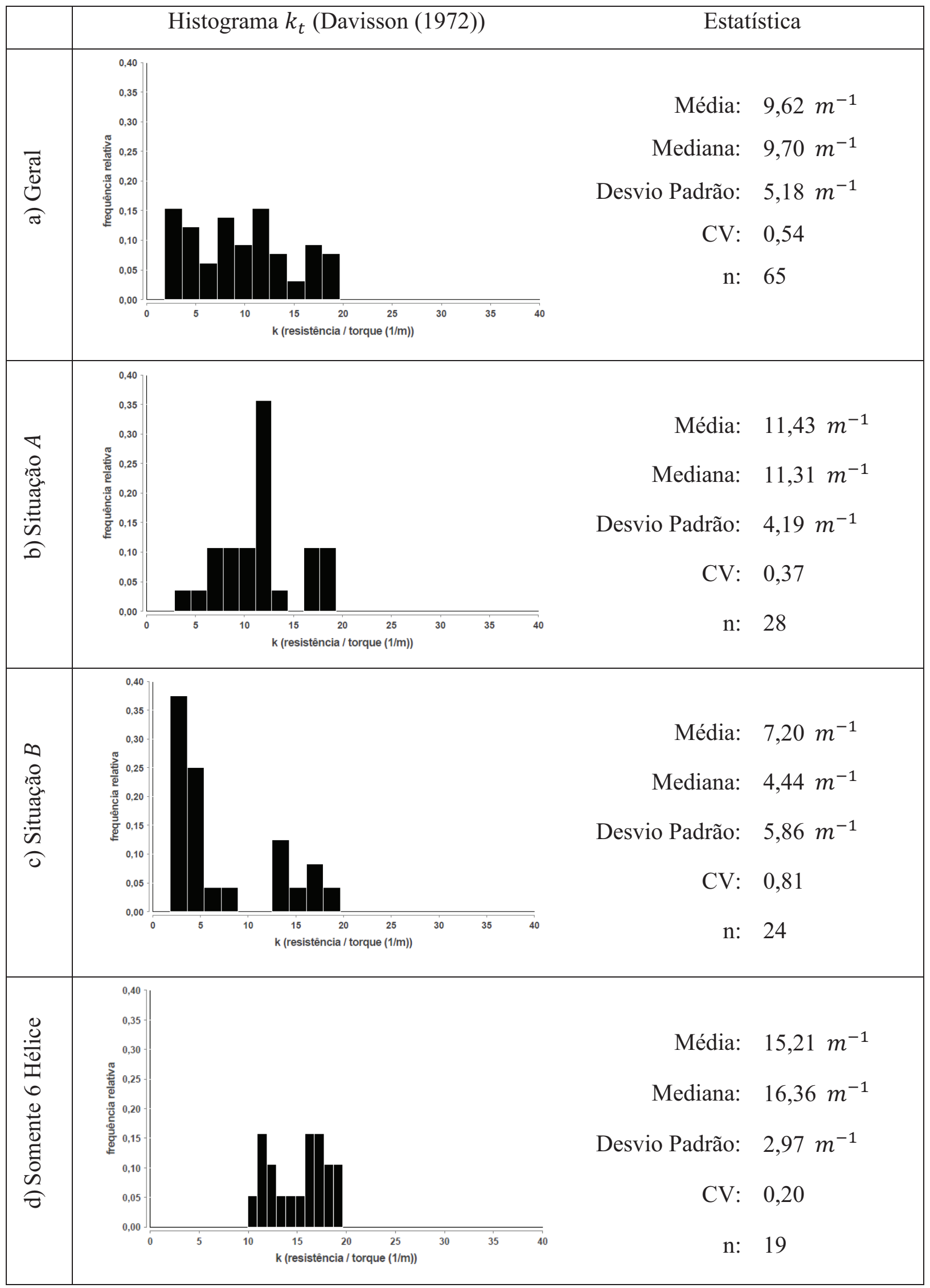

Figura 1: Histogramas de $k_{t}$ utilizando Davisson (1972) para: a) todas as amostras, b) situação $A$, c) situação $B$ e d) somente estacas com 6 hélices. 


\subsubsection{Estacas com 2, 3 e 4 hélices: situação $A$}

O histograma (Figura 2) apresentou conformação normal satisfatória. Há a presença de dois picos muitos próximos. Tal problema pode ser facilmente resolvido modificando o número de divisões do gráfico. A média e mediana estão próxima dos valores centrais, indicando haver boa simetria. Para este caso, o $M M Q$ é um estimador válido.

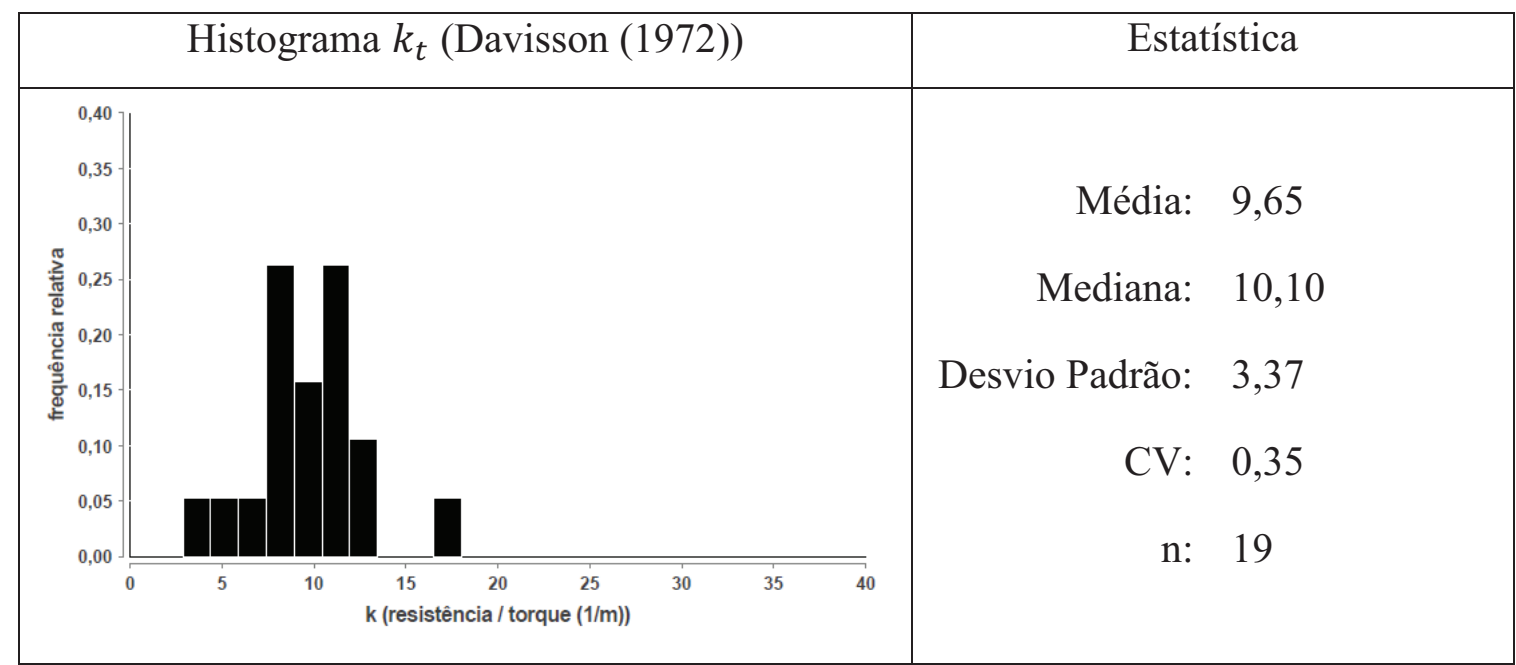

Figura 2: Histogramas de $k_{t}$ utilizando Davisson (1972) para estacas entre 2 e 4 hélices na situação $A$.

Estimando $k_{t}$ por meio do $M M Q$, o valor encontrado foi de 9,19 $\mathrm{m}^{-1}$, com $C V$ de 0,07 e $n$ igual a 19 estacas. Este valor é ligeiramente inferior à média $\left(9,65 \mathrm{~m}^{-1}\right)$ e mediana $\left(10,10 \mathrm{~m}^{-1}\right)$. O coeficiente de determinação foi de 0,93 , demonstrando que o modelo proposto é capaz de explicar uma parcela significativa da variação da resistência. A probabilidade de o regressor ser nulo foi de 2,3e-11, a qual permite concluir que a amostra é significativa (o comportamento da amostra pode ser extrapolado para a população). Não houve nenhum outliers.

O gráfico de resistência estimada versus observada (Figura 3) possui aleatoriedade desejada, indicando inexistência de vício no estimador. 


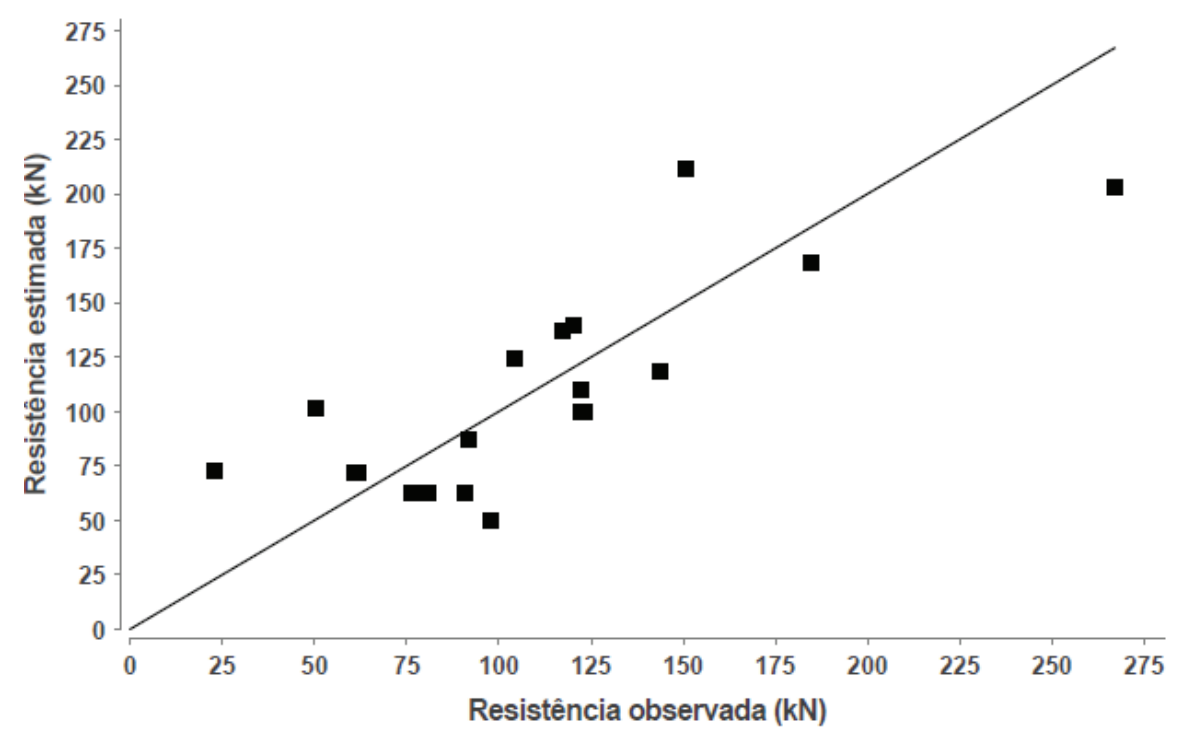

Figura 3: Gráfico de resistência observada versus resistência estimada para $A$ utilizando Davisson (1972).

O histograma de resíduo padrão (Figura 4) não apresenta boa conformação normal. Pode-se solucionar este problema aumentando o número de amostra.

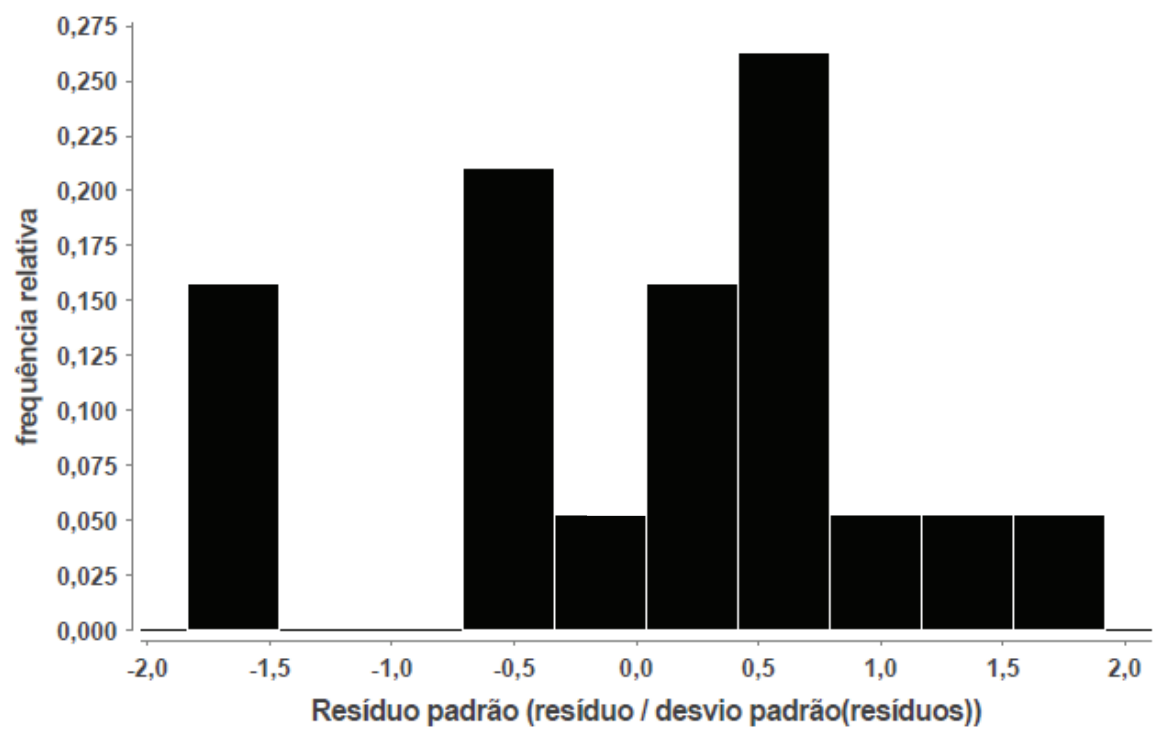

Figura 4: Histograma de resíduo padrão para situação $A$ utilizando Davisson (1972).

Verifica-se um bom comportamento dos resíduos (variância constante, forma típica de ajuste linear, inexistência de dados atípicos e outliers) no gráfico de resíduo padrão versus resistência estimada (Figura 5). 


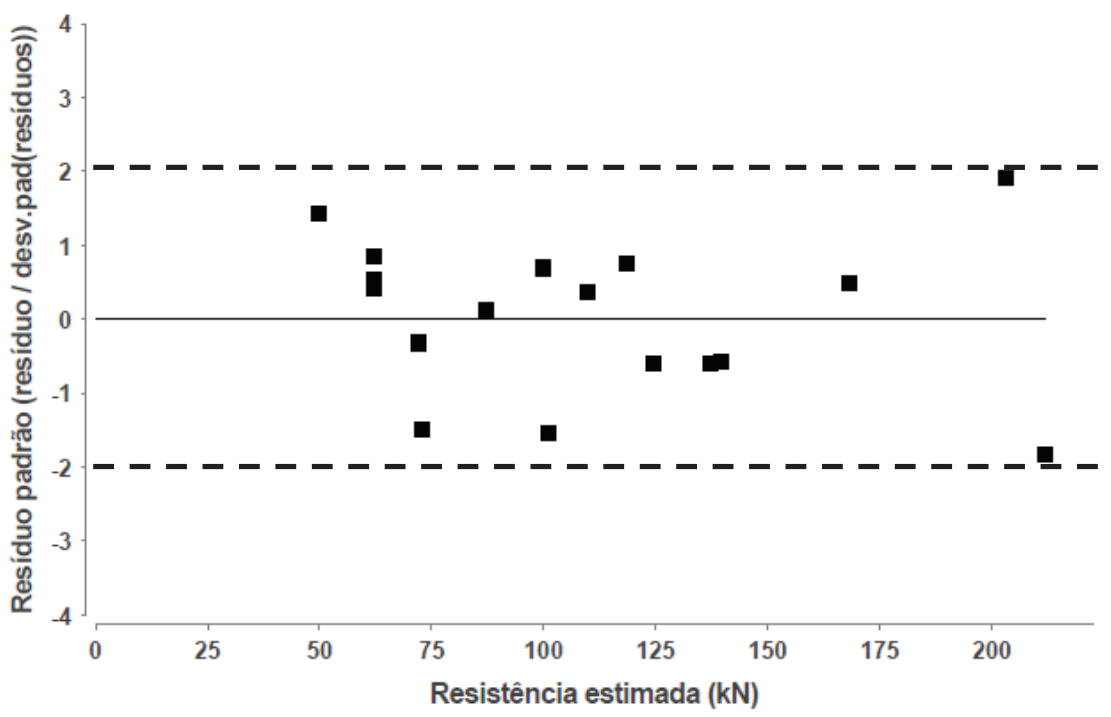

Figura 5: Histograma de resíduo padrão para situação $A$ utilizando Davisson (1972).

O histograma do BIAS (Figura 6) não é simétrico devido à influência de 3 pontos com alto valores. Neste caso, a média assume valores maiores que a mediana e moda. Analisando o gráfico de frequência acumulada do BIAS (Figura 7), verifica-se que aproximadamente $85 \%$ do valores são inferiores a $1,25.0 \mathrm{CV}$ foi de 0,54 , é considerado elevado.

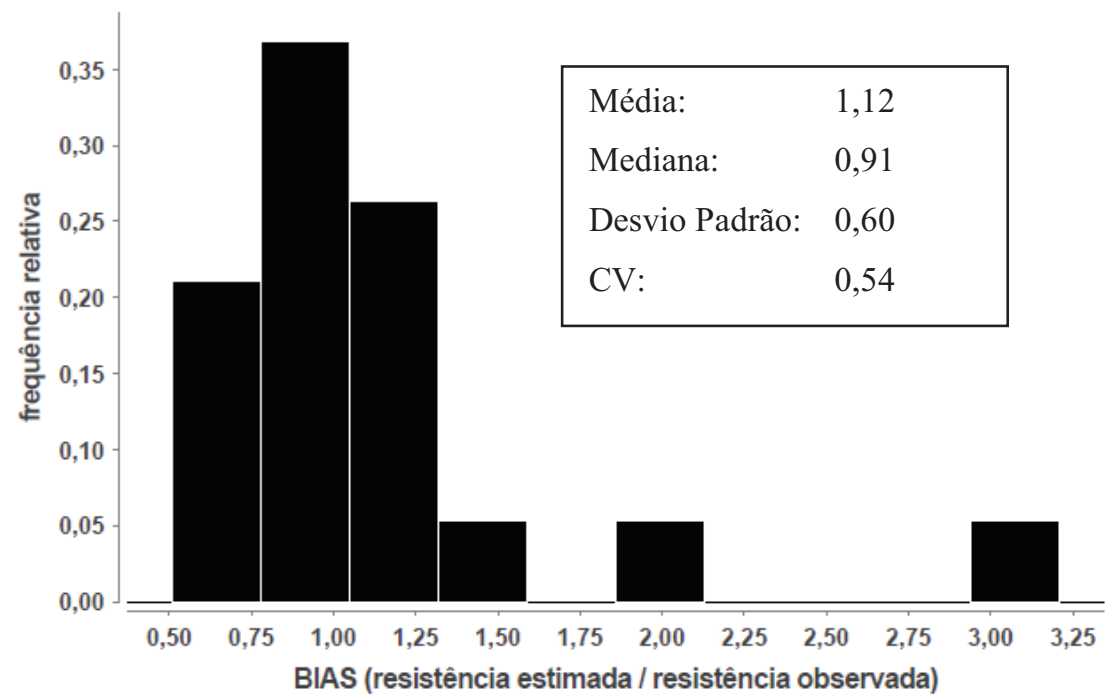

Figura 6: Histograma do BIAS para situação $A$ utilizando Davisson (1972). 


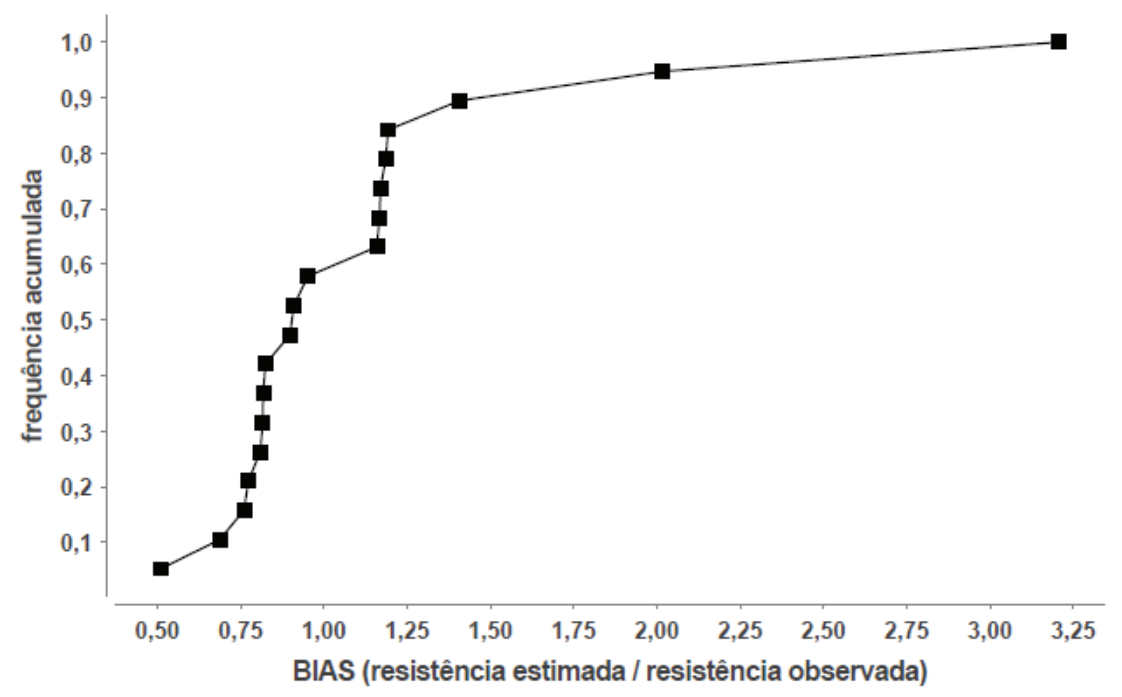

Figura 7: Gráfico de frequência acumulada do BIAS para situação A utilizando Davisson (1972).

\subsubsection{Estacas com 2, 3 e 4 hélices: situação $B$}

O histograma de $k_{t}$ para análise entre 2 e 4 hélices (Figura 8) é assimétrico. Neste caso, o valor do regressor recomendado é o da mediana $\left(4 \mathrm{~m}^{-1}\right)$.

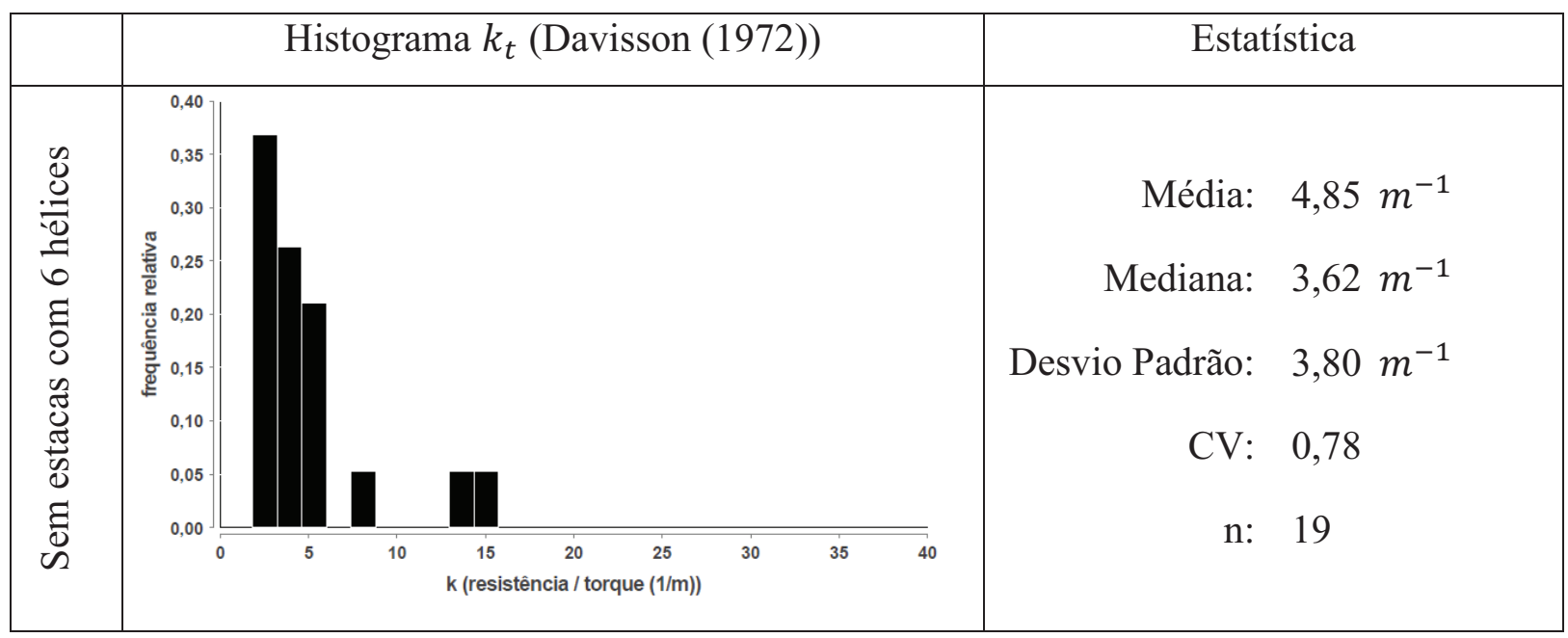

Figura 8: Histogramas de $k_{t}$ utilizando Davisson (1972) para estacas entre 2 e 4 hélices na situação $B$.

O $C V$ é extremamente elevado $(0,78)$, ocasionando grande dispersão no histograma do $B I A S$ (Figura 9). Nele, era esperado apenas um pico próximo de 1,0, mas foram encontrado 3, sendo um contra a segurança (entre 1,75 e 2,00). 


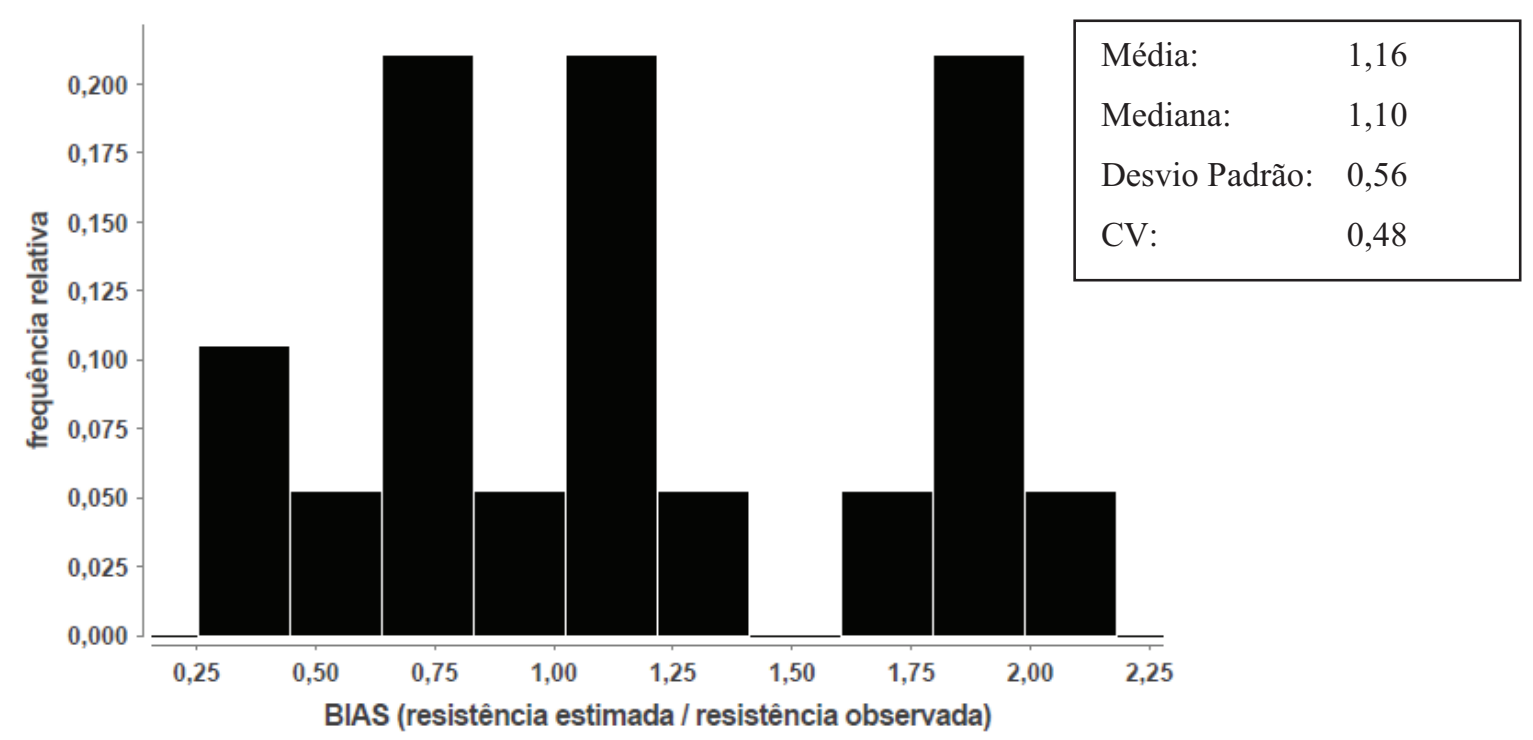

Figura 9: Histograma do BIAS para situação $B$ utilizando Davisson (1972).

O gráfico de frequência acumulada do BIAS (Figura 10) não possui o crescimento exponencial próximo de 1,0. Apenas $45 \%$ dos valores estimados estão a favor da segurança.

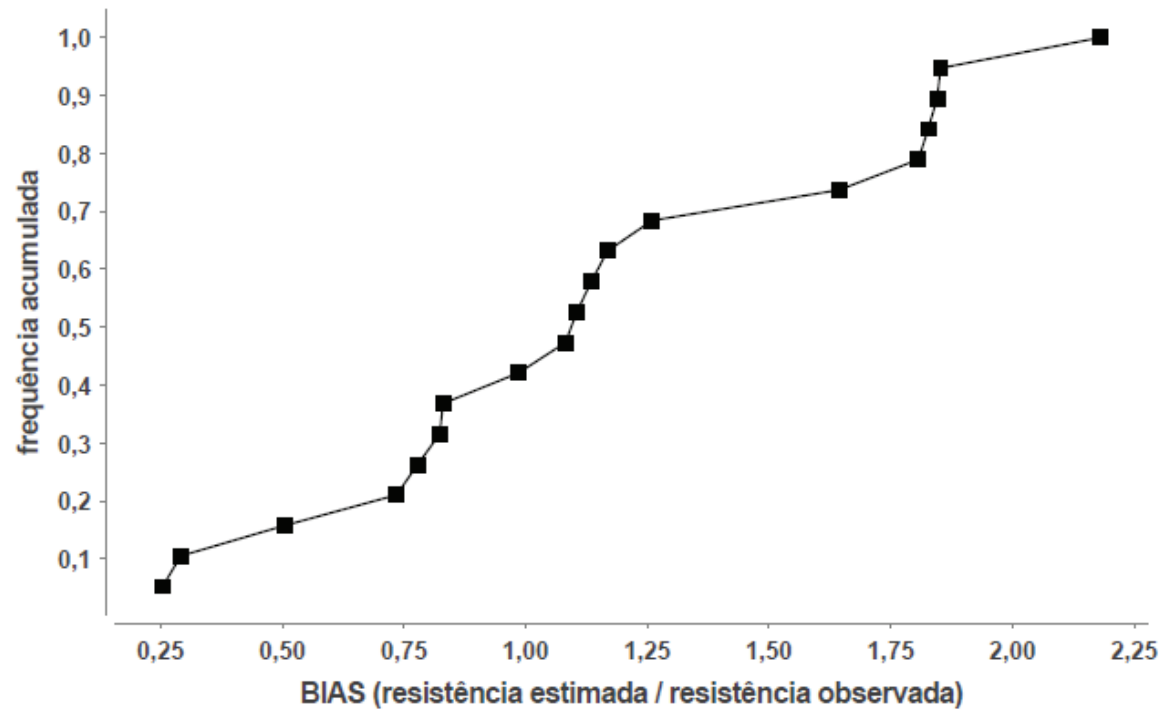

Figura 10: Gráfico de frequência acumulada do $B I A S$ para situação $B$ utilizando Davisson (1972). 


\subsubsection{Estacas com 6 hélices}

A variável $k_{t}$ possui comportamento similar nas duas situações de projeto: média e mediana próximas de $16 \mathrm{~m}^{-1}$ (Figura 11). Portanto, a análise global (com todas as estacas) será tomada como referência para análise.

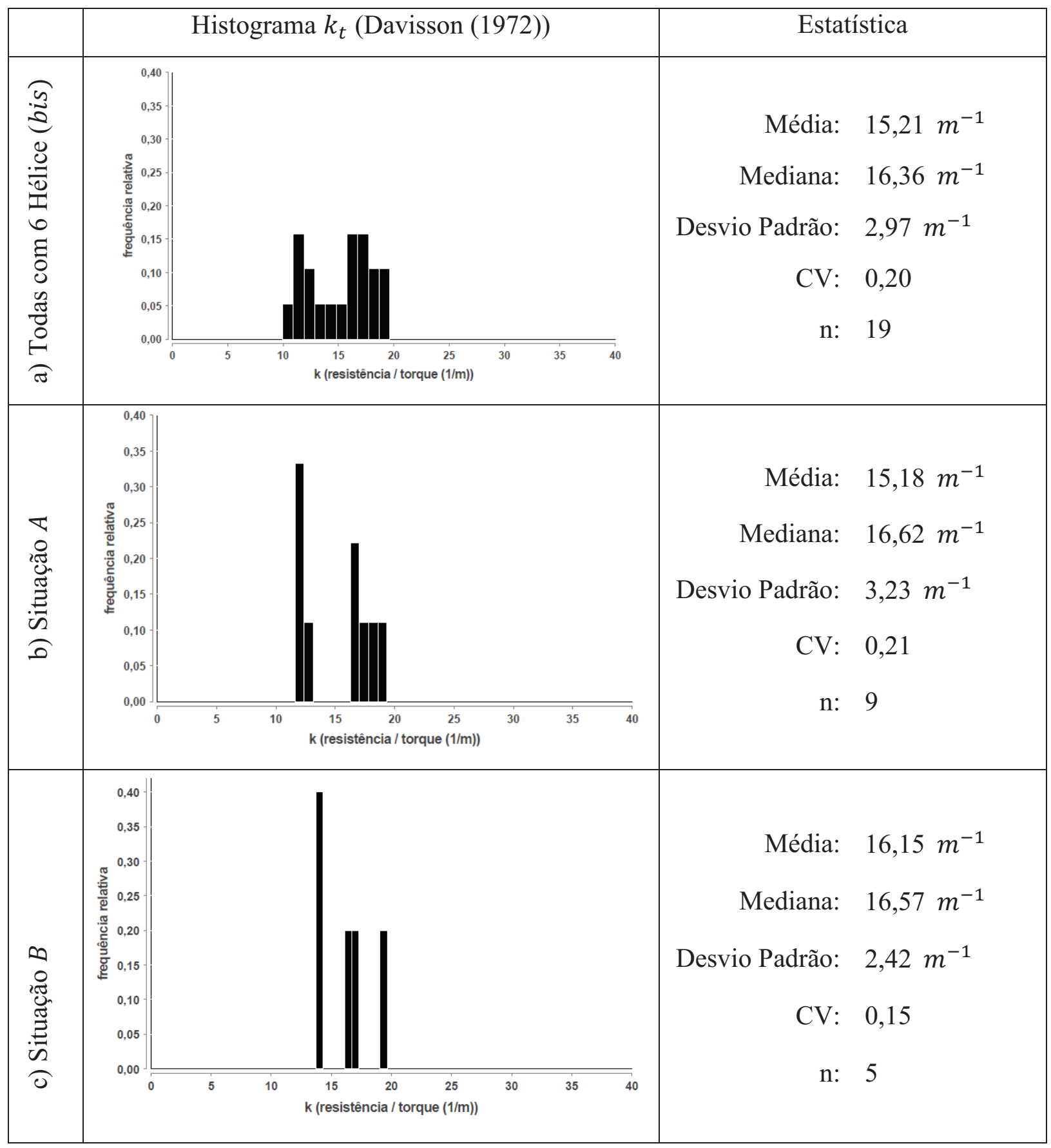

Figura 11: Histogramas de $k_{t}$ utilizando Davisson (1972) para estacas com 6 hélices na situação: a) todas as estacas, b) $A$, c) $B$ 
O histograma para todas as estacas possui dois picos: um próximo de $12 \mathrm{~m}^{-1}$ e outro de $17 \mathrm{~m}^{-1}$ - primeiro aparece somente na situação $A$, o segundo é decorrente da junção das duas situações.

$\mathrm{O}$ valor de $k_{t}$ recomendado é de $15 \mathrm{~m}^{-1}$. Ele foi estimado a partir da média devido à inexistência de valores extremos e por ela ser mais conservadora que a mediana.

O histograma do BIAS (Figura 12) possui mediana e moda (pico) próximos de 0,90 e média igual a 1,0 (conformação típica de lognormal). O CV é igual a 0,21 , valor considerado satisfatório. O intervalo do BIAS é relativamente curto (varia entre 0,75 e 1,50), porém não há uma grande concentração de determinado valor, ficando o gráfico de frequência acumulada (Figura 13) mais esparso e sem o crescimento exponencial desejado próximo de 1.

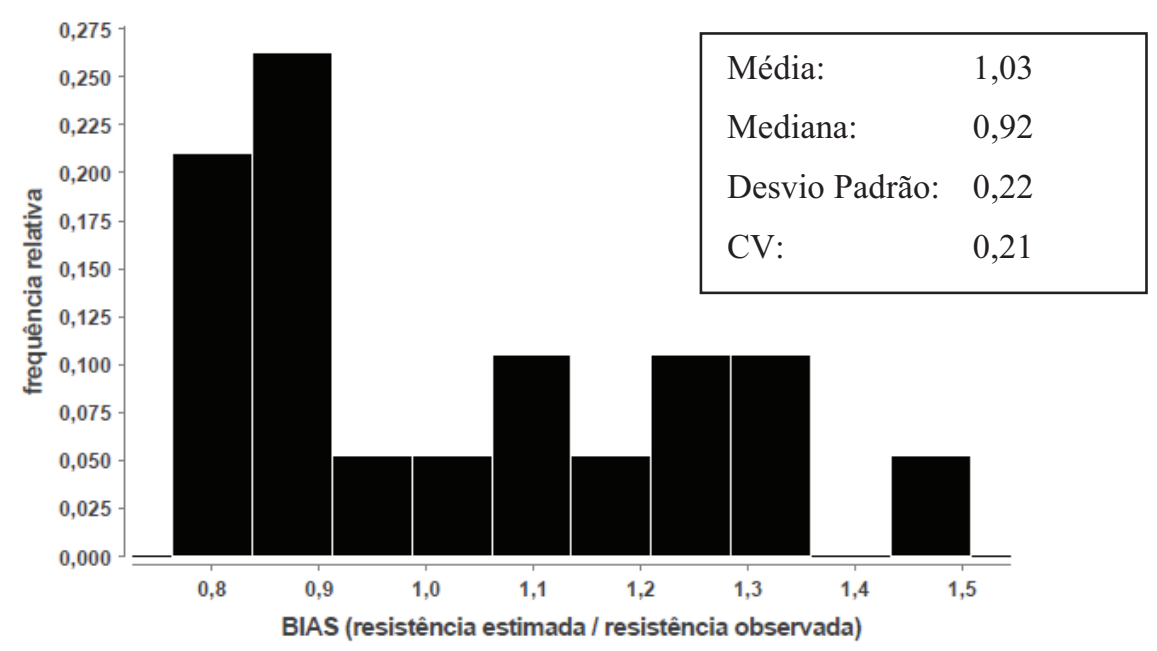

Figura 12: Histograma do BIAS para estacas com 6 hélices utilizando Davisson (1972).

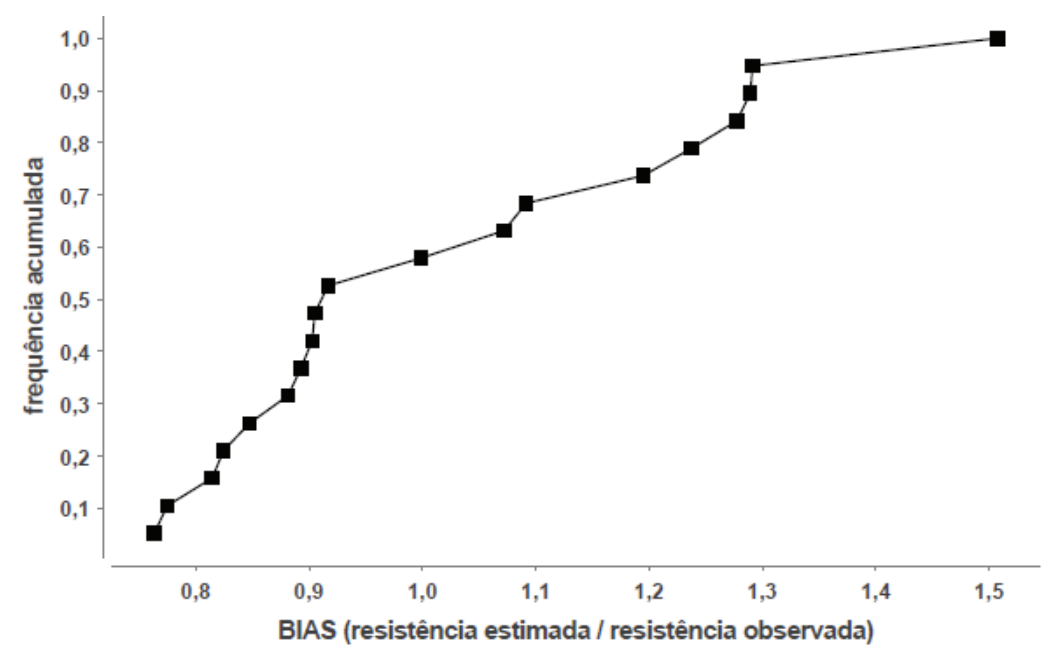

Figura 13: Gráfico de frequência acumulada do BIAS para estacas com 6 hélices utilizando Davisson (1972). 


\section{$1.2 \quad$ NBR $6122(2010)$}

\subsubsection{Análise Geral}

Para resistência estimada com o método da norma brasileira, o histograma de $k_{t}$ para todas as estacas (Figura 14 a.) possui picos com frequência acumulados muito próximos, indicando que devem existir variáveis não consideradas no modelo. O comportamento é muito próximo ao encontrado em Davisson (1972).

$\mathrm{Na}$ análise com todos os dados (Figura 14 a.), a média e media de $k_{t}$ estão próximas de $12 \mathrm{~m}^{-1}$, mas o gráfico não apresenta conformação normal. O CV é 0,49 , com desvio padrão de $5,97 \mathrm{~m}^{-1}$ e quantidade de amostra igual a 64 .

Para a situação $A$ (Figura 14 b.), a média e mediana possuem de $k_{t}$ próximos de $14 \mathrm{~m}^{-1}$ e histograma com boa conformação normal. Neste caso, o $M M Q$ pode ser utilizando para estimar a variável. $\mathrm{O}$ valor médio é um pouco superior ao encontrado na análise de todos os dados.

O histograma na situação $B$ (Figura 14 c.) é assimétrico, com média de $k_{t}$ muito superior à mediana devido aos valores das estacas com 6 hélices. $\mathrm{O} C V$ foi de 0,74 considerado elevado. A moda encontra-se abaixo dos valores centrais da análise com todos os dados.

Nas estacas com 6 hélices (Figura 14 d.), a média e mediana de $k_{t}$ estão próximas de $19 \mathrm{~m}^{-1}$, valor muito superior ao encontrado nas análises anteriores. O gráfico não possui conformação normal, portanto não é recomendado utilizar o $M M Q$.

Como feito em Davisson (1972), a amostra será dividida em três grupos: estacas com 2, 3 e 4 hélices nas situações $A$ e $B$ e estacas com 6 hélices . 


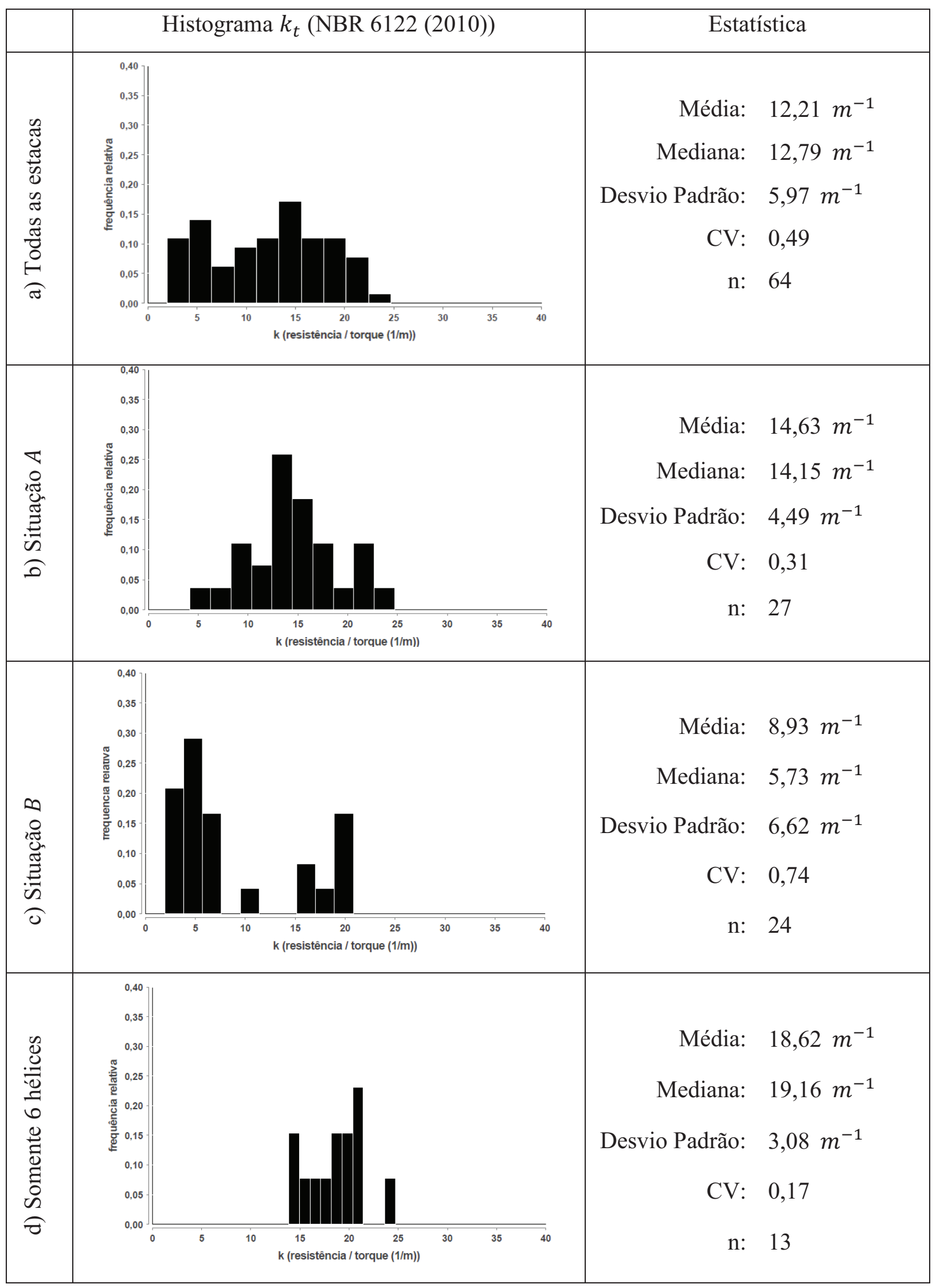

Figura 14: Histogramas de $k_{t}$ utilizando NBR 6122 (2010) para: a) todas as amostras, b) situação $A$, c) situação $B$ e d) somente estacas com 6 hélices. 


\subsubsection{Estacas com 2, 3 e 4 hélices: situação $A$}

O histograma de $k_{t}$ (Figura 15) possui boa conformação normal, com média e media próximas de $13 \mathrm{~m}^{-1}$. Neste caso, será utilizado o $M M Q$ como estimador da variável.

O valor de $k_{t}$ estimado na $R L S$ é igual a $13 \mathrm{~m}^{-1}$, com $C V$ igual a 0,05 e $n$ igual a 19 estacas. Este valor está entre a média e a mediana. Coeficiente de determinação $\left(R^{2}\right)$ foi 0,96 demonstrando que o modelo proposto explica parcela significativa da variação da resistência. A amostra é significativa porque probabilidade do regressor ser nulo é baixa (2,7e-13). Não houve outliers.

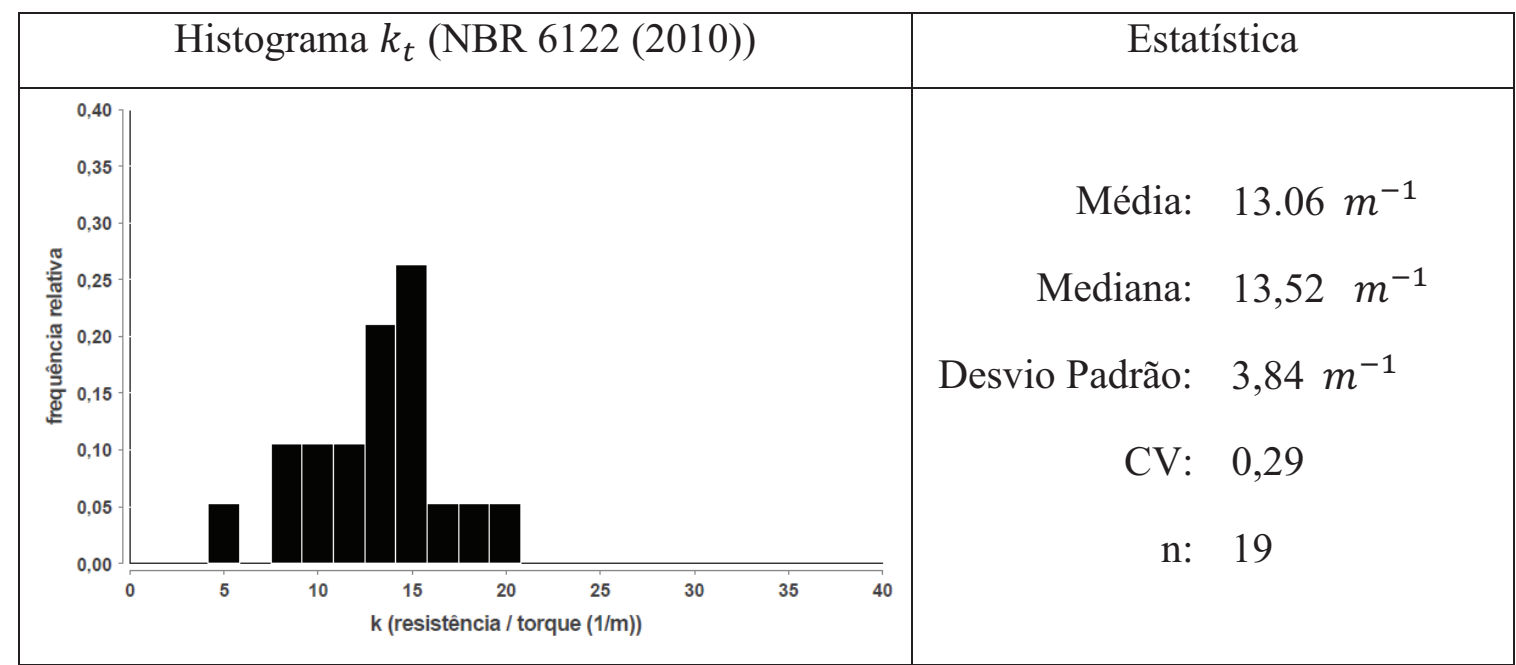

Figura 15: Histogramas de $k_{t}$ utilizando NBR 6122 (2010) para estacas entre 2 e 4 hélices na situação $A$.

O gráfico de resistência estimada versus observada (Figura 16) não possui boa aleatoriedade para valores superiores a $225 \mathrm{kN}$. Isto pode indicar algum vício no estimador. 


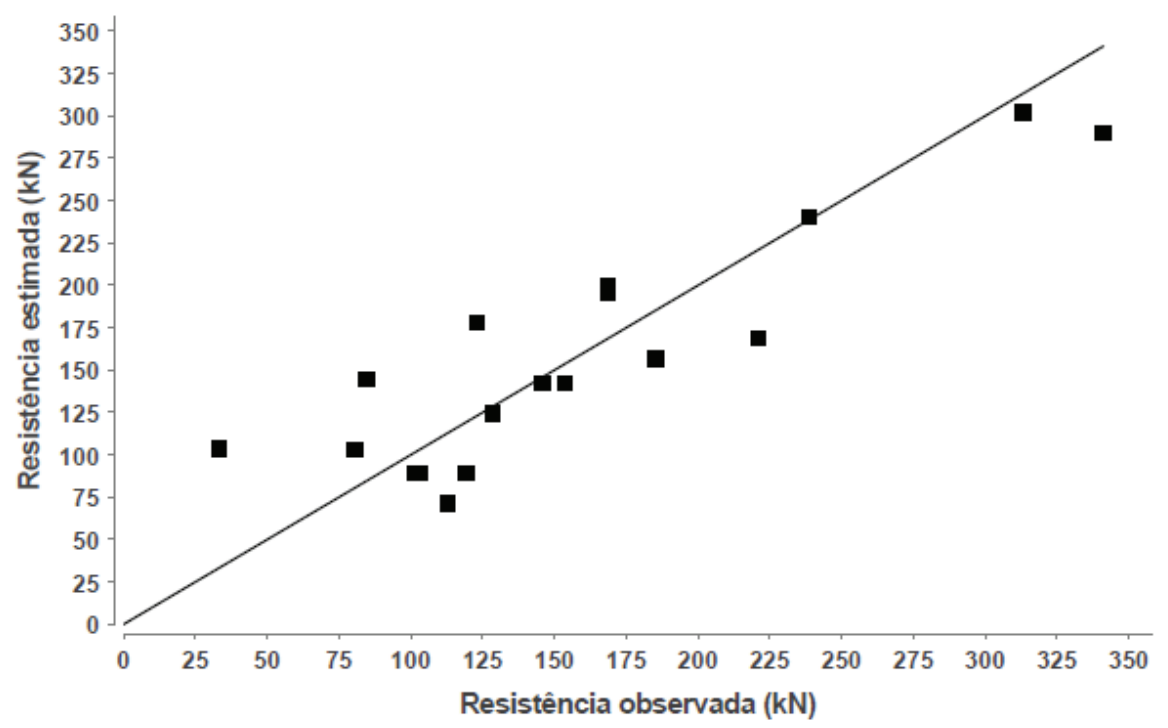

Figura 16: Gráfico de resistência observada versus resistência estimada para situação $A$ utilizando NBR 6122 (2010).

O histograma de resíduos (Figura 17) não possui forma típica de distribuição normal e diversas partes sem resíduos. O gráfico de resíduo padrão versus resistência estimada (Figura 18) possui forma típica de relação não linear e problema de heteroscedasticidade (variância não constante). Pela análise dos resíduos, não seria recomendado utilizar o $M M Q$, mas como valor estimado é próximo da média e mediana, ele continuará a ser a referência, mas com ressalva.

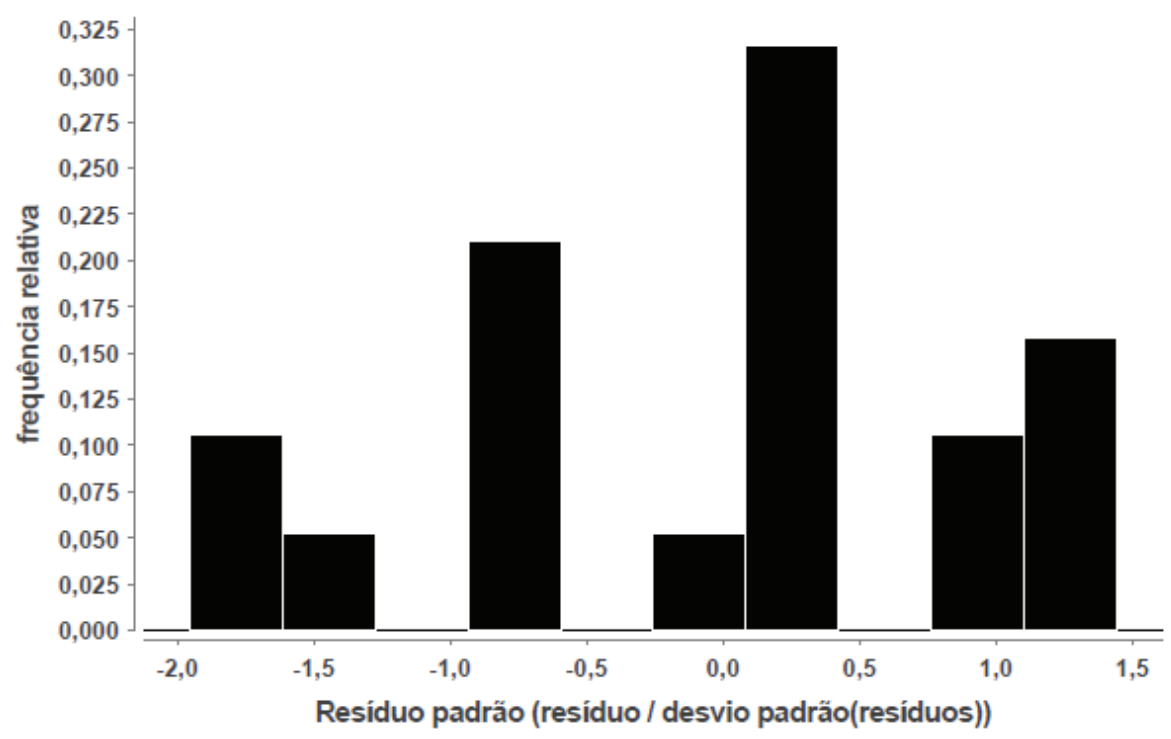

Figura 17: Histograma de resíduo padrão para situação $A$ utilizando NBR 6122 (2010) 


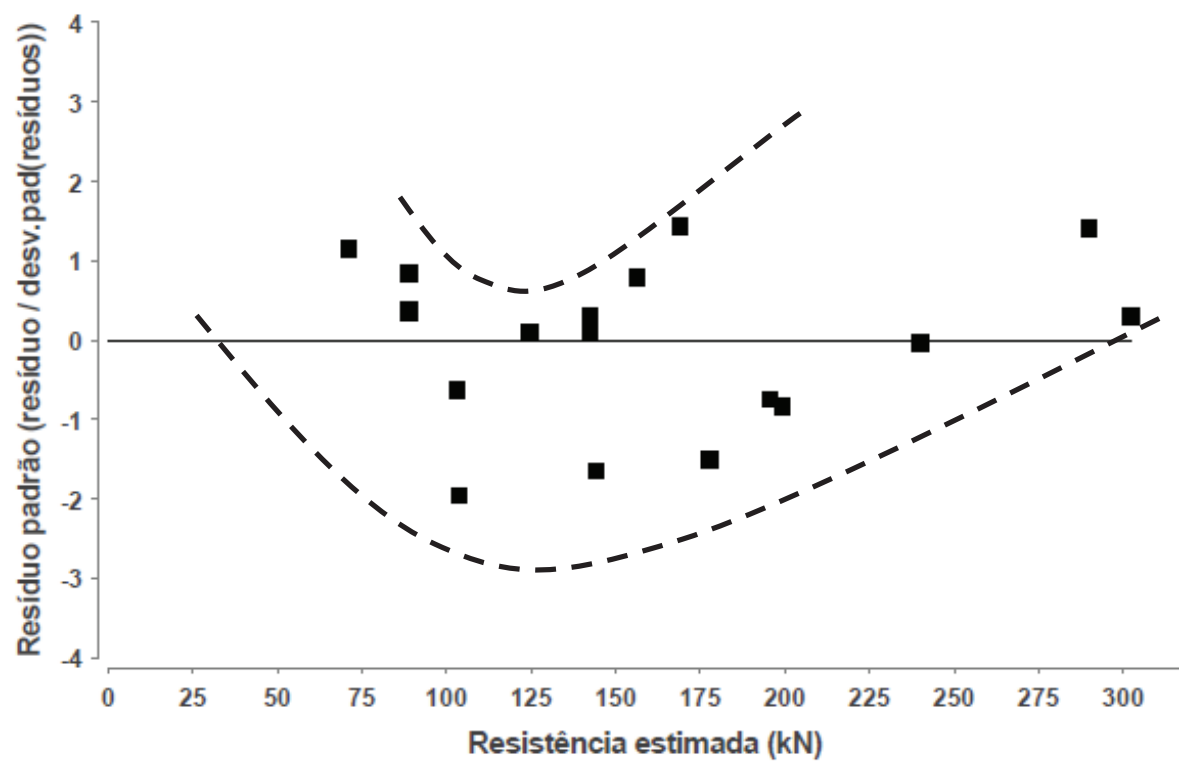

Figura 18: Histograma de resíduo padrão para $A$ utilizando NBR 6122 (2010).

O histograma do BIAS (Figura 19) possui $C V$ igual a 0,49 , valor fortemente influenciado por 3 estacas com BIAS maiores que 1,4. Analisando o gráfico de frequência acumulada (Figura 20) verifica-se que aproximadamente $90 \%$ dos valores são inferiores a 1,25 e a presença do crescimento exponencial desejado em torno de 1.

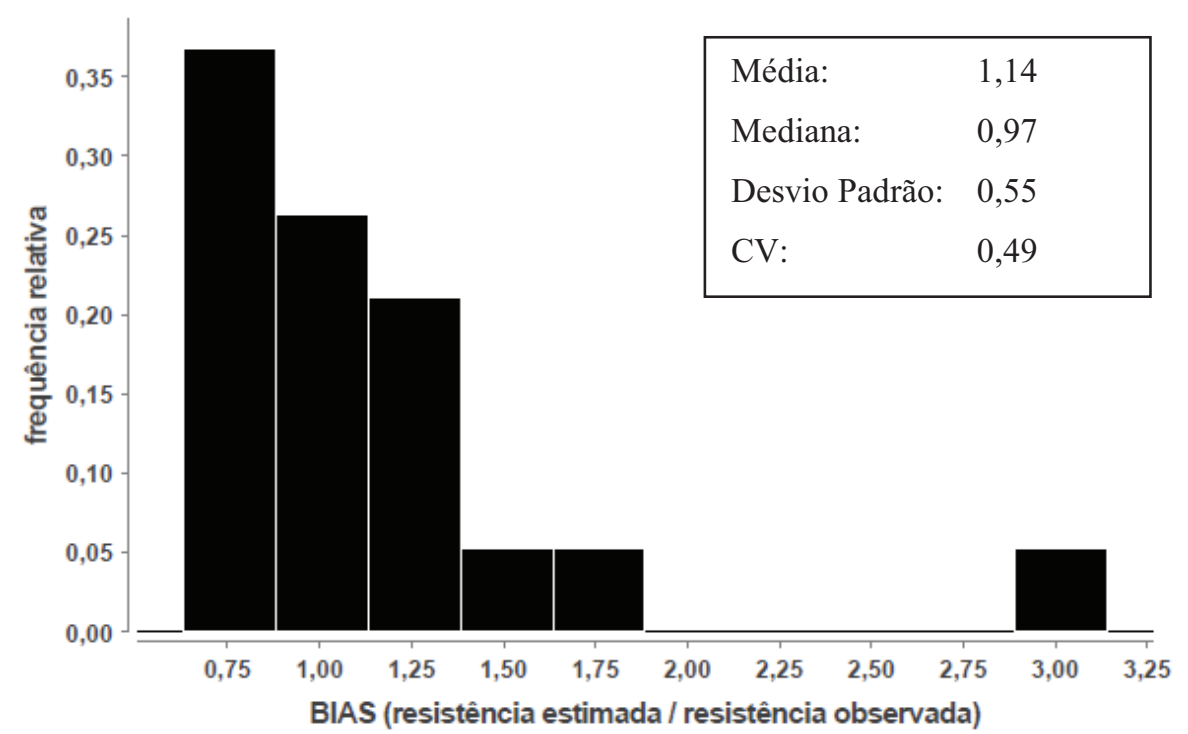

Figura 19: Histograma do BIAS para situação $A$ utilizando NBR 6122 (2010). 


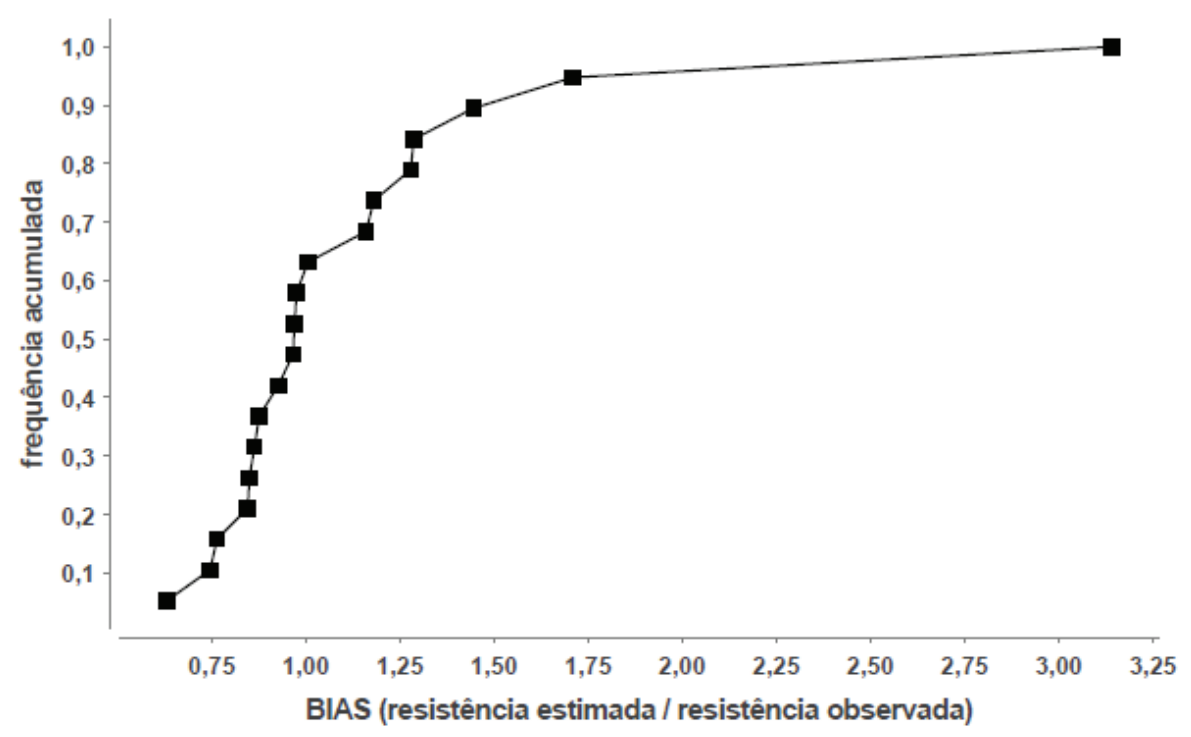

Figura 20: Gráfico de frequência acumulada do BIAS para $A$ utilizando NBR 6122 (2010).

\subsubsection{Estacas com 2, 3 e 4 hélices: situação $B$}

O histograma de $k_{t}$ (Figura 21) é assimétrico. Neste caso, o valor do regressor recomendado é o da mediana $\left(5 \mathrm{~m}^{-1}\right)$.

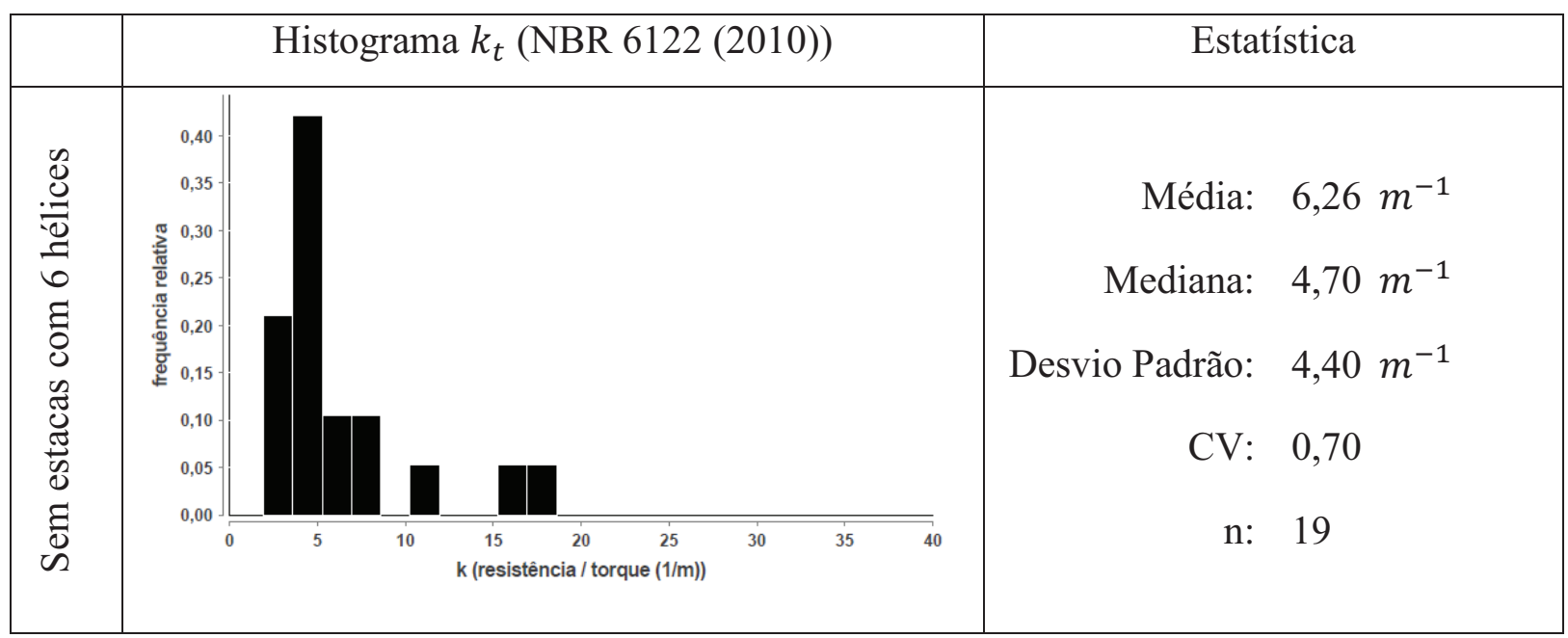

Figura 21: Histogramas de $k_{t}$ utilizando NBR 6122 (2010) para estacas entre 2 e 4 hélices na situação $B$.

No histograma do BIAS (Figura 22), o pico próximo de 1,0 é ligeiramente superior aos demais. A concentração dos valores afastado de 1 aumenta a dispersão, elevando o $C V$. Há o 
crescimento exponencial desejado da frequência acumulada do BIAS no entorno de 1,0 (Figura 23), porém apenas $40 \%$ das estimativas estão a favor da segurança.

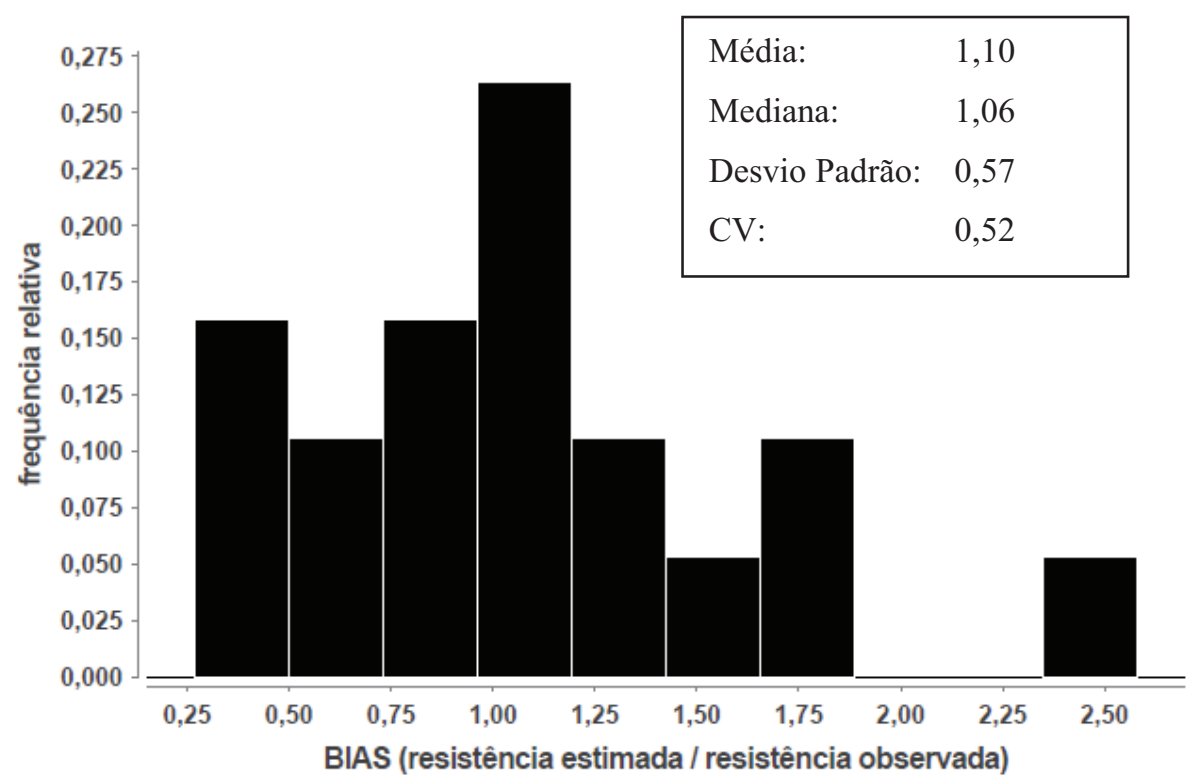

Figura 22: Histogramas do BIAS utilizando NBR 6122 (2010) para estacas entre 2 e 4 hélices na situação $B$.

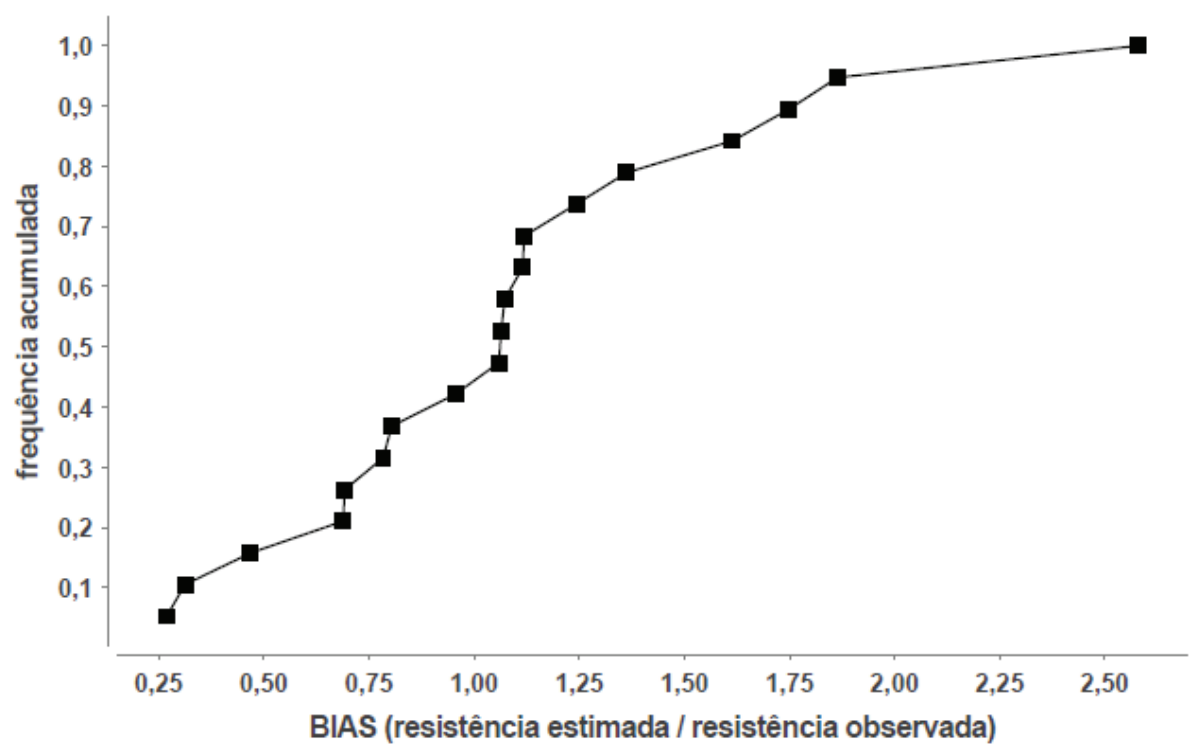

Figura 23: Gráfico de frequência acumulada do BIAS para situação $B$ utilizando NBR 6122 (2010). 


\subsubsection{Estacas com 6 hélices}

Como aconteceu em Davisson (1972), as estacas com 6 hélices apresentaram valores superiores de $k_{t}$, independente da situação de projeto. Neste caso, a variável será estimada pela mediana (19 $\mathrm{m}^{-1}$, vide Figura $14 \mathrm{~d}$.).

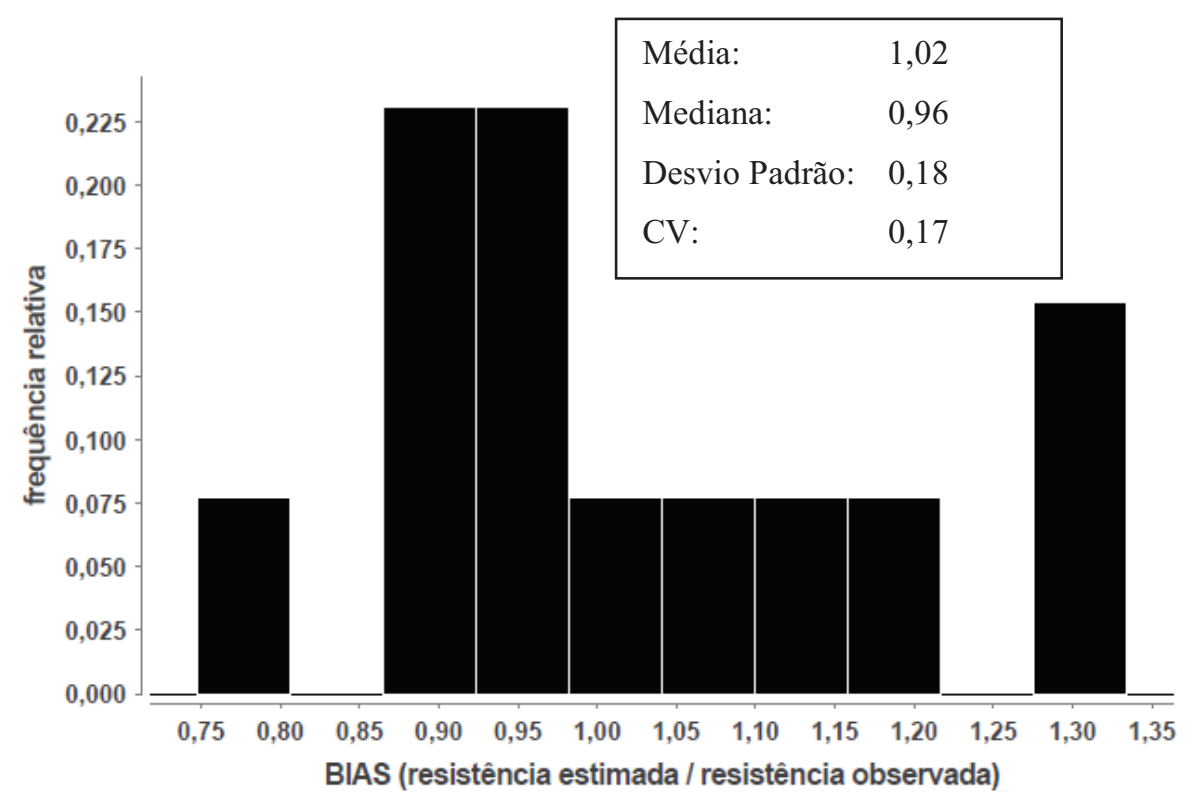

Figura 24: Histogramas do BIAS utilizando NBR 6122 (2010) para estacas com 6 hélices.

O histograma do BIAS (Figura 24) possui baixo $C V(0,17)$, ficando o intervalo de previsão entre 0,75 e 1,35. 


\section{ANEXO II $Q_{u} v s N_{S P T}$ PARA DAVISSON (1972) E NBR 6122 (2010)}

\subsection{DAVISSON (1972)}

\subsubsection{Regressores para estacas com 2, 3 e 4 hélices.}

Os regressores estimados pelo método dos $M M Q$ são apresentados na Tabela 1. A probabilidade de serem nulos para a situação $A$ foi inferior a 3,0e-9.

Tabela 1: Regressores estimados utilizando Davisson (1972).

\begin{tabular}{|r|c|c|c|c|}
\hline & \multicolumn{4}{|c|}{$\alpha_{\boldsymbol{S}}\left(\boldsymbol{k N} / \boldsymbol{m}^{\mathbf{2}}\right)$} \\
\hline & Argila & Silte Argiloso & Silte Arenoso & Areia \\
\hline Situação $\boldsymbol{A}$ & 32 & $16^{*}$ & 24 & 18 \\
\hline Situação $\boldsymbol{B}$ & 32 & 12 & 18 & $14^{*}$ \\
\hline
\end{tabular}

* Regressor estimado com base na situação de projeto oposta devido ao reduzido número de amostras.

Devido à ausência de amostra em solos silte-argiloso na situação $A$ e solos arenosos na situação $B$, o valor adotado dos regressores foi de $16 k N$ e $14 k N$, respectivamente. Eles foram estimados com base na proporção encontrada para solos silte arenosos.

\subsubsection{Estatística da regressão para situação $A$ em estacas com 2, 3 e 4 hélices}

O coeficiente de determinação $\left(R^{2}\right)$ foi de 0,99 , indicando que modelo proposto é capaz de explicar a variação na resistência. O conjunto amostral é de 26 estacas, onde 16 foram utilizadas na regressão e 10 eliminadas por serem outliers - o motivo da elevada quantidade de exclusão é porque o $R^{2}$ assume valores muito próximos de 1,0 e um pequeno desvio é o suficiente para a amostra ser considera um outliers.

O gráfico de resistência observada versus estimada (Figura 25) possui boa aleatoriedade. Por Davisson (1972) ser muito conservador, existem poucos valores de resistência observada superiores a $110 \mathrm{kN}$. Como o $R^{2}$ foi muito elevado, a dispersão dos pontos em relação à reta de referência é baixa. 


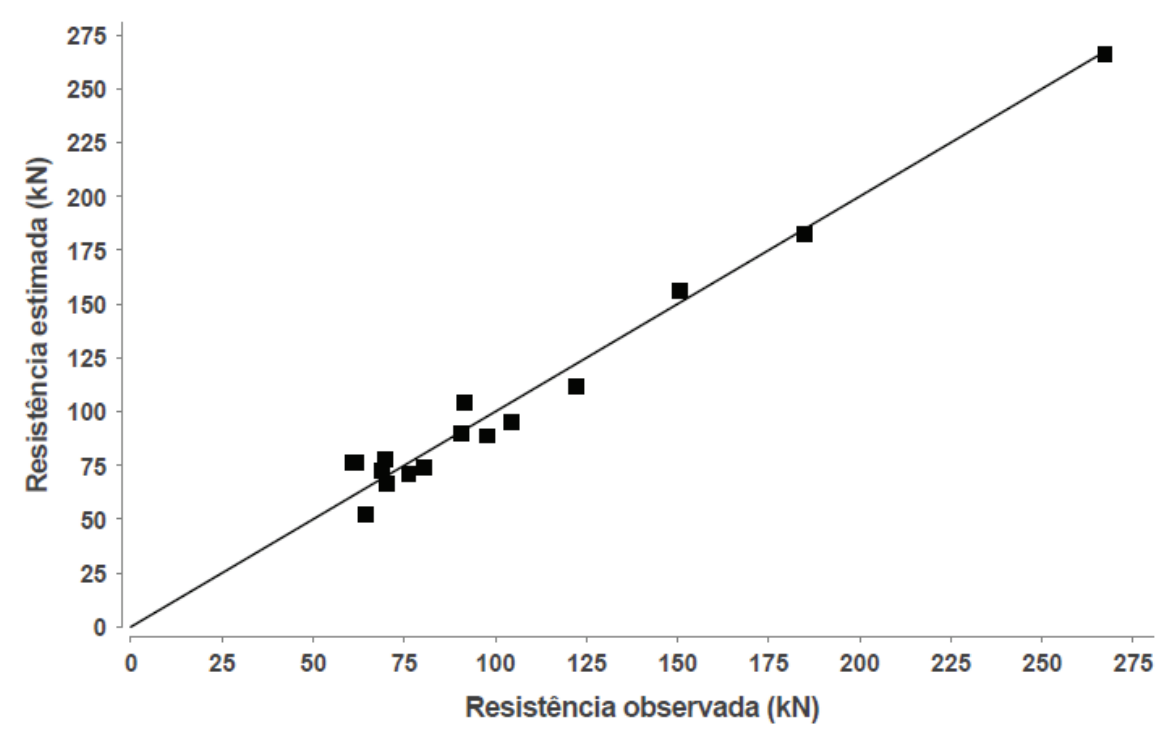

Figura 25: Gráfico de resistência estimada versus resistência observada utilizando Davisson (1972).

No histograma do BIAS (Figura 26), os valores se concentram próximo de 1,0. O CV é baixo $(0,12)$. O valor máximo e mínimo do BIAS é, respectivamente, inferior a 1,25 e superior a 0,80 .

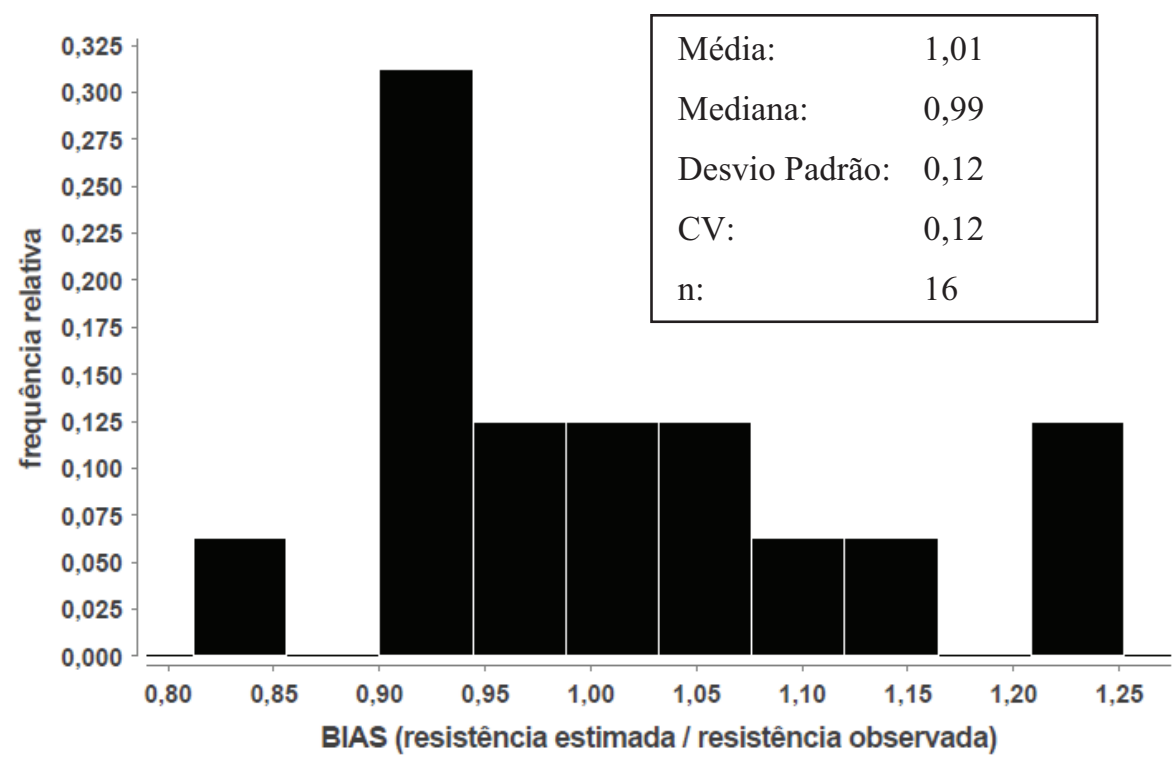

Figura 26: Histograma do BIAS utilizando Davisson (1972).

O histograma de resíduo padrão (Figura 27) não possui forma de distribuição normal e sua moda (pico) não está próxima de 0,0. A forma do gráfico de resíduo padrão versus resistência (Figura 28) é típica de resíduos com heteroscedasticidade. Estes problemas podem estar relacionados à pequena quantidade de amostras para resistências superiores a $110 \mathrm{kN}$. 


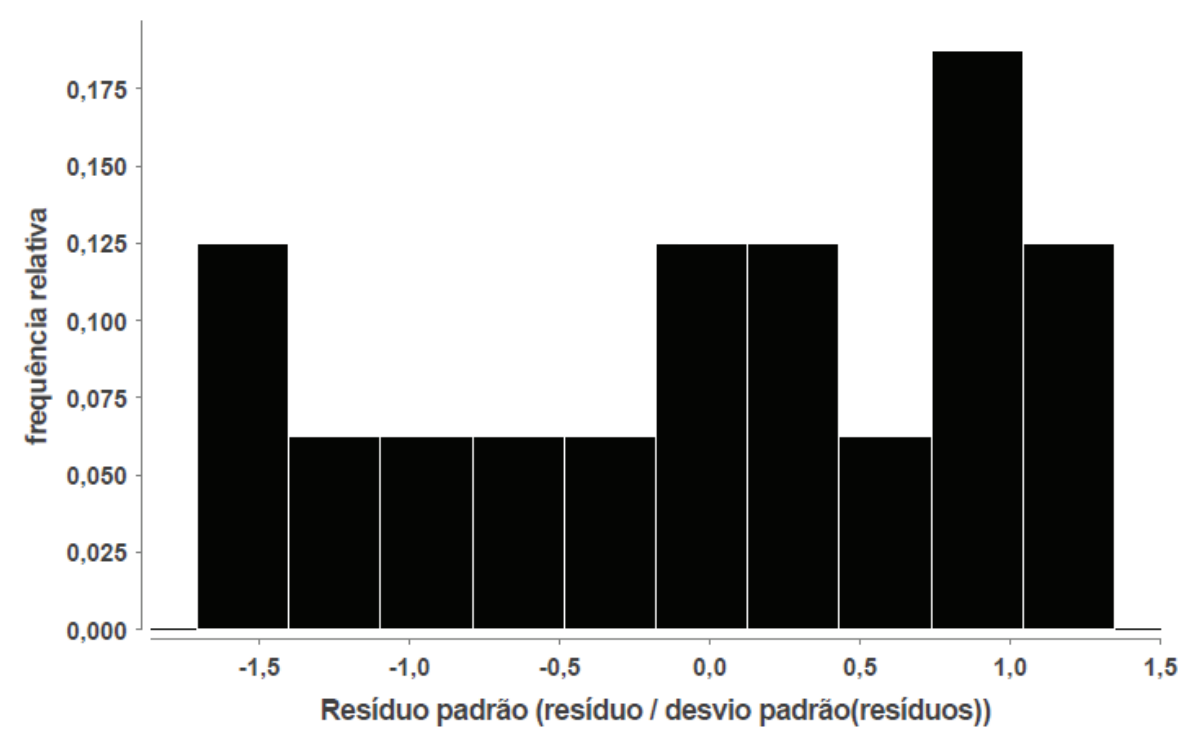

Figura 27: Histograma de resíduo padrão utilizando Davisson (1972).

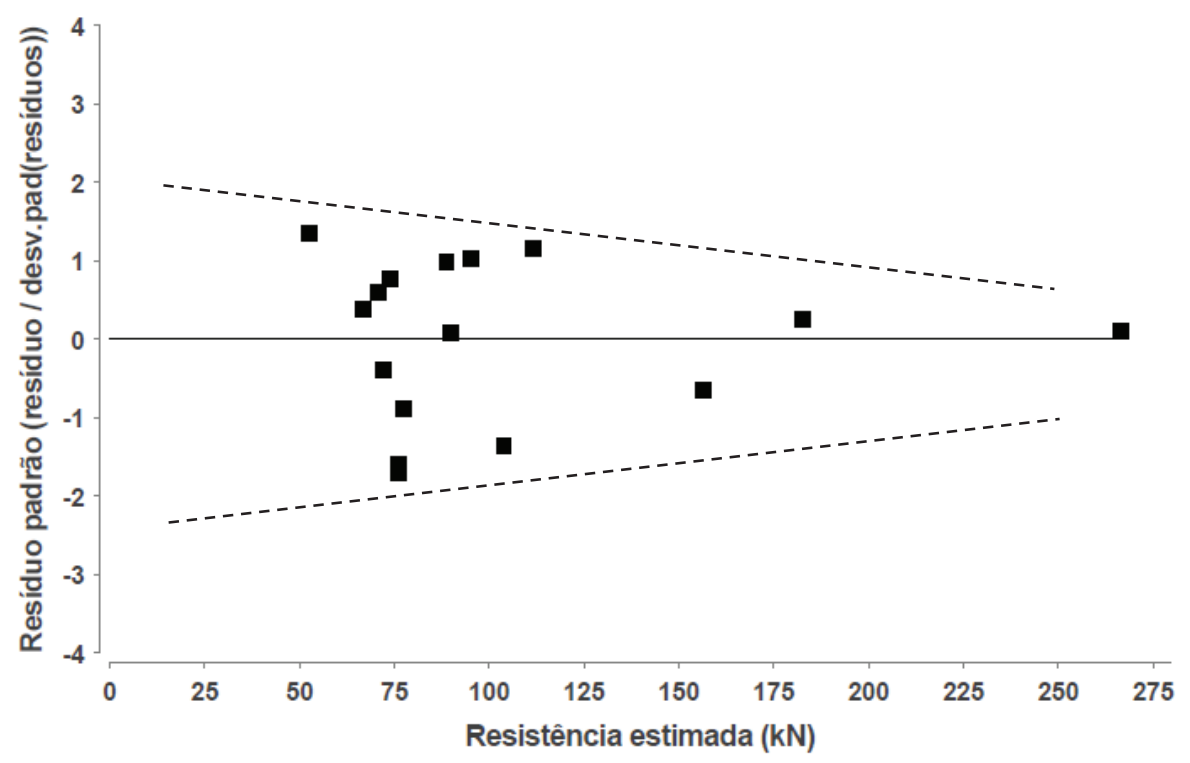

Figura 28: Gráfico de resíduo padrão versus resistência estimada utilizando Davisson (1972).

\subsubsection{Estacas com 6 hélices}

Os regressores da situação $A$ são conservadores para as estacas com 6 hélices. Analisando o histograma do BIAS (Figura 29), verifica-se a existência de apenas uma estaca superestimada. 


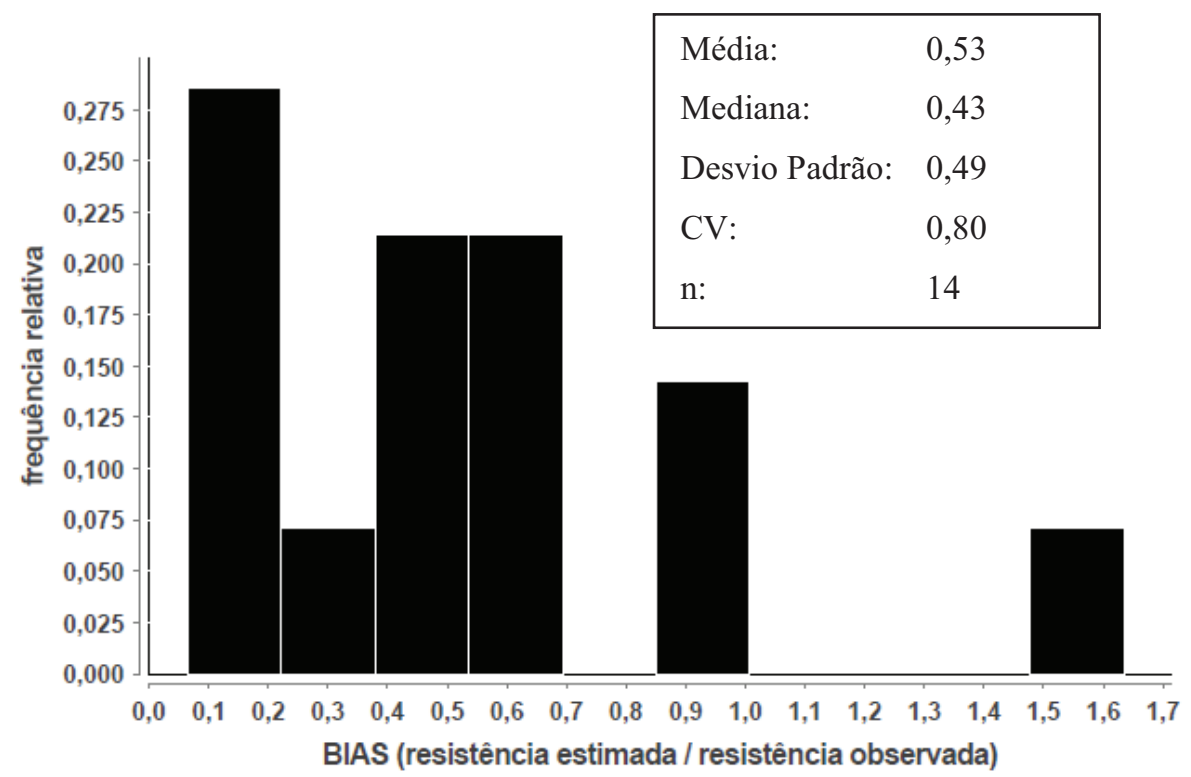

Figura 29: Histograma do BIAS para estacas com 6 hélices para os regressores da situação $A$ utilizando Davisson (1972).

\section{$1.2 \quad$ NBR $6122(2010)$}

\subsubsection{Regressores para estacas com 2, 3 e 4 hélices}

Os regressores estimados pelo método dos $M M Q$ são apresentados na Tabela 2. A probabilidade de serem nulos para a situação $A$ foi inferior a 3,0e-9.

Tabela 2: Regressores estimados utilizando NBR 6122 (2010).

\begin{tabular}{|l|c|c|c|c|}
\hline & \multicolumn{4}{|c|}{$\boldsymbol{\alpha}_{\boldsymbol{S}}\left(\boldsymbol{k N} / \boldsymbol{m}^{\mathbf{2}}\right)$} \\
\hline & Argila & Silte Argiloso & Silte Arenoso & Areia \\
\hline Situação $\boldsymbol{A}$ & 38 & $18^{*}$ & 32 & 36 \\
\hline Situação $\boldsymbol{B}$ & 44 & 16 & 29 & $33^{*}$ \\
\hline
\end{tabular}

* Regressor estimado com base na situação de projeto oposta devido ao reduzido número de amostras.

Devido à ausência de amostra em solos silte-argiloso na situação $A$ e solos arenosos na $B$, o valor adotado dos regressores foi de $18 k N$ e $33 k N$, respectivamente. Eles foram estimados com base na proporção encontrada para solos silte arenosos. 
1.2.2 Estatística da regressão para situação $A$ em estacas com 2, 3 e 4 hélices

O comportamento das estacas helicoidais em Davisson (1972) e NBR (6122) são próximos. O mesmo ocorre na estatística da regressão: o $R^{2}$ é igual 0,99 , o conjunto amostral é composto por 26 estacas, com 10 outliers (as mesmas amostras de Davisson (1972)).

O gráfico de resistência observada versus estimada (Figura 30) possui aleatoriedade desejada. Porém, há poucas amostras para resistências superiores a $160 \mathrm{kN}$. Como o $R^{2}$ é elevado, a dispersão dos pontos em relação à reta de referência é baixa.

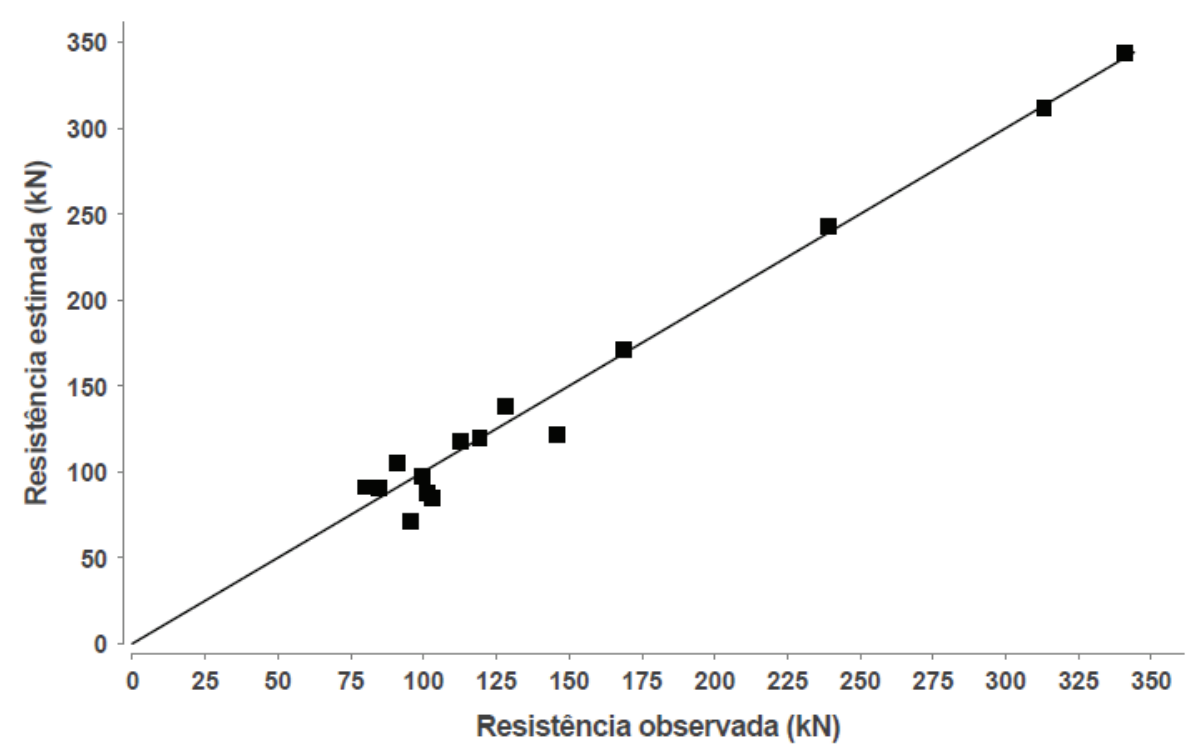

Figura 30: Gráfico de resistência estimada versus resistência observada utilizando NBR 6122 (2010).

O histograma do BIAS (Figura 31) possui o moda, média e mediana próximas de 1,0 e baixo $C V$. O valor máximo e mínimo são, respectivamente, 1,15 e 0,75. 


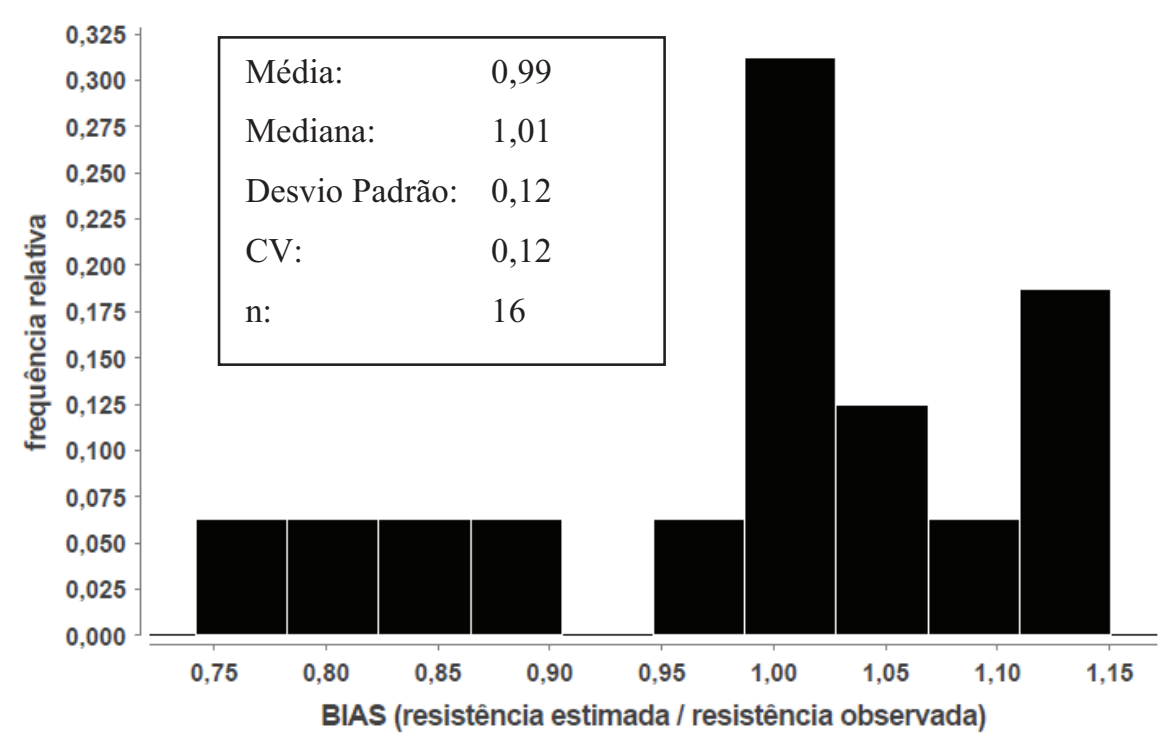

Figura 31: Histograma do BIAS utilizando NBR 6122 (2010).

O histograma de resíduo padrão (Figura 32) não possui forma de distribuição normal e sua moda não está próxima de zero. A análise do gráfico de resíduo padrão versus resistência estimada (Figura 33) permite concluir que existe heteroscedasticidade. Estes problemas podem estar relacionados à pequena quantidade de amostras para resistências superiores a $160 \mathrm{kN}$.

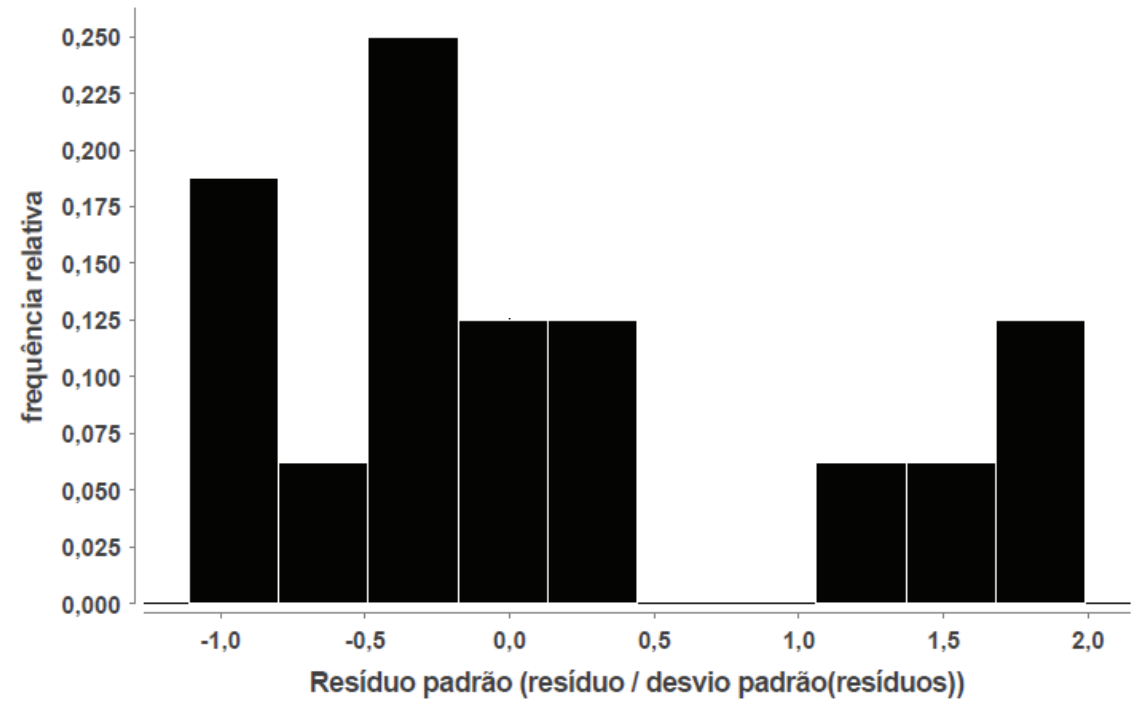

Figura 32: Histograma de resíduo padrão utilizando NBR 6122 (2010). 


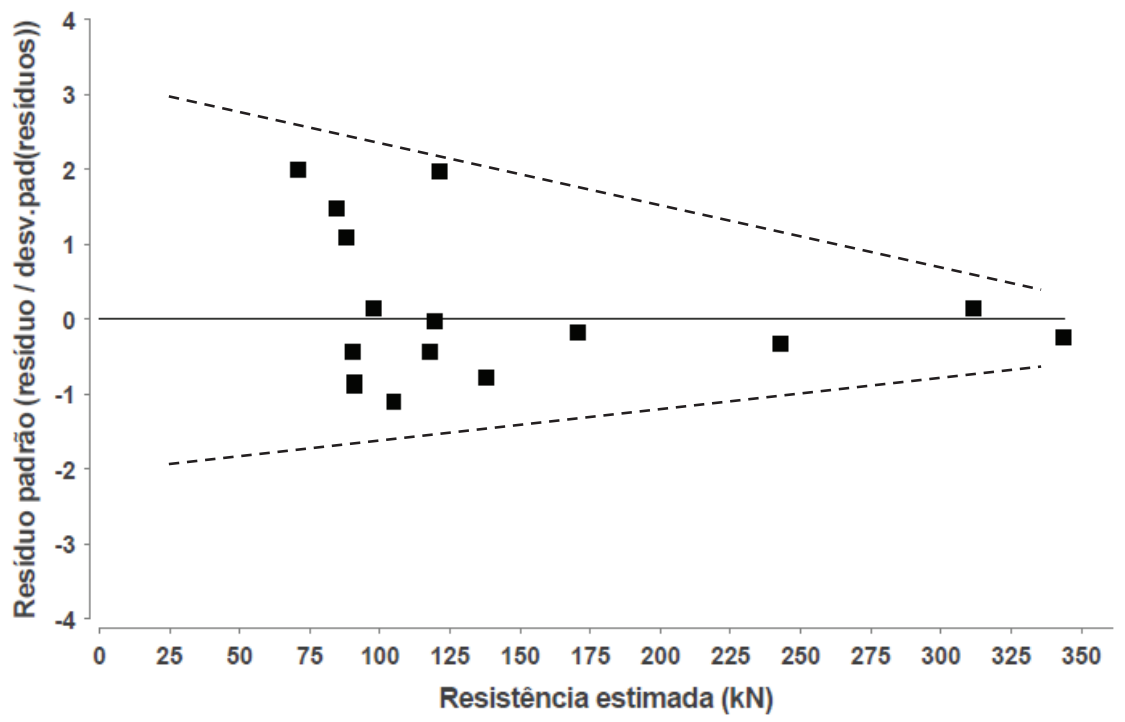

Figura 33: Gráfico de resíduo padrão versus resistência estimada utilizando NBR 6122 (2010).

\subsubsection{Estacas com 6 hélices}

Os regressores da situação $A$ são conservadores para as estacas com 6 hélices. Analisando o histograma do BIAS (Figura 34), verificam-se a existência de apenas 3 estacas superestimadas, todas $N_{S P T}$ da primeira hélice superiores a 44 .

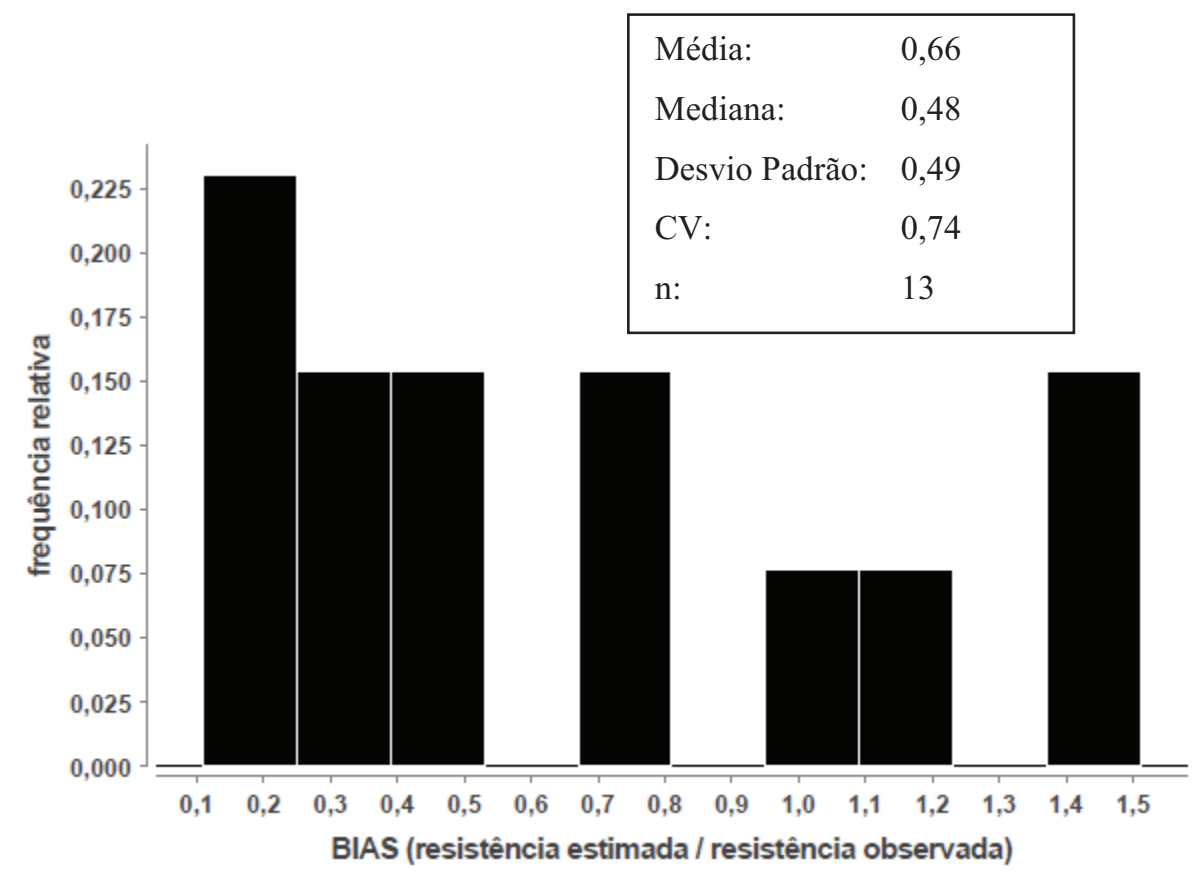

Figura 34: Histograma do BIAS para estacas com 6 hélices para os regressores da situação de projeto utilizando NBR 6122 (2010). 


\section{ANEXO III EXEMPLO DE RELATÓRIO DO MÓDULO CALCULADORA}




\section{ANEXO IV EXEMPLO DE RELATÓRIO DO MÓDULO SOLVER}


ANEXO V BASE DE DADOS 


\section{ANEXO III EXEMPLO DE RELATÓRIO DO MÓDULO CALCULADORA}




\section{MEMÓRIA DE CÁLCULO: VCASTANHAL138-1 (60)}

\subsection{Dados}

Carga de Projeto $(\mathrm{kN}):$ : 132.83

Helice (m): : 0.30, 0.36

Fuste: : Circular Vazada $-0.07 \mathrm{~m}$

Inclinação $\left(^{\circ}\right):$ : 40.00

Core RP : Helicoidal somente $\alpha$

Core RL : Helicoidal somente $\alpha$

Fator de correção : Livneh e Naggar (2008)

\subsection{SPT e Torque}

\begin{tabular}{cc}
\hline \multicolumn{2}{c}{ Torque } \\
\hline $\begin{array}{c}\text { Profundidade } \\
(\mathrm{kN} . \mathrm{m})\end{array}$ & Torque (kN.m) \\
\hline 1.15 & 1.36 \\
\hline 1.53 & 1.36 \\
\hline 1.92 & 1.36 \\
\hline 2.30 & 2.71 \\
\hline 2.68 & 2.71 \\
\hline 3.06 & 4.07 \\
\hline 3.45 & 6.78 \\
\hline 3.83 & 6.78
\end{tabular}

\begin{tabular}{ccc}
\hline & \multicolumn{2}{c}{ SPT } \\
\hline Profundidade $(\mathrm{m})$ & Nspt & \multicolumn{1}{c}{ Solo } \\
\hline 1.00 & 4.00 & Argila arenosa \\
\hline 2.00 & 2.00 & Argila arenosa \\
\hline 3.00 & 20.00 & Argila siltosa \\
\hline 4.00 & 23.00 & Argila siltosa \\
\hline 5.00 & 25.00 & Argila siltosa \\
\hline 6.00 & 32.00 & Argila siltosa \\
\hline 7.00 & 26.00 & Argila arenosa \\
\hline 8.00 & 31.00 & Argila arenosa \\
\hline 9.00 & 38.00 & Argila arenosa \\
\hline 10.00 & 39.00 & Argila arenosa
\end{tabular}

\subsection{Variáveis do modelo}

\begin{tabular}{|r|c|c|c|c|}
\hline \multicolumn{1}{|c|}{ Projeto } & Argila & Silte argiloso & Silte Arenoso & Areia \\
\hline$\alpha(\mathrm{kPa})$ & 36.00 & 31.00 & 51.00 & 72.00 \\
\hline$\beta(\mathrm{kPa})$ & 0.00 & 0.00 & 0.00 & 0.00 \\
\hline $\mathrm{K}(1 / \mathrm{m})$ & \multicolumn{4}{|c|}{21.00} \\
\hline
\end{tabular}

\begin{tabular}{|r|c|c|c|c|}
\hline Não Projeto & Argila & Silte argiloso & Silte Arenoso & Areia \\
\hline$\alpha(\mathrm{kPa})$ & 55.00 & 31.00 & 62.00 & 72.00 \\
\hline$\beta(\mathrm{kPa})$ & 0.00 & 0.00 & 0.00 & 0.00 \\
\hline $\mathrm{K}(1 / \mathrm{m})$ & \multicolumn{4}{|c|}{8.00} \\
\hline
\end{tabular}

\subsection{Gráficos}




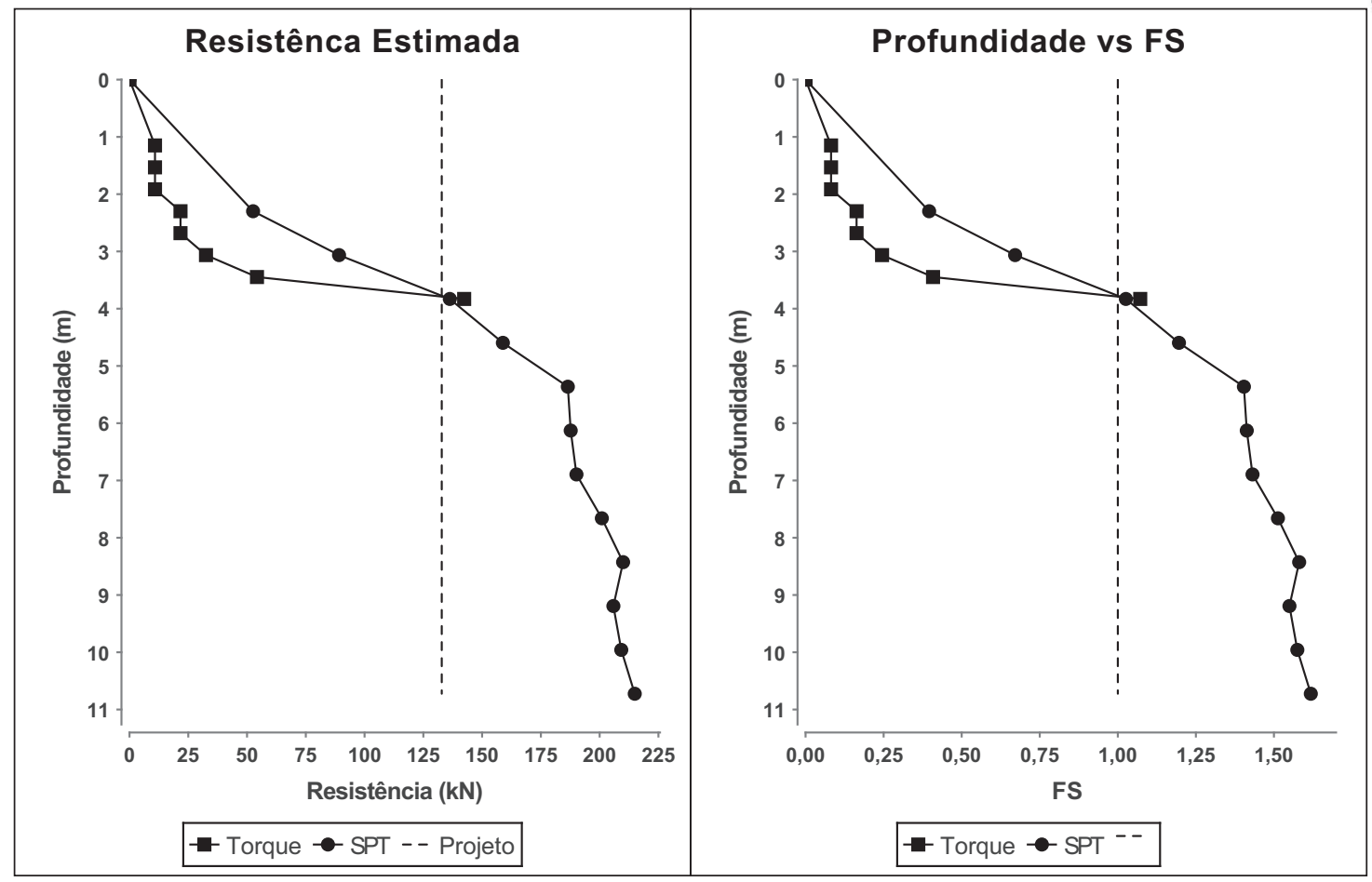

\subsection{Memória Cálculo SPT}

\begin{tabular}{|c|c|c|c|c|}
\hline Prof $(\mathrm{m})$ & Situação de projeto & $\mathrm{R}(\mathrm{kN})$ & fc & R corrigido $(\mathrm{kN})$ \\
\hline 2.30 & Não recomendada & 52.57 & 1.00 & 52.57 \\
\hline 3.06 & Não recomendada & 89.14 & 1.00 & 89.14 \\
\hline 3.83 & Recomendada & 87.19 & 0.64 & 136.26 \\
\hline 4.60 & Recomendada & 117.74 & 0.74 & 158.84 \\
\hline 5.36 & Recomendada & 144.53 & 0.78 & 186.47 \\
\hline 6.13 & Recomendada & 157.01 & 0.87 & 187.69 \\
\hline 6.89 & Recomendada & 164.47 & 0.86 & 20.13 \\
\hline 7.66 & Recomendada & 172.16 & 0.86 & 200.93 \\
\hline 8.43 & Recomendada & 181.50 & 0.95 & 209.97 \\
\hline 9.19 & Recomendada & 194.97 & 1.01 & 205.85 \\
\hline 9.96 & Recomendada & 211.37 & 1.04 & 214.93 \\
\hline 10.72 & Recomendada & 223.29 & & \\
\hline
\end{tabular}

\begin{tabular}{|c|c|c|c|c|c|c|c|c|}
\hline Prof $(\mathrm{m})$ & $\mathrm{rl}(\mathrm{kPa})$ & $\mathrm{rp} 1(\mathrm{kPa})$ & $\mathrm{rp} 2(\mathrm{kPa})$ & $\mathrm{RP} 1(\mathrm{kN})$ & $\mathrm{RP} 2(\mathrm{kN})$ & $\mathrm{RP}(\mathrm{kN})$ & $\mathrm{RL}(\mathrm{kN})$ & $\mathrm{R}(\mathrm{kN})$ \\
\hline 2.30 & 0.00 & 456.94 & 222.24 & 31.43 & 21.14 & 52.57 & 0.00 & 52.57 \\
\hline 3.06 & 0.00 & 716.73 & 418.86 & 49.30 & 39.85 & 89.14 & 0.00 & 89.14 \\
\hline 3.83 & 0.00 & 665.64 & 435.31 & 45.78 & 41.41 & 87.19 & 0.00 & 87.19 \\
\hline 4.60 & 0.00 & 847.86 & 624.70 & 58.32 & 59.43 & 117.74 & 0.00 & 117.74 \\
\hline 5.36 & 0.00 & 958.17 & 826.50 & 65.90 & 78.62 & 144.53 & 0.00 & 144.53 \\
\hline 6.13 & 0.00 & 987.12 & 936.81 & 67.89 & 89.12 & 157.01 & 0.00 & 157.01 \\
\hline 6.89 & 0.00 & $1,033.40$ & 981.78 & 71.08 & 93.40 & 164.47 & 0.00 & 164.47 \\
\hline 7.66 & 0.00 & $1,088.55$ & $1,022.72$ & 74.87 & 97.29 & 172.16 & 0.00 & 172.16 \\
\hline 8.43 & 0.00 & $1,148.03$ & $1,077.87$ & 78.96 & 102.54 & 181.50 & 0.00 & 181.50 \\
\hline 9.19 & 0.00 & $1,267.54$ & $1,133.03$ & 87.18 & 107.78 & 194.97 & 0.00 & 194.97 \\
\hline 9.96 & 0.00 & $1,352.02$ & $1,244.39$ & 92.99 & 118.38 & 211.37 & 0.00 & 211.37 \\
\hline 10.72 & 0.00 & $1,396.20$ & $1,337.78$ & 96.03 & 127.26 & 223.29 & 0.00 & 223.29 \\
\hline
\end{tabular}




\subsection{Memória Cálculo Torque}

\begin{tabular}{|c|c|c|c|c|}
\hline Prof $(\mathrm{m})$ & Situação & K $(1 / \mathrm{m})$ & Torque $(\mathrm{kN} . \mathrm{m})$ & Resistência $(\mathrm{kN})$ \\
\hline 1.15 & Não recomendada & 8.00 & 1.36 & 10.85 \\
\hline 1.53 & Não recomendada & 8.00 & 1.36 & 10.85 \\
\hline 1.92 & Não recomendada & 8.00 & 1.36 & 10.85 \\
\hline 2.30 & Não recomendada & 8.00 & 2.71 & 21.69 \\
\hline 2.68 & Não recomendada & 8.00 & 2.71 & 21.69 \\
\hline 3.06 & Não recomendada & 8.00 & 4.07 & 32.54 \\
\hline 3.45 & Não recomendada & 8.00 & 6.78 & 54.23 \\
\hline 3.83 & Recomendada & 21.00 & 6.78 & 142.36 \\
\hline
\end{tabular}




\section{ANEXO IV EXEMPLO DE RELATÓRIO DO MÓDULO SOLVER}




\title{
1. CONSIDERAÇÕES SOBRE ANÁLISE DA REGRESSÃO
}

\subsection{Configuração}

\author{
Modelo : Spt x Ru Hipótese 1 \\ Prova de carga : Tração \\ Interpretação : D/10 \\ Tipo Nspt : Corrigido \\ Hélices/estaca :2,3,4 \\ Seção das hélices : Circular
}

\author{
Unidade \\ Força : $\mathrm{kN}$ \\ Área : $\mathrm{m} 2$ \\ Comprimento : $\mathrm{m}$ \\ Tensão : $\mathrm{kPa}$ \\ Torque :kN.m \\ Ângulo : ${ }^{\circ}$
}

\subsection{Solo}

$\begin{array}{lll}\text { ( X ) Areia (1) } & \text { ( X ) Areia siltosa (12) } & \text { ( X ) Areia silto argilosa (123) } \\ \text { ( X ) Areia argilosa (13) } & \text { ( X ) Areia argilo siltosa (132) } & \text { ( X ) Silte arenoso (21) } \\ \text { ( X ) Silte areno argiloso (213) } & \text { ( X ) Silte (2) } & \text { ( X ) Silte argilo arenoso (231) } \\ \text { ( X ) Silte argiloso (23) } & \text { ( X ) Argila arenosa (31) } & \text { ( X ) Argila silto arenosa (321) } \\ \text { ( X ) Argila areno siltosa (312) } & \text { ( X ) Argila siltosa (32) } & \text { ( X ) Argila (3) } \\ \text { * Caso todos os solos sejam selecionados o sistema desconsiderará este filtro. } & \end{array}$

\subsection{Resumo}

Tamanho da amostra :22

Outliers : 2
Areia : 4

Silte Arenoso : 6

Silte Argiloso : 6

Argila : 6

Outros : 0

\subsection{Siglas}

\author{
C : Circular \\ $\mathrm{CV}$ : Circular vazada \\ Q : Quadrada \\ $\mathrm{R}$ : Retangular \\ $\mathrm{RV}$ : Retangular vazada
}




\section{ANÁLISE DA REGRESSÃO}

\subsection{Modelo}

$$
\mathrm{Ru}=\Sigma \alpha . \text { Nmed.Ae }+\Sigma \beta \text {.N.L.U }+\varepsilon
$$

\subsection{Regressão}

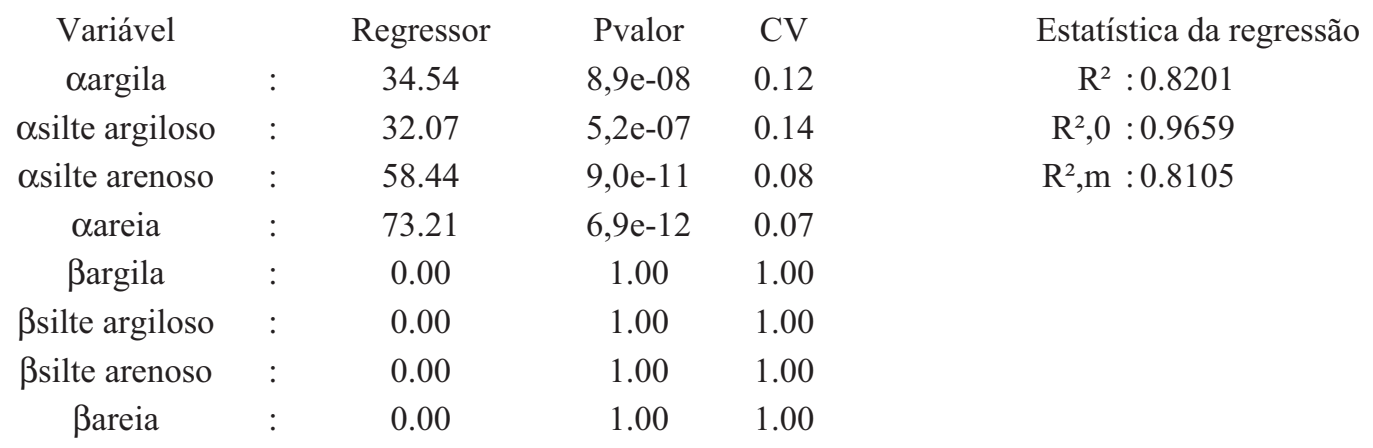

\subsection{Matriz correlação}

\begin{tabular}{|c|c|c|c|c|c|}
\hline & $\alpha$ argila & $\alpha$ silte argiloso & $\alpha$ silte arenoso & $\alpha$ areia & $\mathrm{Y}$ \\
\hline$\alpha$ argila & 1.0000 & & & & \\
\hline$\alpha$ silte argiloso & -0.3317 & 1.0000 & & & \\
\hline$\alpha$ silte arenoso & -0.3257 & -0.3379 & 1.0000 & & \\
\hline$\alpha$ areia & -0.0655 & -0.2555 & -0.2509 & 1.0000 & \\
\hline $\mathrm{Y}$ & 0.0125 & -0.3737 & 0.2261 & 0.7898 & 1.0000 \\
\hline
\end{tabular}

\subsection{Anova}

\begin{tabular}{|c|c|c|c|c|c|}
\hline & SS & GL & MS & F & P \\
\hline$R$ & $1,5 \mathrm{e}+06$ & 4 & $3,8 \mathrm{e}+05$ & 127.51 & $6,0 \mathrm{e}-13$ \\
\hline $\mathrm{E}$ & $5,4 \mathrm{e}+04$ & 18 & $3,0 \mathrm{e}+03$ & & \\
\hline$T$ & $1,6 \mathrm{e}+06$ & & & & \\
\hline
\end{tabular}




\subsection{Ycalc vs Yobs}

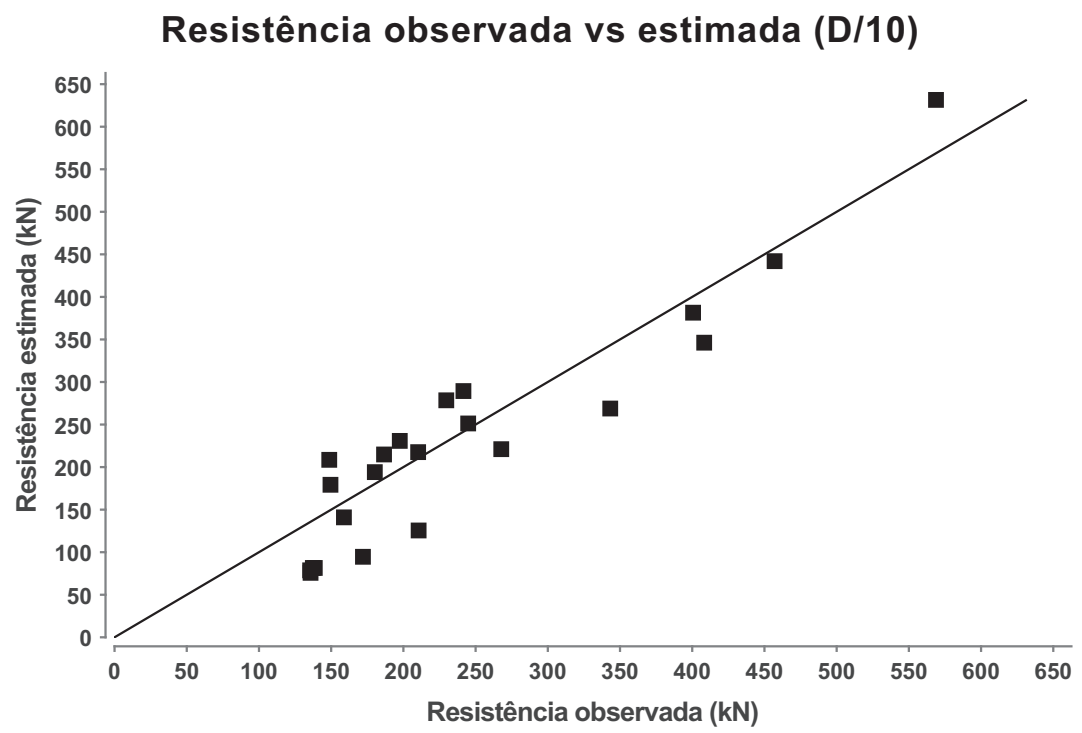

2.6. BIAS

Média : 0.92

Desvio Padrão : 0.26

CV : 0.28

Mediana : 0.96

Histograma do BIAS (D/10)

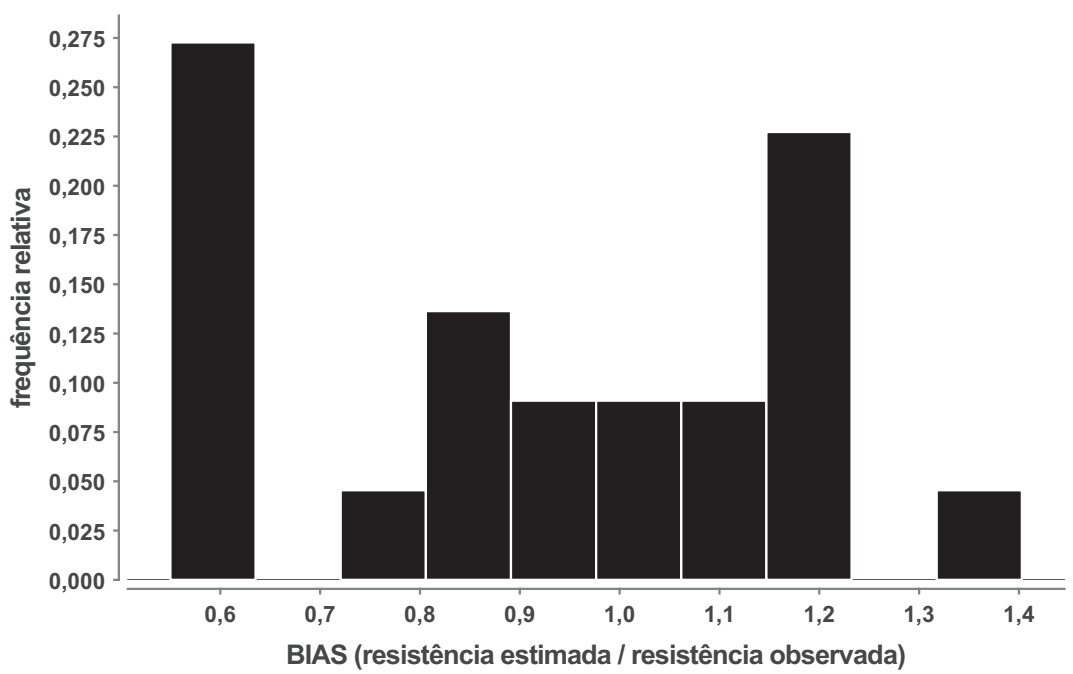




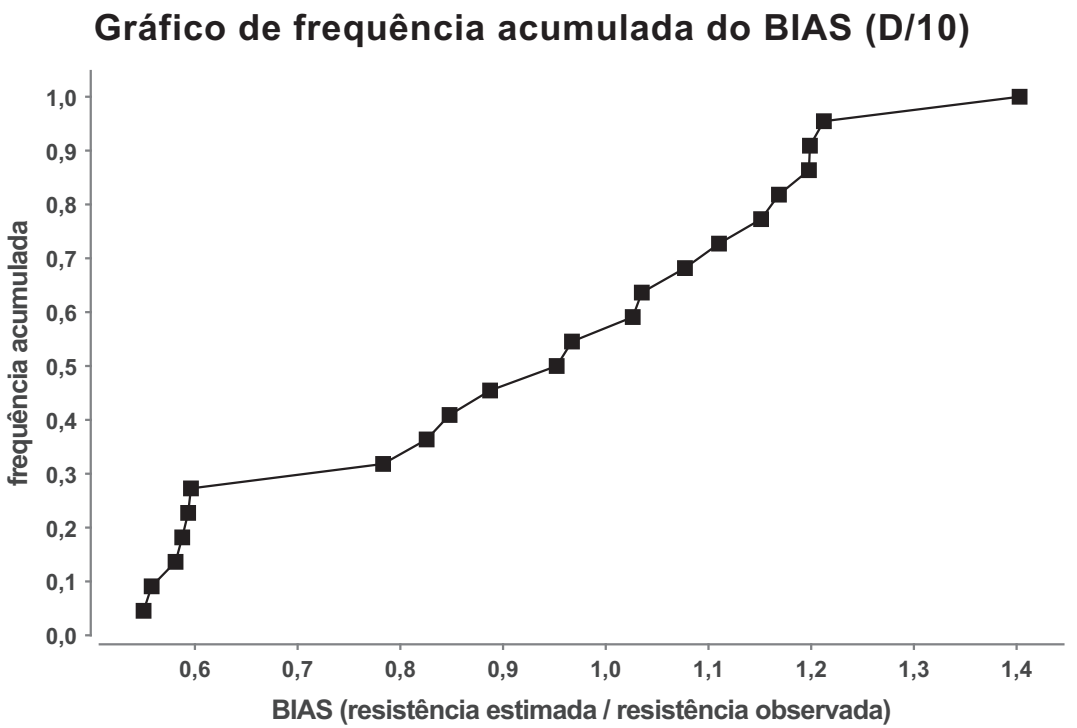

2.7. Resíduos

Histograma resíduo padrão (D/10)

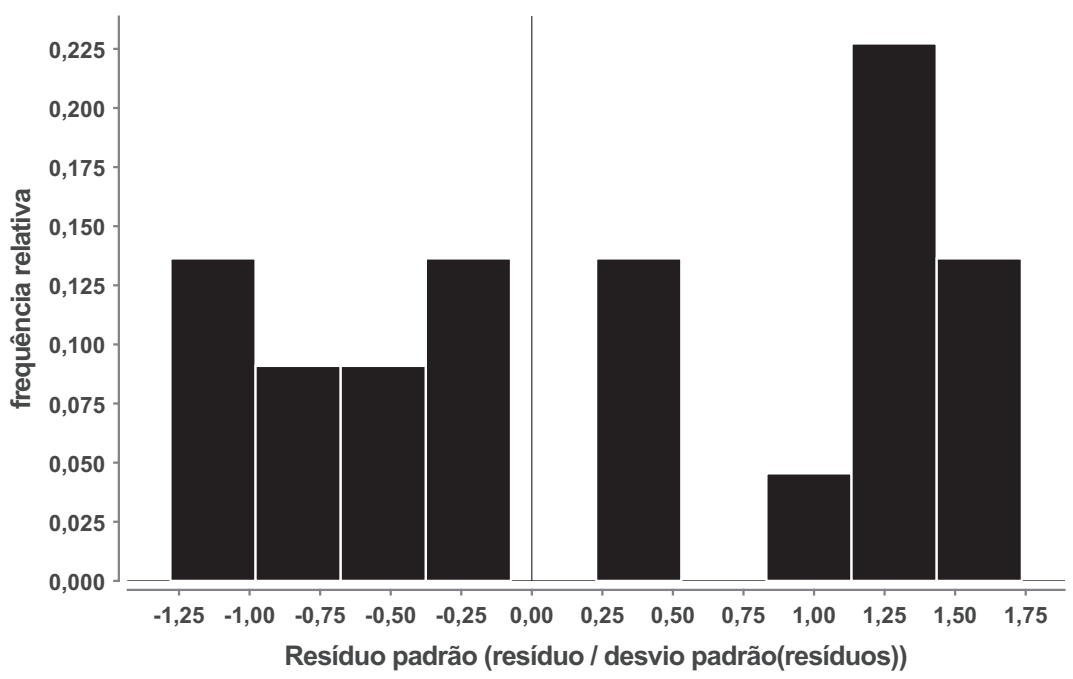

Resistência estimada vs Resíduo padrão (D/10)

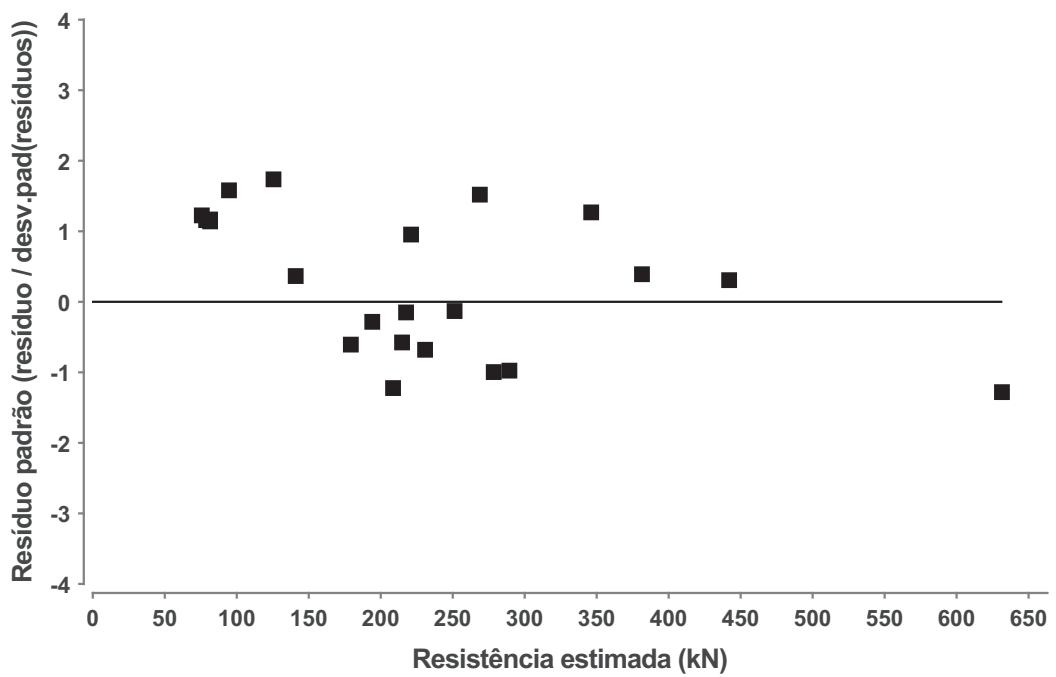




\section{ANÁLISE RESUMIDA DO K}

\subsection{Resultado}

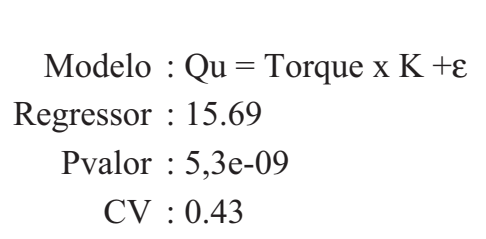

Estatística do $\mathrm{K}$

Média : 18.74

Mediana : 19.05

Desvio Padrão : 7.98

$\mathrm{R}^{2}: 0.82$

\subsection{Gráfico K vs T}

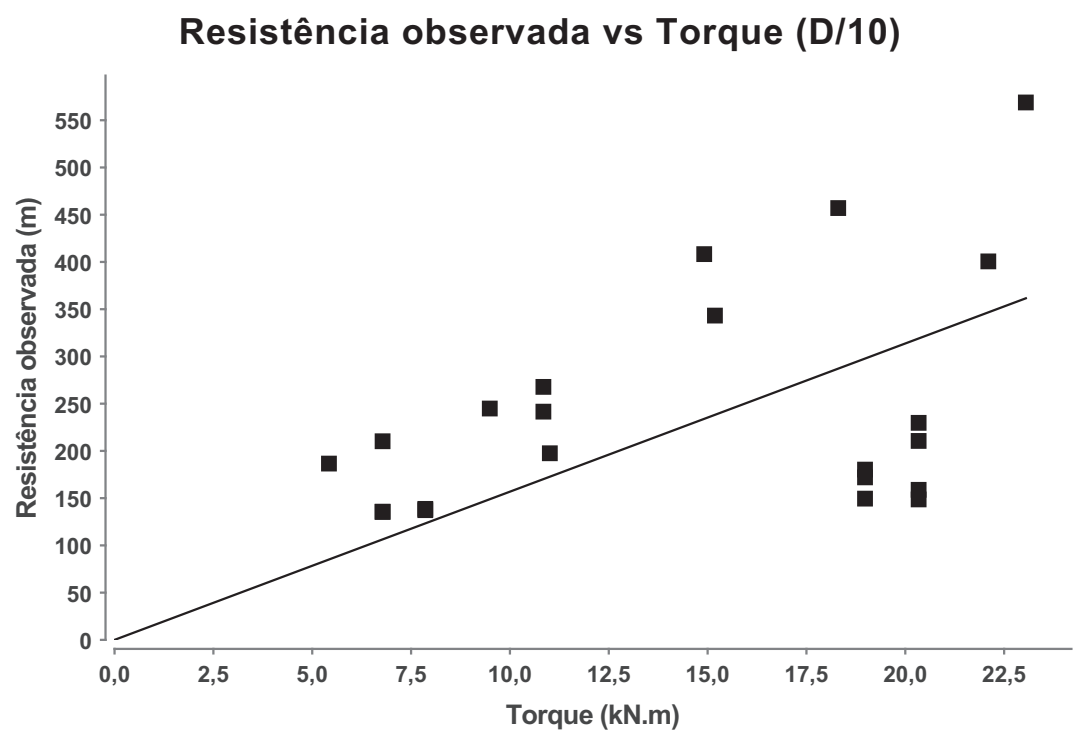

\subsection{Gráfico Ycalc vs Yobs}

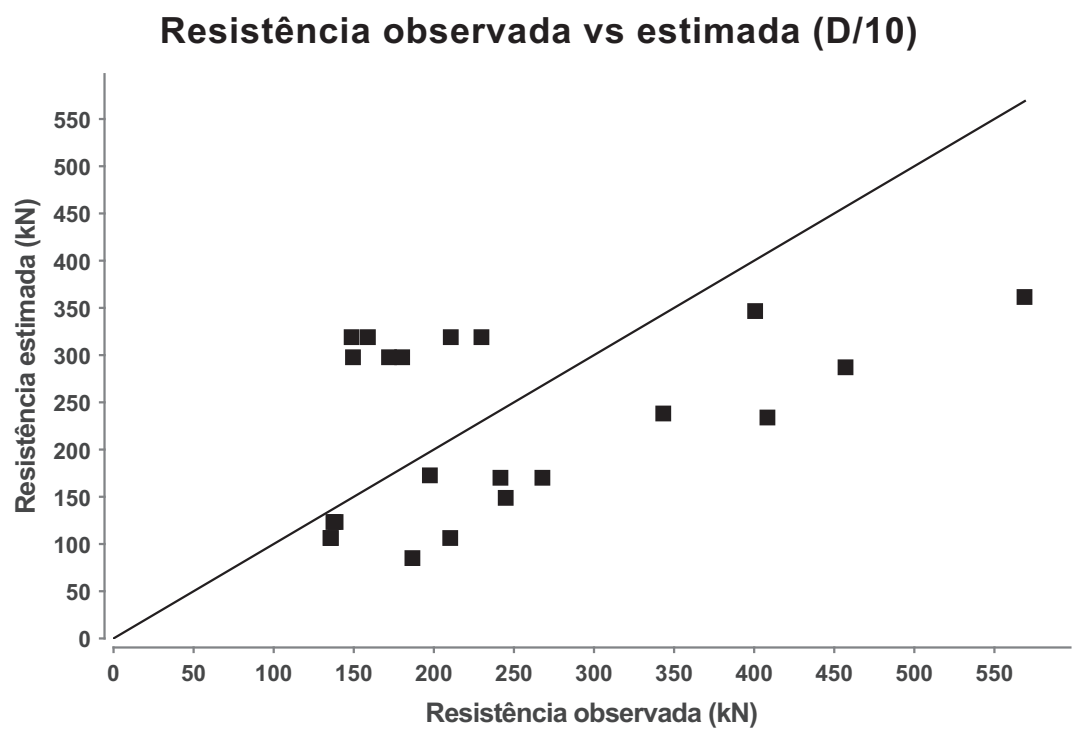




\subsection{Histograma}

Histograma k (D/10)

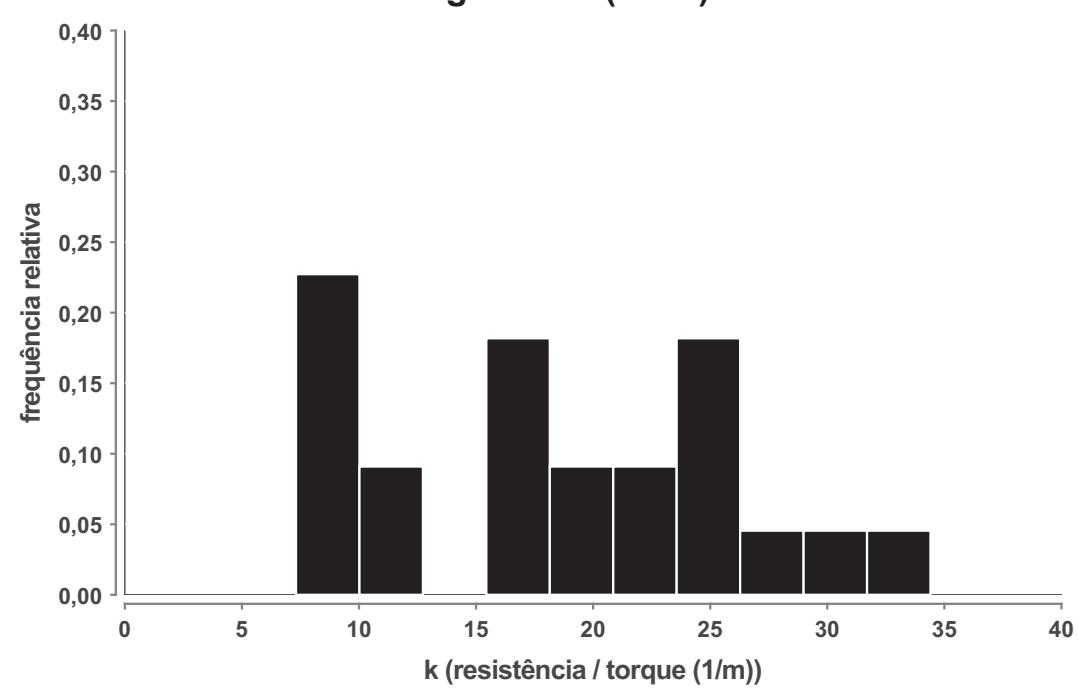

\subsection{Resumo}

\begin{tabular}{|c|c|c|c|c|c|c|c|c|}
\hline Estaca & $\mathrm{L}$ & $\mathrm{Dm}$ & $\mathrm{n}$ & $\mathrm{SPT} \mathrm{h} 1$ & Dext & Torque & $\mathrm{Qu}$ & $\mathrm{k}$ \\
\hline 1 & 5.70 & 0.33 & 2 & 24.20 & 0.07 & 6.78 & 210.22 & 31.01 \\
\hline 2 & 5.30 & 0.29 & 3 & 23.40 & 0.07 & 5.42 & 186.60 & 34.41 \\
\hline 3 & 5.90 & 0.29 & 3 & 24.60 & 0.10 & 10.85 & 267.76 & 24.69 \\
\hline 4 & 5.90 & 0.30 & 3 & 24.60 & 0.10 & 9.49 & 244.86 & 25.80 \\
\hline 16 & 8.00 & 0.32 & 4 & 18.51 & 0.10 & 15.19 & 343.23 & 22.60 \\
\hline 18 & 9.00 & 0.32 & 4 & 19.00 & 0.10 & 14.91 & 408.28 & 27.38 \\
\hline 28 & 15.70 & 0.32 & 4 & 60.00 & 0.10 & 22.10 & 400.60 & 18.13 \\
\hline 47 & 11.59 & 0.32 & 4 & 26.92 & 0.10 & 18.98 & 180.21 & 9.49 \\
\hline 48 & 11.29 & 0.32 & 4 & 60.00 & 0.10 & 20.34 & 229.71 & 11.29 \\
\hline 51 & 12.10 & 0.32 & 4 & 29.37 & 0.10 & 18.98 & 149.51 & 7.88 \\
\hline 52 & 16.30 & 0.32 & 4 & 27.81 & 0.10 & 20.34 & 148.66 & 7.31 \\
\hline 53 & 14.40 & 0.32 & 4 & 23.42 & 0.10 & 20.34 & 158.82 & 7.81 \\
\hline 54 & 12.50 & 0.32 & 4 & 13.46 & 0.10 & 18.98 & 172.00 & 9.06 \\
\hline 55 & 12.00 & 0.37 & 4 & 12.23 & 0.10 & 20.34 & 210.55 & 10.35 \\
\hline 58 & 10.79 & 0.37 & 4 & 29.00 & 0.10 & 23.05 & 568.79 & 24.68 \\
\hline 59 & 5.55 & 0.37 & 4 & 22.87 & 0.10 & 18.30 & 457.04 & 24.97 \\
\hline 60 & 4.60 & 0.33 & 2 & 20.51 & 0.07 & 6.78 & 135.71 & 20.02 \\
\hline 61 & 4.70 & 0.33 & 2 & 20.74 & 0.07 & 6.78 & 135.43 & 19.98 \\
\hline 69 & 6.75 & 0.32 & 4 & 31.56 & 0.09 & 10.85 & 241.58 & 22.27 \\
\hline 77 & 2.76 & 0.33 & 2 & 16.41 & 0.10 & 7.86 & 138.64 & 17.64 \\
\hline 78 & 2.76 & 0.33 & 2 & 16.41 & 0.10 & 7.86 & 137.30 & 17.47 \\
\hline 79 & 9.50 & 0.32 & 4 & 16.39 & 0.10 & 11.01 & 197.50 & 17.94 \\
\hline
\end{tabular}




\section{DADOS}

\subsection{Dados}

\begin{tabular}{|c|c|c|c|c|c|c|c|c|c|}
\hline Id & Código & Yobs & Ycalc & $\begin{array}{l}\text { Erro } \\
\text { padrão }\end{array}$ & BIAS & $\begin{array}{l}\text { Nr. } \\
\text { Hélice }\end{array}$ & K & $\begin{array}{c}\text { Nspt } \\
\text { H1 }\end{array}$ & Solo H1 \\
\hline 1 & Contagem-1 & 210.22 & 217.60 & -0.15 & 1.04 & 2 & 31.01 & 24.20 & Silte arenoso \\
\hline 2 & Contagem-2 & 186.60 & 214.82 & -0.58 & 1.15 & 3 & 34.41 & 23.40 & Silte arenoso \\
\hline 3 & Contagem-3 & 267.76 & 221.07 & 0.95 & 0.83 & 3 & 24.69 & 24.60 & Silte arenoso \\
\hline 4 & Contagem-4 & 244.86 & 251.29 & -0.13 & 1.03 & 3 & 25.80 & 24.60 & Silte arenoso \\
\hline 16 & E2366-2-1 & 343.23 & 268.83 & 1.52 & 0.78 & 4 & 22.60 & 18.51 & Areia siltosa \\
\hline 18 & E2366-2-3 & 408.28 & 346.19 & 1.27 & 0.85 & 4 & 27.38 & 19.00 & Areia siltosa \\
\hline 28 & E1162-1-4H & 400.60 & 381.46 & 0.39 & 0.95 & 4 & 18.13 & 60.00 & Areia argilosa \\
\hline 47 & E37-2 & 180.21 & 194.11 & -0.28 & 1.08 & 4 & 9.49 & 26.92 & Silte argiloso \\
\hline 48 & $\mathrm{E} 42-2$ & 229.71 & 278.48 & -1.00 & 1.21 & 4 & 11.29 & 60.00 & Argila siltosa \\
\hline 51 & E57-3 & 149.51 & 179.23 & -0.61 & 1.20 & 4 & 7.88 & 29.37 & Silte argiloso \\
\hline 52 & E66-1-1 & 148.66 & 208.56 & -1.22 & 1.40 & 4 & 7.31 & 27.81 & Silte argiloso \\
\hline 53 & E66-1-2 & 158.82 & 140.94 & 0.37 & 0.89 & 4 & 7.81 & 23.42 & Silte argiloso \\
\hline 54 & E66-1-3 & 172.00 & 94.60 & 1.58 & 0.55 & 4 & 9.06 & 13.46 & Silte argiloso \\
\hline 55 & E66-1-4 & 210.55 & 125.52 & 1.74 & 0.60 & 4 & 10.35 & 12.23 & Silte argiloso \\
\hline 58 & E45-2 & 568.79 & 631.50 & -1.28 & 1.11 & 4 & 24.68 & 29.00 & Areia argilosa \\
\hline 59 & E173-2 & 457.04 & 442.00 & 0.31 & 0.97 & 4 & 24.97 & 22.87 & Silte arenoso \\
\hline 60 & $\begin{array}{c}\text { VCastanhal1 } \\
38-1\end{array}$ & 135.71 & 75.71 & 1.23 & 0.56 & 2 & 20.02 & 20.51 & Argila siltosa \\
\hline 61 & $\begin{array}{c}\text { VCastanhal1 } \\
38-2 \\
\end{array}$ & 135.43 & 78.70 & 1.16 & 0.58 & 2 & 19.98 & 20.74 & Argila siltosa \\
\hline 69 & $\begin{array}{c}\text { VElecnor25- } \\
4 \mathrm{~h}\end{array}$ & 241.58 & 289.36 & -0.98 & 1.20 & 4 & 22.27 & 31.56 & Argila siltosa \\
\hline 77 & IGOR-T1 & 138.64 & 81.47 & 1.17 & 0.59 & 2 & 17.64 & 16.41 & Argila silto arenosa \\
\hline 78 & IGOR-T2 & 137.30 & 81.47 & 1.14 & 0.59 & 2 & 17.47 & 16.41 & Argila silto arenosa \\
\hline 79 & JOAO-PC1 & 197.50 & 230.81 & -0.68 & 1.17 & 4 & 17.94 & 16.39 & Silte arenoso \\
\hline
\end{tabular}

\subsection{Outlayers}

\begin{tabular}{ccccccc}
\hline Id & Código & Yobs & Nr. Hélice & K & Nspt H1 & Tipo solo H1 \\
\hline 80 & JOAO-PC3 & 126.63 & 4 & 15.99 & 18.15 & Silte arenoso \\
\hline 75 & VElecnor258-4h & 223.96 & 4 & 16.52 & 17.04 & Areia siltosa
\end{tabular}

\subsection{Geral}

\begin{tabular}{|c|c|c|c|c|c|c|c|c|}
\hline \multirow[b]{2}{*}{ Id } & \multirow[b]{2}{*}{ Comprimento } & \multirow[b]{2}{*}{ Inclinação } & \multirow[b]{2}{*}{ Fuste } & \multirow[b]{2}{*}{$\begin{array}{c}\text { Seção } \\
\text { Fuste }\end{array}$} & \multicolumn{4}{|c|}{ Hélice } \\
\hline & & & & & Posição & $\mathrm{D}$ & Solo & Spt \\
\hline \multirow{2}{*}{1} & \multirow{2}{*}{5.70} & \multirow{2}{*}{0.00} & \multirow{2}{*}{$0.07 \times 0.07$} & \multirow{2}{*}{$\mathrm{CV}$} & 1 & 0.30 & 21 & 24.20 \\
\hline & & & & & 2 & 0.36 & 21 & 22.40 \\
\hline \multirow{3}{*}{2} & \multirow{3}{*}{5.30} & \multirow{3}{*}{0.00} & \multirow{3}{*}{$0.07 \times 0.07$} & \multirow{3}{*}{$\mathrm{CV}$} & 1 & 0.25 & 21 & 23.40 \\
\hline & & & & & 2 & 0.30 & 21 & 21.60 \\
\hline & & & & & 3 & 0.30 & 21 & 18.00 \\
\hline \multirow{3}{*}{3} & \multirow{3}{*}{5.90} & \multirow{3}{*}{0.00} & \multirow{3}{*}{$0.10 \times 0.09$} & \multirow{3}{*}{$\mathrm{CV}$} & 1 & 0.25 & 21 & 24.60 \\
\hline & & & & & 2 & 0.30 & 21 & 23.08 \\
\hline & & & & & 3 & 0.30 & 21 & 20.49 \\
\hline
\end{tabular}




\begin{tabular}{|c|c|c|c|c|c|c|c|c|}
\hline & & & & & & & & \\
\hline Id & Comprimento & Inclinação & Fuste & $\begin{array}{l}\text { Seção } \\
\text { Fuste }\end{array}$ & Posição & $\mathrm{D}$ & Solo & Spt \\
\hline & & & & & 1 & 0.25 & 21 & 24.60 \\
\hline 4 & 5.90 & 0.00 & $0.10 \times 0.09$ & $\mathrm{CV}$ & 2 & 0.30 & 21 & 23.08 \\
\hline & & & & & 3 & 0.36 & 21 & 20.49 \\
\hline & & & & & 1 & 0.25 & 12 & 18.51 \\
\hline 16 & 8.00 & 0.00 & $0.10 \times 0.08$ & $\mathrm{CV}$ & 2 & 0.30 & 12 & 18.00 \\
\hline & & & & & 3 & 0.36 & 12 & 16.18 \\
\hline & & & & & 4 & 0.36 & 13 & 4.34 \\
\hline & & & & & 1 & 0.25 & 12 & 19.00 \\
\hline 18 & 9.00 & 0.00 & $0.10 \times 0.08$ & $\mathrm{CV}$ & 2 & 0.30 & 12 & 18.70 \\
\hline & & & & & 3 & 0.36 & 12 & 18.00 \\
\hline & & & & & 4 & 0.36 & 13 & 15.14 \\
\hline & & & & & 1 & 0.25 & 13 & 60.00 \\
\hline 28 & 15.70 & 39.00 & $0.10 \times 0.09$ & $\mathrm{CV}$ & 2 & 0.30 & 1 & 46.63 \\
\hline 20 & 15.10 & 39.00 & $0.10 \times 0.0$ & C & 3 & 0.36 & 1 & 19.97 \\
\hline & & & & & 4 & 0.36 & 1 & 22.26 \\
\hline & & & & & 1 & 0.25 & 23 & 26.92 \\
\hline 47 & 1159 & 32.00 & $0.10 \times 0.09$ & $\mathrm{CV}$ & 2 & 0.30 & 23 & 25.63 \\
\hline & & & & & 3 & 0.36 & 23 & 24.07 \\
\hline & & & & & 4 & 0.36 & 23 & 11.86 \\
\hline & & & & & 1 & 0.25 & 32 & 60.00 \\
\hline 48 & 11.29 & 32.00 & $0.10 \times 0.09$ & $\mathrm{CV}$ & 2 & 0.30 & 32 & 49.28 \\
\hline & & & $0.10 \mathrm{~N} V .0$ & & 3 & 0.36 & 32 & 29.40 \\
\hline & & & & & 4 & 0.36 & 32 & 2.00 \\
\hline & & & & & 1 & 0.25 & 23 & 29.37 \\
\hline 51 & 12.10 & 32.00 & $0.10 \times 0.09$ & $\mathrm{CV}$ & 2 & 0.30 & 23 & 30.66 \\
\hline & & & & & 3 & 0.36 & 23 & 17.68 \\
\hline & & & & & 4 & 0.36 & 23 & 8.49 \\
\hline & & & & & 1 & 0.25 & 23 & 27.81 \\
\hline 52 & 16.30 & 32.00 & $0.10 \times 0.09$ & $\mathrm{CV}$ & 2 & 0.30 & 23 & 25.81 \\
\hline & & & & & 3 & 0.36 & 23 & 25.03 \\
\hline & & & & & 4 & 0.36 & 23 & 16.27 \\
\hline & & & & & 1 & 0.25 & 23 & 23.42 \\
\hline 53 & 14.40 & 32.00 & $0.10 \times 0.09$ & $\mathrm{CV}$ & 2 & 0.30 & 23 & 16.96 \\
\hline ה & 14.40 & 52.00 & $0.10 \mathrm{SO}$ & & 3 & 0.36 & 23 & 13.84 \\
\hline & & & & & 4 & 0.36 & 23 & 11.06 \\
\hline & & & & & 1 & 0.25 & 23 & 13.46 \\
\hline 54 & 12.50 & 32.00 & $0.10 \times 0.09$ & $\mathrm{CV}$ & 2 & 0.30 & 23 & 11.34 \\
\hline & & & & & 3 & 0.36 & 23 & 8.62 \\
\hline & & & & & 4 & 0.36 & 23 & 7.29 \\
\hline & & & & & 1 & 0.30 & 23 & 12.23 \\
\hline 55 & 12.00 & 32.00 & $0.10 \times 0.09$ & $\mathrm{CV}$ & 2 & 0.36 & 23 & 9.12 \\
\hline & & & & & 3 & 0.41 & 23 & 7.25 \\
\hline & & & & & 4 & 0.41 & 23 & 9.72 \\
\hline & & & & & 1 & 0.30 & 13 & 29.00 \\
\hline 58 & 10.79 & 39.00 & $0.10 \times 0.09$ & $\mathrm{CV}$ & 2 & 0.36 & 1 & 21.35 \\
\hline 58 & 10.19 & 39.00 & $0.10 \times 0.09$ & $\mathrm{Cr}$ & 3 & 0.41 & 1 & 21.15 \\
\hline & & & & & 4 & 0.41 & 1 & 18.81 \\
\hline & & & & & 1 & 0.30 & 21 & 22.87 \\
\hline 59 & 5.55 & 39.00 & $0.10 \times 2,3 \mathrm{e}-03$ & $\mathrm{CV}$ & 2 & 0.36 & 21 & 22.16 \\
\hline & & & & & 3 & 0.41 & 21 & 20.66 \\
\hline & & & & & 4 & 0.41 & 21 & 13.81 \\
\hline 60 & 4.60 & 40.00 & $0.07 \times 0.07$ & $\mathrm{CV}$ & 1 & 0.30 & 32 & 20.51 \\
\hline & & & & & 2 & 0.36 & 31 & 10.45 \\
\hline 61 & 4.70 & 40.00 & $0.07 \times 0.07$ & $\mathrm{CV}$ & 1 & 0.30 & 32 & 20.74 \\
\hline 01 & 4.10 & 40.00 & $0.07 \times 0.07$ & & 2 & 0.36 & 31 & 11.83 \\
\hline
\end{tabular}


Hélice

\begin{tabular}{|c|c|c|c|c|c|c|c|c|}
\hline Id & Comprimento & Inclinação & Fuste & $\begin{array}{l}\text { Seção } \\
\text { Fuste }\end{array}$ & Posição & $\mathrm{D}$ & Solo & Spt \\
\hline \multirow{4}{*}{69} & \multirow{4}{*}{6.75} & \multirow{4}{*}{41.50} & \multirow{4}{*}{$0.09 \times 0.08$} & \multirow{4}{*}{$\mathrm{CV}$} & 1 & 0.25 & 32 & 31.56 \\
\hline & & & & & 2 & 0.30 & 32 & 38.41 \\
\hline & & & & & 3 & 0.36 & 32 & 27.84 \\
\hline & & & & & 4 & 0.36 & 32 & 13.43 \\
\hline \multirow{4}{*}{75} & \multirow{4}{*}{12.43} & \multirow{4}{*}{41.25} & \multirow{4}{*}{$0.09 \times 0.08$} & \multirow{4}{*}{$\mathrm{CV}$} & 1 & 0.25 & 12 & 17.04 \\
\hline & & & & & 2 & 0.30 & 12 & 17.61 \\
\hline & & & & & 3 & 0.36 & 12 & 18.00 \\
\hline & & & & & 4 & 0.36 & 12 & 17.81 \\
\hline \multirow{2}{*}{77} & \multirow{2}{*}{2.76} & \multirow{2}{*}{0.00} & \multirow{2}{*}{$0.10 \times 0.08$} & \multirow{2}{*}{$\mathrm{CV}$} & 1 & 0.30 & 321 & 16.41 \\
\hline & & & & & 2 & 0.36 & 321 & 10.05 \\
\hline \multirow{2}{*}{78} & \multirow{2}{*}{2.76} & \multirow{2}{*}{0.00} & \multirow{2}{*}{$0.10 \times 0.08$} & \multirow{2}{*}{$\mathrm{CV}$} & 1 & 0.30 & 321 & 16.41 \\
\hline & & & & & 2 & 0.36 & 321 & 10.05 \\
\hline \multirow{4}{*}{79} & \multirow{4}{*}{9.50} & \multirow{4}{*}{0.00} & \multirow{4}{*}{$0.10 \times 0.09$} & \multirow{4}{*}{$\mathrm{CV}$} & 1 & 0.25 & 21 & 16.39 \\
\hline & & & & & 2 & 0.30 & 21 & 14.10 \\
\hline & & & & & 3 & 0.36 & 21 & 11.91 \\
\hline & & & & & 4 & 0.36 & 21 & 13.45 \\
\hline \multirow{4}{*}{80} & \multirow{4}{*}{15.00} & \multirow{4}{*}{0.00} & \multirow{4}{*}{$0.10 \times 0.09$} & \multirow{4}{*}{$\mathrm{CV}$} & 1 & 0.25 & 21 & 18.15 \\
\hline & & & & & 2 & 0.30 & 21 & 14.47 \\
\hline & & & & & 3 & 0.36 & 21 & 10.95 \\
\hline & & & & & 4 & 0.36 & 21 & 9.66 \\
\hline
\end{tabular}


ANEXO V BASE DE DADOS 


\section{RELATÓRIO GERENCIAL}

\subsection{Resumo}

\begin{tabular}{cccccc}
\hline Qntd. Hélice & Total & Davisson & NBR & D/10 & $\begin{array}{c}\text { Livneh e } \\
\text { Naggar }\end{array}$ \\
\hline 1 & 2 & $2(2)$ & $2(2)$ & $2(2)$ & $2(2)$ \\
\hline 2 & 8 & $8(8)$ & $8(8)$ & $8(8)$ & $8(8)$ \\
\hline 3 & 9 & $7(7)$ & $7(7)$ & $7(7)$ & $7(7)$ \\
\hline 4 & 36 & $31(23)$ & $31(23)$ & $27(19)$ & $27(19)$ \\
\hline 5 & 0 & $0(0)$ & $0(0)$ & $0(0)$ & $0(0)$ \\
\hline 6 & 21 & $19(14)$ & $18(13)$ & $8(6)$ & $5(3)$ \\
\hline Soma & 76 & $67(54)$ & $66(53)$ & $52(42)$ & $49(39)$
\end{tabular}

\subsection{Estacas}

\begin{tabular}{|c|c|c|c|c|c|c|}
\hline Estaca & Davison & $\mathrm{D} / 10$ & Naggar & NBR 6122 & SPT & $\begin{array}{c}\text { Prova de } \\
\text { Carga }\end{array}$ \\
\hline Contagem-1 & $\mathrm{x}$ & $\mathrm{x}$ & $\mathrm{x}$ & $\mathrm{x}$ & $\mathrm{x}$ & Tração \\
\hline Contagem-2 & $\mathrm{x}$ & $\mathrm{x}$ & $\mathrm{x}$ & $\mathrm{x}$ & $\mathrm{x}$ & Tração \\
\hline Contagem-3 & $\mathrm{x}$ & $\mathrm{x}$ & $\mathrm{x}$ & $\mathrm{x}$ & $\mathrm{x}$ & Tração \\
\hline Contagem-4 & $\mathrm{x}$ & $\mathrm{x}$ & $\mathrm{x}$ & $\mathrm{x}$ & $\mathrm{x}$ & Tração \\
\hline Contagem-5 & $\mathrm{x}$ & $\mathrm{x}$ & $\mathrm{x}$ & $\mathrm{x}$ & $\mathrm{x}$ & Tração \\
\hline Contagem- 6 & $\mathrm{x}$ & $\mathrm{x}$ & $\mathrm{x}$ & $\mathrm{x}$ & $\mathrm{x}$ & Tração \\
\hline Contagem-7 & $\mathrm{x}$ & $\mathrm{x}$ & $\mathrm{x}$ & $\mathrm{x}$ & $\mathrm{x}$ & Tração \\
\hline Contagem- 8 & $\mathrm{x}$ & $\mathrm{x}$ & $\mathrm{x}$ & $\mathrm{x}$ & $\mathrm{x}$ & Tração \\
\hline B1-2038-2 & $\mathrm{x}$ & $\mathrm{x}$ & & $\mathrm{x}$ & $\mathrm{x}$ & Tração \\
\hline B5-E2045-1 & & & & & & Tração \\
\hline B9-E2096-2 & & & & & $\mathrm{x}$ & Tração \\
\hline B4 -E2045-1 & $\mathrm{x}$ & $\mathrm{x}$ & $\mathrm{x}$ & $\mathrm{x}$ & & Tração \\
\hline E2310-2-1 & $\mathrm{x}$ & $\mathrm{x}$ & $\mathrm{x}$ & $\mathrm{x}$ & & Tração \\
\hline E2310-2-2 & $\mathrm{x}$ & $\mathrm{x}$ & $\mathrm{x}$ & $\mathrm{x}$ & & Compressão \\
\hline E2310-2-3 & $\mathrm{x}$ & $\mathrm{x}$ & $\mathrm{x}$ & $\mathrm{x}$ & & Tração \\
\hline E2366-2-1 & $\mathrm{x}$ & $\mathrm{x}$ & $\mathrm{x}$ & $\mathrm{x}$ & $\mathrm{x}$ & Tração \\
\hline E2366-2-2 & $\mathrm{x}$ & $\mathrm{x}$ & & $\mathrm{x}$ & $\mathrm{x}$ & Compressão \\
\hline E2366-2-3 & $\mathrm{x}$ & $\mathrm{x}$ & $\mathrm{x}$ & $\mathrm{x}$ & $\mathrm{x}$ & Tração \\
\hline E2377-1-1 & $\mathrm{x}$ & $\mathrm{x}$ & $\mathrm{x}$ & $\mathrm{x}$ & & Tração \\
\hline E2377-1-2 & $\mathrm{x}$ & $\mathrm{x}$ & $\mathrm{x}$ & $\mathrm{x}$ & & Compressão \\
\hline E2377-1-3 & $\mathrm{x}$ & $\mathrm{x}$ & $\mathrm{x}$ & $\mathrm{x}$ & & Tração \\
\hline E2413-2 & $\mathrm{x}$ & $\mathrm{x}$ & & $\mathrm{x}$ & & Tração \\
\hline E55-2 & $\mathrm{x}$ & $\mathrm{x}$ & $\mathrm{x}$ & $\mathrm{x}$ & $\mathrm{x}$ & Tração \\
\hline E61-1 & $\mathrm{x}$ & $\mathrm{x}$ & & $\mathrm{x}$ & & Tração \\
\hline E94-2 & $\mathrm{x}$ & $\mathrm{x}$ & $\mathrm{x}$ & $\mathrm{x}$ & $\mathrm{x}$ & Tração \\
\hline E119-1 & $\mathrm{x}$ & $\mathrm{x}$ & & $\mathrm{x}$ & $\mathrm{x}$ & Tração \\
\hline E1131-1-6H & $\mathrm{x}$ & $\mathrm{x}$ & $\mathrm{x}$ & $\mathrm{x}$ & & Tração \\
\hline E1162-1-4H & $\mathrm{x}$ & $\mathrm{x}$ & $\mathrm{x}$ & $\mathrm{x}$ & $\mathrm{x}$ & Tração \\
\hline E1162-1-6H & $\mathrm{x}$ & $\mathrm{x}$ & & $\mathrm{x}$ & $\mathrm{x}$ & Tração \\
\hline E1324 -2-4H & $\mathrm{x}$ & $\mathrm{x}$ & & $\mathrm{x}$ & $\mathrm{x}$ & Tração \\
\hline $1324-2-6 \mathrm{H}-7.35 \mathrm{~m}$ & $\mathrm{X}$ & $\mathrm{X}$ & & $\mathrm{x}$ & $\mathrm{x}$ & Tração \\
\hline
\end{tabular}


DEPARTAMENTO DE GEOTECNIA

\begin{tabular}{|c|c|c|c|c|c|c|}
\hline E1324-2-6H-7.45m & $\mathrm{x}$ & $\mathrm{x}$ & & $\mathrm{x}$ & $\mathrm{x}$ & Tração \\
\hline E1324-2-6H-9.95m & $\mathrm{x}$ & & & & $\mathrm{x}$ & Tração \\
\hline E1414-2-4H & $\mathrm{x}$ & $\mathrm{x}$ & & $\mathrm{x}$ & $\mathrm{x}$ & Tração \\
\hline E1414-2-6H-7.95m & $\mathrm{x}$ & $\mathrm{x}$ & & $\mathrm{x}$ & $\mathrm{x}$ & Tração \\
\hline E1414-2-6H-8.75m & $\mathrm{x}$ & $\mathrm{x}$ & & $\mathrm{x}$ & $\mathrm{x}$ & Tração \\
\hline E1414-2-6H-9.15m & $\mathrm{x}$ & $\mathrm{x}$ & & $\mathrm{x}$ & $\mathrm{x}$ & Tração \\
\hline Thiago-A1 & $\mathrm{x}$ & $\mathrm{x}$ & $\mathrm{x}$ & $\mathrm{x}$ & $\mathrm{x}$ & Tração \\
\hline Thiago-A2 & $\mathrm{x}$ & $\mathrm{x}$ & $\mathrm{x}$ & $\mathrm{x}$ & $\mathrm{x}$ & Tração \\
\hline Thiago-A3 & $\mathrm{x}$ & $\mathrm{x}$ & $\mathrm{x}$ & $\mathrm{x}$ & $\mathrm{x}$ & Tração \\
\hline Thiago-B1 & $\mathrm{x}$ & $\mathrm{x}$ & $\mathrm{x}$ & $\mathrm{x}$ & $\mathrm{x}$ & Tração \\
\hline Thiago-B2 & $\mathrm{x}$ & $\mathrm{x}$ & $\mathrm{x}$ & $\mathrm{x}$ & $\mathrm{x}$ & Tração \\
\hline Thiago-B3 & $\mathrm{x}$ & $\mathrm{x}$ & $\mathrm{x}$ & $\mathrm{x}$ & $\mathrm{x}$ & Tração \\
\hline Thiago-C2 & $\mathrm{x}$ & $\mathrm{x}$ & $\mathrm{x}$ & $\mathrm{x}$ & $\mathrm{x}$ & Tração \\
\hline Thiago-C3 & $\mathrm{x}$ & $\mathrm{x}$ & $\mathrm{x}$ & $\mathrm{x}$ & $\mathrm{x}$ & Tração \\
\hline E37-2 & $\mathrm{x}$ & $\mathrm{x}$ & $\mathrm{x}$ & $\mathrm{x}$ & $\mathrm{x}$ & Tração \\
\hline $\mathrm{E} 42-2$ & $\mathrm{x}$ & $\mathrm{x}$ & $\mathrm{x}$ & $\mathrm{x}$ & $\mathrm{x}$ & Tração \\
\hline E51-2 & $\mathrm{x}$ & $\mathrm{x}$ & $\mathrm{x}$ & $\mathrm{x}$ & & Tração \\
\hline E54-2 & $\mathrm{x}$ & $\mathrm{x}$ & $\mathrm{x}$ & $\mathrm{x}$ & & Tração \\
\hline E57-3 & $\mathrm{x}$ & $\mathrm{x}$ & $\mathrm{x}$ & $\mathrm{x}$ & $\mathrm{x}$ & Tração \\
\hline E66-1-1 & $\mathrm{x}$ & $\mathrm{x}$ & $\mathrm{x}$ & $\mathrm{x}$ & $\mathrm{x}$ & Tração \\
\hline E66-1-2 & $\mathrm{x}$ & $\mathrm{x}$ & $\mathrm{x}$ & $\mathrm{x}$ & $\mathrm{x}$ & Tração \\
\hline E66-1-3 & $\mathrm{x}$ & $\mathrm{x}$ & $\mathrm{x}$ & $\mathrm{x}$ & $\mathrm{x}$ & Tração \\
\hline E66-1-4 & $\mathrm{x}$ & $\mathrm{x}$ & $\mathrm{x}$ & $\mathrm{x}$ & $\mathrm{x}$ & Tração \\
\hline E149-1-1 & $\mathrm{x}$ & $\mathrm{x}$ & $\mathrm{x}$ & $\mathrm{x}$ & & Tração \\
\hline E149-1-2 & $\mathrm{x}$ & $\mathrm{x}$ & $\mathrm{x}$ & $\mathrm{x}$ & & Tração \\
\hline E45-2 & $\mathrm{x}$ & $\mathrm{x}$ & $\mathrm{x}$ & $\mathrm{x}$ & $\mathrm{x}$ & Tração \\
\hline E173-2 & $\mathrm{x}$ & $\mathrm{x}$ & $\mathrm{x}$ & $\mathrm{x}$ & $\mathrm{x}$ & Tração \\
\hline VCastanhal138-1 & $\mathrm{x}$ & $\mathrm{x}$ & $\mathrm{x}$ & $\mathrm{x}$ & $\mathrm{x}$ & Tração \\
\hline VCastanhal138-2 & $\mathrm{x}$ & $\mathrm{x}$ & $\mathrm{x}$ & $\mathrm{x}$ & $\mathrm{x}$ & Tração \\
\hline VRJ27 & & & & & $\mathrm{x}$ & Tração \\
\hline VRJ28 & & & & & $\mathrm{x}$ & Tração \\
\hline VRJ114 & & & & & $\mathrm{x}$ & Tração \\
\hline VRJ119 & & & & & $\mathrm{x}$ & Tração \\
\hline VRJ120 & & & & & $\mathrm{x}$ & Tração \\
\hline VRJ121 & & & & & $\mathrm{x}$ & Tração \\
\hline VRJ122 & & & & & $\mathrm{x}$ & Tração \\
\hline VElecnor25-4h & $\mathrm{x}$ & $\mathrm{x}$ & $\mathrm{x}$ & $\mathrm{x}$ & $\mathrm{x}$ & Tração \\
\hline VElecnor25-6h & $\mathrm{x}$ & $\mathrm{x}$ & & $\mathrm{x}$ & $\mathrm{x}$ & Tração \\
\hline VElecnor34-4h & $\mathrm{x}$ & $\mathrm{x}$ & & $\mathrm{x}$ & $\mathrm{x}$ & Tração \\
\hline VElecnor34-6h & $\mathrm{x}$ & $\mathrm{x}$ & & $\mathrm{x}$ & & Tração \\
\hline VElecnor239-4h & $\mathrm{x}$ & $\mathrm{x}$ & & $\mathrm{x}$ & $\mathrm{x}$ & Tração \\
\hline VElecnor239-6h & $\mathrm{x}$ & $\mathrm{x}$ & & $\mathrm{x}$ & $\mathrm{x}$ & Tração \\
\hline VElecnor258-4h & $\mathrm{x}$ & $\mathrm{x}$ & $\mathrm{x}$ & $\mathrm{x}$ & $\mathrm{x}$ & Tração \\
\hline VElecnor258-6h & $\mathrm{x}$ & $\mathrm{x}$ & $\mathrm{x}$ & $\mathrm{x}$ & $\mathrm{x}$ & Tração \\
\hline IGOR-T1 & $\mathrm{x}$ & $\mathrm{x}$ & $\mathrm{x}$ & $\mathrm{x}$ & $\mathrm{x}$ & Tração \\
\hline IGOR-T2 & $\mathrm{x}$ & $\mathrm{x}$ & $\mathrm{x}$ & $\mathrm{x}$ & $\mathrm{x}$ & Tração \\
\hline JOAO-PC1 & $\mathrm{x}$ & $\mathrm{x}$ & $\mathrm{x}$ & $\mathrm{x}$ & $\mathrm{x}$ & Tração \\
\hline JOAO-PC3 & $\mathrm{x}$ & $\mathrm{x}$ & $\mathrm{x}$ & $\mathrm{x}$ & $\mathrm{x}$ & Tração \\
\hline
\end{tabular}




\section{CONTAGEM-1}

\subsection{Geral}

Id : 1

Comprimento $\mathrm{m}: 5.70$

Inclinação ${ }^{\circ}: 0.00$

Correção da profundidade (m) : 0.00

\subsection{SPT e Torque}

\begin{tabular}{cc}
\hline \multicolumn{2}{c}{ Torque } \\
\hline Profundidade $\mathrm{m}$ & Torque kN.m \\
\hline 6.00 & 6.78 \\
\hline 1.50 & 4.07 \\
\hline 2.00 & 5.42 \\
\hline 2.50 & 4.07 \\
\hline 3.00 & 4.07 \\
\hline 4.00 & 4.07 \\
\hline 4.50 & 4.07 \\
\hline 5.00 & 5.42 \\
\hline 5.50 & 5.42
\end{tabular}

\begin{tabular}{ccl}
\hline & \multicolumn{2}{c}{ SPT } \\
\hline Profundidade $\mathrm{m}$ & Nspt & \multicolumn{1}{c}{ Solo } \\
\hline 13.00 & 51.00 & Silte arenoso \\
\hline 12.00 & 47.00 & Silte arenoso \\
\hline 11.00 & 44.00 & Silte arenoso \\
\hline 10.00 & 40.00 & Silte arenoso \\
\hline 9.00 & 36.00 & Silte arenoso \\
\hline 8.00 & 33.00 & Silte arenoso \\
\hline 7.00 & 28.00 & Silte arenoso \\
\hline 6.00 & 26.00 & Silte arenoso \\
\hline 5.00 & 24.00 & Silte arenoso \\
\hline 4.00 & 22.00 & Silte arenoso \\
\hline 3.00 & 18.00 & Silte arenoso \\
\hline 2.00 & 12.00 & Silte arenoso \\
\hline 1.00 & 8.00 & Silte arenoso
\end{tabular}

2.3. Hélice

\begin{tabular}{cccccc}
\hline Posição & Profundidade m & Diâmetro cm & SPT & Interpolado & Ajustado \\
\hline 2 & 4.50 & 35.56 & 22.00 & 22.40 & 22.40 \\
\hline 1 & 5.40 & 30.48 & 24.00 & 24.20 & 24.20
\end{tabular}

\subsection{Fuste}

\begin{tabular}{cccccc}
\hline Comprimento m & Seção & $\begin{array}{c}\text { Diâmetro externo } \\
\mathrm{cm}\end{array}$ & $\begin{array}{c}\text { Diâmetro interno } \\
\mathrm{cm}\end{array}$ & $\mathrm{cm}$ & $\mathrm{cm}$ \\
\hline 4.50 & Circular Vazada & 7.30 & 6.60 & &
\end{tabular}

\subsection{Prova de Carga}




\begin{tabular}{ll}
\hline 32.36 & 2.41 \\
\hline 47.07 & 4.11 \\
\hline 70.61 & 6.23 \\
\hline 94.14 & 8.96 \\
\hline 117.68 & 13.20 \\
\hline 141.22 & 18.71 \\
\hline 164.75 & 23.35 \\
\hline 188.29 & 28.61 \\
\hline 211.82 & 33.27 \\
\hline 235.36 & 38.37 \\
\hline 188.29 & 37.78 \\
\hline 141.22 & 35.41 \\
\hline 94.14 & 33.67 \\
\hline 47.07 & 31.23 \\
\hline 32.36 & 30.36 \\
\hline 56.88 & 30.95 \\
\hline 85.32 & 32.02 \\
\hline 113.76 & 33.08 \\
\hline 142.20 & 34.16 \\
\hline 170.64 & 35.51 \\
\hline 199.07 & 36.84 \\
\hline 227.51 & 38.70 \\
\hline 255.95 & 42.61 \\
\hline 284.39 & 46.98 \\
\hline 227.51 & 45.73 \\
\hline 170.64 & 43.80 \\
\hline 113.76 & 41.41 \\
\hline 56.88 & 38.50 \\
\hline 32.36 & 37.26 \\
\hline 284.39 & 48.83 \\
\hline 313.81 & 51.55 \\
\hline & \\
\hline & \\
\hline & \\
\hline & \\
\hline & \\
\hline & \\
\hline & \\
\hline & \\
\hline & \\
\hline & \\
\hline & \\
\hline & \\
\hline & \\
\hline & \\
\hline & \\
\hline
\end{tabular}

\subsection{Carga de Ruptura}

\begin{tabular}{rc}
\hline Método & Força MN \\
\hline Davisson (1972) & 0.09 \\
\hline $\mathrm{D} / 10$ & 0.21 \\
\hline Livneh e El Naggar (2008) & 0.20 \\
\hline NBR 6122 (2010) & 0.12
\end{tabular}




\section{CONTAGEM-2}

\subsection{Geral}

$$
\text { Id :2 }
$$

Comprimento $\mathrm{m}: 5.30$

Inclinação $^{\circ}: 0.00$

Correção da profundidade (m) : 0.00

\subsection{SPT e Torque}

\begin{tabular}{cc}
\hline \multicolumn{2}{c}{ Torque } \\
\hline Profundidade $\mathrm{m}$ & Torque kN.m \\
\hline 6.00 & 5.42 \\
\hline 1.50 & 2.71 \\
\hline 3.00 & 4.07 \\
\hline 2.00 & 2.71 \\
\hline 2.50 & 2.71 \\
\hline 3.50 & 4.07 \\
\hline 4.00 & 4.07 \\
\hline 4.50 & 6.78 \\
\hline 5.00 & 5.42
\end{tabular}

\begin{tabular}{ccl}
\hline & \multicolumn{2}{c}{ SPT } \\
\hline Profundidade $\mathrm{m}$ & Nspt & \multicolumn{1}{c}{ Solo } \\
\hline 13.00 & 51.00 & Silte arenoso \\
\hline 12.00 & 47.00 & Silte arenoso \\
\hline 11.00 & 44.00 & Silte arenoso \\
\hline 10.00 & 40.00 & Silte arenoso \\
\hline 9.00 & 36.00 & Silte arenoso \\
\hline 8.00 & 33.00 & Silte arenoso \\
\hline 7.00 & 28.00 & Silte arenoso \\
\hline 6.00 & 26.00 & Silte arenoso \\
\hline 5.00 & 24.00 & Silte arenoso \\
\hline 4.00 & 22.00 & Silte arenoso \\
\hline 3.00 & 18.00 & Silte arenoso \\
\hline 2.00 & 12.00 & Silte arenoso \\
\hline 1.00 & 8.00 & Silte arenoso
\end{tabular}

3.3. Hélice

\begin{tabular}{cccccc}
\hline Posição & Profundidade m & Diâmetro cm & SPT & Interpolado & Ajustado \\
\hline 3 & 3.30 & 30.48 & 18.00 & 18.00 & 18.00 \\
\hline 2 & 4.20 & 30.48 & 18.00 & 21.60 & 21.60 \\
\hline 1 & 5.00 & 25.40 & 22.00 & 23.40 & 23.40
\end{tabular}

\subsection{Fuste}

\begin{tabular}{cccccc}
\hline Comprimento m & Seção & $\begin{array}{c}\text { Diâmetro externo } \\
\mathrm{cm}\end{array}$ & $\begin{array}{c}\text { Diâmetro interno } \\
\mathrm{cm}\end{array}$ & $\mathrm{cm}$ & $\mathrm{cm}$ \\
\hline 3.30 & Circular Vazada & 7.30 & 6.60
\end{tabular}

\subsection{Prova de Carga}


Força kN

\begin{tabular}{|c|c|}
\hline 0.00 & 0.00 \\
\hline 32.36 & 3.00 \\
\hline 38.25 & 3.86 \\
\hline 50.99 & 4.87 \\
\hline 63.74 & 5.83 \\
\hline 76.49 & 6.71 \\
\hline 89.24 & 7.56 \\
\hline 101.99 & 9.38 \\
\hline 114.74 & 12.18 \\
\hline 127.49 & 16.04 \\
\hline 101.99 & 15.66 \\
\hline 76.49 & 15.15 \\
\hline 50.99 & 14.59 \\
\hline 32.36 & 14.12 \\
\hline 47.07 & 14.42 \\
\hline 62.76 & 14.58 \\
\hline 78.45 & 14.90 \\
\hline 94.14 & 15.21 \\
\hline 109.83 & 15.70 \\
\hline 125.53 & 16.38 \\
\hline 141.22 & 19.10 \\
\hline 156.91 & 22.07 \\
\hline 125.53 & 21.66 \\
\hline 94.14 & 21.09 \\
\hline 62.76 & 20.18 \\
\hline 32.36 & 19.17 \\
\hline 156.91 & 22.99 \\
\hline 176.52 & 26.41 \\
\hline 196.13 & 31.73 \\
\hline 215.75 & 36.04 \\
\hline 235.36 & 40.61 \\
\hline 254.97 & 43.92 \\
\hline 274.59 & 46.35 \\
\hline 294.20 & 50.44 \\
\hline 313.81 & 54.44 \\
\hline 333.43 & 59.47 \\
\hline
\end{tabular}

\subsection{Carga de Ruptura}

\begin{tabular}{rc}
\hline Método & Força MN \\
\hline Livneh e El Naggar (2008) & 0.19 \\
\hline $\mathrm{D} / 10$ & 0.19 \\
\hline Davisson (1972) & 0.10 \\
\hline NBR 6122 (2010) & 0.11
\end{tabular}




\section{CONTAGEM-3}

\subsection{Geral}

$$
\text { Id }: 3
$$

Comprimento $\mathrm{m}: 5.90$

Inclinação ${ }^{\circ}: 0.00$

Correção da profundidade (m) : 0.00

\subsection{SPT e Torque}

\begin{tabular}{cc}
\hline \multicolumn{2}{c}{ Torque } \\
\hline Profundidade $\mathrm{m}$ & Torque kN.m \\
\hline 6.00 & 10.85 \\
\hline 1.50 & 2.71 \\
\hline 3.50 & 8.13 \\
\hline 3.00 & 8.13 \\
\hline 2.00 & 4.07 \\
\hline 2.50 & 8.13 \\
\hline 4.00 & 9.49 \\
\hline 4.50 & 9.49 \\
\hline 5.00 & 9.49 \\
\hline 5.50 & 9.49
\end{tabular}

\begin{tabular}{ccl}
\hline & \multicolumn{2}{c}{ SPT } \\
\hline Profundidade $\mathrm{m}$ & Nspt & \multicolumn{1}{c}{ Solo } \\
\hline 13.00 & 51.00 & Silte arenoso \\
\hline 12.00 & 47.00 & Silte arenoso \\
\hline 11.00 & 44.00 & Silte arenoso \\
\hline 10.00 & 40.00 & Silte arenoso \\
\hline 9.00 & 36.00 & Silte arenoso \\
\hline 8.00 & 33.00 & Silte arenoso \\
\hline 7.00 & 28.00 & Silte arenoso \\
\hline 6.00 & 26.00 & Silte arenoso \\
\hline 5.00 & 24.00 & Silte arenoso \\
\hline 4.00 & 22.00 & Silte arenoso \\
\hline 3.00 & 18.00 & Silte arenoso \\
\hline 2.00 & 12.00 & Silte arenoso \\
\hline 1.00 & 8.00 & Silte arenoso
\end{tabular}

\subsection{Hélice}

\begin{tabular}{cccccc}
\hline Posição & Profundidade m & Diâmetro cm & SPT & Interpolado & Ajustado \\
\hline 3 & 3.92 & 30.48 & 18.00 & 20.49 & 20.49 \\
\hline 2 & 4.84 & 30.48 & 22.00 & 23.08 & 23.08 \\
\hline 1 & 5.60 & 25.40 & 24.00 & 24.60 & 24.60
\end{tabular}

\subsection{Fuste}

\begin{tabular}{cccccc}
\hline Comprimento m & Seção & $\begin{array}{c}\text { Diâmetro externo } \\
\mathrm{cm}\end{array}$ & $\begin{array}{c}\text { Diâmetro interno } \\
\mathrm{cm}\end{array}$ & $\mathrm{cm}$ & $\mathrm{cm}$ \\
\hline 3.92 & Circular Vazada & 10.16 & 9.35
\end{tabular}

\subsection{Prova de Carga}


Força kN

\begin{tabular}{|c|c|}
\hline 0.00 & 0.00 \\
\hline 32.36 & 2.00 \\
\hline 47.07 & 2.53 \\
\hline 70.61 & 4.19 \\
\hline 94.14 & 6.22 \\
\hline 117.68 & 7.52 \\
\hline 141.22 & 11.02 \\
\hline 164.75 & 14.43 \\
\hline 188.29 & 17.94 \\
\hline 211.82 & 21.18 \\
\hline 235.36 & 24.36 \\
\hline 188.29 & 23.79 \\
\hline 141.22 & 22.83 \\
\hline 94.14 & 21.68 \\
\hline 47.07 & 20.90 \\
\hline 32.36 & 20.53 \\
\hline 56.88 & 21.25 \\
\hline 85.32 & 21.89 \\
\hline 113.76 & 22.40 \\
\hline 142.20 & 22.96 \\
\hline 170.64 & 23.52 \\
\hline 199.07 & 24.30 \\
\hline 227.51 & 25.32 \\
\hline 255.95 & 27.63 \\
\hline 284.39 & 30.36 \\
\hline 227.51 & 29.77 \\
\hline 170.64 & 28.77 \\
\hline 113.76 & 27.77 \\
\hline 56.88 & 26.14 \\
\hline 32.36 & 25.25 \\
\hline 284.39 & 32.10 \\
\hline 313.81 & 35.47 \\
\hline 343.23 & 39.59 \\
\hline 372.65 & 44.17 \\
\hline 402.07 & 48.42 \\
\hline 431.49 & 51.51 \\
\hline
\end{tabular}

\subsection{Carga de Ruptura}

\begin{tabular}{rc}
\hline Método & Força MN \\
\hline Livneh e El Naggar (2008) & 0.24 \\
\hline Davisson (1972) & 0.12 \\
\hline D/10 & 0.27 \\
\hline NBR 6122 (2010) & 0.15
\end{tabular}




\section{CONTAGEM-4}

\subsection{Geral}

Id :4

Comprimento $\mathrm{m}: 5.90$

Inclinação ${ }^{\circ}: 0.00$

Correção da profundidade (m) $: 0.00$

\subsection{SPT e Torque}

\begin{tabular}{cc}
\hline \multicolumn{2}{c}{ Torque } \\
\hline Profundidade $\mathrm{m}$ & Torque kN.m \\
\hline 3.50 & 5.42 \\
\hline 3.00 & 6.78 \\
\hline 2.00 & 5.42 \\
\hline 2.50 & 5.42 \\
\hline 4.00 & 8.13 \\
\hline 1.50 & 4.07 \\
\hline 4.50 & 8.13 \\
\hline 5.00 & 6.78 \\
\hline 5.50 & 8.13 \\
\hline 6.00 & 9.49 \\
\hline 6.50 & 10.85
\end{tabular}

\begin{tabular}{ccl}
\hline & \multicolumn{2}{c}{ SPT } \\
\hline Profundidade $\mathrm{m}$ & Nspt & \multicolumn{1}{c}{ Solo } \\
\hline 10.00 & 40.00 & Silte arenoso \\
\hline 9.00 & 36.00 & Silte arenoso \\
\hline 8.00 & 33.00 & Silte arenoso \\
\hline 7.00 & 28.00 & Silte arenoso \\
\hline 6.00 & 26.00 & Silte arenoso \\
\hline 13.00 & 51.00 & Silte arenoso \\
\hline 12.00 & 47.00 & Silte arenoso \\
\hline 11.00 & 44.00 & Silte arenoso \\
\hline 5.00 & 24.00 & Silte arenoso \\
\hline 4.00 & 22.00 & Silte arenoso \\
\hline 3.00 & 18.00 & Silte arenoso \\
\hline 2.00 & 12.00 & Silte arenoso \\
\hline 1.00 & 8.00 & Silte arenoso
\end{tabular}

\subsection{Hélice}

\begin{tabular}{cccccc}
\hline Posição & Profundidade m & Diâmetro cm & SPT & Interpolado & Ajustado \\
\hline 3 & 3.92 & 35.56 & 18.00 & 20.49 & 20.49 \\
\hline 2 & 4.84 & 30.48 & 22.00 & 23.08 & 23.08 \\
\hline 1 & 5.60 & 25.40 & 24.00 & 24.60 & 24.60
\end{tabular}

\subsection{Fuste}

\begin{tabular}{cccccc}
\hline Comprimento m & Seção & $\begin{array}{c}\text { Diâmetro externo } \\
\mathrm{cm}\end{array}$ & $\begin{array}{c}\text { Diâmetro interno } \\
\mathrm{cm}\end{array}$ & $\mathrm{cm}$ & $\mathrm{cm}$ \\
\hline 3.92 & Circular Vazada & 10.16 & 9.35
\end{tabular}

\subsection{Prova de Carga}


Força kN

\begin{tabular}{|c|c|}
\hline 0.00 & 0.00 \\
\hline 32.36 & 2.77 \\
\hline 47.07 & 4.32 \\
\hline 70.61 & 6.07 \\
\hline 94.14 & 7.55 \\
\hline 117.68 & 10.47 \\
\hline 141.22 & 13.78 \\
\hline 164.75 & 17.08 \\
\hline 188.29 & 20.42 \\
\hline 211.82 & 24.62 \\
\hline 235.36 & 27.86 \\
\hline 188.29 & 27.39 \\
\hline 141.22 & 26.46 \\
\hline 94.14 & 25.40 \\
\hline 47.07 & 24.57 \\
\hline 32.36 & 23.88 \\
\hline 56.88 & 24.27 \\
\hline 85.32 & 24.71 \\
\hline 113.76 & 25.38 \\
\hline 142.20 & 26.03 \\
\hline 170.64 & 26.80 \\
\hline 199.07 & 27.72 \\
\hline 227.51 & 28.93 \\
\hline 255.95 & 31.66 \\
\hline 284.39 & 34.96 \\
\hline 227.51 & 34.58 \\
\hline 170.64 & 33.65 \\
\hline 113.76 & 32.40 \\
\hline 56.88 & 30.56 \\
\hline 32.36 & 29.81 \\
\hline 284.39 & 36.45 \\
\hline 313.81 & 39.81 \\
\hline 343.23 & 45.17 \\
\hline 372.65 & 48.19 \\
\hline 402.07 & 52.49 \\
\hline
\end{tabular}

\subsection{Carga de Ruptura}

\begin{tabular}{rc}
\hline Método & Força MN \\
\hline Davisson (1972) & 0.09 \\
\hline $\mathrm{D} / 10$ & 0.24 \\
\hline Livneh e El Naggar (2008) & 0.23 \\
\hline NBR 6122 (2010) & 0.13
\end{tabular}




\section{CONTAGEM-5}

\subsection{Geral}

$$
\text { Id }: 5
$$

Comprimento $m: 6.20$

Inclinação ${ }^{\circ}: 0.00$

Correção da profundidade (m) $: 0.00$

\subsection{SPT e Torque}

\begin{tabular}{cc}
\hline \multicolumn{2}{c}{ Torque } \\
\hline Profundidade $\mathrm{m}$ & Torque kN.m \\
\hline 6.50 & 10.85 \\
\hline 1.50 & 4.07 \\
\hline 2.00 & 5.42 \\
\hline 2.50 & 5.42 \\
\hline 3.00 & 6.78 \\
\hline 3.50 & 5.42 \\
\hline 4.00 & 8.13 \\
\hline 4.50 & 8.13 \\
\hline 5.00 & 6.78 \\
\hline 5.50 & 8.13 \\
\hline 6.00 & 9.49
\end{tabular}

\begin{tabular}{ccc}
\hline & \multicolumn{2}{c}{ SPT } \\
\hline Profundidade $\mathrm{m}$ & Nspt & Solo \\
\hline 1.00 & 6.00 & Argila \\
\hline 2.00 & 7.00 & Argila \\
\hline 3.00 & 6.00 & Argila \\
\hline 4.00 & 6.00 & Argila \\
\hline 5.00 & 4.00 & Argila \\
\hline 6.00 & 4.00 & Argila \\
\hline 7.00 & 4.00 & Argila \\
\hline 8.00 & 4.00 & Argila \\
\hline 9.00 & 5.00 & Argila \\
\hline 10.00 & 6.00 & Argila \\
\hline 11.00 & 6.00 & Silte \\
\hline 12.00 & 7.00 & Silte \\
\hline 13.00 & 8.00 & Silte \\
\hline 14.00 & 11.00 & Silte
\end{tabular}

\subsection{Hélice}

\begin{tabular}{cccccc}
\hline Posição & Profundidade $m$ & Diâmetro cm & SPT & Interpolado & Ajustado \\
\hline 4 & 2.85 & 35.56 & 7.00 & 6.45 & 6.45 \\
\hline 3 & 3.92 & 35.56 & 6.00 & 6.00 & 6.00 \\
\hline 2 & 4.99 & 35.56 & 6.00 & 4.63 & 4.63 \\
\hline 1 & 5.90 & 30.48 & 4.00 & 4.00 & 4.00
\end{tabular}

\subsection{Fuste}

\begin{tabular}{cccccc}
\hline Comprimento m & Seção & $\begin{array}{c}\text { Diâmetro externo } \\
\mathrm{cm}\end{array}$ & $\begin{array}{c}\text { Diâmetro interno } \\
\mathrm{cm}\end{array}$ & $\mathrm{cm}$ & $\mathrm{cm}$ \\
\hline 2.85 & Circular Vazada & 7.30 & 6.74 & &
\end{tabular}




\begin{tabular}{cc}
\hline Força kN & Deslocamento mm \\
\hline 0.00 & 0.00 \\
\hline 32.36 & 3.54 \\
\hline 38.25 & 4.58 \\
\hline 50.99 & 13.14 \\
\hline 63.74 & 20.49 \\
\hline 76.49 & 27.87 \\
\hline 89.24 & 33.63 \\
\hline 101.99 & 38.92 \\
\hline 114.74 & 44.22 \\
\hline 127.49 & 50.17 \\
\hline 101.99 & 49.65 \\
\hline 76.49 & 48.70 \\
\hline 50.99 & 47.58 \\
\hline 32.36 & 46.89 \\
\hline 47.07 & 47.27 \\
\hline 62.76 & 47.77 \\
\hline 78.45 & 48.61 \\
\hline 94.14 & 49.03 \\
\hline 109.83 & 49.62 \\
\hline 125.53 & 50.86 \\
\hline 141.22 & 53.24
\end{tabular}

\subsection{Carga de Ruptura}

\begin{tabular}{rc}
\hline \multicolumn{1}{c}{ Método } & Força MN \\
\hline D/10 & 0.09 \\
\hline Livneh e El Naggar (2008) & 0.08 \\
\hline Davisson (1972) & 0.04 \\
\hline NBR 6122 (2010) & 0.05
\end{tabular}




\section{CONTAGEM-6}

\subsection{Geral}

$$
\text { Id :6 }
$$

Comprimento $\mathrm{m}: 9.20$

$$
\text { Inclinação }{ }^{\circ}: 0.00
$$

Correção da profundidade (m) : 0.00

\subsection{SPT e Torque}

\begin{tabular}{cc}
\hline \multicolumn{2}{c}{ Torque } \\
\hline Profundidade $\mathrm{m}$ & Torque kN.m \\
\hline 1.50 & 2.71 \\
\hline 2.00 & 2.71 \\
\hline 2.50 & 4.07 \\
\hline 3.00 & 2.71 \\
\hline 3.50 & 2.71 \\
\hline 4.00 & 2.71 \\
\hline 4.50 & 2.71 \\
\hline 5.00 & 2.71 \\
\hline 5.50 & 4.07 \\
\hline 6.00 & 4.07 \\
\hline 6.50 & 5.42 \\
\hline 7.00 & 4.07 \\
\hline 7.50 & 5.42 \\
\hline 8.00 & 5.42 \\
\hline 8.50 & 4.07 \\
\hline 9.00 & 5.42 \\
\hline 9.50 & 5.42 \\
\hline & \\
\hline
\end{tabular}

\begin{tabular}{ccc}
\hline & \multicolumn{2}{c}{ SPT } \\
\hline Profundidade $\mathrm{m}$ & Nspt & Solo \\
\hline 1.00 & 6.00 & Argila \\
\hline 2.00 & 7.00 & Argila \\
\hline 3.00 & 6.00 & Argila \\
\hline 4.00 & 6.00 & Argila \\
\hline 5.00 & 4.00 & Argila \\
\hline 6.00 & 4.00 & Argila \\
\hline 7.00 & 4.00 & Argila \\
\hline 8.00 & 4.00 & Argila \\
\hline 9.00 & 5.00 & Argila \\
\hline 10.00 & 6.00 & Argila \\
\hline 11.00 & 6.00 & Silte \\
\hline 12.00 & 7.00 & Silte \\
\hline 13.00 & 8.00 & Silte \\
\hline 14.00 & 11.00 & Silte
\end{tabular}

7.3. Hélice

\begin{tabular}{cccccc}
\hline Posição & Profundidade $m$ & Diâmetro cm & SPT & Interpolado & Ajustado \\
\hline 3 & 7.22 & 35.56 & 4.00 & 4.00 & 4.00 \\
\hline 2 & 8.14 & 30.48 & 4.00 & 4.00 & 4.00 \\
\hline 1 & 8.90 & 25.40 & 4.00 & 4.60 & 4.60
\end{tabular}

\subsection{Fuste}

\begin{tabular}{cccccc}
\hline Comprimento m & Seção & $\begin{array}{c}\text { Diâmetro externo } \\
\mathrm{cm}\end{array}$ & $\begin{array}{c}\text { Diâmetro interno } \\
\mathrm{cm}\end{array}$ & $\mathrm{cm}$ & $\mathrm{cm}$ \\
\hline 7.22 & Circular Vazada & 7.30 & 6.74 & &
\end{tabular}




\subsection{Prova de Carga}

\begin{tabular}{|c|c|}
\hline Força kN & Deslocamento $\mathrm{mm}$ \\
\hline 0.00 & 0.00 \\
\hline 32.36 & 8.71 \\
\hline 38.25 & 11.37 \\
\hline 50.99 & 18.80 \\
\hline 63.74 & 24.41 \\
\hline 76.49 & 30.55 \\
\hline 89.24 & 34.00 \\
\hline 101.99 & 39.23 \\
\hline 114.74 & 44.14 \\
\hline 127.49 & 50.79 \\
\hline 101.99 & 49.86 \\
\hline 76.49 & 48.50 \\
\hline 50.99 & 47.05 \\
\hline 32.36 & 45.91 \\
\hline 47.07 & 46.62 \\
\hline 62.76 & 47.50 \\
\hline 78.45 & 48.45 \\
\hline 94.14 & 49.25 \\
\hline 109.83 & 50.30 \\
\hline 125.53 & 51.69 \\
\hline 141.22 & 57.35 \\
\hline
\end{tabular}

\subsection{Carga de Ruptura}

\begin{tabular}{rc}
\hline Método & Força MN \\
\hline Davisson (1972) & 0.03 \\
\hline D/10 & 0.08 \\
\hline Livneh e El Naggar (2008) & 0.07 \\
\hline NBR 6122 (2010) & 0.04
\end{tabular}




\section{CONTAGEM-7}

\subsection{Geral}

Id : 7

Comprimento $\mathrm{m}: 10.10$

Inclinação ${ }^{\circ}: 0.00$

Correção da profundidade (m) $: 0.00$

\subsection{SPT e Torque}

\begin{tabular}{|c|c|}
\hline \multicolumn{2}{|c|}{ Torque } \\
\hline Profundidade $\mathrm{m}$ & Torque kN.m \\
\hline 1.50 & 4.07 \\
\hline 11.00 & 12.20 \\
\hline 2.00 & 2.71 \\
\hline 2.50 & 4.07 \\
\hline 3.00 & 4.07 \\
\hline 3.50 & 5.42 \\
\hline 4.00 & 6.78 \\
\hline 4.50 & 6.78 \\
\hline 5.00 & 6.78 \\
\hline 5.50 & 6.78 \\
\hline 6.00 & 6.78 \\
\hline 6.50 & 8.13 \\
\hline 7.00 & 8.13 \\
\hline 7.50 & 8.13 \\
\hline 8.00 & 8.13 \\
\hline 8.50 & 9.49 \\
\hline 9.00 & 9.49 \\
\hline 10.00 & 10.85 \\
\hline 10.50 & 12.20 \\
\hline
\end{tabular}

\begin{tabular}{ccc}
\hline & \multicolumn{2}{c}{ SPT } \\
\hline Profundidade $\mathrm{m}$ & Nspt & Solo \\
\hline 1.00 & 6.00 & Argila \\
\hline 2.00 & 7.00 & Argila \\
\hline 3.00 & 6.00 & Argila \\
\hline 4.00 & 6.00 & Argila \\
\hline 5.00 & 4.00 & Argila \\
\hline 6.00 & 4.00 & Argila \\
\hline 7.00 & 4.00 & Argila \\
\hline 8.00 & 4.00 & Argila \\
\hline 9.00 & 5.00 & Argila \\
\hline 10.00 & 6.00 & Argila \\
\hline 11.00 & 6.00 & Silte \\
\hline 12.00 & 7.00 & Silte \\
\hline 13.00 & 8.00 & Silte \\
\hline 14.00 & 11.00 & Silte
\end{tabular}

\subsection{Hélice}

\begin{tabular}{cccccc}
\hline Posição & Profundidade m & Diâmetro cm & SPT & Interpolado & Ajustado \\
\hline 4 & 6.75 & 35.56 & 4.00 & 4.00 & 4.00 \\
\hline 3 & 7.82 & 35.56 & 4.00 & 4.00 & 4.00 \\
\hline 2 & 8.89 & 35.56 & 4.00 & 4.59 & 4.59 \\
\hline 1 & 9.80 & 30.48 & 5.00 & 5.50 & 5.50
\end{tabular}

\subsection{Fuste}



6.75
Circular Vazada
10.16
9.59

\subsection{Prova de Carga}

\begin{tabular}{|c|c|}
\hline Força kN & Deslocamento mm \\
\hline 0.00 & 0.00 \\
\hline 32.36 & 2.41 \\
\hline 47.07 & 4.11 \\
\hline 70.61 & 6.23 \\
\hline 94.14 & 8.96 \\
\hline 117.68 & 13.20 \\
\hline 141.22 & 18.71 \\
\hline 164.75 & 23.35 \\
\hline 188.29 & 28.61 \\
\hline 211.82 & 33.27 \\
\hline 235.36 & 38.37 \\
\hline 188.29 & 37.78 \\
\hline 141.22 & 35.41 \\
\hline 94.14 & 33.67 \\
\hline 47.07 & 31.23 \\
\hline 32.36 & 30.36 \\
\hline 56.88 & 30.96 \\
\hline 85.32 & 31.99 \\
\hline 85.32 & 32.02 \\
\hline 113.76 & 33.08 \\
\hline 142.20 & 34.16 \\
\hline 170.64 & 35.51 \\
\hline 199.07 & 36.84 \\
\hline 227.51 & 38.70 \\
\hline 255.95 & 42.61 \\
\hline 284.39 & 46.98 \\
\hline 227.51 & 45.73 \\
\hline 170.64 & 43.80 \\
\hline 113.76 & 41.41 \\
\hline 56.88 & 38.50 \\
\hline 32.36 & 37.26 \\
\hline 284.39 & 48.83 \\
\hline 313.81 & 51.55 \\
\hline
\end{tabular}

\subsection{Carga de Ruptura}

\begin{tabular}{rc}
\hline \multicolumn{1}{c}{ Método } & Força MN \\
\hline D/10 & 0.21 \\
\hline Livneh e El Naggar (2008) & 0.21 \\
\hline Davisson (1972) & 0.10 \\
\hline NBR 6122(2010) & 0.13
\end{tabular}




\section{CONTAGEM-8}

\subsection{Geral}

Id $: 8$

Comprimento $\mathrm{m}: 10.30$

Inclinação $^{\circ}: 0.00$

Correção da profundidade (m) : 0.00

\subsection{SPT e Torque}

\begin{tabular}{|c|c|}
\hline \multicolumn{2}{|c|}{ Torque } \\
\hline Profundidade $\mathrm{m}$ & Torque kN.m \\
\hline 9.00 & 6.78 \\
\hline 7.00 & 6.78 \\
\hline 2.50 & 2.71 \\
\hline 2.00 & 2.71 \\
\hline 1.50 & 4.07 \\
\hline 3.00 & 4.07 \\
\hline 3.50 & 5.42 \\
\hline 4.00 & 5.42 \\
\hline 4.50 & 5.42 \\
\hline 5.00 & 6.78 \\
\hline 5.50 & 5.42 \\
\hline 6.00 & 5.42 \\
\hline 6.60 & 5.42 \\
\hline 8.50 & 6.78 \\
\hline 8.00 & 6.78 \\
\hline 7.50 & 6.78 \\
\hline 10.50 & 8.13 \\
\hline 10.00 & 8.13 \\
\hline 9.50 & 8.13 \\
\hline
\end{tabular}

\begin{tabular}{ccc}
\hline & \multicolumn{2}{c}{ SPT } \\
\hline Profundidade $\mathrm{m}$ & Nspt & Solo \\
\hline 1.00 & 6.00 & Argila \\
\hline 2.00 & 7.00 & Argila \\
\hline 3.00 & 6.00 & Argila \\
\hline 4.00 & 6.00 & Argila \\
\hline 5.00 & 4.00 & Argila \\
\hline 6.00 & 4.00 & Argila \\
\hline 7.00 & 4.00 & Argila \\
\hline 8.00 & 4.00 & Argila \\
\hline 9.00 & 5.00 & Argila \\
\hline 10.00 & 6.00 & Argila \\
\hline 11.00 & 6.00 & Silte \\
\hline 12.00 & 7.00 & Silte \\
\hline 13.00 & 8.00 & Silte \\
\hline 14.00 & 11.00 & Silte
\end{tabular}

\subsection{Hélice}

\begin{tabular}{cccccc}
\hline Posição & Profundidade $m$ & Diâmetro cm & SPT & Interpolado & Ajustado \\
\hline 4 & 6.95 & 35.56 & 4.00 & 4.00 & 4.00 \\
\hline 3 & 8.02 & 35.56 & 4.00 & 4.00 & 4.00 \\
\hline 2 & 9.09 & 35.56 & 5.00 & 4.79 & 4.79 \\
\hline 1 & 10.00 & 30.48 & 5.00 & 5.70 & 5.70
\end{tabular}

\subsection{Fuste}




$\begin{array}{llll}6.95 & \text { Circular Vazada } & 7.30 & 6.78\end{array}$

\subsection{Prova de Carga}

\begin{tabular}{|c|c|}
\hline Força kN & Deslocamento $\mathrm{mm}$ \\
\hline 0.00 & 0.00 \\
\hline 32.36 & 5.28 \\
\hline 38.25 & 6.70 \\
\hline 50.99 & 11.38 \\
\hline 63.74 & 15.93 \\
\hline 76.49 & 22.52 \\
\hline 89.24 & 26.66 \\
\hline 101.99 & 31.13 \\
\hline 114.74 & 35.97 \\
\hline 127.49 & 40.66 \\
\hline 101.99 & 39.62 \\
\hline 76.49 & 38.14 \\
\hline 50.99 & 36.60 \\
\hline 32.36 & 35.30 \\
\hline 47.07 & 35.85 \\
\hline 62.76 & 36.65 \\
\hline 78.45 & 37.64 \\
\hline 94.14 & 38.72 \\
\hline 109.83 & 39.60 \\
\hline 125.53 & 40.98 \\
\hline 141.22 & 43.58 \\
\hline 156.91 & 50.34 \\
\hline 125.53 & 49.06 \\
\hline 94.14 & 47.49 \\
\hline 62.76 & 45.51 \\
\hline 32.36 & 43.18 \\
\hline 156.91 & 53.86 \\
\hline 176.52 & 55.72 \\
\hline
\end{tabular}

\subsection{Carga de Ruptura}

\begin{tabular}{rc}
\hline \multicolumn{1}{c}{ Método } & Força MN \\
\hline D/10 & 0.11 \\
\hline Davisson (1972) & 0.04 \\
\hline Livneh e El Naggar (2008) & 0.11 \\
\hline NBR 6122(2010) & 0.06
\end{tabular}




\section{B1-2038-2}

\subsection{Geral}

Id :9

Comprimento $\mathrm{m}: 22.00$

Inclinação $^{\circ}: 43.82$

Correção da profundidade (m) : 0.00

\subsection{SPT e Torque}

\begin{tabular}{|c|c|}
\hline \multicolumn{2}{|c|}{ Torque } \\
\hline Profundidade m & Torque kN.m \\
\hline 2.16 & 1.63 \\
\hline 2.89 & 2.71 \\
\hline 3.61 & 3.80 \\
\hline 4.33 & 5.15 \\
\hline 5.05 & 6.51 \\
\hline 5.77 & 6.78 \\
\hline 6.49 & 8.27 \\
\hline 7.22 & 8.95 \\
\hline 7.94 & 8.81 \\
\hline 8.66 & 7.86 \\
\hline 9.38 & 9.22 \\
\hline 10.10 & 9.49 \\
\hline 10.82 & 11.52 \\
\hline 11.54 & 12.88 \\
\hline 12.27 & 15.19 \\
\hline 12.99 & 11.80 \\
\hline 13.71 & 15.59 \\
\hline 14.43 & 16.54 \\
\hline 15.15 & 18.30 \\
\hline 15.87 & 18.44 \\
\hline
\end{tabular}

\begin{tabular}{|c|c|c|}
\hline \multicolumn{3}{|c|}{ SPT } \\
\hline Profundidade m & Nspt & Solo \\
\hline 1.00 & 3.00 & Areia argilosa \\
\hline 2.00 & 2.00 & Areia argilosa \\
\hline 3.00 & 6.00 & Areia argilosa \\
\hline 4.00 & 4.00 & Areia argilosa \\
\hline 5.00 & 7.00 & Areia argilosa \\
\hline 6.00 & 4.00 & Areia argilosa \\
\hline 7.00 & 4.00 & Areia argilosa \\
\hline 8.00 & 5.00 & Areia argilosa \\
\hline 9.00 & 12.00 & Areia argilosa \\
\hline 10.00 & 14.00 & Areia argilosa \\
\hline 11.00 & 13.00 & Areia argilosa \\
\hline 12.00 & 20.00 & Areia argilosa \\
\hline 13.00 & 20.00 & Areia argilosa \\
\hline 14.00 & 17.00 & Areia \\
\hline 15.00 & 35.00 & Areia \\
\hline 16.00 & 13.00 & Areia argilosa \\
\hline 17.00 & 11.00 & Areia argilosa \\
\hline 18.00 & 10.00 & Areia argilosa \\
\hline 19.00 & 11.00 & Areia argilosa \\
\hline 20.00 & 11.00 & Areia argilosa \\
\hline 21.00 & 11.00 & Areia argilosa \\
\hline 22.00 & 15.00 & Areia argilosa \\
\hline
\end{tabular}

\subsection{Hélice}

\begin{tabular}{cccccc}
\hline Posição & Profundidade $m$ & Diâmetro cm & SPT & Interpolado & Ajustado \\
\hline 6 & 11.54 & 40.64 & 13.00 & 14.68 & 14.68 \\
\hline 5 & 12.41 & 40.64 & 20.00 & 20.00 & 20.00 \\
\hline 4 & 13.29 & 40.64 & 20.00 & 20.00 & 20.00 \\
\hline 3 & 14.17 & 40.64 & 17.00 & 17.39 & 17.39 \\
\hline 2 & 15.05 & 35.56 & 17.00 & 30.50 & 30.50 \\
\hline 1 & 15.82 & 30.48 & 35.00 & 23.56 & 23.56
\end{tabular}


10.4. Fuste

\begin{tabular}{cccccc}
\hline Comprimento m & Seção & $\begin{array}{c}\text { Diâmetro externo } \\
\mathrm{cm}\end{array}$ & $\begin{array}{c}\text { Diâmetro interno } \\
\mathrm{cm}\end{array}$ & $\mathrm{cm}$ & $\mathrm{cm}$ \\
\hline 15.96 & Circular Vazada & 10.00 & 8.50
\end{tabular}

\subsection{Prova de Carga}

\begin{tabular}{cc}
\hline Força kN & Deslocamento mm \\
\hline 0.00 & 0.00 \\
\hline 182.40 & 8.00 \\
\hline 243.20 & 11.99 \\
\hline 304.01 & 14.85 \\
\hline 364.81 & 18.72 \\
\hline 425.61 & 23.57 \\
\hline 486.41 & 30.25 \\
\hline 547.21 & 34.45 \\
\hline 486.41 & 33.53 \\
\hline 364.81 & 32.30 \\
\hline 243.20 & 26.34 \\
\hline 121.60 & 19.48 \\
\hline 182.40 & 21.65 \\
\hline 243.20 & 23.48 \\
\hline 304.01 & 26.77 \\
\hline 364.81 & 28.76 \\
\hline 425.61 & 31.84 \\
\hline 486.41 & 32.66 \\
\hline 364.81 & 32.25 \\
\hline 243.20 & 26.37 \\
\hline 121.60 & 20.30 \\
\hline & \\
\hline
\end{tabular}

\subsection{Carga de Ruptura}

\begin{tabular}{cc}
\hline Método & Força MN \\
\hline Davisson (1972) & 0.34 \\
\hline NBR 6122(2010) & 0.46
\end{tabular}




\section{B5-E2045-1}

\subsection{Geral}

Id $: 10$

Comprimento $\mathrm{m}: 26.00$ Inclinação ${ }^{\circ}: 39.62$

Correção da profundidade (m) : 0.00

\subsection{SPT e Torque}

\begin{tabular}{cc}
\hline \multicolumn{2}{c}{ Torque } \\
\hline Profundidade m & Torque kN.m \\
\hline 25.00 & 21.02 \\
\hline 24.00 & 20.07 \\
\hline 23.00 & 19.66 \\
\hline 26.00 & 21.96
\end{tabular}

\begin{tabular}{ccc}
\hline \multicolumn{3}{c}{ SPT } \\
\hline Profundidade m & Nspt & Solo \\
\hline 1.00 & 6.00 & Areia silto argilosa \\
\hline 2.00 & 1.00 & Areia silto argilosa \\
\hline 3.00 & 3.00 & Areia argilosa \\
\hline 4.00 & 1.00 & Areia argilosa \\
\hline 5.00 & 2.00 & Areia argilosa \\
\hline 6.00 & 3.00 & Areia argilosa \\
\hline 7.00 & 4.00 & Areia argilosa \\
\hline 8.00 & 31.00 & Areia argilosa \\
\hline 9.00 & 20.00 & Areia argilosa \\
\hline 10.00 & 28.00 & Areia argilosa \\
\hline 11.00 & 30.00 & Areia argilosa \\
\hline 12.00 & 30.00 & Areia argilosa
\end{tabular}

\subsection{Hélice}

\begin{tabular}{|c|c|c|c|c|c|}
\hline Posição & Profundidade $\mathrm{m}$ & Diâmetro cm & SPT & Interpolado & Ajustado \\
\hline 6 & 13.94 & 40.64 & & & \\
\hline 5 & 14.78 & 40.64 & & & \\
\hline 4 & 15.63 & 40.64 & & & \\
\hline 3 & 16.47 & 40.64 & & & \\
\hline 2 & 17.14 & 35.56 & & & \\
\hline 1 & 17.85 & 30.48 & & & \\
\hline
\end{tabular}

\subsection{Fuste}

\begin{tabular}{cccccc}
\hline Comprimento m & Seção & $\begin{array}{c}\text { Diâmetro externo } \\
\mathrm{cm}\end{array}$ & $\begin{array}{c}\text { Diâmetro interno } \\
\mathrm{cm}\end{array}$ & $\mathrm{cm}$ & $\mathrm{cm}$ \\
\hline 20.06 & Circular Vazada & 10.00 & 8.50 & &
\end{tabular}

\subsection{Prova de Carga}




\begin{tabular}{|c|c|}
\hline Força kN & Deslocamento $\mathrm{mm}$ \\
\hline 0.00 & 0.00 \\
\hline 182.40 & 0.90 \\
\hline 243.20 & 1.40 \\
\hline 304.01 & 2.00 \\
\hline 364.81 & 2.60 \\
\hline 425.61 & 3.10 \\
\hline 486.41 & 3.80 \\
\hline 547.21 & 4.50 \\
\hline 486.41 & 4.50 \\
\hline 364.81 & 4.10 \\
\hline 243.20 & 3.40 \\
\hline 121.60 & 2.50 \\
\hline 182.40 & 2.70 \\
\hline 243.20 & 3.10 \\
\hline 304.01 & 3.40 \\
\hline 364.81 & 3.80 \\
\hline 425.61 & 4.10 \\
\hline 486.41 & 4.50 \\
\hline 547.21 & 4.50 \\
\hline 486.41 & 4.50 \\
\hline 364.81 & 4.30 \\
\hline 243.20 & 3.60 \\
\hline 121.60 & 2.70 \\
\hline 0.00 & 1.10 \\
\hline 182.40 & 1.20 \\
\hline 243.20 & 1.70 \\
\hline 304.01 & 2.20 \\
\hline 364.81 & 2.60 \\
\hline 425.61 & 3.20 \\
\hline 486.41 & 3.70 \\
\hline 547.21 & 4.40 \\
\hline 364.81 & 3.90 \\
\hline 243.20 & 3.10 \\
\hline
\end{tabular}

\subsection{Carga de Ruptura}




\section{B9-E2096-2}

\subsection{Geral}

Id : 11

Comprimento $\mathrm{m}: 8.34$

Inclinação $^{\circ}: 39.64$

Correção da profundidade (m) : 0.00

\subsection{SPT e Torque}

\begin{tabular}{cc}
\hline \multicolumn{2}{c}{ Torque } \\
\hline Profundidade $\mathrm{m}$ & Torque kN.m \\
\hline 6.93 & 20.47 \\
\hline 3.08 & 2.58 \\
\hline 3.85 & 3.93 \\
\hline 4.62 & 11.52 \\
\hline 5.39 & 14.91 \\
\hline 6.16 & 17.63 \\
\hline 2.31 & 2.30
\end{tabular}

\begin{tabular}{ccc}
\hline & \multicolumn{2}{c}{ SPT } \\
\hline Profundidade $\mathrm{m}$ & Nspt & Solo \\
\hline 1.00 & 1.67 & Areia argilosa \\
\hline 2.00 & 0.00 & Areia argilosa \\
\hline 3.00 & 4.00 & Areia argilosa \\
\hline 4.00 & 23.00 & Areia argilosa \\
\hline 5.00 & 79.92 & Areia \\
\hline 6.00 & 60.00 & Areia \\
\hline 7.00 & 51.92 & Areia
\end{tabular}

\subsection{Hélice}

\begin{tabular}{cccccc}
\hline Posição & Profundidade m & Diâmetro cm & SPT & Interpolado & Ajustado \\
\hline 6 & 1.85 & 40.64 & 1.67 & 0.75 & 0.75 \\
\hline 5 & 2.78 & 40.64 & 0.00 & 1.92 & 1.92 \\
\hline 4 & 3.72 & 40.64 & 4.00 & 11.98 & 11.98 \\
\hline 3 & 4.66 & 40.64 & 23.00 & 43.49 & 43.49 \\
\hline 2 & 5.48 & 35.56 & 79.92 & 60.00 & 60.00 \\
\hline 1 & 6.18 & 30.48 & 60.00 & 60.00 & 60.00
\end{tabular}

\subsection{Fuste}

\begin{tabular}{cccccc}
\hline Comprimento m & Seção & $\begin{array}{c}\text { Diâmetro externo } \\
\mathrm{cm}\end{array}$ & $\begin{array}{c}\text { Diâmetro interno } \\
\mathrm{cm}\end{array}$ & $\mathrm{cm}$ & $\mathrm{cm}$ \\
\hline 2.40 & Circular Vazada & 9.00 & 8.34 & &
\end{tabular}

\subsection{Prova de Carga}

\begin{tabular}{cc}
\hline Força kN & Deslocamento mm \\
\hline 0.00 & 0.00 \\
\hline 121.60 & 0.80 \\
\hline 182.40 & 1.20
\end{tabular}




\begin{tabular}{|c|c|}
\hline 243.20 & 1.70 \\
\hline 304.01 & 2.20 \\
\hline 364.81 & 2.40 \\
\hline 425.61 & 2.80 \\
\hline 486.41 & 3.50 \\
\hline 547.21 & 3.80 \\
\hline 568.79 & 4.00 \\
\hline 486.41 & 3.80 \\
\hline 364.81 & 3.70 \\
\hline 243.20 & 3.30 \\
\hline 121.60 & 2.80 \\
\hline 182.40 & 3.00 \\
\hline 243.20 & 3.20 \\
\hline 304.01 & 3.40 \\
\hline 364.81 & 3.60 \\
\hline 425.61 & 3.70 \\
\hline 486.41 & 3.80 \\
\hline 547.21 & 3.80 \\
\hline 568.79 & 3.80 \\
\hline 486.41 & 3.70 \\
\hline 364.81 & 3.70 \\
\hline 243.20 & 3.40 \\
\hline 121.60 & 2.80 \\
\hline
\end{tabular}

\subsection{Carga de Ruptura}




\section{B4 -E2045-1}

\subsection{Geral}

$$
\text { Id : } 12
$$

Comprimento $\mathrm{m}: 21.89$

Inclinação $^{\circ}: 39.62$

Correção da profundidade (m) : 0.00

\subsection{SPT e Torque}

\begin{tabular}{|c|c|}
\hline \multicolumn{2}{|c|}{ Torque } \\
\hline Profundidade m & Torque kN.m \\
\hline 3.85 & 2.71 \\
\hline 3.08 & 2.03 \\
\hline 2.31 & 1.36 \\
\hline 4.62 & 3.80 \\
\hline 5.39 & 5.42 \\
\hline 6.16 & 7.46 \\
\hline 6.93 & 9.63 \\
\hline 7.70 & 10.17 \\
\hline 8.47 & 11.52 \\
\hline 9.24 & 12.20 \\
\hline 10.01 & 11.52 \\
\hline 10.78 & 12.07 \\
\hline 11.55 & 11.52 \\
\hline 12.32 & 12.20 \\
\hline 13.09 & 12.88 \\
\hline 13.87 & 14.24 \\
\hline 14.64 & 14.78 \\
\hline 15.41 & 15.19 \\
\hline 16.18 & 16.00 \\
\hline 16.95 & 16.95 \\
\hline
\end{tabular}

\begin{tabular}{ccc}
\hline \multicolumn{3}{c}{ SPT } \\
\hline Profundidade m & Nspt & Solo \\
\hline 1.00 & 6.00 & Areia silto argilosa \\
\hline 2.00 & 1.00 & Areia silto argilosa \\
\hline 3.00 & 3.00 & Areia argilosa \\
\hline 4.00 & 1.00 & Areia argilosa \\
\hline 5.00 & 2.00 & Areia argilosa \\
\hline 6.00 & 3.00 & Areia argilosa \\
\hline 7.00 & 4.00 & Areia argilosa \\
\hline 8.00 & 31.00 & Areia argilosa \\
\hline 9.00 & 20.00 & Areia argilosa \\
\hline 10.00 & 28.00 & Areia argilosa \\
\hline 11.00 & 30.00 & Areia argilosa \\
\hline 12.00 & 30.00 & Areia argilosa
\end{tabular}

\subsection{Hélice}

\begin{tabular}{|c|c|c|c|c|c|}
\hline Posição & Profundidade $\mathrm{m}$ & Diâmetro cm & \multirow[t]{7}{*}{ SPT } & Interpolado & \multirow[t]{7}{*}{ Ajustado } \\
\hline 6 & 12.29 & 40.64 & & \multirow[t]{6}{*}{30.00} & \\
\hline 5 & 13.23 & 40.64 & & & \\
\hline 4 & 14.17 & 40.64 & & & \\
\hline 3 & 15.10 & 40.64 & & & \\
\hline 2 & 15.93 & 35.56 & & & \\
\hline 1 & 16.63 & 30.48 & & & \\
\hline
\end{tabular}

\subsection{Fuste}




\begin{tabular}{cccccc}
\hline Comprimento m & Seção & $\begin{array}{c}\text { Diâmetro externo } \\
\mathrm{cm}\end{array}$ & $\begin{array}{c}\text { Diâmetro interno } \\
\mathrm{cm}\end{array}$ & $\mathrm{cm}$ & $\mathrm{cm}$ \\
\hline 15.95 & Circular Vazada & 10.00 & 8.50
\end{tabular}

\subsection{Prova de Carga}

\begin{tabular}{cc}
\hline Força kN & Deslocamento mm \\
\hline 0.00 & 0.00 \\
\hline 182.40 & 9.77 \\
\hline 243.20 & 13.29 \\
\hline 304.01 & 17.54 \\
\hline 364.81 & 25.65 \\
\hline 425.61 & 67.50 \\
\hline 121.60 & 44.46 \\
\hline 182.40 & 8.26 \\
\hline 243.20 & 11.57 \\
\hline 304.01 & 16.38 \\
\hline 364.81 & 20.93 \\
\hline 425.61 & 44.39 \\
\hline 486.41 & 55.25 \\
\hline 243.20 & 49.92 \\
\hline 121.60 & 43.27 \\
\hline 0.00 & 34.50
\end{tabular}

\subsection{Carga de Ruptura}

\begin{tabular}{rc}
\hline Método & Força MN \\
\hline Davisson (1972) & 0.28 \\
\hline $\mathrm{D} / 10$ & 0.42 \\
\hline Livneh e El Naggar (2008) & 0.42 \\
\hline NBR 6122 (2010) & 0.36
\end{tabular}




\section{E2310-2-1}

\subsection{Geral}

$$
\text { Id }: 13
$$

Comprimento $\mathrm{m}: 15.20$

$$
\text { Inclinação }{ }^{\circ}: 0.00
$$

Correção da profundidade (m) : 0.00

\subsection{SPT e Torque}

\begin{tabular}{cc}
\hline \multicolumn{2}{c}{ Torque } \\
\hline Profundidade $\mathrm{m}$ & Torque kN.m \\
\hline 4.00 & 2.03 \\
\hline 3.00 & 2.98 \\
\hline 5.00 & 4.75 \\
\hline 6.00 & 5.83 \\
\hline 7.00 & 6.91 \\
\hline 8.00 & 7.19 \\
\hline 9.00 & 7.73 \\
\hline 10.00 & 8.13 \\
\hline 11.00 & 8.68 \\
\hline 12.00 & 9.36 \\
\hline 13.00 & 12.20 \\
\hline 14.00 & 15.73 \\
\hline 15.00 & 16.68
\end{tabular}

\begin{tabular}{ccl}
\hline & \multicolumn{2}{c}{ SPT } \\
\hline Profundidade $\mathrm{m}$ & Nspt & Solo \\
\hline 1.00 & 1.00 & Areia \\
\hline 2.00 & 1.00 & Areia \\
\hline 3.00 & 1.00 & Areia \\
\hline 4.00 & 1.00 & Areia \\
\hline 5.00 & 1.00 & Areia \\
\hline 6.00 & 5.00 & Areia \\
\hline 7.00 & 10.00 & Areia \\
\hline 8.00 & 27.00 & Areia \\
\hline 9.00 & 28.00 & Areia \\
\hline 10.00 & 25.00 & Areia
\end{tabular}

\begin{tabular}{|c|c|c|c|c|c|}
\hline Posição & Profundidade $\mathrm{m}$ & Diâmetro cm & SPT & Interpolado & Ajustado \\
\hline 4 & 12.08 & 35.56 & & & \\
\hline 3 & 13.16 & 35.56 & & & \\
\hline 2 & 14.00 & 30.48 & & & \\
\hline 1 & 14.81 & 25.40 & & & \\
\hline
\end{tabular}

14.3. Hélice

\subsection{Fuste}

\begin{tabular}{cccccc}
\hline Comprimento m & Seção & $\begin{array}{c}\text { Diâmetro externo } \\
\mathrm{cm}\end{array}$ & $\begin{array}{c}\text { Diâmetro interno } \\
\mathrm{cm}\end{array}$ & $\mathrm{cm}$ & $\mathrm{cm}$ \\
\hline 12.08 & Circular Vazada & 10.00 & 8.50 & &
\end{tabular}

\subsection{Prova de Carga}


Força kN

\begin{tabular}{|c|c|}
\hline 0.00 & 0.00 \\
\hline 16.67 & 0.55 \\
\hline 33.34 & 1.65 \\
\hline 66.69 & 3.85 \\
\hline 100.03 & 6.48 \\
\hline 133.37 & 9.21 \\
\hline 166.71 & 12.18 \\
\hline 200.06 & 15.38 \\
\hline 233.40 & 19.10 \\
\hline 266.74 & 23.16 \\
\hline 300.08 & 27.16 \\
\hline 333.43 & 33.14 \\
\hline 300.08 & 32.24 \\
\hline 266.74 & 30.95 \\
\hline 233.40 & 29.37 \\
\hline 200.06 & 27.88 \\
\hline 166.71 & 26.55 \\
\hline 133.37 & 24.62 \\
\hline 100.03 & 23.11 \\
\hline 66.69 & 21.39 \\
\hline 33.34 & 19.27 \\
\hline 0.00 & 16.26 \\
\hline 0.00 & 16.26 \\
\hline 16.67 & 16.62 \\
\hline 33.34 & 17.74 \\
\hline 66.69 & 19.56 \\
\hline 100.03 & 21.24 \\
\hline 133.37 & 22.95 \\
\hline 166.71 & 24.78 \\
\hline 200.06 & 26.47 \\
\hline 233.40 & 28.36 \\
\hline 266.74 & 30.06 \\
\hline 300.08 & 32.04 \\
\hline 333.43 & 34.98 \\
\hline 300.08 & 34.04 \\
\hline 266.74 & 32.86 \\
\hline 233.40 & 31.18 \\
\hline 200.06 & 29.90 \\
\hline 166.71 & 28.25 \\
\hline 133.37 & 25.19 \\
\hline 100.03 & 24.98 \\
\hline 66.69 & 23.25 \\
\hline 33.34 & 21.26 \\
\hline 0.00 & 18.27 \\
\hline 0.00 & 18.27 \\
\hline 33.34 & 19.80 \\
\hline 133.37 & 25.53 \\
\hline 200.06 & 29.18 \\
\hline 266.74 & 33.28 \\
\hline 333.43 & 39.10 \\
\hline 350.10 & 39.97 \\
\hline 366.77 & 43.02 \\
\hline
\end{tabular}




\begin{tabular}{ll}
\hline 383.44 & 46.00 \\
\hline 400.11 & 48.67 \\
\hline 416.78 & 52.60 \\
\hline 433.45 & 56.48 \\
\hline 450.13 & 63.12 \\
\hline 466.80 & 65.20
\end{tabular}

\subsection{Carga de Ruptura}

\begin{tabular}{rc}
\hline Método & Força MN \\
\hline Davisson (1972) & 0.13 \\
\hline D/10 & 0.31 \\
\hline Livneh e El Naggar (2008) & 0.32 \\
\hline NBR 6122(2010) & 0.20
\end{tabular}




\section{E2310-2-2}

\subsection{Geral}

$$
\text { Id : } 14
$$

Comprimento $\mathrm{m}: 15.00$

$$
\text { Inclinação }{ }^{\circ}: 0.00
$$

Correção da profundidade (m) : 0.00

\subsection{SPT e Torque}

\begin{tabular}{cc}
\hline \multicolumn{2}{c}{ Torque } \\
\hline Profundidade $\mathrm{m}$ & Torque kN.m \\
\hline 3.00 & 3.12 \\
\hline 4.00 & 3.39 \\
\hline 5.00 & 4.47 \\
\hline 6.00 & 5.69 \\
\hline 7.00 & 6.78 \\
\hline 8.00 & 6.91 \\
\hline 9.00 & 7.59 \\
\hline 10.00 & 7.86 \\
\hline 11.00 & 8.13 \\
\hline 12.00 & 8.27 \\
\hline 13.00 & 10.44 \\
\hline 14.00 & 15.32 \\
\hline 15.00 & 16.68
\end{tabular}

\begin{tabular}{ccl}
\hline & \multicolumn{2}{c}{ SPT } \\
\hline Profundidade $\mathrm{m}$ & Nspt & Solo \\
\hline 1.00 & 1.00 & Areia \\
\hline 2.00 & 1.00 & Areia \\
\hline 3.00 & 1.00 & Areia \\
\hline 4.00 & 1.00 & Areia \\
\hline 5.00 & 1.00 & Areia \\
\hline 6.00 & 5.00 & Areia \\
\hline 7.00 & 10.00 & Areia \\
\hline 8.00 & 27.00 & Areia \\
\hline 9.00 & 28.00 & Areia \\
\hline 10.00 & 25.00 & Areia
\end{tabular}

\begin{tabular}{|c|c|c|c|c|c|}
\hline Posição & Profundidade $\mathrm{m}$ & Diâmetro cm & SPT & Interpolado & Ajustado \\
\hline 4 & 12.08 & 35.56 & & & \\
\hline 3 & 13.16 & 35.56 & & & \\
\hline 2 & 14.00 & 30.48 & & & \\
\hline 1 & 14.81 & 25.40 & & & \\
\hline
\end{tabular}

15.3. Hélice

\subsection{Fuste}

\begin{tabular}{cccccc}
\hline Comprimento m & Seção & $\begin{array}{c}\text { Diâmetro externo } \\
\mathrm{cm}\end{array}$ & $\begin{array}{c}\text { Diâmetro interno } \\
\mathrm{cm}\end{array}$ & $\mathrm{cm}$ & $\mathrm{cm}$ \\
\hline 12.08 & Circular Vazada & 10.00 & 8.50 & &
\end{tabular}

\subsection{Prova de Carga}


Força kN

\begin{tabular}{|c|c|}
\hline 0.00 & 0.00 \\
\hline 16.67 & 0.55 \\
\hline 33.34 & 1.44 \\
\hline 66.69 & 2.61 \\
\hline 100.03 & 4.94 \\
\hline 133.37 & 7.29 \\
\hline 166.71 & 10.71 \\
\hline 200.06 & 13.64 \\
\hline 233.40 & 16.55 \\
\hline 266.74 & 19.43 \\
\hline 300.08 & 22.45 \\
\hline 333.43 & 25.41 \\
\hline 300.08 & 25.27 \\
\hline 266.74 & 24.43 \\
\hline 233.40 & 23.62 \\
\hline 200.06 & 22.31 \\
\hline 166.71 & 20.94 \\
\hline 133.37 & 19.39 \\
\hline 100.03 & 17.73 \\
\hline 66.69 & 16.15 \\
\hline 33.34 & 14.28 \\
\hline 0.00 & 11.95 \\
\hline 0.00 & 11.95 \\
\hline 16.67 & 12.57 \\
\hline 33.34 & 13.18 \\
\hline 66.69 & 14.88 \\
\hline 100.03 & 16.27 \\
\hline 133.37 & 17.88 \\
\hline 166.71 & 19.37 \\
\hline 200.06 & 20.83 \\
\hline 233.40 & 22.41 \\
\hline 266.74 & 23.94 \\
\hline 300.08 & 25.65 \\
\hline 333.43 & 27.03 \\
\hline 300.08 & 27.70 \\
\hline 266.74 & 26.91 \\
\hline 233.40 & 25.51 \\
\hline 200.06 & 23.97 \\
\hline 166.71 & 22.58 \\
\hline 133.37 & 20.89 \\
\hline 100.03 & 19.40 \\
\hline 66.69 & 17.66 \\
\hline 33.34 & 15.73 \\
\hline 0.00 & 13.46 \\
\hline 0.00 & 13.46 \\
\hline 33.34 & 15.49 \\
\hline 133.37 & 19.80 \\
\hline 200.06 & 22.79 \\
\hline 266.74 & 25.65 \\
\hline 333.43 & 28.51 \\
\hline 350.10 & 29.67 \\
\hline 366.77 & 31.27 \\
\hline
\end{tabular}




\subsection{Carga de Ruptura}

\begin{tabular}{rc}
\hline Método & Força MN \\
\hline Davisson (1972) & 0.16 \\
\hline Livneh e El Naggar (2008) & 0.38 \\
\hline D/10 & 0.38 \\
\hline NBR 6122(2010) & 0.22
\end{tabular}




\section{E2310-2-3}

\subsection{Geral}

$$
\text { Id : } 15
$$

Comprimento $\mathrm{m}: 15.00$

$$
\text { Inclinação }{ }^{\circ}: 0.00
$$

Correção da profundidade (m) : 0.00

\subsection{SPT e Torque}

\begin{tabular}{cc}
\hline \multicolumn{2}{c}{ Torque } \\
\hline Profundidade $\mathrm{m}$ & Torque kN.m \\
\hline 3.00 & 3.12 \\
\hline 4.00 & 3.66 \\
\hline 5.00 & 4.61 \\
\hline 6.00 & 5.56 \\
\hline 7.00 & 6.51 \\
\hline 8.00 & 6.78 \\
\hline 9.00 & 7.05 \\
\hline 10.00 & 7.86 \\
\hline 11.00 & 9.08 \\
\hline 12.00 & 9.76 \\
\hline 13.00 & 12.20 \\
\hline 14.00 & 14.37 \\
\hline 15.00 & 16.95
\end{tabular}

\begin{tabular}{ccl}
\hline & \multicolumn{2}{c}{ SPT } \\
\hline Profundidade $\mathrm{m}$ & Nspt & Solo \\
\hline 1.00 & 1.00 & Areia \\
\hline 2.00 & 1.00 & Areia \\
\hline 3.00 & 1.00 & Areia \\
\hline 4.00 & 1.00 & Areia \\
\hline 5.00 & 1.00 & Areia \\
\hline 6.00 & 5.00 & Areia \\
\hline 7.00 & 10.00 & Areia \\
\hline 8.00 & 27.00 & Areia \\
\hline 9.00 & 28.00 & Areia \\
\hline 10.00 & 25.00 & Areia
\end{tabular}

\begin{tabular}{|c|c|c|c|c|c|}
\hline Posição & Profundidade $\mathrm{m}$ & Diâmetro cm & SPT & Interpolado & Ajustado \\
\hline 4 & 12.08 & 35.56 & & & \\
\hline 3 & 13.16 & 35.56 & & & \\
\hline 2 & 14.00 & 30.48 & & & \\
\hline 1 & 14.81 & 25.40 & & & \\
\hline
\end{tabular}

16.3. Hélice

\subsection{Fuste}

\begin{tabular}{cccccc}
\hline Comprimento m & Seção & $\begin{array}{c}\text { Diâmetro externo } \\
\mathrm{cm}\end{array}$ & $\begin{array}{c}\text { Diâmetro interno } \\
\mathrm{cm}\end{array}$ & $\mathrm{cm}$ & $\mathrm{cm}$ \\
\hline 12.08 & Circular Vazada & 10.00 & 8.50 & &
\end{tabular}

\subsection{Prova de Carga}


Força kN

\begin{tabular}{|c|c|}
\hline 0.00 & 0.00 \\
\hline 16.67 & 0.12 \\
\hline 33.34 & 1.09 \\
\hline 66.69 & 3.14 \\
\hline 100.03 & 5.63 \\
\hline 133.37 & 8.65 \\
\hline 166.71 & 12.25 \\
\hline 200.06 & 16.34 \\
\hline 233.40 & 20.71 \\
\hline 266.74 & 25.43 \\
\hline 300.08 & 29.20 \\
\hline 333.43 & 34.65 \\
\hline 300.08 & 33.84 \\
\hline 266.74 & 32.65 \\
\hline 233.40 & 30.64 \\
\hline 200.06 & 29.00 \\
\hline 166.71 & 27.22 \\
\hline 133.37 & 25.59 \\
\hline 100.03 & 23.84 \\
\hline 66.69 & 21.95 \\
\hline 33.34 & 19.93 \\
\hline 0.00 & 17.09 \\
\hline 0.00 & 17.09 \\
\hline 16.67 & 17.38 \\
\hline 33.34 & 18.50 \\
\hline 66.69 & 20.35 \\
\hline 100.03 & 22.18 \\
\hline 133.37 & 23.71 \\
\hline 166.71 & 25.95 \\
\hline 200.06 & 27.73 \\
\hline 233.40 & 29.66 \\
\hline 266.74 & 31.75 \\
\hline 300.08 & 34.06 \\
\hline 333.43 & 36.73 \\
\hline 300.08 & 35.72 \\
\hline 266.74 & 34.36 \\
\hline 233.40 & 32.53 \\
\hline 200.06 & 31.86 \\
\hline 166.71 & 29.73 \\
\hline 133.37 & 28.00 \\
\hline 100.03 & 26.22 \\
\hline 66.69 & 24.80 \\
\hline 33.34 & 22.47 \\
\hline 0.00 & 19.36 \\
\hline
\end{tabular}

\subsection{Carga de Ruptura}

Método

Livneh e El Naggar (2008)

$\mathrm{D} / 10$
Força MN

0.32

0.32 
Davisson (1972)

0.14

NBR 6122 (2010)

0.18 


\section{E2366-2-1}

\subsection{Geral}

$$
\text { Id }: 16
$$

Comprimento $\mathrm{m}: 8.00$ Inclinação ${ }^{\circ}: 0.00$

Correção da profundidade (m) : 0.00

\subsection{SPT e Torque}

\begin{tabular}{cc}
\hline \multicolumn{2}{c}{ Torque } \\
\hline Profundidade $\mathrm{m}$ & Torque kN.m \\
\hline 3.00 & 2.98 \\
\hline 4.00 & 2.58 \\
\hline 5.00 & 3.53 \\
\hline 6.00 & 4.34 \\
\hline 7.00 & 7.46 \\
\hline 8.00 & 15.19
\end{tabular}

\begin{tabular}{ccl}
\hline & \multicolumn{2}{c}{ SPT } \\
\hline Profundidade m & Nspt & Solo \\
\hline 8.00 & 19.00 & Areia siltosa \\
\hline 7.00 & 18.00 & Areia siltosa \\
\hline 6.00 & 18.00 & Areia siltosa \\
\hline 5.00 & 5.00 & Areia argilosa \\
\hline 4.00 & 2.00 & Areia argilosa \\
\hline 3.00 & 2.00 & Areia argilosa \\
\hline 2.00 & 1.82 & Areia argilosa \\
\hline 1.00 & 2.00 & Areia argilosa
\end{tabular}

\subsection{Hélice}

\begin{tabular}{cccccc}
\hline Posição & Profundidade $m$ & Diâmetro cm & SPT & Interpolado & Ajustado \\
\hline 4 & 5.08 & 35.56 & 2.00 & 4.34 & 4.34 \\
\hline 3 & 6.16 & 35.56 & 18.00 & 16.18 & 16.18 \\
\hline 2 & 7.00 & 30.48 & 18.00 & 18.00 & 18.00 \\
\hline 1 & 7.81 & 25.40 & 18.00 & 18.51 & 18.51
\end{tabular}

17.4. Fuste

\begin{tabular}{cccccc}
\hline Comprimento m & Seção & $\begin{array}{c}\text { Diâmetro externo } \\
\mathrm{cm}\end{array}$ & $\begin{array}{c}\text { Diâmetro interno } \\
\mathrm{cm}\end{array}$ & $\mathrm{cm}$ & $\mathrm{cm}$ \\
\hline 5.08 & Circular Vazada & 10.00 & 8.50
\end{tabular}

\subsection{Prova de Carga}

\begin{tabular}{cc}
\hline Força kN & Deslocamento mm \\
\hline 0.00 & 0.00 \\
\hline 16.67 & 0.84 \\
\hline 33.34 & 1.44 \\
\hline 66.69 & 2.79
\end{tabular}




\begin{tabular}{|c|c|}
\hline 100.03 & 5.31 \\
\hline 133.37 & 9.12 \\
\hline 166.71 & 11.96 \\
\hline 200.06 & 15.38 \\
\hline 233.40 & 18.64 \\
\hline 266.74 & 21.84 \\
\hline 300.08 & 25.14 \\
\hline 333.43 & 28.24 \\
\hline 300.08 & 27.65 \\
\hline 266.74 & 27.04 \\
\hline 233.40 & 26.05 \\
\hline 200.06 & 24.96 \\
\hline 166.71 & 24.04 \\
\hline 133.37 & 23.06 \\
\hline 100.03 & 21.99 \\
\hline 66.69 & 20.83 \\
\hline 33.34 & 19.31 \\
\hline 0.00 & 12.68 \\
\hline 0.00 & 12.68 \\
\hline 16.67 & 17.50 \\
\hline 33.34 & 18.32 \\
\hline 66.69 & 19.41 \\
\hline 100.03 & 20.46 \\
\hline 133.37 & 21.67 \\
\hline 166.71 & 22.79 \\
\hline 200.06 & 23.92 \\
\hline 233.40 & 25.37 \\
\hline 266.74 & 26.73 \\
\hline 300.08 & 28.14 \\
\hline 333.43 & 30.09 \\
\hline 300.08 & 29.56 \\
\hline 266.74 & 28.56 \\
\hline 233.40 & 27.75 \\
\hline 200.06 & 26.76 \\
\hline 166.71 & 25.94 \\
\hline 133.37 & 24.89 \\
\hline 100.03 & 23.95 \\
\hline 66.69 & 22.62 \\
\hline 33.34 & 21.31 \\
\hline 0.00 & 19.61 \\
\hline
\end{tabular}

\subsection{Carga de Ruptura}

\begin{tabular}{rc}
\hline \multicolumn{1}{c}{ Método } & Força MN \\
\hline D/10 & 0.34 \\
\hline Livneh e El Naggar (2008) & 0.33 \\
\hline Davisson (1972) & 0.12 \\
\hline NBR 6122 (2010) & 0.17
\end{tabular}


18. E2366-2-2

\subsection{Geral}

Id : 17

Comprimento $\mathrm{m}: 8.00$

Inclinação $^{\circ}: 0.00$

Correção da profundidade (m) : 0.00

\subsection{SPT e Torque}

\begin{tabular}{cc}
\hline \multicolumn{2}{c}{ Torque } \\
\hline Profundidade $\mathrm{m}$ & Torque kN.m \\
\hline 3.00 & 3.25 \\
\hline 4.00 & 4.20 \\
\hline 5.00 & 5.02 \\
\hline 6.00 & 6.51 \\
\hline 7.00 & 8.95 \\
\hline 8.00 & 14.91
\end{tabular}

\begin{tabular}{ccc}
\hline & \multicolumn{2}{c}{ SPT } \\
\hline Profundidade $\mathrm{m}$ & Nspt & Solo \\
\hline 1.00 & 2.00 & Areia argilosa \\
\hline 2.00 & 1.82 & Areia argilosa \\
\hline 3.00 & 2.00 & Areia argilosa \\
\hline 4.00 & 2.00 & Areia argilosa \\
\hline 5.00 & 5.00 & Areia argilosa \\
\hline 6.00 & 18.00 & Areia siltosa \\
\hline 7.00 & 18.00 & Areia siltosa \\
\hline 8.00 & 19.00 & Areia siltosa
\end{tabular}

\subsection{Hélice}

\begin{tabular}{cccccc}
\hline Posição & Profundidade $m$ & Diâmetro cm & SPT & Interpolado & Ajustado \\
\hline 4 & 5.08 & 35.56 & 2.00 & 4.34 & 4.34 \\
\hline 3 & 6.16 & 35.56 & 5.00 & 16.18 & 16.18 \\
\hline 2 & 7.00 & 30.48 & 18.00 & 18.00 & 18.00 \\
\hline 1 & 7.81 & 25.40 & 18.00 & 18.51 & 18.51
\end{tabular}

18.4. Fuste

\begin{tabular}{cccccc}
\hline Comprimento m & Seção & $\begin{array}{c}\text { Diâmetro externo } \\
\mathrm{cm}\end{array}$ & $\begin{array}{c}\text { Diâmetro interno } \\
\mathrm{cm}\end{array}$ & $\mathrm{cm}$ & $\mathrm{cm}$ \\
\hline 5.08 & Circular Vazada & 10.00 & 8.50
\end{tabular}

\subsection{Prova de Carga}

\begin{tabular}{cc}
\hline Força kN & Deslocamento $\mathrm{mm}$ \\
\hline 0.00 & 0.00 \\
\hline 16.67 & 0.42 \\
\hline 33.34 & 0.96 \\
\hline 66.69 & 1.85
\end{tabular}




\begin{tabular}{|c|c|}
\hline 100.03 & 2.88 \\
\hline 133.37 & 3.75 \\
\hline 166.71 & 4.76 \\
\hline 200.06 & 5.75 \\
\hline 233.40 & 6.87 \\
\hline 266.74 & 8.11 \\
\hline 300.08 & 9.88 \\
\hline 333.43 & 11.76 \\
\hline 300.08 & 11.57 \\
\hline 266.74 & 10.92 \\
\hline 233.40 & 9.88 \\
\hline 200.06 & 9.07 \\
\hline 166.71 & 8.17 \\
\hline 133.37 & 7.26 \\
\hline 100.03 & 6.29 \\
\hline 66.69 & 5.21 \\
\hline 33.34 & 4.02 \\
\hline 0.00 & 2.37 \\
\hline 0.00 & 2.37 \\
\hline 16.67 & 2.48 \\
\hline 33.34 & 2.92 \\
\hline 66.69 & 3.50 \\
\hline 100.03 & 4.89 \\
\hline 133.37 & 5.79 \\
\hline 166.71 & 6.77 \\
\hline 200.06 & 7.67 \\
\hline 233.40 & 8.59 \\
\hline 266.74 & 9.53 \\
\hline 300.08 & 10.50 \\
\hline 333.43 & 11.65 \\
\hline 300.08 & 11.06 \\
\hline 266.74 & 10.42 \\
\hline 233.40 & 9.71 \\
\hline 200.06 & 8.87 \\
\hline 166.71 & 8.27 \\
\hline 133.37 & 7.58 \\
\hline 100.03 & 6.38 \\
\hline 66.69 & 5.47 \\
\hline 33.34 & 4.64 \\
\hline 0.00 & 3.65 \\
\hline 0.00 & 3.65 \\
\hline 33.34 & 4.95 \\
\hline 133.37 & 9.31 \\
\hline 266.74 & 10.51 \\
\hline 333.43 & 12.93 \\
\hline 350.10 & 12.99 \\
\hline 366.77 & 14.14 \\
\hline 383.44 & 15.08 \\
\hline 400.11 & 15.92 \\
\hline 416.78 & 17.68 \\
\hline 433.45 & 19.13 \\
\hline 450.13 & 21.18 \\
\hline 466.80 & 22.35 \\
\hline
\end{tabular}


18.6. Carga de Ruptura

\begin{tabular}{cc}
\hline Método & Força MN \\
\hline Davisson (1972) & 0.29 \\
\hline NBR 6122 (2010) & 0.37
\end{tabular}


19. E2366-2-3

\subsection{Geral}

$$
\text { Id }: 18
$$

Comprimento $\mathrm{m}: 9.00$ Inclinação ${ }^{\circ}: 0.00$

Correção da profundidade (m) : 0.00

\subsection{SPT e Torque}

\begin{tabular}{cc}
\hline \multicolumn{2}{c}{ Torque } \\
\hline Profundidade $\mathrm{m}$ & Torque kN.m \\
\hline 3.00 & 2.58 \\
\hline 4.00 & 2.58 \\
\hline 5.00 & 2.71 \\
\hline 6.00 & 4.20 \\
\hline 7.00 & 7.46 \\
\hline 8.00 & 11.66 \\
\hline 9.00 & 14.91
\end{tabular}

\begin{tabular}{ccc}
\hline & \multicolumn{2}{c}{ SPT } \\
\hline Profundidade $\mathrm{m}$ & Nspt & Solo \\
\hline 1.00 & 2.00 & Areia argilosa \\
\hline 8.00 & 19.00 & Areia siltosa \\
\hline 7.00 & 18.00 & Areia siltosa \\
\hline 6.00 & 18.00 & Areia siltosa \\
\hline 5.00 & 5.00 & Areia argilosa \\
\hline 4.00 & 2.00 & Areia argilosa \\
\hline 3.00 & 2.00 & Areia argilosa \\
\hline 2.00 & 1.82 & Areia argilosa
\end{tabular}

\subsection{Hélice}

\begin{tabular}{cccccc}
\hline Posição & Profundidade $m$ & Diâmetro cm & SPT & Interpolado & Ajustado \\
\hline 4 & 6.08 & 35.56 & 5.00 & 15.14 & 15.14 \\
\hline 3 & 7.16 & 35.56 & 18.00 & 18.00 & 18.00 \\
\hline 2 & 8.00 & 30.48 & 18.00 & 18.70 & 18.70 \\
\hline 1 & 8.81 & 25.40 & 19.00 & 19.00 & 19.00
\end{tabular}

19.4. Fuste

\begin{tabular}{cccccc}
\hline Comprimento m & Seção & $\begin{array}{c}\text { Diâmetro externo } \\
\mathrm{cm}\end{array}$ & $\begin{array}{c}\text { Diâmetro interno } \\
\mathrm{cm}\end{array}$ & $\mathrm{cm}$ & $\mathrm{cm}$ \\
\hline 6.08 & Circular Vazada & 10.00 & 8.50
\end{tabular}

\subsection{Prova de Carga}

\begin{tabular}{cc}
\hline Força kN & Deslocamento mm \\
\hline 0.00 & 0.00 \\
\hline 16.67 & 1.04 \\
\hline 33.34 & 1.96 \\
\hline 66.69 & 3.57
\end{tabular}




\begin{tabular}{|c|c|}
\hline 100.03 & 5.73 \\
\hline 133.37 & 8.98 \\
\hline 166.71 & 12.38 \\
\hline 200.06 & 15.84 \\
\hline 233.40 & 19.10 \\
\hline 266.74 & 23.36 \\
\hline 300.08 & 26.48 \\
\hline 333.43 & 30.84 \\
\hline 300.08 & 29.84 \\
\hline 266.74 & 29.00 \\
\hline 233.40 & 28.11 \\
\hline 200.06 & 27.31 \\
\hline 166.71 & 26.18 \\
\hline 133.37 & 24.75 \\
\hline 100.03 & 24.30 \\
\hline 66.69 & 23.08 \\
\hline 33.34 & 21.61 \\
\hline 0.00 & 18.76 \\
\hline 0.00 & 18.76 \\
\hline 16.67 & 19.08 \\
\hline 33.34 & 19.98 \\
\hline 66.69 & 21.26 \\
\hline 100.03 & 22.46 \\
\hline 133.37 & 23.50 \\
\hline 166.71 & 24.77 \\
\hline 200.06 & 25.74 \\
\hline 233.40 & 26.95 \\
\hline 266.74 & 28.14 \\
\hline 300.08 & 29.64 \\
\hline 333.43 & 31.33 \\
\hline 300.08 & 30.66 \\
\hline 266.74 & 29.72 \\
\hline 233.40 & 28.86 \\
\hline 200.06 & 28.18 \\
\hline 166.71 & 27.24 \\
\hline 133.37 & 26.14 \\
\hline 100.03 & 25.00 \\
\hline 66.69 & 24.29 \\
\hline 33.34 & 22.48 \\
\hline 0.00 & 19.39 \\
\hline 0.00 & 19.39 \\
\hline 33.34 & 21.40 \\
\hline 133.37 & 24.67 \\
\hline 266.74 & 27.96 \\
\hline 333.43 & 25.11 \\
\hline 350.10 & 25.87 \\
\hline 366.77 & 27.42 \\
\hline 383.44 & 28.82 \\
\hline 400.11 & 30.55 \\
\hline 416.78 & 32.64 \\
\hline 433.45 & 35.39 \\
\hline 450.13 & 38.06 \\
\hline 466.80 & 40.38 \\
\hline
\end{tabular}


19.6. Carga de Ruptura

\begin{tabular}{cc}
\multicolumn{1}{c}{ Método } & Força MN \\
\hline D/10 & 0.41 \\
\hline Livneh e El Naggar (2008) & 0.39 \\
\hline Davisson (1972) & 0.12 \\
\hline NBR 6122 (2010) & 0.17
\end{tabular}




\section{E2377-1-1}

\subsection{Geral}

$$
\text { Id }: 19
$$

Comprimento $\mathrm{m}: 10.00$

$$
\text { Inclinação }{ }^{\circ}: 0.00
$$

Correção da profundidade (m) : 0.00

\subsection{SPT e Torque}

\begin{tabular}{cc}
\hline \multicolumn{2}{c}{ Torque } \\
\hline Profundidade $\mathrm{m}$ & Torque kN.m \\
\hline 3.00 & 2.98 \\
\hline 4.00 & 4.47 \\
\hline 5.00 & 5.02 \\
\hline 6.00 & 5.97 \\
\hline 7.00 & 6.10 \\
\hline 8.00 & 9.63 \\
\hline 9.00 & 11.25 \\
\hline 10.00 & 16.13
\end{tabular}

\begin{tabular}{ccc}
\hline \multicolumn{2}{c}{ SPT } \\
\hline Profundidade m & Nspt & Solo \\
\hline 1.00 & 4.00 & Areia siltosa \\
\hline 2.00 & 4.00 & Areia siltosa \\
\hline 3.00 & 1.58 & Areia siltosa \\
\hline 4.00 & 2.00 & Areia siltosa \\
\hline 5.00 & 3.00 & Areia argilosa \\
\hline 6.00 & 6.00 & Areia silto argilosa \\
\hline 7.00 & 8.00 & Areia silto argilosa \\
\hline 8.00 & 18.00 & Areia siltosa
\end{tabular}

\begin{tabular}{|c|c|c|c|c|c|}
\hline Posição & Profundidade $\mathrm{m}$ & Diâmetro cm & \multirow[t]{5}{*}{ SPT } & Interpolado & \multirow[t]{5}{*}{ Ajustado } \\
\hline 4 & 7.08 & 35.56 & & 7.56 & \\
\hline 3 & 8.16 & 35.56 & & \multirow[t]{3}{*}{16.60} & \\
\hline 2 & 9.00 & 30.48 & & & \\
\hline 1 & 9.81 & 25.40 & & & \\
\hline
\end{tabular}

20.3. Hélice

\subsection{Fuste}

\begin{tabular}{cccccc}
\hline Comprimento m & Seção & $\begin{array}{c}\text { Diâmetro externo } \\
\mathrm{cm}\end{array}$ & $\begin{array}{c}\text { Diâmetro interno } \\
\mathrm{cm}\end{array}$ & $\mathrm{cm}$ & $\mathrm{cm}$ \\
\hline 7.08 & Circular Vazada & 10.00 & 8.50 & &
\end{tabular}

\subsection{Prova de Carga}

\begin{tabular}{cc}
\hline Força kN & Deslocamento mm \\
\hline 0.00 & 0.00 \\
\hline 16.67 & 1.45 \\
\hline 33.34 & 2.90 \\
\hline 66.69 & 5.62
\end{tabular}




\begin{tabular}{|c|c|}
\hline 100.03 & 8.26 \\
\hline 133.37 & 11.24 \\
\hline 166.71 & 14.82 \\
\hline 200.06 & 18.91 \\
\hline 233.40 & 22.40 \\
\hline 266.74 & 26.27 \\
\hline 300.08 & 31.33 \\
\hline 333.43 & 36.83 \\
\hline 300.08 & 35.65 \\
\hline 266.74 & 34.80 \\
\hline 233.40 & 34.30 \\
\hline 200.06 & 32.66 \\
\hline 166.71 & 31.60 \\
\hline 133.37 & 30.18 \\
\hline 100.03 & 28.84 \\
\hline 66.69 & 27.34 \\
\hline 33.34 & 25.47 \\
\hline 0.00 & 12.96 \\
\hline 0.00 & 12.96 \\
\hline 16.67 & 19.83 \\
\hline 33.34 & 20.67 \\
\hline 66.69 & 22.45 \\
\hline 100.03 & 24.20 \\
\hline 133.37 & 25.86 \\
\hline 166.71 & 27.36 \\
\hline 200.06 & 28.76 \\
\hline 233.40 & 30.30 \\
\hline 266.74 & 32.06 \\
\hline 300.08 & 33.81 \\
\hline 333.43 & 36.52 \\
\hline 300.08 & 35.77 \\
\hline 266.74 & 35.00 \\
\hline 233.40 & 33.80 \\
\hline 200.06 & 32.84 \\
\hline 166.71 & 31.64 \\
\hline 133.37 & 30.47 \\
\hline 100.03 & 29.15 \\
\hline 66.69 & 27.55 \\
\hline 33.34 & 25.84 \\
\hline 0.00 & 13.16 \\
\hline 0.00 & 13.16 \\
\hline 33.34 & 14.61 \\
\hline 133.37 & 18.11 \\
\hline 200.06 & 20.72 \\
\hline 266.74 & 24.03 \\
\hline 333.43 & 27.70 \\
\hline 350.10 & 35.30 \\
\hline 366.77 & 37.39 \\
\hline
\end{tabular}

\subsection{Carga de Ruptura}


Método

Livneh e El Naggar (2008)

$\mathrm{D} / 10$

Davisson (1972)

NBR 6122 (2010)
Força MN

0.35

0.36

0.09

0.15 


\section{E2377-1-2}

\subsection{Geral}

Id :20

Comprimento $\mathrm{m}: 10.00$

Inclinação ${ }^{\circ}: 0.00$

Correção da profundidade (m) : 0.00

\subsection{SPT e Torque}

\begin{tabular}{cc}
\hline \multicolumn{2}{c}{ Torque } \\
\hline Profundidade $\mathrm{m}$ & Torque kN.m \\
\hline 3.00 & 3.25 \\
\hline 4.00 & 5.42 \\
\hline 5.00 & 5.97 \\
\hline 6.00 & 6.91 \\
\hline 7.00 & 7.46 \\
\hline 8.00 & 11.80 \\
\hline 9.00 & 13.96 \\
\hline 10.00 & 15.32
\end{tabular}

\begin{tabular}{ccc}
\hline & \multicolumn{2}{c}{ SPT } \\
\hline Profundidade m & Nspt & Solo \\
\hline 1.00 & 4.00 & Areia siltosa \\
\hline 2.00 & 4.00 & Areia siltosa \\
\hline 3.00 & 1.58 & Areia siltosa \\
\hline 4.00 & 2.00 & Areia siltosa \\
\hline 5.00 & 3.00 & Areia argilosa \\
\hline 6.00 & 6.00 & Areia silto argilosa \\
\hline 7.00 & 8.00 & Areia silto argilosa \\
\hline 8.00 & 18.00 & Areia siltosa
\end{tabular}

21.3. Hélice

\begin{tabular}{|c|c|c|c|c|c|}
\hline Posição & Profundidade $\mathrm{m}$ & Diâmetro cm & SPT & Interpolado & Ajustado \\
\hline 4 & 7.08 & 35.56 & & 7.56 & \\
\hline 3 & 8.16 & 35.56 & & 16.60 & \\
\hline 2 & 9.00 & 30.48 & & & \\
\hline 1 & 9.81 & 25.40 & & & \\
\hline
\end{tabular}

\subsection{Fuste}

\begin{tabular}{cccccc}
\hline Comprimento m & Seção & $\begin{array}{c}\text { Diâmetro externo } \\
\mathrm{cm}\end{array}$ & $\begin{array}{c}\text { Diâmetro interno } \\
\mathrm{cm}\end{array}$ & $\mathrm{cm}$ & $\mathrm{cm}$ \\
\hline 7.08 & Circular Vazada & 10.00 & 8.50
\end{tabular}

\subsection{Prova de Carga}

\begin{tabular}{cc}
\hline Força kN & Deslocamento mm \\
\hline 0.00 & 0.00 \\
\hline 0.00 & 0.00 \\
\hline 0.00 & 0.00 \\
\hline 66.69 & 3.69
\end{tabular}




\begin{tabular}{|c|c|}
\hline 100.03 & 6.43 \\
\hline 133.37 & 8.01 \\
\hline 166.71 & 9.66 \\
\hline 200.06 & 11.57 \\
\hline 233.40 & 13.66 \\
\hline 266.74 & 15.67 \\
\hline 300.08 & 17.91 \\
\hline 333.43 & 20.55 \\
\hline 300.08 & 19.90 \\
\hline 266.74 & 18.98 \\
\hline 233.40 & 17.69 \\
\hline 200.06 & 17.18 \\
\hline 166.71 & 16.12 \\
\hline 133.37 & 14.91 \\
\hline 100.03 & 13.76 \\
\hline 66.69 & 12.82 \\
\hline 33.34 & 10.87 \\
\hline 0.00 & 9.07 \\
\hline 0.00 & 9.07 \\
\hline 16.67 & 9.55 \\
\hline 33.34 & 10.34 \\
\hline 66.69 & 11.59 \\
\hline 100.03 & 13.31 \\
\hline 133.37 & 14.56 \\
\hline 166.71 & 15.33 \\
\hline 200.06 & 16.46 \\
\hline 233.40 & 17.62 \\
\hline 266.74 & 18.79 \\
\hline 300.08 & 20.01 \\
\hline 333.43 & 21.44 \\
\hline 300.08 & 20.76 \\
\hline 266.74 & 19.97 \\
\hline 233.40 & 19.04 \\
\hline 200.06 & 18.04 \\
\hline 166.71 & 17.08 \\
\hline 133.37 & 15.90 \\
\hline 100.03 & 14.73 \\
\hline 66.69 & 13.32 \\
\hline 33.34 & 11.83 \\
\hline 0.00 & 9.92 \\
\hline 0.00 & 9.92 \\
\hline 33.34 & 11.37 \\
\hline 133.37 & 14.86 \\
\hline 200.06 & 17.47 \\
\hline 266.74 & 20.78 \\
\hline 333.43 & 24.45 \\
\hline 350.10 & 32.05 \\
\hline 366.77 & 34.15 \\
\hline
\end{tabular}

\subsection{Carga de Ruptura}


$\mathrm{D} / 10$ 0.35

Davisson (1972)

0.15

Livneh e El Naggar (2008)

0.35

NBR 6122 (2010) 


\section{E2377-1-3}

\subsection{Geral}

Id $: 21$

Comprimento $\mathrm{m}: 10.00$ Inclinação $^{\circ}: 0.00$

Correção da profundidade (m) : 0.00

\subsection{SPT e Torque}

\begin{tabular}{cc}
\hline \multicolumn{2}{c}{ Torque } \\
\hline Profundidade $\mathrm{m}$ & Torque kN.m \\
\hline 3.00 & 3.12 \\
\hline 4.00 & 5.02 \\
\hline 5.00 & 5.97 \\
\hline 6.00 & 6.51 \\
\hline 7.00 & 7.86 \\
\hline 8.00 & 8.54 \\
\hline 9.00 & 10.30 \\
\hline 10.00 & 16.41
\end{tabular}

\begin{tabular}{ccc}
\hline & \multicolumn{2}{c}{ SPT } \\
\hline Profundidade m & Nspt & Solo \\
\hline 1.00 & 4.00 & Areia siltosa \\
\hline 2.00 & 4.00 & Areia siltosa \\
\hline 3.00 & 1.58 & Areia siltosa \\
\hline 4.00 & 2.00 & Areia siltosa \\
\hline 5.00 & 3.00 & Areia argilosa \\
\hline 6.00 & 6.00 & Areia silto argilosa \\
\hline 7.00 & 8.00 & Areia silto argilosa \\
\hline 8.00 & 18.00 & Areia siltosa
\end{tabular}

\subsection{Hélice}

\begin{tabular}{|c|c|c|c|c|c|}
\hline Posição & Profundidade $\mathrm{m}$ & Diâmetro cm & \multirow[t]{5}{*}{ SPT } & Interpolado & \multirow[t]{5}{*}{ Ajustado } \\
\hline 4 & 7.08 & 35.56 & & 7.56 & \\
\hline 3 & 8.16 & 35.56 & & \multirow[t]{3}{*}{16.60} & \\
\hline 2 & 9.00 & 30.48 & & & \\
\hline 1 & 9.81 & 25.40 & & & \\
\hline
\end{tabular}

22.4. Fuste

\begin{tabular}{cccccc}
\hline Comprimento $\mathrm{m}$ & Seção & $\begin{array}{c}\text { Diâmetro externo } \\
\mathrm{cm}\end{array}$ & $\begin{array}{c}\text { Diâmetro interno } \\
\mathrm{cm}\end{array}$ & $\mathrm{cm}$ & $\mathrm{cm}$ \\
\hline 7.08 & Circular Vazada & 10.00 & 8.50
\end{tabular}

\subsection{Prova de Carga}

\begin{tabular}{cc}
\hline Força kN & Deslocamento mm \\
\hline 0.00 & 0.00 \\
\hline 16.67 & 0.94 \\
\hline 33.34 & 1.95 \\
\hline 66.69 & 3.62
\end{tabular}




\begin{tabular}{|c|c|}
\hline 100.03 & 5.12 \\
\hline 133.37 & 8.02 \\
\hline 166.71 & 11.56 \\
\hline 200.06 & 15.20 \\
\hline 233.40 & 19.13 \\
\hline 266.74 & 22.74 \\
\hline 300.08 & 27.52 \\
\hline 333.43 & 32.46 \\
\hline 300.08 & 31.70 \\
\hline 266.74 & 30.76 \\
\hline 233.40 & 29.67 \\
\hline 200.06 & 28.64 \\
\hline 166.71 & 27.43 \\
\hline 133.37 & 27.27 \\
\hline 100.03 & 25.00 \\
\hline 66.69 & 23.64 \\
\hline 33.34 & 22.29 \\
\hline 0.00 & 16.18 \\
\hline 0.00 & 16.18 \\
\hline 16.67 & 18.79 \\
\hline 33.34 & 19.32 \\
\hline 66.69 & 20.89 \\
\hline 100.03 & 22.61 \\
\hline 133.37 & 24.14 \\
\hline 166.71 & 25.55 \\
\hline 200.06 & 27.05 \\
\hline 233.40 & 28.57 \\
\hline 266.74 & 30.14 \\
\hline 300.08 & 32.25 \\
\hline 333.43 & 34.51 \\
\hline 300.08 & 33.24 \\
\hline 266.74 & 32.55 \\
\hline 233.40 & 31.26 \\
\hline 200.06 & 30.29 \\
\hline 166.71 & 28.54 \\
\hline 133.37 & 27.30 \\
\hline 100.03 & 26.34 \\
\hline 66.69 & 24.84 \\
\hline 33.34 & 23.32 \\
\hline 0.00 & 20.57 \\
\hline
\end{tabular}

\subsection{Carga de Ruptura}

\begin{tabular}{rc}
\hline Método & Força MN \\
\hline Davisson (1972) & 0.13 \\
\hline Livneh e El Naggar (2008) & 0.32 \\
\hline D/10 & 0.33 \\
\hline NBR 6122 (2010) & 0.18
\end{tabular}




\section{E2413-2}

\subsection{Geral}

$$
\text { Id :22 }
$$

Comprimento $\mathrm{m}: 11.00$ Inclinação $^{\circ}: 39.00$

Correção da profundidade (m) : 0.00

\subsection{SPT e Torque}

\begin{tabular}{cc}
\hline \multicolumn{2}{c}{ Torque } \\
\hline Profundidade m & Torque kN.m \\
\hline 3.11 & 3.66 \\
\hline 3.89 & 4.20 \\
\hline 2.33 & 2.98 \\
\hline 8.55 & 21.56 \\
\hline 7.78 & 18.71 \\
\hline 6.99 & 15.05 \\
\hline 6.22 & 12.88 \\
\hline 5.44 & 10.85 \\
\hline 4.66 & 5.83
\end{tabular}

\begin{tabular}{ccc}
\hline & \multicolumn{2}{c}{ SPT } \\
\hline Profundidade $\mathrm{m}$ & Nspt & Solo \\
\hline 1.00 & 4.00 & Areia argilosa \\
\hline 2.00 & 1.00 & Areia argilosa \\
\hline 3.00 & 6.00 & Areia argilosa \\
\hline 4.00 & 9.00 & Areia argilosa \\
\hline 5.00 & 4.00 & Argila \\
\hline 6.00 & 12.00 & Areia argilosa \\
\hline 7.00 & 20.00 & Areia argilosa
\end{tabular}

23.3. Hélice

\begin{tabular}{|c|c|c|c|c|c|}
\hline Posição & Profundidade $\mathrm{m}$ & Diâmetro cm & \multirow[t]{7}{*}{ SPT } & Interpolado & \multirow[t]{7}{*}{ Ajustado } \\
\hline 6 & 4.29 & 35.56 & & 8.97 & \\
\hline 5 & 5.12 & 35.56 & & 4.91 & \\
\hline 4 & 5.95 & 35.56 & & 9.17 & \\
\hline 3 & 6.78 & 35.56 & & 15.81 & \\
\hline 2 & 7.60 & 35.56 & & 20.00 & \\
\hline 1 & 8.32 & 30.48 & & & \\
\hline
\end{tabular}

\subsection{Fuste}

\begin{tabular}{cccccc}
\hline Comprimento m & Seção & $\begin{array}{c}\text { Diâmetro externo } \\
\mathrm{cm}\end{array}$ & $\begin{array}{c}\text { Diâmetro interno } \\
\mathrm{cm}\end{array}$ & $\mathrm{cm}$ & $\mathrm{cm}$ \\
\hline 5.52 & Circular Vazada & 10.00 & 8.50 & &
\end{tabular}

\subsection{Prova de Carga}




\begin{tabular}{ll}
\hline 182.40 & 7.96 \\
\hline 243.20 & 12.10 \\
\hline 304.01 & 14.21 \\
\hline 364.81 & 16.61 \\
\hline 425.61 & 20.37 \\
\hline 486.41 & 25.98
\end{tabular}

\subsection{Carga de Ruptura}

\begin{tabular}{cc}
\hline Método & Força MN \\
\hline Davisson (1972) & 0.21 \\
\hline NBR 6122(2010) & 0.37
\end{tabular}




\section{E55-2}

\subsection{Geral}

Id $: 23$

Comprimento $\mathrm{m}: 8.04$

Inclinação $^{\circ}: 29.00$

Correção da profundidade (m) : 0.00

\subsection{SPT e Torque}

\begin{tabular}{cc}
\hline \multicolumn{2}{c}{ Torque } \\
\hline Profundidade $\mathrm{m}$ & Torque kN.m \\
\hline 2.47 & 2.17 \\
\hline 3.29 & 5.56 \\
\hline 4.11 & 9.76 \\
\hline 4.93 & 15.19 \\
\hline 5.75 & 18.71 \\
\hline 6.58 & 18.98 \\
\hline 7.40 & 20.07
\end{tabular}

\begin{tabular}{ccl}
\hline & \multicolumn{2}{c}{ SPT } \\
\hline Profundidade m & Nspt & \multicolumn{1}{c}{ Solo } \\
\hline 12.00 & 23.00 & Argila siltosa \\
\hline 11.00 & 21.00 & Argila siltosa \\
\hline 10.00 & 17.00 & Argila siltosa \\
\hline 9.00 & 19.00 & Argila siltosa \\
\hline 8.00 & 15.00 & Argila siltosa \\
\hline 7.00 & 22.00 & Argila siltosa \\
\hline 6.00 & 17.00 & Argila siltosa \\
\hline 5.00 & 16.00 & Argila siltosa \\
\hline 4.00 & 9.00 & Argila siltosa \\
\hline 3.00 & 6.00 & Argila siltosa \\
\hline 2.00 & 3.00 & Argila siltosa \\
\hline 1.00 & 2.00 & Argila siltosa
\end{tabular}

\subsection{Hélice}

\begin{tabular}{cccccc}
\hline Posição & Profundidade $m$ & Diâmetro cm & SPT & Interpolado & Ajustado \\
\hline 6 & 2.64 & 35.56 & 3.00 & 4.02 & 4.02 \\
\hline 5 & 3.57 & 35.56 & 6.00 & 6.81 & 6.81 \\
\hline 4 & 4.50 & 35.56 & 9.00 & 10.40 & 10.40 \\
\hline 3 & 5.44 & 35.56 & 16.00 & 16.14 & 16.14 \\
\hline 2 & 6.24 & 30.48 & 17.00 & 16.94 & 16.94 \\
\hline 1 & 6.90 & 25.40 & 17.00 & 20.00 & 20.00
\end{tabular}

\subsection{Fuste}

\begin{tabular}{cccccc}
\hline Comprimento m & Seção & $\begin{array}{c}\text { Diâmetro externo } \\
\mathrm{cm}\end{array}$ & $\begin{array}{c}\text { Diâmetro interno } \\
\mathrm{cm}\end{array}$ & $\mathrm{cm}$ & $\mathrm{cm}$ \\
\hline 2.64 & Circular Vazada & 10.16 & 9.35 & &
\end{tabular}

\subsection{Prova de Carga}




\begin{tabular}{|c|c|}
\hline Força kN & Deslocamento mm \\
\hline 0.00 & 0.00 \\
\hline 57.86 & 1.20 \\
\hline 87.28 & 1.42 \\
\hline 115.72 & 2.03 \\
\hline 145.14 & 2.57 \\
\hline 174.56 & 3.72 \\
\hline 203.00 & 4.13 \\
\hline 232.42 & 5.81 \\
\hline 260.86 & 12.80 \\
\hline 290.28 & 24.84 \\
\hline 232.42 & 23.33 \\
\hline 174.56 & 22.46 \\
\hline 115.72 & 18.59 \\
\hline 57.86 & 14.55 \\
\hline 87.28 & 16.37 \\
\hline 115.72 & 16.74 \\
\hline 145.14 & 17.71 \\
\hline 174.56 & 17.94 \\
\hline 203.00 & 18.38 \\
\hline 232.42 & 19.33 \\
\hline 260.86 & 20.23 \\
\hline 290.28 & 22.41 \\
\hline 232.42 & 22.07 \\
\hline 174.56 & 21.07 \\
\hline 115.72 & 19.35 \\
\hline 57.86 & 16.96 \\
\hline 319.70 & 29.01 \\
\hline 348.14 & 30.21 \\
\hline 377.56 & 33.66 \\
\hline 406.00 & 37.55 \\
\hline
\end{tabular}

\subsection{Carga de Ruptura}

\begin{tabular}{rc}
\hline \multicolumn{1}{c}{ Método } & Força MN \\
\hline D/10 & 0.37 \\
\hline Davisson (1972) & 0.25 \\
\hline Livneh e El Naggar (2008) & 0.37 \\
\hline NBR 6122 (2010) & 0.28
\end{tabular}




\section{E61-1}

\subsection{Geral}

$$
\text { Id }: 24
$$

Comprimento $\mathrm{m}: 14.34$

$$
\text { Inclinação }{ }^{\circ}: 9.00
$$

Correção da profundidade (m) : 0.00

\subsection{SPT e Torque}

\begin{tabular}{cc}
\hline \multicolumn{2}{c}{ Torque } \\
\hline Profundidade $\mathrm{m}$ & Torque kN.m \\
\hline 3.00 & 5.83 \\
\hline 4.00 & 9.08 \\
\hline 5.00 & 12.74 \\
\hline 6.00 & 13.15 \\
\hline 7.00 & 11.25 \\
\hline 8.00 & 10.58 \\
\hline 9.00 & 12.88 \\
\hline 10.00 & 14.78 \\
\hline 11.00 & 15.86 \\
\hline 12.00 & 17.35 \\
\hline 13.00 & 16.95 \\
\hline 14.00 & 18.30 \\
\hline 15.00 & 18.57 \\
\hline 16.00 & 18.85
\end{tabular}

\begin{tabular}{ccl}
\hline & \multicolumn{2}{c}{ SPT } \\
\hline Profundidade $\mathrm{m}$ & Nspt & Solo \\
\hline 1.00 & 2.00 & Argila siltosa \\
\hline 2.00 & 18.00 & Argila siltosa \\
\hline 3.00 & 2.00 & Argila siltosa \\
\hline 4.00 & 3.00 & Argila siltosa \\
\hline 5.00 & 10.00 & Argila siltosa \\
\hline 6.00 & 15.00 & Argila siltosa \\
\hline 7.00 & 12.00 & Argila siltosa \\
\hline 8.00 & 19.00 & Argila siltosa \\
\hline 9.00 & 32.00 & Argila siltosa \\
\hline 10.00 & 30.00 & Argila siltosa
\end{tabular}

\begin{tabular}{|c|c|c|c|c|c|}
\hline Posição & Profundidade $\mathrm{m}$ & Diâmetro cm & \multirow[t]{7}{*}{ SPT } & Interpolado & \multirow[t]{7}{*}{ Ajustado } \\
\hline 6 & 9.21 & 35.56 & & 30.79 & \\
\hline 5 & 10.26 & 35.56 & & 30.08 & \\
\hline 4 & 11.31 & 35.56 & & & \\
\hline 3 & 12.37 & 35.56 & & & \\
\hline 2 & 13.27 & 30.48 & & & \\
\hline 1 & 14.02 & 25.40 & & & \\
\hline
\end{tabular}

25.3. Hélice

\subsection{Fuste}

\begin{tabular}{cccccc}
\hline Comprimento m & Seção & $\begin{array}{c}\text { Diâmetro externo } \\
\mathrm{cm}\end{array}$ & $\begin{array}{c}\text { Diâmetro interno } \\
\mathrm{cm}\end{array}$ & $\mathrm{cm}$ & $\mathrm{cm}$ \\
\hline 9.21 & Circular Vazada & 10.16 & 9.35 & &
\end{tabular}




\subsection{Prova de Carga}

\begin{tabular}{|c|c|}
\hline Força kN & Deslocamento $\mathrm{mm}$ \\
\hline 0.00 & 0.00 \\
\hline 57.86 & 1.00 \\
\hline 87.28 & 1.35 \\
\hline 115.72 & 3.64 \\
\hline 145.14 & 4.32 \\
\hline 174.56 & 4.65 \\
\hline 203.00 & 5.47 \\
\hline 232.42 & 6.69 \\
\hline 260.86 & 8.19 \\
\hline 290.28 & 10.66 \\
\hline 232.42 & 9.51 \\
\hline 174.56 & 7.58 \\
\hline 115.72 & 5.42 \\
\hline 57.86 & 2.53 \\
\hline 87.28 & 2.85 \\
\hline 115.72 & 3.72 \\
\hline 145.14 & 4.14 \\
\hline 174.56 & 5.79 \\
\hline 203.00 & 6.86 \\
\hline 232.42 & 7.98 \\
\hline 260.86 & 9.33 \\
\hline 290.28 & 11.03 \\
\hline 232.42 & 10.05 \\
\hline 174.56 & 8.04 \\
\hline 115.72 & 5.86 \\
\hline 57.86 & 3.55 \\
\hline 319.70 & 14.46 \\
\hline 348.14 & 20.65 \\
\hline
\end{tabular}

\subsection{Carga de Ruptura}

\begin{tabular}{cc}
\hline Método & Força MN \\
\hline Davisson (1972) & 0.34 \\
\hline NBR 6122(2010) & 0.37
\end{tabular}




\section{E94-2}

\subsection{Geral}

$$
\text { Id }: 25
$$

Comprimento $\mathrm{m}: 11.64$ Inclinação ${ }^{\circ}: 9.00$

Correção da profundidade (m) : 0.00

\subsection{SPT e Torque}

\begin{tabular}{cc}
\hline \multicolumn{2}{c}{ Torque } \\
\hline Profundidade $\mathrm{m}$ & Torque kN.m \\
\hline 2.96 & 2.03 \\
\hline 3.95 & 2.30 \\
\hline 4.94 & 2.98 \\
\hline 5.93 & 3.66 \\
\hline 6.91 & 6.64 \\
\hline 7.90 & 10.98 \\
\hline 8.89 & 12.74 \\
\hline 9.88 & 16.00 \\
\hline 10.86 & 18.30 \\
\hline 11.85 & 18.57
\end{tabular}

\begin{tabular}{ccl}
\hline & \multicolumn{2}{c}{ SPT } \\
\hline Profundidade $\mathrm{m}$ & Nspt & Solo \\
\hline 11.00 & 46.00 & Silte arenoso \\
\hline 10.00 & 44.00 & Silte arenoso \\
\hline 9.00 & 36.00 & Silte arenoso \\
\hline 8.00 & 28.00 & Silte arenoso \\
\hline 7.00 & 23.00 & Silte arenoso \\
\hline 6.00 & 9.00 & Argila siltosa \\
\hline 5.00 & 4.00 & Argila siltosa \\
\hline 4.00 & 2.00 & Argila siltosa \\
\hline 3.00 & 2.00 & Argila arenosa \\
\hline 2.00 & 2.00 & Argila arenosa \\
\hline 1.00 & 2.00 & Argila arenosa
\end{tabular}

\subsection{Hélice}

\begin{tabular}{cccccc}
\hline Posição & Profundidade $m$ & Diâmetro cm & SPT & Interpolado & Ajustado \\
\hline 6 & 6.54 & 35.56 & 9.00 & 12.37 & 12.37 \\
\hline 5 & 7.59 & 35.56 & 23.00 & 24.47 & 24.47 \\
\hline 4 & 8.65 & 35.56 & 28.00 & 30.79 & 30.79 \\
\hline 3 & 9.70 & 35.56 & 36.00 & 39.22 & 39.22 \\
\hline 2 & 10.60 & 30.48 & 44.00 & 44.61 & 44.61 \\
\hline 1 & 11.36 & 25.40 & 46.00 & 46.00 & 46.00
\end{tabular}

\subsection{Fuste}

\begin{tabular}{cccccc}
\hline Comprimento m & Seção & $\begin{array}{c}\text { Diâmetro externo } \\
\mathrm{cm}\end{array}$ & $\begin{array}{c}\text { Diâmetro interno } \\
\mathrm{cm}\end{array}$ & $\mathrm{cm}$ & $\mathrm{cm}$ \\
\hline 6.64 & Circular Vazada & 10.16 & 9.35 & &
\end{tabular}

\subsection{Prova de Carga}


Força kN

\begin{tabular}{cc}
\hline 0.00 & 0.00 \\
\hline 88.26 & 3.00 \\
\hline 132.39 & 8.53 \\
\hline 176.52 & 10.03 \\
\hline 220.65 & 12.97 \\
\hline 264.78 & 14.58 \\
\hline 308.91 & 18.13 \\
\hline 353.04 & 23.30 \\
\hline 397.17 & 32.94 \\
\hline 441.30 & 44.48 \\
\hline 353.04 & 39.28 \\
\hline 264.78 & 34.11 \\
\hline 176.52 & 32.65 \\
\hline 88.26 & 30.17 \\
\hline 132.39 & 30.30 \\
\hline 176.52 & 31.54 \\
\hline 220.65 & 32.68 \\
\hline 264.78 & 34.52 \\
\hline 308.91 & 36.11 \\
\hline 353.04 & 37.66 \\
\hline 397.17 & 39.65 \\
\hline 441.30 & 47.08 \\
\hline 353.04 & 46.10 \\
\hline 264.78 & 43.71 \\
\hline 176.52 & 40.76 \\
\hline 88.26 & 37.29 \\
\hline 0.00 & 33.60 \\
\hline 475.62 & 54.55 \\
\hline 529.56 & 55.75 \\
\hline & \\
\hline & \\
\hline & \\
\hline & \\
\hline & \\
\hline & \\
\hline & \\
\hline & \\
\hline & \\
\hline & \\
\hline & \\
\hline & \\
\hline & \\
\hline & \\
\hline & \\
\hline
\end{tabular}

\subsection{Carga de Ruptura}

\begin{tabular}{rc}
\hline Método & Força MN \\
\hline Livneh e El Naggar (2008) & 0.42 \\
\hline Davisson (1972) & 0.22 \\
\hline D/10 & 0.40 \\
\hline NBR 6122 (2010) & 0.32
\end{tabular}




\section{E119-1}

\subsection{Geral}

Id $: 26$

Comprimento $\mathrm{m}: 6.75$

Inclinação $^{\circ}: 29.00$

Correção da profundidade (m) : 0.00

\subsection{SPT e Torque}

\begin{tabular}{cc}
\hline \multicolumn{2}{c}{ Torque } \\
\hline Profundidade $\mathrm{m}$ & Torque kN.m \\
\hline 2.62 & 17.90 \\
\hline 3.50 & 18.98 \\
\hline 4.37 & 19.25 \\
\hline 5.25 & 21.15 \\
\hline 6.12 & 21.56
\end{tabular}

\begin{tabular}{ccc}
\hline & \multicolumn{2}{c}{ SPT } \\
\hline Profundidade m & Nspt & \multicolumn{1}{c}{ Solo } \\
\hline 1.00 & 4.00 & Argila arenosa \\
\hline 2.00 & 5.00 & Argila siltosa \\
\hline 3.00 & 6.00 & Argila siltosa \\
\hline 4.00 & 13.00 & Argila siltosa \\
\hline 5.00 & 16.00 & Silte argiloso \\
\hline 6.00 & 23.00 & Silte argiloso \\
\hline 7.00 & 29.00 & Silte argiloso \\
\hline 8.00 & 29.00 & Silte argiloso \\
\hline 9.00 & 37.00 & Silte argiloso \\
\hline 10.00 & 42.00 & Silte argiloso
\end{tabular}

\subsection{Hélice}

\begin{tabular}{cccccc}
\hline Posição & Profundidade $m$ & Diâmetro cm & SPT & Interpolado & Ajustado \\
\hline 6 & 1.51 & 35.56 & 4.00 & 4.21 & 4.21 \\
\hline 5 & 2.45 & 35.56 & 5.00 & 5.15 & 5.15 \\
\hline 4 & 3.38 & 35.56 & 6.00 & 6.57 & 6.57 \\
\hline 3 & 4.31 & 35.56 & 13.00 & 13.04 & 13.04 \\
\hline 2 & 5.11 & 30.48 & 16.00 & 15.44 & 15.44 \\
\hline 1 & 5.78 & 25.40 & 16.00 & 19.36 & 19.36
\end{tabular}

\subsection{Fuste}

\begin{tabular}{cccccc}
\hline Comprimento m & Seção & $\begin{array}{c}\text { Diâmetro externo } \\
\mathrm{cm}\end{array}$ & $\begin{array}{c}\text { Diâmetro interno } \\
\mathrm{cm}\end{array}$ & $\mathrm{cm}$ & $\mathrm{cm}$ \\
\hline 1.51 & Circular Vazada & 10.16 & 9.35
\end{tabular}

\subsection{Prova de Carga}


Força kN

\begin{tabular}{cc}
\hline 0.00 & 0.00 \\
\hline 57.86 & 0.00 \\
\hline 87.28 & 0.59 \\
\hline 115.72 & 1.13 \\
\hline 145.14 & 1.58 \\
\hline 174.56 & 2.99 \\
\hline 203.00 & 7.41 \\
\hline 232.42 & 8.53 \\
\hline 260.86 & 11.50 \\
\hline 290.28 & 14.41 \\
\hline 232.42 & 14.26 \\
\hline 174.56 & 13.68 \\
\hline 115.72 & 11.47 \\
\hline 57.86 & 10.72 \\
\hline 87.28 & 11.16 \\
\hline 115.72 & 11.40 \\
\hline 145.14 & 11.73 \\
\hline 174.56 & 12.09 \\
\hline 203.00 & 12.62 \\
\hline 232.42 & 13.02 \\
\hline 260.86 & 13.46 \\
\hline 290.28 & 14.30 \\
\hline 232.42 & 14.10 \\
\hline 174.56 & 13.60 \\
\hline 115.72 & 12.76 \\
\hline 57.86 & 11.62 \\
\hline 0.00 & 11.03 \\
\hline 319.70 & 17.88 \\
\hline & \\
\hline & \\
\hline & \\
\hline & \\
\hline & \\
\hline & \\
\hline & \\
\hline & \\
\hline & \\
\hline & \\
\hline & \\
\hline & \\
\hline & \\
\hline & \\
\hline
\end{tabular}

\subsection{Carga de Ruptura}

\begin{tabular}{cc}
\hline Método & Força MN \\
\hline Davisson (1972) & 0.25 \\
\hline NBR 6122 (2010) & 0.30
\end{tabular}




\section{E1131-1-6H}

\subsection{Geral}

Id $: 27$

Comprimento m : 10.57

Inclinação ${ }^{\circ}: 39.00$

Correção da profundidade (m) : 0.00

\subsection{SPT e Torque}

\begin{tabular}{cc}
\hline \multicolumn{2}{c}{ Torque } \\
\hline Profundidade $\mathrm{m}$ & Torque kN.m \\
\hline 2.33 & 3.39 \\
\hline 3.11 & 4.88 \\
\hline 3.89 & 6.10 \\
\hline 4.66 & 7.05 \\
\hline 5.44 & 8.13 \\
\hline 6.22 & 11.52 \\
\hline 6.99 & 16.95 \\
\hline 7.77 & 22.37 \\
\hline 8.55 & 23.05
\end{tabular}

\begin{tabular}{ccc}
\hline & \multicolumn{2}{c}{ SPT } \\
\hline Profundidade m & Nspt & Solo \\
\hline 1.00 & 0.00 & Areia siltosa \\
\hline 2.00 & 2.00 & Argila arenosa \\
\hline 3.00 & 1.00 & Argila arenosa \\
\hline 4.00 & 3.00 & Argila arenosa \\
\hline 5.00 & 3.00 & Argila arenosa \\
\hline 6.00 & 6.00 & Argila arenosa
\end{tabular}

28.3. Hélice

\begin{tabular}{|c|c|c|c|c|c|}
\hline Posição & Profundidade $\mathrm{m}$ & Diâmetro cm & SPT & Interpolado & Ajustado \\
\hline 6 & 4.31 & 35.56 & & 3.00 & \\
\hline 5 & 5.12 & 35.56 & & 3.00 & \\
\hline 4 & 5.94 & 35.56 & & 4.93 & \\
\hline 3 & 6.76 & 35.56 & & 6.00 & \\
\hline 2 & 7.46 & 30.48 & & & \\
\hline 1 & 8.04 & 25.40 & & & \\
\hline
\end{tabular}

\subsection{Fuste}

\begin{tabular}{cccccc}
\hline Comprimento m & Seção & $\begin{array}{c}\text { Diâmetro externo } \\
\mathrm{cm}\end{array}$ & $\begin{array}{c}\text { Diâmetro interno } \\
\mathrm{cm}\end{array}$ & $\mathrm{cm}$ & $\mathrm{cm}$ \\
\hline 5.62 & Circular Vazada & 10.16 & 9.35 & &
\end{tabular}

\subsection{Prova de Carga}




\begin{tabular}{cc}
\hline 92.18 & 2.00 \\
\hline 138.27 & 3.32 \\
\hline 184.76 & 5.34 \\
\hline 231.44 & 9.28 \\
\hline 277.53 & 13.19 \\
\hline 323.62 & 17.06 \\
\hline 369.71 & 22.77 \\
\hline 415.80 & 29.12 \\
\hline 461.89 & 33.45 \\
\hline 369.71 & 33.05 \\
\hline 277.53 & 30.88 \\
\hline 184.37 & 28.18 \\
\hline 92.18 & 24.77 \\
\hline 138.27 & 25.41 \\
\hline 184.76 & 26.64 \\
\hline 231.44 & 28.04 \\
\hline 277.53 & 29.34 \\
\hline 323.62 & 30.25 \\
\hline 369.71 & 31.86 \\
\hline 415.80 & 33.31 \\
\hline 461.89 & 35.33 \\
\hline 369.71 & 34.98 \\
\hline 277.53 & 32.66 \\
\hline 184.37 & 29.96 \\
\hline 92.18 & 26.62 \\
\hline & \\
\hline & \\
\hline & \\
\hline & \\
\hline & \\
\hline & \\
\hline & \\
\hline
\end{tabular}

\subsection{Carga de Ruptura}

\begin{tabular}{cc}
\hline \multicolumn{1}{c}{ Método } & Força MN \\
\hline D/10 & 0.46 \\
\hline Livneh e El Naggar (2008) & 0.48 \\
\hline Davisson (1972) & 0.28 \\
\hline NBR 6122 (2010) & 0.34
\end{tabular}




\subsection{Geral}

$$
\text { Id }: 28
$$

Comprimento $\mathrm{m}: 15.70$

Inclinação $^{\circ}: 39.00$

Correção da profundidade (m) : 5.00

\subsection{SPT e Torque}

\begin{tabular}{cc}
\hline \multicolumn{2}{c}{ Torque } \\
\hline Profundidade $\mathrm{m}$ & Torque kN.m \\
\hline 2.30 & 3.12 \\
\hline 3.06 & 3.39 \\
\hline 3.83 & 3.80 \\
\hline 4.60 & 4.34 \\
\hline 5.36 & 4.88 \\
\hline 6.13 & 4.88 \\
\hline 6.89 & 5.02 \\
\hline 7.66 & 5.42 \\
\hline 8.43 & 6.78 \\
\hline 9.19 & 11.52 \\
\hline 9.96 & 13.29 \\
\hline 10.72 & 15.05 \\
\hline 11.49 & 20.07 \\
\hline 12.26 & 22.10
\end{tabular}

\begin{tabular}{ccc}
\hline & \multicolumn{2}{c}{ SPT } \\
\hline Profundidade $\mathrm{m}$ & Nspt & Solo \\
\hline 17.00 & 77.14 & Argila siltosa \\
\hline 16.00 & 54.00 & Argila siltosa \\
\hline 15.00 & 19.75 & Argila siltosa \\
\hline 14.00 & 20.91 & Areia argilosa \\
\hline 13.00 & 25.00 & Areia argilosa \\
\hline 12.00 & 0.64 & Areia argilosa \\
\hline 11.00 & 0.61 & Areia \\
\hline 10.00 & 0.67 & Areia \\
\hline 9.00 & 0.65 & Areia \\
\hline 8.00 & 1.83 & Areia \\
\hline 7.00 & 2.00 & Areia \\
\hline 6.00 & 2.00 & Areia argilosa \\
\hline 5.00 & 2.00 & Areia argilosa \\
\hline 4.00 & 0.83 & Areia argilosa \\
\hline 3.00 & 2.00 & Areia argilosa \\
\hline 2.00 & 0.83 & Areia siltosa
\end{tabular}

29.3. Hélice

\begin{tabular}{cccccc}
\hline Posição & Profundidade $m$ & Diâmetro cm & SPT & Interpolado & Ajustado \\
\hline 4 & 9.04 & 35.56 & 0.65 & 1.04 & 22.26 \\
\hline 3 & 10.18 & 35.56 & 0.67 & 0.66 & 19.97 \\
\hline 2 & 11.16 & 30.48 & 0.61 & 0.62 & 46.63 \\
\hline 1 & 11.97 & 25.40 & 0.64 & 0.63 & 60.00
\end{tabular}

\subsection{Fuste}

\begin{tabular}{cccccc}
\hline Comprimento m & Seção & $\begin{array}{c}\text { Diâmetro externo } \\
\mathrm{cm}\end{array}$ & $\begin{array}{c}\text { Diâmetro interno } \\
\mathrm{cm}\end{array}$ & $\mathrm{cm}$ & $\mathrm{cm}$ \\
\hline 11.81 & Circular Vazada & 10.16 & 9.35 & &
\end{tabular}




\subsection{Prova de Carga}

\begin{tabular}{cc}
\hline Força kN & Deslocamento mm \\
\hline 0.00 & 0.00 \\
\hline 92.18 & 3.00 \\
\hline 138.27 & 5.50 \\
\hline 184.76 & 8.72 \\
\hline 231.44 & 11.14 \\
\hline 277.53 & 17.34 \\
\hline 323.62 & 20.68 \\
\hline 369.71 & 27.38 \\
\hline 415.80 & 34.05 \\
\hline 461.89 & 38.33 \\
\hline 369.71 & 37.13 \\
\hline 277.53 & 33.27 \\
\hline 184.37 & 29.23 \\
\hline 92.18 & 24.06 \\
\hline 138.27 & 25.22 \\
\hline 184.76 & 27.35 \\
\hline 231.44 & 29.04 \\
\hline 277.53 & 31.52 \\
\hline 323.62 & 33.23 \\
\hline 369.71 & 35.70 \\
\hline 415.80 & 37.45 \\
\hline 461.89 & 39.64 \\
\hline 369.71 & 40.61 \\
\hline 277.53 & 34.02 \\
\hline 184.37 & 29.63 \\
\hline 92.18 & 24.95 \\
\hline & \\
\hline & \\
\hline & \\
\hline & \\
\hline & \\
\hline & \\
\hline & \\
\hline & \\
\hline & \\
\hline & \\
\hline & \\
\hline & \\
\hline & \\
\hline & \\
\hline
\end{tabular}

\subsection{Carga de Ruptura}

\begin{tabular}{rc}
\hline \multicolumn{1}{c}{ Método } & Força MN \\
\hline D/10 & 0.40 \\
\hline Davisson (1972) & 0.27 \\
\hline Livneh e El Naggar (2008) & 0.48 \\
\hline NBR 6122 (2010) & 0.34
\end{tabular}




\section{E1162-1-6H}

\subsection{Geral}

Id : 29

Comprimento $\mathrm{m}: 15.55$

Inclinação $^{\circ}: 39.00$

Correção da profundidade (m) : 5.00

\subsection{SPT e Torque}

\begin{tabular}{cc}
\hline \multicolumn{2}{c}{ Torque } \\
\hline Profundidade $\mathrm{m}$ & Torque kN.m \\
\hline 2.30 & 2.98 \\
\hline 3.06 & 3.39 \\
\hline 3.83 & 4.75 \\
\hline 4.60 & 5.42 \\
\hline 5.36 & 6.78 \\
\hline 6.13 & 7.32 \\
\hline 6.89 & 7.19 \\
\hline 7.66 & 7.05 \\
\hline 8.43 & 7.32 \\
\hline 9.19 & 7.73 \\
\hline 9.96 & 12.20 \\
\hline 10.72 & 18.03 \\
\hline 11.49 & 19.39 \\
\hline 12.26 & 19.66
\end{tabular}

\begin{tabular}{ccc}
\hline & \multicolumn{2}{c}{ SPT } \\
\hline Profundidade $\mathrm{m}$ & Nspt & Solo \\
\hline 17.00 & 77.14 & Argila siltosa \\
\hline 16.00 & 54.00 & Argila siltosa \\
\hline 15.00 & 19.75 & Argila siltosa \\
\hline 14.00 & 20.91 & Areia argilosa \\
\hline 13.00 & 25.00 & Areia argilosa \\
\hline 12.00 & 0.64 & Areia argilosa \\
\hline 11.00 & 0.61 & Areia \\
\hline 10.00 & 0.67 & Areia \\
\hline 9.00 & 0.65 & Areia \\
\hline 8.00 & 1.83 & Areia \\
\hline 7.00 & 2.00 & Areia \\
\hline 6.00 & 2.00 & Areia argilosa \\
\hline 5.00 & 2.00 & Areia argilosa \\
\hline 4.00 & 0.83 & Areia argilosa \\
\hline 3.00 & 2.00 & Areia argilosa \\
\hline 2.00 & 0.83 & Areia siltosa
\end{tabular}

\subsection{Hélice}

\begin{tabular}{cccccc}
\hline Posição & Profundidade $m$ & Diâmetro cm & SPT & Interpolado & Ajustado \\
\hline 6 & 8.12 & 35.56 & 1.83 & 1.86 & 20.68 \\
\hline 5 & 8.94 & 35.56 & 1.83 & 1.08 & 22.38 \\
\hline 4 & 9.76 & 35.56 & 0.65 & 0.66 & 20.38 \\
\hline 3 & 10.57 & 35.56 & 0.67 & 0.65 & 29.14 \\
\hline 2 & 11.27 & 30.48 & 0.61 & 0.61 & 53.13 \\
\hline 1 & 11.86 & 25.40 & 0.61 & 0.63 & 60.00
\end{tabular}

\subsection{Fuste}

\begin{tabular}{cccccc}
\hline Comprimento m & Seção & $\begin{array}{c}\text { Diâmetro externo } \\
\mathrm{cm}\end{array}$ & $\begin{array}{c}\text { Diâmetro interno } \\
\mathrm{cm}\end{array}$ & $\mathrm{cm}$ & $\mathrm{cm}$ \\
\hline 10.60 & Circular Vazada & 10.16 & 9.35
\end{tabular}




\subsection{Prova de Carga}

\begin{tabular}{cc}
\hline Força kN & Deslocamento mm \\
\hline 0.00 & 0.00 \\
\hline 92.18 & 3.00 \\
\hline 138.27 & 4.91 \\
\hline 184.76 & 7.91 \\
\hline 231.44 & 10.25 \\
\hline 277.53 & 13.86 \\
\hline 323.62 & 16.73 \\
\hline 369.71 & 21.36 \\
\hline 415.80 & 26.50 \\
\hline 461.89 & 31.62 \\
\hline 369.71 & 30.26 \\
\hline 277.53 & 27.25 \\
\hline 184.37 & 23.62 \\
\hline 92.18 & 18.12 \\
\hline 138.27 & 19.08 \\
\hline 184.76 & 20.91 \\
\hline 231.44 & 22.50 \\
\hline 277.53 & 24.55 \\
\hline 323.62 & 26.09 \\
\hline 369.71 & 28.43 \\
\hline 415.80 & 30.62 \\
\hline 461.89 & 33.28 \\
\hline 369.71 & 33.08 \\
\hline 277.53 & 29.98 \\
\hline 184.37 & 25.80 \\
\hline 92.18 & 20.48 \\
\hline & \\
\hline & \\
\hline & \\
\hline & \\
\hline & \\
\hline & \\
\hline & \\
\hline & \\
\hline & \\
\hline & \\
\hline & \\
\hline & \\
\hline & \\
\hline & \\
\hline
\end{tabular}

\subsection{Carga de Ruptura}

\begin{tabular}{rc}
\hline \multicolumn{1}{l}{ Método } & Força MN \\
\hline D/10 & 0.47 \\
\hline Davisson (1972) & 0.35 \\
\hline NBR 6122(2010) & 0.41
\end{tabular}




\section{E1324 -2-4H}

\subsection{Geral}

Id : 30

Comprimento $\mathrm{m}: 7.45$

Inclinação $^{\circ}: 39.00$

Correção da profundidade (m) : 0.00

\subsection{SPT e Torque}

\begin{tabular}{cc}
\hline \multicolumn{2}{c}{ Torque } \\
\hline Profundidade $\mathrm{m}$ & Torque kN.m \\
\hline 3.06 & 5.83 \\
\hline 2.30 & 1.36 \\
\hline 3.83 & 13.56 \\
\hline 4.60 & 17.63 \\
\hline 5.36 & 18.98 \\
\hline 6.13 & 19.66
\end{tabular}

\begin{tabular}{ccl}
\hline & \multicolumn{2}{c}{ SPT } \\
\hline Profundidade $\mathrm{m}$ & Nspt & \multicolumn{1}{c}{ Solo } \\
\hline 1.00 & 1.50 & Areia argilosa \\
\hline 2.00 & 0.67 & Areia argilosa \\
\hline 3.00 & 5.00 & Areia argilosa \\
\hline 4.00 & 7.00 & Areia argilosa \\
\hline 5.00 & 12.00 & Argila arenosa \\
\hline 6.00 & 22.00 & Argila arenosa \\
\hline 7.00 & 30.00 & Argila arenosa \\
\hline 8.00 & 37.00 & Argila arenosa
\end{tabular}

31.3. Hélice

\begin{tabular}{cccccc}
\hline Posição & Profundidade $\mathrm{m}$ & Diâmetro cm & SPT & Interpolado & Ajustado \\
\hline 4 & 3.55 & 35.56 & 5.00 & 5.50 & 5.50 \\
\hline 3 & 4.37 & 35.56 & 7.00 & 7.35 & 7.35 \\
\hline 2 & 5.07 & 30.48 & 12.00 & 10.85 & 10.85 \\
\hline 1 & 5.65 & 25.40 & 12.00 & 15.53 & 15.53
\end{tabular}

31.4. Fuste

\begin{tabular}{cccccc}
\hline Comprimento m & Seção & $\begin{array}{c}\text { Diâmetro externo } \\
\mathrm{cm}\end{array}$ & $\begin{array}{c}\text { Diâmetro interno } \\
\mathrm{cm}\end{array}$ & $\mathrm{cm}$ & $\mathrm{cm}$ \\
\hline 4.64 & Circular Vazada & 10.16 & 9.35
\end{tabular}

\subsection{Prova de Carga}

\begin{tabular}{cc}
\hline Força kN & Deslocamento $\mathrm{mm}$ \\
\hline 0.00 & 0.00 \\
\hline 92.38 & 1.00 \\
\hline 138.57 & 1.49 \\
\hline 184.76 & 2.44
\end{tabular}




\begin{tabular}{|c|c|}
\hline 230.95 & 4.62 \\
\hline 277.14 & 8.13 \\
\hline 323.33 & 13.33 \\
\hline 369.51 & 17.88 \\
\hline 415.70 & 21.75 \\
\hline 461.89 & 24.64 \\
\hline 369.51 & 24.63 \\
\hline 277.14 & 22.73 \\
\hline 184.76 & 21.37 \\
\hline 92.38 & 18.48 \\
\hline 138.57 & 18.89 \\
\hline 184.76 & 19.65 \\
\hline 230.95 & 20.87 \\
\hline 277.14 & 21.30 \\
\hline 323.33 & 22.27 \\
\hline 369.51 & 23.62 \\
\hline 415.70 & 24.59 \\
\hline 461.89 & 26.31 \\
\hline 369.51 & 26.21 \\
\hline 277.14 & 24.72 \\
\hline 184.76 & 23.15 \\
\hline 92.38 & 20.66 \\
\hline
\end{tabular}

\subsection{Carga de Ruptura}

\begin{tabular}{cc}
\hline Método & Força MN \\
\hline Davisson (1972) & 0.31 \\
\hline NBR 6122(2010) & 0.37
\end{tabular}




\section{E1324-2-6H-7.35M}

\subsection{Geral}

Id $: 31$

Comprimento $\mathrm{m}: 7.35$

Inclinação $^{\circ}: 39.00$

Correção da profundidade (m) : 0.00

\subsection{SPT e Torque}

\begin{tabular}{cc}
\hline \multicolumn{2}{c}{ Torque } \\
\hline Profundidade $\mathrm{m}$ & Torque kN.m \\
\hline 3.06 & 5.29 \\
\hline 2.30 & 2.44 \\
\hline 3.83 & 12.88 \\
\hline 4.60 & 16.54 \\
\hline 5.36 & 19.93 \\
\hline 6.13 & 23.05
\end{tabular}

\begin{tabular}{ccl}
\hline & \multicolumn{2}{c}{ SPT } \\
\hline Profundidade $\mathrm{m}$ & Nspt & \multicolumn{1}{c}{ Solo } \\
\hline 1.00 & 1.50 & Areia argilosa \\
\hline 2.00 & 0.67 & Areia argilosa \\
\hline 3.00 & 5.00 & Areia argilosa \\
\hline 4.00 & 7.00 & Areia argilosa \\
\hline 5.00 & 12.00 & Argila arenosa \\
\hline 6.00 & 22.00 & Argila arenosa \\
\hline 7.00 & 30.00 & Argila arenosa \\
\hline 8.00 & 37.00 & Argila arenosa
\end{tabular}

\subsection{Hélice}

\begin{tabular}{cccccc}
\hline Posição & Profundidade $m$ & Diâmetro cm & SPT & Interpolado & Ajustado \\
\hline 6 & 1.84 & 35.56 & 1.50 & 1.05 & 1.05 \\
\hline 5 & 2.66 & 35.56 & 0.67 & 2.22 & 2.22 \\
\hline 4 & 3.48 & 35.56 & 5.00 & 5.35 & 5.35 \\
\hline 3 & 4.29 & 35.56 & 7.00 & 6.99 & 6.99 \\
\hline 2 & 4.99 & 30.48 & 12.00 & 10.47 & 10.47 \\
\hline 1 & 5.58 & 25.40 & 12.00 & 14.77 & 14.77
\end{tabular}

\subsection{Fuste}

\begin{tabular}{cccccc}
\hline Comprimento m & Seção & $\begin{array}{c}\text { Diâmetro externo } \\
\mathrm{cm}\end{array}$ & $\begin{array}{c}\text { Diâmetro interno } \\
\mathrm{cm}\end{array}$ & $\mathrm{cm}$ & $\mathrm{cm}$ \\
\hline 2.40 & Circular Vazada & 10.16 & 9.35
\end{tabular}

\subsection{Prova de Carga}




\begin{tabular}{|c|c|}
\hline 138.57 & 1.96 \\
\hline 184.76 & 3.01 \\
\hline 230.95 & 4.90 \\
\hline 277.14 & 8.25 \\
\hline 323.33 & 12.85 \\
\hline 369.51 & 17.00 \\
\hline 415.70 & 21.05 \\
\hline 461.89 & 25.11 \\
\hline 369.51 & 24.62 \\
\hline 277.14 & 22.91 \\
\hline 184.76 & 20.90 \\
\hline 92.38 & 18.16 \\
\hline 138.57 & 18.54 \\
\hline 184.76 & 20.07 \\
\hline 230.95 & 20.82 \\
\hline 277.14 & 21.67 \\
\hline 323.33 & 22.59 \\
\hline 369.51 & 23.80 \\
\hline 415.70 & 24.70 \\
\hline 461.89 & 26.66 \\
\hline 369.51 & 26.10 \\
\hline 277.14 & 24.46 \\
\hline 184.76 & 22.48 \\
\hline 92.38 & 19.98 \\
\hline
\end{tabular}

\subsection{Carga de Ruptura}

\begin{tabular}{cc}
\hline Método & Força MN \\
\hline Davisson (1972) & 0.32 \\
\hline NBR 6122 (2010) & 0.38
\end{tabular}




\section{E1324-2-6H-7.45M}

\subsection{Geral}

Id $: 32$

Comprimento $\mathrm{m}: 7.45$

Inclinação $^{\circ}: 39.00$

Correção da profundidade (m) : 0.00

\subsection{SPT e Torque}

\begin{tabular}{cc}
\hline \multicolumn{2}{c}{ Torque } \\
\hline Profundidade $\mathrm{m}$ & Torque kN.m \\
\hline 3.83 & 11.25 \\
\hline 3.06 & 5.15 \\
\hline 2.30 & 3.25 \\
\hline 4.60 & 18.98 \\
\hline 5.36 & 18.71 \\
\hline 6.13 & 19.66
\end{tabular}

\begin{tabular}{ccl}
\hline & \multicolumn{2}{c}{ SPT } \\
\hline Profundidade $\mathrm{m}$ & Nspt & \multicolumn{1}{c}{ Solo } \\
\hline 1.00 & 1.50 & Areia argilosa \\
\hline 2.00 & 0.67 & Areia argilosa \\
\hline 3.00 & 5.00 & Areia argilosa \\
\hline 4.00 & 7.00 & Areia argilosa \\
\hline 5.00 & 12.00 & Argila arenosa \\
\hline 6.00 & 22.00 & Argila arenosa \\
\hline 7.00 & 30.00 & Argila arenosa \\
\hline 8.00 & 37.00 & Argila arenosa
\end{tabular}

33.3. Hélice

\begin{tabular}{cccccc}
\hline Posição & Profundidade $m$ & Diâmetro cm & SPT & Interpolado & Ajustado \\
\hline 6 & 1.92 & 35.56 & 1.50 & 0.99 & 0.99 \\
\hline 5 & 2.73 & 35.56 & 0.67 & 2.55 & 2.55 \\
\hline 4 & 3.55 & 35.56 & 5.00 & 5.50 & 5.50 \\
\hline 3 & 4.37 & 35.56 & 7.00 & 7.35 & 7.35 \\
\hline 2 & 5.07 & 30.48 & 12.00 & 10.85 & 10.85 \\
\hline 1 & 5.65 & 25.40 & 12.00 & 15.53 & 15.53
\end{tabular}

\subsection{Fuste}

\begin{tabular}{cccccc}
\hline Comprimento $\mathrm{m}$ & Seção & $\begin{array}{c}\text { Diâmetro externo } \\
\mathrm{cm}\end{array}$ & $\begin{array}{c}\text { Diâmetro interno } \\
\mathrm{cm}\end{array}$ & $\mathrm{cm}$ & $\mathrm{cm}$ \\
\hline 2.50 & Circular Vazada & 10.16 & 9.35 &
\end{tabular}

\subsection{Prova de Carga}




\begin{tabular}{|c|c|}
\hline 138.57 & 2.38 \\
\hline 184.76 & 3.42 \\
\hline 230.95 & 5.25 \\
\hline 277.14 & 9.50 \\
\hline 323.33 & 11.93 \\
\hline 369.51 & 17.30 \\
\hline 415.70 & 21.20 \\
\hline 461.89 & 25.61 \\
\hline 369.51 & 25.52 \\
\hline 277.14 & 24.10 \\
\hline 184.76 & 21.99 \\
\hline 92.38 & 19.63 \\
\hline 138.57 & 20.05 \\
\hline 184.76 & 22.00 \\
\hline 230.95 & 22.61 \\
\hline 277.14 & 23.12 \\
\hline 323.33 & 23.70 \\
\hline 369.51 & 25.02 \\
\hline 415.70 & 26.26 \\
\hline 461.89 & 27.28 \\
\hline 369.51 & 27.18 \\
\hline 277.14 & 25.75 \\
\hline 184.76 & 23.73 \\
\hline 92.38 & 21.21 \\
\hline
\end{tabular}

\subsection{Carga de Ruptura}

\begin{tabular}{cc}
\hline Método & Força MN \\
\hline Davisson (1972) & 0.33 \\
\hline NBR 6122 (2010) & 0.38
\end{tabular}




\section{E1324-2-6H-9.95M}

\subsection{Geral}

$$
\text { Id }: 33
$$

Comprimento $\mathrm{m}: 9.95$

Inclinação $^{\circ}: 39.00$

Correção da profundidade (m) : 0.00

\subsection{SPT e Torque}

\begin{tabular}{cc}
\hline \multicolumn{2}{c}{ Torque } \\
\hline Profundidade m & Torque kN.m \\
\hline 3.06 & 3.80 \\
\hline 2.30 & 2.03 \\
\hline 3.83 & 5.42 \\
\hline 4.60 & 8.13 \\
\hline 5.36 & 4.75 \\
\hline 6.13 & 16.27 \\
\hline 6.89 & 14.24 \\
\hline 7.66 & 18.30 \\
\hline 8.43 & 23.05
\end{tabular}

\begin{tabular}{ccl}
\hline & \multicolumn{2}{c}{ SPT } \\
\hline Profundidade $\mathrm{m}$ & Nspt & \multicolumn{1}{c}{ Solo } \\
\hline 1.00 & 1.50 & Areia argilosa \\
\hline 2.00 & 0.67 & Areia argilosa \\
\hline 3.00 & 5.00 & Areia argilosa \\
\hline 4.00 & 7.00 & Areia argilosa \\
\hline 5.00 & 12.00 & Argila arenosa \\
\hline 6.00 & 22.00 & Argila arenosa \\
\hline 7.00 & 30.00 & Argila arenosa \\
\hline 8.00 & 37.00 & Argila arenosa
\end{tabular}

34.3. Hélice

\begin{tabular}{cccccc}
\hline Posição & Profundidade $m$ & Diâmetro cm & SPT & Interpolado & Ajustado \\
\hline 6 & 3.83 & 35.56 & 5.00 & 6.07 & 6.07 \\
\hline 5 & 4.65 & 35.56 & 7.00 & 8.75 & 8.75 \\
\hline 4 & 5.47 & 35.56 & 12.00 & 13.67 & 13.67 \\
\hline 3 & 6.28 & 35.56 & 22.00 & 21.84 & 21.84 \\
\hline 2 & 6.98 & 30.48 & 22.00 & 27.48 & 27.48 \\
\hline 1 & 7.57 & 25.40 & 30.00 & 31.88 & 31.88
\end{tabular}

\subsection{Fuste}

\begin{tabular}{cccccc}
\hline Comprimento m & Seção & $\begin{array}{c}\text { Diâmetro externo } \\
\mathrm{cm}\end{array}$ & $\begin{array}{c}\text { Diâmetro interno } \\
\mathrm{cm}\end{array}$ & $\mathrm{cm}$ & $\mathrm{cm}$ \\
\hline 5.00 & Circular Vazada & 10.16 & 9.35 & &
\end{tabular}

\subsection{Prova de Carga}




\begin{tabular}{|c|c|}
\hline 76.10 & 1.00 \\
\hline 114.15 & 1.13 \\
\hline 152.20 & 2.15 \\
\hline 190.25 & 3.50 \\
\hline 228.30 & 5.59 \\
\hline 266.35 & 7.76 \\
\hline 304.40 & 9.05 \\
\hline 342.45 & 11.31 \\
\hline 380.50 & 14.20 \\
\hline 304.40 & 12.39 \\
\hline 228.30 & 11.73 \\
\hline 152.20 & 11.09 \\
\hline 76.10 & 7.97 \\
\hline 114.15 & 8.23 \\
\hline 152.20 & 9.78 \\
\hline 190.25 & 10.71 \\
\hline 228.30 & 11.80 \\
\hline 266.35 & 12.89 \\
\hline 304.40 & 13.77 \\
\hline 342.45 & 15.10 \\
\hline 380.50 & 16.61 \\
\hline 304.40 & 16.57 \\
\hline 228.30 & 15.46 \\
\hline 152.20 & 13.70 \\
\hline 76.10 & 11.14 \\
\hline
\end{tabular}

\subsection{Carga de Ruptura}

$\begin{array}{lc}\text { Método } & \text { Força MN } \\ \text { Davisson (1972) } & 0.39\end{array}$




\section{E1414-2-4H}

\subsection{Geral}

Id $: 34$

Comprimento $\mathrm{m}: 8.55$

Inclinação $^{\circ}: 39.00$

Correção da profundidade (m) : 0.00

\subsection{SPT e Torque}

\begin{tabular}{cc}
\hline \multicolumn{2}{c}{ Torque } \\
\hline Profundidade $\mathrm{m}$ & Torque kN.m \\
\hline 3.06 & 4.20 \\
\hline 2.30 & 2.17 \\
\hline 3.83 & 5.97 \\
\hline 4.60 & 8.95 \\
\hline 5.36 & 14.10 \\
\hline 6.13 & 18.44 \\
\hline 6.89 & 23.05
\end{tabular}

\begin{tabular}{ccc}
\hline & \multicolumn{2}{c}{ SPT } \\
\hline Profundidade $\mathrm{m}$ & Nspt & Solo \\
\hline 1.00 & 1.00 & Areia siltosa \\
\hline 2.00 & 1.00 & Areia siltosa \\
\hline 3.00 & 1.00 & Areia siltosa \\
\hline 4.00 & 2.00 & Areia siltosa \\
\hline 5.00 & 4.00 & Areia siltosa \\
\hline 6.00 & 7.00 & Areia siltosa \\
\hline 7.00 & 15.00 & Silte arenoso \\
\hline 8.00 & 11.00 & Areia siltosa \\
\hline 9.00 & 18.00 & Areia siltosa
\end{tabular}

35.3. Hélice

\begin{tabular}{cccccc}
\hline Posição & Profundidade $\mathrm{m}$ & Diâmetro cm & SPT & Interpolado & Ajustado \\
\hline 4 & 4.39 & 35.56 & 2.00 & 2.19 & 2.19 \\
\hline 3 & 5.21 & 35.56 & 4.00 & 3.82 & 3.82 \\
\hline 2 & 5.91 & 30.48 & 4.00 & 5.84 & 5.84 \\
\hline 1 & 6.50 & 25.40 & 7.00 & 8.57 & 8.57
\end{tabular}

35.4. Fuste

\begin{tabular}{cccccc}
\hline Comprimento m & Seção & $\begin{array}{c}\text { Diâmetro externo } \\
\mathrm{cm}\end{array}$ & $\begin{array}{c}\text { Diâmetro interno } \\
\mathrm{cm}\end{array}$ & $\mathrm{cm}$ & $\mathrm{cm}$ \\
\hline 5.74 & Circular Vazada & 10.16 & 9.35 & &
\end{tabular}

\subsection{Prova de Carga}

\begin{tabular}{cc}
\hline Força kN & Deslocamento $\mathrm{mm}$ \\
\hline 0.00 & 0.00 \\
\hline 92.38 & 2.00 \\
\hline 138.57 & 3.09
\end{tabular}




\begin{tabular}{|c|c|}
\hline 184.76 & 5.01 \\
\hline 230.95 & 6.87 \\
\hline 277.14 & 10.30 \\
\hline 323.33 & 13.24 \\
\hline 369.51 & 18.14 \\
\hline 415.70 & 24.75 \\
\hline 461.89 & 28.26 \\
\hline 369.51 & 27.64 \\
\hline 277.14 & 26.27 \\
\hline 184.76 & 22.65 \\
\hline 92.38 & 19.12 \\
\hline 138.57 & 19.58 \\
\hline 184.76 & 20.81 \\
\hline 230.95 & 21.96 \\
\hline 277.14 & 23.49 \\
\hline 323.33 & 24.59 \\
\hline 369.51 & 26.18 \\
\hline 415.70 & 26.98 \\
\hline 461.89 & 27.99 \\
\hline 369.51 & 27.55 \\
\hline 277.14 & 26.26 \\
\hline 184.76 & 23.55 \\
\hline 92.38 & 21.03 \\
\hline
\end{tabular}

\subsection{Carga de Ruptura}

\begin{tabular}{cc}
\hline Método & Força MN \\
\hline Davisson (1972) & 0.32 \\
\hline NBR 6122 (2010) & 0.37
\end{tabular}




\section{E1414-2-6H-7.95M}

\subsection{Geral}

Id $: 35$

Comprimento $\mathrm{m}: 7.95$

Inclinação $^{\circ}: 39.00$

Correção da profundidade (m) : 0.00

\subsection{SPT e Torque}

\begin{tabular}{cc}
\hline \multicolumn{2}{c}{ Torque } \\
\hline Profundidade $\mathrm{m}$ & Torque kN.m \\
\hline 2.30 & 2.71 \\
\hline 3.06 & 4.61 \\
\hline 3.83 & 7.46 \\
\hline 4.60 & 15.32 \\
\hline 5.36 & 17.63 \\
\hline 6.13 & 21.42
\end{tabular}

\begin{tabular}{ccc}
\hline & \multicolumn{2}{c}{ SPT } \\
\hline Profundidade m & Nspt & Solo \\
\hline 1.00 & 1.00 & Areia siltosa \\
\hline 2.00 & 1.00 & Areia siltosa \\
\hline 3.00 & 1.00 & Areia siltosa \\
\hline 4.00 & 2.00 & Areia siltosa \\
\hline 5.00 & 4.00 & Areia siltosa \\
\hline 6.00 & 7.00 & Areia siltosa \\
\hline 7.00 & 15.00 & Silte arenoso \\
\hline 8.00 & 11.00 & Areia siltosa \\
\hline 9.00 & 18.00 & Areia siltosa
\end{tabular}

36.3. Hélice

\begin{tabular}{cccccc}
\hline Posição & Profundidade $m$ & Diâmetro cm & SPT & Interpolado & Ajustado \\
\hline 6 & 2.30 & 35.56 & 1.00 & 1.00 & 1.00 \\
\hline 5 & 3.12 & 35.56 & 1.00 & 1.00 & 1.00 \\
\hline 4 & 3.94 & 35.56 & 1.00 & 1.64 & 1.64 \\
\hline 3 & 4.75 & 35.56 & 2.00 & 2.90 & 2.90 \\
\hline 2 & 5.45 & 30.48 & 4.00 & 4.46 & 4.46 \\
\hline 1 & 6.04 & 25.40 & 7.00 & 6.21 & 6.21
\end{tabular}

\subsection{Fuste}

\begin{tabular}{cccccc}
\hline Comprimento m & Seção & $\begin{array}{c}\text { Diâmetro externo } \\
\mathrm{cm}\end{array}$ & $\begin{array}{c}\text { Diâmetro interno } \\
\mathrm{cm}\end{array}$ & $\mathrm{cm}$ & $\mathrm{cm}$ \\
\hline 3.00 & Circular Vazada & 10.16 & 9.35 & &
\end{tabular}

\subsection{Prova de Carga}




\begin{tabular}{ll}
\hline 92.38 & 2.00 \\
\hline 138.57 & 2.77 \\
\hline 184.76 & 3.84 \\
\hline 230.95 & 5.03 \\
\hline 277.14 & 7.33 \\
\hline 323.33 & 10.43 \\
\hline 369.51 & 14.12 \\
\hline 415.70 & 18.36 \\
\hline 461.89 & 24.12 \\
\hline 369.51 & 23.93 \\
\hline 277.14 & 21.91 \\
\hline 184.76 & 20.07 \\
\hline 92.38 & 16.66 \\
\hline 138.57 & 17.27 \\
\hline 184.76 & 18.29 \\
\hline 230.95 & 19.32 \\
\hline 277.14 & 20.30 \\
\hline 323.33 & 21.44 \\
\hline 369.51 & 22.68 \\
\hline 415.70 & 23.81 \\
\hline 461.89 & 26.91 \\
\hline 369.51 & 26.76 \\
\hline 277.14 & 24.87 \\
\hline 184.76 & 22.78 \\
\hline 92.38 & 19.62 \\
\hline
\end{tabular}

\subsection{Carga de Ruptura}

\begin{tabular}{cc}
\hline Método & Força MN \\
\hline Davisson (1972) & 0.36 \\
\hline NBR 6122(2010) & 0.42
\end{tabular}




\section{E1414-2-6H-8.75M}

\subsection{Geral}

Id $: 36$

Comprimento $\mathrm{m}: 8.75$

Inclinação $^{\circ}: 39.00$

Correção da profundidade (m) : 0.00

\subsection{SPT e Torque}

\begin{tabular}{cc}
\hline \multicolumn{2}{c}{ Torque } \\
\hline Profundidade $\mathrm{m}$ & Torque kN.m \\
\hline 3.06 & 3.66 \\
\hline 2.30 & 2.30 \\
\hline 3.83 & 5.83 \\
\hline 4.60 & 7.46 \\
\hline 5.36 & 14.64 \\
\hline 6.13 & 18.57 \\
\hline 6.89 & 20.47
\end{tabular}

\begin{tabular}{ccc}
\hline & \multicolumn{2}{c}{ SPT } \\
\hline Profundidade $\mathrm{m}$ & Nspt & Solo \\
\hline 1.00 & 1.00 & Areia siltosa \\
\hline 2.00 & 1.00 & Areia siltosa \\
\hline 3.00 & 1.00 & Areia siltosa \\
\hline 4.00 & 2.00 & Areia siltosa \\
\hline 5.00 & 4.00 & Areia siltosa \\
\hline 6.00 & 7.00 & Areia siltosa \\
\hline 7.00 & 15.00 & Silte arenoso \\
\hline 8.00 & 11.00 & Areia siltosa \\
\hline 9.00 & 18.00 & Areia siltosa
\end{tabular}

\subsection{Hélice}

\begin{tabular}{cccccc}
\hline Posição & Profundidade $m$ & Diâmetro cm & SPT & Interpolado & Ajustado \\
\hline 6 & 2.91 & 35.56 & 1.00 & 1.00 & 1.00 \\
\hline 5 & 3.73 & 35.56 & 1.00 & 1.43 & 1.43 \\
\hline 4 & 4.55 & 35.56 & 2.00 & 2.50 & 2.50 \\
\hline 3 & 5.37 & 35.56 & 4.00 & 4.20 & 4.20 \\
\hline 2 & 6.07 & 30.48 & 7.00 & 6.30 & 6.30 \\
\hline 1 & 6.65 & 25.40 & 7.00 & 9.79 & 9.79
\end{tabular}

\subsection{Fuste}

\begin{tabular}{cccccc}
\hline Comprimento m & Seção & $\begin{array}{c}\text { Diâmetro externo } \\
\mathrm{cm}\end{array}$ & $\begin{array}{c}\text { Diâmetro interno } \\
\mathrm{cm}\end{array}$ & $\mathrm{cm}$ & $\mathrm{cm}$ \\
\hline 3.80 & Circular Vazada & 10.16 & 9.35 & &
\end{tabular}

\subsection{Prova de Carga}




\begin{tabular}{|c|c|}
\hline 76.10 & 2.00 \\
\hline 114.15 & 3.28 \\
\hline 152.20 & 4.55 \\
\hline 190.25 & 6.12 \\
\hline 228.30 & 8.27 \\
\hline 266.35 & 11.18 \\
\hline 304.40 & 14.76 \\
\hline 342.45 & 15.66 \\
\hline 380.50 & 17.89 \\
\hline 304.40 & 17.69 \\
\hline 228.30 & 17.06 \\
\hline 152.20 & 16.07 \\
\hline 76.10 & 15.34 \\
\hline 114.15 & 15.93 \\
\hline 152.20 & 17.04 \\
\hline 190.25 & 17.95 \\
\hline 228.30 & 18.97 \\
\hline 266.35 & 20.02 \\
\hline 304.40 & 21.51 \\
\hline 342.45 & 22.55 \\
\hline 380.50 & 24.68 \\
\hline 304.40 & 23.73 \\
\hline 228.30 & 22.54 \\
\hline 152.20 & 20.55 \\
\hline 76.10 & 18.06 \\
\hline
\end{tabular}

\subsection{Carga de Ruptura}

\begin{tabular}{cc}
\hline Método & Força MN \\
\hline Davisson (1972) & 0.29 \\
\hline NBR 6122(2010) & 0.39
\end{tabular}




\section{E1414-2-6H-9.15M}

\subsection{Geral}

Id $: 37$

Comprimento $\mathrm{m}: 9.15$

Inclinação $^{\circ}: 39.00$

Correção da profundidade (m) : 0.00

\subsection{SPT e Torque}

\begin{tabular}{cc}
\hline \multicolumn{2}{c}{ Torque } \\
\hline Profundidade $\mathrm{m}$ & Torque kN.m \\
\hline 3.06 & 2.44 \\
\hline 2.30 & 1.63 \\
\hline 3.83 & 4.07 \\
\hline 4.60 & 6.78 \\
\hline 5.36 & 10.85 \\
\hline 6.13 & 15.59 \\
\hline 6.89 & 19.12 \\
\hline 7.66 & 20.07
\end{tabular}

\begin{tabular}{ccc}
\hline & \multicolumn{2}{c}{ SPT } \\
\hline Profundidade $\mathrm{m}$ & Nspt & Solo \\
\hline 1.00 & 1.00 & Areia siltosa \\
\hline 2.00 & 1.00 & Areia siltosa \\
\hline 3.00 & 1.00 & Areia siltosa \\
\hline 4.00 & 2.00 & Areia siltosa \\
\hline 5.00 & 4.00 & Areia siltosa \\
\hline 6.00 & 7.00 & Areia siltosa \\
\hline 7.00 & 15.00 & Silte arenoso \\
\hline 8.00 & 11.00 & Areia siltosa \\
\hline 9.00 & 18.00 & Areia siltosa
\end{tabular}

38.3. Hélice

\begin{tabular}{cccccc}
\hline Posição & Profundidade $m$ & Diâmetro cm & SPT & Interpolado & Ajustado \\
\hline 6 & 3.22 & 35.56 & 1.00 & 1.00 & 1.00 \\
\hline 5 & 4.04 & 35.56 & 2.00 & 1.74 & 1.74 \\
\hline 4 & 4.85 & 35.56 & 2.00 & 3.11 & 3.11 \\
\hline 3 & 5.67 & 35.56 & 4.00 & 5.11 & 5.11 \\
\hline 2 & 6.37 & 30.48 & 7.00 & 7.58 & 7.58 \\
\hline 1 & 6.96 & 25.40 & 7.00 & 12.25 & 12.25
\end{tabular}

\subsection{Fuste}

\begin{tabular}{cccccc}
\hline Comprimento m & Seção & $\begin{array}{c}\text { Diâmetro externo } \\
\mathrm{cm}\end{array}$ & $\begin{array}{c}\text { Diâmetro interno } \\
\mathrm{cm}\end{array}$ & $\mathrm{cm}$ & $\mathrm{cm}$ \\
\hline 4.20 & Circular Vazada & 10.16 & 9.35 & &
\end{tabular}

\subsection{Prova de Carga}




\begin{tabular}{|c|c|}
\hline 83.55 & 1.30 \\
\hline 125.33 & 1.54 \\
\hline 167.11 & 3.02 \\
\hline 208.88 & 3.83 \\
\hline 250.66 & 5.38 \\
\hline 292.43 & 7.74 \\
\hline 334.21 & 10.19 \\
\hline 375.99 & 13.88 \\
\hline 417.76 & 18.25 \\
\hline 334.21 & 17.18 \\
\hline 250.66 & 15.32 \\
\hline 167.11 & 13.40 \\
\hline 83.55 & 10.09 \\
\hline 125.33 & 10.81 \\
\hline 167.11 & 12.29 \\
\hline 208.88 & 12.94 \\
\hline 250.66 & 14.28 \\
\hline 292.43 & 15.23 \\
\hline 334.21 & 16.39 \\
\hline 375.99 & 17.87 \\
\hline 417.76 & 20.25 \\
\hline 334.21 & 19.21 \\
\hline 250.66 & 17.58 \\
\hline 167.11 & 15.56 \\
\hline 83.55 & 12.11 \\
\hline
\end{tabular}

\subsection{Carga de Ruptura}

\begin{tabular}{cc}
\hline Método & Força MN \\
\hline Davisson (1972) & 0.39 \\
\hline NBR 6122(2010) & 0.42
\end{tabular}




\section{THIAGO-A1}

\subsection{Geral}

$$
\text { Id }: 39
$$

Comprimento $\mathrm{m}: 10.00$

$$
\text { Inclinação }{ }^{\circ}: 0.00
$$

Correção da profundidade (m) : 0.00

\begin{tabular}{|c|c|}
\hline \multicolumn{2}{|c|}{ Torque } \\
\hline Profundidade m & Torque kN.m \\
\hline 0.50 & 3.05 \\
\hline 1.00 & 2.46 \\
\hline 1.50 & 2.72 \\
\hline 2.00 & 2.79 \\
\hline 2.50 & 3.19 \\
\hline 3.00 & 2.92 \\
\hline 3.50 & 3.05 \\
\hline 4.00 & 3.19 \\
\hline 4.50 & 3.19 \\
\hline 5.00 & 2.99 \\
\hline 5.50 & 3.59 \\
\hline 6.00 & 3.52 \\
\hline 6.50 & 3.98 \\
\hline 7.00 & 3.45 \\
\hline 7.50 & 3.72 \\
\hline 8.00 & 4.32 \\
\hline 8.50 & 4.25 \\
\hline 9.00 & 4.58 \\
\hline 9.50 & 4.71 \\
\hline 10.00 & 4.58 \\
\hline
\end{tabular}

\subsection{SPT e Torque}

\begin{tabular}{ccc}
\hline & \multicolumn{2}{c}{ SPT } \\
\hline Profundidade $\mathrm{m}$ & Nspt & Solo \\
\hline 1.00 & 1.90 & Argila arenosa \\
\hline 2.00 & 2.06 & Argila arenosa \\
\hline 3.00 & 2.41 & Argila arenosa \\
\hline 4.00 & 5.03 & Argila arenosa \\
\hline 5.00 & 5.67 & Argila arenosa \\
\hline 6.00 & 6.33 & Argila arenosa \\
\hline 7.00 & 5.82 & Argila arenosa \\
\hline 8.00 & 6.33 & Silte arenoso \\
\hline 9.00 & 7.19 & Silte arenoso \\
\hline 10.00 & 5.96 & Silte arenoso \\
\hline 11.00 & 8.78 & Silte arenoso \\
\hline 12.00 & 7.00 & Silte arenoso
\end{tabular}

\subsection{Hélice}

\begin{tabular}{cccccc}
\hline Posição & Profundidade m & Diâmetro cm & SPT & Interpolado & Ajustado \\
\hline 1 & 10.00 & 20.32 & 7.19 & 6.33 & 6.33
\end{tabular}

\subsection{Fuste}

\begin{tabular}{cccccc}
\hline Comprimento m & Seção & $\begin{array}{c}\text { Diâmetro externo } \\
\mathrm{cm}\end{array}$ & $\begin{array}{c}\text { Diâmetro interno } \\
\mathrm{cm}\end{array}$ & $\mathrm{cm}$ & $\mathrm{cm}$ \\
\hline 10.00 & Circular Vazada & 7.30 & 6.32 & &
\end{tabular}




\subsection{Prova de Carga}

\begin{tabular}{|c|c|}
\hline Força kN & Deslocamento $\mathrm{mm}$ \\
\hline 0.00 & 0.00 \\
\hline 2.00 & 1.50 \\
\hline 4.00 & 1.78 \\
\hline 6.00 & 2.18 \\
\hline 8.00 & 2.90 \\
\hline 10.00 & 3.95 \\
\hline 12.00 & 5.13 \\
\hline 14.00 & 19.92 \\
\hline 16.00 & 25.82 \\
\hline 18.00 & 28.63 \\
\hline 20.00 & 32.52 \\
\hline 22.00 & 36.82 \\
\hline 24.00 & 41.36 \\
\hline 26.00 & 46.94 \\
\hline 28.00 & 52.60 \\
\hline 30.00 & 58.10 \\
\hline 32.00 & 62.20 \\
\hline 34.00 & 67.52 \\
\hline 36.00 & 74.04 \\
\hline 38.00 & 79.17 \\
\hline 40.00 & 83.63 \\
\hline 42.00 & 88.20 \\
\hline 44.00 & 94.35 \\
\hline 46.00 & 99.50 \\
\hline 48.00 & 102.62 \\
\hline 50.00 & 110.41 \\
\hline 52.00 & 121.48 \\
\hline 33.60 & 121.35 \\
\hline 25.20 & 120.98 \\
\hline 16.80 & 120.41 \\
\hline 8.40 & 119.26 \\
\hline 0.00 & 111.00 \\
\hline
\end{tabular}

\subsection{Carga de Ruptura}

\begin{tabular}{rc}
\hline Método & Força MN \\
\hline Davisson (1972) & 0.01 \\
\hline Livneh e El Naggar (2008) & 0.01 \\
\hline D/10 & 0.01 \\
\hline NBR 6122 (2010) & 0.01
\end{tabular}




\section{THIAGO-A2}

\subsection{Geral}

$$
\begin{aligned}
\text { Id } & : 40 \\
\text { Comprimento } \mathrm{m} & : 10.00 \\
\text { Inclinação }^{\circ} & : 0.00
\end{aligned}
$$

\begin{tabular}{|c|c|}
\hline \multicolumn{2}{|c|}{ Torque } \\
\hline Profundidade m & Torque kN.m \\
\hline 0.50 & 3.32 \\
\hline 1.00 & 3.05 \\
\hline 1.50 & 3.19 \\
\hline 2.00 & 3.25 \\
\hline 2.50 & 3.45 \\
\hline 3.00 & 2.92 \\
\hline 3.50 & 3.45 \\
\hline 4.00 & 3.19 \\
\hline 4.50 & 3.78 \\
\hline 5.00 & 3.52 \\
\hline 5.50 & 3.92 \\
\hline 6.00 & 4.32 \\
\hline 6.50 & 4.58 \\
\hline 7.00 & 3.59 \\
\hline 7.50 & 4.45 \\
\hline 8.00 & 4.52 \\
\hline 8.50 & 4.85 \\
\hline 9.00 & 4.45 \\
\hline 9.50 & 5.11 \\
\hline 10.00 & 4.85 \\
\hline
\end{tabular}

Correção da profundidade (m) : 0.00

\subsection{SPT e Torque}

\begin{tabular}{ccc}
\hline & \multicolumn{2}{c}{ SPT } \\
\hline Profundidade $\mathrm{m}$ & Nspt & Solo \\
\hline 1.00 & 1.90 & Argila arenosa \\
\hline 2.00 & 2.06 & Argila arenosa \\
\hline 3.00 & 2.41 & Argila arenosa \\
\hline 4.00 & 5.03 & Argila arenosa \\
\hline 5.00 & 5.67 & Argila arenosa \\
\hline 6.00 & 6.33 & Argila arenosa \\
\hline 7.00 & 5.82 & Argila arenosa \\
\hline 8.00 & 6.33 & Silte arenoso \\
\hline 9.00 & 7.19 & Silte arenoso \\
\hline 10.00 & 5.96 & Silte arenoso \\
\hline 11.00 & 8.78 & Silte arenoso \\
\hline 12.00 & 7.00 & Silte arenoso
\end{tabular}

\subsection{Hélice}

\begin{tabular}{cccccc}
\hline Posição & Profundidade m & Diâmetro cm & SPT & Interpolado & Ajustado \\
\hline 2 & 8.83 & 20.32 & 6.33 & 6.78 & 6.78 \\
\hline 1 & 9.73 & 20.32 & 7.19 & 6.66 & 6.66
\end{tabular}

\subsection{Fuste}

\begin{tabular}{cccccc}
\hline Comprimento m & Seção & $\begin{array}{c}\text { Diâmetro externo } \\
\mathrm{cm}\end{array}$ & $\begin{array}{c}\text { Diâmetro interno } \\
\mathrm{cm}\end{array}$ & $\mathrm{cm}$ & $\mathrm{cm}$ \\
\hline 8.83 & Circular Vazada & 7.30 & 6.32
\end{tabular}




\subsection{Prova de Carga}

\begin{tabular}{|c|c|}
\hline Força kN & Deslocamento $\mathrm{mm}$ \\
\hline 0.00 & 0.00 \\
\hline 2.75 & 2.00 \\
\hline 5.50 & 3.70 \\
\hline 8.25 & 5.07 \\
\hline 11.00 & 6.17 \\
\hline 13.75 & 7.29 \\
\hline 16.50 & 9.57 \\
\hline 19.25 & 15.54 \\
\hline 22.00 & 19.73 \\
\hline 24.75 & 22.02 \\
\hline 27.50 & 26.16 \\
\hline 30.25 & 29.08 \\
\hline 33.00 & 32.01 \\
\hline 35.75 & 34.02 \\
\hline 38.50 & 36.44 \\
\hline 41.25 & 39.58 \\
\hline 44.00 & 43.66 \\
\hline 46.75 & 46.35 \\
\hline 49.50 & 49.80 \\
\hline 52.25 & 53.88 \\
\hline 55.00 & 59.72 \\
\hline 57.80 & 66.42 \\
\hline 60.50 & 66.96 \\
\hline 63.25 & 72.11 \\
\hline 66.00 & 77.31 \\
\hline 68.75 & 82.74 \\
\hline 49.43 & 81.76 \\
\hline 39.38 & 81.33 \\
\hline 25.02 & 80.88 \\
\hline 10.67 & 80.00 \\
\hline
\end{tabular}

\subsection{Carga de Ruptura}

\begin{tabular}{cc}
\hline \multicolumn{1}{c}{ Método } & Força MN \\
\hline D/10 & 0.02 \\
\hline Livneh e El Naggar (2008) & 0.02 \\
\hline Davisson (1972) & 0.01 \\
\hline NBR 6122 (2010) & 0.01
\end{tabular}




\section{THIAGO-A3}

\subsection{Geral}

Id $: 41$

Comprimento $\mathrm{m}: 10.00$

Inclinação $^{\circ}: 0.00$

Correção da profundidade $(\mathrm{m}): 0.00$

\subsection{SPT e Torque}

\begin{tabular}{|c|c|}
\hline \multicolumn{2}{|c|}{ Torque } \\
\hline Profundidade m & Torque kN.m \\
\hline 0.50 & 2.39 \\
\hline 1.00 & 2.79 \\
\hline 1.50 & 2.66 \\
\hline 2.00 & 2.92 \\
\hline 2.50 & 3.98 \\
\hline 3.00 & 3.25 \\
\hline 3.50 & 3.19 \\
\hline 4.00 & 3.59 \\
\hline 4.50 & 4.18 \\
\hline 5.00 & 3.85 \\
\hline 5.50 & 3.72 \\
\hline 6.00 & 4.65 \\
\hline 6.50 & 4.98 \\
\hline 7.00 & 5.31 \\
\hline 7.50 & 4.18 \\
\hline 8.00 & 5.31 \\
\hline 8.50 & 6.37 \\
\hline 9.00 & 6.31 \\
\hline 9.50 & 5.71 \\
\hline 10.00 & 5.11 \\
\hline
\end{tabular}

\begin{tabular}{ccc}
\hline & \multicolumn{2}{c}{ SPT } \\
\hline Profundidade $\mathrm{m}$ & Nspt & Solo \\
\hline 1.00 & 1.90 & Argila arenosa \\
\hline 2.00 & 2.06 & Argila arenosa \\
\hline 3.00 & 2.41 & Argila arenosa \\
\hline 4.00 & 5.03 & Argila arenosa \\
\hline 5.00 & 5.67 & Argila arenosa \\
\hline 6.00 & 6.33 & Argila arenosa \\
\hline 7.00 & 5.82 & Argila arenosa \\
\hline 8.00 & 6.33 & Silte arenoso \\
\hline 9.00 & 7.19 & Silte arenoso \\
\hline 10.00 & 5.96 & Silte arenoso \\
\hline 11.00 & 8.78 & Silte arenoso \\
\hline 12.00 & 7.00 & Silte arenoso
\end{tabular}

\subsection{Hélice}

\begin{tabular}{cccccc}
\hline Posição & Profundidade $m$ & Diâmetro cm & SPT & Interpolado & Ajustado \\
\hline 3 & 7.93 & 20.32 & 5.82 & 6.14 & 6.14 \\
\hline 2 & 8.83 & 20.32 & 6.33 & 6.78 & 6.78 \\
\hline 1 & 9.73 & 20.32 & 7.19 & 6.66 & 6.66
\end{tabular}

\subsection{Fuste}

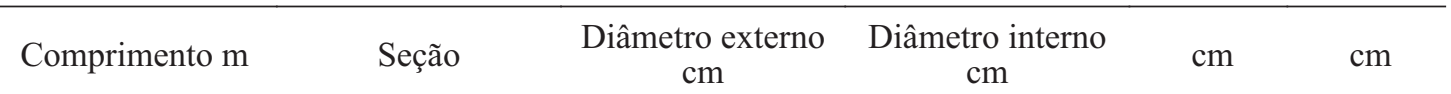




$\begin{array}{lll}7.93 & \text { Circular Vazada } & 7.30\end{array}$

\subsection{Prova de Carga}

\begin{tabular}{|c|c|}
\hline Força kN & Deslocamento $\mathrm{mm}$ \\
\hline 0.00 & 0.00 \\
\hline 4.00 & 2.00 \\
\hline 8.00 & 4.34 \\
\hline 12.00 & 6.03 \\
\hline 16.00 & 7.40 \\
\hline 20.00 & 10.58 \\
\hline 24.00 & 14.16 \\
\hline 28.00 & 16.99 \\
\hline 32.00 & 19.88 \\
\hline 36.00 & 22.10 \\
\hline 40.00 & 24.37 \\
\hline 44.00 & 26.97 \\
\hline 48.00 & 29.05 \\
\hline 52.00 & 31.85 \\
\hline 56.00 & 34.50 \\
\hline 60.00 & 35.88 \\
\hline 64.00 & 39.45 \\
\hline 68.00 & 42.09 \\
\hline 72.00 & 45.24 \\
\hline 76.00 & 48.35 \\
\hline 80.00 & 51.85 \\
\hline 84.00 & 54.80 \\
\hline 88.00 & 58.09 \\
\hline 92.00 & 61.93 \\
\hline 100.00 & 71.28 \\
\hline 108.00 & 79.58 \\
\hline 116.00 & 93.39 \\
\hline 86.29 & 92.47 \\
\hline 69.06 & 92.01 \\
\hline 44.17 & 91.54 \\
\hline 20.24 & 89.83 \\
\hline 0.00 & 75.96 \\
\hline
\end{tabular}

\subsection{Carga de Ruptura}

\begin{tabular}{rc}
\hline \multicolumn{1}{c}{ Método } & Força MN \\
\hline $\mathrm{D} / 10$ & 0.03 \\
\hline Davisson (1972) & 0.01 \\
\hline Livneh e El Naggar (2008) & 0.03 \\
\hline NBR 6122 (2010) & 0.02
\end{tabular}




\section{THIAGO-B1}

\subsection{Geral}

$$
\text { Id }: 42
$$

Comprimento $\mathrm{m}: 10.00$

$$
\text { Inclinação }^{\circ}: 0.00
$$

Correção da profundidade (m) : 0.00

\begin{tabular}{|c|c|}
\hline \multicolumn{2}{|c|}{ Torque } \\
\hline Profundidade m & Torque kN.m \\
\hline 0.50 & 2.92 \\
\hline 1.00 & 2.59 \\
\hline 1.50 & 2.52 \\
\hline 2.00 & 2.52 \\
\hline 2.50 & 2.46 \\
\hline 3.00 & 2.79 \\
\hline 3.50 & 2.72 \\
\hline 4.00 & 2.99 \\
\hline 4.50 & 2.99 \\
\hline 5.00 & 3.25 \\
\hline 5.50 & 3.45 \\
\hline 6.00 & 3.52 \\
\hline 6.50 & 3.95 \\
\hline 7.00 & 3.98 \\
\hline 7.50 & 3.85 \\
\hline 8.00 & 3.75 \\
\hline 8.50 & 4.52 \\
\hline 9.00 & 4.52 \\
\hline 9.50 & 4.38 \\
\hline 10.00 & 4.38 \\
\hline
\end{tabular}

\subsection{SPT e Torque}

\begin{tabular}{ccc}
\hline & \multicolumn{2}{c}{ SPT } \\
\hline Profundidade $\mathrm{m}$ & Nspt & Solo \\
\hline 1.00 & 1.90 & Argila arenosa \\
\hline 2.00 & 2.06 & Argila arenosa \\
\hline 3.00 & 2.41 & Argila arenosa \\
\hline 4.00 & 5.03 & Argila arenosa \\
\hline 5.00 & 5.67 & Argila arenosa \\
\hline 6.00 & 6.33 & Argila arenosa \\
\hline 7.00 & 5.82 & Argila arenosa \\
\hline 8.00 & 6.33 & Silte arenoso \\
\hline 9.00 & 7.19 & Silte arenoso \\
\hline 10.00 & 5.96 & Silte arenoso \\
\hline 11.00 & 8.78 & Silte arenoso \\
\hline 12.00 & 7.00 & Silte arenoso
\end{tabular}

\subsection{Hélice}

\begin{tabular}{cccccc}
\hline Posição & Profundidade m & Diâmetro cm & SPT & Interpolado & Ajustado \\
\hline 1 & 9.78 & 15.24 & 5.96 & 6.60 & 6.60
\end{tabular}

\subsection{Fuste}

\begin{tabular}{cccccc}
\hline Comprimento m & Seção & $\begin{array}{c}\text { Diâmetro externo } \\
\mathrm{cm}\end{array}$ & $\begin{array}{c}\text { Diâmetro interno } \\
\mathrm{cm}\end{array}$ & $\mathrm{cm}$ & $\mathrm{cm}$ \\
\hline 9.78 & Circular Vazada & 7.30 & 6.32 &
\end{tabular}




\subsection{Prova de Carga}

\begin{tabular}{cc}
\hline Força kN & Deslocamento $\mathrm{mm}$ \\
\hline 0.00 & 0.00 \\
\hline 2.50 & 2.00 \\
\hline 5.00 & 5.90 \\
\hline 7.50 & 6.23 \\
\hline 10.00 & 9.45 \\
\hline 12.50 & 11.01 \\
\hline 15.00 & 26.62 \\
\hline 17.50 & 40.65 \\
\hline 20.00 & 55.26 \\
\hline 22.50 & 64.93 \\
\hline 25.00 & 76.57 \\
\hline 27.50 & 88.54 \\
\hline 30.00 & 102.28 \\
\hline 32.50 & 121.98 \\
\hline 35.00 & 132.22 \\
\hline 37.50 & 157.96 \\
\hline 39.38 & 193.66
\end{tabular}

\subsection{Carga de Ruptura}

Método

Força MN

Livneh e El Naggar (2008) $\quad 0.01$

$\mathrm{D} / 10$

0.01

Davisson (1972) 6,3e-03

NBR 6122 (2010) 5,1e-03 


\section{THIAGO-B2}

\subsection{Geral}

$$
\text { Id }: 43
$$

Comprimento $\mathrm{m}: 10.00$

$$
\text { Inclinação }{ }^{\circ}: 0.00
$$

Correção da profundidade (m) : 0.00

\begin{tabular}{|c|c|}
\hline \multicolumn{2}{|c|}{ Torque } \\
\hline Profundidade m & Torque kN.m \\
\hline 0.50 & 5.05 \\
\hline 1.00 & 4.25 \\
\hline 1.50 & 4.98 \\
\hline 2.00 & 4.91 \\
\hline 2.50 & 4.65 \\
\hline 3.00 & 4.38 \\
\hline 3.50 & 4.65 \\
\hline 4.00 & 4.78 \\
\hline 4.50 & 4.91 \\
\hline 5.00 & 4.32 \\
\hline 5.50 & 4.78 \\
\hline 6.00 & 5.11 \\
\hline 6.50 & 4.98 \\
\hline 7.00 & 4.85 \\
\hline 7.50 & 4.98 \\
\hline 8.00 & 5.05 \\
\hline 8.50 & 5.18 \\
\hline 9.00 & 4.91 \\
\hline 9.50 & 5.05 \\
\hline 10.00 & 5.05 \\
\hline
\end{tabular}

\subsection{SPT e Torque}

\begin{tabular}{ccc}
\hline & \multicolumn{2}{c}{ SPT } \\
\hline Profundidade $\mathrm{m}$ & Nspt & Solo \\
\hline 1.00 & 1.90 & Argila arenosa \\
\hline 2.00 & 2.06 & Argila arenosa \\
\hline 3.00 & 2.41 & Argila arenosa \\
\hline 4.00 & 5.03 & Argila arenosa \\
\hline 5.00 & 5.67 & Argila arenosa \\
\hline 6.00 & 6.33 & Argila arenosa \\
\hline 7.00 & 5.82 & Argila arenosa \\
\hline 8.00 & 6.33 & Silte arenoso \\
\hline 9.00 & 7.19 & Silte arenoso \\
\hline 10.00 & 5.96 & Silte arenoso \\
\hline 11.00 & 8.78 & Silte arenoso \\
\hline 12.00 & 7.00 & Silte arenoso
\end{tabular}

\subsection{Hélice}

\begin{tabular}{cccccc}
\hline Posição & Profundidade m & Diâmetro cm & SPT & Interpolado & Ajustado \\
\hline 2 & 8.83 & 20.32 & 6.33 & 6.78 & 6.78 \\
\hline 1 & 9.73 & 15.24 & 7.19 & 6.66 & 6.66
\end{tabular}

\subsection{Fuste}

\begin{tabular}{cccccc}
\hline Comprimento m & Seção & $\begin{array}{c}\text { Diâmetro externo } \\
\mathrm{cm}\end{array}$ & $\begin{array}{c}\text { Diâmetro interno } \\
\mathrm{cm}\end{array}$ & $\mathrm{cm}$ & $\mathrm{cm}$ \\
\hline 8.83 & Circular Vazada & 7.30 & 6.32
\end{tabular}




\subsection{Prova de Carga}

\begin{tabular}{|c|c|}
\hline Força kN & Deslocamento $\mathrm{mm}$ \\
\hline 0.00 & 0.00 \\
\hline 2.50 & 2.00 \\
\hline 5.00 & 4.24 \\
\hline 7.50 & 5.19 \\
\hline 10.00 & 7.12 \\
\hline 12.50 & 7.86 \\
\hline 15.00 & 8.38 \\
\hline 17.50 & 8.93 \\
\hline 20.00 & 10.05 \\
\hline 22.50 & 11.92 \\
\hline 25.00 & 14.08 \\
\hline 27.50 & 16.52 \\
\hline 30.00 & 19.01 \\
\hline 32.50 & 22.21 \\
\hline 35.00 & 25.02 \\
\hline 37.50 & 27.40 \\
\hline 40.00 & 30.17 \\
\hline 42.50 & 34.30 \\
\hline 45.00 & 38.28 \\
\hline 47.50 & 41.70 \\
\hline 50.00 & 45.51 \\
\hline 52.50 & 50.58 \\
\hline 55.00 & 58.06 \\
\hline 57.50 & 62.45 \\
\hline 60.00 & 69.91 \\
\hline 62.50 & 81.10 \\
\hline 44.17 & 80.54 \\
\hline 36.99 & 80.37 \\
\hline 24.07 & 79.85 \\
\hline 10.19 & 79.25 \\
\hline 0.00 & 69.38 \\
\hline
\end{tabular}

\subsection{Carga de Ruptura}

\begin{tabular}{rc}
\hline Método & Força MN \\
\hline Davisson (1972) & 0.01 \\
\hline Livneh e El Naggar (2008) & 0.03 \\
\hline D/10 & 0.03 \\
\hline NBR 6122 (2010) & 0.01
\end{tabular}




\section{THIAGO-B3}

\subsection{Geral}

Id : 44

Comprimento $\mathrm{m}: 10.00$

Inclinação ${ }^{\circ}: 0.00$

Correção da profundidade (m) : 0.00

\subsection{SPT e Torque}

\begin{tabular}{|c|c|}
\hline \multicolumn{2}{|c|}{ Torque } \\
\hline Profundidade m & Torque kN.m \\
\hline 0.50 & 2.79 \\
\hline 1.00 & 2.79 \\
\hline 1.50 & 3.05 \\
\hline 2.00 & 3.72 \\
\hline 2.50 & 4.12 \\
\hline 3.00 & 3.92 \\
\hline 3.50 & 4.32 \\
\hline 4.00 & 4.71 \\
\hline 4.50 & 4.91 \\
\hline 5.00 & 4.98 \\
\hline 5.50 & 5.71 \\
\hline 6.00 & 5.84 \\
\hline 6.50 & 5.71 \\
\hline 7.00 & 5.58 \\
\hline 7.50 & 6.11 \\
\hline 8.00 & 6.44 \\
\hline 8.50 & 6.37 \\
\hline 9.00 & 6.51 \\
\hline 9.50 & 6.31 \\
\hline 10.00 & 6.11 \\
\hline
\end{tabular}

\begin{tabular}{ccc}
\hline & \multicolumn{2}{c}{ SPT } \\
\hline Profundidade $\mathrm{m}$ & Nspt & Solo \\
\hline 1.00 & 1.90 & Argila arenosa \\
\hline 2.00 & 2.06 & Argila arenosa \\
\hline 3.00 & 2.41 & Argila arenosa \\
\hline 4.00 & 5.03 & Argila arenosa \\
\hline 5.00 & 5.67 & Argila arenosa \\
\hline 6.00 & 6.33 & Argila arenosa \\
\hline 7.00 & 5.82 & Argila arenosa \\
\hline 8.00 & 6.33 & Silte arenoso \\
\hline 9.00 & 7.19 & Silte arenoso \\
\hline 10.00 & 5.96 & Silte arenoso \\
\hline 11.00 & 8.78 & Silte arenoso \\
\hline 12.00 & 7.00 & Silte arenoso
\end{tabular}

\subsection{Hélice}

\begin{tabular}{cccccc}
\hline Posição & Profundidade $m$ & Diâmetro cm & SPT & Interpolado & Ajustado \\
\hline 3 & 7.93 & 25.40 & 5.82 & 6.14 & 6.14 \\
\hline 2 & 8.83 & 20.32 & 6.33 & 6.78 & 6.78 \\
\hline 1 & 9.73 & 15.24 & 7.19 & 6.66 & 6.66
\end{tabular}

\subsection{Fuste}

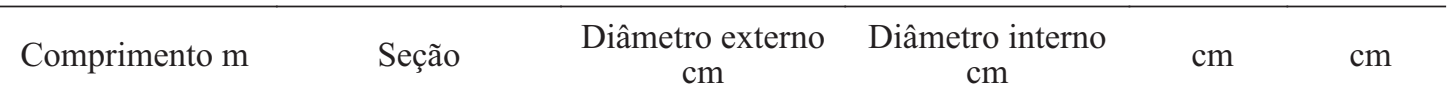




$\begin{array}{llll}7.93 & \text { Circular Vazada } & 7.30 & 6.32\end{array}$

\subsection{Prova de Carga}

\begin{tabular}{|c|c|}
\hline Força kN & Deslocamento $\mathrm{mm}$ \\
\hline 0.00 & 0.00 \\
\hline 6.50 & 3.00 \\
\hline 13.00 & 5.80 \\
\hline 19.50 & 8.37 \\
\hline 26.00 & 14.55 \\
\hline 32.50 & 19.23 \\
\hline 39.00 & 23.10 \\
\hline 45.50 & 27.08 \\
\hline 52.00 & 30.66 \\
\hline 58.50 & 34.86 \\
\hline 65.00 & 39.83 \\
\hline 71.50 & 45.03 \\
\hline 78.00 & 53.09 \\
\hline 84.50 & 60.23 \\
\hline 91.00 & 73.03 \\
\hline 97.50 & 79.79 \\
\hline 104.00 & 89.46 \\
\hline 110.50 & 98.87 \\
\hline 117.00 & 107.80 \\
\hline 123.50 & 115.93 \\
\hline 130.00 & 132.51 \\
\hline 103.52 & 132.33 \\
\hline 76.71 & 131.61 \\
\hline 49.91 & 130.81 \\
\hline 23.11 & 127.63 \\
\hline 0.00 & 127.67 \\
\hline
\end{tabular}

\subsection{Carga de Ruptura}

\begin{tabular}{rc}
\hline \multicolumn{1}{c}{ Método } & Força MN \\
\hline D/10 & 0.04 \\
\hline Davisson (1972) & 0.01 \\
\hline Livneh e El Naggar (2008) & 0.03 \\
\hline NBR 6122 (2010) & 0.02
\end{tabular}




\section{THIAGO-C2}

\subsection{Geral}

$$
\text { Id }: 45
$$

Comprimento $\mathrm{m}: 10.00$

$$
\text { Inclinação }{ }^{\circ}: 0.00
$$

Correção da profundidade (m) : 0.00

\begin{tabular}{|c|c|}
\hline \multicolumn{2}{|c|}{ Torque } \\
\hline Profundidade m & Torque kN.m \\
\hline 0.50 & 3.45 \\
\hline 1.00 & 3.19 \\
\hline 1.50 & 3.98 \\
\hline 2.00 & 4.12 \\
\hline 2.50 & 4.12 \\
\hline 3.00 & 3.78 \\
\hline 3.50 & 4.45 \\
\hline 4.00 & 4.58 \\
\hline 4.50 & 4.65 \\
\hline 5.00 & 4.65 \\
\hline 5.50 & 5.18 \\
\hline 6.00 & 5.25 \\
\hline 6.50 & 5.44 \\
\hline 7.00 & 5.58 \\
\hline 7.50 & 5.78 \\
\hline 8.00 & 5.98 \\
\hline 8.50 & 5.44 \\
\hline 9.00 & 5.78 \\
\hline 9.50 & 5.64 \\
\hline 10.00 & 5.98 \\
\hline
\end{tabular}

\subsection{SPT e Torque}

\begin{tabular}{ccc}
\hline & \multicolumn{2}{c}{ SPT } \\
\hline Profundidade $\mathrm{m}$ & Nspt & Solo \\
\hline 1.00 & 1.90 & Argila arenosa \\
\hline 2.00 & 2.06 & Argila arenosa \\
\hline 3.00 & 2.41 & Argila arenosa \\
\hline 4.00 & 5.03 & Argila arenosa \\
\hline 5.00 & 5.67 & Argila arenosa \\
\hline 6.00 & 6.33 & Argila arenosa \\
\hline 7.00 & 5.82 & Argila arenosa \\
\hline 8.00 & 6.33 & Silte arenoso \\
\hline 9.00 & 7.19 & Silte arenoso \\
\hline 10.00 & 5.96 & Silte arenoso \\
\hline 11.00 & 8.78 & Silte arenoso \\
\hline 12.00 & 7.00 & Silte arenoso
\end{tabular}

45.3. Hélice

\begin{tabular}{cccccc}
\hline Posição & Profundidade m & Diâmetro cm & SPT & Interpolado & Ajustado \\
\hline 2 & 8.78 & 25.40 & 6.33 & 6.74 & 6.74 \\
\hline 1 & 9.68 & 20.32 & 7.19 & 6.73 & 6.73
\end{tabular}

\subsection{Fuste}

\begin{tabular}{cccccc}
\hline Comprimento m & Seção & $\begin{array}{c}\text { Diâmetro externo } \\
\mathrm{cm}\end{array}$ & $\begin{array}{c}\text { Diâmetro interno } \\
\mathrm{cm}\end{array}$ & $\mathrm{cm}$ & $\mathrm{cm}$ \\
\hline 8.78 & Circular Vazada & 7.30 & 6.32
\end{tabular}




\subsection{Prova de Carga}

\begin{tabular}{cc}
\hline Força kN & Deslocamento $\mathrm{mm}$ \\
\hline 0.00 & 0.00 \\
\hline 6.00 & 2.00 \\
\hline 12.00 & 5.20 \\
\hline 18.00 & 6.88 \\
\hline 24.00 & 10.11 \\
\hline 30.00 & 14.13 \\
\hline 36.00 & 17.93 \\
\hline 42.00 & 21.61 \\
\hline 48.00 & 24.74 \\
\hline 54.00 & 30.81 \\
\hline 60.00 & 36.25 \\
\hline 66.00 & 42.98 \\
\hline 72.00 & 48.62 \\
\hline 78.00 & 55.94 \\
\hline 84.00 & 64.52 \\
\hline 90.00 & 73.56 \\
\hline 96.00 & 82.99 \\
\hline 102.00 & 94.20 \\
\hline 108.00 & 102.86 \\
\hline 114.00 & 116.58 \\
\hline 120.00 & 135.00 \\
\hline 89.64 & 134.06 \\
\hline 70.40 & 133.44 \\
\hline 45.70 & 132.37 \\
\hline 21.00 & 127.33 \\
\hline & \\
\hline & \\
\hline & \\
\hline & \\
\hline & \\
\hline & \\
\hline & \\
\hline & \\
\hline & \\
\hline & \\
\hline & \\
\hline & \\
\hline
\end{tabular}

\subsection{Carga de Ruptura}

\begin{tabular}{rc}
\hline \multicolumn{1}{c}{ Método } & Força MN \\
\hline Livneh e El Naggar (2008) & 0.04 \\
\hline D/10 & 0.05 \\
\hline Davisson (1972) & 0.01 \\
\hline NBR 6122 (2010) & 0.02
\end{tabular}




\section{THIAGO-C3}

\subsection{Geral}

Id : 46

Comprimento $\mathrm{m}: 10.00$

Inclinação ${ }^{\circ}: 0.00$

Correção da profundidade (m) : 0.00

\subsection{SPT e Torque}

\begin{tabular}{|c|c|}
\hline \multicolumn{2}{|c|}{ Torque } \\
\hline Profundidade m & Torque kN.m \\
\hline 0.50 & 3.65 \\
\hline 1.00 & 3.65 \\
\hline 1.50 & 3.85 \\
\hline 2.00 & 4.91 \\
\hline 2.50 & 5.31 \\
\hline 3.00 & 4.25 \\
\hline 3.50 & 4.98 \\
\hline 4.00 & 5.25 \\
\hline 4.50 & 5.44 \\
\hline 5.00 & 5.71 \\
\hline 5.50 & 5.71 \\
\hline 6.00 & 6.24 \\
\hline 6.50 & 6.44 \\
\hline 7.00 & 6.57 \\
\hline 7.50 & 6.44 \\
\hline 8.00 & 7.10 \\
\hline 8.50 & 7.10 \\
\hline 9.00 & 7.44 \\
\hline 9.50 & 7.50 \\
\hline 10.00 & 6.97 \\
\hline
\end{tabular}

\begin{tabular}{ccc}
\hline & \multicolumn{2}{c}{ SPT } \\
\hline Profundidade $\mathrm{m}$ & Nspt & Solo \\
\hline 1.00 & 1.90 & Argila arenosa \\
\hline 2.00 & 2.06 & Argila arenosa \\
\hline 3.00 & 2.41 & Argila arenosa \\
\hline 4.00 & 5.03 & Argila arenosa \\
\hline 5.00 & 5.67 & Argila arenosa \\
\hline 6.00 & 6.33 & Argila arenosa \\
\hline 7.00 & 5.82 & Argila arenosa \\
\hline 8.00 & 6.33 & Silte arenoso \\
\hline 9.00 & 7.19 & Silte arenoso \\
\hline 10.00 & 5.96 & Silte arenoso \\
\hline 11.00 & 8.78 & Silte arenoso \\
\hline 12.00 & 7.00 & Silte arenoso
\end{tabular}

46.3. Hélice

\begin{tabular}{cccccc}
\hline Posição & Profundidade $m$ & Diâmetro cm & SPT & Interpolado & Ajustado \\
\hline 3 & 7.88 & 30.48 & 5.82 & 6.12 & 6.12 \\
\hline 2 & 8.78 & 25.40 & 6.33 & 6.74 & 6.74 \\
\hline 1 & 9.68 & 20.32 & 7.19 & 6.73 & 6.73
\end{tabular}

\subsection{Fuste}



7.88
Circular Vazada
7.30
6.32

46.5. Prova de Carga

\begin{tabular}{|c|c|}
\hline Força kN & Deslocamento $\mathrm{mm}$ \\
\hline 0.00 & 0.00 \\
\hline 8.00 & 2.00 \\
\hline 16.00 & 5.44 \\
\hline 24.00 & 7.59 \\
\hline 32.00 & 11.19 \\
\hline 40.00 & 16.18 \\
\hline 48.00 & 21.10 \\
\hline 56.00 & 26.10 \\
\hline 64.00 & 31.18 \\
\hline 72.00 & 35.65 \\
\hline 80.00 & 39.09 \\
\hline 88.00 & 45.48 \\
\hline 96.00 & 50.13 \\
\hline 104.00 & 56.36 \\
\hline 112.00 & 62.50 \\
\hline 120.00 & 68.76 \\
\hline 128.00 & 75.79 \\
\hline 136.00 & 82.50 \\
\hline 144.00 & 90.89 \\
\hline 152.00 & 97.11 \\
\hline 160.00 & 112.17 \\
\hline 82.46 & 108.97 \\
\hline 61.40 & 108.26 \\
\hline 28.85 & 106.69 \\
\hline 0.00 & 89.81 \\
\hline
\end{tabular}

\subsection{Carga de Ruptura}

\begin{tabular}{rc}
\hline Método & Força MN \\
\hline Davisson (1972) & 0.02 \\
\hline D/10 & 0.05 \\
\hline Livneh e El Naggar (2008) & 0.05 \\
\hline NBR 6122 (2010) & 0.03
\end{tabular}




\section{E37-2}

\subsection{Geral}

$$
\text { Id }: 47
$$

Comprimento $\mathrm{m}: 11.59$

Inclinação $^{\circ}: 32.00$

Correção da profundidade (m) : 0.00

\subsection{SPT e Torque}

\begin{tabular}{cc}
\hline \multicolumn{2}{c}{ Torque } \\
\hline Profundidade $\mathrm{m}$ & Torque kN.m \\
\hline 2.54 & 3.53 \\
\hline 3.39 & 2.85 \\
\hline 4.24 & 4.47 \\
\hline 5.09 & 5.69 \\
\hline 5.94 & 7.46 \\
\hline 6.78 & 7.19 \\
\hline 7.63 & 11.25 \\
\hline 8.48 & 14.24 \\
\hline 9.33 & 16.27 \\
\hline 10.18 & 18.98
\end{tabular}

\begin{tabular}{ccl}
\hline & \multicolumn{2}{c}{ SPT } \\
\hline Profundidade $\mathrm{m}$ & Nspt & \multicolumn{1}{c}{ Solo } \\
\hline 11.00 & 27.00 & Silte argiloso \\
\hline 10.00 & 28.00 & Silte argiloso \\
\hline 9.00 & 26.00 & Silte argiloso \\
\hline 8.00 & 24.00 & Silte argiloso \\
\hline 7.00 & 10.00 & Silte argiloso \\
\hline 6.00 & 14.00 & Silte argiloso \\
\hline 5.00 & 16.00 & Silte argiloso \\
\hline 4.00 & 11.00 & Silte argiloso \\
\hline 3.00 & 8.00 & Silte argiloso \\
\hline 2.00 & 6.00 & Silte argiloso \\
\hline 1.00 & 4.00 & Silte argiloso
\end{tabular}

\subsection{Hélice}

\begin{tabular}{cccccc}
\hline Posição & Profundidade $m$ & Diâmetro $\mathrm{cm}$ & SPT & Interpolado & Ajustado \\
\hline 4 & 7.43 & 35.56 & 10.00 & 11.86 & 11.86 \\
\hline 3 & 8.34 & 35.56 & 24.00 & 24.07 & 24.07 \\
\hline 2 & 9.11 & 30.48 & 26.00 & 25.63 & 25.63 \\
\hline 1 & 9.76 & 25.40 & 26.00 & 26.92 & 26.92
\end{tabular}

\subsection{Fuste}

\begin{tabular}{cccccc}
\hline Comprimento m & Seção & $\begin{array}{c}\text { Diâmetro externo } \\
\mathrm{cm}\end{array}$ & $\begin{array}{c}\text { Diâmetro interno } \\
\mathrm{cm}\end{array}$ & $\mathrm{cm}$ & $\mathrm{cm}$ \\
\hline 8.76 & Circular Vazada & 10.16 & 9.35 & &
\end{tabular}

\subsection{Prova de Carga}




\begin{tabular}{|c|c|}
\hline 63.74 & 7.00 \\
\hline 98.07 & 12.95 \\
\hline 132.39 & 20.40 \\
\hline 166.71 & 28.58 \\
\hline 201.04 & 36.14 \\
\hline 235.36 & 42.56 \\
\hline 269.68 & 52.11 \\
\hline 313.81 & 64.66 \\
\hline 250.07 & 63.53 \\
\hline 186.33 & 62.09 \\
\hline 122.58 & 59.94 \\
\hline 63.74 & 57.26 \\
\hline 98.07 & 58.96 \\
\hline 132.39 & 60.13 \\
\hline 166.71 & 61.70 \\
\hline 201.04 & 63.11 \\
\hline 235.36 & 64.19 \\
\hline 269.68 & 66.72 \\
\hline 313.81 & 71.40 \\
\hline 250.07 & 70.31 \\
\hline 186.33 & 68.86 \\
\hline 122.58 & 66.76 \\
\hline 63.74 & 64.45 \\
\hline 313.81 & 65.17 \\
\hline 348.14 & 70.43 \\
\hline
\end{tabular}

\subsection{Carga de Ruptura}

\begin{tabular}{rc}
\hline \multicolumn{1}{c}{ Método } & Força MN \\
\hline Livneh e El Naggar (2008) & 0.17 \\
\hline Davisson (1972) & 0.07 \\
\hline D/10 & 0.18 \\
\hline NBR 6122(2010) & 0.10
\end{tabular}




\section{E42-2}

\subsection{Geral}

$$
\text { Id }: 48
$$

Comprimento $\mathrm{m}: 11.29$

Inclinação $^{\circ}: 32.00$

Correção da profundidade (m) : 0.00

\subsection{SPT e Torque}

\begin{tabular}{cc}
\hline \multicolumn{2}{c}{ Torque } \\
\hline Profundidade $\mathrm{m}$ & Torque kN.m \\
\hline 2.54 & 2.03 \\
\hline 3.39 & 1.63 \\
\hline 4.24 & 1.90 \\
\hline 5.09 & 3.53 \\
\hline 5.94 & 5.29 \\
\hline 6.78 & 7.05 \\
\hline 7.63 & 11.66 \\
\hline 8.48 & 13.15 \\
\hline 9.33 & 16.27 \\
\hline 10.18 & 20.34
\end{tabular}

\begin{tabular}{ccl}
\hline & \multicolumn{2}{c}{ SPT } \\
\hline Profundidade $\mathrm{m}$ & Nspt & \multicolumn{1}{c}{ Solo } \\
\hline 8.00 & 37.00 & Argila siltosa \\
\hline 7.00 & 2.00 & Argila siltosa \\
\hline 6.00 & 2.00 & Argila siltosa \\
\hline 5.00 & 4.00 & Argila siltosa \\
\hline 4.00 & 5.00 & Argila siltosa \\
\hline 3.00 & 6.00 & Silte argiloso \\
\hline 2.00 & 2.00 & Silte argiloso \\
\hline 1.00 & 2.00 & Silte argiloso \\
\hline 10.00 & 69.00 & Argila siltosa \\
\hline 9.00 & 59.00 & Argila siltosa
\end{tabular}

\subsection{Hélice}

\begin{tabular}{cccccc}
\hline Posição & Profundidade $m$ & Diâmetro cm & SPT & Interpolado & Ajustado \\
\hline 4 & 7.18 & 35.56 & 2.00 & 2.00 & 2.00 \\
\hline 3 & 8.08 & 35.56 & 37.00 & 29.40 & 29.40 \\
\hline 2 & 8.86 & 30.48 & 37.00 & 49.28 & 49.28 \\
\hline 1 & 9.50 & 25.40 & 59.00 & 60.00 & 60.00
\end{tabular}

\subsection{Fuste}

\begin{tabular}{cccccc}
\hline Comprimento m & Seção & $\begin{array}{c}\text { Diâmetro externo } \\
\mathrm{cm}\end{array}$ & $\begin{array}{c}\text { Diâmetro interno } \\
\mathrm{cm}\end{array}$ & $\mathrm{cm}$ & $\mathrm{cm}$ \\
\hline 8.46 & Circular Vazada & 10.16 & 9.35 &
\end{tabular}

\subsection{Prova de Carga}




\begin{tabular}{|c|c|}
\hline 98.07 & 8.92 \\
\hline 132.39 & 15.21 \\
\hline 166.71 & 20.48 \\
\hline 201.04 & 26.58 \\
\hline 235.36 & 33.03 \\
\hline 269.68 & 42.10 \\
\hline 313.81 & 45.72 \\
\hline 250.07 & 45.39 \\
\hline 186.33 & 44.59 \\
\hline 122.58 & 42.03 \\
\hline 63.74 & 39.72 \\
\hline 98.07 & 41.41 \\
\hline 132.39 & 42.66 \\
\hline 166.71 & 44.26 \\
\hline 201.04 & 45.81 \\
\hline 235.36 & 47.16 \\
\hline 269.68 & 50.85 \\
\hline 313.81 & 61.71 \\
\hline 250.07 & 61.31 \\
\hline 186.33 & 59.81 \\
\hline 122.58 & 57.37 \\
\hline 63.74 & 54.91 \\
\hline 313.81 & 48.38 \\
\hline 348.14 & 57.22 \\
\hline 382.46 & 70.02 \\
\hline
\end{tabular}

\subsection{Carga de Ruptura}

\begin{tabular}{rc}
\hline Método & Força MN \\
\hline Livneh e El Naggar (2008) & 0.22 \\
\hline Davisson (1972) & 0.10 \\
\hline D/10 & 0.23 \\
\hline NBR 6122(2010) & 0.13
\end{tabular}




\section{E51-2}

\subsection{Geral}

$$
\text { Id :49 }
$$

Comprimento $\mathrm{m}: 11.09$ Inclinação $^{\circ}: 32.00$

Correção da profundidade (m) : 0.00

\subsection{SPT e Torque}

\begin{tabular}{cc}
\hline \multicolumn{2}{c}{ Torque } \\
\hline Profundidade $\mathrm{m}$ & Torque kN.m \\
\hline 2.54 & 1.76 \\
\hline 3.39 & 2.03 \\
\hline 4.24 & 4.07 \\
\hline 5.09 & 6.10 \\
\hline 5.94 & 10.58 \\
\hline 6.78 & 12.88 \\
\hline 7.63 & 16.00 \\
\hline 8.48 & 18.17 \\
\hline 9.33 & 20.34
\end{tabular}

\begin{tabular}{lll}
\hline \multicolumn{2}{c}{ SPT } \\
\hline Profundidade m & Nspt & Solo
\end{tabular}

\subsection{Hélice}

\begin{tabular}{|c|c|c|c|c|c|}
\hline Posição & Profundidade $\mathrm{m}$ & Diâmetro cm & SPT & Interpolado & Ajustado \\
\hline 4 & 7.01 & 35.56 & & & \\
\hline 3 & 7.91 & 35.56 & & & \\
\hline 2 & 8.69 & 30.48 & & & \\
\hline 1 & 9.33 & 25.40 & & & \\
\hline
\end{tabular}

\subsection{Fuste}

\begin{tabular}{cccccc}
\hline Comprimento m & Seção & $\begin{array}{c}\text { Diâmetro externo } \\
\mathrm{cm}\end{array}$ & $\begin{array}{c}\text { Diâmetro interno } \\
\mathrm{cm}\end{array}$ & $\mathrm{cm}$ & $\mathrm{cm}$ \\
\hline 8.26 & Circular Vazada & 10.16 & 9.35 & &
\end{tabular}

\subsection{Prova de Carga}

\begin{tabular}{cc}
\hline Força kN & Deslocamento mm \\
\hline 0.00 & 0.00 \\
\hline 63.74 & 2.00 \\
\hline 98.07 & 3.57
\end{tabular}




\begin{tabular}{|c|c|}
\hline 132.39 & 9.55 \\
\hline 166.71 & 15.24 \\
\hline 201.04 & 21.13 \\
\hline 235.36 & 26.48 \\
\hline 269.68 & 33.63 \\
\hline 313.81 & 41.61 \\
\hline 250.07 & 36.43 \\
\hline 186.33 & 34.55 \\
\hline 122.58 & 32.60 \\
\hline 63.74 & 29.99 \\
\hline 98.07 & 31.94 \\
\hline 132.39 & 33.35 \\
\hline 166.71 & 34.56 \\
\hline 201.04 & 35.97 \\
\hline 235.36 & 37.35 \\
\hline 269.68 & 38.97 \\
\hline 313.81 & 43.84 \\
\hline 250.07 & 43.11 \\
\hline 186.33 & 41.79 \\
\hline 122.58 & 39.05 \\
\hline 63.74 & 36.44 \\
\hline 313.81 & 38.70 \\
\hline 348.14 & 44.28 \\
\hline
\end{tabular}

\subsection{Carga de Ruptura}

\begin{tabular}{rc}
\hline \multicolumn{1}{c}{ Método } & Força MN \\
\hline D/10 & 0.26 \\
\hline Livneh e El Naggar (2008) & 0.26 \\
\hline Davisson (1972) & 0.14 \\
\hline NBR 6122(2010) & 0.16
\end{tabular}




\section{E54-2}

\subsection{Geral}

Id : 50

Comprimento $\mathrm{m}: 11.00$

Inclinação $^{\circ}: 32.00$

Correção da profundidade (m) : 0.00

\subsection{SPT e Torque}

\begin{tabular}{cc}
\hline \multicolumn{2}{c}{ Torque } \\
\hline Profundidade $\mathrm{m}$ & Torque kN.m \\
\hline 2.54 & 1.36 \\
\hline 3.39 & 1.63 \\
\hline 4.24 & 1.76 \\
\hline 5.09 & 2.03 \\
\hline 5.94 & 3.39 \\
\hline 6.78 & 6.78 \\
\hline 7.63 & 9.49 \\
\hline 8.48 & 14.91 \\
\hline 9.33 & 20.34
\end{tabular}

\begin{tabular}{ccc}
\hline & \multicolumn{2}{c}{ SPT } \\
\hline Profundidade m & Nspt & Solo \\
\hline 1.00 & 3.00 & Silte argiloso \\
\hline 2.00 & 2.00 & Argila siltosa \\
\hline 3.00 & 6.00 & Argila \\
\hline 4.00 & 26.00 & Argila \\
\hline 5.00 & 35.00 & Argila silto arenosa \\
\hline 6.00 & 40.00 & Argila silto arenosa
\end{tabular}

50.3. Hélice

\begin{tabular}{|c|c|c|c|c|c|}
\hline Posição & Profundidade $\mathrm{m}$ & Diâmetro cm & \multirow[t]{5}{*}{ SPT } & Interpolado & \multirow[t]{5}{*}{ Ajustado } \\
\hline 4 & 6.93 & 35.56 & & \multirow[t]{4}{*}{40.00} & \\
\hline 3 & 7.84 & 35.56 & & & \\
\hline 2 & 8.61 & 30.48 & & & \\
\hline 1 & 9.26 & 25.40 & & & \\
\hline
\end{tabular}

\subsection{Fuste}

\begin{tabular}{cccccc}
\hline Comprimento m & Seção & $\begin{array}{c}\text { Diâmetro externo } \\
\mathrm{cm}\end{array}$ & $\begin{array}{c}\text { Diâmetro interno } \\
\mathrm{cm}\end{array}$ & $\mathrm{cm}$ & $\mathrm{cm}$ \\
\hline 8.17 & Circular Vazada & 10.16 & 9.35 & &
\end{tabular}

\subsection{Prova de Carga}

\begin{tabular}{cc}
\hline Força kN & Deslocamento mm \\
\hline 0.00 & 0.00 \\
\hline 63.74 & 3.00 \\
\hline 98.07 & 12.35
\end{tabular}




\begin{tabular}{|c|c|}
\hline 132.39 & 15.60 \\
\hline 166.71 & 20.71 \\
\hline 201.04 & 25.60 \\
\hline 235.36 & 30.32 \\
\hline 269.68 & 34.41 \\
\hline 313.81 & 42.78 \\
\hline 250.07 & 41.40 \\
\hline 186.33 & 40.12 \\
\hline 122.58 & 37.94 \\
\hline 63.74 & 34.78 \\
\hline 98.07 & 35.52 \\
\hline 132.39 & 36.64 \\
\hline 166.71 & 37.94 \\
\hline 201.04 & 39.40 \\
\hline 235.36 & 40.43 \\
\hline 269.68 & 42.22 \\
\hline 313.81 & 44.92 \\
\hline 250.07 & 43.96 \\
\hline 186.33 & 42.55 \\
\hline 122.58 & 39.98 \\
\hline 63.74 & 36.87 \\
\hline 313.81 & 43.85 \\
\hline 348.14 & 45.86 \\
\hline
\end{tabular}

\subsection{Carga de Ruptura}

\begin{tabular}{rc}
\hline \multicolumn{1}{c}{ Método } & Força MN \\
\hline D/10 & 0.25 \\
\hline Davisson (1972) & 0.08 \\
\hline Livneh e El Naggar (2008) & 0.24 \\
\hline NBR 6122 (2010) & 0.10
\end{tabular}




\section{E57-3}

\subsection{Geral}

$$
\text { Id :51 }
$$

Comprimento $\mathrm{m}: 12.10$

Inclinação $^{\circ}: 32.00$

Correção da profundidade (m) : 5.00

\subsection{SPT e Torque}

\begin{tabular}{cc}
\hline \multicolumn{2}{c}{ Torque } \\
\hline Profundidade $\mathrm{m}$ & Torque kN.m \\
\hline 2.54 & 1.76 \\
\hline 3.39 & 2.85 \\
\hline 4.24 & 4.07 \\
\hline 5.09 & 4.07 \\
\hline 5.94 & 4.61 \\
\hline 6.78 & 9.08 \\
\hline 7.63 & 10.58 \\
\hline 8.48 & 15.59 \\
\hline 9.33 & 16.27 \\
\hline 10.18 & 18.98
\end{tabular}

\begin{tabular}{ccl}
\hline & \multicolumn{2}{c}{ SPT } \\
\hline Profundidade $\mathrm{m}$ & Nspt & \multicolumn{1}{c}{ Solo } \\
\hline 13.00 & 31.00 & Silte argiloso \\
\hline 12.00 & 29.00 & Silte argiloso \\
\hline 11.00 & 31.00 & Silte argiloso \\
\hline 10.00 & 9.00 & Silte argiloso \\
\hline 9.00 & 8.00 & Silte argiloso \\
\hline 8.00 & 6.00 & Silte argiloso \\
\hline 7.00 & 5.00 & Silte argiloso \\
\hline 6.00 & 3.00 & Silte argiloso \\
\hline 5.00 & 3.00 & Silte argiloso \\
\hline 4.00 & 5.00 & Silte argiloso \\
\hline 3.00 & 4.00 & Silte argiloso \\
\hline 2.00 & 3.00 & Silte argiloso \\
\hline 1.00 & 1.00 & Silte argiloso
\end{tabular}

\subsection{Hélice}

\begin{tabular}{cccccc}
\hline Posição & Profundidade $m$ & Diâmetro cm & SPT & Interpolado & Ajustado \\
\hline 4 & 7.87 & 35.56 & 5.00 & 5.49 & 8.49 \\
\hline 3 & 8.77 & 35.56 & 6.00 & 6.79 & 17.68 \\
\hline 2 & 9.55 & 30.48 & 8.00 & 8.17 & 30.66 \\
\hline 1 & 10.19 & 25.40 & 9.00 & 8.82 & 29.37
\end{tabular}

\subsection{Fuste}

\begin{tabular}{cccccc}
\hline Comprimento m & Seção & $\begin{array}{c}\text { Diâmetro externo } \\
\mathrm{cm}\end{array}$ & $\begin{array}{c}\text { Diâmetro interno } \\
\mathrm{cm}\end{array}$ & $\mathrm{cm}$ & $\mathrm{cm}$ \\
\hline 9.27 & Circular Vazada & 10.16 & 9.35 & &
\end{tabular}

\subsection{Prova de Carga}


Força kN

\begin{tabular}{cc}
\hline 0.00 & 0.00 \\
\hline 63.74 & 7.00 \\
\hline 98.07 & 17.53 \\
\hline 132.39 & 26.63 \\
\hline 206.71 & 34.68 \\
\hline 235.36 & 44.81 \\
\hline 269.68 & 52.81 \\
\hline 313.81 & 62.19 \\
\hline 250.07 & 96.39 \\
\hline 186.33 & 95.99 \\
\hline 122.58 & 94.41 \\
\hline 63.74 & 91.58 \\
\hline 98.07 & 89.58 \\
\hline 132.39 & 90.31 \\
\hline 166.71 & 91.15 \\
\hline 201.04 & 92.55 \\
\hline 235.36 & 93.73 \\
\hline 269.68 & 94.53 \\
\hline 313.81 & 96.21 \\
\hline 250.07 & 101.50 \\
\hline 186.33 & 100.73 \\
\hline 122.58 & 99.48 \\
\hline 63.74 & 96.92 \\
\hline 313.81 & 94.48 \\
\hline 348.14 & 98.53 \\
\hline & 102.93 \\
\hline & \\
\hline & \\
\hline & \\
\hline & \\
\hline & \\
\hline & \\
\hline & \\
\hline & \\
\hline & \\
\hline & \\
\hline & \\
\hline & \\
\hline
\end{tabular}

\subsection{Carga de Ruptura}

\begin{tabular}{rc}
\hline Método & Força MN \\
\hline Davisson (1972) & 0.07 \\
\hline $\mathrm{D} / 10$ & 0.15 \\
\hline Livneh e El Naggar (2008) & 0.14 \\
\hline NBR 6122 (2010) & 0.08
\end{tabular}




\section{E66-1-1}

\subsection{Geral}

$$
\text { Id : } 52
$$

Comprimento $\mathrm{m}: 16.30$

Inclinação $^{\circ}: 32.00$

Correção da profundidade (m) : 0.00

\subsection{SPT e Torque}

\begin{tabular}{cc}
\hline \multicolumn{2}{c}{ Torque } \\
\hline Profundidade $\mathrm{m}$ & Torque kN.m \\
\hline 2.54 & 2.30 \\
\hline 3.39 & 1.36 \\
\hline 4.24 & 1.49 \\
\hline 5.09 & 2.85 \\
\hline 5.94 & 6.37 \\
\hline 6.78 & 10.85 \\
\hline 7.63 & 13.56 \\
\hline 8.48 & 13.56 \\
\hline 9.33 & 13.15 \\
\hline 10.18 & 16.81 \\
\hline 11.02 & 14.51 \\
\hline 11.87 & 16.27 \\
\hline 12.72 & 13.56 \\
\hline 13.57 & 20.34
\end{tabular}

\begin{tabular}{ccl}
\hline & \multicolumn{2}{c}{ SPT } \\
\hline Profundidade $\mathrm{m}$ & Nspt & \multicolumn{1}{c}{ Solo } \\
\hline 1.00 & 1.50 & Silte argiloso \\
\hline 14.00 & 30.00 & Silte argiloso \\
\hline 13.00 & 26.00 & Silte argiloso \\
\hline 12.00 & 25.00 & Silte argiloso \\
\hline 11.00 & 15.00 & Silte argiloso \\
\hline 10.00 & 13.00 & Silte argiloso \\
\hline 9.00 & 9.00 & Silte argiloso \\
\hline 8.00 & 7.00 & Silte argiloso \\
\hline 7.00 & 10.00 & Silte argiloso \\
\hline 6.00 & 13.00 & Silte argiloso \\
\hline 5.00 & 12.00 & Silte argiloso \\
\hline 4.00 & 13.00 & Silte argiloso \\
\hline 3.00 & 9.00 & Silte argiloso \\
\hline 2.00 & 3.00 & Silte argiloso
\end{tabular}

\subsection{Hélice}

\begin{tabular}{cccccc}
\hline Posição & Profundidade $\mathrm{m}$ & Diâmetro cm & SPT & Interpolado & Ajustado \\
\hline 4 & 11.43 & 35.56 & 15.00 & 16.27 & 16.27 \\
\hline 3 & 12.33 & 35.56 & 25.00 & 25.03 & 25.03 \\
\hline 2 & 13.11 & 30.48 & 26.00 & 25.81 & 25.81 \\
\hline 1 & 13.75 & 25.40 & 26.00 & 27.81 & 27.81
\end{tabular}

\subsection{Fuste}

\begin{tabular}{cccccc}
\hline Comprimento m & Seção & $\begin{array}{c}\text { Diâmetro externo } \\
\mathrm{cm}\end{array}$ & $\begin{array}{c}\text { Diâmetro interno } \\
\mathrm{cm}\end{array}$ & $\mathrm{cm}$ & $\mathrm{cm}$ \\
\hline 13.47 & Circular Vazada & 10.16 & 9.35 & &
\end{tabular}




\begin{tabular}{cc}
\hline Força kN & Deslocamento mm \\
\hline 0.00 & 0.00 \\
\hline 63.74 & 7.00 \\
\hline 98.07 & 16.38 \\
\hline 132.39 & 25.12 \\
\hline 166.71 & 36.65 \\
\hline 201.04 & 48.20 \\
\hline 235.36 & 57.84 \\
\hline 269.68 & 97.04
\end{tabular}

\subsection{Carga de Ruptura}

\begin{tabular}{rc}
\hline Método & Força MN \\
\hline Livneh e El Naggar (2008) & 0.15 \\
\hline $\mathrm{D} / 10$ & 0.15 \\
\hline Davisson (1972) & 0.07 \\
\hline NBR 6122(2010) & 0.09
\end{tabular}




\section{E66-1-2}

\subsection{Geral}

$$
\text { Id }: 53
$$

Comprimento $\mathrm{m}: 14.40$

Inclinação $^{\circ}: 32.00$

Correção da profundidade (m) $: 0.00$

\subsection{SPT e Torque}

\begin{tabular}{cc}
\hline \multicolumn{2}{c}{ Torque } \\
\hline Profundidade $\mathrm{m}$ & Torque kN.m \\
\hline 2.54 & 2.85 \\
\hline 3.39 & 1.90 \\
\hline 4.24 & 1.76 \\
\hline 5.09 & 2.44 \\
\hline 5.94 & 6.10 \\
\hline 6.78 & 10.85 \\
\hline 7.63 & 12.20 \\
\hline 8.48 & 16.27 \\
\hline 9.33 & 15.46 \\
\hline 10.18 & 16.95 \\
\hline 11.02 & 18.71 \\
\hline 11.87 & 18.98 \\
\hline 12.72 & 20.34
\end{tabular}

\begin{tabular}{ccl}
\hline & \multicolumn{2}{c}{ SPT } \\
\hline Profundidade $\mathrm{m}$ & Nspt & \multicolumn{1}{c}{ Solo } \\
\hline 14.00 & 30.00 & Silte argiloso \\
\hline 13.00 & 26.00 & Silte argiloso \\
\hline 12.00 & 25.00 & Silte argiloso \\
\hline 11.00 & 15.00 & Silte argiloso \\
\hline 10.00 & 13.00 & Silte argiloso \\
\hline 9.00 & 9.00 & Silte argiloso \\
\hline 8.00 & 7.00 & Silte argiloso \\
\hline 7.00 & 10.00 & Silte argiloso \\
\hline 6.00 & 13.00 & Silte argiloso \\
\hline 5.00 & 12.00 & Silte argiloso \\
\hline 4.00 & 13.00 & Silte argiloso \\
\hline 3.00 & 9.00 & Silte argiloso \\
\hline 2.00 & 3.00 & Silte argiloso \\
\hline 1.00 & 1.50 & Silte argiloso
\end{tabular}

\subsection{Hélice}

\begin{tabular}{cccccc}
\hline Posição & Profundidade $\mathrm{m}$ & Diâmetro cm & SPT & Interpolado & Ajustado \\
\hline 4 & 9.82 & 35.56 & 9.00 & 11.06 & 11.06 \\
\hline 3 & 10.72 & 35.56 & 13.00 & 13.84 & 13.84 \\
\hline 2 & 11.50 & 30.48 & 15.00 & 16.96 & 16.96 \\
\hline 1 & 12.14 & 25.40 & 25.00 & 23.42 & 23.42
\end{tabular}

\subsection{Fuste}

\begin{tabular}{cccccc}
\hline Comprimento m & Seção & $\begin{array}{c}\text { Diâmetro externo } \\
\mathrm{cm}\end{array}$ & $\begin{array}{c}\text { Diâmetro interno } \\
\mathrm{cm}\end{array}$ & $\mathrm{cm}$ & $\mathrm{cm}$ \\
\hline 11.57 & Circular Vazada & 10.16 & 9.35 & &
\end{tabular}




\begin{tabular}{cc}
\hline Força kN & Deslocamento mm \\
\hline 0.00 & 0.00 \\
\hline 63.74 & 8.00 \\
\hline 98.07 & 15.65 \\
\hline 132.39 & 21.87 \\
\hline 166.71 & 33.77 \\
\hline 201.04 & 43.15 \\
\hline 235.36 & 55.25 \\
\hline 269.68 & 72.02 \\
\hline 313.81 & 84.26 \\
\hline 250.07 & 81.88 \\
\hline 186.33 & 81.18 \\
\hline 122.58 & 79.37 \\
\hline 63.74 & 76.28 \\
\hline 98.07 & 78.61 \\
\hline 132.39 & 80.05 \\
\hline 166.71 & 81.08 \\
\hline 201.04 & 82.63 \\
\hline 235.36 & 84.57 \\
\hline 269.68 & 93.44 \\
\hline 313.81 & 124.96 \\
\hline & \\
\hline
\end{tabular}

\subsection{Carga de Ruptura}

\begin{tabular}{rc}
\hline Método & Força MN \\
\hline Davisson (1972) & 0.06 \\
\hline D/10 & 0.16 \\
\hline Livneh e El Naggar (2008) & 0.16 \\
\hline NBR 6122 (2010) & 0.10
\end{tabular}




\section{E66-1-3}

\subsection{Geral}

$$
\text { Id : } 54
$$

Comprimento $\mathrm{m}: 12.50$

Inclinação $^{\circ}: 32.00$

Correção da profundidade (m) $: 0.00$

\subsection{SPT e Torque}

\begin{tabular}{cc}
\hline \multicolumn{2}{c}{ Torque } \\
\hline Profundidade $\mathrm{m}$ & Torque kN.m \\
\hline 2.54 & 1.76 \\
\hline 3.39 & 2.03 \\
\hline 4.24 & 1.63 \\
\hline 5.09 & 2.03 \\
\hline 5.94 & 5.15 \\
\hline 6.78 & 8.13 \\
\hline 7.63 & 12.20 \\
\hline 8.48 & 16.95 \\
\hline 9.33 & 15.19 \\
\hline 10.18 & 17.63 \\
\hline 11.02 & 18.98
\end{tabular}

\begin{tabular}{ccl}
\hline & \multicolumn{2}{c}{ SPT } \\
\hline Profundidade $\mathrm{m}$ & Nspt & \multicolumn{1}{c}{ Solo } \\
\hline 14.00 & 30.00 & Silte argiloso \\
\hline 13.00 & 26.00 & Silte argiloso \\
\hline 12.00 & 25.00 & Silte argiloso \\
\hline 11.00 & 15.00 & Silte argiloso \\
\hline 10.00 & 13.00 & Silte argiloso \\
\hline 9.00 & 9.00 & Silte argiloso \\
\hline 8.00 & 7.00 & Silte argiloso \\
\hline 7.00 & 10.00 & Silte argiloso \\
\hline 6.00 & 13.00 & Silte argiloso \\
\hline 5.00 & 12.00 & Silte argiloso \\
\hline 4.00 & 13.00 & Silte argiloso \\
\hline 3.00 & 9.00 & Silte argiloso \\
\hline 2.00 & 3.00 & Silte argiloso \\
\hline 1.00 & 1.50 & Silte argiloso
\end{tabular}

\subsection{Hélice}

\begin{tabular}{cccccc}
\hline Posição & Profundidade $m$ & Diâmetro cm & SPT & Interpolado & Ajustado \\
\hline 4 & 8.20 & 35.56 & 7.00 & 7.29 & 7.29 \\
\hline 3 & 9.11 & 35.56 & 9.00 & 8.62 & 8.62 \\
\hline 2 & 9.88 & 30.48 & 9.00 & 11.34 & 11.34 \\
\hline 1 & 10.53 & 25.40 & 13.00 & 13.46 & 13.46
\end{tabular}

\subsection{Fuste}

\begin{tabular}{cccccc}
\hline Comprimento m & Seção & $\begin{array}{c}\text { Diâmetro externo } \\
\mathrm{cm}\end{array}$ & $\begin{array}{c}\text { Diâmetro interno } \\
\mathrm{cm}\end{array}$ & $\mathrm{cm}$ & $\mathrm{cm}$ \\
\hline 9.67 & Circular Vazada & 10.16 & 9.35 & &
\end{tabular}




\begin{tabular}{cc}
\hline Força kN & Deslocamento $\mathrm{mm}$ \\
\hline 0.00 & 0.00 \\
\hline 63.74 & 8.00 \\
\hline 98.07 & 15.22 \\
\hline 132.39 & 22.00 \\
\hline 166.71 & 30.26 \\
\hline 201.04 & 39.85 \\
\hline 235.36 & 48.91 \\
\hline 269.68 & 56.26 \\
\hline 313.81 & 106.26
\end{tabular}

\subsection{Carga de Ruptura}

\begin{tabular}{rc}
\hline Método & Força MN \\
\hline Livneh e El Naggar (2008) & 0.17 \\
\hline D/10 & 0.17 \\
\hline Davisson (1972) & 0.07 \\
\hline NBR 6122(2010) & 0.09
\end{tabular}




\section{E66-1-4}

\subsection{Geral}

$$
\text { Id }: 55
$$

Comprimento $\mathrm{m}: 12.00$

Inclinação $^{\circ}: 32.00$

Correção da profundidade (m) : 0.00

\subsection{SPT e Torque}

\begin{tabular}{cc}
\hline \multicolumn{2}{c}{ Torque } \\
\hline Profundidade $\mathrm{m}$ & Torque kN.m \\
\hline 2.54 & 2.44 \\
\hline 3.39 & 2.17 \\
\hline 4.24 & 2.30 \\
\hline 5.09 & 3.12 \\
\hline 5.94 & 7.86 \\
\hline 6.78 & 11.66 \\
\hline 7.63 & 13.96 \\
\hline 8.48 & 16.27 \\
\hline 9.33 & 18.44 \\
\hline 10.18 & 20.34
\end{tabular}

\begin{tabular}{ccl}
\hline & \multicolumn{2}{c}{ SPT } \\
\hline Profundidade $\mathrm{m}$ & Nspt & \multicolumn{1}{c}{ Solo } \\
\hline 14.00 & 30.00 & Silte argiloso \\
\hline 13.00 & 26.00 & Silte argiloso \\
\hline 12.00 & 25.00 & Silte argiloso \\
\hline 11.00 & 15.00 & Silte argiloso \\
\hline 10.00 & 13.00 & Silte argiloso \\
\hline 9.00 & 9.00 & Silte argiloso \\
\hline 8.00 & 7.00 & Silte argiloso \\
\hline 7.00 & 10.00 & Silte argiloso \\
\hline 6.00 & 13.00 & Silte argiloso \\
\hline 5.00 & 12.00 & Silte argiloso \\
\hline 4.00 & 13.00 & Silte argiloso \\
\hline 3.00 & 9.00 & Silte argiloso \\
\hline 2.00 & 3.00 & Silte argiloso \\
\hline 1.00 & 1.50 & Silte argiloso
\end{tabular}

\subsection{Hélice}

\begin{tabular}{cccccc}
\hline Posição & Profundidade $m$ & Diâmetro cm & SPT & Interpolado & Ajustado \\
\hline 4 & 7.39 & 40.64 & 10.00 & 9.72 & 9.72 \\
\hline 3 & 8.43 & 40.64 & 7.00 & 7.25 & 7.25 \\
\hline 2 & 9.33 & 35.56 & 9.00 & 9.12 & 9.12 \\
\hline 1 & 10.11 & 30.48 & 13.00 & 12.23 & 12.23
\end{tabular}

\subsection{Fuste}

\begin{tabular}{cccccc}
\hline Comprimento m & Seção & $\begin{array}{c}\text { Diâmetro externo } \\
\mathrm{cm}\end{array}$ & $\begin{array}{c}\text { Diâmetro interno } \\
\mathrm{cm}\end{array}$ & $\mathrm{cm}$ & $\mathrm{cm}$ \\
\hline 8.72 & Circular Vazada & 10.16 & 9.35 & &
\end{tabular}




\begin{tabular}{cc}
\hline Força kN & Deslocamento $\mathrm{mm}$ \\
\hline 0.00 & 0.00 \\
\hline 63.74 & 5.00 \\
\hline 98.07 & 10.09 \\
\hline 132.39 & 17.07 \\
\hline 166.71 & 25.95 \\
\hline 201.04 & 34.36 \\
\hline 235.36 & 43.23 \\
\hline 269.68 & 51.77 \\
\hline 313.81 & 67.83 \\
\hline 250.07 & 67.46 \\
\hline 186.33 & 66.08 \\
\hline 122.58 & 63.12 \\
\hline 63.74 & 61.41 \\
\hline 98.07 & 61.87 \\
\hline 132.39 & 63.18 \\
\hline 166.71 & 63.73 \\
\hline 201.04 & 64.92 \\
\hline 235.36 & 66.18 \\
\hline 269.68 & 67.62 \\
\hline 313.81 & 72.59 \\
\hline 250.07 & 71.83 \\
\hline 186.33 & 68.44 \\
\hline 122.58 & 66.40 \\
\hline 63.74 & 64.38 \\
\hline 313.81 & 70.37 \\
\hline 348.14 & 87.54 \\
\hline & 6 \\
\hline & \\
\hline & \\
\hline & \\
\hline & \\
\hline & \\
\hline & \\
\hline & \\
\hline & \\
\hline & \\
\hline & \\
\hline & \\
\hline & \\
\hline
\end{tabular}

\subsection{Carga de Ruptura}

\begin{tabular}{rc}
\hline Método & Força MN \\
\hline Davisson (1972) & 0.10 \\
\hline $\mathrm{D} / 10$ & 0.21 \\
\hline Livneh e El Naggar (2008) & 0.21 \\
\hline NBR 6122 (2010) & 0.13
\end{tabular}




\section{E149-1-1}

\subsection{Geral}

$$
\begin{aligned}
\text { Id } & : 56 \\
\text { Comprimento } \mathrm{m} & : 8.30 \\
\text { Inclinação }^{\circ} & : 39.00
\end{aligned}
$$

Correção da profundidade (m) : 0.00

\subsection{SPT e Torque}

\begin{tabular}{cc}
\hline \multicolumn{2}{c}{ Torque } \\
\hline Profundidade $\mathrm{m}$ & Torque kN.m \\
\hline 2.33 & 1.36 \\
\hline 3.11 & 4.07 \\
\hline 3.89 & 5.42 \\
\hline 4.66 & 6.78 \\
\hline 5.44 & 5.42 \\
\hline 6.22 & 14.91 \\
\hline 6.99 & 20.34
\end{tabular}

\begin{tabular}{|c|c|c|c|c|c|}
\hline Posição & Profundidade $\mathrm{m}$ & Diâmetro cm & SPT & Interpolado & Ajustado \\
\hline 4 & 4.25 & 35.56 & & & \\
\hline 3 & 5.08 & 35.56 & & & \\
\hline 2 & 5.79 & 30.48 & & & \\
\hline 1 & 6.38 & 25.40 & & & \\
\hline
\end{tabular}

\begin{tabular}{lll}
\hline \multicolumn{2}{c}{ SPT } \\
\hline Profundidade m Nspt & Solo
\end{tabular}

\subsection{Hélice}

\subsection{Fuste}

\begin{tabular}{cccccc}
\hline Comprimento m & Seção & $\begin{array}{c}\text { Diâmetro externo } \\
\mathrm{cm}\end{array}$ & $\begin{array}{c}\text { Diâmetro interno } \\
\mathrm{cm}\end{array}$ & $\mathrm{cm}$ & $\mathrm{cm}$ \\
\hline 5.47 & Circular Vazada & 10.16 & 9.35 & &
\end{tabular}

\subsection{Prova de Carga}

\begin{tabular}{cc}
\hline Força kN & Deslocamento mm \\
\hline 0.00 & 0.00 \\
\hline 58.84 & 2.00 \\
\hline 88.26 & 3.76 \\
\hline 117.68 & 5.17 \\
\hline 147.10 & 7.13
\end{tabular}




\begin{tabular}{|c|c|}
\hline 176.52 & 8.48 \\
\hline 205.94 & 10.08 \\
\hline 235.36 & 13.25 \\
\hline 264.78 & 17.53 \\
\hline 289.30 & 24.05 \\
\hline 230.46 & 23.45 \\
\hline 171.62 & 21.65 \\
\hline 112.78 & 19.70 \\
\hline 58.84 & 17.20 \\
\hline 88.26 & 17.32 \\
\hline 117.68 & 17.62 \\
\hline 147.10 & 18.27 \\
\hline 176.52 & 18.91 \\
\hline 205.94 & 19.46 \\
\hline 235.36 & 20.66 \\
\hline 264.78 & 21.93 \\
\hline 289.30 & 22.16 \\
\hline 230.46 & 22.15 \\
\hline 171.62 & 21.09 \\
\hline 112.78 & 19.86 \\
\hline 58.84 & 18.75 \\
\hline 0.00 & 17.65 \\
\hline 318.72 & 28.38 \\
\hline 343.23 & 30.62 \\
\hline
\end{tabular}

\subsection{Carga de Ruptura}

\begin{tabular}{rc}
\hline \multicolumn{1}{c}{ Método } & Força MN \\
\hline $\mathrm{D} / 10$ & 0.36 \\
\hline Davisson (1972) & 0.21 \\
\hline Livneh e El Naggar (2008) & 0.36 \\
\hline NBR 6122(2010) & 0.25
\end{tabular}


57. E149-1-2

\subsection{Geral}

Id : 57

Comprimento $\mathrm{m}: 8.20$

Inclinação $^{\circ}: 39.00$

Correção da profundidade (m) : 0.00

\subsection{SPT e Torque}

\begin{tabular}{cc}
\hline \multicolumn{2}{c}{ Torque } \\
\hline Profundidade $\mathrm{m}$ & Torque kN.m \\
\hline 2.33 & 4.07 \\
\hline 3.11 & 6.78 \\
\hline 3.89 & 6.78 \\
\hline 4.66 & 4.07 \\
\hline 5.44 & 6.78 \\
\hline 6.22 & 18.98
\end{tabular}

\begin{tabular}{lll}
\hline \multicolumn{2}{c}{ SPT } \\
\hline Profundidade m Nspt & Solo
\end{tabular}

\subsection{Hélice}

\begin{tabular}{|c|c|c|c|c|c|}
\hline Posição & Profundidade $\mathrm{m}$ & Diâmetro cm & SPT & Interpolado & Ajustado \\
\hline 4 & 4.17 & 35.56 & & & \\
\hline 3 & 5.00 & 35.56 & & & \\
\hline 2 & 5.71 & 30.48 & & & \\
\hline 1 & 6.30 & 25.40 & & & \\
\hline
\end{tabular}

\subsection{Fuste}

\begin{tabular}{cccccc}
\hline Comprimento m & Seção & $\begin{array}{c}\text { Diâmetro externo } \\
\mathrm{cm}\end{array}$ & $\begin{array}{c}\text { Diâmetro interno } \\
\mathrm{cm}\end{array}$ & $\mathrm{cm}$ & $\mathrm{cm}$ \\
\hline 5.37 & Circular Vazada & 10.16 & 9.35 & &
\end{tabular}

\subsection{Prova de Carga}

\begin{tabular}{cc}
\hline Força kN & Deslocamento mm \\
\hline 0.00 & 0.00 \\
\hline 58.84 & 1.50 \\
\hline 88.26 & 2.18 \\
\hline 117.68 & 4.75 \\
\hline 147.10 & 6.88 \\
\hline 176.52 & 8.90
\end{tabular}




\begin{tabular}{|c|c|}
\hline 205.94 & 12.79 \\
\hline 235.36 & 16.91 \\
\hline 264.78 & 23.98 \\
\hline 289.30 & 26.11 \\
\hline 230.46 & 25.17 \\
\hline 171.62 & 22.68 \\
\hline 112.78 & 20.40 \\
\hline 58.84 & 18.67 \\
\hline 88.26 & 19.44 \\
\hline 117.68 & 20.16 \\
\hline 147.10 & 22.26 \\
\hline 176.52 & 23.53 \\
\hline 205.94 & 24.73 \\
\hline 235.36 & 25.30 \\
\hline 264.78 & 30.07 \\
\hline 289.30 & 32.69 \\
\hline 230.46 & 31.50 \\
\hline 171.62 & 30.51 \\
\hline 112.78 & 19.62 \\
\hline 58.84 & 27.44 \\
\hline 0.00 & 21.10 \\
\hline 318.72 & 34.35 \\
\hline 343.23 & 40.62 \\
\hline
\end{tabular}

\subsection{Carga de Ruptura}

\begin{tabular}{rc}
\hline \multicolumn{1}{c}{ Método } & Força MN \\
\hline Livneh e El Naggar (2008) & 0.27 \\
\hline D/10 & 0.28 \\
\hline Davisson (1972) & 0.18 \\
\hline NBR 6122 (2010) & 0.22
\end{tabular}




\section{E45-2}

\subsection{Geral}

$$
\begin{aligned}
\text { Id } & : 58 \\
\text { Comprimento } \mathrm{m} & : 10.79 \\
\text { Inclinação }^{\circ} & : 39.00
\end{aligned}
$$

Correção da profundidade (m) : 5.00

\subsection{SPT e Torque}

\begin{tabular}{cc}
\hline \multicolumn{2}{c}{ Torque } \\
\hline Profundidade $\mathrm{m}$ & Torque kN.m \\
\hline 2.33 & 9.08 \\
\hline 3.11 & 10.44 \\
\hline 3.89 & 10.58 \\
\hline 4.66 & 14.24 \\
\hline 5.44 & 16.27 \\
\hline 6.22 & 17.63 \\
\hline 6.99 & 14.91 \\
\hline 7.77 & 23.05 \\
\hline 8.55 & 23.05
\end{tabular}

\begin{tabular}{ccc}
\hline & \multicolumn{2}{c}{ SPT } \\
\hline Profundidade $\mathrm{m}$ & Nspt & Solo \\
\hline 13.00 & 29.00 & Areia argilosa \\
\hline 12.00 & 18.00 & Areia argilosa \\
\hline 11.00 & 24.00 & Areia argilosa \\
\hline 10.00 & 13.00 & Areia argilosa \\
\hline 9.00 & 19.00 & Areia argilosa \\
\hline 8.00 & 11.00 & Areia argilosa \\
\hline 7.00 & 15.00 & Areia \\
\hline 6.00 & 2.00 & Areia \\
\hline 5.00 & 21.00 & Areia \\
\hline 4.00 & 8.00 & Argila arenosa \\
\hline 3.00 & 8.00 & Silte argiloso \\
\hline 2.00 & 7.00 & Silte argiloso \\
\hline 1.00 & 4.00 & Silte argiloso
\end{tabular}

58.3. Hélice

\begin{tabular}{cccccc}
\hline Posição & Profundidade $m$ & Diâmetro cm & SPT & Interpolado & Ajustado \\
\hline 4 & 5.83 & 40.64 & 21.00 & 10.96 & 18.81 \\
\hline 3 & 6.78 & 40.64 & 2.00 & 8.18 & 21.15 \\
\hline 2 & 7.60 & 35.56 & 15.00 & 13.78 & 21.35 \\
\hline 1 & 8.32 & 30.48 & 11.00 & 11.12 & 29.00
\end{tabular}

\subsection{Fuste}

\begin{tabular}{cccccc}
\hline Comprimento m & Seção & $\begin{array}{c}\text { Diâmetro externo } \\
\mathrm{cm}\end{array}$ & $\begin{array}{c}\text { Diâmetro interno } \\
\mathrm{cm}\end{array}$ & $\mathrm{cm}$ & $\mathrm{cm}$ \\
\hline 7.50 & Circular Vazada & 10.16 & 9.35 & &
\end{tabular}

\subsection{Prova de Carga}


Força kN

\begin{tabular}{|c|c|}
\hline 0.00 & 0.00 \\
\hline 78.45 & 2.00 \\
\hline 117.68 & 7.81 \\
\hline 156.91 & 11.03 \\
\hline 196.13 & 13.83 \\
\hline 235.36 & 16.13 \\
\hline 274.59 & 18.37 \\
\hline 313.81 & 20.65 \\
\hline 353.04 & 23.85 \\
\hline 392.27 & 26.25 \\
\hline 313.81 & 25.19 \\
\hline 235.36 & 24.20 \\
\hline 156.91 & 22.50 \\
\hline 78.45 & 19.37 \\
\hline 117.68 & 21.64 \\
\hline 156.91 & 23.15 \\
\hline 196.13 & 24.87 \\
\hline 235.36 & 26.79 \\
\hline 274.59 & 27.79 \\
\hline 313.81 & 28.46 \\
\hline 353.04 & 30.08 \\
\hline 392.27 & 31.80 \\
\hline 313.81 & 30.66 \\
\hline 235.36 & 29.63 \\
\hline 156.91 & 27.26 \\
\hline 78.45 & 24.66 \\
\hline 431.49 & 28.58 \\
\hline 470.72 & 31.10 \\
\hline 509.95 & 32.83 \\
\hline 549.17 & 35.61 \\
\hline 392.27 & 26.69 \\
\hline 78.45 & 25.09 \\
\hline
\end{tabular}

\subsection{Carga de Ruptura}

\begin{tabular}{rc}
\hline \multicolumn{1}{c}{ Método } & Força MN \\
\hline Livneh e El Naggar (2008) & 0.57 \\
\hline $\mathrm{D} / 10$ & 0.57 \\
\hline Davisson (1972) & 0.15 \\
\hline NBR 6122 (2010) & 0.31
\end{tabular}


59. E173-2

\subsection{Geral}

Id $: 59$

Comprimento $\mathrm{m}: 5.55$

Inclinação $^{\circ}: 39.00$

Correção da profundidade (m) : 11.00

59.2. SPT e Torque

\begin{tabular}{cc}
\hline \multicolumn{2}{c}{ Torque } \\
\hline Profundidade $\mathrm{m}$ & Torque kN.m \\
\hline 2.33 & 6.64 \\
\hline 3.11 & 11.80 \\
\hline 3.89 & 13.56 \\
\hline 4.66 & 16.81 \\
\hline 5.44 & 18.30
\end{tabular}

\begin{tabular}{ccl}
\hline & \multicolumn{2}{c}{ SPT } \\
\hline Profundidade $\mathrm{m}$ & Nspt & \multicolumn{1}{c}{ Solo } \\
\hline 1.00 & 6.00 & Silte arenoso \\
\hline 16.00 & 24.00 & Silte arenoso \\
\hline 15.00 & 23.00 & Silte arenoso \\
\hline 14.00 & 22.00 & Silte arenoso \\
\hline 13.00 & 20.00 & Silte arenoso \\
\hline 12.00 & 10.00 & Silte arenoso \\
\hline 11.00 & 10.00 & Silte arenoso \\
\hline 10.00 & 8.00 & Silte arenoso \\
\hline 9.00 & 8.00 & Silte arenoso \\
\hline 8.00 & 8.00 & Silte arenoso \\
\hline 7.00 & 6.00 & Silte arenoso \\
\hline 6.00 & 6.00 & Silte arenoso \\
\hline 5.00 & 6.00 & Silte arenoso \\
\hline 4.00 & 6.00 & Silte arenoso \\
\hline 3.00 & 5.00 & Silte arenoso \\
\hline 2.00 & 5.00 & Silte arenoso
\end{tabular}

59.3. Hélice

\begin{tabular}{cccccc}
\hline Posição & Profundidade $\mathrm{m}$ & Diâmetro cm & SPT & Interpolado & Ajustado \\
\hline 4 & 1.76 & 40.64 & 6.00 & 5.62 & 13.81 \\
\hline 3 & 2.70 & 40.64 & 5.00 & 5.00 & 20.66 \\
\hline 2 & 3.53 & 35.56 & 5.00 & 5.16 & 22.16 \\
\hline 1 & 4.24 & 30.48 & 6.00 & 5.87 & 22.87
\end{tabular}

\subsection{Fuste}

\begin{tabular}{cccccc}
\hline Comprimento m & Seção & $\begin{array}{c}\text { Diâmetro externo } \\
\mathrm{cm}\end{array}$ & $\begin{array}{c}\text { Diâmetro interno } \\
\mathrm{cm}\end{array}$ & $\mathrm{cm}$ & $\mathrm{cm}$ \\
\hline 2.26 & Circular Vazada & 10.16 & 0.23 & &
\end{tabular}




\subsection{Prova de Carga}

\begin{tabular}{|c|c|}
\hline Força kN & Deslocamento $\mathrm{mm}$ \\
\hline 0.00 & 0.00 \\
\hline 78.45 & 2.00 \\
\hline 117.68 & 3.43 \\
\hline 156.91 & 4.94 \\
\hline 196.13 & 8.03 \\
\hline 235.36 & 12.45 \\
\hline 274.59 & 15.33 \\
\hline 313.81 & 18.48 \\
\hline 353.04 & 22.07 \\
\hline 392.27 & 27.35 \\
\hline 313.81 & 27.06 \\
\hline 235.36 & 26.82 \\
\hline 156.91 & 25.87 \\
\hline 78.45 & 23.00 \\
\hline 117.68 & 23.74 \\
\hline 156.91 & 24.23 \\
\hline 196.13 & 24.00 \\
\hline 235.36 & 25.80 \\
\hline 274.59 & 26.37 \\
\hline 313.81 & 27.04 \\
\hline 353.04 & 27.93 \\
\hline 392.27 & 29.54 \\
\hline 313.81 & 29.47 \\
\hline 235.36 & 29.04 \\
\hline 156.91 & 27.19 \\
\hline 78.45 & 25.23 \\
\hline 431.49 & 34.29 \\
\hline 470.72 & 37.91 \\
\hline 509.95 & 41.80 \\
\hline 392.27 & 30.32 \\
\hline 78.45 & 28.72 \\
\hline
\end{tabular}

\subsection{Carga de Ruptura}

\begin{tabular}{rc}
\hline Método & Força MN \\
\hline Livneh e El Naggar (2008) & 0.41 \\
\hline $\mathrm{D} / 10$ & 0.46 \\
\hline Davisson (1972) & 0.18 \\
\hline NBR 6122 (2010) & 0.24
\end{tabular}


60. VCASTANHAL138-1

\subsection{Geral}

Id : 60

Comprimento $\mathrm{m}: 4.60$

Inclinação $^{\circ}: 40.00$

Correção da profundidade (m) : 0.00

\subsection{SPT e Torque}

\begin{tabular}{cc}
\hline \multicolumn{2}{c}{ Torque } \\
\hline Profundidade $\mathrm{m}$ & Torque kN.m \\
\hline 1.15 & 1.36 \\
\hline 1.53 & 1.36 \\
\hline 1.92 & 1.36 \\
\hline 2.30 & 2.71 \\
\hline 2.68 & 2.71 \\
\hline 3.06 & 4.07 \\
\hline 3.45 & 6.78 \\
\hline 3.83 & 6.78
\end{tabular}

\begin{tabular}{ccc}
\hline & \multicolumn{2}{c}{ SPT } \\
\hline Profundidade $\mathrm{m}$ & Nspt & Solo \\
\hline 8.00 & 31.00 & Argila arenosa \\
\hline 7.00 & 26.00 & Argila arenosa \\
\hline 6.00 & 32.00 & Argila siltosa \\
\hline 5.00 & 25.00 & Argila siltosa \\
\hline 4.00 & 23.00 & Argila siltosa \\
\hline 3.00 & 20.00 & Argila siltosa \\
\hline 2.00 & 2.00 & Argila arenosa \\
\hline 1.00 & 4.00 & Argila arenosa \\
\hline 10.00 & 39.00 & Argila arenosa \\
\hline 9.00 & 38.00 & Argila arenosa
\end{tabular}

\subsection{Hélice}

\begin{tabular}{cccccc}
\hline Posição & Profundidade m & Diâmetro cm & SPT & Interpolado & Ajustado \\
\hline 2 & 2.77 & 35.56 & 2.00 & 10.45 & 10.45 \\
\hline 1 & 3.47 & 30.48 & 20.00 & 20.51 & 20.51
\end{tabular}

60.4. Fuste

\begin{tabular}{cccccc}
\hline Comprimento m & Seção & $\begin{array}{c}\text { Diâmetro externo } \\
\mathrm{cm}\end{array}$ & $\begin{array}{c}\text { Diâmetro interno } \\
\mathrm{cm}\end{array}$ & $\mathrm{cm}$ & $\mathrm{cm}$ \\
\hline 3.62 & Circular Vazada & 7.30 & 7.00
\end{tabular}

\subsection{Prova de Carga}

\begin{tabular}{cc}
\hline Força kN & Deslocamento mm \\
\hline 0.00 & 0.00 \\
\hline 19.61 & 2.00 \\
\hline 39.23 & 4.30 \\
\hline 58.84 & 7.79
\end{tabular}




\begin{tabular}{|c|c|}
\hline 78.45 & 10.15 \\
\hline 98.07 & 13.55 \\
\hline 117.68 & 21.98 \\
\hline 98.07 & 21.95 \\
\hline 78.45 & 21.83 \\
\hline 58.84 & 21.11 \\
\hline 19.61 & 18.12 \\
\hline 39.23 & 21.14 \\
\hline 58.84 & 22.97 \\
\hline 78.45 & 25.27 \\
\hline 98.07 & 27.26 \\
\hline 117.68 & 29.85 \\
\hline 137.29 & 33.91 \\
\hline 156.91 & 42.89 \\
\hline 137.29 & 42.84 \\
\hline 98.07 & 42.20 \\
\hline 58.84 & 40.65 \\
\hline 19.61 & 37.53 \\
\hline 156.91 & 46.64 \\
\hline 176.52 & 56.04 \\
\hline 196.13 & 59.92 \\
\hline
\end{tabular}

\subsection{Carga de Ruptura}

\begin{tabular}{rc}
\hline Método & Força MN \\
\hline Davisson (1972) & 0.08 \\
\hline D/10 & 0.14 \\
\hline Livneh e El Naggar (2008) & 0.13 \\
\hline NBR 6122 (2010) & 0.10
\end{tabular}




\section{VCASTANHAL138-2}

\subsection{Geral}

Id : 61

Comprimento $\mathrm{m}: 4.70$

Inclinação $^{\circ}: 40.00$

Correção da profundidade (m) : 0.00

\subsection{SPT e Torque}

\begin{tabular}{cc}
\hline \multicolumn{2}{c}{ Torque } \\
\hline Profundidade $\mathrm{m}$ & Torque kN.m \\
\hline 1.53 & 2.71 \\
\hline 1.15 & 1.36 \\
\hline 1.92 & 2.71 \\
\hline 2.30 & 4.07 \\
\hline 2.68 & 4.07 \\
\hline 3.06 & 5.42 \\
\hline 3.45 & 6.78 \\
\hline 3.83 & 6.78
\end{tabular}

\begin{tabular}{ccc}
\hline & \multicolumn{2}{c}{ SPT } \\
\hline Profundidade $\mathrm{m}$ & Nspt & Solo \\
\hline 9.00 & 38.00 & Argila arenosa \\
\hline 8.00 & 31.00 & Argila arenosa \\
\hline 7.00 & 26.00 & Argila arenosa \\
\hline 10.00 & 39.00 & Argila arenosa \\
\hline 6.00 & 32.00 & Argila siltosa \\
\hline 5.00 & 25.00 & Argila siltosa \\
\hline 4.00 & 23.00 & Argila siltosa \\
\hline 3.00 & 20.00 & Argila siltosa \\
\hline 2.00 & 2.00 & Argila arenosa \\
\hline 1.00 & 4.00 & Argila arenosa
\end{tabular}

\subsection{Hélice}

\begin{tabular}{cccccc}
\hline Posição & Profundidade $\mathrm{m}$ & Diâmetro cm & SPT & Interpolado & Ajustado \\
\hline 2 & 2.85 & 35.56 & 2.00 & 11.83 & 11.83 \\
\hline 1 & 3.55 & 30.48 & 20.00 & 20.74 & 20.74
\end{tabular}

61.4. Fuste

\begin{tabular}{cccccc}
\hline Comprimento m & Seção & $\begin{array}{c}\text { Diâmetro externo } \\
\mathrm{cm}\end{array}$ & $\begin{array}{c}\text { Diâmetro interno } \\
\mathrm{cm}\end{array}$ & $\mathrm{cm}$ & $\mathrm{cm}$ \\
\hline 3.72 & Circular Vazada & 7.30 & 7.00
\end{tabular}

\subsection{Prova de Carga}

\begin{tabular}{cc}
\hline Força kN & Deslocamento mm \\
\hline 0.00 & 0.00 \\
\hline 19.61 & 2.00 \\
\hline 39.23 & 3.15 \\
\hline 58.84 & 5.00
\end{tabular}




\begin{tabular}{|c|c|}
\hline 78.45 & 8.59 \\
\hline 98.07 & 13.74 \\
\hline 127.49 & 29.60 \\
\hline 98.07 & 29.24 \\
\hline 78.45 & 27.25 \\
\hline 58.84 & 25.71 \\
\hline 19.61 & 22.97 \\
\hline 39.23 & 23.09 \\
\hline 58.84 & 23.80 \\
\hline 78.45 & 24.62 \\
\hline 98.07 & 25.57 \\
\hline 117.68 & 27.60 \\
\hline 137.29 & 33.88 \\
\hline 156.91 & 51.54 \\
\hline 137.29 & 50.79 \\
\hline 98.07 & 50.29 \\
\hline 58.84 & 49.97 \\
\hline 19.61 & 47.65 \\
\hline 156.91 & 55.93 \\
\hline
\end{tabular}

\subsection{Carga de Ruptura}

\begin{tabular}{cc}
\hline \multicolumn{1}{c}{ Método } & Força MN \\
\hline D/10 & 0.14 \\
\hline Livneh e El Naggar (2008) & 0.13 \\
\hline Davisson (1972) & 0.08 \\
\hline NBR 6122 (2010) & 0.10
\end{tabular}




\section{VRJ27}

\subsection{Geral}

Id : 62

Comprimento $\mathrm{m}: 10.63$

Inclinação ${ }^{\circ}: 14.00$

Correção da profundidade (m) : 0.00

\subsection{SPT e Torque}

\begin{tabular}{cc}
\hline \multicolumn{2}{c}{ Torque } \\
\hline Profundidade $\mathrm{m}$ & Torque kN.m \\
\hline 2.91 & 8.13 \\
\hline 3.88 & 6.78 \\
\hline 4.85 & 6.24 \\
\hline 5.82 & 5.15 \\
\hline 6.79 & 5.56 \\
\hline 7.76 & 4.88 \\
\hline 8.73 & 5.56 \\
\hline 9.70 & 6.51 \\
\hline 10.67 & 7.46
\end{tabular}

\begin{tabular}{|c|c|c|}
\hline \multicolumn{3}{|c|}{ SPT } \\
\hline Profundidade m & Nspt & Solo \\
\hline 1.00 & 4.00 & Argila siltosa \\
\hline 2.00 & 6.00 & Areia siltosa \\
\hline 3.00 & 6.00 & Areia siltosa \\
\hline 4.00 & 6.00 & Areia siltosa \\
\hline 5.00 & 7.00 & Areia siltosa \\
\hline 6.00 & 10.00 & Areia siltosa \\
\hline 7.00 & 14.00 & Areia siltosa \\
\hline 8.00 & 16.00 & Areia siltosa \\
\hline 9.00 & 0.00 & Argila \\
\hline 10.00 & 0.00 & Argila \\
\hline 11.00 & 0.00 & Argila \\
\hline 12.00 & 0.00 & Argila \\
\hline 13.00 & 17.00 & Argila siltosa \\
\hline 14.00 & 21.00 & Argila siltosa \\
\hline 15.00 & 25.00 & Argila siltosa \\
\hline 16.00 & 21.00 & Argila siltosa \\
\hline 17.00 & 17.00 & Argila siltosa \\
\hline 18.00 & 15.00 & Argila siltosa \\
\hline 19.00 & 15.00 & Areia \\
\hline 20.00 & 18.00 & Areia \\
\hline 21.00 & 24.00 & Areia \\
\hline 22.00 & 24.00 & Areia \\
\hline 23.00 & 26.00 & Areia \\
\hline 24.00 & 26.00 & Areia \\
\hline 25.00 & 28.00 & Areia \\
\hline 26.00 & 28.00 & Areia \\
\hline 27.00 & 28.00 & Areia \\
\hline 28.00 & 31.00 & Areia \\
\hline 29.00 & 35.00 & Areia \\
\hline 30.00 & 32.00 & Areia \\
\hline 31.00 & 34.00 & Areia \\
\hline 32.00 & 36.00 & Areia \\
\hline 33.00 & 38.00 & Areia \\
\hline
\end{tabular}




\subsection{Hélice}

\begin{tabular}{cccccc}
\hline Posição & Profundidade $m$ & Diâmetro cm & SPT & Interpolado & Ajustado \\
\hline 3 & 8.62 & 35.56 & 16.00 & 10.88 & 10.88 \\
\hline 2 & 9.51 & 30.48 & 0.00 & 0.00 & 0.00 \\
\hline 1 & 10.25 & 25.40 & 0.00 & 0.00 & 0.00
\end{tabular}

\subsection{Fuste}

\begin{tabular}{cccccc}
\hline Comprimento m & Seção & $\begin{array}{c}\text { Diâmetro externo } \\
\mathrm{cm}\end{array}$ & $\begin{array}{c}\text { Diâmetro interno } \\
\mathrm{cm}\end{array}$ & $\mathrm{cm}$ & $\mathrm{cm}$ \\
\hline 8.88 & Circular Vazada & 11.40 & 10.80 & &
\end{tabular}

\subsection{Prova de Carga}

\begin{tabular}{|c|c|}
\hline Força kN & Deslocamento $\mathrm{mm}$ \\
\hline 0.00 & 0.00 \\
\hline 24.12 & 0.30 \\
\hline 36.19 & 0.38 \\
\hline 48.25 & 0.62 \\
\hline 60.31 & 0.84 \\
\hline 72.37 & 1.84 \\
\hline 84.44 & 2.23 \\
\hline 96.50 & 2.92 \\
\hline 108.56 & 3.60 \\
\hline 120.62 & 5.45 \\
\hline 96.50 & 5.18 \\
\hline 72.37 & 4.26 \\
\hline 48.25 & 3.33 \\
\hline 24.12 & 2.65 \\
\hline 36.19 & 2.75 \\
\hline 48.25 & 2.93 \\
\hline 60.31 & 3.48 \\
\hline 72.37 & 3.83 \\
\hline 84.44 & 4.37 \\
\hline 96.50 & 5.03 \\
\hline 108.56 & 5.58 \\
\hline 120.62 & 6.75 \\
\hline 96.50 & 6.38 \\
\hline 72.37 & 5.60 \\
\hline 48.25 & 4.64 \\
\hline 24.12 & 3.81 \\
\hline
\end{tabular}

\subsection{Carga de Ruptura}




\section{VRJ28}

\subsection{Geral}

Id :63

Comprimento $\mathrm{m}: 16.30$

Inclinação $^{\circ}: 14.00$

Correção da profundidade (m) : 0.00

\subsection{SPT e Torque}

\begin{tabular}{cc}
\hline \multicolumn{2}{c}{ Torque } \\
\hline Profundidade $\mathrm{m}$ & Torque kN.m \\
\hline 2.91 & 5.42 \\
\hline 3.88 & 6.78 \\
\hline 4.85 & 9.49 \\
\hline 5.82 & 8.81 \\
\hline 6.79 & 3.39 \\
\hline 7.76 & 3.39 \\
\hline 8.73 & 5.15 \\
\hline 9.70 & 5.42 \\
\hline 10.67 & 8.13 \\
\hline 11.64 & 6.51 \\
\hline 12.61 & 7.86 \\
\hline 13.58 & 9.49 \\
\hline 14.55 & 13.56 \\
\hline 15.52 & 16.68 \\
\hline 16.50 & 16.68
\end{tabular}

\begin{tabular}{|c|c|c|}
\hline \multicolumn{3}{|c|}{ SPT } \\
\hline Profundidade $\mathrm{m}$ & Nspt & Solo \\
\hline 1.00 & 6.00 & Argila siltosa \\
\hline 2.00 & 8.00 & Argila siltosa \\
\hline 3.00 & 5.00 & Areia siltosa \\
\hline 4.00 & 4.00 & Areia siltosa \\
\hline 5.00 & 8.00 & Areia siltosa \\
\hline 6.00 & 7.00 & Areia siltosa \\
\hline 7.00 & 7.00 & Areia siltosa \\
\hline 8.00 & 5.00 & Areia siltosa \\
\hline 9.00 & 9.00 & Areia siltosa \\
\hline 10.00 & 10.00 & Areia siltosa \\
\hline 11.00 & 4.00 & Areia siltosa \\
\hline 12.00 & 12.00 & Argila siltosa \\
\hline 13.00 & 10.00 & Argila siltosa \\
\hline 14.00 & 10.00 & Argila siltosa \\
\hline 15.00 & 13.00 & Argila siltosa \\
\hline 16.00 & 11.00 & Argila siltosa \\
\hline 17.00 & 9.00 & Argila siltosa \\
\hline 18.00 & 10.00 & Argila siltosa \\
\hline 19.00 & 10.00 & Argila siltosa \\
\hline 20.00 & 15.00 & Argila siltosa \\
\hline 21.00 & 16.00 & Areia \\
\hline 22.00 & 16.00 & Areia siltosa \\
\hline 23.00 & 15.00 & Areia \\
\hline 24.00 & 20.00 & Areia siltosa \\
\hline 25.00 & 22.00 & Areia \\
\hline 26.00 & 23.00 & Areia \\
\hline 27.00 & 24.00 & Areia \\
\hline 28.00 & 26.00 & Areia \\
\hline 29.00 & 27.00 & Areia \\
\hline 30.00 & 30.00 & Areia \\
\hline 31.00 & 33.00 & Areia \\
\hline 32.00 & 35.00 & Areia \\
\hline 33.00 & 37.00 & Areia \\
\hline 34.00 & 35.00 & Areia \\
\hline
\end{tabular}




\subsection{Hélice}

\begin{tabular}{cccccc}
\hline Posição & Profundidade m & Diâmetro cm & SPT & Interpolado & Ajustado \\
\hline 4 & 13.09 & 35.56 & 12.00 & 10.43 & 10.43 \\
\hline 3 & 14.12 & 35.56 & 10.00 & 10.00 & 10.00 \\
\hline 2 & 15.01 & 30.48 & 10.00 & 12.13 & 12.13 \\
\hline 1 & 15.75 & 25.40 & 13.00 & 12.10 & 12.10
\end{tabular}

\subsection{Fuste}

\begin{tabular}{cccccc}
\hline Comprimento m & Seção & $\begin{array}{c}\text { Diâmetro externo } \\
\mathrm{cm}\end{array}$ & $\begin{array}{c}\text { Diâmetro interno } \\
\mathrm{cm}\end{array}$ & $\mathrm{cm}$ & $\mathrm{cm}$ \\
\hline 13.49 & Circular Vazada & 11.40 & 10.80 &
\end{tabular}

\subsection{Prova de Carga}

\begin{tabular}{|c|c|}
\hline Força kN & Deslocamento $\mathrm{mm}$ \\
\hline 0.00 & 0.00 \\
\hline 43.15 & 1.00 \\
\hline 64.72 & 2.06 \\
\hline 86.30 & 3.54 \\
\hline 107.87 & 5.38 \\
\hline 129.45 & 6.38 \\
\hline 151.02 & 7.85 \\
\hline 172.60 & 8.95 \\
\hline 194.17 & 10.55 \\
\hline 215.75 & 13.55 \\
\hline 172.60 & 11.00 \\
\hline 129.45 & 9.81 \\
\hline 86.30 & 6.99 \\
\hline 43.15 & 4.62 \\
\hline 64.72 & 4.79 \\
\hline 86.30 & 5.97 \\
\hline 107.87 & 7.20 \\
\hline 129.45 & 8.32 \\
\hline 151.02 & 9.68 \\
\hline 172.60 & 10.64 \\
\hline 194.17 & 11.87 \\
\hline 215.75 & 13.59 \\
\hline 172.60 & 11.45 \\
\hline 129.45 & 10.50 \\
\hline 86.30 & 8.07 \\
\hline 43.15 & 6.62 \\
\hline
\end{tabular}


63.6. Carga de Ruptura 


\section{VRJ114}

\subsection{Geral}

Id : 64

Comprimento $\mathrm{m}: 5.40$

Inclinação $^{\circ}: 15.00$

Correção da profundidade (m) : 0.00

\subsection{SPT e Torque}

\begin{tabular}{cc}
\hline \multicolumn{2}{c}{ Torque } \\
\hline Profundidade $\mathrm{m}$ & Torque kN.m \\
\hline 2.99 & 5.83 \\
\hline 2.51 & 3.93 \\
\hline 3.48 & 12.20 \\
\hline 3.96 & 14.64 \\
\hline 4.44 & 16.00 \\
\hline 4.93 & 17.22 \\
\hline 5.41 & 22.37
\end{tabular}

\begin{tabular}{|c|c|c|}
\hline \multicolumn{3}{|c|}{ SPT } \\
\hline Profundidade $\mathrm{m}$ & Nspt & Solo \\
\hline 1.00 & 11.00 & Areia \\
\hline 2.00 & 10.00 & Areia \\
\hline 3.00 & 15.00 & Areia \\
\hline 4.00 & 13.00 & Areia \\
\hline 5.00 & 14.00 & Areia \\
\hline 6.00 & 11.00 & Areia \\
\hline 7.00 & 13.00 & Areia \\
\hline 8.00 & 14.00 & Areia \\
\hline 9.00 & 22.00 & Areia \\
\hline 10.00 & 20.00 & Areia \\
\hline 11.00 & 33.00 & Areia \\
\hline 12.00 & 42.00 & Areia \\
\hline 13.00 & 47.00 & Areia \\
\hline 14.00 & 40.00 & Areia \\
\hline 15.00 & 24.00 & Areia \\
\hline 16.00 & 14.00 & Areia \\
\hline 17.00 & 12.00 & Argila arenosa \\
\hline 18.00 & 9.00 & Argila arenosa \\
\hline 19.00 & 8.00 & Argila arenosa \\
\hline 20.00 & 10.00 & Argila arenosa \\
\hline 21.00 & 9.00 & Argila arenosa \\
\hline 22.00 & 10.00 & Argila arenosa \\
\hline 23.00 & 14.00 & Areia \\
\hline 24.00 & 12.00 & Areia \\
\hline 25.00 & 9.00 & Argila siltosa \\
\hline 26.00 & 8.00 & Argila siltosa \\
\hline 27.00 & 18.00 & Argila siltosa \\
\hline 28.00 & 14.00 & Argila siltosa \\
\hline 29.00 & 19.00 & Argila siltosa \\
\hline 30.00 & 13.00 & Argila siltosa \\
\hline 31.00 & 14.00 & Argila siltosa \\
\hline 32.00 & 10.00 & Argila siltosa \\
\hline 33.00 & 19.00 & Argila siltosa \\
\hline 34.00 & 30.00 & Areia \\
\hline 35.00 & 33.00 & Areia \\
\hline 36.00 & 30.00 & Areia \\
\hline
\end{tabular}




\begin{tabular}{lll}
\hline 37.00 & 32.00 & Areia \\
\hline 38.00 & 37.00 & Areia \\
\hline 39.00 & 38.00 & Areia \\
\hline 40.00 & 41.00 & Areia
\end{tabular}

\subsection{Hélice}

\begin{tabular}{cccccc}
\hline Posição & Profundidade $m$ & Diâmetro cm & SPT & Interpolado & Ajustado \\
\hline 3 & 3.23 & 40.64 & 15.00 & 14.67 & 14.67 \\
\hline 2 & 4.27 & 35.56 & 13.00 & 13.07 & 13.07 \\
\hline 1 & 5.15 & 30.48 & 14.00 & 13.85 & 13.85
\end{tabular}

\subsection{Fuste}

\begin{tabular}{cccccc}
\hline Comprimento m & Seção & $\begin{array}{c}\text { Diâmetro externo } \\
\mathrm{cm}\end{array}$ & $\begin{array}{c}\text { Diâmetro interno } \\
\mathrm{cm}\end{array}$ & $\mathrm{cm}$ & $\mathrm{cm}$ \\
\hline 3.35 & Circular Vazada & 11.40 & 10.80 & &
\end{tabular}

\subsection{Prova de Carga}

\begin{tabular}{|c|c|}
\hline Força kN & Deslocamento $\mathrm{mm}$ \\
\hline 0.00 & 0.00 \\
\hline 43.15 & 0.50 \\
\hline 64.72 & 0.83 \\
\hline 86.30 & 1.41 \\
\hline 107.87 & 2.04 \\
\hline 129.45 & 2.90 \\
\hline 151.02 & 3.90 \\
\hline 172.60 & 4.65 \\
\hline 194.17 & 5.85 \\
\hline 215.75 & 7.22 \\
\hline 172.60 & 6.72 \\
\hline 129.45 & 6.00 \\
\hline 86.30 & 4.91 \\
\hline 43.15 & 3.56 \\
\hline 64.72 & 3.82 \\
\hline 86.30 & 4.25 \\
\hline 107.87 & 4.83 \\
\hline 129.45 & 5.42 \\
\hline 151.02 & 5.96 \\
\hline 172.60 & 6.46 \\
\hline 194.17 & 7.15 \\
\hline 215.75 & 7.95 \\
\hline 172.60 & 7.53 \\
\hline 129.45 & 6.77 \\
\hline 86.30 & 5.56 \\
\hline 43.15 & 4.38 \\
\hline
\end{tabular}


64.6. Carga de Ruptura

Método

Força MN 


\section{VRJ119}

\subsection{Geral}

Id $: 65$

Comprimento $\mathrm{m}: 5.70$

Inclinação $^{\circ}: 23.62$

Correção da profundidade (m) : 0.00

65.2. SPT e Torque

\begin{tabular}{cc}
\hline \multicolumn{2}{c}{ Torque } \\
\hline Profundidade $\mathrm{m}$ & Torque kN.m \\
\hline 0.46 & 0.68 \\
\hline 0.92 & 1.36 \\
\hline 1.37 & 2.03 \\
\hline 1.83 & 2.71 \\
\hline 2.29 & 3.80 \\
\hline 2.75 & 5.42 \\
\hline 3.21 & 8.13 \\
\hline 3.66 & 10.85 \\
\hline 4.12 & 13.56 \\
\hline 4.58 & 21.69 \\
\hline 5.04 & 22.37
\end{tabular}

\begin{tabular}{|c|c|c|}
\hline \multicolumn{3}{|c|}{ SPT } \\
\hline Profundidade $\mathrm{m}$ & Nspt & Solo \\
\hline 1.00 & 8.00 & Areia siltosa \\
\hline 2.00 & 12.00 & Areia \\
\hline 3.00 & 15.00 & Areia \\
\hline 4.00 & 12.00 & Areia \\
\hline 5.00 & 17.00 & Areia \\
\hline 6.00 & 11.00 & Areia \\
\hline 7.00 & 35.00 & Areia \\
\hline 8.00 & 43.00 & Areia \\
\hline 9.00 & 39.00 & Areia \\
\hline 10.00 & 23.00 & Argila arenosa \\
\hline 11.00 & 27.00 & Argila arenosa \\
\hline 12.00 & 22.00 & Argila arenosa \\
\hline 13.00 & 17.00 & Argila arenosa \\
\hline 14.00 & 16.00 & Argila arenosa \\
\hline 15.00 & 13.00 & Argila arenosa \\
\hline 16.00 & 9.00 & Argila arenosa \\
\hline 17.00 & 17.00 & Argila arenosa \\
\hline 18.00 & 10.00 & Argila arenosa \\
\hline 19.00 & 21.00 & Argila arenosa \\
\hline 20.00 & 15.00 & Argila arenosa \\
\hline 21.00 & 21.00 & Argila arenosa \\
\hline 22.00 & 15.00 & Argila arenosa \\
\hline 23.00 & 18.00 & Argila arenosa \\
\hline 24.00 & 15.00 & Argila arenosa \\
\hline 25.00 & 24.00 & Argila arenosa \\
\hline 26.00 & 18.00 & Argila arenosa \\
\hline 27.00 & 18.00 & Argila arenosa \\
\hline 28.00 & 15.00 & Argila arenosa \\
\hline 29.00 & 22.00 & Areia \\
\hline 30.00 & 18.00 & Areia \\
\hline 31.00 & 20.00 & Areia \\
\hline 32.00 & 14.00 & Areia \\
\hline 33.00 & 26.00 & Areia \\
\hline 34.00 & 29.00 & Areia \\
\hline 35.00 & 33.00 & Areia \\
\hline 36.00 & 33.00 & Areia \\
\hline
\end{tabular}




\begin{tabular}{lll}
\hline 37.00 & 36.00 & Areia \\
\hline 38.00 & 39.00 & Areia \\
\hline 39.00 & 40.00 & Areia \\
\hline 40.00 & 41.00 & Areia
\end{tabular}

\subsection{Hélice}

\begin{tabular}{cccccc}
\hline Posição & Profundidade $m$ & Diâmetro cm & SPT & Interpolado & Ajustado \\
\hline 4 & 2.23 & 40.64 & 12.00 & 11.70 & 11.70 \\
\hline 3 & 3.34 & 40.64 & 15.00 & 14.87 & 14.87 \\
\hline 2 & 4.32 & 35.56 & 12.00 & 12.10 & 12.10 \\
\hline 1 & 5.16 & 30.48 & 17.00 & 16.29 & 16.29
\end{tabular}

65.4. Fuste

\begin{tabular}{cccccc}
\hline Comprimento m & Seção & $\begin{array}{c}\text { Diâmetro externo } \\
\mathrm{cm}\end{array}$ & $\begin{array}{c}\text { Diâmetro interno } \\
\mathrm{cm}\end{array}$ & $\mathrm{cm}$ & $\mathrm{cm}$ \\
\hline 2.43 & Circular Vazada & 11.43 & 10.83 &
\end{tabular}

\subsection{Prova de Carga}

\begin{tabular}{|c|c|}
\hline Força kN & Deslocamento $\mathrm{mm}$ \\
\hline 0.00 & 0.00 \\
\hline 43.15 & 0.80 \\
\hline 64.72 & 1.55 \\
\hline 86.30 & 2.17 \\
\hline 107.87 & 2.91 \\
\hline 129.45 & 3.54 \\
\hline 151.02 & 4.19 \\
\hline 172.60 & 4.88 \\
\hline 194.17 & 5.58 \\
\hline 215.75 & 6.64 \\
\hline 172.60 & 6.25 \\
\hline 129.45 & 5.47 \\
\hline 86.30 & 4.50 \\
\hline 43.15 & 3.33 \\
\hline 64.72 & 3.95 \\
\hline 86.30 & 4.90 \\
\hline 107.87 & 5.68 \\
\hline 129.45 & 5.91 \\
\hline 151.02 & 6.29 \\
\hline 172.60 & 7.13 \\
\hline 194.17 & 7.67 \\
\hline 215.75 & 8.16 \\
\hline 172.60 & 7.73 \\
\hline 129.45 & 6.99 \\
\hline 86.30 & 6.00 \\
\hline
\end{tabular}


65.6. Carga de Ruptura

Método

Força MN 


\section{VRJ120}

\subsection{Geral}

Id :66

Comprimento $\mathrm{m}: 5.30$

Inclinação $^{\circ}: 15.00$

Correção da profundidade (m) : 0.00

66.2. SPT e Torque

\begin{tabular}{cc}
\hline \multicolumn{2}{c}{ Torque } \\
\hline Profundidade $\mathrm{m}$ & Torque $\mathrm{kN} . \mathrm{m}$ \\
\hline 0.48 & 0.68 \\
\hline 0.97 & 1.36 \\
\hline 1.45 & 2.03 \\
\hline 1.93 & 2.98 \\
\hline 2.41 & 4.07 \\
\hline 2.90 & 5.42 \\
\hline 3.38 & 8.13 \\
\hline 3.86 & 12.20 \\
\hline 4.35 & 21.69 \\
\hline 4.83 & 21.69 \\
\hline 5.31 & 21.69
\end{tabular}

\begin{tabular}{|c|c|c|}
\hline \multicolumn{3}{|c|}{ SPT } \\
\hline Profundidade $\mathrm{m}$ & Nspt & Solo \\
\hline 1.00 & 7.00 & Areia \\
\hline 2.00 & 10.00 & Areia \\
\hline 3.00 & 9.00 & Areia \\
\hline 4.00 & 10.00 & Areia \\
\hline 5.00 & 16.00 & Areia \\
\hline 6.00 & 35.00 & Areia \\
\hline 7.00 & 34.00 & Areia \\
\hline 8.00 & 37.00 & Areia argilosa \\
\hline 9.00 & 10.00 & Areia argilosa \\
\hline 10.00 & 9.00 & Areia argilosa \\
\hline 11.00 & 7.00 & Areia argilosa \\
\hline 12.00 & 5.00 & Areia argilosa \\
\hline 13.00 & 8.00 & Areia argilosa \\
\hline 14.00 & 2.00 & Argila siltosa \\
\hline 15.00 & 4.00 & Argila siltosa \\
\hline 16.00 & 3.00 & Argila siltosa \\
\hline 17.00 & 2.00 & Argila siltosa \\
\hline 18.00 & 3.00 & Areia argilosa \\
\hline 19.00 & 8.00 & Areia argilosa \\
\hline 20.00 & 9.00 & Areia argilosa \\
\hline 21.00 & 13.00 & Areia argilosa \\
\hline 22.00 & 14.00 & Areia argilosa \\
\hline 23.00 & 11.00 & Areia argilosa \\
\hline 24.00 & 18.00 & Areia argilosa \\
\hline 25.00 & 20.00 & Areia argilosa \\
\hline 26.00 & 18.00 & Areia argilosa \\
\hline 27.00 & 18.00 & Areia argilosa \\
\hline 28.00 & 20.00 & Areia argilosa \\
\hline 29.00 & 25.00 & Areia siltosa \\
\hline 30.00 & 33.00 & Areia siltosa \\
\hline 31.00 & 22.00 & Areia siltosa \\
\hline 32.00 & 25.00 & Areia siltosa \\
\hline 33.00 & 30.00 & Areia siltosa \\
\hline 34.00 & 30.00 & Areia siltosa \\
\hline 35.00 & 32.00 & Areia siltosa \\
\hline 36.00 & 29.00 & Areia siltosa \\
\hline
\end{tabular}


DEPARTAMENTO DE GEOTECNIA

\begin{tabular}{lll}
\hline 37.00 & 40.00 & Areia siltosa \\
\hline 38.00 & 43.00 & Areia siltosa \\
\hline 39.00 & 40.00 & Areia siltosa \\
\hline 40.00 & 48.00 & Areia siltosa
\end{tabular}

\subsection{Hélice}

\begin{tabular}{cccccc}
\hline Posição & Profundidade m & Diâmetro cm & SPT & Interpolado & Ajustado \\
\hline 4 & 1.96 & 40.64 & 7.00 & 8.98 & 8.98 \\
\hline 3 & 3.14 & 40.64 & 10.00 & 9.16 & 9.16 \\
\hline 2 & 4.17 & 35.56 & 9.00 & 9.87 & 9.87 \\
\hline 1 & 5.05 & 30.48 & 10.00 & 14.51 & 14.51
\end{tabular}

66.4. Fuste

\begin{tabular}{cccccc}
\hline Comprimento m & Seção & $\begin{array}{c}\text { Diâmetro externo } \\
\mathrm{cm}\end{array}$ & $\begin{array}{c}\text { Diâmetro interno } \\
\mathrm{cm}\end{array}$ & $\mathrm{cm}$ & $\mathrm{cm}$ \\
\hline 2.03 & Circular Vazada & 11.40 & 10.80 & &
\end{tabular}

\subsection{Prova de Carga}

\begin{tabular}{|c|c|}
\hline Força kN & Deslocamento $\mathrm{mm}$ \\
\hline 0.00 & 0.00 \\
\hline 43.15 & 0.70 \\
\hline 64.72 & 1.32 \\
\hline 86.30 & 2.10 \\
\hline 107.87 & 2.92 \\
\hline 129.45 & 3.58 \\
\hline 151.02 & 4.47 \\
\hline 172.60 & 4.95 \\
\hline 194.17 & 5.75 \\
\hline 215.75 & 6.42 \\
\hline 172.60 & 5.51 \\
\hline 129.45 & 5.07 \\
\hline 86.30 & 4.25 \\
\hline 43.15 & 3.08 \\
\hline 64.72 & 3.90 \\
\hline 86.30 & 4.16 \\
\hline 107.87 & 5.25 \\
\hline 129.45 & 5.62 \\
\hline 151.02 & 5.86 \\
\hline 172.60 & 6.35 \\
\hline 194.17 & 6.75 \\
\hline 215.75 & 7.51 \\
\hline 172.60 & 7.09 \\
\hline 129.45 & 6.41 \\
\hline 86.30 & 5.30 \\
\hline
\end{tabular}


66.6. Carga de Ruptura

Método

Força MN 


\section{VRJ121}

\subsection{Geral}

Id $: 67$

Comprimento $\mathrm{m}: 4.80$

Inclinação $^{\circ}: 25.00$

Correção da profundidade (m) : 0.00

\subsection{SPT e Torque}

\begin{tabular}{cc}
\hline \multicolumn{2}{c}{ Torque } \\
\hline Profundidade $\mathrm{m}$ & Torque kN.m \\
\hline 0.45 & 0.68 \\
\hline 0.91 & 1.08 \\
\hline 1.36 & 2.71 \\
\hline 1.81 & 4.07 \\
\hline 2.27 & 4.75 \\
\hline 2.72 & 6.78 \\
\hline 3.17 & 9.49 \\
\hline 3.63 & 14.91 \\
\hline 4.08 & 21.69 \\
\hline 4.53 & 21.69
\end{tabular}

\begin{tabular}{|c|c|c|}
\hline \multicolumn{3}{|c|}{ SPT } \\
\hline Profundidade $\mathrm{m}$ & Nspt & Solo \\
\hline 1.00 & 6.00 & Areia \\
\hline 2.00 & 9.00 & Areia \\
\hline 3.00 & 11.00 & Areia \\
\hline 4.00 & 14.00 & Areia \\
\hline 5.00 & 17.00 & Areia \\
\hline 6.00 & 57.00 & Areia \\
\hline 7.00 & 35.00 & Areia \\
\hline 8.00 & 41.00 & Areia \\
\hline 9.00 & 29.00 & Areia \\
\hline 10.00 & 4.00 & Areia \\
\hline 11.00 & 4.00 & Areia \\
\hline 12.00 & 4.00 & Areia \\
\hline 13.00 & 2.00 & Areia \\
\hline 14.00 & 0.00 & Argila \\
\hline 15.00 & 0.00 & Argila \\
\hline 16.00 & 0.00 & Argila \\
\hline 17.00 & 0.00 & Argila \\
\hline 18.00 & 8.00 & Argila siltosa \\
\hline 19.00 & 11.00 & Argila siltosa \\
\hline 20.00 & 8.00 & Areia \\
\hline 21.00 & 11.00 & Areia \\
\hline 22.00 & 11.00 & Areia \\
\hline 23.00 & 15.00 & Areia \\
\hline 24.00 & 17.00 & Areia \\
\hline 25.00 & 20.00 & Areia \\
\hline 26.00 & 20.00 & Areia \\
\hline 27.00 & 19.00 & Argila siltosa \\
\hline 28.00 & 23.00 & Argila siltosa \\
\hline 29.00 & 25.00 & Argila siltosa \\
\hline 30.00 & 23.00 & Argila siltosa \\
\hline 31.00 & 19.00 & Argila siltosa \\
\hline 32.00 & 27.00 & Argila siltosa \\
\hline 33.00 & 34.00 & Argila siltosa \\
\hline 34.00 & 34.00 & Argila siltosa \\
\hline 35.00 & 33.00 & Areia \\
\hline 36.00 & 40.00 & Areia \\
\hline
\end{tabular}




\begin{tabular}{lll}
\hline 37.00 & 42.00 & Areia \\
\hline 38.00 & 46.00 & Areia \\
\hline 39.00 & 37.00 & Areia \\
\hline 40.00 & 49.00 & Areia
\end{tabular}

\subsection{Hélice}

\begin{tabular}{cccccc}
\hline Posição & Profundidade $m$ & Diâmetro cm & SPT & Interpolado & Ajustado \\
\hline 4 & 1.39 & 40.64 & 6.00 & 6.26 & 6.26 \\
\hline 3 & 2.49 & 40.64 & 9.00 & 9.38 & 9.38 \\
\hline 2 & 3.46 & 35.56 & 11.00 & 11.47 & 11.47 \\
\hline 1 & 4.29 & 30.48 & 14.00 & 13.96 & 13.96
\end{tabular}

67.4. Fuste

\begin{tabular}{cccccc}
\hline Comprimento m & Seção & $\begin{array}{c}\text { Diâmetro externo } \\
\mathrm{cm}\end{array}$ & $\begin{array}{c}\text { Diâmetro interno } \\
\mathrm{cm}\end{array}$ & $\mathrm{cm}$ & $\mathrm{cm}$ \\
\hline 1.53 & Circular Vazada & 11.40 & 10.80 & &
\end{tabular}

\subsection{Prova de Carga}

\begin{tabular}{|c|c|}
\hline Força kN & Deslocamento $\mathrm{mm}$ \\
\hline 0.00 & 0.00 \\
\hline 43.15 & 0.30 \\
\hline 64.72 & 1.18 \\
\hline 86.30 & 1.25 \\
\hline 107.87 & 1.95 \\
\hline 129.45 & 2.67 \\
\hline 151.02 & 3.50 \\
\hline 172.60 & 4.08 \\
\hline 194.17 & 4.92 \\
\hline 215.75 & 5.65 \\
\hline 172.60 & 4.98 \\
\hline 129.45 & 4.15 \\
\hline 86.30 & 3.00 \\
\hline 43.15 & 2.00 \\
\hline 64.72 & 2.27 \\
\hline 86.30 & 2.71 \\
\hline 107.87 & 3.24 \\
\hline 129.45 & 3.74 \\
\hline 151.02 & 4.26 \\
\hline 172.60 & 4.62 \\
\hline 194.17 & 5.19 \\
\hline 215.75 & 5.85 \\
\hline 172.60 & 5.60 \\
\hline 129.45 & 4.78 \\
\hline 86.30 & 3.89 \\
\hline
\end{tabular}




\subsection{Carga de Ruptura}

Método

Força MN 


\section{VRJ122}

\subsection{Geral}

Id : 68

Comprimento $\mathrm{m}: 6.70$

Inclinação $^{\circ}: 15.00$

Correção da profundidade (m) : 0.00

\subsection{SPT e Torque}

\begin{tabular}{cc}
\hline \multicolumn{2}{c}{ Torque } \\
\hline Profundidade $\mathrm{m}$ & Torque kN.m \\
\hline 0.48 & 0.68 \\
\hline 0.97 & 0.68 \\
\hline 1.45 & 2.03 \\
\hline 1.93 & 3.39 \\
\hline 2.41 & 4.07 \\
\hline 2.90 & 8.13 \\
\hline 3.86 & 9.49 \\
\hline 4.35 & 10.85 \\
\hline 4.83 & 17.63 \\
\hline 5.31 & 21.69 \\
\hline 5.80 & 21.69 \\
\hline 6.28 & 21.69 \\
\hline 6.76 & 22.37 \\
\hline 3.38 & $8,8 \mathrm{e}-03$
\end{tabular}

\begin{tabular}{|c|c|c|}
\hline \multicolumn{3}{|c|}{ SPT } \\
\hline Profundidade $\mathrm{m}$ & Nspt & Solo \\
\hline 1.00 & 11.00 & Areia \\
\hline 2.00 & 12.00 & Areia \\
\hline 3.00 & 8.00 & Areia \\
\hline 4.00 & 13.00 & Areia \\
\hline 5.00 & 19.00 & Areia \\
\hline 6.00 & 36.00 & Areia \\
\hline 7.00 & 32.00 & Areia \\
\hline 8.00 & 32.00 & Areia \\
\hline 9.00 & 7.00 & Areia \\
\hline 10.00 & 11.00 & Areia \\
\hline 11.00 & 7.00 & Areia \\
\hline 12.00 & 9.00 & Areia \\
\hline 13.00 & 0.00 & Argila \\
\hline 14.00 & 0.00 & Argila \\
\hline 15.00 & 0.00 & Argila \\
\hline 16.00 & 0.00 & Argila \\
\hline 17.00 & 0.00 & Argila \\
\hline 18.00 & 0.00 & Argila \\
\hline 19.00 & 14.00 & Argila arenosa \\
\hline 20.00 & 12.00 & Argila arenosa \\
\hline 21.00 & 18.00 & Argila arenosa \\
\hline 22.00 & 17.00 & Areia \\
\hline 23.00 & 11.00 & Areia \\
\hline 24.00 & 15.00 & Areia \\
\hline 25.00 & 19.00 & Areia \\
\hline 26.00 & 17.00 & Areia \\
\hline 27.00 & 15.00 & Areia \\
\hline 28.00 & 20.00 & Areia \\
\hline 29.00 & 20.00 & Areia siltosa \\
\hline 30.00 & 22.00 & Areia siltosa \\
\hline 31.00 & 17.00 & Areia siltosa \\
\hline 32.00 & 20.00 & Areia siltosa \\
\hline 33.00 & 30.00 & Areia siltosa \\
\hline 34.00 & 29.00 & Areia siltosa \\
\hline 35.00 & 35.00 & Areia siltosa \\
\hline 36.00 & 38.00 & Areia siltosa \\
\hline
\end{tabular}


DEPARTAMENTO DE GEOTECNIA

\begin{tabular}{lll}
\hline 37.00 & 35.00 & Areia siltosa \\
\hline 38.00 & 40.00 & Areia siltosa \\
\hline 39.00 & 40.00 & Areia siltosa \\
\hline 40.00 & 42.00 & Areia siltosa
\end{tabular}

\subsection{Hélice}

\begin{tabular}{cccccc}
\hline Posição & Profundidade m & Diâmetro cm & SPT & Interpolado & Ajustado \\
\hline 4 & 3.31 & 40.64 & 8.00 & 8.06 & 8.06 \\
\hline 3 & 4.49 & 40.64 & 13.00 & 14.14 & 14.14 \\
\hline 2 & 5.52 & 35.56 & 19.00 & 22.75 & 22.75 \\
\hline 1 & 6.40 & 30.48 & 36.00 & 35.58 & 35.58
\end{tabular}

68.4. Fuste

\begin{tabular}{cccccc}
\hline Comprimento m & Seção & $\begin{array}{c}\text { Diâmetro externo } \\
\mathrm{cm}\end{array}$ & $\begin{array}{c}\text { Diâmetro interno } \\
\mathrm{cm}\end{array}$ & $\mathrm{cm}$ & $\mathrm{cm}$ \\
\hline 3.43 & Circular Vazada & 11.40 & 10.80 & &
\end{tabular}

\subsection{Prova de Carga}

\begin{tabular}{|c|c|}
\hline Força kN & Deslocamento $\mathrm{mm}$ \\
\hline 0.00 & 0.00 \\
\hline 43.15 & 0.80 \\
\hline 64.72 & 1.69 \\
\hline 86.30 & 2.62 \\
\hline 107.87 & 3.36 \\
\hline 129.45 & 4.37 \\
\hline 151.02 & 5.26 \\
\hline 172.60 & 6.77 \\
\hline 194.17 & 7.46 \\
\hline 215.75 & 8.47 \\
\hline 172.60 & 7.95 \\
\hline 129.45 & 7.32 \\
\hline 86.30 & 6.12 \\
\hline 43.15 & 4.42 \\
\hline 64.72 & 4.93 \\
\hline 86.30 & 5.53 \\
\hline 107.87 & 6.04 \\
\hline 129.45 & 6.78 \\
\hline 151.02 & 7.57 \\
\hline 172.60 & 7.90 \\
\hline 194.17 & 8.63 \\
\hline 215.75 & 9.47 \\
\hline 172.60 & 8.95 \\
\hline 129.45 & 8.32 \\
\hline 86.30 & 7.10 \\
\hline
\end{tabular}


68.6. Carga de Ruptura

Método

Força MN 


\section{VELECNOR25-4H}

\subsection{Geral}

$$
\text { Id }: 69
$$

Comprimento $\mathrm{m}: 6.75$

Inclinação $^{\circ}: 41.50$

Correção da profundidade (m) : 0.00

\subsection{SPT e Torque}

\begin{tabular}{cc}
\hline \multicolumn{2}{c}{ Torque } \\
\hline Profundidade $\mathrm{m}$ & Torque kN.m \\
\hline 2.25 & 4.07 \\
\hline 3.00 & 7.59 \\
\hline 3.74 & 9.22 \\
\hline 4.49 & 10.17 \\
\hline 5.24 & 10.85
\end{tabular}

\begin{tabular}{ccc}
\hline & \multicolumn{2}{c}{ SPT } \\
\hline Profundidade $\mathrm{m}$ & Nspt & Solo \\
\hline 11.00 & 24.00 & Areia \\
\hline 10.00 & 44.00 & Areia \\
\hline 9.00 & 5.00 & Areia \\
\hline 8.00 & 16.00 & Areia \\
\hline 7.00 & 11.00 & Areia \\
\hline 6.00 & 18.00 & Areia siltosa \\
\hline 5.00 & 28.00 & Areia siltosa \\
\hline 4.00 & 40.00 & Argila siltosa \\
\hline 3.00 & 18.00 & Argila siltosa \\
\hline 2.00 & 5.00 & Argila siltosa \\
\hline 1.00 & 5.00 & Argila siltosa \\
\hline 15.00 & 45.00 & Areia \\
\hline 14.00 & 44.00 & Areia \\
\hline 13.00 & 37.00 & Areia \\
\hline 12.00 & 26.00 & Areia
\end{tabular}

\subsection{Hélice}

\begin{tabular}{cccccc}
\hline Posição & Profundidade m & Diâmetro cm & SPT & Interpolado & Ajustado \\
\hline 4 & 2.95 & 35.56 & 5.00 & 13.43 & 13.43 \\
\hline 3 & 3.75 & 35.56 & 18.00 & 27.84 & 27.84 \\
\hline 2 & 4.43 & 30.48 & 40.00 & 38.41 & 38.41 \\
\hline 1 & 5.00 & 25.40 & 40.00 & 31.56 & 31.56
\end{tabular}

\subsection{Fuste}

\begin{tabular}{cccccc}
\hline Comprimento m & Seção & $\begin{array}{c}\text { Diâmetro externo } \\
\mathrm{cm}\end{array}$ & $\begin{array}{c}\text { Diâmetro interno } \\
\mathrm{cm}\end{array}$ & $\mathrm{cm}$ & $\mathrm{cm}$ \\
\hline 2.95 & Circular Vazada & 8.80 & 8.16 & &
\end{tabular}


69.5. Prova de Carga

\begin{tabular}{cc}
\hline Força $\mathrm{kN}$ & Deslocamento $\mathrm{mm}$ \\
\hline 0.00 & 0.00 \\
\hline 48.64 & 2.20 \\
\hline 72.96 & 3.20 \\
\hline 97.28 & 5.20 \\
\hline 121.60 & 9.20 \\
\hline 145.92 & 13.20 \\
\hline 170.24 & 16.20 \\
\hline 194.56 & 21.20 \\
\hline 218.88 & 25.20 \\
\hline 243.20 & 33.20 \\
\hline 194.56 & 31.20 \\
\hline 145.92 & 29.20 \\
\hline 97.28 & 27.20 \\
\hline 48.64 & 24.20 \\
\hline 72.96 & 25.20 \\
\hline 97.28 & 26.20 \\
\hline 121.60 & 27.20 \\
\hline 145.92 & 29.20 \\
\hline 170.24 & 30.20 \\
\hline 194.56 & 31.20 \\
\hline 218.88 & 32.20 \\
\hline 243.20 & 35.20 \\
\hline 194.56 & 32.20 \\
\hline 145.92 & 31.20 \\
\hline 97.28 & 29.20 \\
\hline 48.64 & 28.20 \\
\hline & \\
\hline & \\
\hline & \\
\hline & \\
\hline & \\
\hline & \\
\hline & \\
\hline & \\
\hline & \\
\hline & \\
\hline & \\
\hline & \\
\hline
\end{tabular}

\subsection{Carga de Ruptura}

\begin{tabular}{rc}
\hline Método & Força MN \\
\hline Livneh e El Naggar (2008) & 0.24 \\
\hline NBR 6122 (2010) & 0.15 \\
\hline D/10 & 0.24 \\
\hline Davisson (1972) & 0.12
\end{tabular}


70. VELECNOR25-6H

\subsection{Geral}

$$
\text { Id : } 70
$$

Comprimento $\mathrm{m}: 21.49$

Inclinação $^{\circ}: 41.50$

Correção da profundidade (m) $: 0.00$

\subsection{SPT e Torque}

\begin{tabular}{|c|c|}
\hline \multicolumn{2}{|c|}{ Torque } \\
\hline Profundidade $\mathrm{m}$ & Torque kN.m \\
\hline 2.25 & 3.93 \\
\hline 3.00 & 12.20 \\
\hline 3.74 & 14.91 \\
\hline 4.49 & 16.41 \\
\hline 5.24 & 14.10 \\
\hline 5.99 & 10.58 \\
\hline 6.74 & 9.76 \\
\hline 7.49 & 5.56 \\
\hline 8.24 & 9.76 \\
\hline 8.99 & 11.66 \\
\hline 9.74 & 11.12 \\
\hline 10.49 & 15.73 \\
\hline 11.23 & 16.41 \\
\hline 11.98 & 18.44 \\
\hline 12.73 & 15.73 \\
\hline 13.48 & 16.27 \\
\hline 14.23 & 16.54 \\
\hline 14.98 & 18.71 \\
\hline 15.73 & 21.02 \\
\hline 16.48 & 23.73 \\
\hline
\end{tabular}

\begin{tabular}{ccl}
\hline & \multicolumn{2}{c}{ SPT } \\
\hline Profundidade $\mathrm{m}$ & Nspt & Solo \\
\hline 8.00 & 16.00 & Areia \\
\hline 7.00 & 11.00 & Areia \\
\hline 5.00 & 18.00 & Areia siltosa \\
\hline 4.00 & 28.00 & Areia siltosa \\
\hline 3.00 & 40.00 & Argila siltosa \\
\hline 2.00 & 18.00 & Argila siltosa \\
\hline 1.00 & 5.00 & Argila siltosa \\
\hline 16.00 & 5.00 & Argila siltosa \\
\hline 15.00 & 65.00 & Areia \\
\hline 14.00 & 45.00 & Areia \\
\hline 13.00 & 34.00 & Areia \\
\hline 12.00 & 26.00 & Areia \\
\hline 11.00 & 24.00 & Areia \\
\hline 10.00 & 44.00 & Areia \\
\hline 9.00 & 5.00 & Areia \\
\hline & & Areia
\end{tabular}

\subsection{Hélice}

\begin{tabular}{cccccc}
\hline Posição & Profundidade $m$ & Diâmetro cm & SPT & Interpolado & Ajustado \\
\hline 6 & 12.39 & 35.56 & 26.00 & 26.99 & 26.99 \\
\hline 5 & 13.19 & 35.56 & 37.00 & 35.78 & 35.78 \\
\hline 4 & 13.99 & 35.56 & 37.00 & 41.82 & 41.82 \\
\hline 3 & 14.79 & 35.56 & 44.00 & 44.49 & 44.49 \\
\hline 2 & 15.47 & 30.48 & 45.00 & 48.44 & 48.44 \\
\hline 1 & 16.04 & 25.40 & 65.00 & 59.85 & 59.85
\end{tabular}




\begin{tabular}{cccccc}
\hline Comprimento m & Seção & $\begin{array}{c}\text { Diâmetro externo } \\
\mathrm{cm}\end{array}$ & $\begin{array}{c}\text { Diâmetro interno } \\
\mathrm{cm}\end{array}$ & $\mathrm{cm}$ & $\mathrm{cm}$ \\
\hline 16.54 & Circular Vazada & 10.10 & 9.29
\end{tabular}

\subsection{Prova de Carga}

\begin{tabular}{|c|c|}
\hline Força kN & Deslocamento $\mathrm{mm}$ \\
\hline 0.00 & 0.00 \\
\hline 97.28 & 3.00 \\
\hline 145.92 & 8.00 \\
\hline 194.56 & 9.00 \\
\hline 243.20 & 14.00 \\
\hline 291.85 & 16.00 \\
\hline 340.49 & 20.00 \\
\hline 389.13 & 26.00 \\
\hline 437.77 & 33.00 \\
\hline 486.41 & 40.00 \\
\hline 389.13 & 37.00 \\
\hline 291.85 & 33.00 \\
\hline 194.56 & 27.00 \\
\hline 97.28 & 22.00 \\
\hline 145.92 & 23.00 \\
\hline 194.56 & 25.00 \\
\hline 243.20 & 28.00 \\
\hline 291.85 & 31.00 \\
\hline 340.49 & 33.00 \\
\hline 389.13 & 34.00 \\
\hline 437.77 & 38.00 \\
\hline 486.41 & 42.00 \\
\hline 389.13 & 39.00 \\
\hline 291.85 & 34.00 \\
\hline 194.56 & 29.00 \\
\hline 97.28 & 25.00 \\
\hline
\end{tabular}

\subsection{Carga de Ruptura}

\begin{tabular}{rc}
\hline \multicolumn{1}{c}{ Método } & Força MN \\
\hline NBR 6122 (2010) & 0.45 \\
\hline Davisson (1972) & 0.39 \\
\hline D/10 & 0.44
\end{tabular}




\section{VELECNOR34-4H}

\subsection{Geral}

$$
\text { Id }: 71
$$

Comprimento $\mathrm{m}: 8.75$

Inclinação $^{\circ}: 41.50$

Correção da profundidade (m) : 0.00

\subsection{SPT e Torque}

\begin{tabular}{cc}
\hline \multicolumn{2}{c}{ Torque } \\
\hline Profundidade $\mathrm{m}$ & Torque kN.m \\
\hline 2.25 & 0.62 \\
\hline 3.00 & 2.58 \\
\hline 3.74 & 3.93 \\
\hline 4.49 & 5.56 \\
\hline 5.24 & 10.30 \\
\hline 5.99 & 11.93
\end{tabular}

\begin{tabular}{ccc}
\hline & \multicolumn{2}{c}{ SPT } \\
\hline Profundidade m & Nspt & Solo \\
\hline 1.00 & 16.00 & Argila siltosa \\
\hline 2.00 & 16.00 & Argila siltosa \\
\hline 3.00 & 7.00 & Argila siltosa \\
\hline 4.00 & 4.00 & Argila siltosa \\
\hline 5.00 & 11.00 & Argila siltosa \\
\hline 6.00 & 19.00 & Argila siltosa
\end{tabular}

\subsection{Hélice}

\begin{tabular}{cccccc}
\hline Posição & Profundidade $m$ & Diâmetro cm & SPT & Interpolado & Ajustado \\
\hline 4 & 4.45 & 35.56 & 4.00 & 5.02 & 5.02 \\
\hline 3 & 5.25 & 35.56 & 11.00 & 10.62 & 10.62 \\
\hline 2 & 5.93 & 30.48 & 11.00 & 16.04 & 16.04 \\
\hline 1 & 6.50 & 25.40 & 19.00 & 19.00 & 19.00
\end{tabular}

\subsection{Fuste}

\begin{tabular}{cccccc}
\hline Comprimento m & Seção & $\begin{array}{c}\text { Diâmetro externo } \\
\mathrm{cm}\end{array}$ & $\begin{array}{c}\text { Diâmetro interno } \\
\mathrm{cm}\end{array}$ & $\mathrm{cm}$ & $\mathrm{cm}$ \\
\hline 5.94 & Circular Vazada & 8.80 & 8.16 & &
\end{tabular}

\subsection{Prova de Carga}

\begin{tabular}{cc}
\hline Força kN & Deslocamento mm \\
\hline 0.00 & 0.00 \\
\hline 48.64 & 2.00 \\
\hline 72.96 & 4.00 \\
\hline 97.28 & 6.00 \\
\hline 121.60 & 10.00 \\
\hline 145.92 & 12.00
\end{tabular}




\begin{tabular}{|c|c|}
\hline 170.24 & 14.00 \\
\hline 194.56 & 18.00 \\
\hline 218.88 & 21.00 \\
\hline 243.20 & 25.00 \\
\hline 194.56 & 24.00 \\
\hline 145.92 & 23.00 \\
\hline 97.28 & 21.00 \\
\hline 48.64 & 18.00 \\
\hline 72.96 & 19.00 \\
\hline 97.28 & 20.00 \\
\hline 121.60 & 21.00 \\
\hline 145.92 & 23.00 \\
\hline 170.24 & 24.00 \\
\hline 194.56 & 25.00 \\
\hline 218.88 & 26.00 \\
\hline 243.20 & 28.00 \\
\hline 194.56 & 26.00 \\
\hline 145.92 & 25.00 \\
\hline 97.28 & 23.00 \\
\hline 48.64 & 22.00 \\
\hline
\end{tabular}

\subsection{Carga de Ruptura}

\begin{tabular}{cc}
\hline Método & Força MN \\
\hline NBR 6122 (2010) & 0.19 \\
\hline Davisson (1972) & 0.12
\end{tabular}


72. VELECNOR34-6H

\subsection{Geral}

$$
\text { Id }: 72
$$

Comprimento $\mathrm{m}: 13.16$

Inclinação $^{\circ}: 41.50$

Correção da profundidade (m) : 0.00

\subsection{SPT e Torque}

\begin{tabular}{cc}
\hline \multicolumn{2}{c}{ Torque } \\
\hline Profundidade $\mathrm{m}$ & Torque kN.m \\
\hline 2.25 & 1.36 \\
\hline 3.00 & 2.85 \\
\hline 3.74 & 4.61 \\
\hline 4.49 & 6.24 \\
\hline 5.24 & 8.00 \\
\hline 5.99 & 11.52 \\
\hline 6.74 & 13.15 \\
\hline 7.49 & 15.59 \\
\hline 8.24 & 16.00 \\
\hline 8.99 & 18.98 \\
\hline 9.74 & 22.91
\end{tabular}

\begin{tabular}{ccc}
\hline & \multicolumn{2}{c}{ SPT } \\
\hline Profundidade m & Nspt & Solo \\
\hline 1.00 & 16.00 & Argila siltosa \\
\hline 2.00 & 16.00 & Argila siltosa \\
\hline 3.00 & 7.00 & Argila siltosa \\
\hline 4.00 & 4.00 & Argila siltosa \\
\hline 5.00 & 11.00 & Argila siltosa \\
\hline 6.00 & 19.00 & Argila siltosa
\end{tabular}

\subsection{Hélice}

\begin{tabular}{|c|c|c|c|c|c|}
\hline Posição & Profundidade $\mathrm{m}$ & Diâmetro cm & \multirow[t]{7}{*}{ SPT } & Interpolado & \multirow[t]{7}{*}{ Ajustado } \\
\hline 6 & 6.15 & 35.56 & & 17.81 & \\
\hline 5 & 6.95 & 35.56 & & 19.00 & \\
\hline 4 & 7.75 & 35.56 & & & \\
\hline 3 & 8.55 & 35.56 & & & \\
\hline 2 & 9.23 & 30.48 & & & \\
\hline 1 & 9.80 & 25.40 & & & \\
\hline
\end{tabular}

\subsection{Fuste}

\begin{tabular}{cccccc}
\hline Comprimento m & Seção & $\begin{array}{c}\text { Diâmetro externo } \\
\mathrm{cm}\end{array}$ & $\begin{array}{c}\text { Diâmetro interno } \\
\mathrm{cm}\end{array}$ & $\mathrm{cm}$ & $\mathrm{cm}$ \\
\hline 8.21 & Circular Vazada & 10.10 & 9.29 & &
\end{tabular}

\subsection{Prova de Carga}


Força kN

\begin{tabular}{cc}
\hline 0.00 & 0.00 \\
\hline 97.28 & 3.00 \\
\hline 145.92 & 6.00 \\
\hline 194.56 & 7.00 \\
\hline 243.20 & 10.00 \\
\hline 291.85 & 13.00 \\
\hline 340.49 & 17.00 \\
\hline 389.13 & 21.00 \\
\hline 437.77 & 25.00 \\
\hline 486.41 & 28.00 \\
\hline 389.13 & 23.00 \\
\hline 291.85 & 20.00 \\
\hline 194.56 & 22.00 \\
\hline 97.28 & 22.00 \\
\hline 145.92 & 23.00 \\
\hline 194.56 & 25.00 \\
\hline 243.20 & 27.00 \\
\hline 291.85 & 29.00 \\
\hline 340.49 & 32.00 \\
\hline 389.13 & 41.00 \\
\hline 437.77 & 42.00 \\
\hline 486.41 & 46.00 \\
\hline 389.13 & 42.00 \\
\hline 291.85 & 40.00 \\
\hline 194.56 & 38.00 \\
\hline 97.28 & 36.00 \\
\hline & \\
\hline & \\
\hline & \\
\hline & \\
\hline & \\
\hline & \\
\hline & \\
\hline & \\
\hline & \\
\hline & \\
\hline & \\
\hline
\end{tabular}

\subsection{Carga de Ruptura}

\begin{tabular}{cc}
\hline Método & Força MN \\
\hline Davisson (1972) & 0.34 \\
\hline NBR 6122 (2010) & 0.43
\end{tabular}




\section{VELECNOR239-4H}

\subsection{Geral}

Id $: 73$

Comprimento $\mathrm{m}: 10.15$

Inclinação $^{\circ}: 41.50$

Correção da profundidade (m) : 0.00

\subsection{SPT e Torque}

\begin{tabular}{cc}
\hline \multicolumn{2}{c}{ Torque } \\
\hline Profundidade $\mathrm{m}$ & Torque kN.m \\
\hline 2.25 & 7.86 \\
\hline 3.00 & 9.36 \\
\hline 3.74 & 8.27 \\
\hline 4.49 & 9.36 \\
\hline 5.24 & 8.27 \\
\hline 5.99 & 6.51 \\
\hline 6.74 & 7.86 \\
\hline 7.49 & 11.93 \\
\hline 8.24 & 12.88
\end{tabular}

\begin{tabular}{ccl}
\hline & \multicolumn{2}{c}{ SPT } \\
\hline Profundidade $\mathrm{m}$ & Nspt & \multicolumn{1}{c}{ Solo } \\
\hline 1.00 & 6.00 & Silte argiloso \\
\hline 2.00 & 9.00 & Silte arenoso \\
\hline 3.00 & 10.00 & Silte arenoso \\
\hline 4.00 & 10.00 & Silte arenoso \\
\hline 5.00 & 11.00 & Silte arenoso \\
\hline 6.00 & 10.00 & Silte arenoso \\
\hline 7.00 & 14.00 & Silte arenoso \\
\hline 8.00 & 15.00 & Silte arenoso \\
\hline 9.00 & 15.00 & Silte arenoso \\
\hline 10.00 & 15.00 & Silte arenoso \\
\hline 11.00 & 18.00 & Silte arenoso \\
\hline 12.00 & 14.00 & Silte arenoso \\
\hline 13.00 & 15.00 & Silte arenoso \\
\hline 14.00 & 16.00 & Silte arenoso \\
\hline 15.00 & 16.00 & Silte arenoso \\
\hline 16.00 & 17.00 & Silte arenoso \\
\hline 17.00 & 18.00 & Silte arenoso \\
\hline 18.00 & 20.00 & Silte arenoso \\
\hline & & \\
\hline
\end{tabular}

\subsection{Hélice}

\begin{tabular}{cccccc}
\hline Posição & Profundidade $m$ & Diâmetro cm & SPT & Interpolado & Ajustado \\
\hline 4 & 5.49 & 35.56 & 11.00 & 10.81 & 10.81 \\
\hline 3 & 6.29 & 35.56 & 10.00 & 10.01 & 10.01 \\
\hline 2 & 6.98 & 30.48 & 10.00 & 12.72 & 12.72 \\
\hline 1 & 7.55 & 25.40 & 14.00 & 14.25 & 14.25
\end{tabular}

\subsection{Fuste}

\begin{tabular}{cccccc}
\hline Comprimento m & Seção & $\begin{array}{c}\text { Diâmetro externo } \\
\mathrm{cm}\end{array}$ & $\begin{array}{c}\text { Diâmetro interno } \\
\mathrm{cm}\end{array}$ & $\mathrm{cm}$ & $\mathrm{cm}$ \\
\hline 7.34 & Circular Vazada & 8.80 & 8.16
\end{tabular}




\subsection{Prova de Carga}

\begin{tabular}{cc}
\hline Força kN & Deslocamento $\mathrm{mm}$ \\
\hline 0.00 & 0.00 \\
\hline 48.64 & 2.00 \\
\hline 72.96 & 5.00 \\
\hline 97.28 & 7.00 \\
\hline 121.60 & 9.00 \\
\hline 145.92 & 12.00 \\
\hline 170.24 & 13.00 \\
\hline 194.56 & 15.00 \\
\hline 218.88 & 18.00 \\
\hline 243.20 & 22.00 \\
\hline 194.56 & 21.00 \\
\hline 145.92 & 20.00 \\
\hline 97.28 & 19.00 \\
\hline 48.64 & 18.00 \\
\hline 72.96 & 19.00 \\
\hline 97.28 & 20.00 \\
\hline 121.60 & 21.00 \\
\hline 145.92 & 22.00 \\
\hline 170.24 & 23.00 \\
\hline 194.56 & 24.00 \\
\hline 218.88 & 25.00 \\
\hline 243.20 & 26.00 \\
\hline 194.56 & 25.00 \\
\hline 145.92 & 24.00 \\
\hline 97.28 & 23.00 \\
\hline 48.64 & 20.00 \\
\hline & \\
\hline & \\
\hline & \\
\hline & \\
\hline & \\
\hline & \\
\hline & \\
\hline & \\
\hline & \\
\hline & \\
\hline & \\
\hline & \\
\hline & \\
\hline
\end{tabular}

\subsection{Carga de Ruptura}

\begin{tabular}{cc}
\hline Método & Força MN \\
\hline NBR 6122(2010) & 0.22 \\
\hline Davisson (1972) & 0.14
\end{tabular}




\section{VELECNOR239-6H}

\subsection{Geral}

$$
\text { Id : } 74
$$

Comprimento $\mathrm{m}: 21.42$

Inclinação $^{\circ}: 41.50$

Correção da profundidade (m) : 0.00

\subsection{SPT e Torque}

\begin{tabular}{cc}
\hline \multicolumn{2}{c}{ Torque } \\
\hline Profundidade $\mathrm{m}$ & Torque kN.m \\
\hline 3.00 & 9.76 \\
\hline 2.25 & 9.49 \\
\hline 3.74 & 11.25 \\
\hline 4.49 & 13.69 \\
\hline 5.24 & 13.96 \\
\hline 5.99 & 11.12 \\
\hline 6.74 & 11.52 \\
\hline 7.49 & 10.98 \\
\hline 8.24 & 12.47 \\
\hline 8.99 & 15.46 \\
\hline 9.74 & 17.35 \\
\hline 10.49 & 17.63 \\
\hline 11.23 & 19.25 \\
\hline 11.98 & 20.20 \\
\hline 12.73 & 20.34 \\
\hline 13.48 & 21.15 \\
\hline 14.23 & 20.07 \\
\hline 14.98 & 21.56 \\
\hline 15.73 & 23.73 \\
\hline & \\
\hline
\end{tabular}

\begin{tabular}{ccl}
\hline & \multicolumn{2}{c}{ SPT } \\
\hline Profundidade $\mathrm{m}$ & Nspt & \multicolumn{1}{c}{ Solo } \\
\hline 4.00 & 10.00 & Silte arenoso \\
\hline 3.00 & 10.00 & Silte arenoso \\
\hline 2.00 & 9.00 & Silte arenoso \\
\hline 1.00 & 6.00 & Silte argiloso \\
\hline 18.00 & 20.00 & Silte arenoso \\
\hline 17.00 & 18.00 & Silte arenoso \\
\hline 16.00 & 17.00 & Silte arenoso \\
\hline 15.00 & 16.00 & Silte arenoso \\
\hline 14.00 & 16.00 & Silte arenoso \\
\hline 13.00 & 15.00 & Silte arenoso \\
\hline 12.00 & 14.00 & Silte arenoso \\
\hline 11.00 & 18.00 & Silte arenoso \\
\hline 10.00 & 15.00 & Silte arenoso \\
\hline 9.00 & 15.00 & Silte arenoso \\
\hline 8.00 & 15.00 & Silte arenoso \\
\hline 7.00 & 14.00 & Silte arenoso \\
\hline 6.00 & 10.00 & Silte arenoso \\
\hline 5.00 & 11.00 & Silte arenoso \\
\hline & & \\
\hline
\end{tabular}

\subsection{Hélice}

\begin{tabular}{cccccc}
\hline Posição & Profundidade $\mathrm{m}$ & Diâmetro cm & SPT & Interpolado & Ajustado \\
\hline 6 & 12.34 & 35.56 & 14.00 & 14.04 & 14.04 \\
\hline 5 & 13.14 & 35.56 & 15.00 & 14.84 & 14.84 \\
\hline 4 & 13.94 & 35.56 & 15.00 & 15.64 & 15.64 \\
\hline 3 & 14.73 & 35.56 & 16.00 & 16.00 & 16.00 \\
\hline 2 & 15.42 & 30.48 & 16.00 & 16.12 & 16.12 \\
\hline 1 & 15.99 & 25.40 & 16.00 & 16.69 & 16.69
\end{tabular}

\subsection{Fuste}




\begin{tabular}{cccccc}
\hline Comprimento m & Seção & $\begin{array}{c}\text { Diâmetro externo } \\
\mathrm{cm}\end{array}$ & $\begin{array}{c}\text { Diâmetro interno } \\
\mathrm{cm}\end{array}$ & $\mathrm{cm}$ & $\mathrm{cm}$ \\
\hline 16.47 & Circular Vazada & 10.10 & 9.29
\end{tabular}

\subsection{Prova de Carga}

\begin{tabular}{|c|c|}
\hline Força kN & Deslocamento $\mathrm{mm}$ \\
\hline 0.00 & 0.00 \\
\hline 97.28 & 1.00 \\
\hline 145.92 & 9.00 \\
\hline 194.56 & 12.00 \\
\hline 243.20 & 16.00 \\
\hline 291.85 & 19.00 \\
\hline 340.49 & 22.00 \\
\hline 389.13 & 25.00 \\
\hline 437.77 & 26.00 \\
\hline 486.41 & 34.00 \\
\hline 389.13 & 24.00 \\
\hline 291.85 & 23.00 \\
\hline 194.56 & 22.00 \\
\hline 97.28 & 21.00 \\
\hline 145.92 & 24.00 \\
\hline 194.56 & 25.00 \\
\hline 243.20 & 26.00 \\
\hline 291.85 & 29.00 \\
\hline 340.49 & 31.00 \\
\hline 389.13 & 32.00 \\
\hline 437.77 & 33.00 \\
\hline 486.41 & 35.00 \\
\hline 389.13 & 32.00 \\
\hline 291.85 & 30.00 \\
\hline 194.56 & 28.00 \\
\hline 97.28 & 27.00 \\
\hline
\end{tabular}

\subsection{Carga de Ruptura}

\begin{tabular}{rc}
\hline \multicolumn{1}{c}{ Método } & Força MN \\
\hline NBR 6122 (2010) & 0.50 \\
\hline Davisson (1972) & 0.46 \\
\hline D/10 & 0.48
\end{tabular}




\section{VELECNOR258-4H}

\subsection{Geral}

$$
\text { Id }: 75
$$

Comprimento $\mathrm{m}: 12.43$

Inclinação $^{\circ}: 41.25$

Correção da profundidade (m) : 0.00

\subsection{SPT e Torque}

\begin{tabular}{cc}
\hline \multicolumn{2}{c}{ Torque } \\
\hline Profundidade $\mathrm{m}$ & Torque kN.m \\
\hline 2.25 & 3.25 \\
\hline 3.00 & 3.39 \\
\hline 3.74 & 7.05 \\
\hline 4.49 & 7.32 \\
\hline 5.24 & 8.27 \\
\hline 5.99 & 8.68 \\
\hline 6.74 & 6.78 \\
\hline 7.49 & 9.22 \\
\hline 8.24 & 7.59 \\
\hline 8.99 & 13.56 \\
\hline 9.74 & 13.56
\end{tabular}

\begin{tabular}{ccc}
\hline & \multicolumn{2}{c}{ SPT } \\
\hline Profundidade $\mathrm{m}$ & Nspt & Solo \\
\hline 10.00 & 20.00 & Areia siltosa \\
\hline 9.00 & 17.00 & Areia siltosa \\
\hline 8.00 & 18.00 & Areia siltosa \\
\hline 7.00 & 18.00 & Areia siltosa \\
\hline 6.00 & 16.00 & Areia siltosa \\
\hline 5.00 & 16.00 & Areia siltosa \\
\hline 4.00 & 17.00 & Areia siltosa \\
\hline 3.00 & 10.00 & Argila arenosa \\
\hline 2.00 & 13.00 & Argila arenosa \\
\hline 1.00 & 14.00 & Argila arenosa \\
\hline 12.00 & 23.00 & Areia siltosa \\
\hline 11.00 & 21.00 & Areia siltosa
\end{tabular}

\subsection{Hélice}

\begin{tabular}{cccccc}
\hline Posição & Profundidade $m$ & Diâmetro cm & SPT & Interpolado & Ajustado \\
\hline 4 & 7.20 & 35.56 & 18.00 & 17.81 & 17.81 \\
\hline 3 & 8.00 & 35.56 & 18.00 & 18.00 & 18.00 \\
\hline 2 & 8.69 & 30.48 & 18.00 & 17.61 & 17.61 \\
\hline 1 & 9.26 & 25.40 & 17.00 & 17.04 & 17.04
\end{tabular}

75.4. Fuste

\begin{tabular}{cccccc}
\hline Comprimento m & Seção & $\begin{array}{c}\text { Diâmetro externo } \\
\mathrm{cm}\end{array}$ & $\begin{array}{c}\text { Diâmetro interno } \\
\mathrm{cm}\end{array}$ & $\mathrm{cm}$ & $\mathrm{cm}$ \\
\hline 9.62 & Circular Vazada & 8.80 & 8.16 &
\end{tabular}

\subsection{Prova de Carga}


Força kN

\begin{tabular}{cc}
\hline 0.00 & 0.00 \\
\hline 48.64 & 2.50 \\
\hline 72.96 & 5.50 \\
\hline 97.28 & 9.50 \\
\hline 121.60 & 15.50 \\
\hline 145.92 & 19.50 \\
\hline 170.24 & 21.50 \\
\hline 218.88 & 25.50 \\
\hline 243.20 & 30.50 \\
\hline 194.56 & 38.50 \\
\hline 145.92 & 36.50 \\
\hline 97.28 & 34.50 \\
\hline 48.64 & 32.50 \\
\hline 72.96 & 30.50 \\
\hline 97.28 & 31.50 \\
\hline 121.60 & 32.50 \\
\hline 145.92 & 33.50 \\
\hline 170.24 & 34.50 \\
\hline 194.56 & 36.50 \\
\hline 218.88 & 38.50 \\
\hline 243.20 & 40.50 \\
\hline 194.56 & 41.50 \\
\hline 145.92 & 39.50 \\
\hline 97.28 & 37.50 \\
\hline 48.64 & 35.50 \\
\hline & 33.50 \\
\hline & \\
\hline & \\
\hline & \\
\hline & \\
\hline & \\
\hline & \\
\hline & \\
\hline & \\
\hline & \\
\hline & \\
\hline & \\
\hline
\end{tabular}

\subsection{Carga de Ruptura}

\begin{tabular}{rc}
\hline \multicolumn{1}{c}{ Método } & Força MN \\
\hline D/10 & 0.22 \\
\hline Davisson (1972) & 0.10 \\
\hline NBR 6122 (2010) & 0.12 \\
\hline Livneh e El Naggar (2008) & 0.24
\end{tabular}




\section{VELECNOR258-6H}

\subsection{Geral}

Id :76

Comprimento $\mathrm{m}: 11.61$

Inclinação $^{\circ}: 41.25$

Correção da profundidade (m) : 0.00

\subsection{SPT e Torque}

\begin{tabular}{cc}
\hline \multicolumn{2}{c}{ Torque } \\
\hline Profundidade m & Torque kN.m \\
\hline 3.00 & 14.91 \\
\hline 2.25 & 7.32 \\
\hline 3.74 & 16.27 \\
\hline 4.49 & 19.66 \\
\hline 5.24 & 20.61 \\
\hline 5.99 & 17.90 \\
\hline 6.74 & 18.03 \\
\hline 7.49 & 20.34 \\
\hline 8.24 & 22.37 \\
\hline 8.99 & 23.05
\end{tabular}

\begin{tabular}{ccc}
\hline & \multicolumn{2}{c}{ SPT } \\
\hline Profundidade m & Nspt & Solo \\
\hline 10.00 & 20.00 & Areia siltosa \\
\hline 9.00 & 17.00 & Areia siltosa \\
\hline 8.00 & 18.00 & Areia siltosa \\
\hline 7.00 & 18.00 & Areia siltosa \\
\hline 6.00 & 16.00 & Areia siltosa \\
\hline 5.00 & 16.00 & Areia siltosa \\
\hline 4.00 & 17.00 & Areia siltosa \\
\hline 3.00 & 10.00 & Argila arenosa \\
\hline 2.00 & 13.00 & Argila arenosa \\
\hline 1.00 & 14.00 & Argila arenosa \\
\hline 12.00 & 23.00 & Areia siltosa \\
\hline 11.00 & 21.00 & Areia siltosa
\end{tabular}

\subsection{Hélice}

\begin{tabular}{cccccc}
\hline Posição & Profundidade $m$ & Diâmetro cm & SPT & Interpolado & Ajustado \\
\hline 6 & 4.99 & 35.56 & 17.00 & 16.31 & 16.31 \\
\hline 5 & 5.79 & 35.56 & 16.00 & 16.00 & 16.00 \\
\hline 4 & 6.59 & 35.56 & 16.00 & 16.58 & 16.58 \\
\hline 3 & 7.39 & 35.56 & 18.00 & 18.00 & 18.00 \\
\hline 2 & 8.07 & 30.48 & 18.00 & 18.00 & 18.00 \\
\hline 1 & 8.64 & 25.40 & 18.00 & 17.66 & 17.66
\end{tabular}

\subsection{Fuste}

\begin{tabular}{cccccc}
\hline Comprimento m & Seção & $\begin{array}{c}\text { Diâmetro externo } \\
\mathrm{cm}\end{array}$ & $\begin{array}{c}\text { Diâmetro interno } \\
\mathrm{cm}\end{array}$ & $\mathrm{cm}$ & $\mathrm{cm}$ \\
\hline 6.66 & Circular Vazada & 10.10 & 9.29 & &
\end{tabular}




\begin{tabular}{cc}
\hline Força kN & Deslocamento $\mathrm{mm}$ \\
\hline 0.00 & 0.00 \\
\hline 97.28 & 2.00 \\
\hline 145.92 & 5.00 \\
\hline 194.56 & 7.00 \\
\hline 243.20 & 12.00 \\
\hline 291.85 & 16.00 \\
\hline 340.49 & 19.00 \\
\hline 389.13 & 23.00 \\
\hline 437.77 & 31.00 \\
\hline 486.41 & 38.00 \\
\hline 389.13 & 35.00 \\
\hline 291.85 & 32.00 \\
\hline 194.56 & 30.00 \\
\hline 97.28 & 26.00 \\
\hline 145.92 & 27.00 \\
\hline 194.56 & 28.00 \\
\hline 243.20 & 30.00 \\
\hline 291.85 & 31.00 \\
\hline 340.49 & 32.00 \\
\hline 389.13 & 34.00 \\
\hline 437.77 & 37.00 \\
\hline 486.41 & 39.00 \\
\hline 389.13 & 37.00 \\
\hline 291.85 & 35.00 \\
\hline 194.56 & 32.00 \\
\hline 97.28 & 28.00 \\
\hline & \\
\hline & \\
\hline & \\
\hline & \\
\hline & \\
\hline & \\
\hline & \\
\hline & \\
\hline & \\
\hline & \\
\hline & \\
\hline & \\
\hline & \\
\hline
\end{tabular}

\subsection{Carga de Ruptura}

\begin{tabular}{rc}
\hline Método & Força MN \\
\hline Davisson (1972) & 0.27 \\
\hline Livneh e El Naggar (2008) & 0.49 \\
\hline D/10 & 0.46 \\
\hline NBR 6122 (2010) & 0.36
\end{tabular}




\section{IGOR-T1}

\subsection{Geral}

$$
\text { Id }: 77
$$

Comprimento $\mathrm{m}: 2.76$

Inclinação $^{\circ}: 0.00$

Correção da profundidade (m) : 0.00

\subsection{SPT e Torque}

\begin{tabular}{cc}
\hline \multicolumn{2}{c}{ Torque } \\
\hline Profundidade m & Torque kN.m \\
\hline 3.00 & 7.86 \\
\hline 0.00 & 0.00 \\
\hline 2.00 & -0.00 \\
\hline 1.00 & 0.00
\end{tabular}

\begin{tabular}{ccc}
\hline & \multicolumn{2}{c}{ SPT } \\
\hline Profundidade m & Nspt & Solo \\
\hline 5.00 & 23.00 & Silte argiloso \\
\hline 4.00 & 27.00 & Silte argiloso \\
\hline 3.00 & 28.00 & Silte argiloso \\
\hline 2.00 & 9.00 & Argila silto arenosa \\
\hline 1.00 & 11.00 & Argila silto arenosa
\end{tabular}

77.3. Hélice

\begin{tabular}{cccccc}
\hline Posição & Profundidade m & Diâmetro cm & SPT & Interpolado & Ajustado \\
\hline 2 & 1.78 & 35.56 & 11.00 & 10.05 & 10.05 \\
\hline 1 & 2.69 & 30.48 & 9.00 & 16.41 & 16.41
\end{tabular}

\subsection{Fuste}

\begin{tabular}{cccccc}
\hline Comprimento $\mathrm{m}$ & Seção & $\begin{array}{c}\text { Diâmetro externo } \\
\mathrm{cm}\end{array}$ & $\begin{array}{c}\text { Diâmetro interno } \\
\mathrm{cm}\end{array}$ & $\mathrm{cm}$ & $\mathrm{cm}$ \\
\hline 1.78 & Circular Vazada & 10.16 & 8.00
\end{tabular}

\subsection{Prova de Carga}

\begin{tabular}{cc}
\hline Força kN & Deslocamento $\mathrm{mm}$ \\
\hline 0.00 & 0.00 \\
\hline 20.00 & 2.00 \\
\hline 40.00 & 4.00 \\
\hline 60.00 & 6.00 \\
\hline 80.00 & 11.00 \\
\hline 100.00 & 19.00 \\
\hline 120.00 & 24.00 \\
\hline 140.00 & 34.00 \\
\hline 160.00 & 44.00
\end{tabular}




\subsection{Carga de Ruptura}

\begin{tabular}{rc}
\hline Método & Força MN \\
\hline Davisson (1972) & 0.06 \\
\hline $\mathrm{D} / 10$ & 0.14 \\
\hline Livneh e El Naggar (2008) & 0.13 \\
\hline NBR 6122(2010) & 0.08
\end{tabular}




\section{IGOR-T2}

\subsection{Geral}

$$
\text { Id }: 78
$$

Comprimento $\mathrm{m}: 2.76$

Inclinação ${ }^{\circ}: 0.00$

Correção da profundidade (m) : 0.00

\subsection{SPT e Torque}

\begin{tabular}{cc}
\hline \multicolumn{2}{c}{ Torque } \\
\hline Profundidade $\mathrm{m}$ & Torque kN.m \\
\hline 1.00 & 0.00 \\
\hline 3.00 & 7.86 \\
\hline 0.00 & 0.00 \\
\hline 2.00 & 0.00
\end{tabular}

\begin{tabular}{ccc}
\hline & \multicolumn{2}{c}{ SPT } \\
\hline Profundidade m & Nspt & Solo \\
\hline 5.00 & 23.00 & Silte argiloso \\
\hline 4.00 & 27.00 & Silte argiloso \\
\hline 3.00 & 28.00 & Silte argiloso \\
\hline 2.00 & 9.00 & Argila silto arenosa \\
\hline 1.00 & 11.00 & Argila silto arenosa
\end{tabular}

78.3. Hélice

\begin{tabular}{cccccc}
\hline Posição & Profundidade m & Diâmetro cm & SPT & Interpolado & Ajustado \\
\hline 2 & 1.78 & 35.56 & 11.00 & 10.05 & 10.05 \\
\hline 1 & 2.69 & 30.48 & 9.00 & 16.41 & 16.41
\end{tabular}

\subsection{Fuste}

\begin{tabular}{cccccc}
\hline Comprimento m & Seção & $\begin{array}{c}\text { Diâmetro externo } \\
\mathrm{cm}\end{array}$ & $\begin{array}{c}\text { Diâmetro interno } \\
\mathrm{cm}\end{array}$ & $\mathrm{cm}$ & $\mathrm{cm}$ \\
\hline 1.78 & Circular Vazada & 10.16 & 8.00 & &
\end{tabular}

\subsection{Prova de Carga}

\begin{tabular}{cc}
\hline Força kN & Deslocamento mm \\
\hline 0.00 & 0.00 \\
\hline 20.00 & 2.00 \\
\hline 40.00 & 4.00 \\
\hline 60.00 & 6.00 \\
\hline 80.00 & 11.00 \\
\hline 100.00 & 19.00 \\
\hline 120.00 & 24.00 \\
\hline 140.00 & 34.00 \\
\hline 160.00 & 44.00
\end{tabular}




\subsection{Carga de Ruptura}

\begin{tabular}{cc}
\hline Método & Força MN \\
\hline NBR 6122 (2010) & 0.08 \\
\hline Davisson (1972) & 0.06 \\
\hline Livneh e El Naggar (2008) & 0.12 \\
\hline D/10 & 0.14
\end{tabular}


79. JOAO-PC1

\subsection{Geral}

Id : 79

Comprimento $\mathrm{m}: 9.50$

Inclinação $^{\circ}: 0.00$

Correção da profundidade (m) : 0.00

79.2. SPT e Torque

\begin{tabular}{cc}
\hline \multicolumn{2}{c}{ Torque } \\
\hline Profundidade $\mathrm{m}$ & Torque kN.m \\
\hline 1.00 & 0.81 \\
\hline 2.00 & 2.30 \\
\hline 3.00 & 3.39 \\
\hline 4.00 & 4.66 \\
\hline 5.00 & 6.51 \\
\hline 6.00 & 6.78 \\
\hline 7.00 & 7.46 \\
\hline 8.00 & 9.08 \\
\hline 9.00 & 10.49 \\
\hline 9.50 & 11.01
\end{tabular}

\begin{tabular}{ccl}
\hline & \multicolumn{2}{c}{ SPT } \\
\hline Profundidade $\mathrm{m}$ & Nspt & \multicolumn{1}{c}{ Solo } \\
\hline 12.00 & 19.00 & Silte arenoso \\
\hline 11.00 & 17.00 & Silte arenoso \\
\hline 10.00 & 19.00 & Silte arenoso \\
\hline 9.00 & 16.00 & Silte arenoso \\
\hline 8.00 & 13.00 & Silte arenoso \\
\hline 7.00 & 11.00 & Silte arenoso \\
\hline 6.00 & 15.00 & Silte arenoso \\
\hline 5.00 & 11.00 & Silte arenoso \\
\hline 4.00 & 9.00 & Silte arenoso \\
\hline 3.00 & 6.00 & Silte arenoso \\
\hline 2.00 & 6.00 & Silte arenoso \\
\hline 1.00 & 4.00 & Argila siltosa \\
\hline 22.00 & 63.00 & Silte arenoso \\
\hline 21.00 & 53.00 & Silte arenoso \\
\hline 20.00 & 47.00 & Silte arenoso \\
\hline 19.00 & 39.00 & Silte arenoso \\
\hline 18.00 & 32.00 & Silte arenoso \\
\hline 17.00 & 28.00 & Silte arenoso \\
\hline 16.00 & 23.00 & Silte arenoso \\
\hline 15.00 & 21.00 & Silte arenoso \\
\hline 14.00 & 22.00 & Silte arenoso \\
\hline 13.00 & 22.00 & Silte arenoso \\
\hline
\end{tabular}

\subsection{Hélice}

\begin{tabular}{cccccc}
\hline Posição & Profundidade $\mathrm{m}$ & Diâmetro cm & SPT & Interpolado & Ajustado \\
\hline 4 & 6.69 & 35.56 & 15.00 & 13.45 & 13.45 \\
\hline 3 & 7.75 & 35.56 & 11.00 & 11.91 & 11.91 \\
\hline 2 & 8.67 & 30.48 & 13.00 & 14.10 & 14.10 \\
\hline 1 & 9.43 & 25.40 & 16.00 & 16.39 & 16.39
\end{tabular}




\begin{tabular}{cccccc}
\hline Comprimento m & Seção & $\begin{array}{c}\text { Diâmetro externo } \\
\mathrm{cm}\end{array}$ & $\begin{array}{c}\text { Diâmetro interno } \\
\mathrm{cm}\end{array}$ & $\mathrm{cm}$ & $\mathrm{cm}$ \\
\hline 6.69 & Circular Vazada & 10.10 & 9.30
\end{tabular}

\subsection{Prova de Carga}

\begin{tabular}{|c|c|}
\hline Força kN & Deslocamento $\mathrm{mm}$ \\
\hline 0.00 & 0.00 \\
\hline 10.00 & 1.91 \\
\hline 20.00 & 2.69 \\
\hline 30.00 & 3.59 \\
\hline 40.00 & 5.75 \\
\hline 50.00 & 7.46 \\
\hline 60.00 & 8.57 \\
\hline 70.00 & 10.30 \\
\hline 80.00 & 11.83 \\
\hline 90.00 & 13.44 \\
\hline 100.00 & 15.26 \\
\hline 110.00 & 17.04 \\
\hline 120.00 & 18.41 \\
\hline 130.00 & 19.84 \\
\hline 140.00 & 21.75 \\
\hline 150.00 & 23.48 \\
\hline 160.00 & 24.31 \\
\hline 170.00 & 26.22 \\
\hline 180.00 & 28.04 \\
\hline 190.00 & 30.07 \\
\hline 200.00 & 32.58 \\
\hline 210.00 & 34.49 \\
\hline 220.00 & 38.15 \\
\hline 176.00 & 37.23 \\
\hline 132.00 & 36.22 \\
\hline 88.00 & 33.97 \\
\hline 44.00 & 31.72 \\
\hline 0.00 & 21.50 \\
\hline
\end{tabular}

\subsection{Carga de Ruptura}

\begin{tabular}{rc}
\hline \multicolumn{1}{c}{ Método } & Força MN \\
\hline D/10 & 0.20 \\
\hline Davisson (1972) & 0.05 \\
\hline Livneh e El Naggar (2008) & 0.19 \\
\hline NBR 6122 (2010) & 0.08
\end{tabular}




\section{JOAO-PC3}

\subsection{Geral}

$$
\text { Id }: 80
$$

Comprimento $\mathrm{m}: 15.00$

$$
\text { Inclinação }{ }^{\circ}: 0.00
$$

Correção da profundidade (m) $: 0.00$

\begin{tabular}{|c|c|}
\hline \multicolumn{2}{|c|}{ Torque } \\
\hline Profundidade $\mathrm{m}$ & Torque kN.m \\
\hline 1.50 & 0.91 \\
\hline 1.25 & 0.41 \\
\hline 1.75 & 0.94 \\
\hline 2.00 & 1.52 \\
\hline 2.25 & 1.15 \\
\hline 2.50 & 1.55 \\
\hline 2.75 & 1.91 \\
\hline 3.00 & 1.97 \\
\hline 3.25 & 2.03 \\
\hline 3.50 & 2.10 \\
\hline 3.75 & 3.17 \\
\hline 4.00 & 2.98 \\
\hline 4.25 & 2.70 \\
\hline 4.50 & 2.71 \\
\hline 4.75 & 3.19 \\
\hline 5.00 & 3.28 \\
\hline 5.25 & 3.74 \\
\hline 5.50 & 4.07 \\
\hline 5.75 & 3.65 \\
\hline 6.00 & 4.50 \\
\hline 6.25 & 5.03 \\
\hline 6.50 & 4.80 \\
\hline 6.75 & 6.10 \\
\hline 7.00 & 8.04 \\
\hline 7.25 & 6.51 \\
\hline 7.50 & 6.79 \\
\hline 7.75 & 7.50 \\
\hline 8.00 & 8.05 \\
\hline 8.25 & 8.16 \\
\hline 8.50 & 6.44 \\
\hline 8.75 & 6.89 \\
\hline 9.00 & 7.65 \\
\hline 9.25 & 7.19 \\
\hline 9.50 & 7.35 \\
\hline 9.75 & 7.46 \\
\hline 10.00 & 6.85 \\
\hline
\end{tabular}

\subsection{SPT e Torque}

\begin{tabular}{ccl}
\hline & \multicolumn{2}{c}{ SPT } \\
\hline Profundidade $\mathrm{m}$ & Nspt & \multicolumn{1}{c}{ Solo } \\
\hline 6.00 & 7.00 & Silte arenoso \\
\hline 5.00 & 11.00 & Silte arenoso \\
\hline 4.00 & 6.00 & Silte arenoso \\
\hline 3.00 & 6.00 & Silte arenoso \\
\hline 2.00 & 7.00 & Silte arenoso \\
\hline 1.00 & 4.00 & Silte arenoso \\
\hline 8.00 & 5.00 & Silte arenoso \\
\hline 7.00 & 4.00 & Silte arenoso \\
\hline 9.00 & 4.00 & Silte arenoso \\
\hline 10.00 & 4.00 & Silte arenoso \\
\hline 11.00 & 7.00 & Silte arenoso \\
\hline 12.00 & 10.00 & Silte arenoso \\
\hline 13.00 & 11.00 & Silte arenoso \\
\hline 14.00 & 15.00 & Silte arenoso \\
\hline 15.00 & 20.00 & Silte arenoso \\
\hline 16.00 & 31.00 & Silte arenoso \\
\hline 17.00 & 39.00 & Silte arenoso \\
\hline 18.00 & 63.00 & Silte arenoso \\
\hline & & \\
\hline
\end{tabular}




\begin{tabular}{ll}
\hline 10.25 & 7.01 \\
\hline 10.50 & 6.58 \\
\hline 10.75 & 7.25 \\
\hline 11.00 & 6.55 \\
\hline 11.25 & 5.86 \\
\hline 11.50 & 7.19 \\
\hline 11.75 & 7.77 \\
\hline 12.00 & 6.63 \\
\hline 12.25 & 6.64 \\
\hline 12.50 & 6.60 \\
\hline 12.75 & 6.64 \\
\hline 13.00 & 6.87 \\
\hline 13.25 & 6.60 \\
\hline 13.50 & 6.97 \\
\hline 13.75 & 9.26 \\
\hline 14.00 & 7.15 \\
\hline 14.25 & 6.91 \\
\hline 14.50 & 7.05 \\
\hline 14.75 & 7.40 \\
\hline 15.00 & 7.92
\end{tabular}

\subsection{Hélice}

\begin{tabular}{cccccc}
\hline Posição & Profundidade $m$ & Diâmetro cm & SPT & Interpolado & Ajustado \\
\hline 4 & 12.19 & 35.56 & 7.00 & 9.66 & 9.66 \\
\hline 3 & 13.25 & 35.56 & 10.00 & 10.95 & 10.95 \\
\hline 2 & 14.17 & 30.48 & 11.00 & 14.47 & 14.47 \\
\hline 1 & 14.93 & 25.40 & 15.00 & 18.15 & 18.15
\end{tabular}

80.4. Fuste

\begin{tabular}{cccccc}
\hline Comprimento m & Seção & $\begin{array}{c}\text { Diâmetro externo } \\
\mathrm{cm}\end{array}$ & $\begin{array}{c}\text { Diâmetro interno } \\
\mathrm{cm}\end{array}$ & $\mathrm{cm}$ & $\mathrm{cm}$ \\
\hline 12.19 & Circular Vazada & 10.10 & 9.30 & &
\end{tabular}

\subsection{Prova de Carga}

\begin{tabular}{cc}
\hline Força kN & Deslocamento mm \\
\hline 0.00 & 0.00 \\
\hline 15.00 & 3.47 \\
\hline 30.00 & 9.61 \\
\hline 45.00 & 14.18 \\
\hline 60.00 & 17.67 \\
\hline 75.00 & 20.60 \\
\hline 90.00 & 23.91 \\
\hline 105.00 & 27.87 \\
\hline 120.00 & 30.89
\end{tabular}




\begin{tabular}{ll}
\hline 135.00 & 34.34 \\
\hline 150.00 & 37.59 \\
\hline 165.00 & 40.60 \\
\hline 180.00 & 43.28 \\
\hline 195.00 & 46.21 \\
\hline 210.00 & 48.88 \\
\hline 225.00 & 52.37 \\
\hline 240.00 & 54.79 \\
\hline 255.00 & 57.78 \\
\hline 270.00 & 61.23 \\
\hline 285.00 & 64.11 \\
\hline 300.00 & 69.44 \\
\hline 240.00 & 68.12 \\
\hline 180.00 & 66.07 \\
\hline 120.00 & 63.49 \\
\hline 60.00 & 59.33 \\
\hline 0.00 & 42.44 \\
\hline
\end{tabular}

\subsection{Carga de Ruptura}

\begin{tabular}{rc}
\hline Método & Força MN \\
\hline Davisson (1972) & 0.02 \\
\hline NBR 6122 (2010) & 0.03 \\
\hline Livneh e El Naggar (2008) & 0.11 \\
\hline D/10 & 0.13
\end{tabular}

